SAND90-7011

Unlimited Release

UC -721

\title{
Core Analyses for Selected Samples from the Culebra Dolomite at the Waste Isolation Pilot Plant Site
}

Van A. Kelley, George J. Saulnier, Jr. INTERA Inc. 6850 Austin Center Blvd., Suite 300 Austin, TX 78731

Prepared by Sandia National Laboratories Albuquerque, New Mexico 87185 and Livermcre, California 94550 for the United States Department of Energy under Coritract DE-AC04-76DP00789

Printed November 1990 
Issued by Sandia National Laboratories, operated for the United States Department of Energy by Sandia Corporation.

NOTICE: This report was prepared as an account of work sponsored by an agency of the United States Government. Neither the United States Government nor any agency thereof, nor any of their employees, nor any of their contractors, subcontractors, or their employees, makes any warranty, express or implied, or assumes any legal liability or responsibility for the accuracy, completeness, or usefulness of any information, apparatus, product, or process disclosed, or represents that its use would not infringe privately owned rights. Reference herein to any specific commercial product, process, or service by trade name, trademark, manufacturer, or otherwise, does not necessarily constitute or imply its endorsement, recommendation, or favoring by the United States Government, any agency thereof or any of their contractors or subcontractors. The views and opinions expressed herein do not necessarily state or reflec: those of the United States Government, any agency thereof or any of their contractors.

Printed in the United States of America. This report has been reproduced directly from the best available copy.

Available to DOE and DOE contractors from Office of Scientific and Technical Information PO Box 62

Oak Ridge, TN 37831

Prices available from (615) 576-8401, FTS 626-8401

Available to the public from

National Technical Information Service

US Department of Commerce

5285 Port Royal Rd

Springfield, VA 22161

NTIS price codes

Printed copy: A14

Microfiche copy: A01 
SAND90-7011

Unlimited Release

SAND- $-90-7011$

Printed November 1990

DE91 006752

\title{
CORE ANALYSES FOR SELECTED SAMPLES FROM THE CULEBRA DOLOMITE AT THE WASTE ISOLATION PILOT PLANT SITE
}

Van A. Kelley and George J. Saulnier, Jr.

INTERA Inc.

6850 Austin Center Blvd., Suite 300

Austin, TX 78731

\begin{abstract}
Two groups of core samples from the Culebra Dolomite Member of the Rustler Formation at and near the Waste Isolation Pilot Plant were analyzed to provide estimates of hydrologic parameters ior use in flow-and-transport modeling. Whole-core and core-plug samples were analyzed by helium porosimetry, resaturation porosimetry, mercury-intrusion porosimetry, electrical-resistivity techniques, and gas-permeability methods.

Seventy-nine (79) helium-porosity determinations indicated that the distribution of Culebra porosities was skewed toward lower porosity values with an arithmetic mean and standard deviation of 0.153 and 0.053 , respectively.

The vertical heterogeneity of porosity was indicated by 21 pairs of heliumporosity determinations where each sample of the pair was separated by approximately $5 \mathrm{~cm}$. The porosity differences between the samples in the pairs varied from 0.050 to 0.093 .

Water-resaturatiun-porosimetry results showed a near 1-to-1 correlation with the results from helium-porosity determinations. In some cases, the resaturation porosities were slightly larger than the helium porosities, possibly due to mineral dissolution by the resaturation fluid (deionized water) or to the experimental reproducibility of the two measuring techniques.
\end{abstract}

*The work described in this report was done for Sandia National Laboratories under Contract No. 32-1025. 
Endpoint mercury pore-vo' ne saturations for 25 samples ranged from 66.78 to 99.98, with an average endpoint pore-volume saturation of 95.48 . The endpoint pressure was $207 \mathrm{MPa}$. The median pore-throat radius varled over an order of magnitude from $0.077 \mu \mathrm{m}$ to $0.588 \mu \mathrm{m}$, with an arithmetic average value of $0.315 \mu \mathrm{m}$. Eighty-four percent of the pore-throat radil in the samples analyzed were between $0.1 \mu \mathrm{m}$ and $0.5 \mu \mathrm{m}$. The average mercury-intrusion porosity was 0.148 , as compared with the helium-porosity average of 0.154 .

Seventy-three (73) grain-density measurements indicated a skewed distribution toward larger values of grain density with an arithmetic average of $2.82 \mathrm{~g} / \mathrm{cm}^{3}$ and a standard deviation of $0.019 \mathrm{~g} / \mathrm{cm}^{3}$. The most common value of grain density was $2.83 \mathrm{~g} / \mathrm{cm}^{3}$, which was also the median of the distribution.

Electrical-resistivity measurements of 15 saturated core plugs were used to calculate estimates of formation factor and tortuosity. Formation-factor values were log-normally distributed and values ranged from 12 to 407, w1th a geometric mean of 58.8. Tortuosity ranged from 0.04 to 0.33 , with an arithmetic average of 0.14 and a median of 0.12 . The results show a general trend of increasing tortuosity with increasing porosity. The diffusion porosities and diffusion tortuosities determined by Dykhuizen and Casey (1989) agree with the lower range of the values determined by this core-analysis study.

Sixty-six (66) horizontal-permeability measurements ranged from $7.9 \mathrm{E}-18 \mathrm{~m}^{2}$ to $3.6 \mathrm{E}-13 \mathrm{~m}^{2}$, and the distribution had an arithmetic average of $6.2 \mathrm{E}-15 \mathrm{~m}^{2}$, a geometric mean of $4.5 \mathrm{E}-16 \mathrm{~m}^{2}$, and a median of $2.7 \mathrm{E}-16 \mathrm{~m}^{2}$. Twenty-six (26) vertical-permeability measurements ranged from $8.4 \mathrm{E}-18^{-} \mathrm{m}^{2}$ to $5.2 \mathrm{E}-14 \mathrm{~m}^{2}$, with an arithmetic mean of $5.1 \mathrm{E}-15 \mathrm{~m}^{2}$, a geometric mean of $9.0 \mathrm{E}-16 \mathrm{~m}^{2}$, and a median of $3.5 \mathrm{E}-16 \mathrm{~m}^{2}$. Plots of the 10810 of permeability versus porosity indicated a weak correlation between the $\log 10$ of permeability and porosity. A plot of $\log 10$ of horizontal permeability versus the median pore-throat radil determined for the same samples indicated that the $\log _{10}$ horizontal permeability is directly related to median pore-throat radius. 
1.0 INTRODUCTION AND FRAMEWORK FOR INVESTIGATION $\ldots \ldots \ldots \ldots \ldots \ldots \ldots \ldots 1$

2.0 METHODOLOGY AND THEORY FOR ANALYSES $\ldots \ldots \ldots \ldots \ldots \ldots \ldots \ldots \ldots \ldots \ldots$

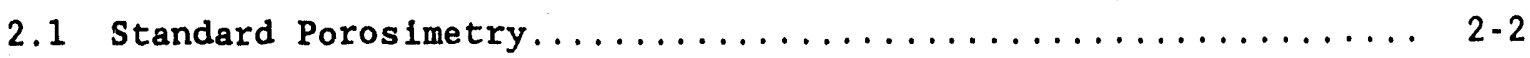

2.1 .1 Helium Porosity............................... 2

2.1 .2 Water-Resaturation Porosity..................... 2-3

2.2 Mercury-Intrusion Porosimetry..................... $2-3$

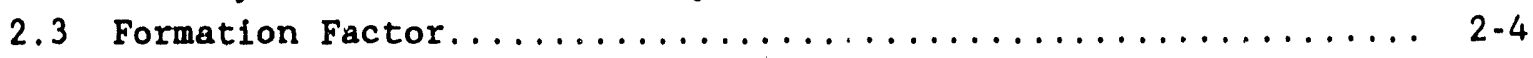

2.3.1 Formation-Factor Determinations................. 2.4

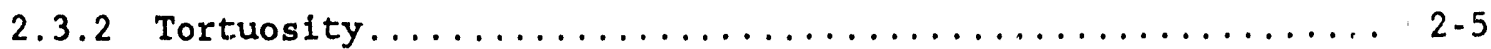

2.3.3 Formation Factor and Its Relation to Diffusive Flux

in Porous Media......................... 2-6

2.4 Gas Permeability........................... 2.9

3.0 SAMPLE SELECTION AND ANALYSES PERFORMED $\ldots \ldots \ldots \ldots \ldots \ldots \ldots \ldots \ldots \ldots$

3.1 Sample Selection and Sample Nomenclature................ 3-1

3.2 Standard Porosimetry......................... $3-2$

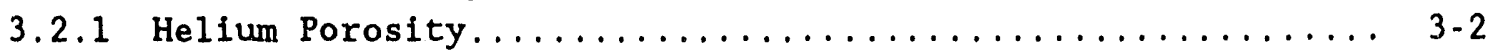

3.2.2 Water-Resaturation Porosity.................... $3-3$

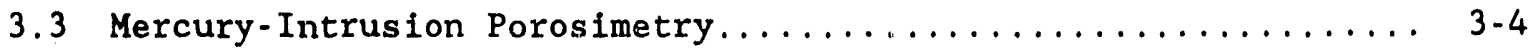

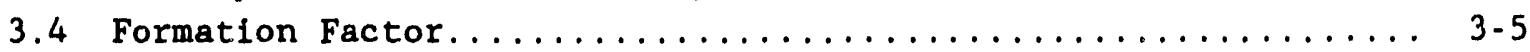

3.5 Gas Permeability........................... $3-5$

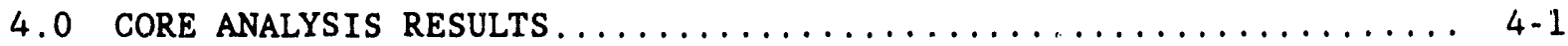

4.1 Standard Porosity Analyses..................... 4-1

4.1 .1 Helium Porosity......................... 4-1

4.1 .2 Water-Resaturation Porosity................... 4-6

4.1 .3 Grain Density........................... 4-8

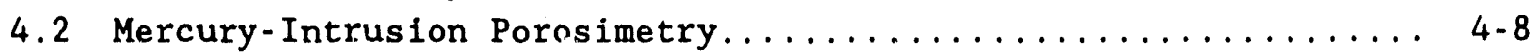

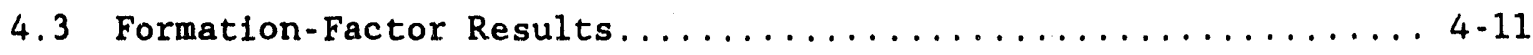

4.4 Gas-Permeability Results...................... 4-15

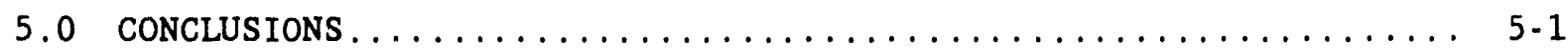

6.0 REFERENCES $\ldots \ldots \ldots \ldots \ldots \ldots \ldots \ldots \ldots \ldots \ldots \ldots \ldots \ldots \ldots \ldots \ldots \ldots$ 


\section{CONTENTS (Continued)}

APPENDICES

APPENDIX A: Sample Descriptions....................... A-1

APPENDIX B: Summary of Results Received from

Core Laboratories, Inc...................... B-1

APPENDIX C: Terra Tek Core Services Report.................. C-1

APPENDIX $D: K \& A$ Laboratories Report................... $D-1$ 


\section{FIGURES}

1.1 Site Location for the Waste Isolation Pilot Plant Showing the Observation-Well Network for Regional-Hydrogeologic-

Characterization Studies............................ 1-5

2.1 Comparison of Tortuosity as Defined by Bear (1972) and

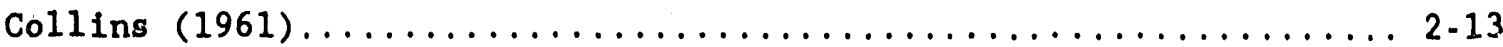

4.1 Relative-Frequency Histogram for Thase 1 Helium Porosities....... 4-19

4.2 Cumulative Relative-Frequency Curve for Phase 1 Helium Porosities.. 4-20

4.3 Comparison of Porosities Between Core-Plug Samples Taken in Close Vertical Proximity........................... 4-21

4.4 Laboratory Comparison of Helium Porosity for Identical Samples.... 4-22

4.5 Relative-Frequency Histogram for Phase 2 Core-Plug Helium

Porosities................................ 4-23

4.6 Relative-Frequency Histogram for Phase 2 Helium Porosities....... 4-24

4.7 Cumulative Relative-Frequency Curve for Phase 2 Helium

Porosities.................................. 4-25

4.8 Relative-Frequency Histogram for Phase 1 and Phase 2 Helium

Porosities................................. 4-26

4.9 Cumulative Relative-Frequency Curve for Phase 1 and Phase 2

Helium Porositles.............................. 4-27

4.10 Comparison Between Phase 1 and Phase 2 Cumulative Relative-

Frequency Curves for Helium Porosity.................. 4-28

4.11 Comparison Between Helium and Resaturation Porosities...........4.29

4.12 Relative-Frequency Histogram for Sample Grain Density..........4-30

4.13 Relative-Frequency Histogram for Formation Factor Determined from Electrical-Resistivity Measurements................ 4-31

4.14 Relative-Frequency Histogram for Log10 of Formation Factor Determined from Electrical-Resistivity Measurements.......... 4-32

4.15 Relative-Frequency Histogram for Calculated Tortuosity Values..... 4-33

4.16 Comparison Between Helium Porosity and Tortuosity Determined from Electrical-Resistivity Measurements.................... 4-34

4.17 Comparison Betweer, the Formation Factor Determined from Electrical-Resistivity Measurements and the Formation Factor Predicted by Archie's Equation ...................... 4-35

4.18 Comparison Between Tortuosity Determined from ElectricalResistivity Measurements and Diffusion Tortuosity........... 4-36

4.19 Relative-Frequency Histogram for Log10 Horizontal Permeability fcr Phase 1 and Phase 2 Core Studies.................... 4-37 
FIGURES (Continued)

4.20 Relative-Frequency Histogram for Log10 Vertical Permeability for Phase 1 and Phase 2 Core Studies...................... 4-38

4.21 Horizontal Permeability Versus Porosity for Phase 1 and Phase 2 Whole-Core and Plug-Core Analyses.................... 4-39

4.22 Vertical Permeability Versus Porosity for Phase 1 and Phase 2 Whole-Core and Plug-Core Analyses.................... 4-40

4.23 Horizontal Permeability Versus Median Pore-Throat Radius for Phase 2 Plug-Core Samples........................ 4-41 
3.1 Summary of Analyses Performed as Pait of the Phase 1 Core Study... 3-7

3.2 Summary of Whole-Core knalyses Performed in the Phase 2 Core

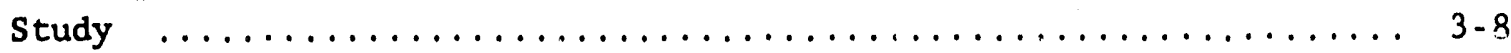

3.3 Summary of Plug-Core Analyses Performed in the Phase 2 Core Study.. 3-9

4.1 Results from the Phase 1 Core study..................... 4-42

4.2 Resilts from Whole-Core Samples, Phase 2 Core Study............ 4-43

4.3 Results from Plug-Core Samples, Phase 2 Core Study............ 4-44

4.4 Summary of Porosities Determined Using Boyle's Law Technique on Culebra Core Samples During Phase 1 and Phase 2 Core Studies...... 4-47

4.5 Summary of Endpoint Saturations and Median Pore-Throat Radii from Mercury-Intrusion Porosimetry..................... 4-50

4.6 Summary of Formation-Factor and Tortuosity Results........... 4-51

4.7 Results from Diffusion Studies Performed on the Culebra by Sandia National Laboratories............................ 4-52

A.1 Core-Sample Descriptions for the Phase 1 Core Study............ A-3

A.2 Core-Sample Descriptions for the Phase 2 Core Study............. A-5 


\subsection{INTRODUCTION AND FRAMEWORK FOR INVESTIGATION}

The follow:ng report presents the results of the analysis of core samples from the Culebra Dolomite Member of the Rustler Formation obtained from drill holes at and near the Waste Isolation Pilot Plant (WIPP) site in southeastern New Mexico (Figure 1.1). The WIPP is a U.S. Department of Energy research-and-development facility designed to demonstrate safe disposal of transuranic radioactive waste resulting from the United States' defense programs. The WI!P underground repository is being constructed in the bedded halite of the Salado Formation, approximately 655 meters below land surface. The core holes from which the core samples were obtained were drilled at the WIPP and the surrounding area from 1980 through 1984. The core holes were driiled as part of the hydrogeologic characterization of the Rustler Formation which overlies the Salado Formation. The core analyses were contracted by INTERA Inc. of Austin, Texas for and under the technical direction of Sandia National Laboratories.(SNL) of Albuquerque, New Mexico.

The Culebra dolomite is the most transmissive confined unit above the proposed waste repository and therefore is considered the most likely transport path by which radionuclides could travel to the accessible environment over time spans of interest to regulatory agencies (Lappin et a]., 1989). Because of the Culebra's importance as a possible transpet pathway to the accessible environment, hydrogeologic and transport characterization of the Culebra forms a very important part of the overall site characterization of the WIPP. Hydrologic data from over 40 observation wells in the vicinity of the WIPP site (Cauffman et al., 1990) are being used to calibrate and validate a ground-water-flow model of the Culebra dolomite (LaVenue et al., 1990). Figure 1.1 shows the location of the observation-well network in the vicinity of the WIPP site.

As part of SNL's WIPP-site characterization program, INTERA contracted two separate core-analysis studies of core samples from the Culebra dolomite. 
The first study, performed in late 1985 to early 1986, is referred to as the Phase 1 core study. The second, more comprehensive study, which was performed from late 1987 to June 1988, is referred to as the Phase 2 core siudy. This report contains estimates of the physical properties of the Culebra dolomite from both Phase 1 and Phase 2. The Phase 1 core study was initiated to determine values of the Culebra matrix parameters, porosity and permeability, for transport and hydraulic-test interpretations. Using these data and hydraulic data from the WIPP site, Reeves et al. (1987) performed a parameter-sensitivity analysis of regional double-porosity transport within the Culebra. Under the conditions and assumptions of that study, it was concluded that matrix porosity was the most sensitive and important parameter governing double-porosity far-field transport in the Culebra. These results identified the need for a better understanding of the physical properties of the pore structure of the Culebra, specificaliy the porosity and tortuosity, and prompted the initiation of the Phase 2 core-characterization study.

The Culebra is a finely crystalline, vuggy dolomite which is often arglilaceous and is fractured over a large part of the WIPP-site area (Beauheim, 1987). The Culebra is very heterogeneous, as indicated by the six order-of-magnitude variation in transmissivity estimates for this unit in the vicinily of the WIPP site. Beauheim (1987) states that the Culebra behaves hydraulically as a double-porosity medium for regions which have a transmissivity greater than $1 \times 10^{-6} \mathrm{~m}^{2} / \mathrm{s}$. Conservative tracer tests performed in these regions, including tests at the $\mathrm{H}-3$ and $\mathrm{H}-11$ hydropads (Figure 1.1), have also required double-porosity conceptualizations to model the observed tracer-breakthrough data (Kelley and Pickens, 1986; Saulnier et al., 1989). The estimated hydrologic travel pathways in the Culebra leading offsite from above the WIPP repository's waste-panel area are within that part of the Culebra characterized as a fractured, doubleporosity formation (Reeves et al., 1987; Lappin et al., 1989). The matrixparameter data base for the Culebra before the results presented in this report was extremely limited. This report augments the Culebra data base for site-characterization and performance-assessment studies. 
Physical core parameters determined and presented in this report are porosity, formation factor, tortuosity, grain density, pore-size distributions, and gas permeability for selected samples. The matrix porosity and tortuosity are important parameters because of their direct effects upon solute transport. The grain density is also important because it is a parameter in the retardation equation.

Section 2 will briefly describe the methods used in determining the physical parameters of the Culebra core samples. In addition, the theoretical relationships from which these parameter determinations were derived will be presented. Section 3 identifies the samples which were analyzed and the analyses performed on each sample. In addition, Section 3 presents the rationale for sample and analysis selections. Section 4 presents the results from the Phase 1 and Phase 2 core studies and the appropriate parameter distributions and dependent-parameter relationships. Section 5 presents general conclusions based on the results of the core studies. 


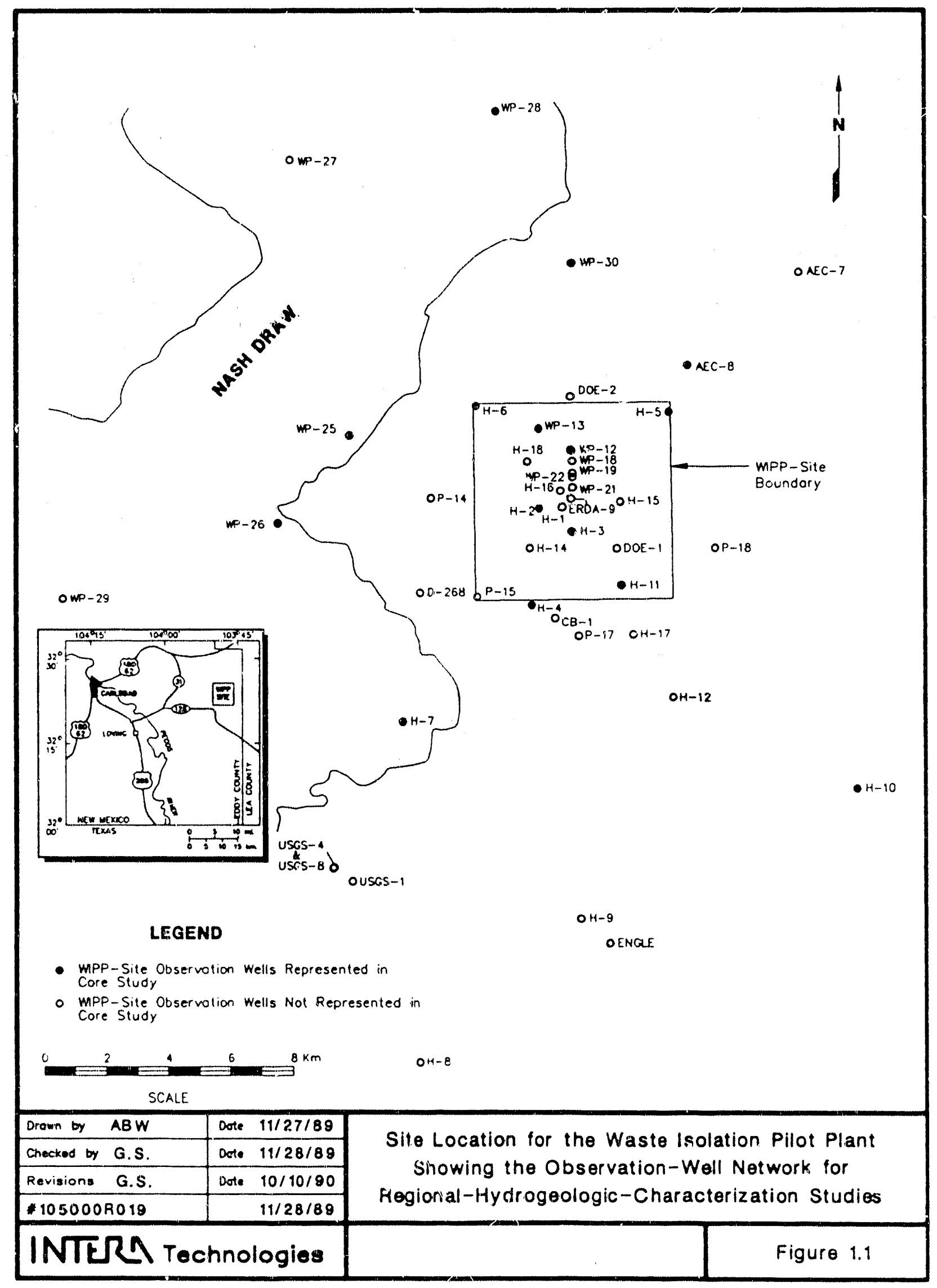




\subsection{METHODOLOGY AND THEORY FOR ANALYSES}

Five different analyses were performed to characterize the physical properties of Culebra core samples. They were:

(1) Boyle's Law helium porosimetry;

(2) resaturation porosiretry;

(3) mercury-intrusion porssimetry;

(4) foxmation-factor determinations (1:0 estimate tortuosities); and

(5) gas permeability.

Analyses (1) and (2) were used to determine the porosity of the samples. Because helium can access much smaller pore spaces than those which water can access, both techniques were used on selected core samples in an effort to characterize the differences between these methods. The porosity determinations also provided estimates of the grain density of the material in most samples. Mercury-intrusion porosimetry is designed to determine the pore-size distribution of a given sample. This type of data is very important when considering the effective porosity of a porous medium. The formation factor provides an empirical approach to determining the tortuosity of a porous medium. The appropriate relationships and their application are discussed fully in Section 2.3. Gas permeability was used to detarmine the intrinsic permeability of the dolomite matrix. Gaspermeability determinations were performed with standard, steady-state techniques for both horizontal and vertical permeabilities of selected samples.

The Phase 1 core study included Boyle's Law helium porosity and gas permeabilities of selected samples. These analyses were performed by Core Laboratories, Inc., Aurora, Colorado. During the Phase 2 study, all five of the above analyses were performed by ferra Tek Core Services, Salt Lake City, Utah, except the mercury-intrusion porosimetry, which was performed by $\mathrm{K} \& \therefore$ Laboratories, Tulsa, Oklahoma. The following sections will 
briefly discuss the techniques used for each analysis and the parameters determined using these methods.

\subsection{Standard Porosimetry}

The total porosity of a sample is equal to the tota] void volume divided by the total bulk volume. To calculate porosity, two of the three variables, bulk volume, pore volume, or grain volume must be determined. The effective porosity is defined as the connected vold volume divided by the bulk volume. Because the size of the helium molecule is small, the hellum method of determining porosity provides an approximate estimate of the total porosity. In addition to Boyle's Law helium-porosity determinations, water-resaturation porosities were measured for some of the samples. Resaturation porosities are considered to provide a better estimate of the connected porosity for ground-water-flow and solutetransport modeling, and also have the advantage of determining the void volume when the mineral $s$ mples are wet, as is the case in situ.

\subsubsection{Helium Porosity}

Boyle's Law hellum porosimetry has the advantage of being: (1) very accurate; (2) fairly rapid except for extremely low-permeability (< $1.0 E-18 \mathrm{~m}^{2}$ ) samples; and (3) the method is non-destructive, allowing the samples to be reused for other analyses. However, Boyle's Law porosimetry can yield erroneously high porosity values when the permeating gas adsorbs on the rock surfaces. Helium is preferred for Boyle's Law porosimetry because helfum is non-adsorbing and has a minimum deviation in behavior from that ol an ideal. gas. Boyle's Law porosinetry determines elther the pore vilume or thie grain volume of a sample through either expansion of a gas out of, or compression of a gas into, the pores of the sample. The bulk volume of the sample is then calculated using caliper measurements or by displacement of the sample in a liquid of a known densicy. The grain densitiv is calculated using the dry weight of the sample and the grair volume. 


\subsubsection{Water-Resaturation Porosity}

Because gas-porosimetry measurements can yield erroneously high porosity estimates due to gas adsorption, the Phase 2 core study included analysis of both Boyle's Law helium porosity and resaturation porosity for selected samples to determine if these methods give significantly different values for the same sample. The resaturation technique also has the advantage of providing a porosity measurement under saturated conditions similar to those found in situ.

In resaturation porosimetry, the first step is calculation of the bulk volume and the dry weight of the sample. The pores of the sample are then filled with a fluid of a known density. The increase in the weight of the sample is divided by the fluid density to obtain the void volume. The void volume divided by the bulk volume yields porosity.

\subsection{Mercury-Intrusion Porosimetry}

Mercury-intrusion porosimetry was used on selected samples in the Phase 2 core study to define the sample pore-size distributions. The method requires enclosing a sample in an air-tight mercury chamber which is then evacuated to a low pressure. Mercury is then intruded into the sample's void spaces in successive steps of increased stabilized pressure and the amount of mercury injected into the core for each pressure step is recorded. The mercury-intrusion stage is referred to as the drainage cycle because the air in the sample is displaced by the non-wetting mercury. The $K \& A$ Laboratories mercury-intrusion apparatus can inject mercury up to a pressure of $207 \mathrm{MPa}$. At this pressure, the mercury invaded an average of 95.58 of the pore space for the 24 samples analyzed in the Phase 2 study.

Mercury-intrusion porosimetry results can also be used to estimate a sample's pore-diameter distribution. Knowing the physical properties of 
the non-wetting phase (mercury), one can calculate the average pore size. The theoretical pore diameter can be calculated from the Washburn equation (Walter, 1982):

$$
d-4+\cos \theta / P
$$

where $d$ is the theoretical pore diameter; $r$ is the surface tension of mercury (typically 484 dynes/cm); $\theta$ is the contact angle for mercury (typically $140^{\circ}$ ); and $P$ is the mercury-intrusion pressure. Studies performed by Terra Tek Core Services indicate that the constants in this equation are ideal and quickly change in magnitude as the mercury comes in contact with the sample. The values used to calculate the results presented in this report were a contact angle of $180^{\circ}$ and a surface tension value of 360 dynes/cm (Rakop and Little, 1988) (see Appendix D). Using the sample's initial void volume, the cumulative volume of mercury intruded into the sample can be used to calculate both the pore-size distribution of the sample and the cumulative pore-size distribution. Mercury-intrusion porosimetry determines the connected porosity, the correct porosity for transport calculations. The pore-size distribution is also used to determine the fraction of the sample pore space accessible to a diffusing solute. Dykhuizen and Casey (1989) have used mercury-intrusion-porosimetry results to provide complex pore-geometry models using data from diffusion experiments performed on core and excavated-rock samples of the Culebra.

\subsection{Formation Factor}

\subsubsection{Formation-Factor Determinations}

The electrical resistivity of a saturated porous medium is directly related to the resistivity of the fluid which saturates the porous medium. The constant of proportionality relating the resistivity of the formation and its saturating fluid is called the formation factor $(F \geq 1.0)$ and is equal to 


$$
F=R_{b} / R_{w}
$$

where $R_{b}$ is equal to the resistivity of the porous media saturated with fluid of resistivity $R_{w}$. The fluid used to saturate the medium is usually a sodium-chloride ( $\mathrm{NaCl}$ ) solution with a concentration higher than $10 \mathrm{~g} / 1$ (Bear, 1972). Values of formation factor were determined for 15 individual core plugs during the Phase 2 core study by Terra Tek Core Services. The samples were first saturated in a $100 \mathrm{~g} / 1$ sodiumchloride solution of known electrical resistivity (Rw). Then the formation electrical resistivity of the saturated core plugs ( $R b$ ) was mersured while the samples were placed under an ambient pressure of $1.4 \mathrm{MPa}$.

\subsubsection{Tortuosity}

The formation factor can be related to the physical properties of saturated porous media and, as derived from geophysical logging data, is a standard parameter used by the petroleum industry (Schlumberger, 1972). The electrical resistivity $\left(R_{b}\right)$ of a saturated porous medium is controlled by the volume fraction of the pore cross section normal to current flow and by the connectivity of the pore volume (Touloukian et al., 1981). Because there are no analytical solutions for the concept of tortuosity, it has been described empirically. The best known description is the empirical relationship known as Archie's Law of total porosity:

$$
F=C / \phi^{m}
$$

where $C$, sometimes called the tortuosity factor, and $m$, the cementation factor, are empirical constants which vary depending upon the porous medium's 1ithology, and $\phi$ is porosity expressed as a decimal fraction. The following rable gives ranges of $C$ and $m$ for various lithologies (Katsube and Hume, 1987). 


\begin{tabular}{lll}
\multicolumn{1}{c}{ Lithology } & C & m \\
\hline Carbonates & 1 & 2 \\
Unconsolidated sand & 0.62 & 2.15 \\
Typical sandstone & 1.45 & 1.54 \\
Shaly sandstone & 1.65 & 1.33 \\
Granites & $5.9 \mathrm{E}-3$ & 2.21
\end{tabular}

All of the formation-factor formulas assume that the electrical current is conducted through the pores, and that surface conduction of the current on the pore walls is minimal. For rocks with varying degrees of clay, the clay may act as a highly conductive portion of the rock and reduce the bilk resistivity of the rock. In these cases, the formation factor represents more than the pore structure of the rock and the resistivity of the saturating fluid. In shale or shaly sands, surface conduction and cation-exchange capacity significantly modify Archle's equation (Hill and Milburn, 1956; Waxman and Smits, 1968). The factors complicating the measurement of formation factor are more easily controlled in the laboratory than when making in situ logging measurements in the field.

\subsubsection{Formation Factor and Its Relation to Diffusive Flux in Porous Media}

The effective molecular diffusion coefficient $\left(D_{e}\right)$ in a porous medium is defined as:

$$
D_{e}=D_{0} \phi^{\prime} \tau
$$

where $D_{0}$ is the free-water diffusion coefficient evaluated at infinite dilution; $\phi^{\prime}$ is the matrix porosity; and $r$ is the matrix tortuosity. Bear (1972) defines tortuosity as

$$
r-\left(L / I_{e}\right)^{2}
$$


where $L$ is the sample length and $L_{e}$ is the actual tortuous flowpath length that a fluid particle would take passing through a sample of length $\mathrm{L}$. The range of tortuosity is $0<\tau \leq 1$, where a value of 1 would be a medium where all the pores were parallel capillary, tubes. Another generally accepted expression for tortuosity is that defined by Collins (1961):

$$
\tau=\left(L_{e} / L\right)
$$

Bear (1972) does not agree with this definition because it does not express tortuosity as affecting both the velocity and the driving forcie within a porous medium. This core-analysis report adopts the definition for porosity given by Equation (5). Because diffusion studies performed at SNL by Dykhuizen and Casey (1989) report tortuosity as defined by Equation (6), Figure 2.1 shows the relationship between the two definitions.

Another empirical geometrical variable which effectively decreases the free-water diffusivity in porous media is $\delta$, the constrictivity factor, $(0<\delta \leq 1)$ (van Brakel and Heertjes, 1974). Because tortuosity and constrictivity cannot be independently determined by experimental means, the following discussion lumps constrictivity with tortuosity.

Klinkenberg (1951) was the first to deduce that, from a theoretical viewpoint, the same factors that impede electrical conductance through a porous medium are also the same factors which impede diffusion of a conservative solute. Based upon the conclusion of Klinkenberg (1951) that diffusion should be analogous to conduction in a porous medium, an analogous equation to Equation (2) is

$$
\mathrm{R}_{\mathrm{b}}=\mathrm{R}_{\mathrm{w}}(\tau \phi)
$$


From Equation (2), F can then be rewritten as

$$
F-1 /(r \phi)
$$

Therefore, by determining a medium's porosity and formation factor, the tortuosity can be estimated as

$$
\tau-1 /(F \phi)
$$

For Equation (9) to be appripriate, it is assumed that flow of the electrical current is only through the saturated vold space. Using Equations (4) and (9), the formation factor can be used to calculate the effective molecular diffusion coefficient $\left(D_{e}\right)$ of a porous medium. The formation factor becomes the reduction factor by which the freewater diffusion coefficient is divided to yield $D_{e}$. Therefore, expressing Equation (4) in terms of formation factor,

$$
D_{e}-\left(D_{0} / F\right)
$$

Through diffusion studies, one can determine values for porosity and tortuosity which are often differentiated from those determined by other methods and can be referred to as diffusion porosity and diffusion tortuosity. From Equation (10) it becomes apparent that an effective diffusion formation factor can be calculated from diffusion studies. Other investigators (Skaglus and Neretnieks, 1986; Katsube et al., 1986) have found that the formation factor determined from diffusion studies is generally higher than the formation factor determined through resistivity measurements. Skagius and Neretnieks (1986) found that the formation factor determined using values of electrical resistivity was not only a function of the rock, but also of the permeating ions. They recognized the importance of electrical resistivity as a tool to yield approximate formation factors with orders of magnitude less effort than through diffusion studies, which are susceptible to experimental difficulties and uncertainties. 


\subsection{Gas Permeability}

Gas-permeability measurements were made on most core samples in both Phase 1 and Phase 2 studies. The measurements were made in a permeameter using standard steady-state techniques. The measirement of permeability utilizes a form of the Darcy equation which states that the flow through a porous medium of cross section (A) and length (L) is

$$
Q=K A d h / d L
$$

where dh is the head (pressure) drop across the sample of length $\mathrm{dL}$ and $\mathrm{K}$ is the hydraulic conductivity of the medium. The hydraulic conductivity is dependent upon the fluid properties density $(\rho)$ and viscosity $(\mu)$, and can be expressed in terms of intrinsic permeability (k) by the relation

$$
\mathrm{K}=\mathrm{k} \rho \mathrm{g} / \mu
$$

Using Equations (11) and (12), where $g$ is the acceleration due to gravity, the flow rate $(Q)$ can be expressed in terms of intrinsic permeability by the expression

$$
Q=k \rho g A d h / \mu d L
$$

Using a permeameter, one can measure the downstream head, the upstrearn head, and the flow rate through the sample, and use the following relationship to calculate the intrinsic permeability:

$$
k-Q \mu d L / \rho g A d h
$$

Gas-permeability measurements presented in this report were performed on intact (whole) core samples collected in the fleld, and on $2.5-\mathrm{cm}$ diameter by $5-\mathrm{cm}$ long cylindrical samples (core plucs) cored from the samples in the laboratory. Where possible, the permeability measurements 
in Phase 1 were made in both vertical and horizontal directions. In Phase 2, the gas permeability was measured in the direction coincident with the maximum dimension of the right-cylinder core plugs, thus corresponding to a horizontal-permeability measurement. For the whole-core samples, three measurements of permeability were obtained. The vertical measurement was made similar to the core-plug permeability determination. The horizontal-permeability measurements were made first in the estimated direction of the maximum or primary permeability axis $\left(0^{\circ}\right)$ and then in the estimated direction of the minimum permeability axis $\left(90^{\circ}\right)$.

For the permeability measurements made in Phase 1 and Phase 2, the permeating substance was helium gas. Gas-permeability measurements are generally performed under a confining pressure because: (1) the permeability of unconsolidated core material changes with confining pressure; (2) confining pressure retards sample bypass; and (3) confining pressure retards gas slippage. For well-cemented rocks, gas permeability is relatively insensitive to confining pressure with maximum deviations of 108 for confining pressures from atmospheric pressure to $14 \mathrm{MPa}$ (Core Laboratories, 1973). Generally, a confining pressure is selected which is just enough to prevent sample bypass. The gas-permeability measurements for this report were performed under ambient conditions of $2.1 \mathrm{MPa}$ net effective stress and $22.2^{\circ} \mathrm{C}$.

The phenomenon known as gas slippage, or the Klinkenberg effect, causes the permeability determined using a gas to be larger than a liquid permeability. Gas slippage occurs when the diameter of the pores approaches the mean free path of the gas which is a function of the molecular weight and the kinetic energy of the gas. The kinetic energy is in turn a function of the mean pressure of the gas. Gas slippage causes the amount of flow through a sample to be greater than that predicted by Darcy's Law. The gas-slippage effect is decreased as the mean pressure on the gas is increased and the mean pore diameter of the sample is increased. Thus, the Klinkenberg effect becomes more 
pronounced as the permeability decreases. Klinkenberg corrections can be used to estimate what an equivalent liquid permeability would be for a sample. In the Phase 1 study, two Klinkenberg permeabilities were performed on two low-permeability core samples to assess the error inherent in gas-permeability determinations in low-permeability media. Typical liquid-to-helium permeability ratios for the range of permeabilities tested in this study are 0.6 to 0.8 (Core Laboratories, 1973).

$2-11 / 2-12$ 


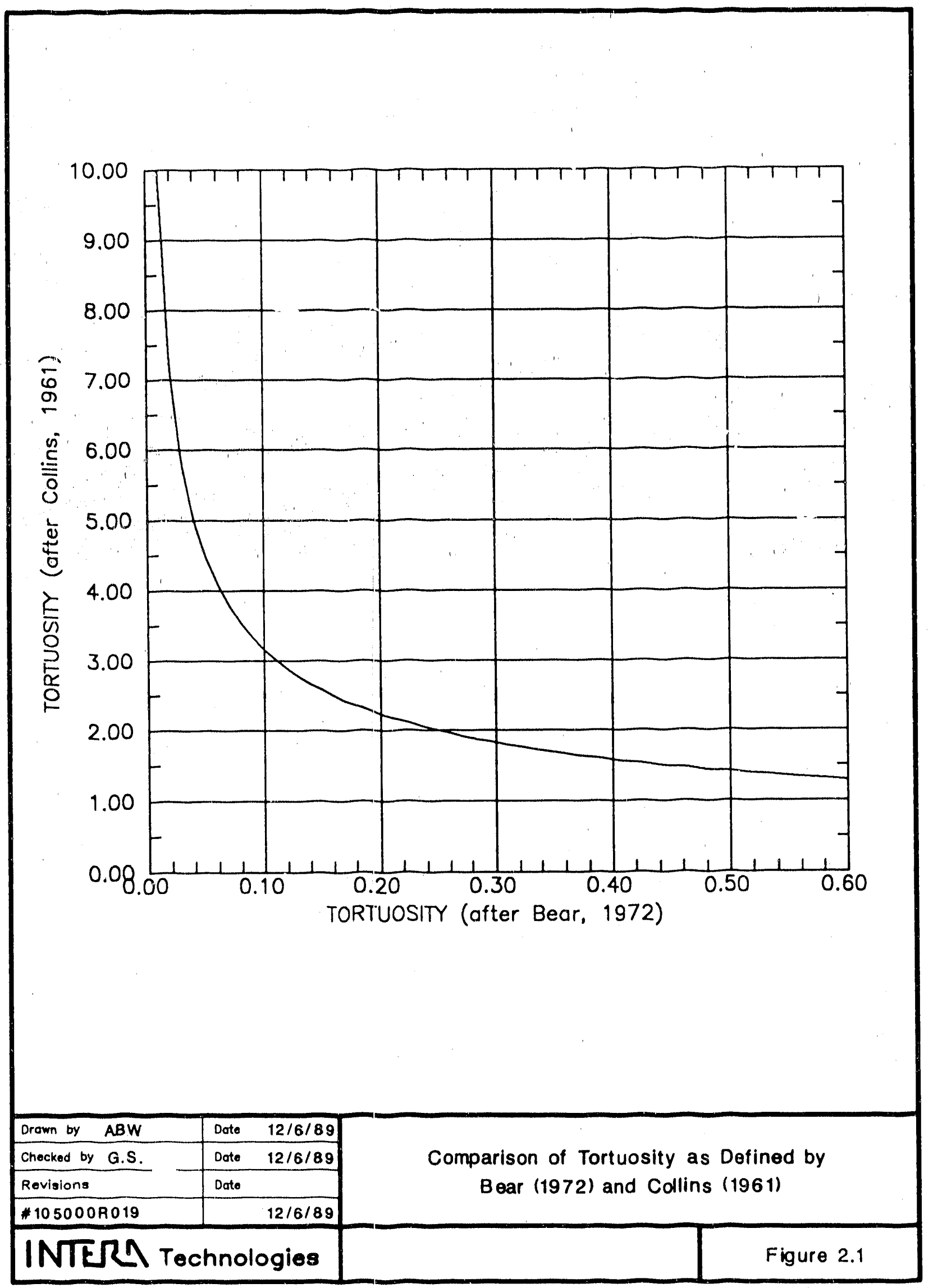




\subsection{SAMPLE SELECTION AND ANALYSES PERFORMED}

\subsection{Sample Selection and Sample Nomenclature}

For all boreholes cored during the characterization of the WIPP site, the representative core samples were cataloged and stored in the WIPP Core Library located at the WIPP site. The goal of sample selection for the analyses presented in this report was to select objectively, from the available Culebra core samples, a complete distribution of Culebra physical textures. The factors which were used in deciding which borehole locations to sample were: (1) availability of core samples; and (2) whether or not the available core samples were sufficiently competent for analysis.

Core samples from 20 different boreholes were chosen for analysis. Hydropads H-2, H-3, H-4, H-5, H-6, H-7, and H-11 (see Figure 1.1) are locations which have at least three wells penetrating the Culebra. Core samples from one or more wells at hydropads $\mathrm{H}-2, \mathrm{H}-3, \mathrm{H}-7$, and $\mathrm{H}-11$ were analyzed for this report. Where possible, whole-core samples were analyzed. The majority of samples analyzed were $2.5-\mathrm{cm}$-diameter core plugs, $5 \mathrm{~cm}$ long. In Phase 1, 3 whole-core samples and 21 core plugs were analyzed. In Phase 2, whole-core samples from 10 different boreholes and 51 core plugs from 15 different locations were analyzed. Combining the results from Phase 1 and Phase 2, 15 whole-core samples and 72 core-plug samples were analyzed.

The Phase 1 vore-analysis reports from Core Laboratories were not presented in s summary document, but were reported in three separate analysis summaries (Appendix B). Therefore, the sample numbers used in this report for Phase 1 represent an identifier designating the sulte of analyses and the sample numbers used by Core Laboratories. For example, sample number 2-3 represents Core Laboratories sample 3, reported in the second results summary. Some samples were reanalyzed and are designated 
by two sample and result numbers, separated by a slash (i.e., 2-3/3-3). Thus, one sample may have two parameter estimates

The results of the Phase 2 core study were reported in summary reports from Terra Tek (Appendix $C$ ) and $K \& A$ Laboratories (Appendix D). These samples are designated with an alphanuneric well identifier followed by a number indicating the number of the sample shosen. For example, H2a-1 indicates that $\mathrm{H} 2 \mathrm{a}$ is the well identifier and 1 is the sample identifier. Core plugs that were used to determine formation factor have an $F$ following the sample identifier (i.e., W-26-1F). Because some whole core samples contained contrasting matrix textures, more than one core plug was obtained from the same core sample in order to study the small-scale vertical heterogeneity in the Culebra. For these paired core plugs, the sample numbers are differentlated from one another by the addition of a lower-case letter $a$ or $b(1, a, w-12-1 a$ and $w-12-1 b)$. In the following sections, core samples will be described on an analysis-by-analysis basis. Tables 3.1 through 3.3 summarize which samples received what analysis during the Phase 1 and Phase 2 core studies.

\subsection{Standard Porosimetry}

\subsubsection{Helium Porosity}

Table 3.1 summarizes the analyses performed in the Phase 1 core study. Helium-porosity determinations were made for 3 whole-core samples, and 26 helium-porosity measurements were performed on 16 different core plugs. Table 3.1 shows that 12 different core plugs were reanalyzed. Six of the core plugs were reanalyzed at an ambient overburden stress of $2.4 \mathrm{MPz}$, and 6 were reanalyzed using the immersion method racher than the caliper method for determining bulk volume.

Tables 3.2 and 3.3 sumartze the analyses performed in the Phase 2 core study. All of the 12 whole-core samples were analyzed for helium 
porosity, gas permeability, and resaturation porosity. Boyle's Law helium-porosity determinations were performed for 51 core plugs. 'Terra Tek performed 45 of these analyses, and $K \& A$ Laboratories analyzed 6 other core plugs which were not analyzed by Terra Tek. K \& A Laboratories reanalyzed 18 of the Terra Tek semples as part of the mercury-intrusion tests. The 18 samples which were analyzed for helium porosity by both laboratories offer a comparison between laboratories, and an independent check of the Terra Tek results.

\subsubsection{Water-Resaturation Porosity}

For resaturation-porosity determinations, samples must be initially dry and then be saturated fully with a fluid of known density. Because all the core samples were storel dry in the WIPP Core Library, and because most samples have been in the library for years, drying of the core samples was judged unnecessary. However, the resaturation fluid choice was complicated.

The available Culebra core samples were all desaturated. The Culebra is composed predominantly of dolomite with lesser amounts of gypsum and halite (Core Laboratories, 1986), minerals which are susceptible to precipitation and dissolution. The possible choices of fluids used to resaturate the core were: (1) formation fluids from the wells from which the core samples were obtained; (2) an average Culebra formation fluid; (3) defonized water; or (4) some organic solvent such as tolulene or methanol. Ideally, one would use a formation fluid which would be at equilibrium with the minerals in each of the core samples. Because the core samples were obtained from a large number of locations with different formation-water chemistries, this approach was not considered to be practical because too many different fluids would be required. Also, a fluid with an average formation-water chenistry might not be at equilibrium in any of the samples and could affect results in an inconsistent manner. Organic solvents vere considered to 
be undesirable because these liquids would not wet the minerals in the samples in the same manner as water would in the formation. Recognizing that none of these liquids would be ideal, it was decided that delonized water be used as the resaturation fluld for all samples because it would be the simplest proceduce and provide a consistent fluid for all samples and would not provide additional contamination (F.J. Pearson, personal communication, 1987).

Resaturation porosity was not determined for any core samples from Phase 1 (Table 3.1). Resaturation porosity was determined for all 12 whole-core samples and 18 of the core plugs analyzed in the Phase 2 core study (Tables 3.2 and 3.3 ). Because helium porosities were also determined for all of these samples, 30 sample results are available to compare helium-porosity versus resaturation-porosity methods. In addition, 4 of these 18 core plugs were also analyzed by the mercuryintrusion method, thus giving a method of comparing the porosities determined by all three methods. While the sample group including all three porosimetry methods is too small to render quantitative conclusions, the comparison gives an intuitive grasp of the differences between the results of these methods. Mercury-intrusion porosimetry was not performed on more of the samples which had undergone resaturation testing because of the concern that the resaturation might have changed the pore structure of the sample through disisolution and/or precipitation.

\subsection{Mercury-Intrusion Porosimetry}

Mercury-intrusion porosimetry provides estimates of a sample's connected porosity and also yields the pore-throat-diameter distribution for a sample. In petroleum engineering, the results of mercury-intrusion porosimetry are used to define capillary-pressure curves for given formations. Twenty-four (24) core plugs were analyzed by the mercury- 
intrusion method by $K \& A$ Laboratorles (Table 3.3). In many cases, core plugs from the same piece of core were analyzed to give an indication of the heterogeneity of pore-size distributions over vertical scales of a few centimeters.

\subsection{Eormation Factor}

Formation factors were estimated from electrical-resistivity measurements for 15 ccre plugs in the Phase 2 core study (Table 3.3). The formation factor results were used to calculate 15 estimates of matrix tortuosity.

\subsection{Gas Permeability}

In the Phase 1 core study, gas-permeability determinations weice performed for 3 whole-core samples (Table 3.1). In addition, 20 gas-permeability determinations were performed on 16 core plugs. In the Phase 2 core study, 12 whole-core samples were analyzed for gas permeability (Table 3.2). The whole-core samples were analyzed twice for horizontal permeability: once in the direction thought to have the maximum permeability (e.g., along a fracture), and once in the direction $90^{\circ}$ from the maximum. Vertical gas permeabilities were also determined using core plugs from each of these same samples. In the Phase 2 core study, gas permeability was determined for 51 core plugs (Table 3.3). 


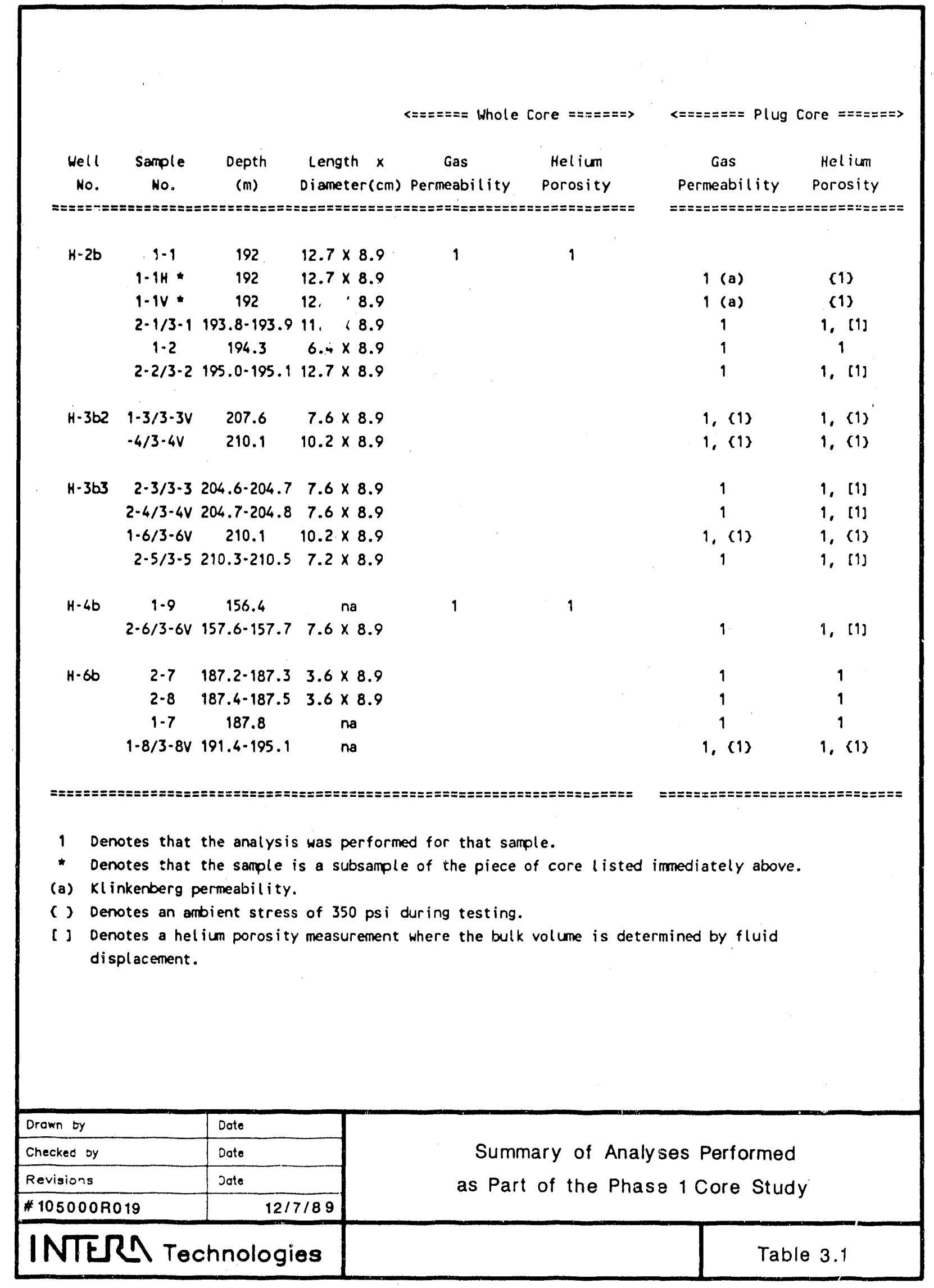


$<======\pi=$ Whole Core Analyses $===\pi=====\Rightarrow>$

\begin{tabular}{|c|c|c|c|c|c|c|}
\hline Hell & Sample & Depth & Length $x$ & Gas & Boyle's Law & Resaturation \\
\hline & No. & (m) & Diameter $(\mathrm{cm})$ & Permeability & Porosity & Porosity \\
\hline
\end{tabular}

\begin{tabular}{|c|c|c|c|c|c|c|}
\hline$H-5 b$ & $H-5 b-3$ & $274.7 \cdot 274.8$ & 13.7 & $\times 11.4$ & 1 & 1 \\
\hline $\mathrm{H}-7 \mathrm{bZ}$ & $\mathrm{H}-7 \mathrm{~b} 2-2$ & $79.2-79.6$ & 43.2 & $\times 8.9$ & 1 & 1 \\
\hline$H-10 b$ & $H-10 b-3$ & $423.1-.2$ & 20.3 & $\times 11.4$ & 1 & 1 \\
\hline$H-11$ & $H-11-1$ & $222.9-223.0$ & 12.7 & $\times 8.9$ & 1 & 1 \\
\hline$H-11 b 3$ & $H-1163-3$ & $226.1-226.2$ & 16.5 & $\times 8.9$ & 1 & 1 \\
\hline HIPP-12. & WIPP-12-3 & $253.6-25.3 .7$ & 13.9 & $\times 11.4$ & 1 & 1 \\
\hline HIPP-25 & HIPP-25-1 & $138.3-138.4$ & 25.4 & $\times 8.9$ & 1 & 1 \\
\hline WIPP-26 & UIPP-26-2 & $58.4-58.5$ & 15.2 & $\times 11.4$ & 1 & 1 \\
\hline \multirow[t]{2}{*}{ WIPP - 28} & WIPP-28-2 & $129.9 \cdot 130$ & 15.2 & $\times 11.4$ & 1 & 1 \\
\hline & WIPP-28.3 & $130.4-130.5$ & 15.2 & $\times 11.4$ & 1 & 1 \\
\hline \multirow[t]{2}{*}{ HIPP-30 } & WIPP-30-1 & $197.4-197.5$ & 10.2 & $\times 11.4$ & 1 & 1 \\
\hline & HIPP-30-2 & -194.6 & 10.2 & $\times 11.4$ & 1 & 1 \\
\hline
\end{tabular}

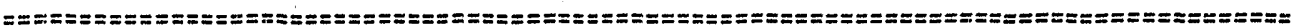
1 Denotes that the analysis was performed for that sample.

\begin{tabular}{|c|c|c|}
\hline Drown by & Dote & \multirow{4}{*}{$\begin{array}{l}\text { Summary of Whole-Core Analyses } \\
\text { Performed in the Phase } 2 \text { Core Study }\end{array}$} \\
\hline Checked by & Dote & \\
\hline Revisions & Dote & \\
\hline \#105000R019 & $10 / 18 / 90$ & \\
\hline$\sqrt{T L}$ & nologies & Table 3. \\
\hline
\end{tabular}




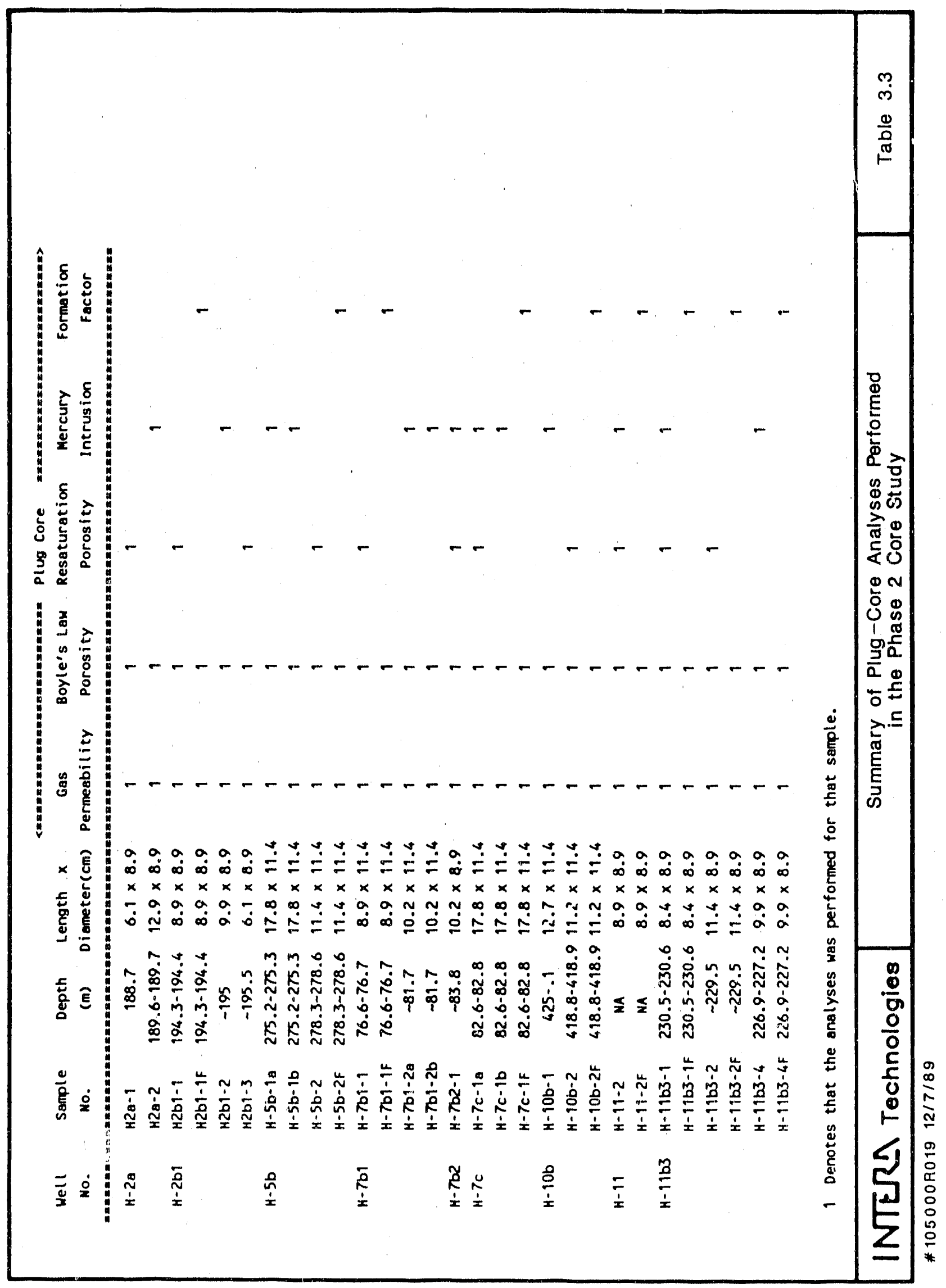




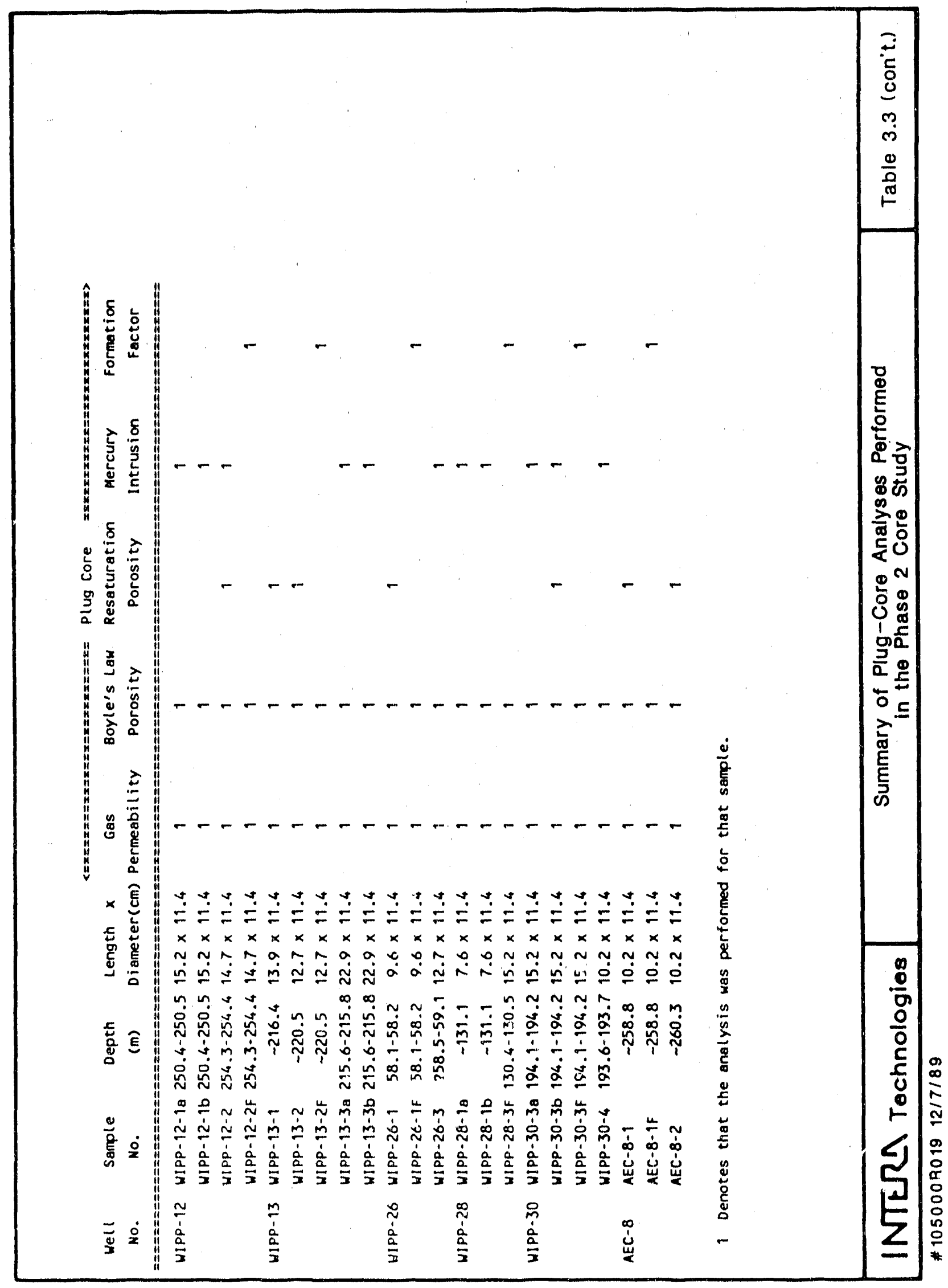




\subsection{CORE ANALYSIS RESULTS}

A summary of the results of the analyses performed by Core Laboratories can be found in Appendix B. Laboratory reports from Terra Tek and $K \& A$ Laboratories are presented in Appendices $C$ and $D$, respectively. An errata page with correct sample numbers is included with the Terra Tek report. The following section will discuss the analyses performed by these laboratories grouped by parameter estimated and test method. The presentation of the resuits will include discussions of parameter distributions and relationships between parameters when possible. Table 4.1 sumnarizes the results of the Phase 1 core study, Table 4.2 presents the results of the Phase 2 whole-core analyses, and Table 4.3 summarizes the Phase 2 plug-core results.

\subsection{Standard Porosity Analyses}

Helium porosity was determined for both whole-core and plug-core samples in both Phase 1 and Phase 2. Results from both studies will be reviewed separately and then combined to increase the sample size for statistical analysis. Data presented in Davis (1969) and Freeze (1975) indicate that porosity is a normally distributed parameter. To determine whether or not the porosity of the Culebra dolomite is also normally distributed, the porosity distributions of the analytical data from the Phase 1 and Phase 2 core-analysis studies are presented in the form of relativefrequency histograms. In some cases, cumulative-frequency distributions of porosity are also included in the discussion of the results.

\subsubsection{Helium Porosity}

Table 4.1 summarizes the results from the Phase 1 core study. Note that for some samples, more than one value is listed for porosity (see Section 3.0). In general, the bulk volume for most samples was determined by the caliper method and volumetric relationships. Because 
of concerns that the bulk volume of some samples might be in error because the samples were not perfect right cylinders, six samples (denoted in square brackets in Table 4.1) had bulk volumes determined by fluid displacement. Where this is the case, the two reported porosities determined for that sample have been averaged and the average value is used in the frequency distributions and other statistical analyses. For six other samples, porosity was determined with an ambient pressure of $2.4 \mathrm{MPa}$. All other Boyle's Law hellumporosity determinations (for both Phase 1 and Phase 2 core studies) were performed at atmospheric conditions. For well-consolidated rocks, the effect of overburden pressures is negligible (Core Laboratories, 1973). Because all other porosity measurements were performed without simulated overburden pressure, the measurements performed with a $2.4 \mathrm{MPa}$ pressure (denoted with a set bracket) are not included with the other values when presenting distribution statistics.

In the Phase 1 core study, three samples were analyzed for whole-core porosity (Table 4.1). Of these three, sample 1-5, from $\mathrm{H}-3 \mathrm{~b} 3$, is not representative of the Culebra dolomite because the sample is dominantly composed of gypsum. In addition, because the sample was excessively dried, some or all of the gypsum may have been converted to anhydrite, thus providing a non-representative porosity for the gypsum interval. Because there are only 2 whole-core porosities, they are lumped with the plug-core data. Excluding porosities determined with a simulated o rerburden pressure, there are 16 helium-porosity determinations from the Phase 1 core study. Figure 4.1 is a relative-frequency histogram of the Phase 1 helium porosities. The distribution in Figure 4.1 does not display a normal distribution. Given the low number of samples (N) used for the relative-frequency histogram $(N-16)$, it is not surprising that the distribution is non-ideal. The arithmetic mean $(\mu)$ of the porosity data is 0.175 with a standard deviation $(\sigma)$ of 0.057 . Figure 4.2 is a cumulative relative-frequency curve for Phase 1 helium porosities. The median (Md) of a distribution is defined as that value 
having a cumulative relative frequency equal to 0.5 , which indicates that one half of the observations has a value less than the median and one half of the observations has a value greater than the median. Figure 4.2 shows that the median of the Phase 1 helium porosities is 0.174 .

The Culebra is a massive, laminated dolomite with pronounced vertical heterogeneity, as can be seen in core samples and on outcrops, such as at Culebra Bluff on the Pecos River, 20 miles wesc of the WItP site. As part of the Phase 2 core study, multiple core plugs were obtained trom some Culebra samples because of a lack of avallable core samples for the desired sulte of analyses and to characterize heterogeneity between closely spaced samples (see Section 3.0). Twenty-one (21) pieces of Culebra core had two plugs cored over vertical distances of less than $10 \mathrm{~cm}$. Figure 4.3 is a bar chart of helium-porosity data for core plugs from the same core sample. The helium porosity of one core plug is compared to the porosity of its close neighbor. The chart illustrates that differences in porosity measured in samples within 5 to $10 \mathrm{~cm}$ of each other vertically can be as small as 0.005 and as high as 0.093 , and demonstrates the heterogeneity of porosity in the Culebra. Because of this heterogeneity, all of these 42 independent porosity measurements were treated as point values.

Elghteen of the 24 core plugs analyzed by $K$ \& A Laboratories using mercury-intrusion porosimetry were first cored and analyzed for porosity by Terra Tek using Boyle's Law helium porosimetry. These samples were shipped from Terra Tek to $K \& A$ Laboratories where helium porosity was remeasured, thus allowing a laboratory-to-laboratory comparison. Figure 4.4 plots $\mathrm{K} \&$ A Laboratorles helium porosity versus Terra Tek hellum porosity for the 18 samples measured by both laboratories. In general, the porosity values are nearly identical 
with the $R^{2}$ of the linear regression of these data equal to 6.93 . Figure 4.4 and Table 4.3 show that the $K$ \& A Laboratories porosities are usually 0.005 to 0.01 larger than the Terra Tek porosities, with a maximum observed difference of 0.056 . This data gives an estimate of the reproducibility of the Boyle's Law hellum porosity. The discrepancies are probably the result of difficulty in the precision of estimating bulk volume and possible differences in the techniques used by the two laboratories in estimating bulk volumes. Because the correct helium porosity cannot be discerned, the arithmetic average between the two reported porosities is the value used in further data reduction and reporting.

In the Phase 2 core study, 51 core plugs were analyzed for hellum porosity by the Boyle's Law method. Figure 4.5 is a relative-frequency histogram of these porosity determinations. The distribution of porosities is not a normal distribution, and is skewed toward the lower values of the range of porosities determined during the Phase 2 core study. The arithmetic average of these determinations is equal to 0.149 , and the standard deviation is equal to 0.055 . Because the distribution is skewed, the mean does not coincide with the peak of the distribution (Figure 4.5). The median core-plug porosity for the helium porosities obtained in the Phase 2 study is 0.138 .

Twelve whole-core hellum-porosity measurements were performed in the Phase 2 core study. Figure 4.6 is a relative-frequency histogram combining all 63 helium-porosity measurements (whole-core and core-plug analyses combined) from the Phase 2 core study. The addition of the whole-core porosities did not significantly affect the distribution of plug-core porosities shown on Figure 4.5. Again, the distribution of porosity is not normal and skewed. The arithmetic mean is equal to 0.147 with a standard deviation of 0.051 . Figure 4.7 is a cumilative relative-frequency curve for all the Phase 2 hellum porosities. The median value is 0.134 . 
All helium porosities for the Culebra dolomite determined during both the Phase 1 and Phase 2 core studies using Boyle's Law techniques are summarized in Table 4.4. Table 4.4 also lists an arithmetic-average porosity value for any samples for which more than one determination was made. Figure 4.8 is a relative-frequency histogram combining all 79 helium porosities measured from both Phase 1 and Phase 2. Heliumporosity values are normally distributed and are slightly skewed toward the lower part of the range of porosities presented, with an arithmetic mean of 0.153 and a standard deviation of 0.053 . The mean porosity does not coincide with the peak of the distribution, quantitatively confirming the skewed nature of the distribution. Figure 4.9 is a cumulative relative-frequency curve for both Phase 1 and Phase 2 helium porosities, and shows that the median porosity is 0.141 .

Figure 4.10 compares the cumulative relative-frequency curves of the Phase 1 and Phase 2 hellum-porosity results. Two differences between these curves are indicated. First, the Phase 2 results create a much smoother distribution, which is not surprising, considering that the sample size for the Phase 2 helium porosities was approximately 4 times greater than that of Phase 1 . The second observation is that the median porosity for the Phase 1 helium porosities is 48 larger than that of the Phase 2 data.

It was noted in Section 1.0 of this report that two hydrologic regimes appear to be present in the vicinity of the WIPP site. One regime acts hydraulically as a fractured medium with transmissivities greater than or equal to $1.0 \mathrm{E}-6 \mathrm{~m} \mathrm{~m}^{2} / \mathrm{s}$ and exhibits double-porosity behavior. The other hydrologic regime has transmissivities less than $1.0 \mathrm{E}-6 \mathrm{~m}^{2}$ and fluld-pressure responses to hydraulic tests generally do not display double-porosity behavior (Beauheim, 1987). LaVenue et al., (1990) Indicate that the estimated fastest travel path from the center of the WIPP site to the WIPP-site boundary includes the $\mathrm{H}-3$ and $\mathrm{H}-11$ hydropads. The average porosity for core samples from $\mathrm{H}-3$ and $\mathrm{H}-11$ is 
0.173 , or two percent higher than the overall average WIPP-site Culebra porosity of 0.153 . Comparing the porosity values on Table 4.4 with the transmissivity data for the Culebra in WIPP-site wells shown in Beauheim (1987, Figure 6.1) Indicates that some locations exhibiting higher permeability and double-porosity behavior have reported porosity values higher than the WIPP-site average Culebra porosity and lower permeability locations such as the $\mathrm{H}-2$ hydropad, have porosity values less than the WIPP-site average Culebra porosity. However, data comparison also shows the heterogeneous distribution of porosity within the Culebra even at the hydropad scale. Thus, while the average WIPPsite Culebra porosity may underestimate the porosity of the fastest offsite flow path, general conclusions concerning the relationship between permeability and porosity are not warranted using the data presented in this report. The porosity and permeability data should be compared on a site-by-site or area-by-area basis for any particular area under investigation.

The quantity and quality of samples recovered during core drilling at WIPP-site wells contributes a further uncertainty to the relationship between Culebra permeability and porosity. For many WTPP-site wells, the large amount of lost core in apparently porous and fractured parts of the Culebra indicates that the most porous material may have been destroyed and not recovered during coring and is, therefore, not represented in the final porosity distribution. Thus, the parameter distributions shown on Figures, 4.8 and 4.10 represent seiected determinations for helium porosity of the Culebra in the vicinity of the WIPP site. This degree to which these distributi ns remain affected by sample selection is unquantifiable.

\subsubsection{Water-Resaturation Porosity}

As discussed in Section 3.2.2, deionized water was the fluid used to determine resaturation porosity. In an attempt to quantify the effect 
of using delonized water as the resaturation fluid, a pair of core plugs was removed from a single plece of core from well $\mathrm{H}-5 \mathrm{~b}$ (sample H-5b-1). Helium porosities were measured for each sample and then compared to the resaturation porosities for each sample, one analyzed using delonized water, and one analyzed using a laboratory approximation of the $\mathrm{H}-5 \mathrm{~b}$ formation fluid. The core from well $\mathrm{H}-5 \mathrm{~b}$ was used in this study because well $\mathrm{H}-5 \mathrm{~b}$ had a large number of core samples, a relatively high formation-fluid density $\left(1.102 \mathrm{~g} / \mathrm{cm}^{3}\right)$, and several dissolved-solid determinations with similar values (Robinson and Lambert, 1987).

Core-plug sample H-5bl-1a had a helium porosity of 0.1078 and a resaturation porosity of 0.1068 measured with deionized water. Core plug $\mathrm{H}-5 \mathrm{bl}-1 \mathrm{~b}$ had $\mathrm{a}$ helium porosity of 0.1245 and a resaturation porosity of 0.1207 measured with formation fluid. It thus appears that the use of delonized water as the resaturation fluid can have minimal effects, although this does not imply that this result can be extrapolated to all the resaturation porosities.

All samples which were analyzed by resaturation techniques were examined after analysis for any outward signs of mineral dissolution. Eighteen (18) core plugs and 12 whole-core samples were analyzed. of the 30 samples analyzed, 8 showed signs of mineral dissolution as a result of the resaturation-porosity determinations. Figure 4.11 is a plot of resaturation porosity versus the associated helium porosity for all 30 samples. The $R^{2}$ of the linear regression of these two sets of data is 0.99 . The difference between the porosity measurements is only greater than 0.01 for two samples, with the average difference being less than 0.005 . In general, the results of the resaturation porcdimetry are similar to those obtained using Boyle's Law helium porosimetry. However, Figure 4.11 indicates that the resaturation porosities in the majority of these samples aie larger than the helfum porosities. The differences in these results can be explained by two 
arguments. Eicher dissolution was important and altered and enlarged the pore volume of the samples during analysis, or the experimental standard error for both methods is greater than the resolution of the results. The differences are likely best explained using both arguments. Because dissolution was not observed to be universally active on all samples, the experimental standard of error probably best explains the variation in the results.

\subsubsection{Grain Density}

In porosity calculations, two of the three sample parameters (bulk volume, pore volume, and grain volume) must be determined. For the porosity determinations discussed thus far, both bulk volume and pore volume were determined. From this data base, calculation of rock grain density is a standard procedure for the analyzing laboratories. Figure 4.12 is a relative-frequency histogram of 73 grain-density determinations from both Phase 1 and Phase 2 core studies. The distribution is skewed toward the larger values of grain density, with an arithmetic mean of $2.82 \mathrm{~g} / \mathrm{cm}^{3}$ and a standard deviation of $0.019 \mathrm{~g} / \mathrm{cm}^{3}$. The median of the distribution of grain densities $1 \mathrm{~s}$ $2.83 \mathrm{~g} / \mathrm{cm}^{3}$. If grain density were a normally distributed parameter, one would expect the best estimate for grain density to be $2.82 \mathrm{~g} / \mathrm{cm}^{3}$. From viewing Figure 4.12 , it is apparent that $2.83 \mathrm{~g} / \mathrm{cm}^{3}$ is the most common grain density, which is consistent with the non-normal, skewed nature of the distribution.

\subsection{Mercury-Intrusion Porosimetry}

$K$ \& A Laboratories used mercury-intrusion porosimetry to analyze 25 Culebra dolomite samples and determine endpoint mercury saturation, mercury-intrusion porosity, and pore-throat radil. The samples analyzed included 24 core plugs and one segment of a core plug, and the results are summarized in Table 4.5, along with the helium porosities determined 
by $\mathrm{K} \& \mathrm{~A}$ Laboratories. The median pore-throat radii were calculated from cumulative-frequency plots of the $K \& A$ mercury-intrusion data. The core-plug segment was obtained from sample H-10b-1 and was analyzed because the analysis of the complete core sample indicated an anomalously low endpoint mercury saturation. The samples were subjected to incremental pressure changes up to $207 \mathrm{MPa}$. The $\mathrm{K} \& \mathrm{~A}$ Laboratories report containing the complete set of results is presented in Appendix $D$, and includes relative-frequency histograms of pore-throat radius and capillary-pressure curves for each sample where mercury is the nonwetting fluid. The pore-size distributions determined using mercuryintrusion porosimetry are based on the simplified capillaric model, Indicated by Equation (1), that does not rigorously satisfy the complex pore geometry of geologic media (Scheidegger, 1974).

Discussion of the mercury-intrusion-porosimetry determinations presented in this report is limited to a comparison between the porosities determined by the intrusion technique and to calculation of median pore-throat radil for ach sample. All samples reached 508 mercury saturation at pressures less than or equal to $10.3 \mathrm{MPa}$. The hellum porosities, endpoint saturations, median pore-throat radil, and mercury-intrusion porosities for the 25 samples analyzed are listed in Table 4.5. The mercury-intrusion porosity for each sample is calculated by multiplying the endpoint saturation by the helium porosity. The endpoint saturations range from a low of 66.78 to a high of 99.98 . The average endpoint wercury saturation at $207 \mathrm{MPa}$ is 95.48 . The average helium porosity for these samples is 0.154 and the average mercury-intrusion porosity is 0.148 . The low endpoint mercury saturation of 66.78 for sample H10-1b-1 when compared to the near-average value of 95.28 determined for a segment of this core plug (Table 4.5) could indicate that pore-throat sizes in this sample of the Culebra may be heterogeneously distributed (Appendix D). The air-perneability values determined for sample HIO-1b-l were also lower for the complete core sample than for the core-plug segment, a further indication of heterogeneity. 
There are several possible explanations for the endpoint mercury saturations being less than 1008 for most samples. The most obvious explanation is that all non-saturated pore spaces have radil less than the radius accessible to mercury at $207 \mathrm{MPa}$. Another possible explanation lies in the sequence of laboratory procedures. K\& A Laboratories determined helium porosity before conducting mercury-intrusion porosimetry and then used that porosity to define sample pore volume. Figure 4.4 shows that $K \& A$ Laboratories consistently determined a higher helium porosity than Terra Tek when testing the same core-plug samples. If Terra Tek's values were actually more representative of the true porosity, this fact could explain the less than 1008 endpoint mercury saturations reported. Alternatively, if large pore spaces were only accessible by extremely small pore radis, it is conceivable that the larger pores could not be accessed by merciry intrusion.

Median pore-throat radii calculated from the cumulative-frequency plots of the results of mercury-intrusion porosimetry range from a low of $0.077 \mu \mathrm{m}$ to a high of $0.588 \mu \mathrm{m}$. The arithmetic mean of the calculated median pore-throat radil is $0.315 \mu \mathrm{m}$. Given the assumptions implicit to mercury-intrusion porosimetry, 508 of the pore-throat radil for the 25 samples are greater than $0.315 \mu \mathrm{m}$. The distributions of pore-throat radil for the samples analyzed by $K \& A$ Laboratories (Appendix D) indicate that the pore-throat radil are distributed differently between samples. However, most pore radii generally range between 0.05 and $0.6 \mu \mathrm{m}$ and the median pore radil for all samples have a range of approximately one order of magnitude.

In the Phase 2 core study, some plug-core samples were taken from the same larger piece of core and were separated generally by 5 to $10 \mathrm{~cm}$. These samples are those which have sample numbers which differ only by the addition of an (a) or a (b) at the end of the sample number, as indicated on Table 4.4. The variation in pore-throat-radius distribution between these closely spaced sample pairs can be as heterogeneous as 
samples taken from different wells. For example, the distributions of pore-throat radil for samples $H-7 b l-2 a$ and $H-7 b 1-2 b$ are significantly different (Appendix D). The median pore radil of the two samples are different while the modal pore radil of the samples are the same. Also, sample $H-7 b l-2 b$ has a significant percentage of 1 ts pore volume occupied by large-diameter pores that are immediately accessible to the external edges of the sample. For some pairs of samples, the variations in the distributions of pore-throat-radil are negligible and the median porethroat radil are equal (samples $\mathrm{H}-5 \mathrm{~b} 1-1 \mathrm{a}$ and $\mathrm{H}-5 \mathrm{bl}-1 \mathrm{~b}$ ).

The results of mercury-intrusion porosimetry indicate the heterogeneous nature of porosity distribution in the Culebra dolomite. The values and variations in endpoint mercury saturation and the distribution of porethroat radil between samples illustrate this heterogeneity. In general, the distribution of pores within the Culebra can vary significantly over small vertical distances. However, the values of the median pore-throat radif range over only one order of magnitude between all samples, and in the majority of samples, the range is much less.

\subsection{Formation-Factor Results}

Terra Tek Core Services determined formation factors for 15 separate core plugs (Table 4.6). Values range from a low of 12 to a high of 407 . Figure 4.13 is a relative-frequency histogram showing the distribution of formation-factor values. Although a value of zero is represented on the abcissa of the histogram, the theoretical lower limit for formation factor is 1. The arithmetic mean of the formation-factor values is 96.1. The distribution appears to be log-normal. Figure 4.14 is a relativefrequency histogram of the $\log$ of the formation-factor values. The geometric mean of this distribution is 58.8, and the histogram approximates a log-normal distribution. Because the formation factor is a function of the pore geometry and non-normal pore-size distribution, it might be expected that the distribution of formation-factor values would be non-normal. 
Table 4.6 presents tortuosity values calculated using formation-factor values for 15 samples using Equation (9). The formation-factor values in Table 4.6 were calculated with Equation (2) from electrical-resistivity data. Figure 4.15 is a relative-frequency histogram of the calculated tortuosity values. The distribution is not well-defined due to the small sample size. The arithmetic average of calculated tortuosity is 0.14 , the standard deviation is 0.08 , and the median is 0.12 . The values of tortuosity ranged from 0.03 to 0.33 . Table 4.6 lists the values of formation factor and tortuosity for each of the samples measured. Figure 4.16 is a plot of the helium porosity of each sample versus the tortuosity of the sample, and indicates a general trend of increasing tortuosity with decreasing porosity. It thus appears that as the fraction of pore space decreases, the intersection of these pore spaces also decreases.

Terra Tek (see Appendix C) calculated the constants for Archie's equation (Equation (3), Section 2.3.1). Using these results, the formation factor for the Culebra can be related to porosity by the relationship

$$
F-1.0 / \phi^{2.13}
$$

where 2.13 represents the cementation ractor. Figure 4.17 plots the formation-factor values determined from electrical-resistivity measurements for each sample against the formation factor calculated for each sample using the sample porosity and Equation (15). The plotted data have an $\mathrm{R}^{2}$ for the linear regression of 0.77 .

The use of resistivity studies to determine matrix diffusivities has proven to be effective and results indicate that the formation factor determined using electrical-resistivity measurements is usually smaller than that determined by diffusion studies (Skagius and Neretnieks, 1986; Katsube et al., 1986). For example, Katsube et al. (1986) determined that the diffusion-flux formation factor for a crystalline granite was 
1.9 times greater than the electrical-resistivity formation factor. The differences between these two methods used to estimate formation factor are most likely due to dead-end pore space, constrictivity, and grain-tofluid interface phenomena.

Sandia National Laboratories (SNL) performed diffusion experiments on four samples of the Culebra dolomite, and the results have been released in a series of internal technical memorandums and a Sandia National Laboratories report (Casey and Stockman, 1988a; Casey and Stockman, 1988b; Casey and Stockman, 1988c; Casey and Stockman, 1989; Dykhuizen and Casey, 1989). Nine different diffusion experiments were performed on four different samples from three different locations. Four experiments were performed on a rock sample of the Culebra dolomite from core recovered from well WIPP-19 (sample WIPP-19). Three experiments were performed on one subsample of the Culebra dolomite from a slab of the Culebra dolomite from the WIPP-site exhaust shaft (sample ESM-143-2), and another experiment was performed on a different subsample of that slab (sample ESM-143-1). One experiment was performed on a rock sample of the Culebra dolomite from the WIPP-site air-intake shaft (sample A1S-SNL-16). The diffusion porosity and diffusion tortuosities were determined using methods described in Katsube et a1. (1986) (Dykhuizen and Casey, 1989). Table 4.7 summarizes the results of these diffusion experiments. When calculating mean values from these data, if a rock sample was used for more than one diffusion experiment using different tracers, the results from all experiments on the same sample were averaged to give an average tortuosity and diffusion porosity for that rock sample. All experimental values were then averaged to arrive at a mean value for the four rock samples. This procedure incorporates the variation within one sample, yet prevents that variation or any one sample from dominating the average.

The results of the SNL diffusion experiments indicate a range in diffusion tortuosity of 0.03 to 0.17 , with a mean value of 0.1 (N - 4). 
The diffusion porosity ranged from 0.01 to 0.13 , with a mean value of $0.07(\mathrm{~N}-4)$. The average diffusion formation factor is 239 (N - 4), which is nearly 2.5 times greater than the mean formation factor of 96.1 calculated from electrical-resistivity measurements. This result is not surprising, given that the porosities of the samples used in the diffusion experiment are on the average much less than the porosities of the samples from which the electrical-resistivity formation factors were calculated. Because of the limited sample sizes, no conclusions or correlations were developed between the results of the diffusion experiments and the results derived from electrical-resistivity calculations.

Figure 4.18 combines the results from the electrical-resistivity calculations and the diffusion experiments. The diffusion tortuosities are plotted as a function of both diffusion porosity (open symbols) and helium porosity (filled symbols). All experiments on the same sample are indicated by the same symbol to indicate the experimental uncertainty in the results for that sample. Figure 4.18 shows that the variability in results for a given sample is hich but the results from the diffusion experiments generally fall within the scatter of the values derived from electrical-resistivity measurements. The data presented in Table 4.7 show that the diffusion porosity is generaliy less than porosity determined by other methods. Dykhuizen and Casey (1989) indicate that this difference is due to the inadequacies of simple versions of Fick's First Law of Diffusion for solutes in a porous medium. The differences may also be due to incomplete resaturation of the pore spaces with the fluid used in the diffusion experiments (Casey and Stockman, 1989) and the low number of samples (4). Also, heterogeneity can contribute significant differences in porosity over distances of several centimeters using various subsamples of a given rock sample, as shown on Figure 4.3. 


\subsection{Gas-Permeabil1ty Results}

Freeze (1975) reported that permeabilities are log-normally distributed within a formation and presented many potential reasons for this distribution pattern. The most reasonable explanation for a log-normal distribution of permeability appears to be that permeability is dependent upon pore-size distributions, and pore-size distributions of rocks and sediments are frequently log-normally distributed. Because this study assumed a log-normal probability-distribution function of permeability and uniform two-dimensional flow, the average permeability was assumed to be equal to the geometric mean of the permeability data (Matheron, 1967). For a log-normal distribution, the geometric mean should coinciue with the mealan. The geometric mean is defined as

$$
G_{m}=\log ^{-1}\left(\left(\Sigma \Sigma^{1-1} \log k\right) / n\right)
$$

n

The permeabilities pret anted in this report appear to be, in must cases, rapresentative of the matrix, as opposed to the formation as a whole, which may be fractured. Portions of the Culebra with transmissivities greater than $1.0 \mathrm{E}-6 \mathrm{~m} \mathrm{~m}^{2} / \mathrm{s}$ are generally thought to be fractured (Beauheim, 1987). LaVenue et al. (1988) indicate that an intrinsic permeability of $1.3 \mathrm{E}-14 \mathrm{~m}^{2}$ corresponds to a transmissivity of $1.0 \mathrm{E}-6 \mathrm{~m}^{2} / \mathrm{s}$, assuming a fluid density of $1000 \mathrm{~kg} / \mathrm{m}^{3}$, a viscosity of $0.001 \mathrm{~Pa} \cdot \mathrm{s}$, a formation thickness of $7.7 \mathrm{~m}$, and a vertically homogeneous formation. A few permeabilities greater than $1.3 \mathrm{E}-14 \mathrm{~m}^{2}$ were measured during Phase 1 and Phase 2 core-analysis studies (see Tables 4.1 through 4.3), and will be used to calculate permeability averages and distributions in this report. Therefore, core-sample analyses ylelded values of permeability in the range of values that have been attributed to the effects of fracturing according to well-test analyses. 
In the Phase 1 core study, 9 measurements of horizontal permeability were made. One measurement was performed on a whole-core sample, and the rest on plug cores. The values ranged from $7.9 \mathrm{E}-18 \mathrm{~m}^{2}$ to $9.9 \mathrm{E}-15 \mathrm{~m}^{2}$ (Table 4.1) for this small sample ( -9$)$. Analysis of these data Indicated a non-normal distribution with a geometric mean of $1.6 \mathrm{E}-15 \mathrm{~m}^{2}$ and a median permeability value of $7.9 \mathrm{E}-17 \mathrm{~m}^{2}$. The Phase 1 core study included 14 measurements of vertical permeability (Table 4.1), 12 from plug cores, and 2 from whole-core samples. The permeabilities ranged from $8.4 \mathrm{E}-18 \mathrm{~m}^{2}$ to $5.2 \mathrm{E}-14 \mathrm{~m}^{2}$. Analysis of the vertical-permeability data indicated a nore well-defined distribution than that for horizontal permeabilities because of the increased sample size. The distribution appears to approach a log-normal distribution, although the geometric mean is $4.8 \mathrm{E}-16 \mathrm{~m}^{2}$ and does not equal the median, which was determined to be $5.4 \mathrm{E}-16 \mathrm{~m}^{2}$.

In Phase 2, horizontal permeabilities were determined for 45 plug-core samples. The permeability ranged from a minimum of $2.0 \mathrm{E}-17 \mathrm{~m}^{2}$ to a maximum of $5.7 \mathrm{E}-14 \mathrm{~m}^{2}$ (Table 4.3 ), with a geometric mean of $3.7 \mathrm{E}-16 \mathrm{~m}^{2}$ and a median of $2.6 \mathrm{E}-16 \mathrm{~m}^{2}$. Figure 4.19 is a relative-frequency histogram of the $\log 10$ of all horizontal permeabilities measured in Phase 1 and Phase $2(N-66)$. For the 12 whole-core samples which had a maximum and a minimum horizontal permeability measured (Table 4.2), the arithmetic average between the two values was used. The lowest horizontal permeability measured was $7.9 \mathrm{E}-18 \mathrm{~m}^{2}$ and the highest was $3.6 \mathrm{E}-13 \mathrm{~m}^{2}$. The permeability distribution appears to be $10 \mathrm{~g}$-normal with an arithmetic mean of $6.2 \mathrm{E}-15 \mathrm{~m}^{2}$, a geometric mean of $4.5 \mathrm{E}-16 \mathrm{~m}^{2}$, and a median of $2.7 \mathrm{E}-16 \mathrm{~m}^{2}$.

Figure 4.20 is a relative-frequency histogram of the log10 of all vertical permeabilities measured in both core studies $(N-26)$. The lowest vertical permeability measured was $8.4 \mathrm{E}-18 \mathrm{~m}^{2}$ and the highest was $5.2 \mathrm{E}-14 \mathrm{~m}^{2}$. The permeability distribution is $\log$-normal with an 
artithmetic mean of $5.1 \mathrm{E}-15 \mathrm{~m}^{2}$, a geometric mean of $9.0 \mathrm{E}-16 \mathrm{~m}^{2}$, and a median of $3.5 \mathrm{E}-16 \mathrm{~m}^{2}$.

Figure 4.21 is a plot of the log10 of 72 horizontal-permeability determinations from the Phase 1 and Phase 2 core studies versus the helium-porosity values for the same samples (Tables 4.1 to 4.3 ). The values plotted on Figure 4.21 include the results of both the plug-core and whole-core analyses. The horizontal permeability plotted for the whole-core samples is the arithmetic average of the two values shown on Table 4.2. Figure 4.21 shows that although the $\log 10$ of horizontal permeability tends to increase with porosity, higher-than-average permeability values were also determined for samples with average porosity values.

Figure 4.22 is a plot of the $\log 10$ of 25 vertical-permeability determinations from the Phase 1 and Phase 2 core studies versus the helium-porosity determinations for the same samples (Tables 4.1 to 4.3). (The vertical-permeability value for sample $\mathrm{H}-3 \mathrm{~b} 31-5$ was not included in the plot because the porosity was considered to be unrepresentative as indicated on Table 4.1.) Figure 4.22 generally shows that the $\log 10$ of vertical permeability increases with increasing porosity. Figure 4.23 is a plot of the $\log 10$ of 23 horizontal-permeability determinations from Phase 2 plug-core samples versus the median pore-throat radil calculated from mercury-intrusion porosimetry for those same samples. Figure 4.23 shows that the $\log _{10}$ of horizontal permeability is apparently directly related to the median pore-throat radius. A comparison of Figures 4.21 and 4.23 indicates that the log10 of horizontal permeability appears to be more directly related to median pore-throat radius than to porosity. 


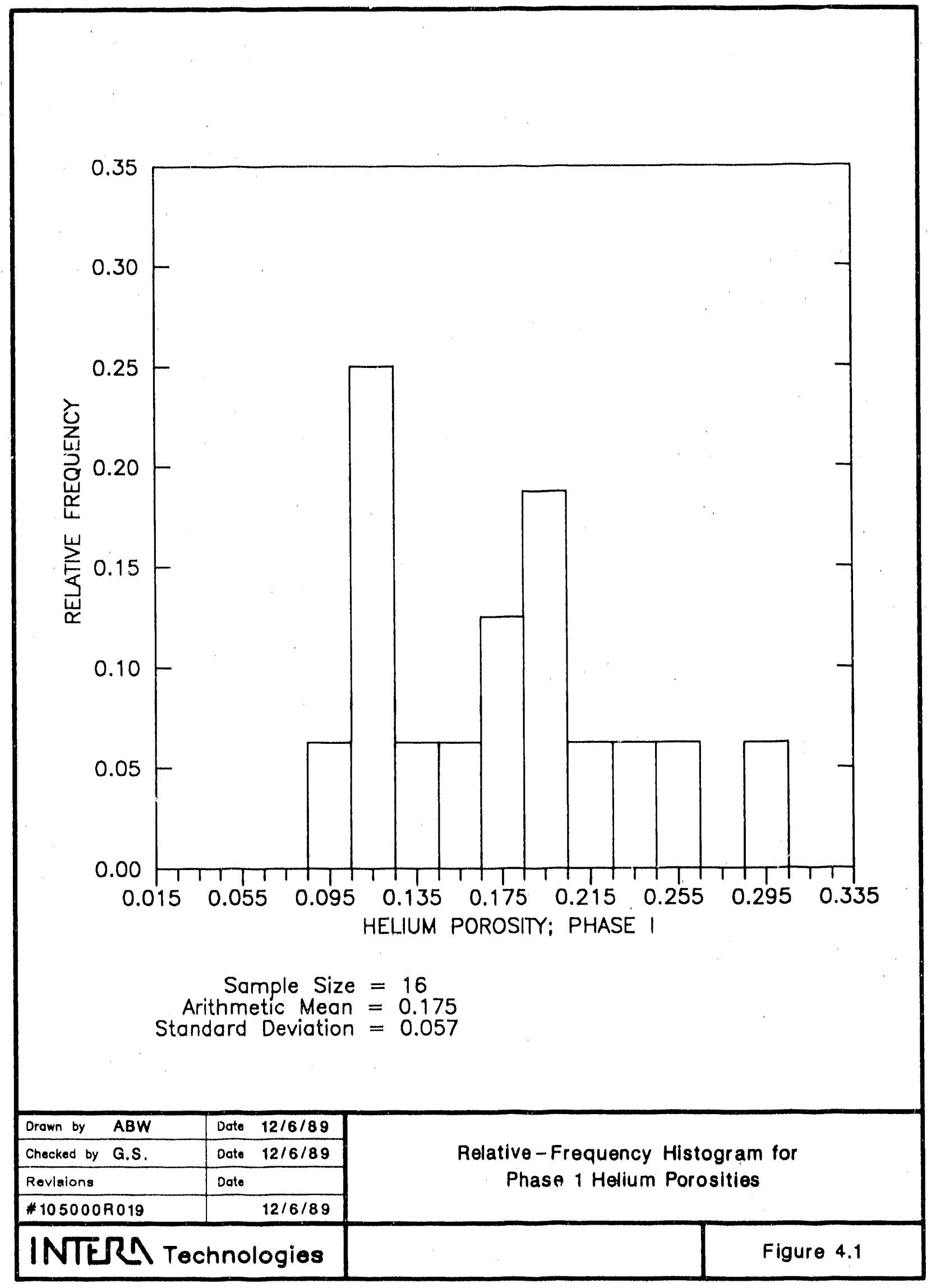




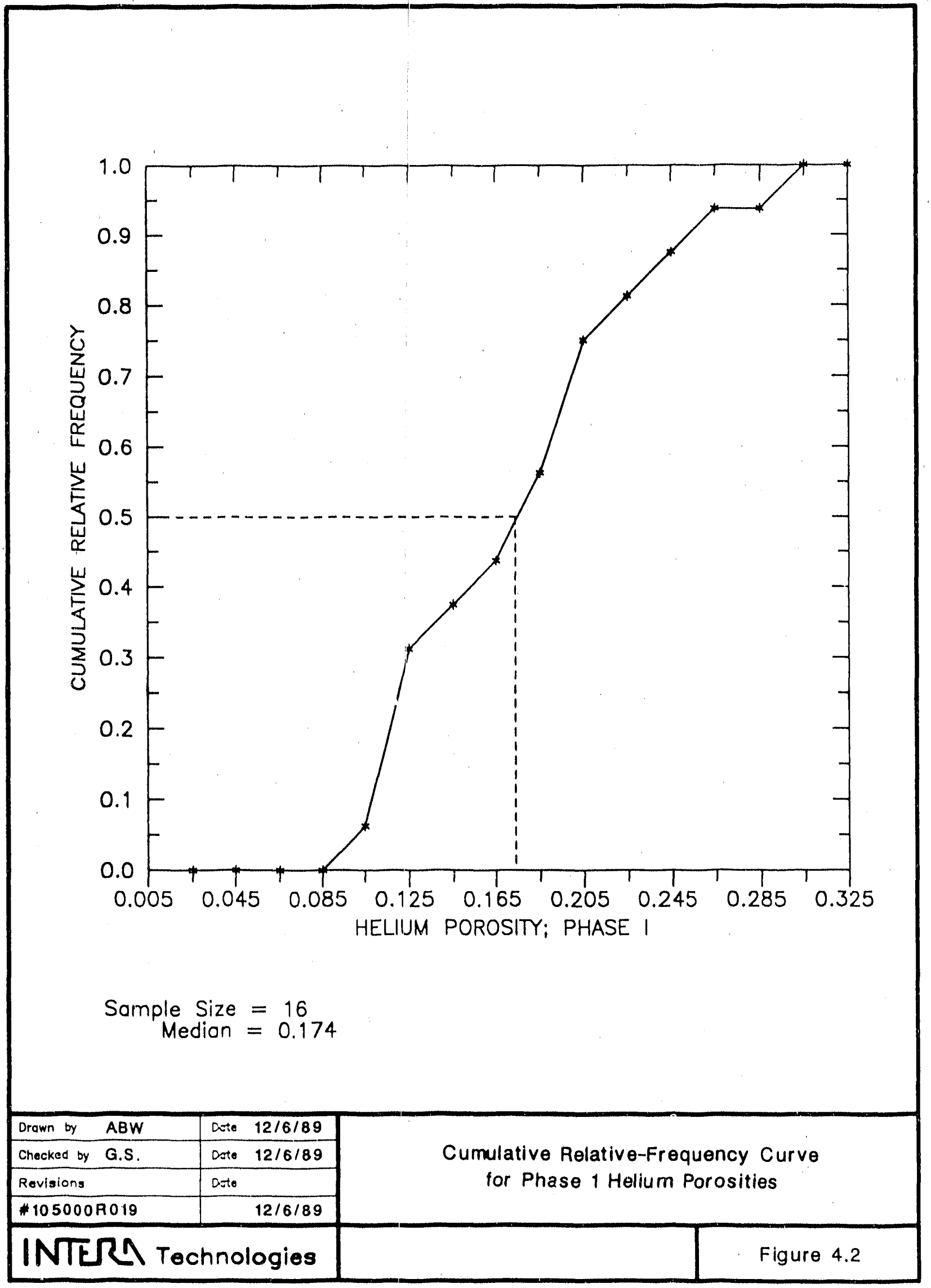




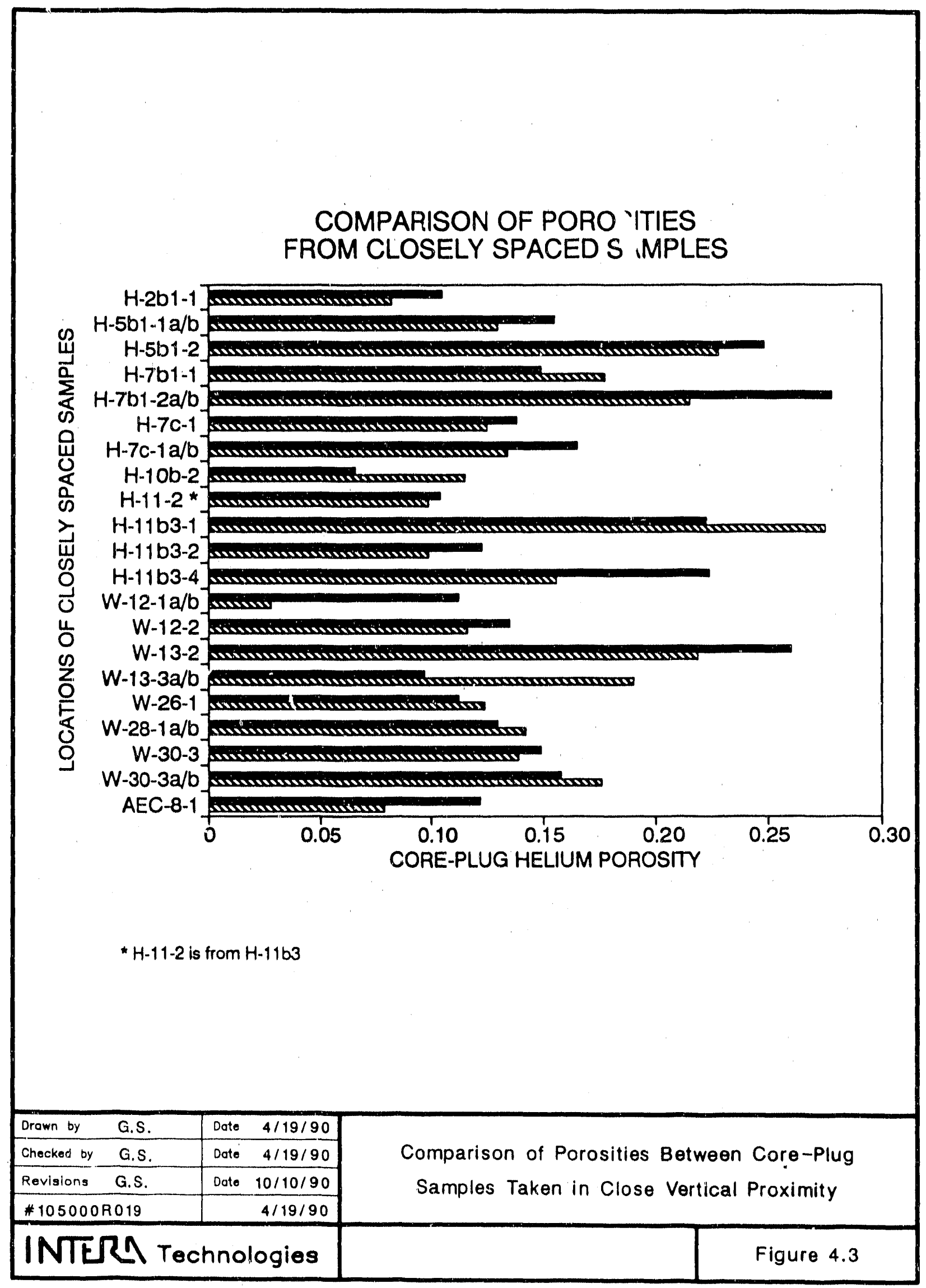




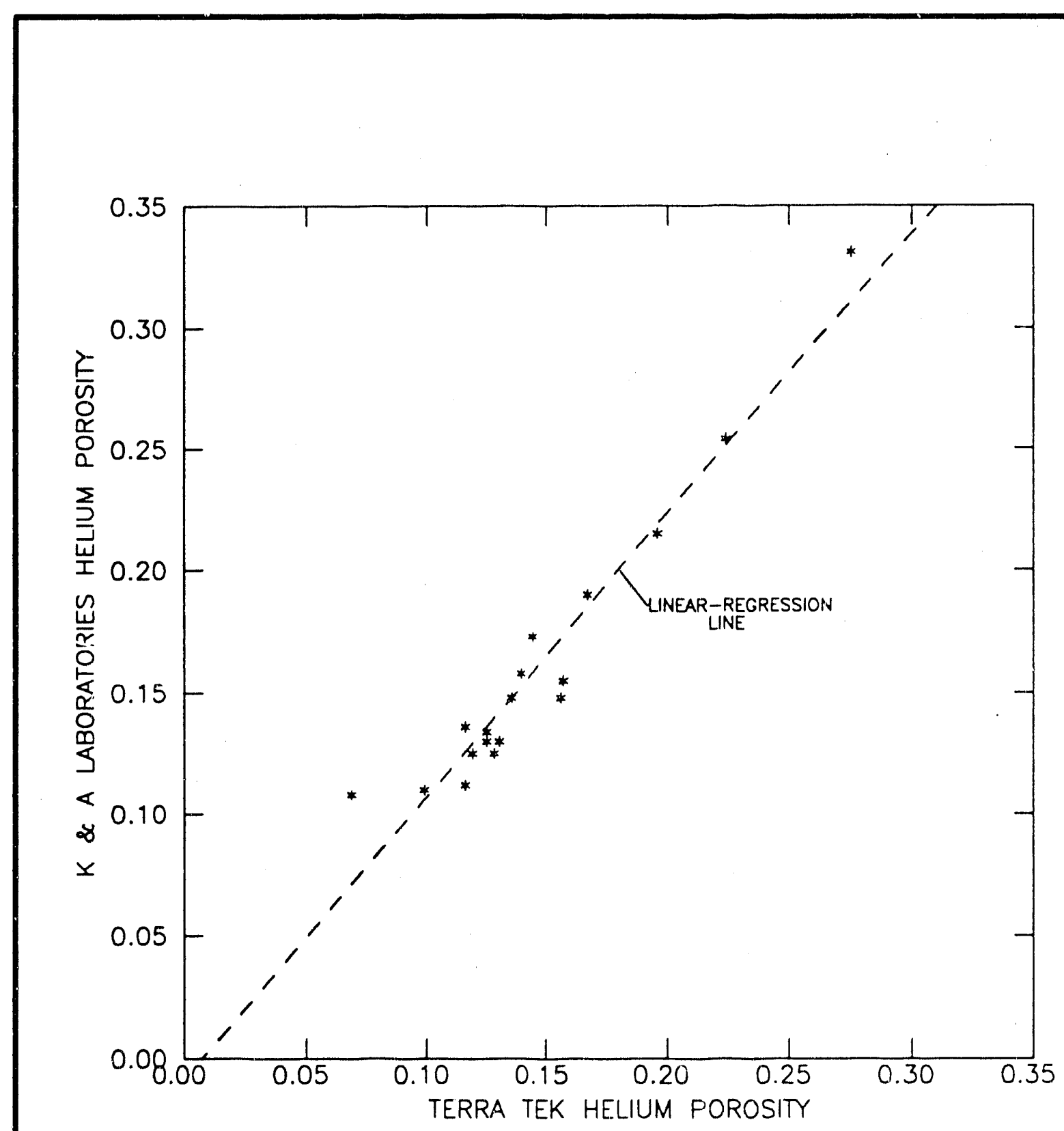

Sample Size $=18$

Correlation Coefficient $=0.93$

\begin{tabular}{|c|c|c|}
\hline Drawn by & Dote $4 / 18 / 90$ & \multirow{4}{*}{$\begin{array}{l}\text { Laboratory Comparison of Helium Porosity } \\
\text { for Idelitical Samples }\end{array}$} \\
\hline Choekad by G.S. & Date $4 / 18 / 90$ & \\
\hline Revisions G.S. & Dote $10 / 10 / 90$ & \\
\hline * $105000 R 019$ & $4 / 18 / 90$ & \\
\hline$\sqrt{T R}$ & olegies & Figure 4.4 \\
\hline
\end{tabular}




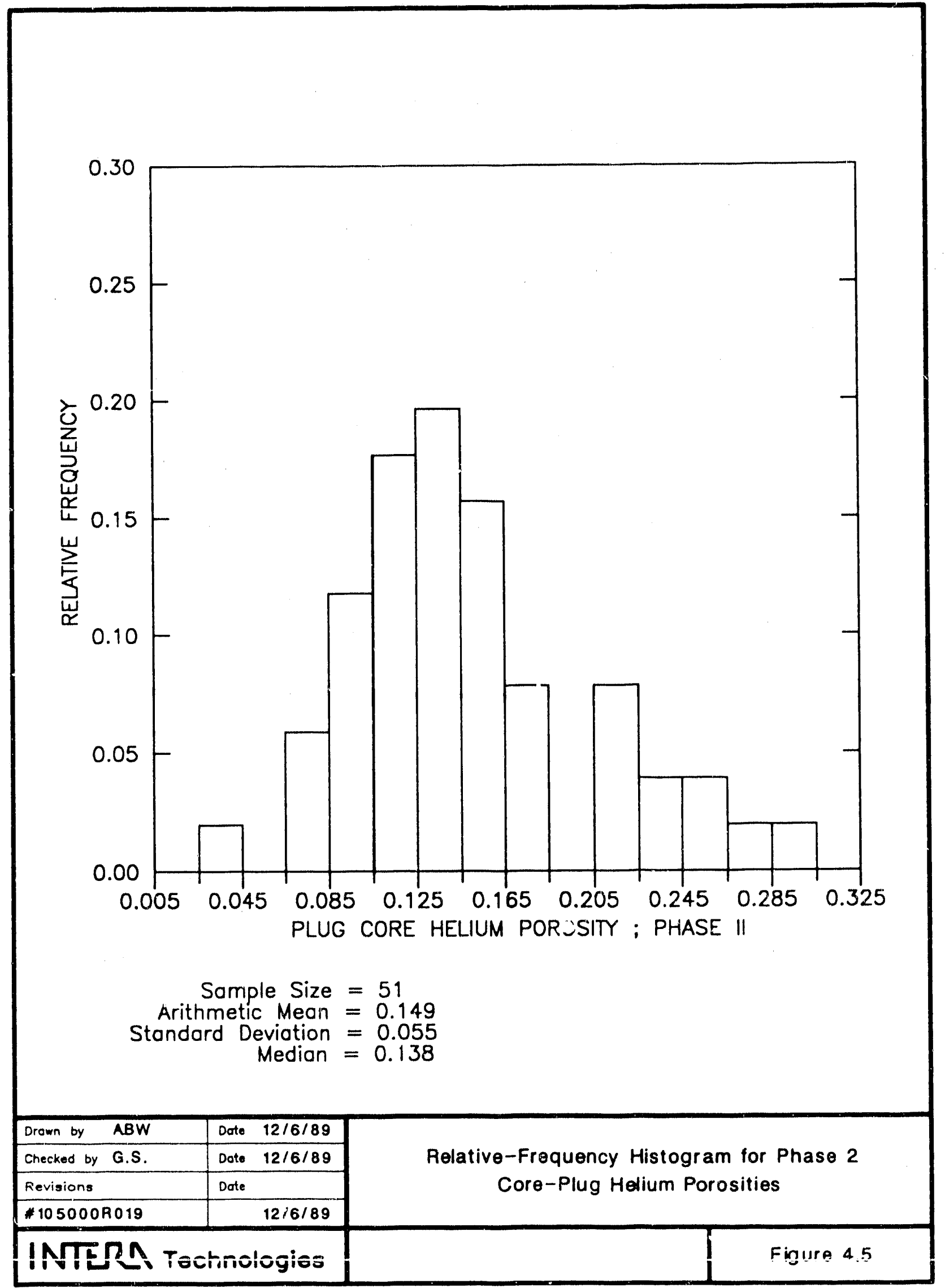




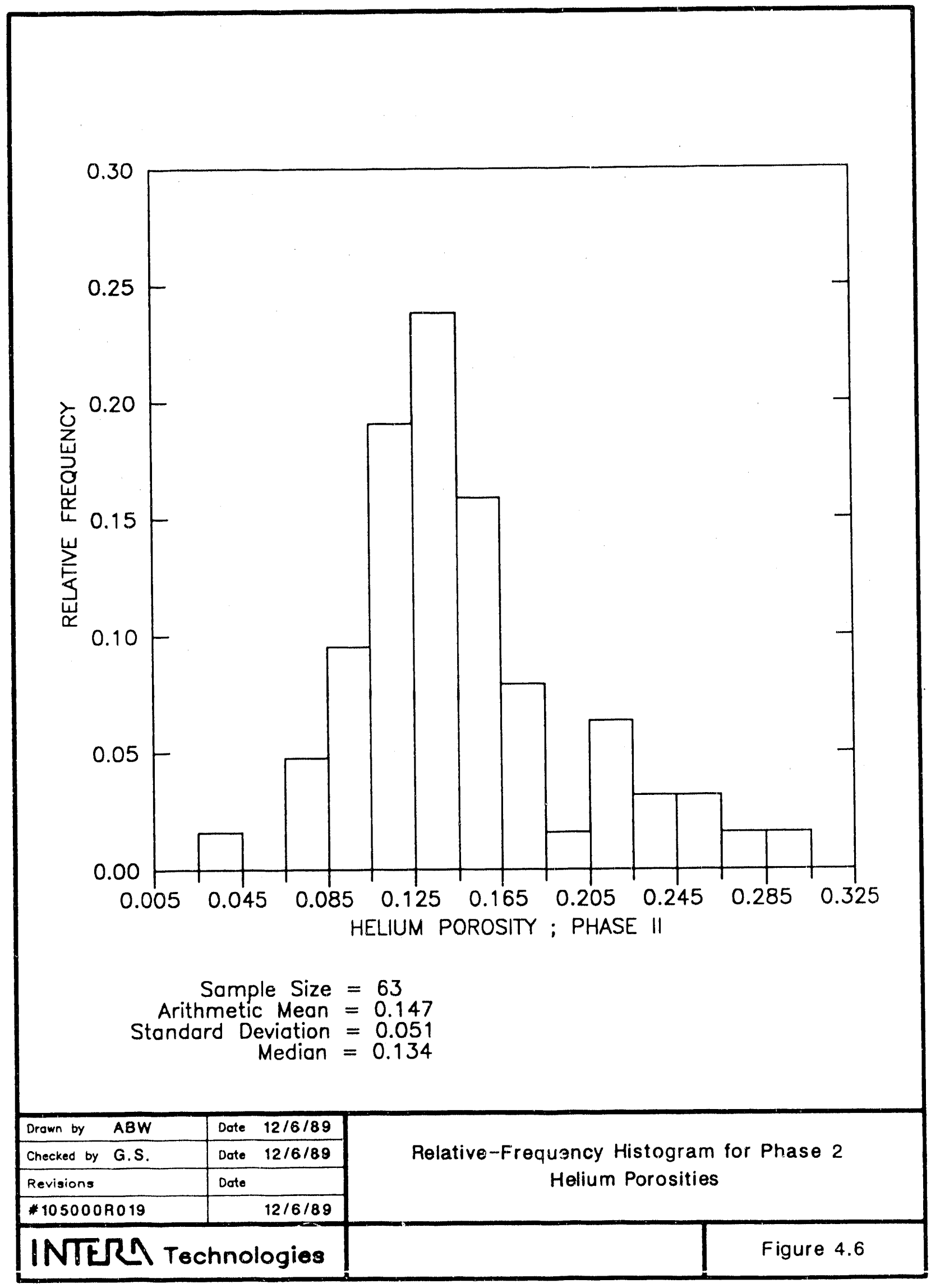




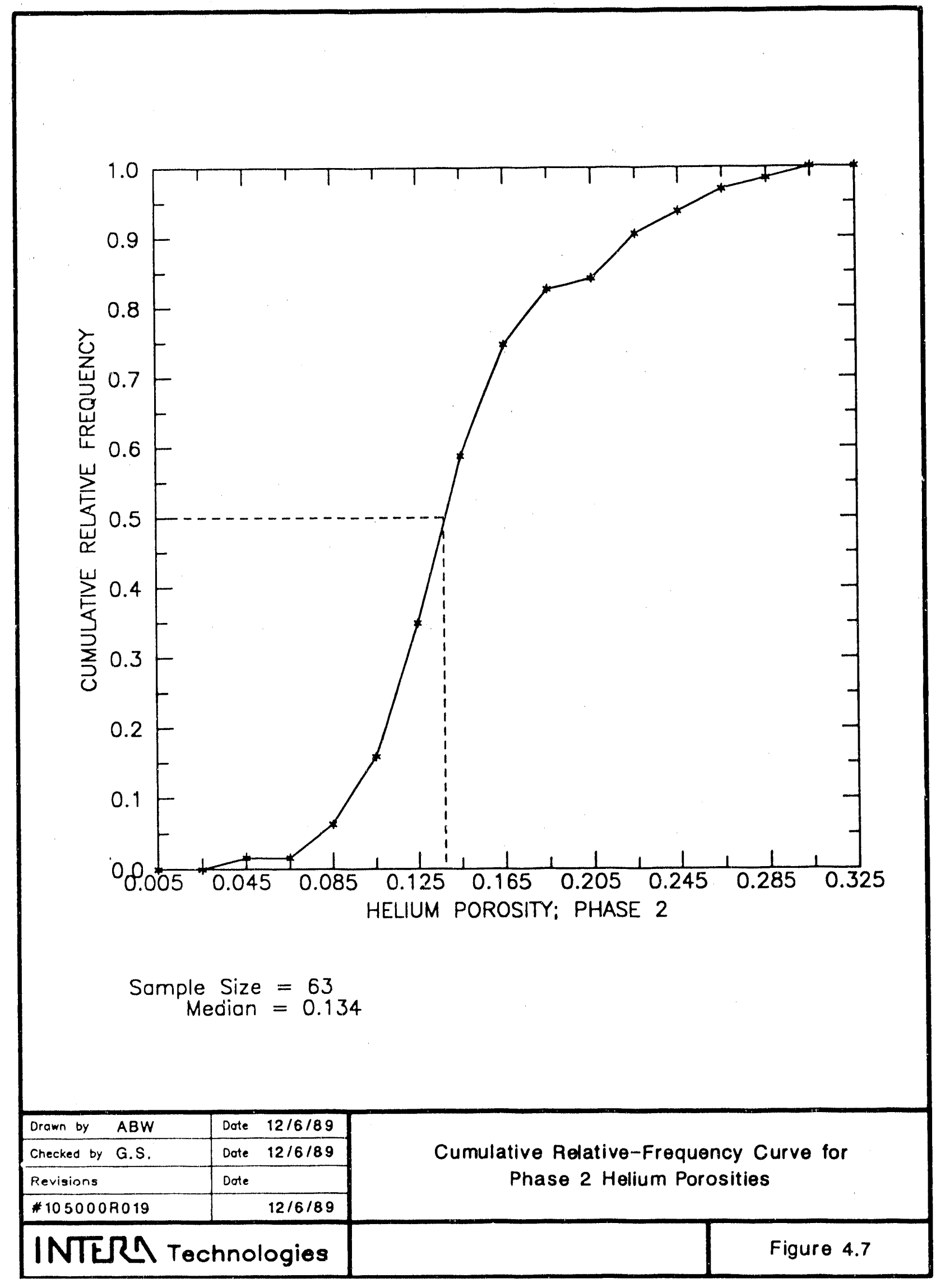




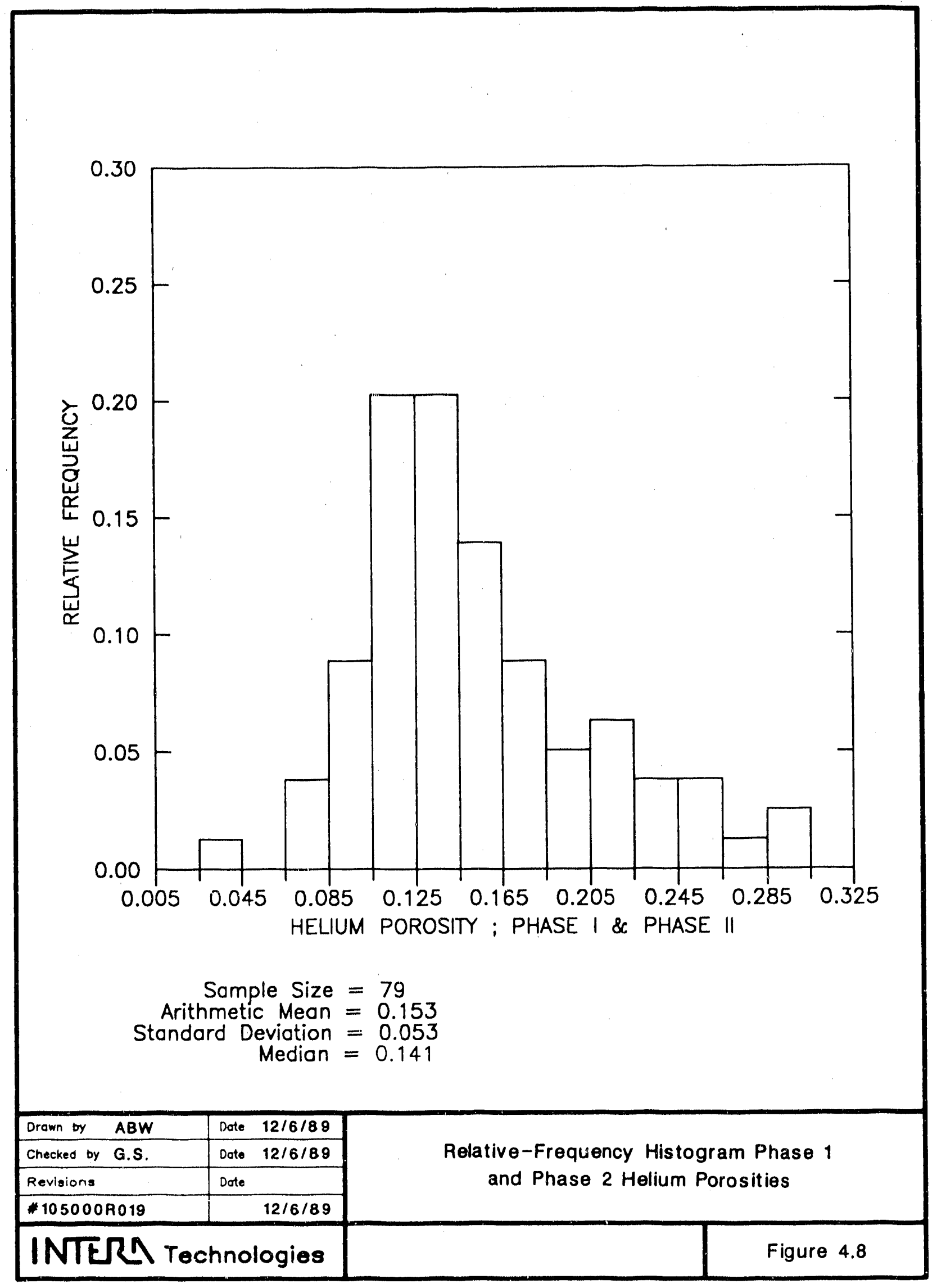




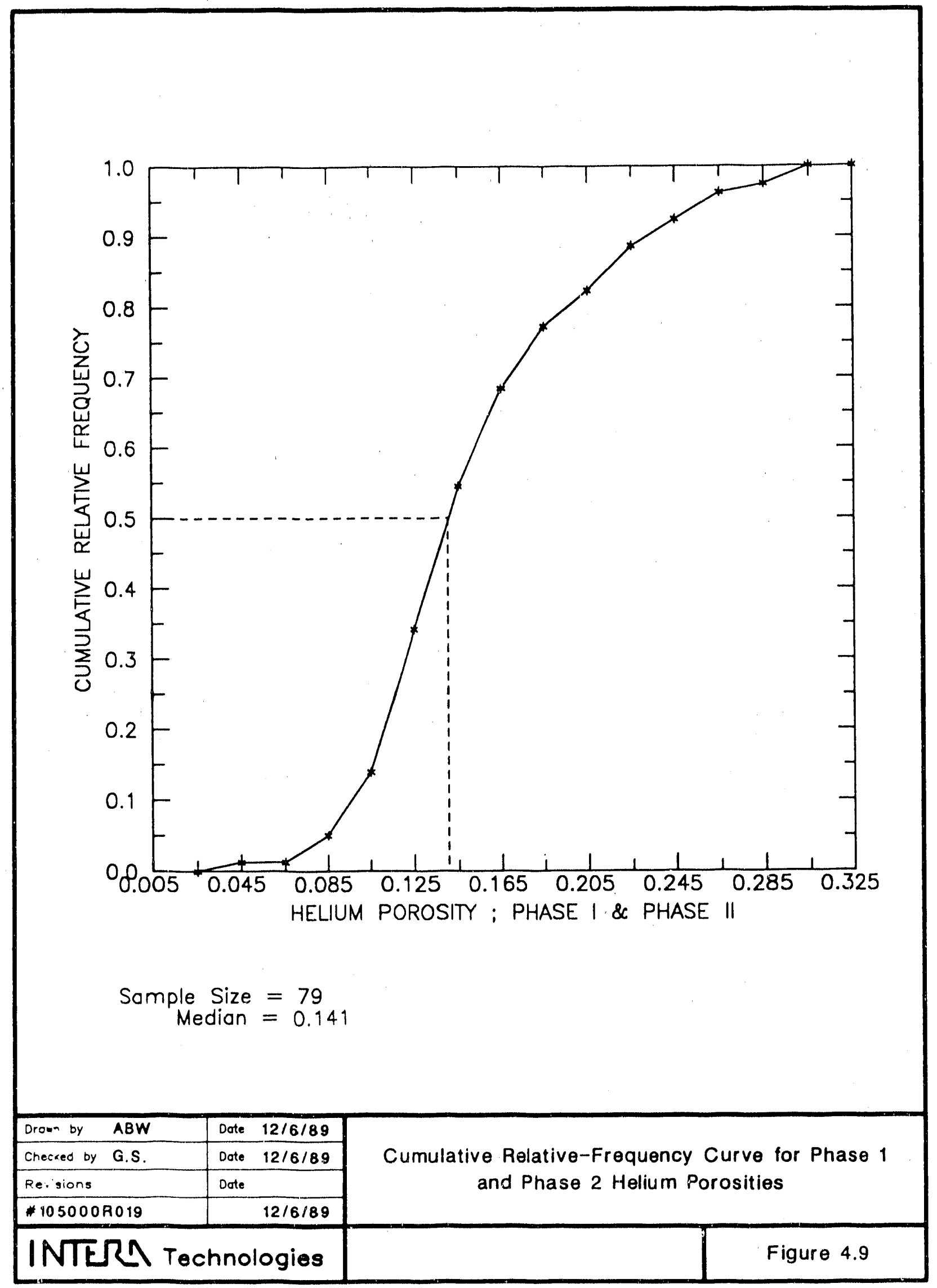




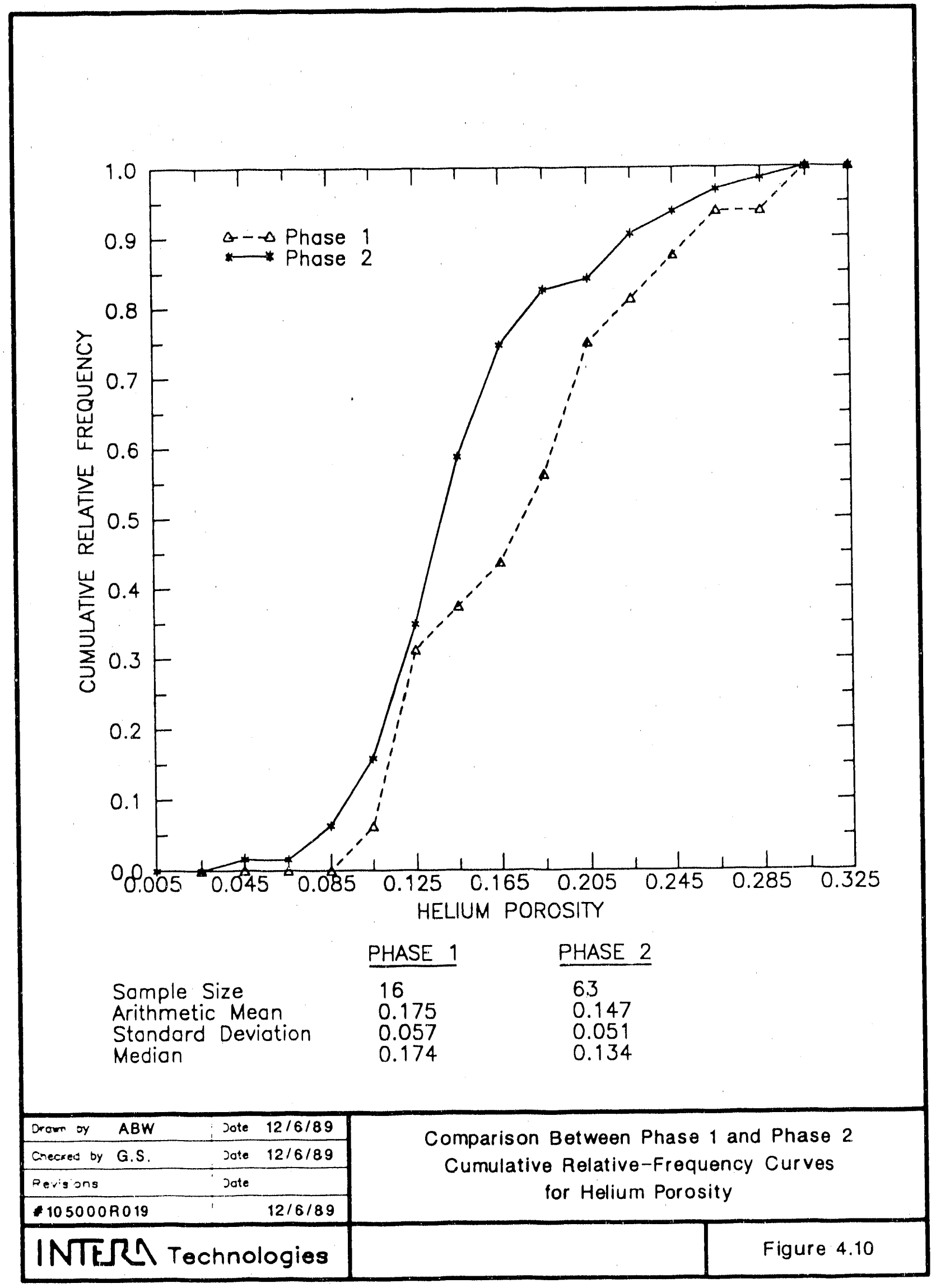




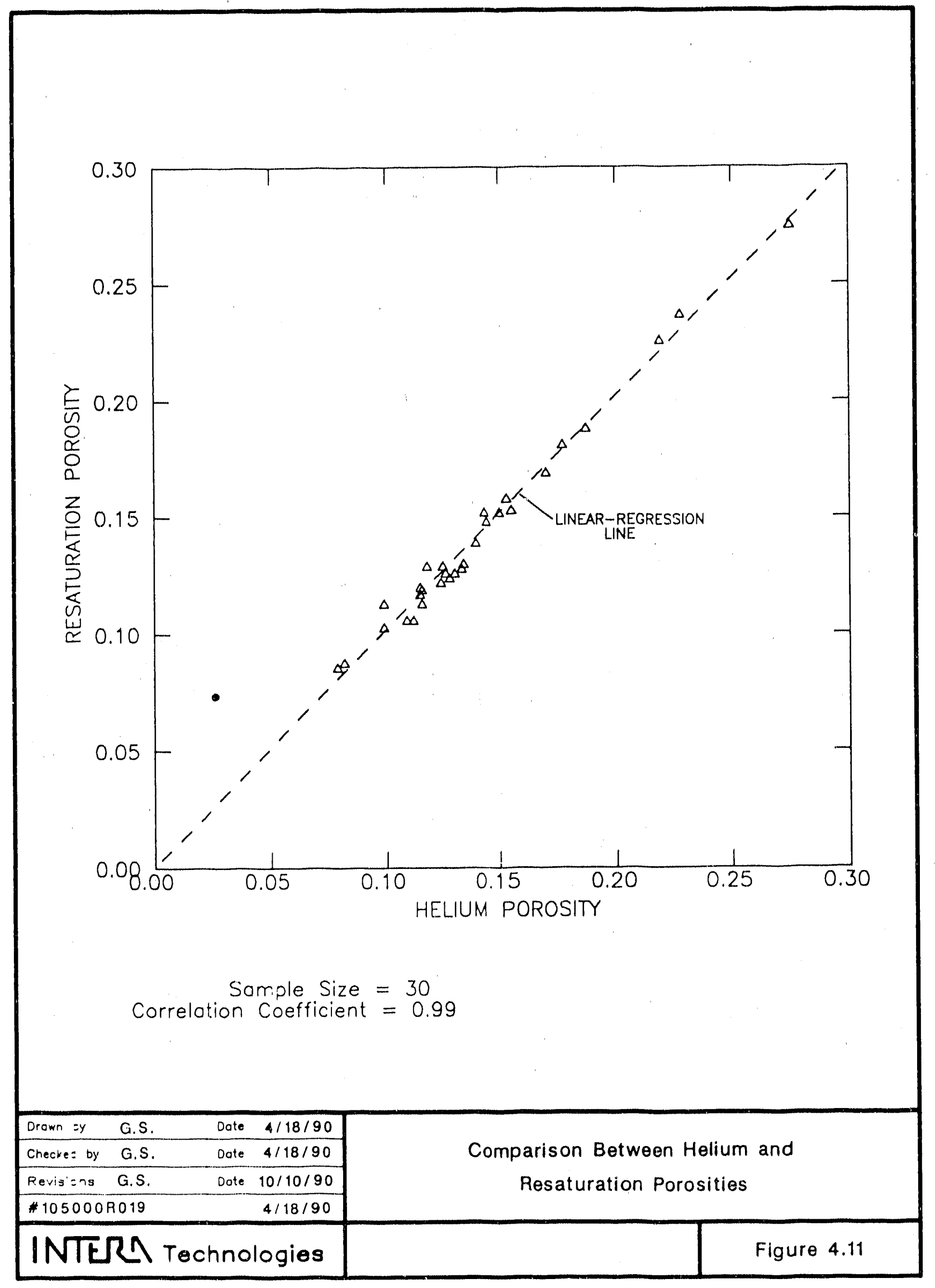

$4-29$ 


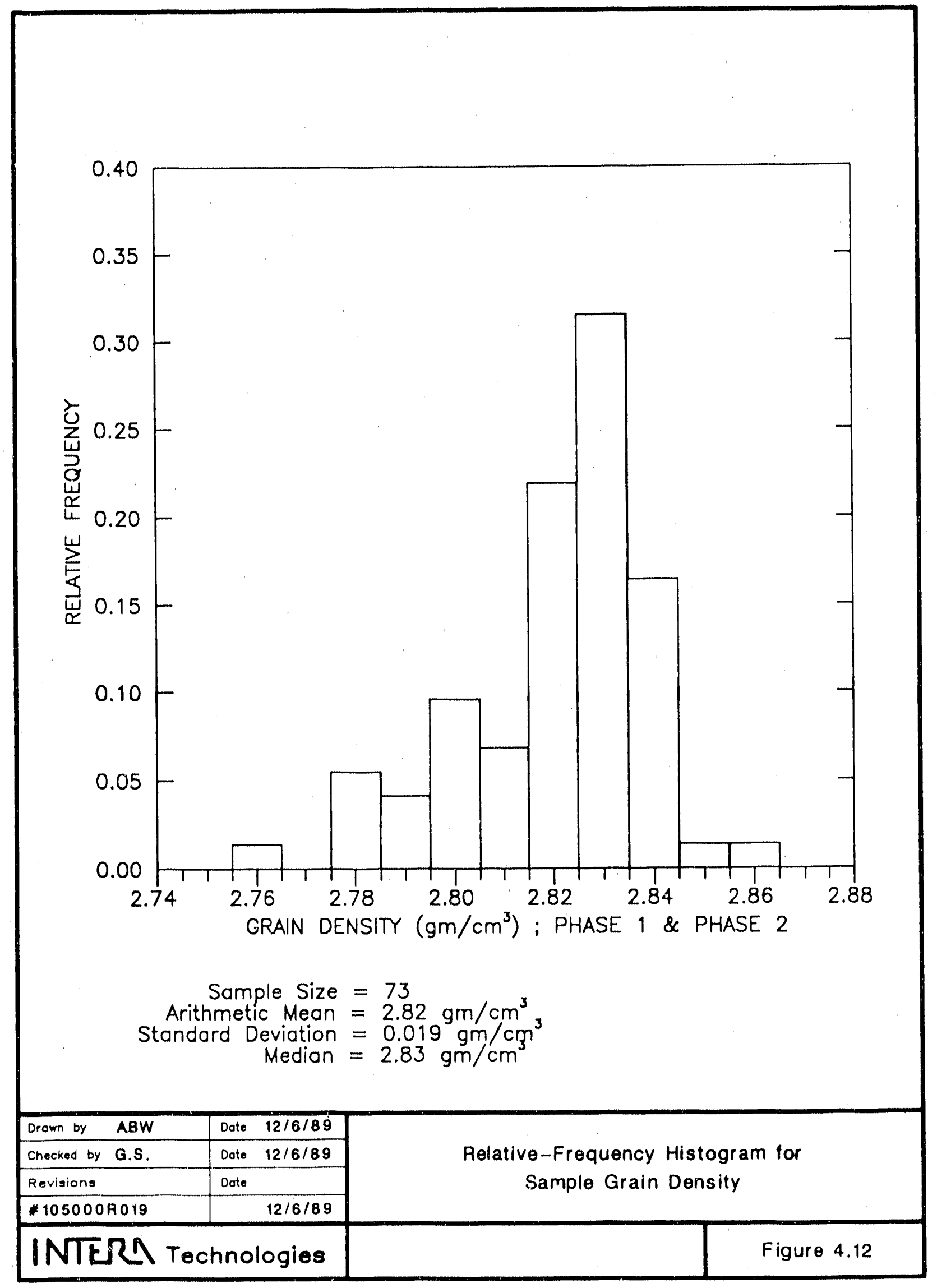




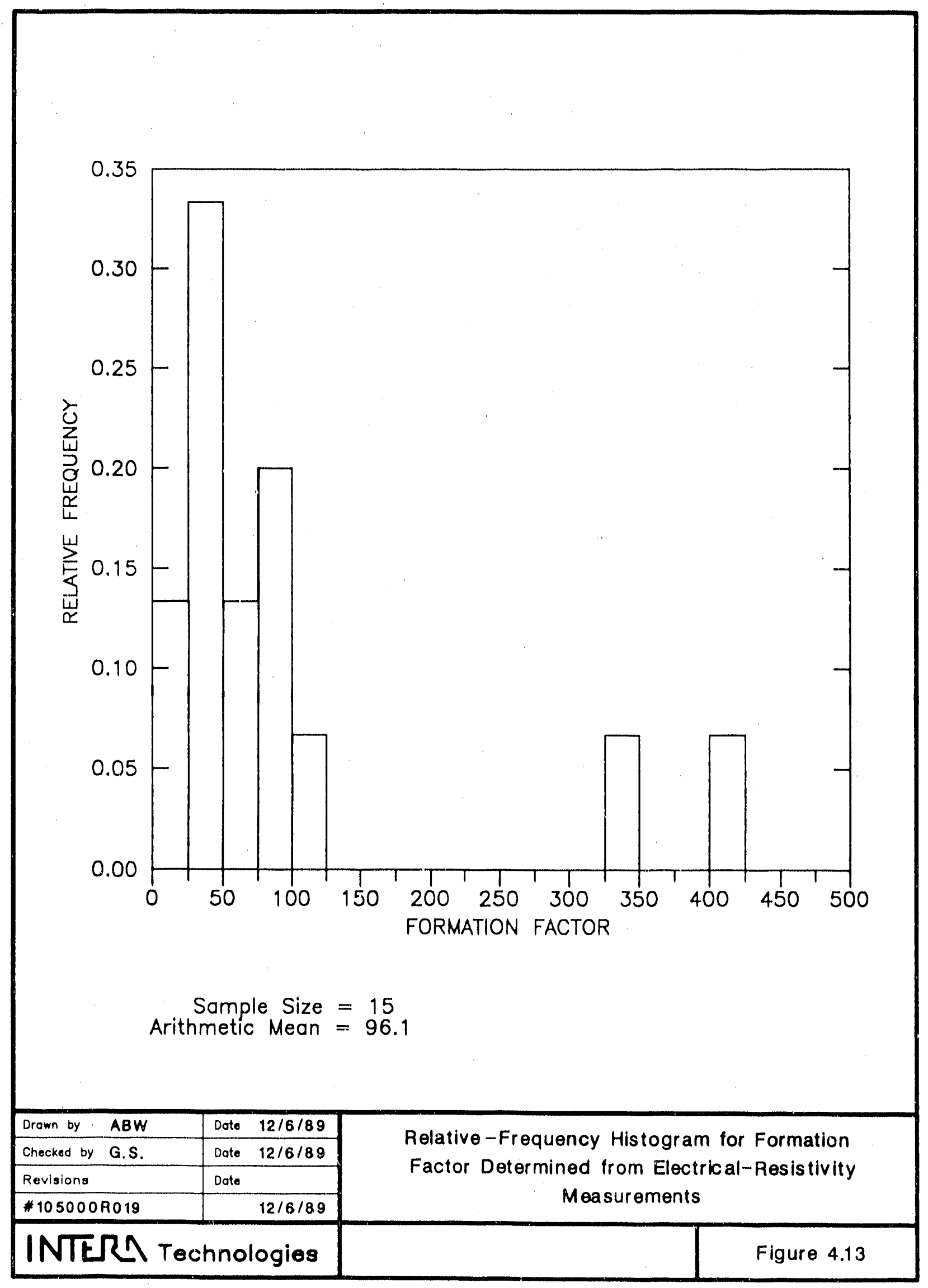




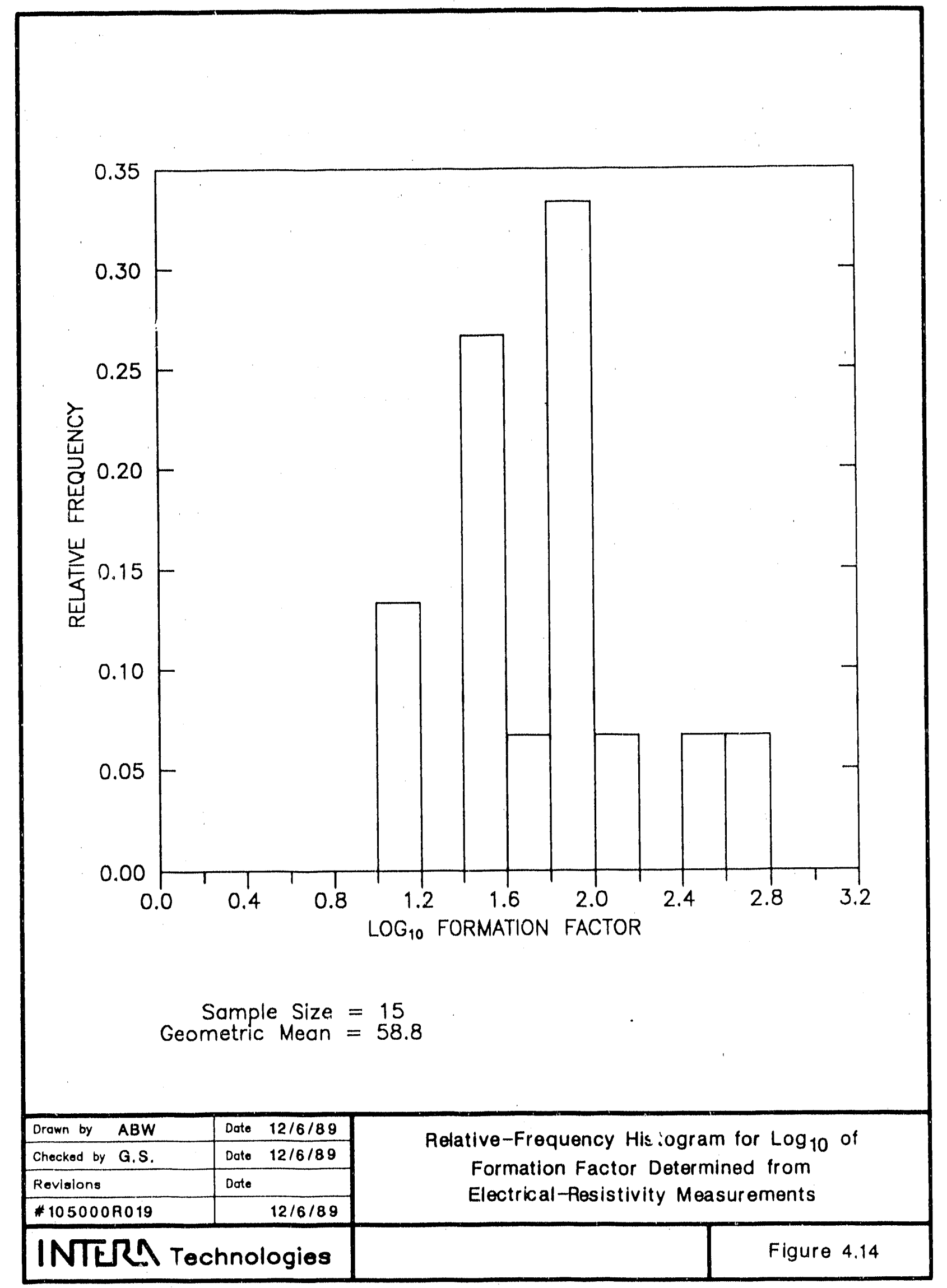

$4-32$ 


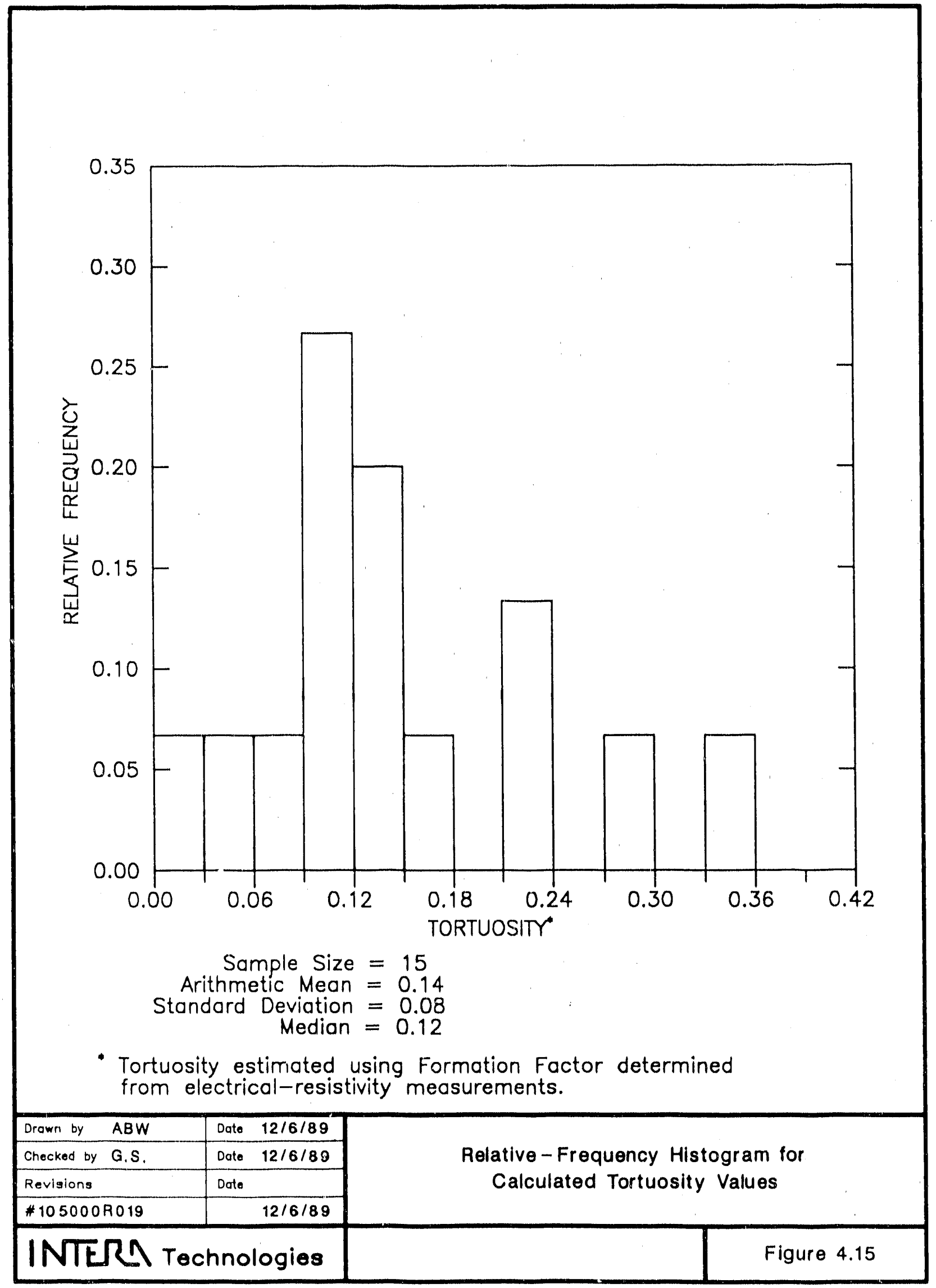




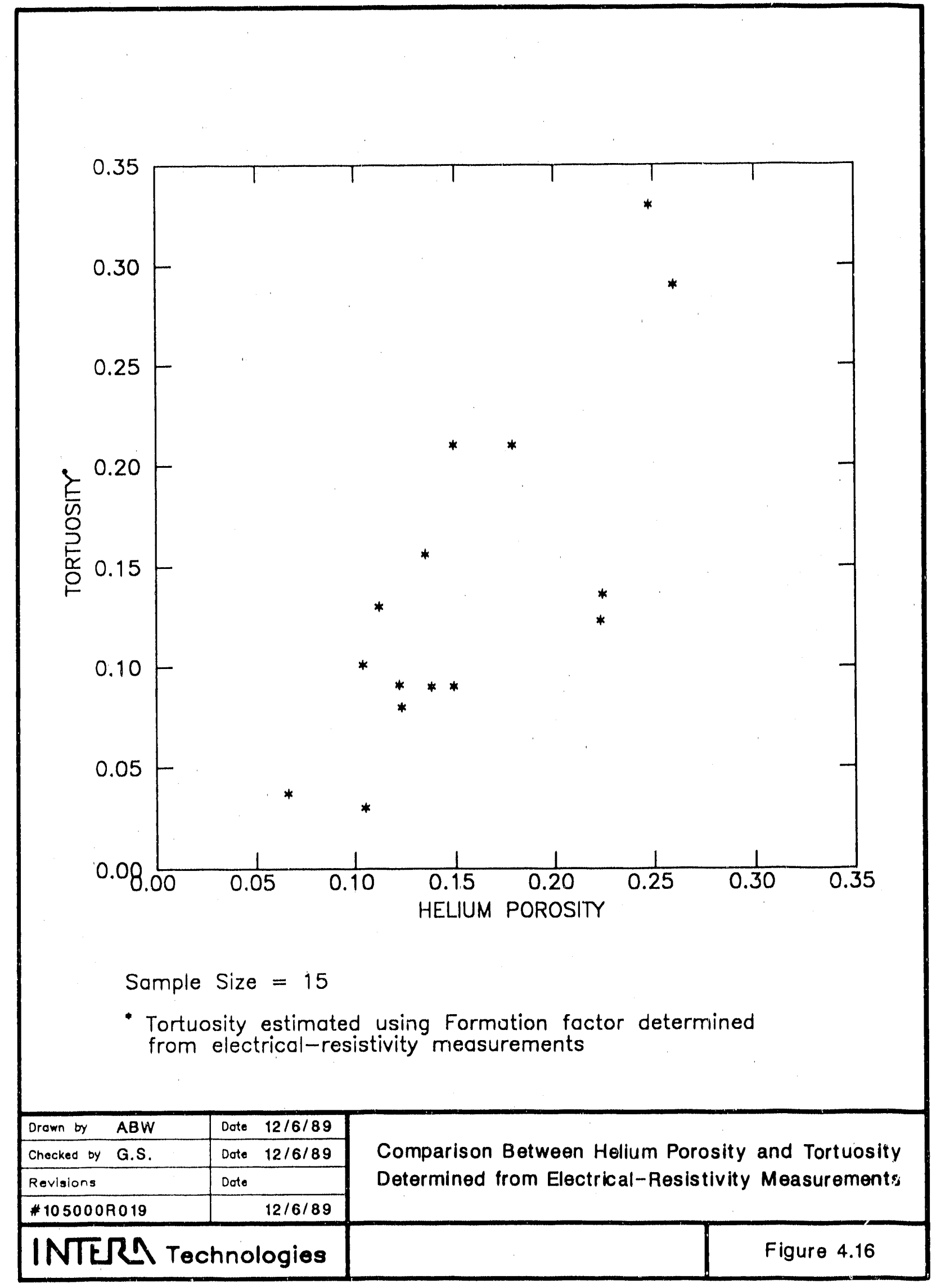




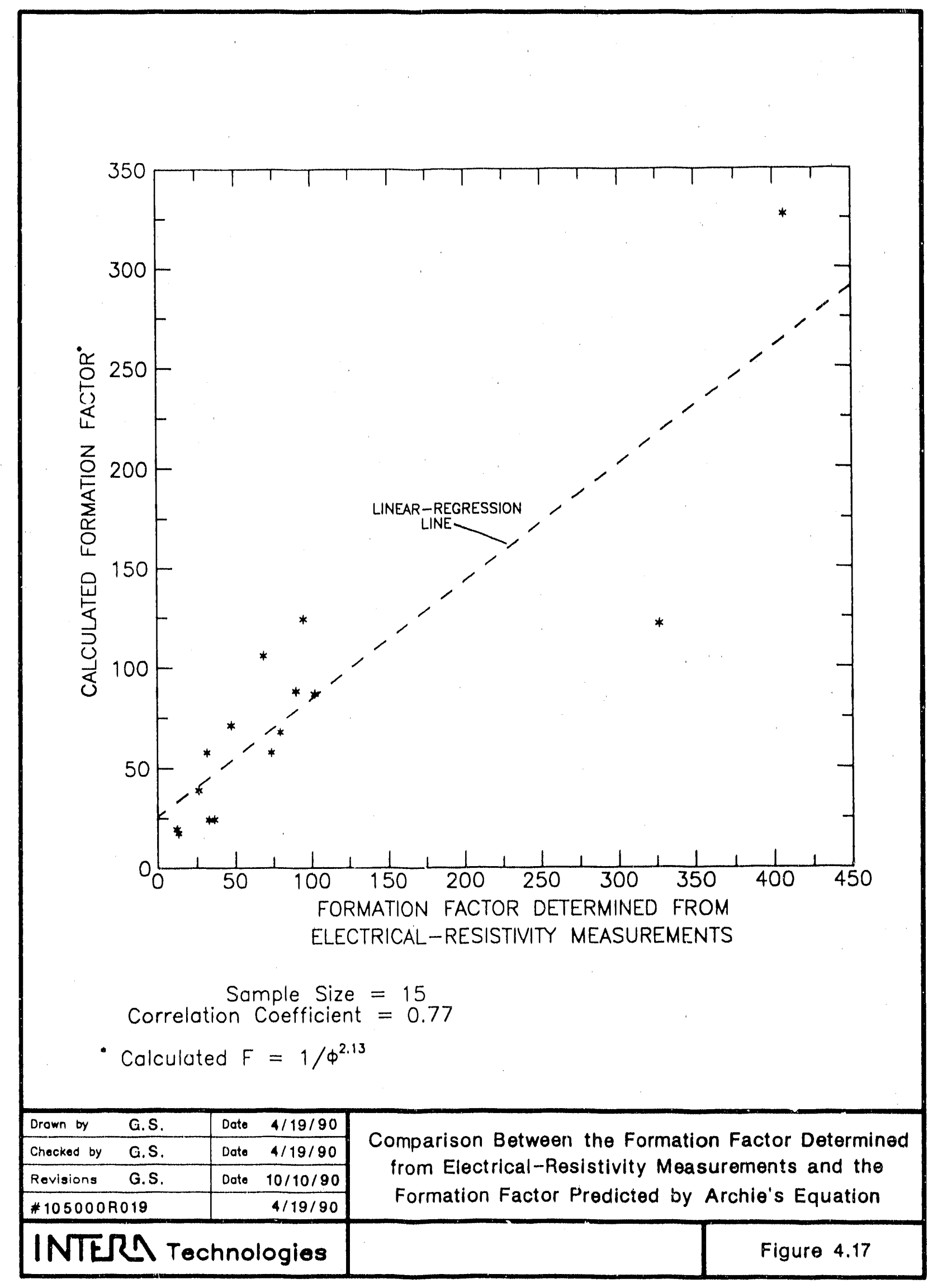




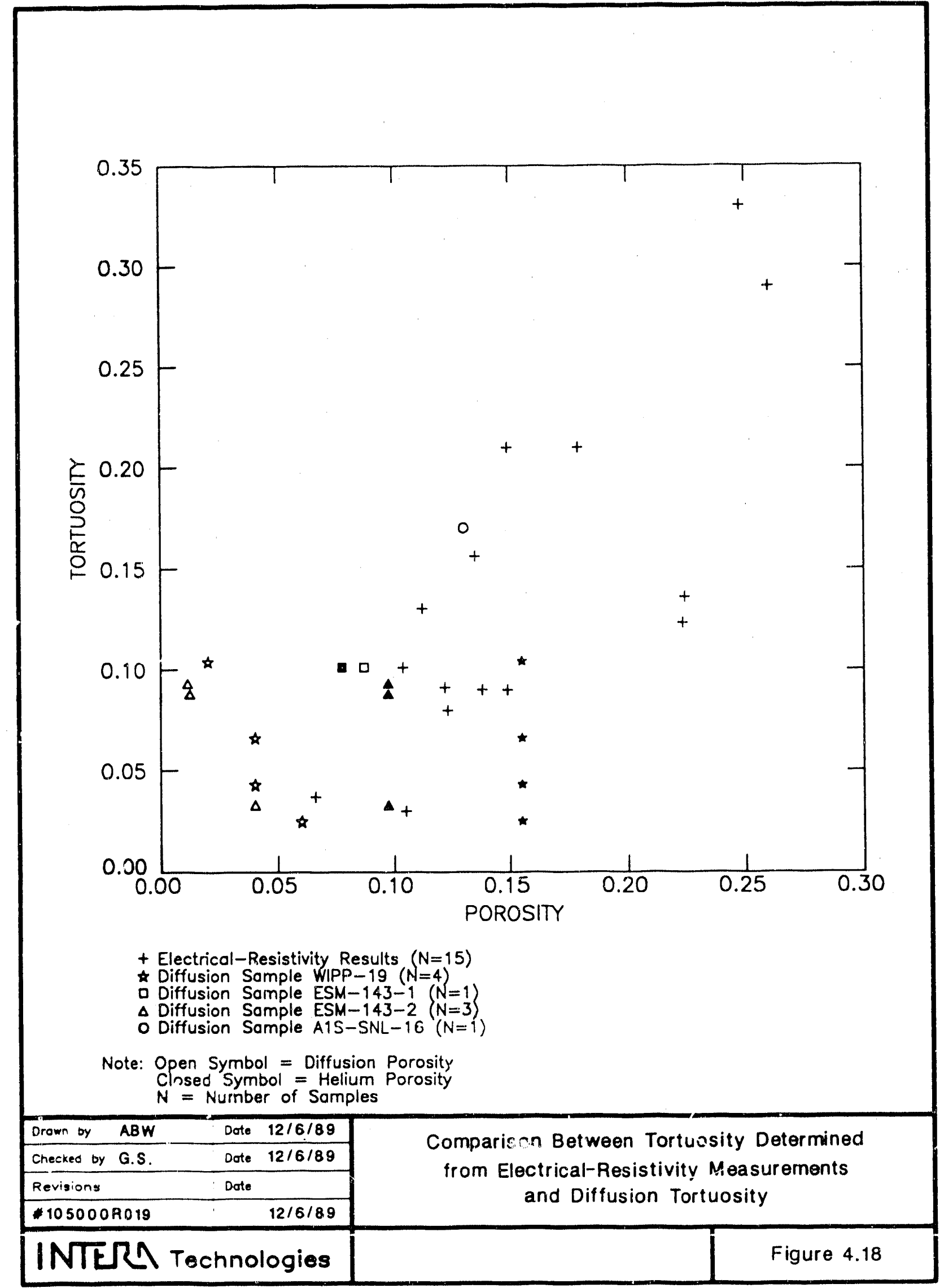

$4-36$ 


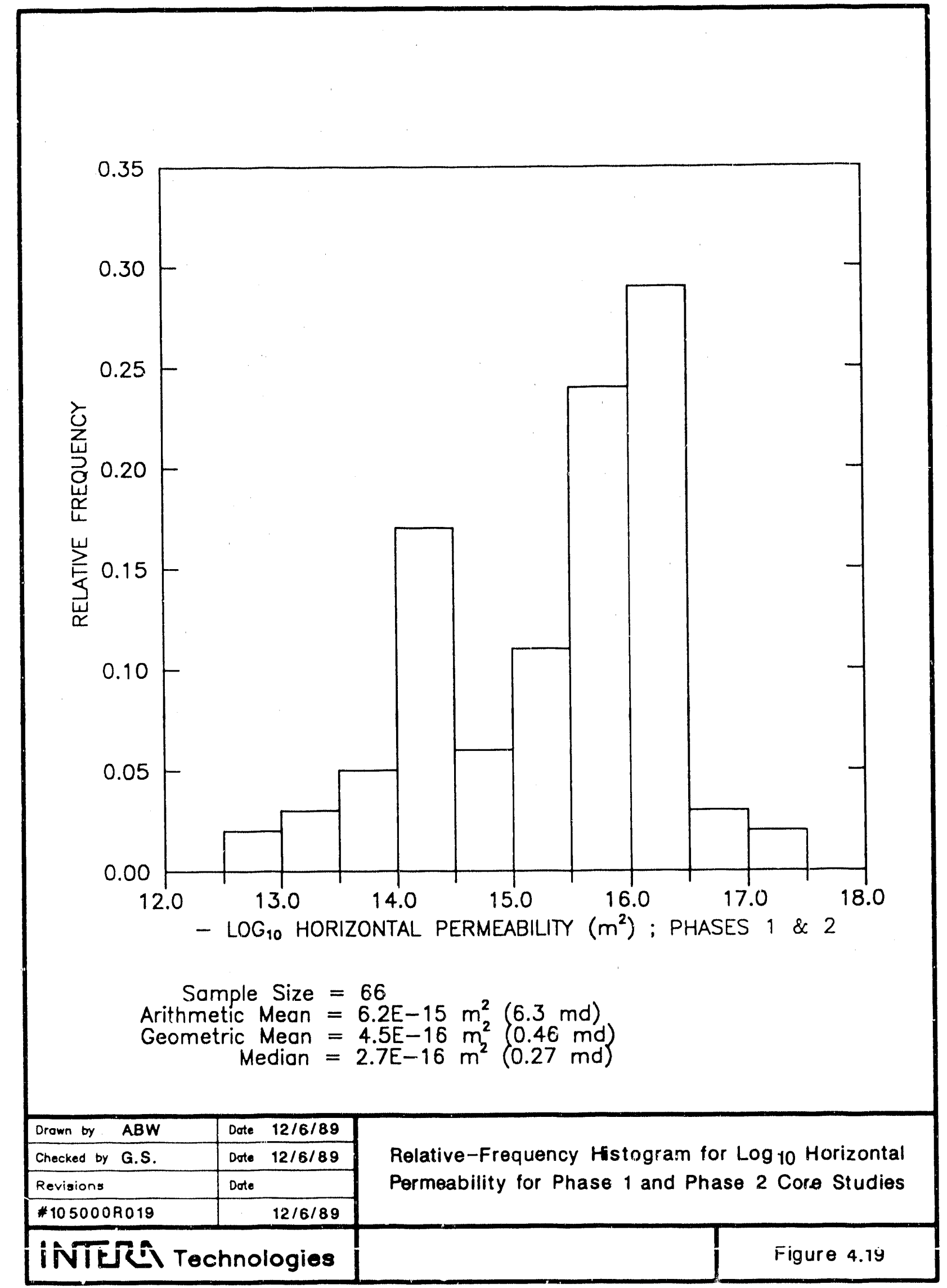




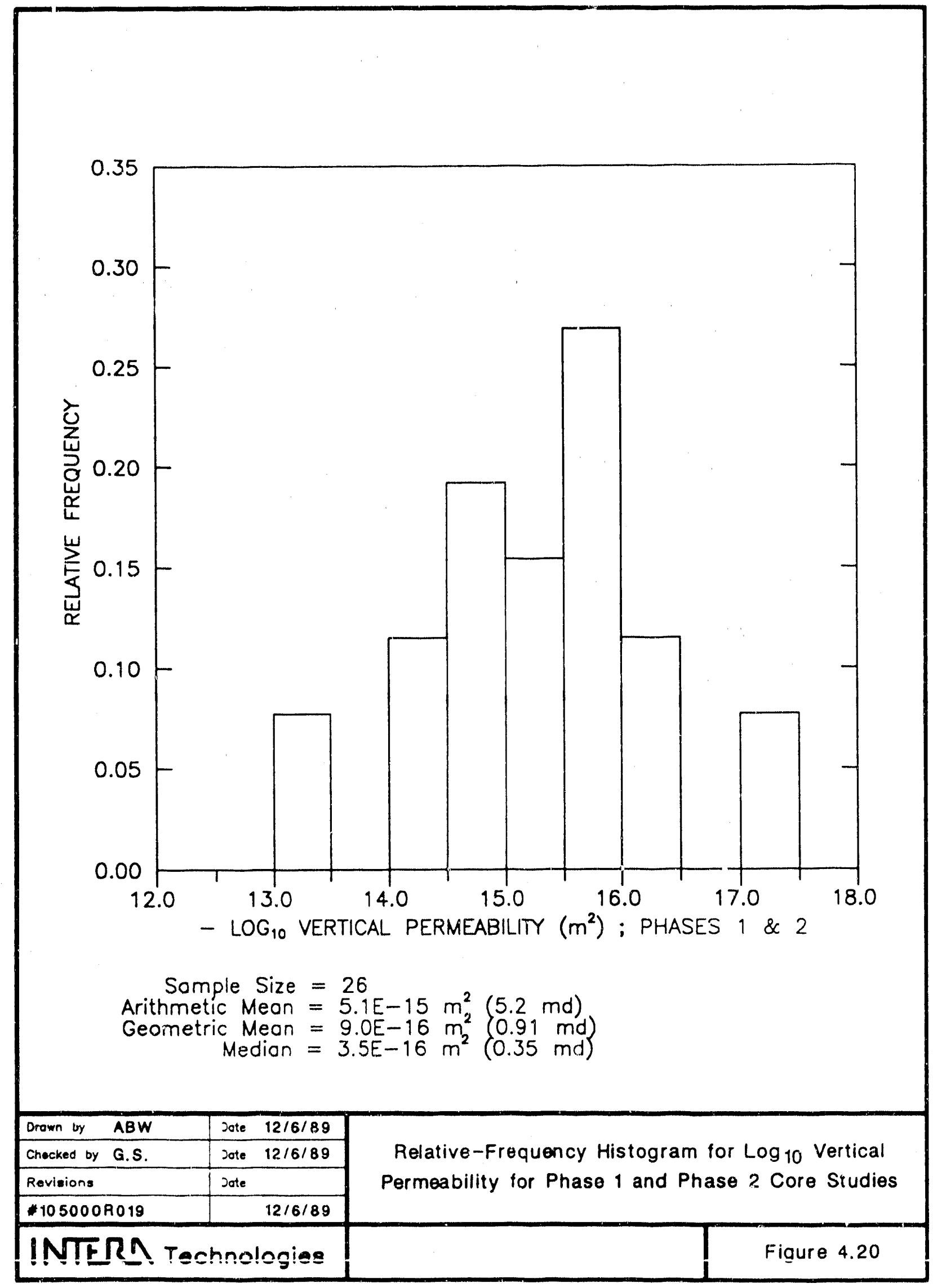




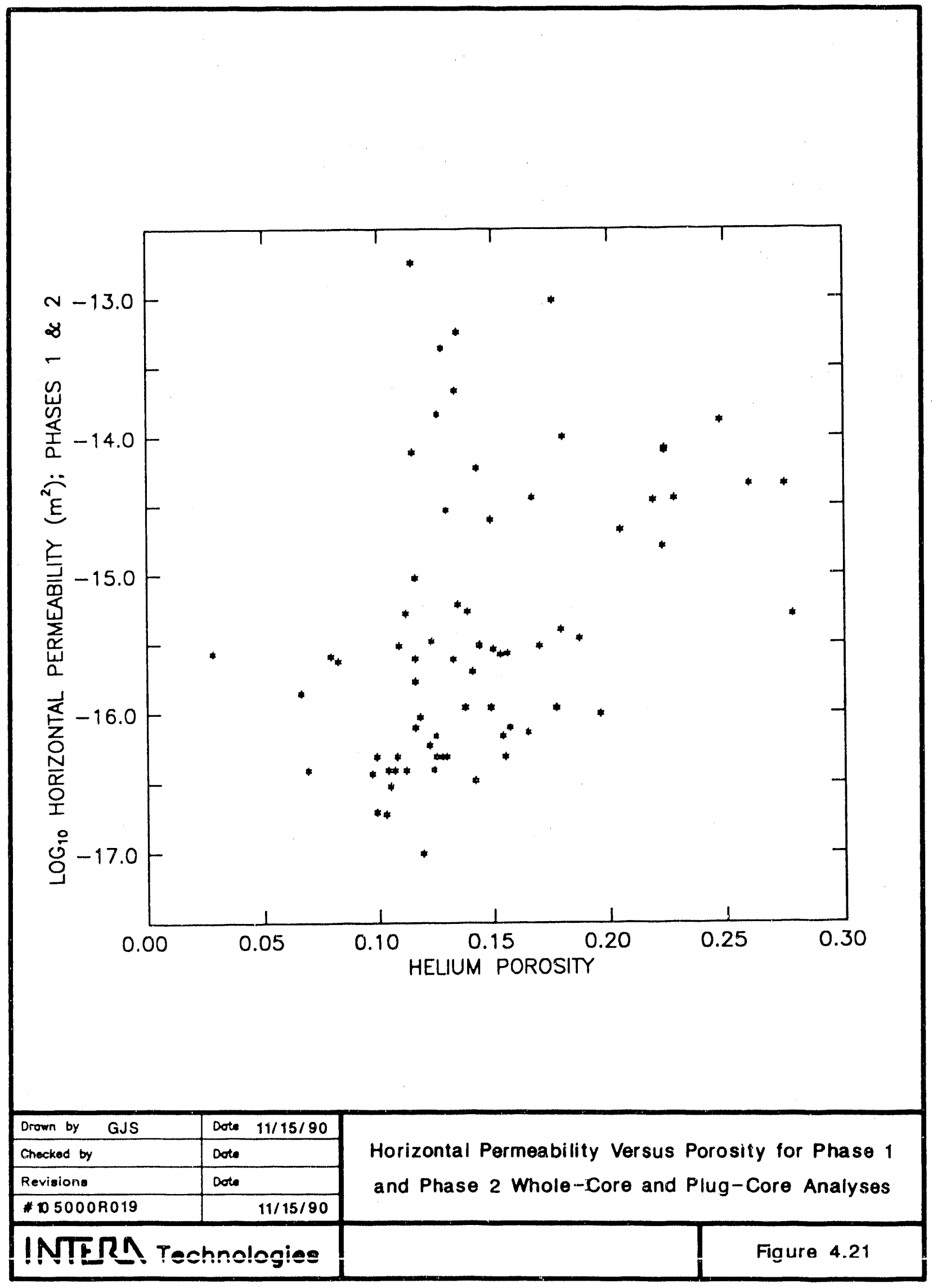




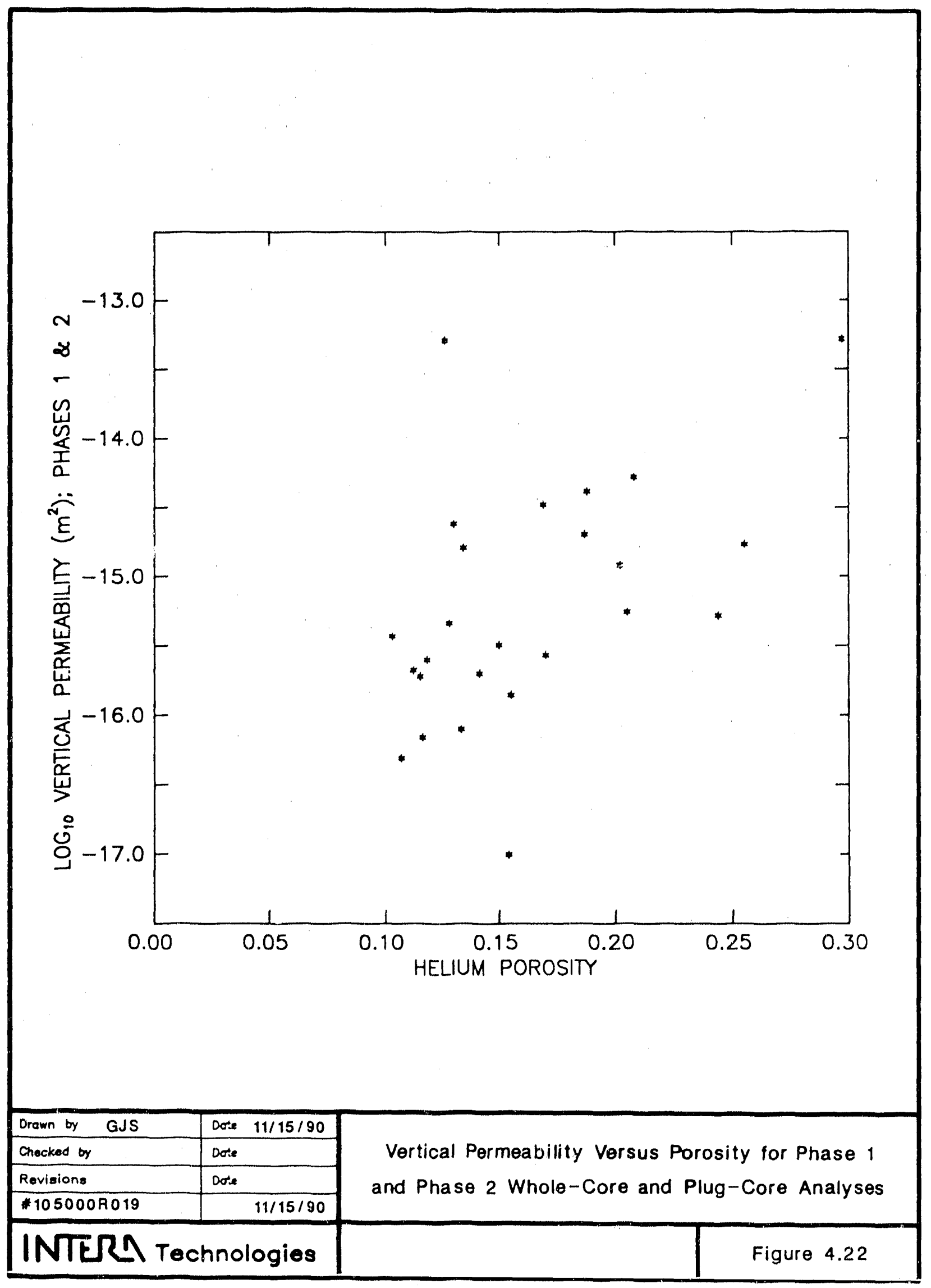




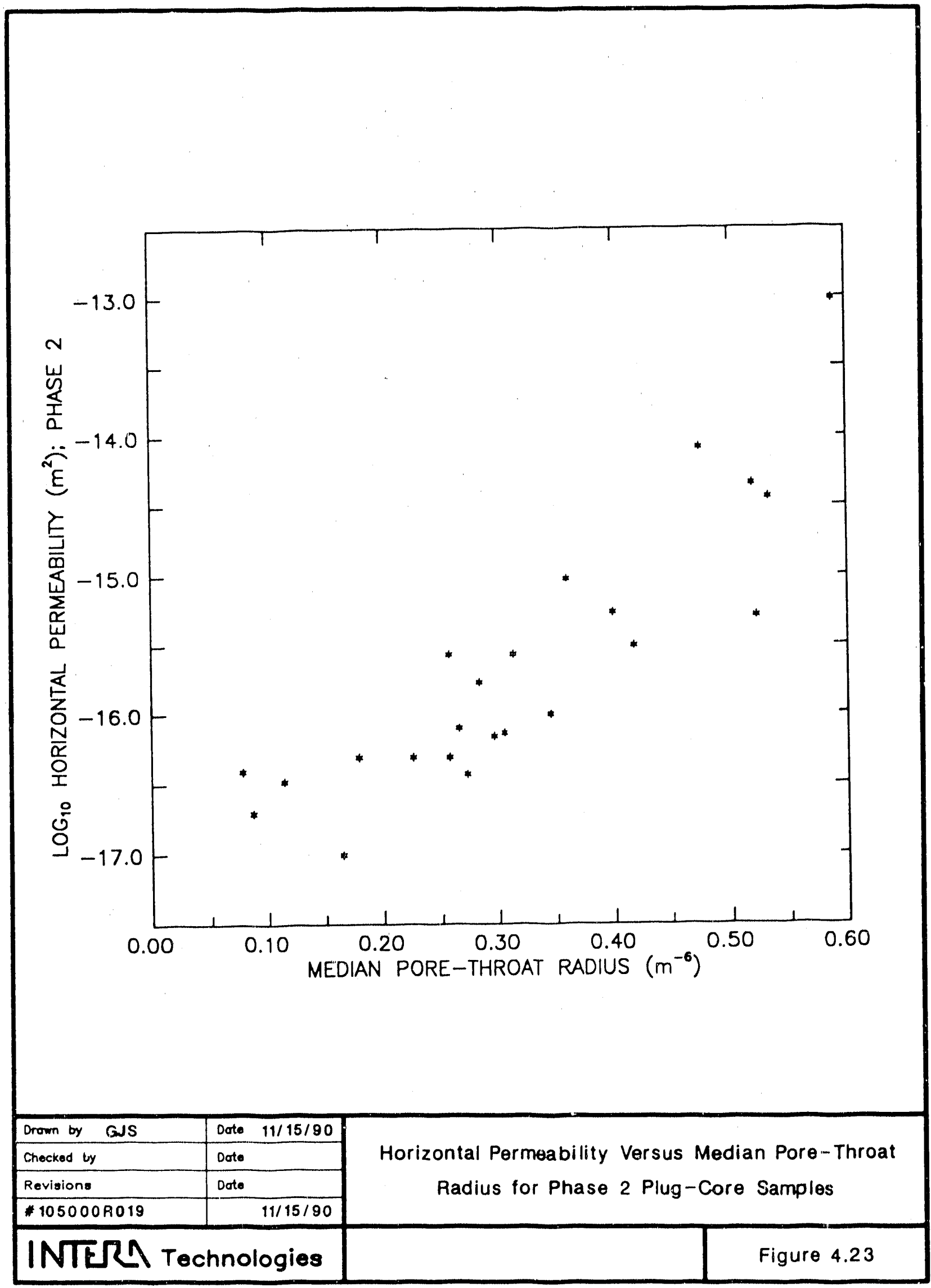

4-41 


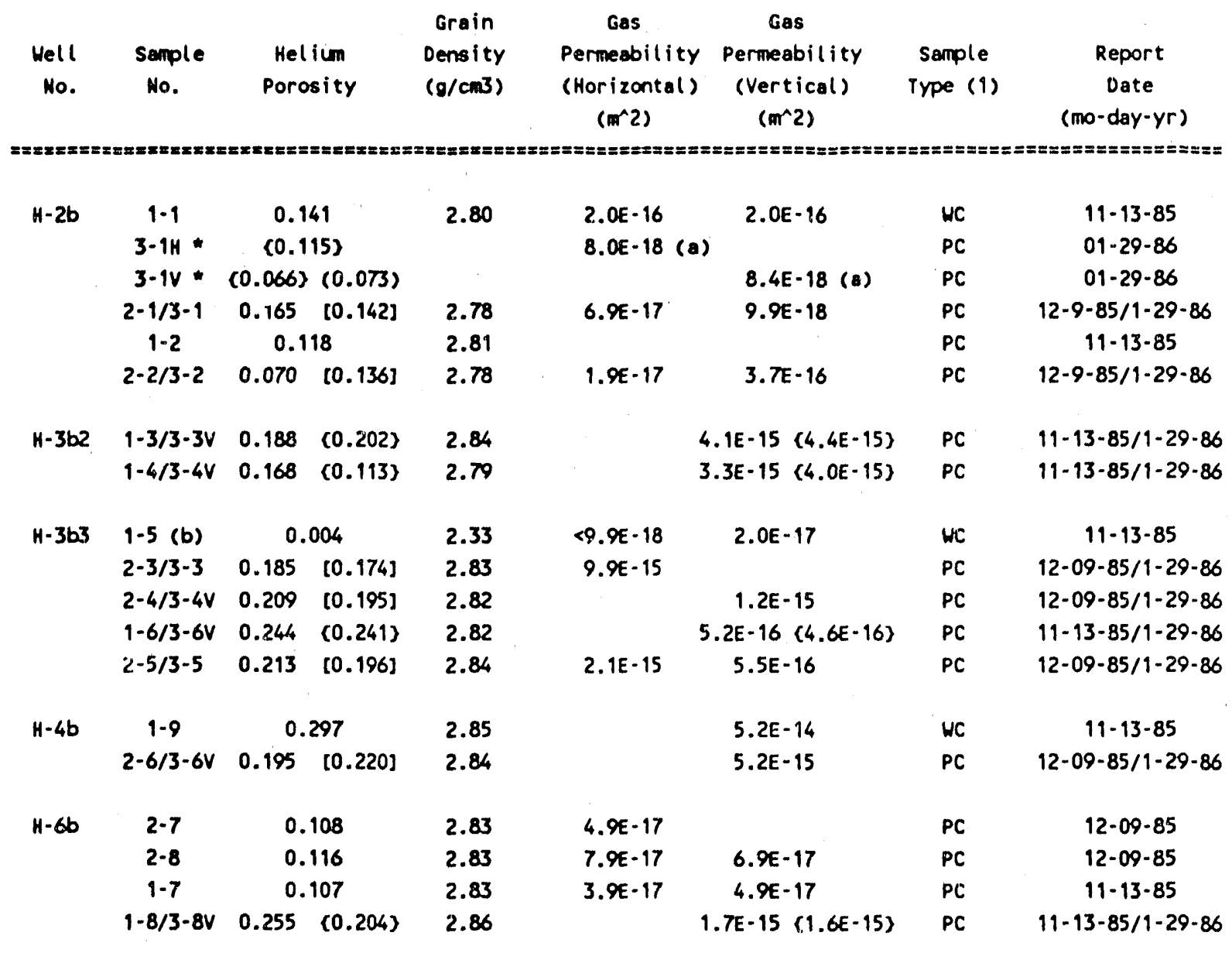

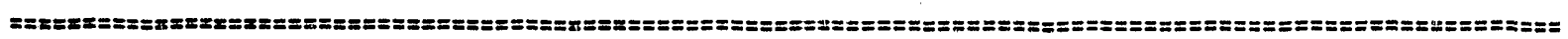

(1) WC mans thole-core sample, and PC means plug-core sample.

- Denotes that the sample is a subsample of the piece of core listed immediately above.

(a) Klinkenberg permeability.

(b) Mineralogic composition of this sample was Gypsum and, due to dehydration during testing, was comverted to anhydrite. The porosity value is therefore considered to be unrepresentative.

( ) Denotes an ambient stress of $2.4 \mathrm{MPa}$ during testing.

(] Denotes a helium porosity measurentent there the bulk volume is deterained by fluid displacement.

( ) Denotes a re-run.

\begin{tabular}{|c|c|c|}
\hline Drown by & Dote & \multirow{4}{*}{ Results from the Phase 1 Core Study } \\
\hline Chockod by & Dote & \\
\hline Revisions & Dote & \\
\hline$\$ 105000 R 019$ & $4 / 18 / 90$ & \\
\hline$\sqrt{7} \pi$ & ologies & Table 4.1 \\
\hline
\end{tabular}




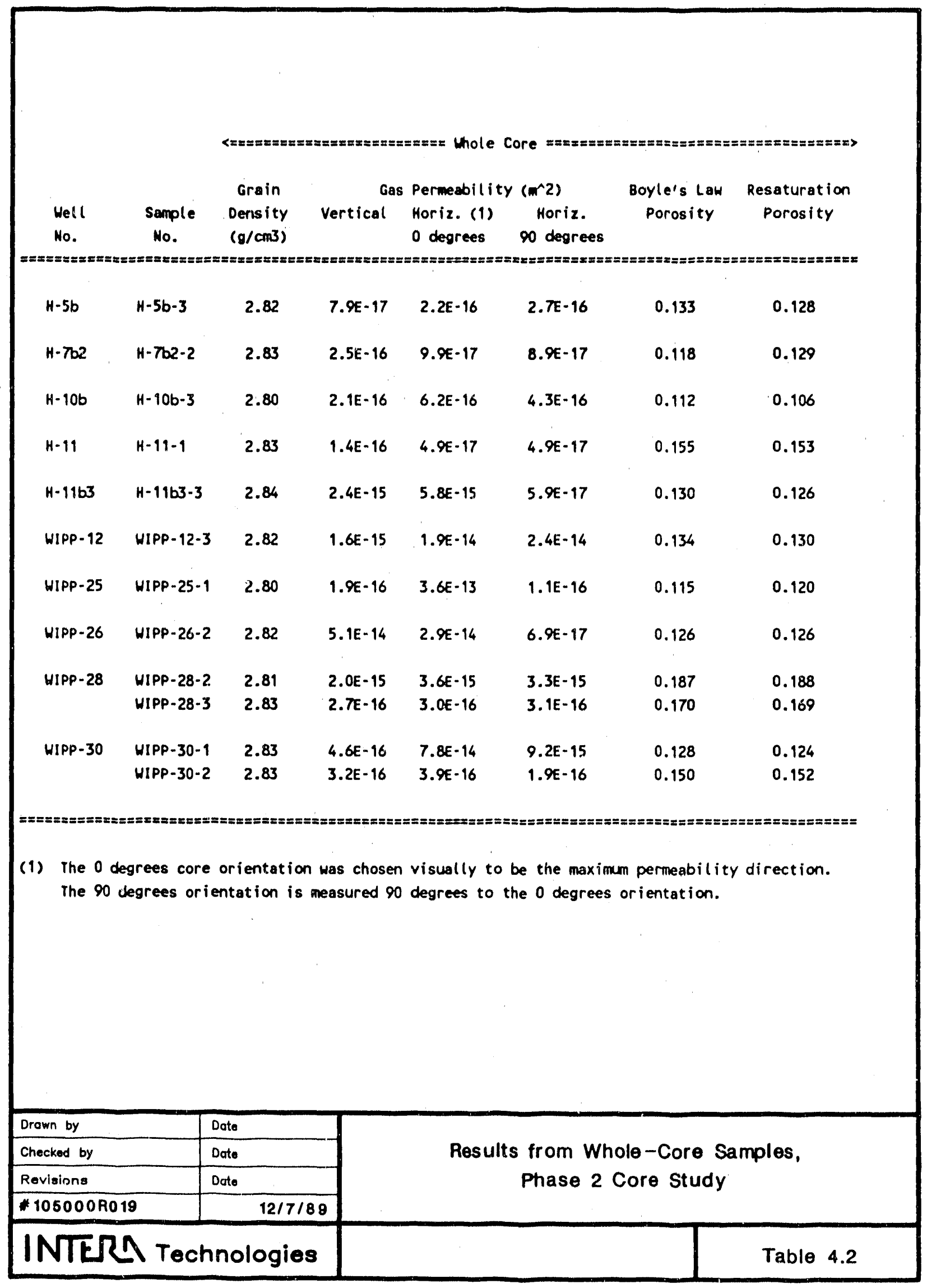




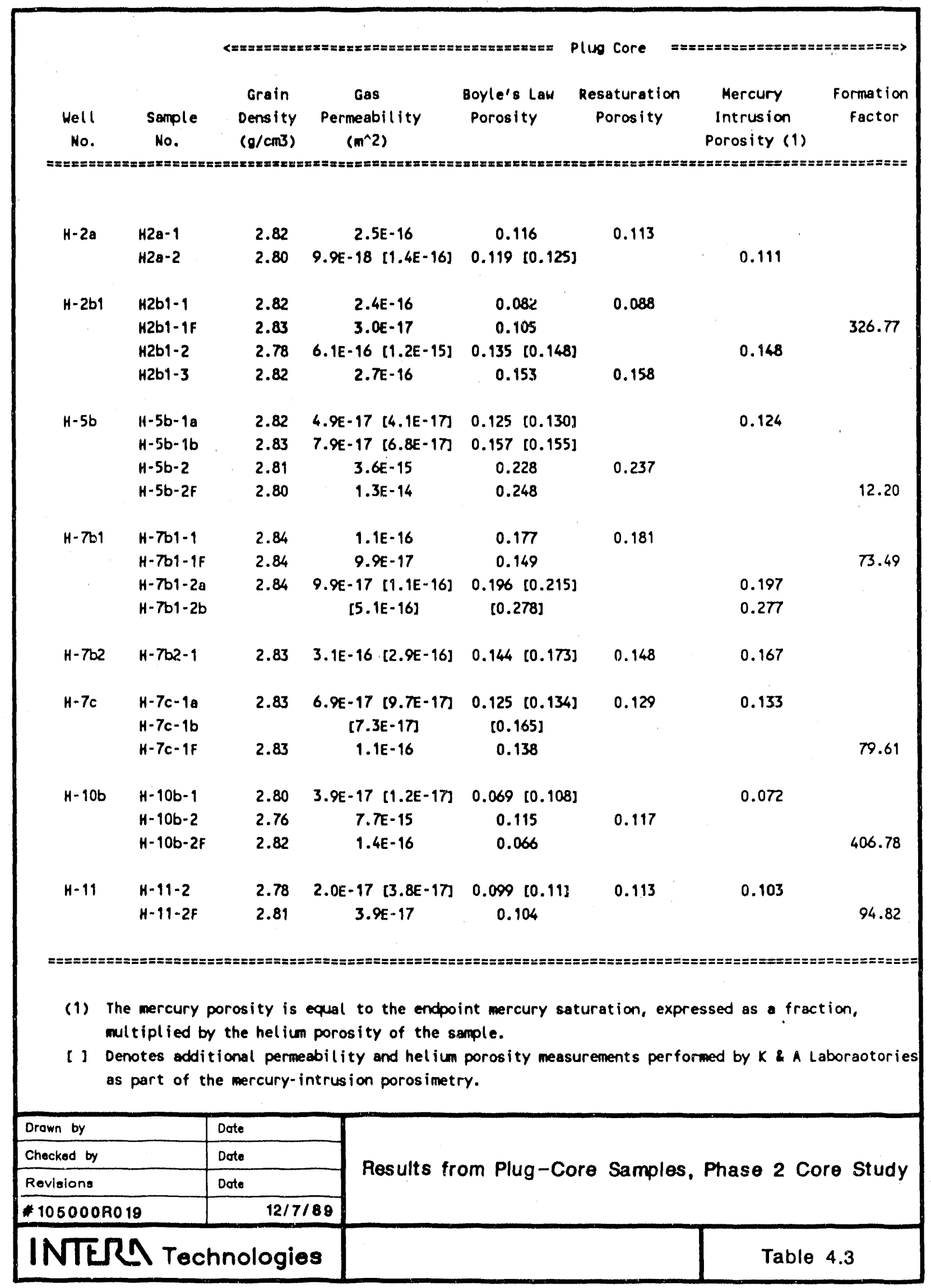




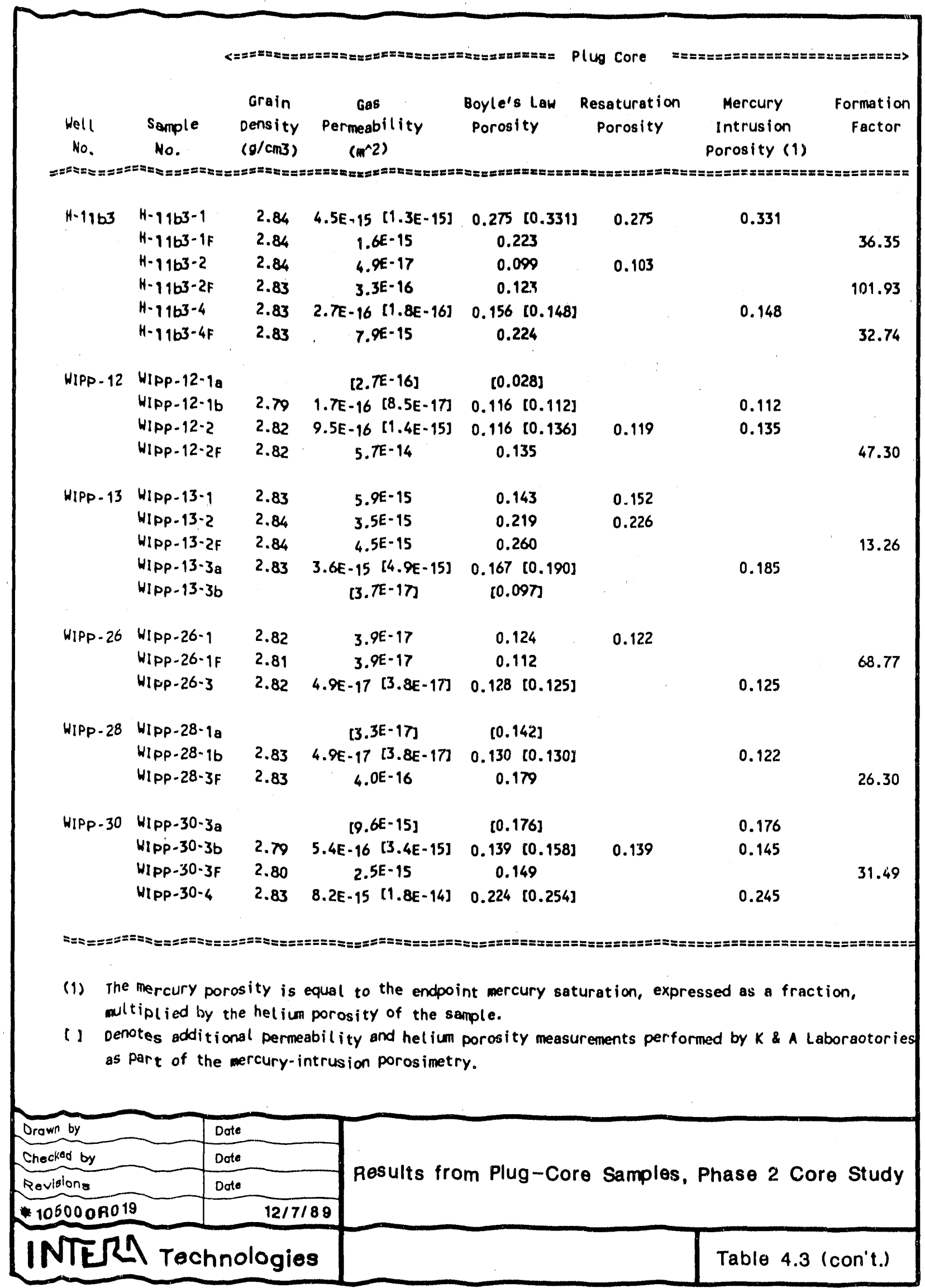




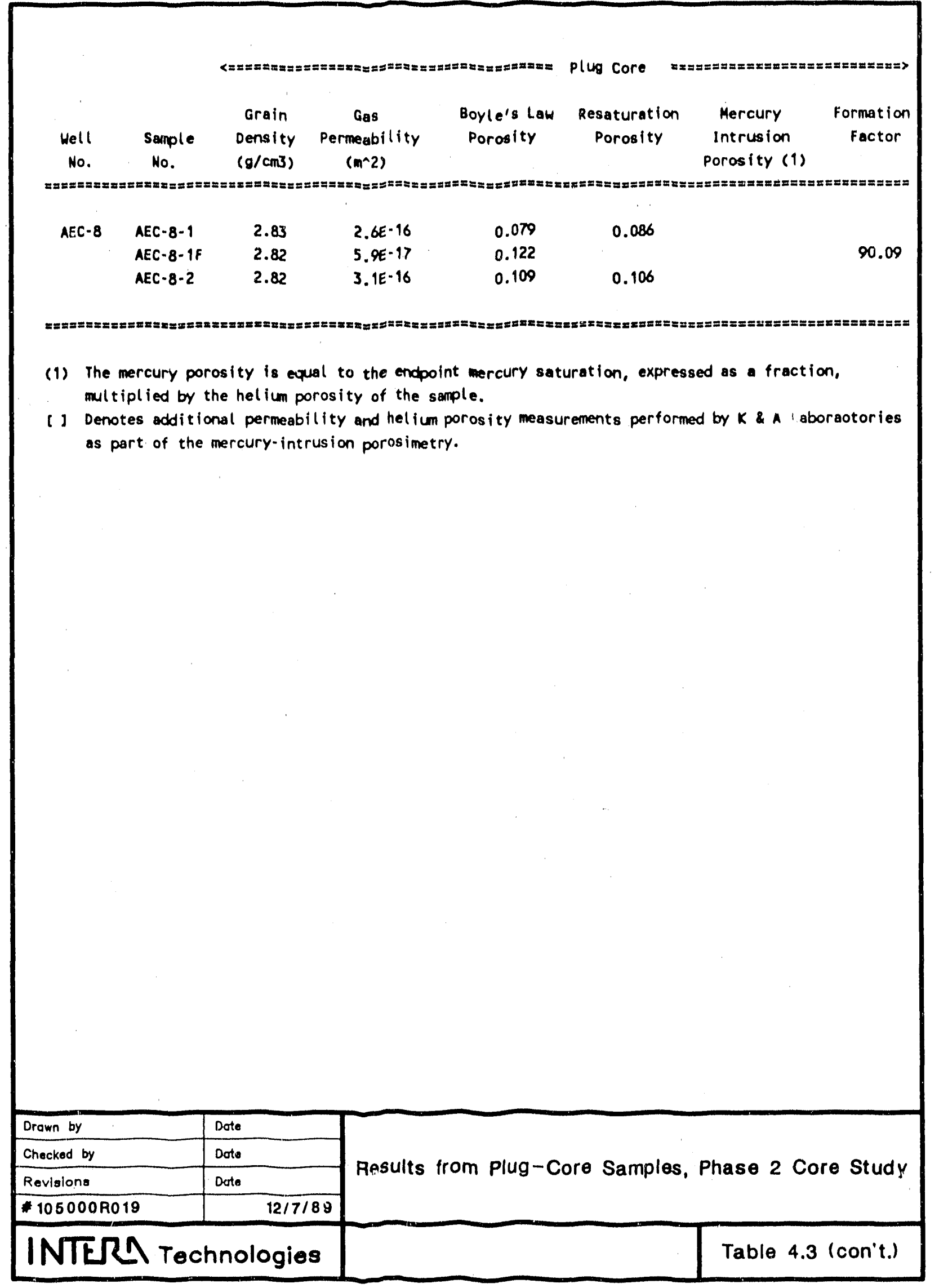




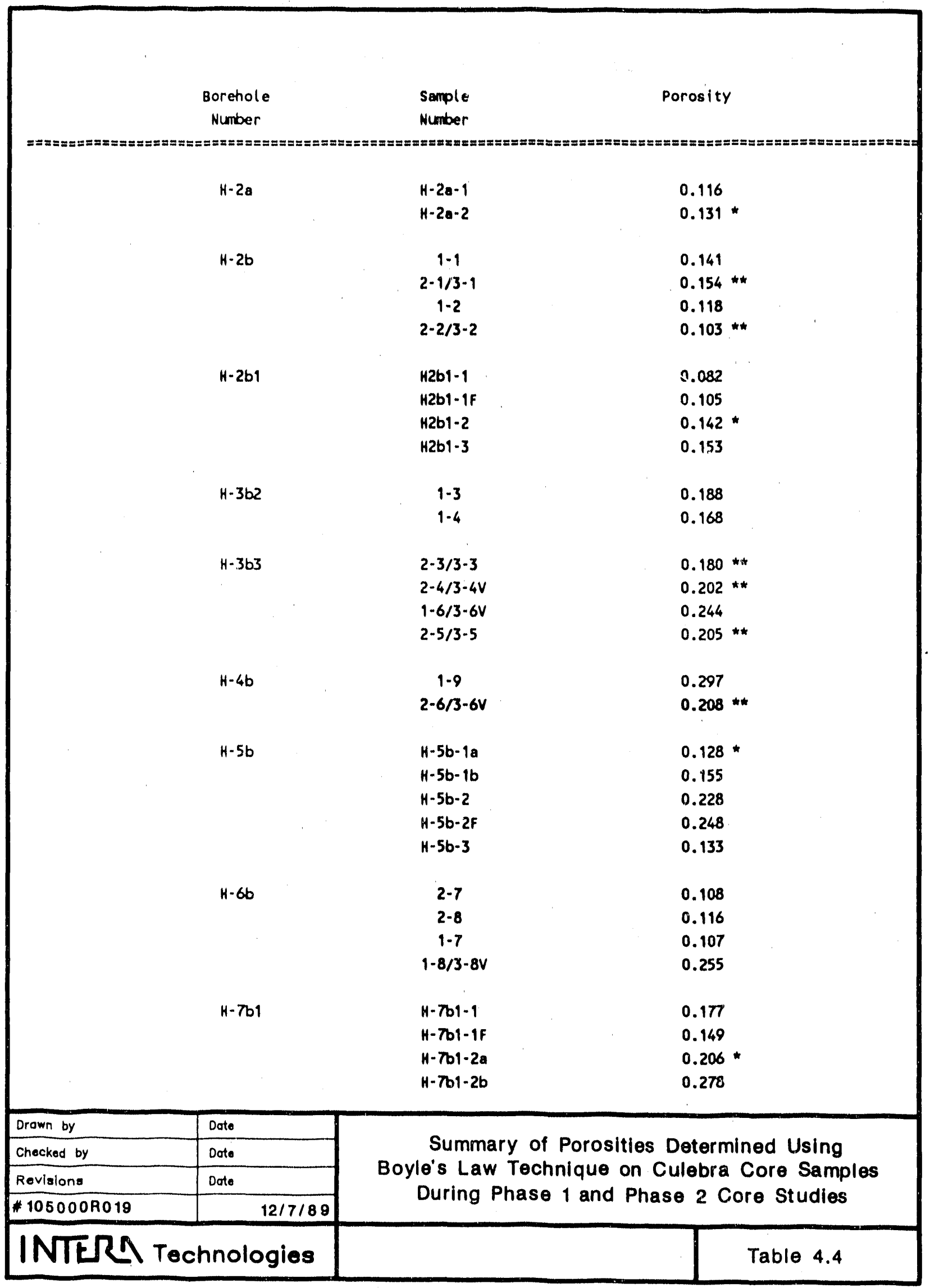




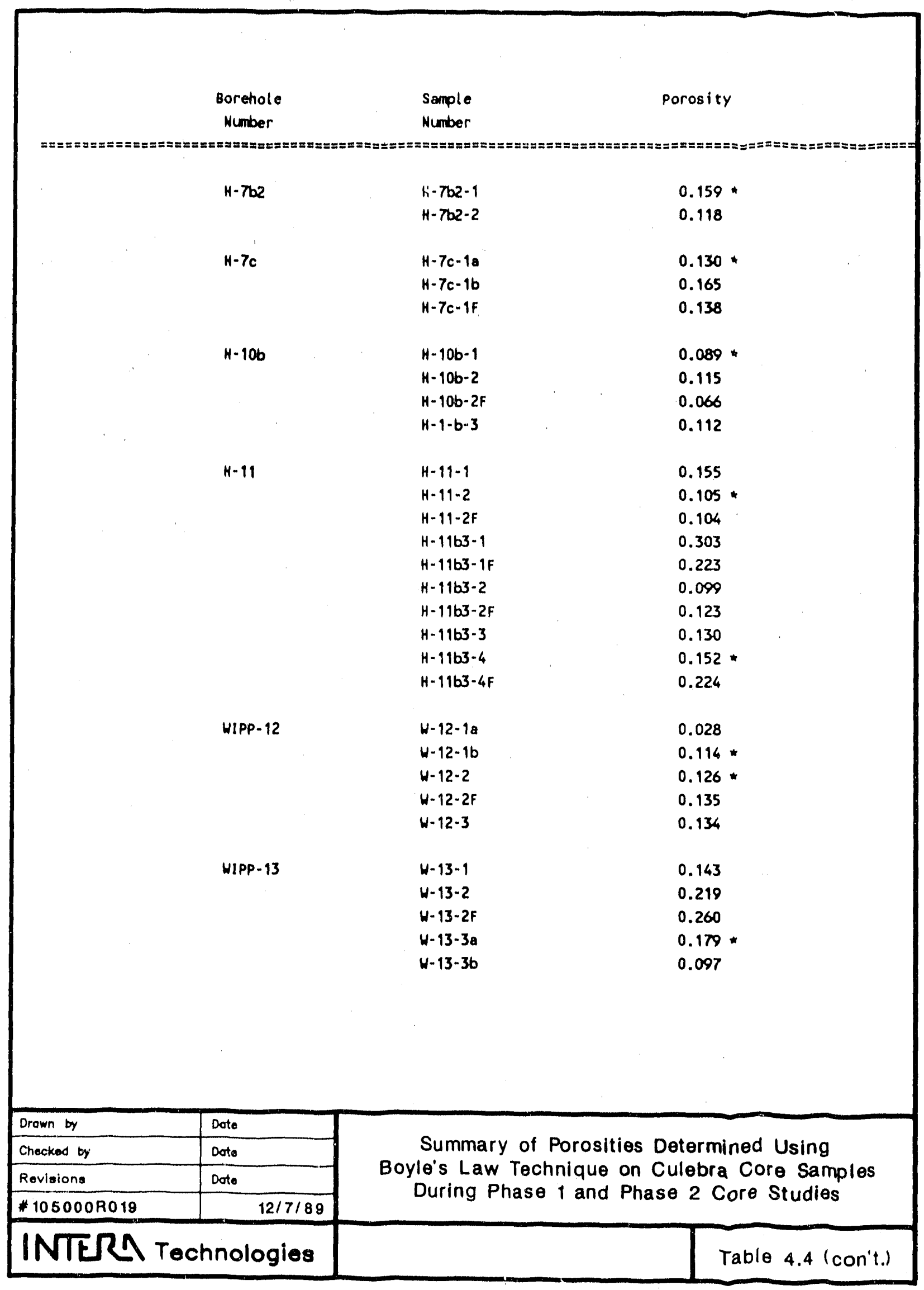




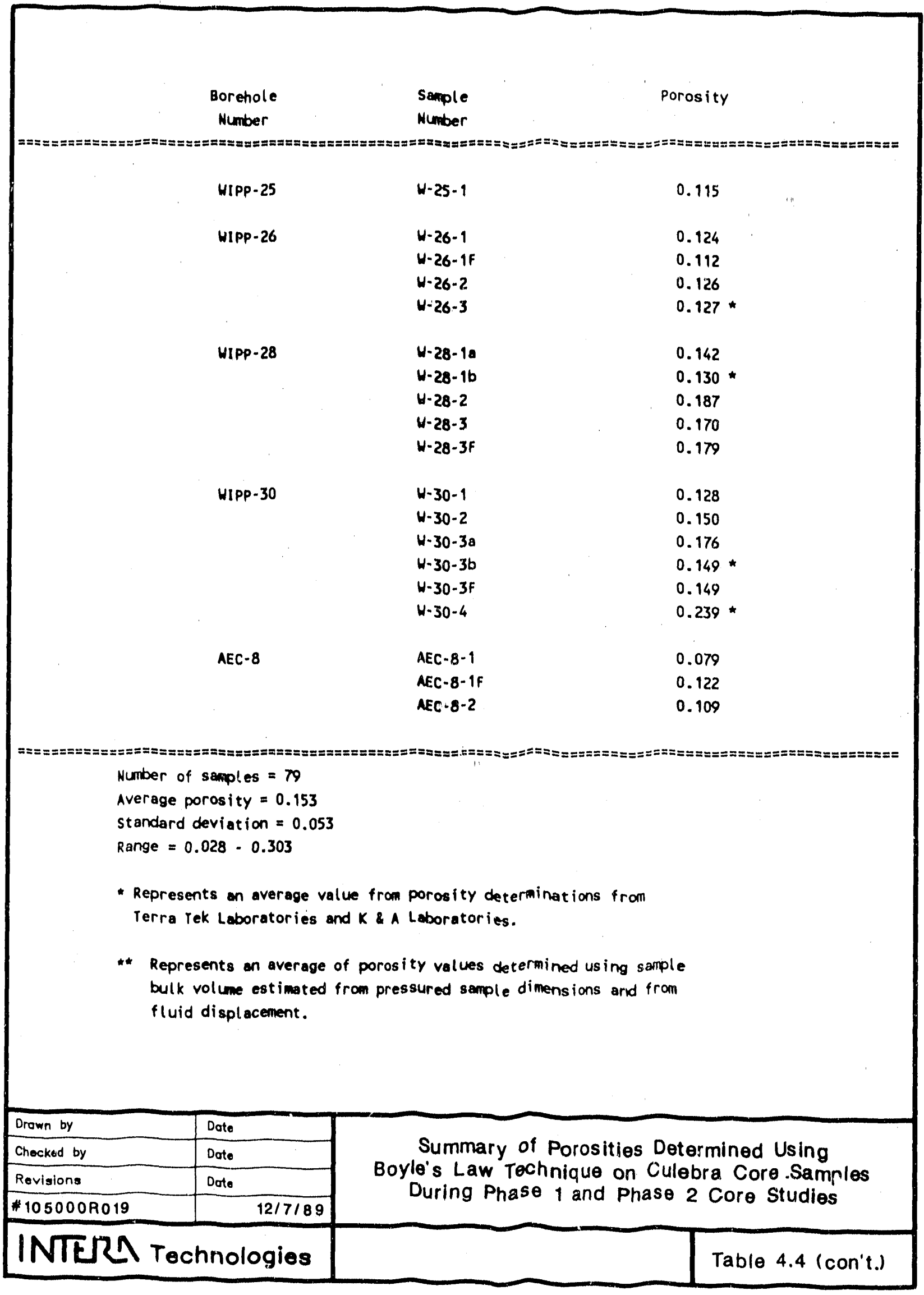




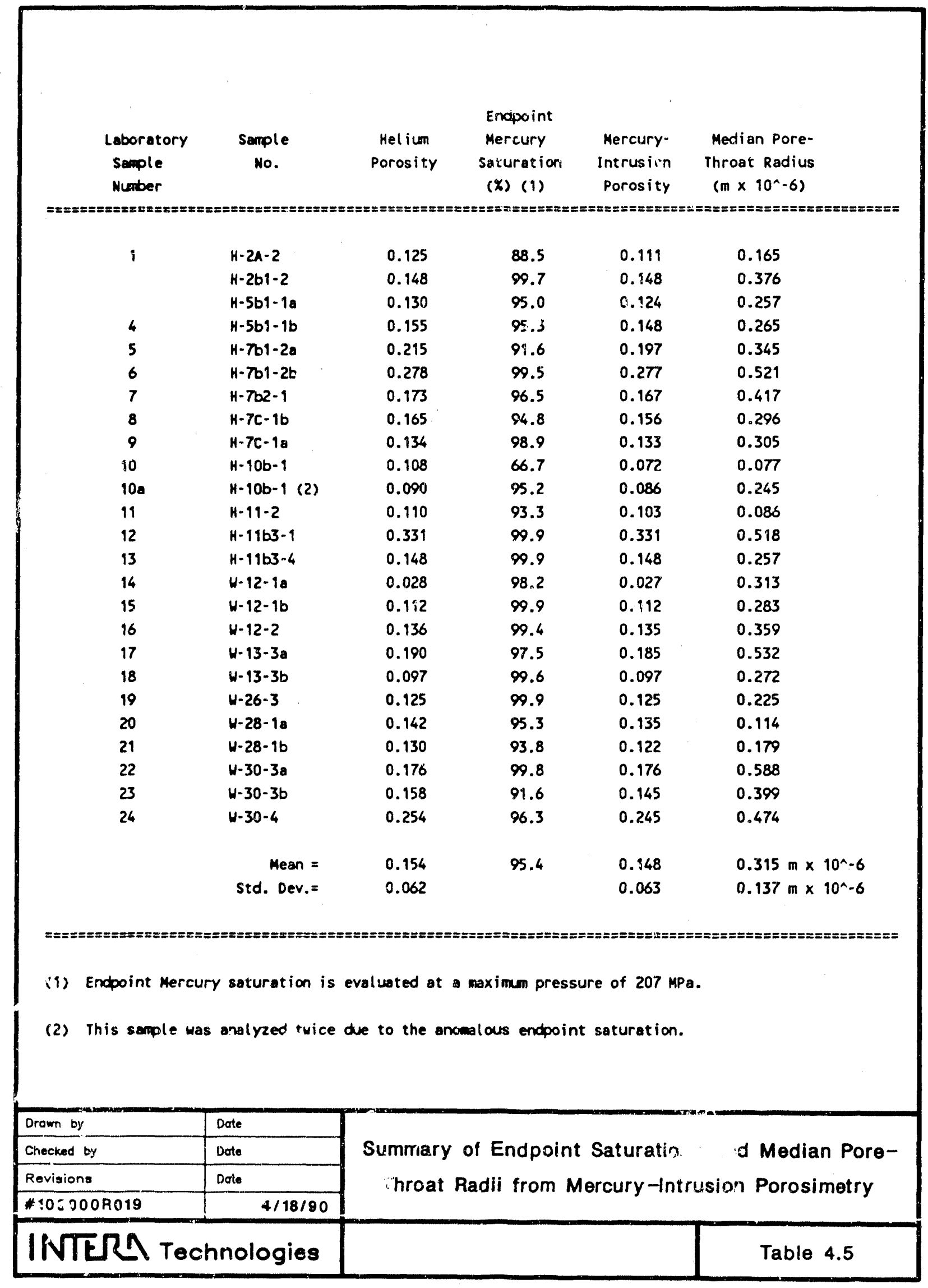




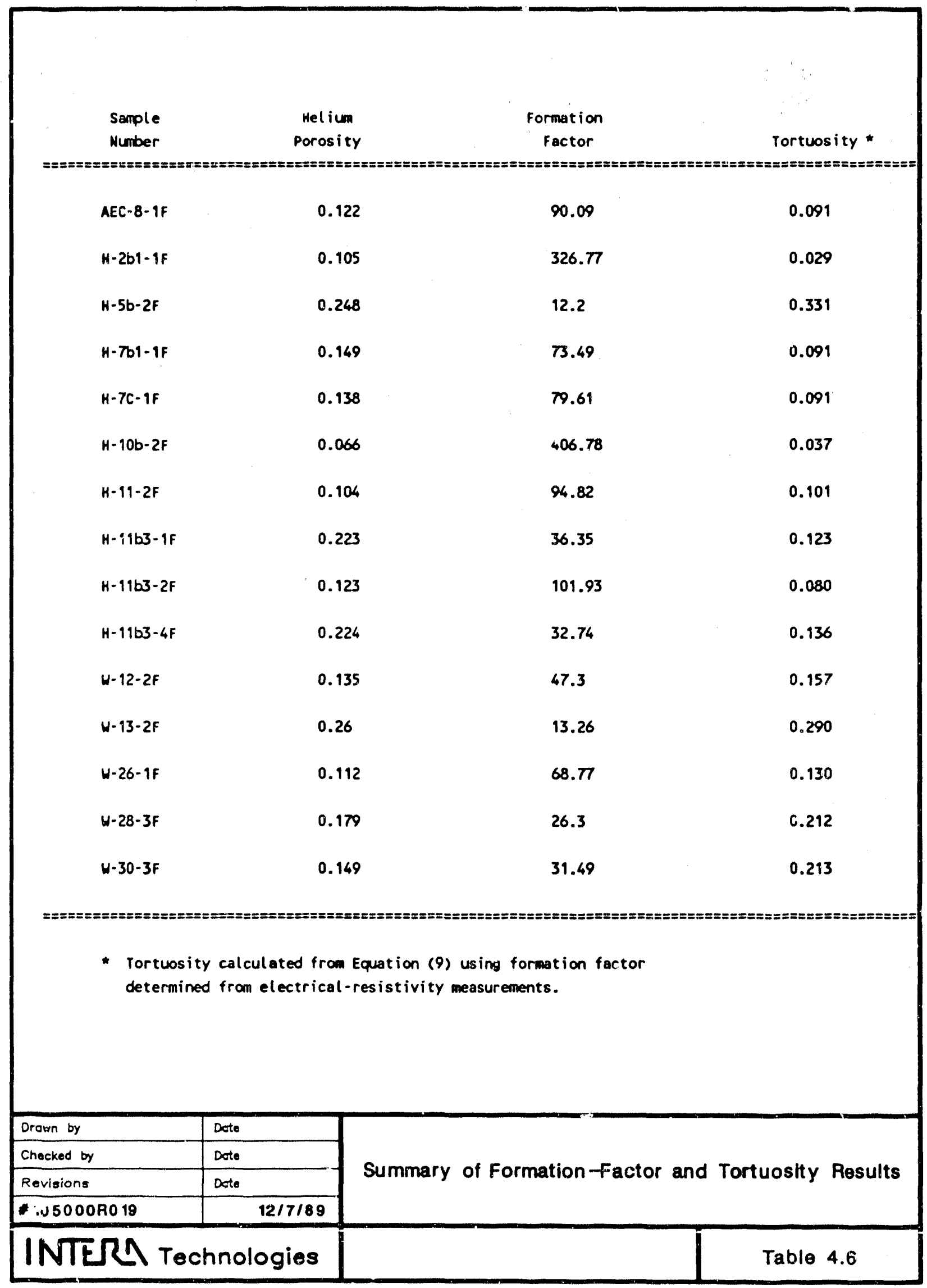




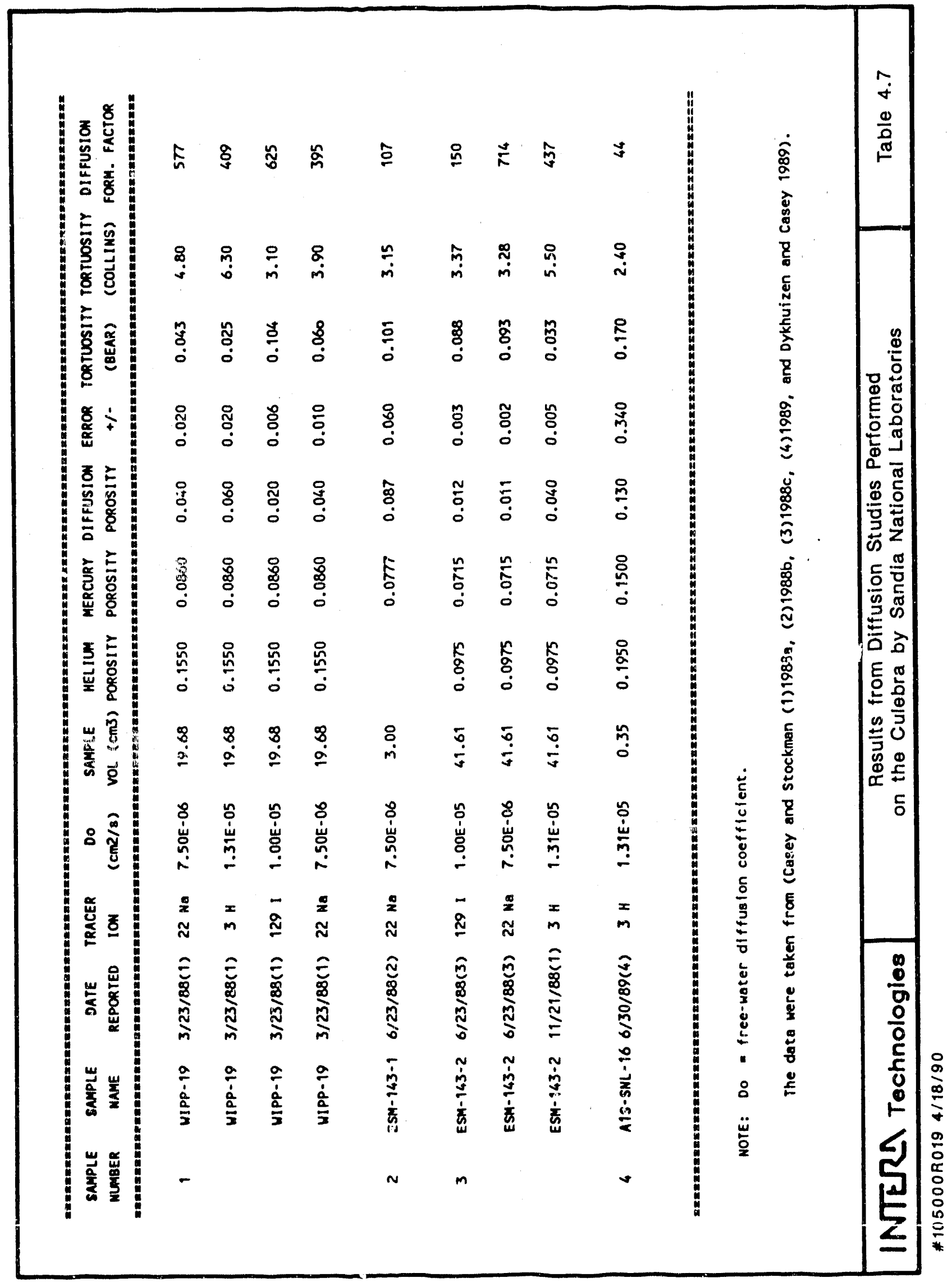




\subsection{CONCLUSIONS}

The Phase 1 and Phase 2 core studies of selected core samples of the Culebra dolomite from WIPP-site observation wells provided useful data in the parameterization of ground-water flow-and-transport modeling of the Culebra at the WIPP site. The samples were analyzed by helium porosimetry, resaturation porosimetry, mercury-intrusion porosimetry, electricalresistivity techniques, and gas pirmeability. The analyses were conducted on whole-core and core-plug samples. This section presents general conclusions based on the combined results of these core studies.

The combined results from the 79 Phase 1 and Phase 2 helium-porosity determinations indicated that the distribution of Culebra porosities was skewed toward lower porosity values. The arithmetic mean and standard deviation of the 79 helium porosities are 0.153 and 0.053 , respectively.

The vertical heterogeneity of porosity within the Culebra was evaluated using the results of core analysis of 21 pairs of core plugs, where each core plug in a pair was taken within about 5 to $10 \mathrm{~cm}$ of the other. The results using helium-porosity determinations showed that differences in porosity between the sample pairs ranged from as little as 0.05 to as high as 0.093 . The paired data indicated significant vertical-permeability differences on this scale.

The water-resaturation-porosimetry results showed a near 1-to-1 correlation with the results from helium-porosity determinations. The linear correlation coefficient between helium porosity and resaturation porosity for 30 samples was 0.99 . The correlation between the two sets of results was not expected to be good because water cannot normally access pore space as easily as helium. In some cases, the resaturation porosities were slightly larger than the helium porosities. It is possible that the results of the resaturation porosimetry may have been affected by. mineral dissolution from the delonized water which was used as the resaturation 
fluid. It is also possible that the actual differences between the porosities determined by both methods were within the experimental reproducibility of the two measuring techniques.

The endpoint mercury pore-volume saturations for the 25 samples analyzed ranged from 66.78 to 99.98 , with an endpoint pressure of $207 \mathrm{MPa}$. The average endpoint pore-volume saturation was 95.48 . The median pore-throat radil varled over an order of magnitude from $0.077 \mu \mathrm{m}$ to $0.588 \mu \mathrm{m}$ with an arithmetic average value of $0.315 \mu \mathrm{m}$. Eighty-four percent of the porethroat radif in the samples analyzed were between $0.1 \mu \mathrm{m}$ and $0.5 \mu \mathrm{m}$. The average mercury-intrusion porosity was 0.148 , as compared with the heliumporosity average of 0.154 . The mercury-intrusion porosimetry analyses confirmed the heterogeneity of pore structure within the Culebra, even over vertical distances of $10 \mathrm{~cm}$.

Seventy-three (73) grain-density measurements were made on the Culerra dolomite. The distribution of grain densities is skewed toward larger values of grain density with an arithmetic average of $2.82 \mathrm{~g} / \mathrm{cm}^{3}$ and a standard deviation of $0.019 \mathrm{~g} / \mathrm{cm}^{3}$. Because of the skewed grain-density distribution, the most common value of grain density is $2.83 \mathrm{~g} / \mathrm{cm}^{3}$, which is also the mertan of the distribution.

The results of electrical-resistivity measurements of saturated core plugs yielded 15 estimates of formation factor and tortuosity. The distribution of formation factor was log-normal and values ranged from 12 to 407 with a geometric mean of 58.8. The 15 values of tortuosity calculated from the formation-factor data ranged from 0.03 to 0.33 with an arithmetic average of 0.14 . The median tortuosity was 0.12 . The results show a general trend of increasing tortuosity with increasing porosity. The diffusion porosities and diffusion tortuosities determined for diffusion experiments on four rock samples by Dykhuizen and Casey (1989) agree with the lower range of the values determined by electrical-resistivity methods used in this core-analysis study. 
Gas-permeability measurements were performed on plug-core samples in both the horizontal and prical directions. Sixty-six (66) horizontalpermeability measuroxistis wexe made in both Phase 1 and Phase 2 core studies. The permeability values ranged from $7.9 \mathrm{E}-18 \mathrm{~m}^{2}$ to $3.6 \mathrm{E}-13 \mathrm{~m}^{2}$, and the distribution had an arithmetic average of $6.2 \mathrm{E}-15 \mathrm{~m}^{2}$, a geometric mean of $4.5 \mathrm{E}-16 \mathrm{~m}^{2}$, and a median of $2.7 \mathrm{E}-16 \mathrm{~m}^{2}$. Twenty-six (26) verticalpermeability measurements were made during both Phase 1 and Phase 2 core studies. The permeabilities ranged from $8.4 \mathrm{E}-18 \mathrm{~m}^{2}$ to $5.2 \mathrm{E}-14 \mathrm{~m}^{2}$, with an arithmetic mean of $5.1 \mathrm{E}-15 \mathrm{~m}^{2}$, a geometric mean of $9.0 \mathrm{E}-16 \mathrm{~m}^{2}$, and a median of $3.5 \mathrm{E}-16 \mathrm{~m}^{2}$. Plots of the $\log 10$ of permeability versus porosity indicated a weak correlation between the $\log 10$ of permeability and porosity. In general, the log10 of vertical permeability appeared to be more directly correlated with porosity than did the $\log 10$ of horizontal permeability. A plot of the loglo of horizontal permeability versus median pore-throat radius indicated that the $\log _{10}$ of horizontal permeability is directly related to median pore-throat radius. 


\subsection{REFERENCES}

Bear, J., 1972. Dynamics of Fluids in Porous Media. Elsevier Publishing Co., New York, 764pp.

Beauheim, R.I., 1987. Interpretations of Single-Well Hydraulic Tests Conducted at and Near the Waste Isolation Pilot Plant (WIPP) Site, 1983-1987. Sandia National Laboratories, Sandia Report SAND87-0039.

Casey, W.H. and H.W. Stockman, 1988a. "Solute Diffusion Through Culebra Dolomite: Additional Results," unpublished Sandia National Laboratories Memorandum to A. Lappin, March 23, 1988.

Casey, W.H. and H.W. Stockman, 1988b. "Diffusion Porosities in Culebra Dolomite: Sample ESM-143," unpublished Sandia National Laboratories Memorandum to A. Lappin, June 23, 1988.

Casey, W.H. and H.W. Stockman, 1988c. "Low Diffusion Porosities in Culebra Dolomite," unpublished Sandia National Laboratories Memorandum to A. Lappin, November 21, 1988.

Casey, W.H. and H.W. Stockman, 1989. "Solute Diffusion Through Sample A1S-SNL-16 of Culebra Dolomite," unpublished Sandia National Laboratories Memorandum to A. Lappin, June 30, 1989.

Cauffman, T.L., A.M. LaVenue, and J.P. McCord, 1990. Ground-water Flow Modeling of the Culebra Dolomite: Volume II - Data Base. Sandia National Laboratories, Contractor Repcrt SAND89-7068/2.

Collins, R.E., 1961. Flow of Fluids Through Porous Materials. Van Nostrand Reinhold Co., Inc., New York, 270 pp.

Core Laboratories, Inc., 1973. Fundamentals of Core Analysis. Core Laboratories, Inc., Dallas, Texas. 
Core Laboratories, Inc., 1986. A Complete Petrographic Study of Various Samples from the Rustler Formation, unpublished report prepared for Intera Technologies, Inc., by Core Laboratories, Aurora, Colorado.

Davis, S.N., 1969. Porosity and Permeability of Natural Materials. In "Flow Through Porous Media," edited by R. De Wiest, Academic Press, New York, p.54-89.

Dykhuizen, R.C. and W.H. Casey, 1989. An Analysis of Solute Diffusion in the Culebra Dolomite. Sandia National Laboratories, Sandia Report SAND89-0750.

Freeze, R.A., 1975. A Stochastic-Conceptual Analysis of One-Dimensional Groundwater Flow in Nonuniform Homogeneous Media. Water Resources Research, Vol. 11, No. 5, p.725-741.

Hill, H.J. and J.D. Milburn, 1956. Effect of Clay and Water Salinity on Electrochemical Behavior of Reservoir Rocks. Trans. of AIME, Vo1. 207, p.65-72.

Katsube, T.J., T.W. Melnyk, and J.P. Hume, 1986. Pore Structure From Diffusion in Granitic Rocks. Atomic Energy of Canada Ltd., Tech. Rept. TR-381, 27pp.

Katsube, T.J. and J.P. Hune, 1987. Permeability Determination in Crystalline Rocks by Standard Geophysical Logs. Geophysics, Vol. 52, No. 3, p. 342-352.

Kelley, V.A. and J.F. Pickens, 1986. Interpretation of the Convergent-Flow Tracer Tests Conducted in the Culebra Dolomite at the $\mathrm{H}-3$ and $\mathrm{H}-4$ Hydropads at the Waste Isolation Pilot Plant (WIPP) Site. Sandia National Laboratories, Contractor Report SAND86-7161. 
Klinkenberg, L.J., 1951. Analogy Between Diffusion and Electrical Conductivity in Porous Rocks. Geological Soclety of America Bulletin, Vo1. 12, p.559.

Lappin, A.R., R.L. Hunter, D.P. Garber, and P.B. Davies, 1989 (Editors). Systems Analysis, Long-Term Radionuclide Transport, and Dose Assessments, Waste Isolation Pilot Plant (WIPP), Southeastern New Mexico, March 1989. Sandia National Laboratories, Sandia Report SAND89-0462.

LaVenue, A.M., T.L. Cauffman, and J.F. Pickens, 1990. Ground-water Flow Modeling of the Culebra Dolomite: Volume I - Model Calibration. Sandia National Laboratories, Contractor Report SAND89-7068/1.

LaVenue, A.M., A. Haug, and V.A. Kelley, 1988. Numerical Simulation of Ground-Water Flow in the Culebra Dolomice at the Waste Isolation Pilot Plant (WIPP) Site: Second Interim Report. Sandia National Laboratories, Contractor Report SAND88-7002.

Matheron, G., 1967. Eléments pour une Théorie des Milieux Poreux. Masson, Paris.

Rakcp, K.C. and T. Little, 1988. Final Report, Special Core Analysis Studies of the Culebra Dolomite. Terra Tek Core Services, Salt Lake City, Utah, Contract Rsport TR 88-48 R1 for INTERA Technologies, Inc.

Reeves, M., V.A. Kelley, and J.F. Pickens, 1987. Regional DoublePorosity Solute Transport in the Culebra Dolomite: An Analysis of Parameter Sensitivity and Importance at the Waste Isolation Pilot Plant (WIPP) Site. Sandia National Laboratories, Contractor Report SAND87-7105. 
Robinson, K.L. and S.J. Lambert, 1987. Analysis of Solutes in Groundwaters from the Rustler Formation at and Near the WIPP-Site. Sandia National Laboratories, Sandia Report SAND86-0917.

Saulnier, G.J., Jr., T.L. Cauffman, V.A. Kelley, J.F. Pickens, and W.A. Stensrud, 1989. Practical Aspects of Design and Field Implementation of a Convergent-Flow Tracer Test [abs.] Groundwater, Vol. 27, No. 5, p. 728 .

Schlumberger, 1972. Log Interpretation, Volume One - Principles. Schlumberger, Ltd., New York, 113pp.

Scheidegger, A.E., 1974. The Physics of Flow Through Porous Media, Third Edition. University of Toronto Press, 353pp.

Skagius, K. and I. Neretnieks, 1986. Porosities and Diffusivities of Some Nonsorbing Species in Crystalline Rocks, Water Resources Research, Vo1. 22, p.389-398.

Touloukian, V.S., W.R. Judd, and R.F. Roy, 1981. Physical Properties of Rocks and Minerals. McGraw-Hill/CINDAS Data Series on Materials Properties, V.S. Touloukian and C.Y. Ho, editors, Vol. II-2, 548pp.

van Brake1, J. and P.M. Heertjes, 1974. Analysis of Diffusion in Terms of a Porosity, a Tortuosity, and a Constrictivity Factor. International Journal of Heat and Mass Transfer, Vol. 17, p.1093-1095.

Walter, G.R., 1982. Theoretical and Experimental Determination of Matrix Diffusion and Related Solute Transport Properties of Fractured Tuffs from the Nevada Test Site. Los Alamos National Laboratories, Los Alamos Report LA-9471-MS.

Waxman, M.H. and L.J.M. Smits, 1968. Electrical Conduction in 011-Bearing Shaly Sands. Society of Petroleum Engineers Journal, Vol. 8, No. 1, p. $107-122$. 
APPEND _a $A$

SAMPLE DESCRIPTIONS 


\begin{tabular}{|c|c|c|}
\hline Sample No. & Depth (ft.). & Core-Sample Descriptions \\
\hline $\begin{array}{l}\mathrm{H} 2 \mathrm{~b} / 1-1,1-1 \mathrm{H} \\
\quad 1-1 \mathrm{~V}\end{array}$ & 630.0 & finely vugular dolomite \\
\hline $\mathrm{H} 2 \mathrm{~b} / 2-3,3-1$ & $635.8-636.2$ & $\begin{array}{l}\text { very vuggy, dolomite, some gypsum- } \\
\text { filled fractures, some up to } 15 \mathrm{~mm} \text {. } \\
\text { in didmeter, some are gypsum filled }\end{array}$ \\
\hline $\mathrm{H} 2 \mathrm{~b} / 1-2$ & 637.5 & finely porous and vuggy dolomite \\
\hline $\mathrm{H} 2 \mathrm{~b} / 2-2,3-2$ & $639.8-640.2$ & $\begin{array}{l}\text { finely vugular dolomite, some } \\
\text { calcite fillings, has a brown silt } \\
\text { (perhaps driliing mud) all over } \\
\text { core, has a corroded appearance in } \\
\text { areas. }\end{array}$ \\
\hline $\mathrm{H} 3 \mathrm{~b} 2 / 1-3,3-3 \mathrm{v}$ & 681 & porous dolomite \\
\hline $\mathrm{H} 3 \mathrm{~b} 2 / 1-4,3-4 \mathrm{v}$ & 689.2 & very vuggy and porous dolomite \\
\hline $\mathrm{H} 3 \mathrm{~b} 3 / 1-5$ & $667.7-668.1$ & massive gypsum \\
\hline $\mathrm{H} 3 \mathrm{~b} 3 / 2-3,3-3$ & $671.4-671.7$ & $\begin{array}{l}\text { finely vugular, finely fractured } \\
\text { dolomite. Sone (less than 10z) vugs } \\
\text { and fractures are filled with } \\
\text { gypsum. fractures are tight }\end{array}$ \\
\hline $\mathrm{H} 3 \mathrm{~b} 3 / 2-4,3-4 \mathrm{v}$ & $671.7-672.0$ & $\begin{array}{l}\text { vuggy dolomite, tight vertical } \\
\text { fracture, seems to be gypsum filled, } \\
\text { some large voids, } 208 \text { or more are } \\
\text { gypsum filled }\end{array}$ \\
\hline $\mathrm{H} 3 \mathrm{~b} 3 / 1-6,3-6 \mathrm{v}$ & 689.3 & finely vugular, porous dolomite \\
\hline $\mathrm{H} 3 \mathrm{~b} 3 / 2-5,3-5$ & $690.0-690.6$ & $\begin{array}{l}\text { very finely vugular, porous core, } \\
\text { large } 25 \text { by } 40 \mathrm{~mm} \text { gypsum fill }\end{array}$ \\
\hline $\mathrm{H} 4 \mathrm{~b} /-9$ & 513 & porous dolomite \\
\hline$H 4 b / 2-6,3-6 v$ & $517.0-517.3$ & $\begin{array}{l}\text { very silty, finely porous dolomite, } \\
\text { friable in sections }\end{array}$ \\
\hline Drawn by & Date & \\
\hline Checked by & Date & Core-Sample Descriptions for the Phase 1 \\
\hline Revisions & Date & \\
\hline
\end{tabular}

A- 3 
We11 No./

Sample No.

$\mathrm{H} 6 \mathrm{~b} / 2-7$

$\mathrm{H} 6 \mathrm{~b} / 2-8$

$\mathrm{H} 6 \mathrm{~b} / 1-7$

$\mathrm{H} 6 \mathrm{~b} / 1-8,3-8 \mathrm{v}$

\section{Depth (ft.) Core-Sample Descriptions}

614.3-614.6 massive dolomite

615.0-615.3 very dense, massive dolomite, has brown spotty precip on outside, one noticeable void, open, $\approx 5$ by $3 \mathrm{~mm}$

616.0

massive dolomite

$628-640$

very porous dolomite

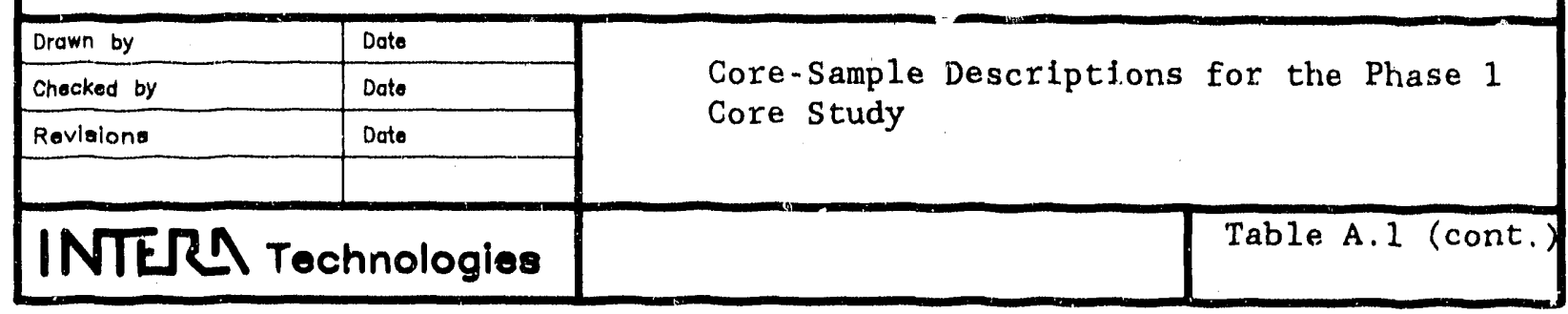

A -4 
We11 No./

Sample No.

$H-2 a-1$

$H-2 a-2$

$\mathrm{H}-2 \mathrm{~b} 1-1$

$H-2 b 1-2$

$H-2 b-3$

$H-5 b-1$

H- $5 b-2$

H $-5 b-3$

$\mathrm{H}-7 \mathrm{~b} 1-1$

$H-7 b 1-2$

$\mathrm{H}-7 \mathrm{~b} 2-1$

$H-7 b 2-2$

$H-7 c-1$
Depth $(f t$,

619

$622-622.4$

$637.6-637.8$

$\approx 640$

$\approx 641.5$

$903-903.6$

$913 \approx 914$

$901.3-901.7$

$251.5-251.9$

$\approx 268$

$\approx 275$

$260-261.25$

$271.1-271.7$
Core-Sample Descriptions

irregular, tight dolomite, some microfractures, some filled vugs $\approx 6$ $\mathrm{cm}$. In length

tight, slightly vuggy dolomite;

full length vertical frac, gypsum filled, Irregular edges

very vuggy dolomite, most unfilled, the remainder are gypsum-filled

vuggy dolomite, some gypsum filled

slightly vuggy dolomite, vugs are not filled

massive dolomite with open vugs

hairline horiz. fractures, finely vugular dolomite

massive dolomite, vuggy near top of sample

open vugs, otherwise wel1. consolidated massive dolomite

very vuggy dolomite, vugs are unfilled and average $1 \mathrm{~cm}$ diameter

vuggy dolomite

massive dolomite, some vertical fractures, and occasional isolated empty vugs

dolomite with large vugs, average diameter is approximately $2 \mathrm{~cm}$

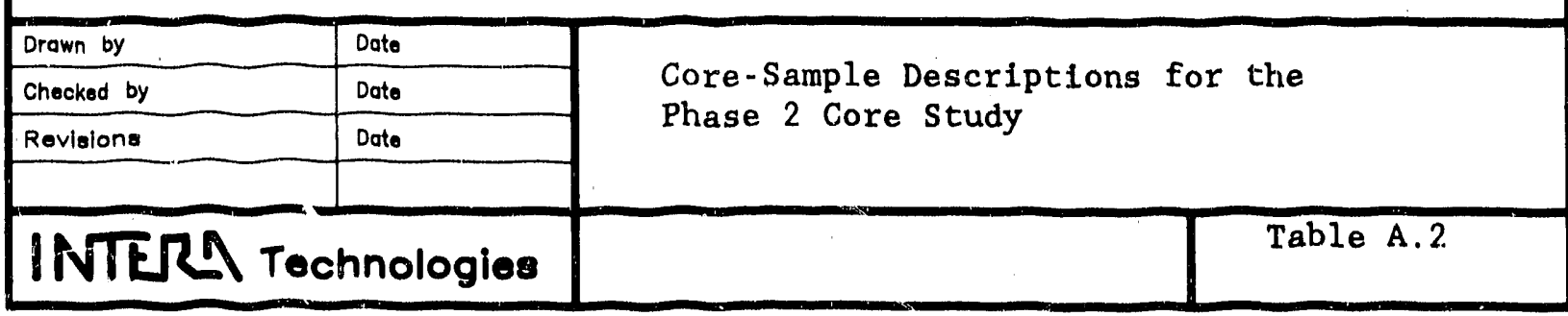


Well No./

Sample No.

$\mathrm{H}-10 \mathrm{~b}-1$

$H-10 b-2$

$\mathrm{H}-10 \mathrm{~b}-3$

H-11-1

H-11-2

$\mathrm{H}-11 \mathrm{~b}-3-1$

$\mathrm{H}-11 \mathrm{~b} 3-2$

H $-11 b 3-3$

$\mathrm{H}-11 \mathrm{~b} 3-4$

WIPP-12-1

WIPP-12-2

WIPP-12-3

WIPP-13-1
Depth (ft.) Core-Sample Descriptions

1394.5-1395.1 brecciated vuggy (filled) dolomite, contains a layer with fine clay infilling

1374-1347.4 consolidated dolostone, slightly fractured, contains fine vugs

1388.1-.8 vuggy dolomite

731.5-731.9 competent dolomite with fine vugs which are not filled

N/A

competent dolomite with filled hairline fracture, one gypsum-filled vug, ovold in shape, $3 \mathrm{~cm}$. in diameter

756.3-756.5 silty dolomite, vuggy and very porous

$\approx 753$

vuggy dolomite with hairline fractures, vugs are open.

741.8-742.3 competent dolomite, a few vugs filled and not filled

744.46-745.33 finely vugular dolomite, micro vugs not filled

821.5-822 vuggy, silty ciolomite

834.3-834.8 vuggy dolomite, with some vugs filled with gypsum, also vertical fractures, some filled, others not

832.3-832.8 fractured dolomite with few vugs, fractures are tight

massive dolomite, a few open halrline fractures; core only $3 / 4$ round so have to take plug sample

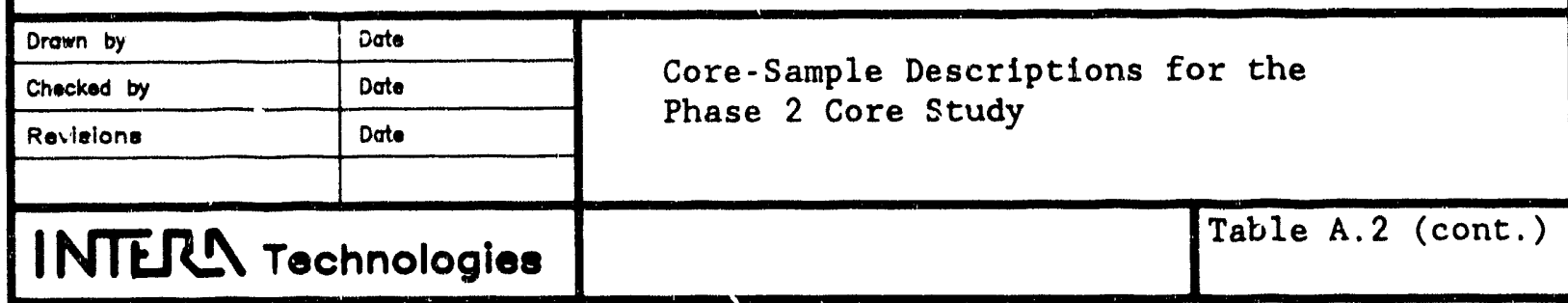


Well No./

Sample Ne.

WIPP $-13-2$

WIPP - 13-3

WIPP - 25-1

WIPP - 26-1

WIPP- 26-2

WIPP- $26-3$

WIPP - 28-1

WIPP - 28-2

WIPP - $28-3$

WIPP - 30-1

WIPP-30-2

WIPP - 30-3

WIPP $-30-4$

AEC - $8-1$

AEC - $8-2$
Depth (ft.) Core-Sample Descriptions

$\approx 723.5 \quad$ vuggy dolomite

707.5-708.1 vuggy silty dolomite

454-454.8 massive dolomite

190.7-191 massive dolomite with a few sma11diameter, open vugs

$191.5-192$

massive dolomite with open vugs

vuggy silty dolomite, vugs open, only good piece; all core below destroyed, hard to determine exact footage

$\approx 430$

finely vuggy dolomite

$426.5-427$

fragmented silty dolomite

$427.9-428.4$

massive silty dolomite, no obvious laminations or structure

$647.7-648$

vuggy dolomite with vertical fractures, some filled

$\approx 638.5$ finely vugular dolomite

636.7-637.2 very vuggy dolomite

635.1-635.4 vuggy, silty dolomite, vugs not filled with gypsum

$\approx 849$

massive finely vugular dolomite

massive dolomite with very large vugs

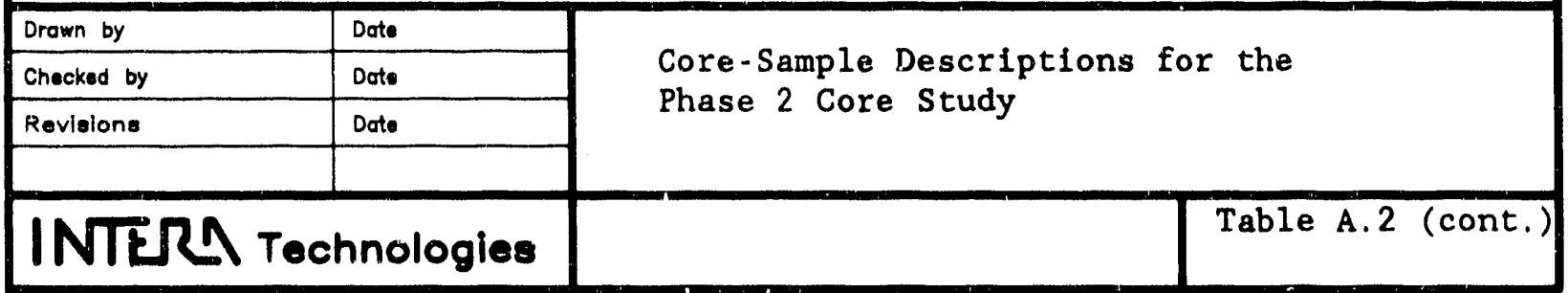


APPENDIX B

\section{SUMGARY OF RESULTS RECEIVED FROM \\ CORE LABORATORIES, INC.}

Note: Laboratory Sample Number 5 from the November 13, 1985 report is a sample of the Tamarisk Member of the Rustler Formation. Analyses performed on this sample are not included in the Culebra sample set presented in this report. 


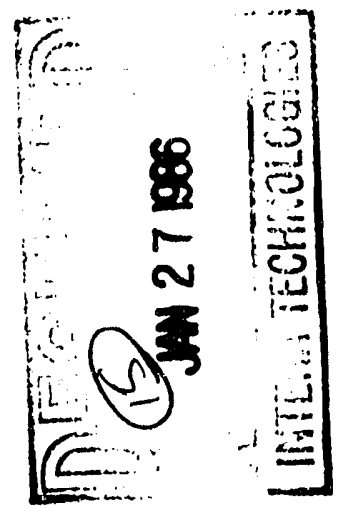

$\sum^{0}=$

i

II) $\infty$

ar

$0=$

$4 \geq$ i

c : s

$0 \approx J$

$\infty \propto<$

45

w

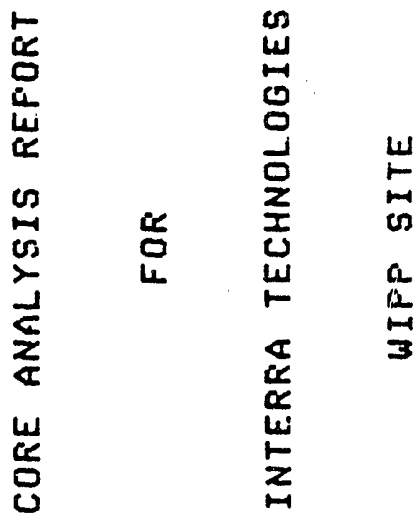

$\propto$

0 :

Ua 

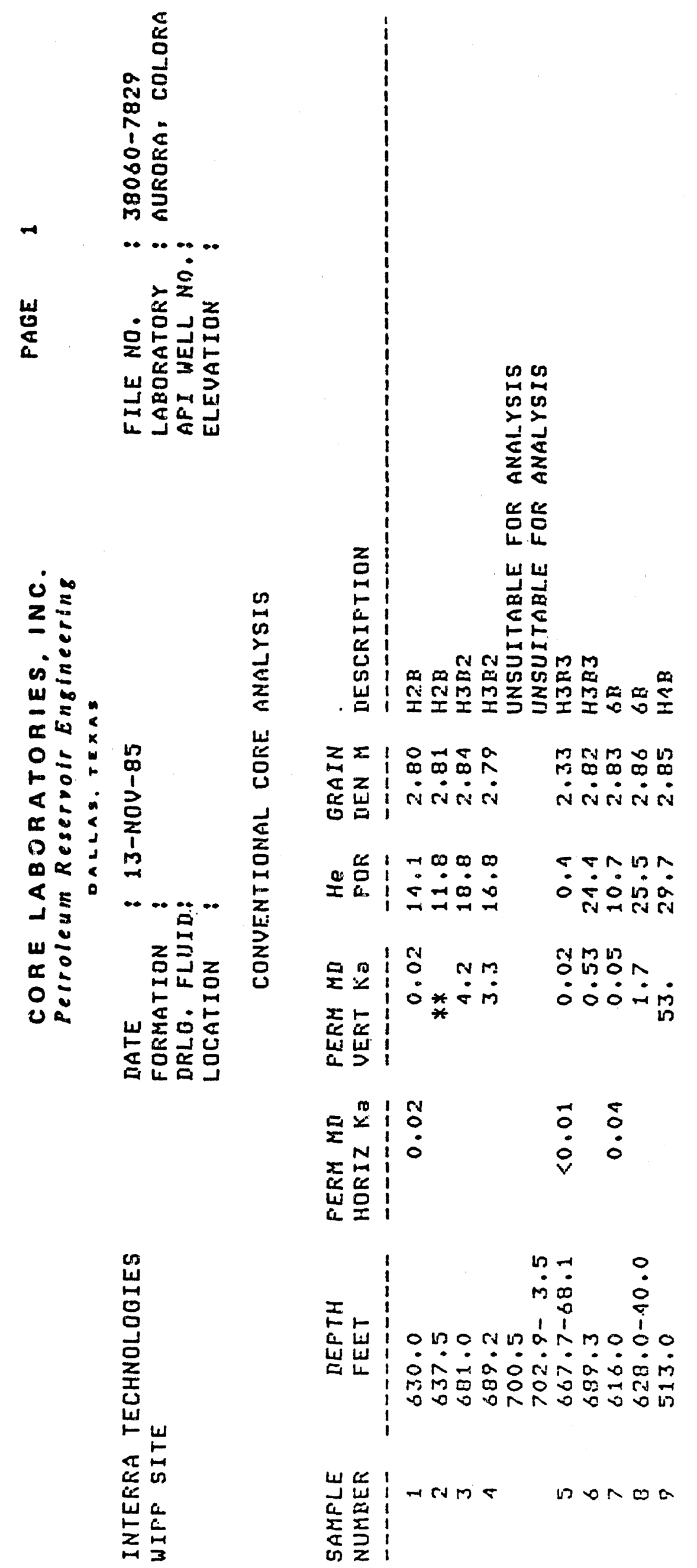

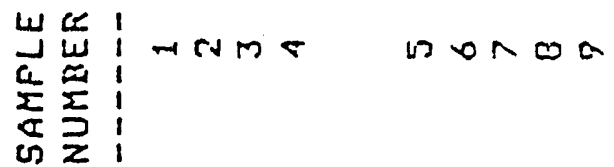


$\sum \sum$

is

UI $\infty$

- $4 x$

$0 \leqslant$

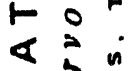

x s

0 a j

or

$<\Sigma^{\circ}$

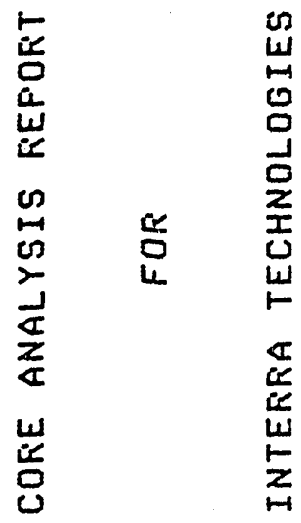

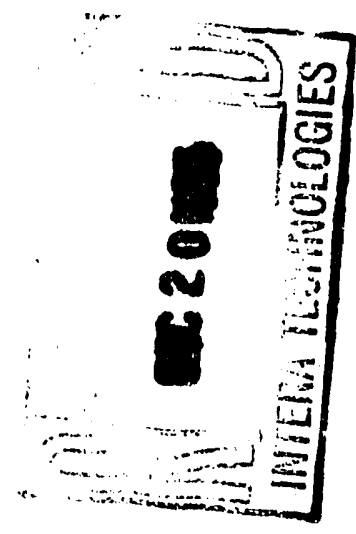

$\omega \div$

a:

$0=$

02 

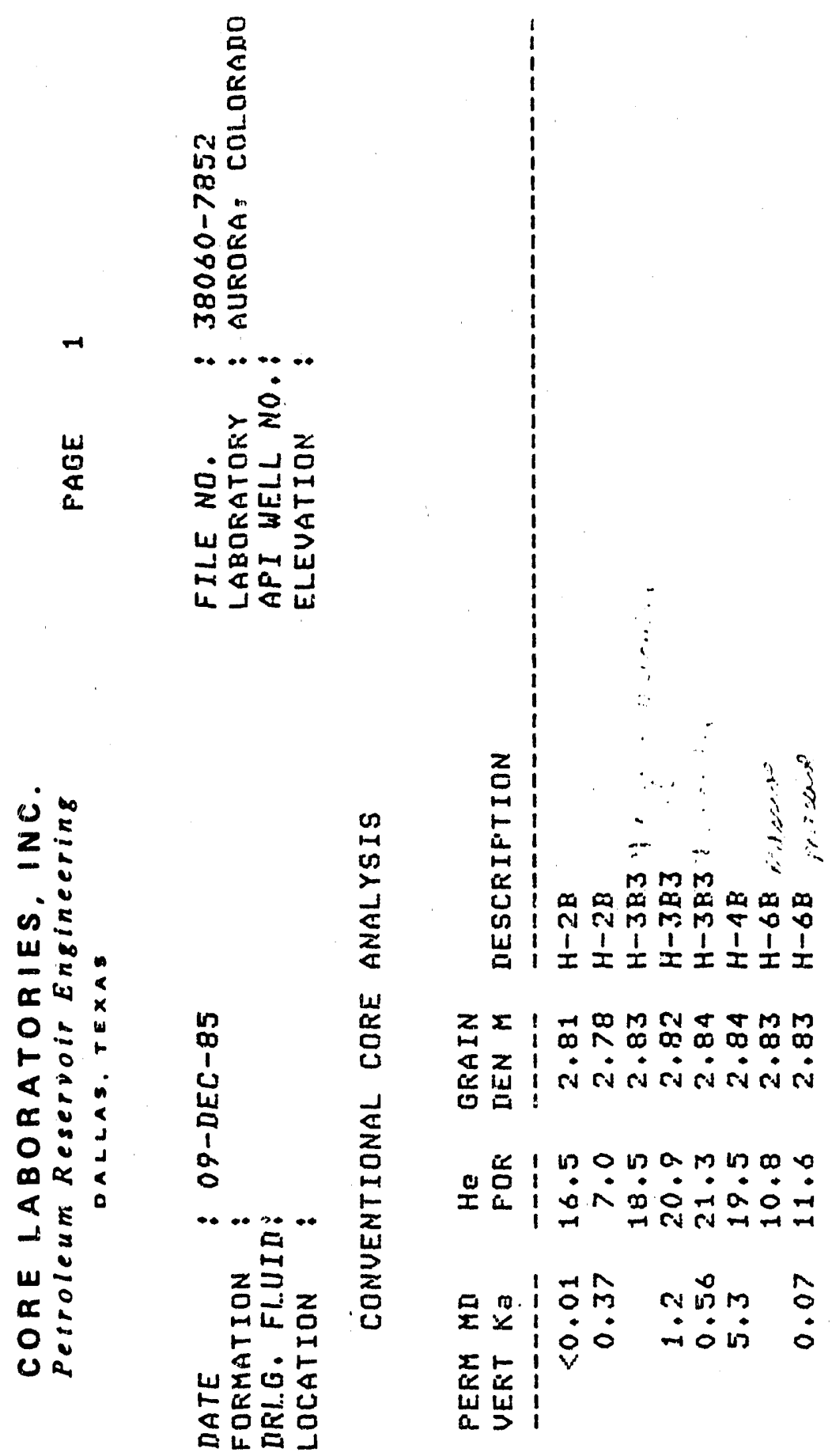

感

$\frac{1}{2}$

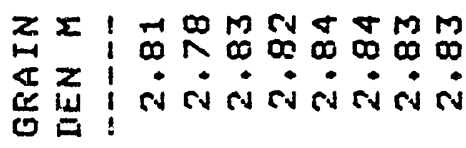

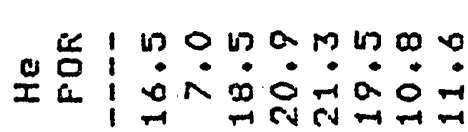

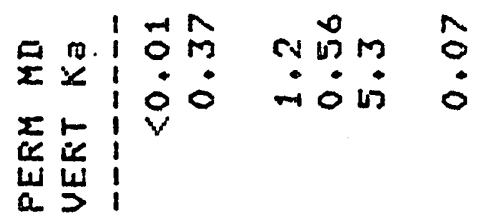

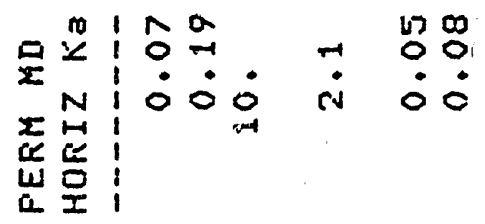

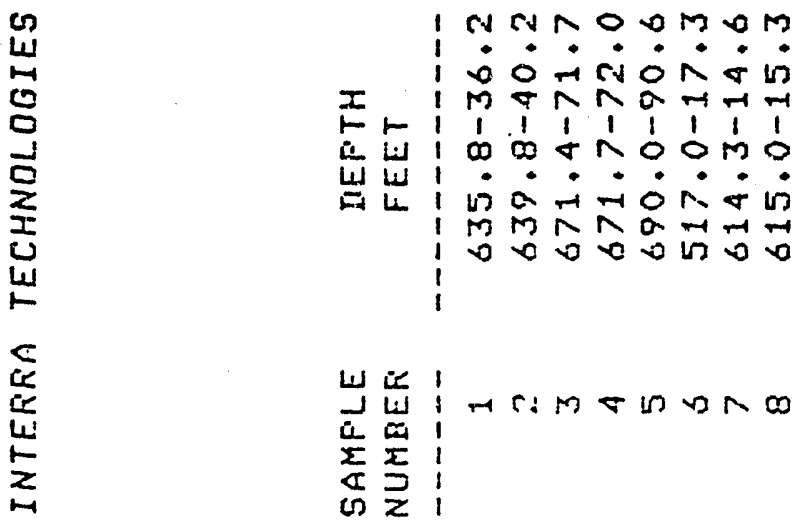


SPECIAL OORE ANAAYSIS STUDY

for

INIERA TIECHNOIOGIES

WIPP SIWE

FIIE NUMBER: SCAL 203-850073 
Jamuary 29, 1986

CORE LABORATORIES, INC.

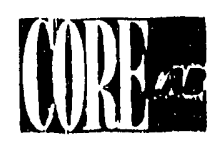

Intera Technologies

6580 Austin Center Boulevard

Suite 300

Austin, TX 78731

Reply To:
10703 E BETHUNY DAIVE AURORA, COLORADO 80014

Attention: Mr. George Saulnier:

Subject:

Special core Analysis stuxdy

WIPP Site

File Number: SCAI 203-850073

\section{Gentlemen:}

On December 12, $1985 \mathrm{Mr}$. George Saulnier of Intera Technologies requested the following special core analyses on core material recovered fr in the subject well:

1) Permeability to Air and Porosity.

2) Klinkenberg Permeability (Gas Slippage Corrected).

Enclosed are the final results of these analyses.

Six, one inch diameter core plugs were abtained from Intera Technologies for this study. Permeability to air and helium porosity values utilizing Boyle's Law technique were obtained with the resultant data presented on Pages 2 and 3. The samples are identiried as to depth and are lithologically described on Fage 1.

The Klinkenberg permeability (gas slippage corrected) was reouested for sample rumbers $I \mathrm{H}, I \mathrm{~V}$, and $8 \mathrm{~V}$. These samples were measured at an effective overburden pressure of $350 \mathrm{psi}$ by the non-steady state method. The results of this test are presented on Page 2 in conjunction with the permeability to air and porosity determinations.

A bibliographic reference for this procedure is:

Freeman, D. and Bush, D. Low Permeability Laboratory Measurements by Non-Steady State and Conventional Methuds. SPE Technical Paper 10075. 
Intera Technologies

Jamuary 16, 1986

Page two

An additional group of samples were examined after completion of the initial study. The core samples listed on Page 2 were re-examined for porosity measurements. A special procechure was utilized for more accurate porosity determination. The parameters used for porosity calculation are pore volume, grain volume and bulk vollume. The vuggy nature of many of the core samples lends to erroneous bulk volume values by the length $\mathrm{X}$ area formula. As a result, al? bulk volume values were remeasured using a different technique. Teflon tape was wrapped around each sample, isolating the vugs. A mercury bulk volume, and measurement was abtained. The teflon tape was removed and its bulk volume was determined and subtracted from the initial bulk volume value. Porosity was recalculated giving generally lower porosity values as compared to the original Conventional Core Analysis data.

It has been a pleasure working with Intera Technologies on this study. Should you have any questions pertaining to these test results or if we may be of further assistance, please do not hesitate to contact us at (303)7519334.

Very truly yours,

CORE IABORATORIES, INC.

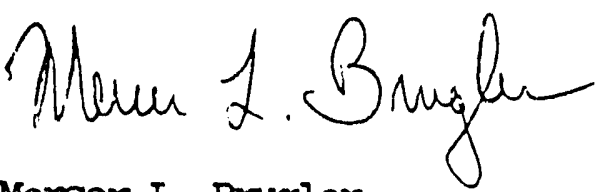

Mercer I. Brugler

Special Core Analysis Supervisor

$\mathrm{MIB} / \mathrm{ssO}$

$4 \infty$ addressee 
CORE LABORATORIES, INC.

Special Core Analysis

Page $\frac{1}{203}$ of $\frac{3}{1}$

\section{IDENIIFICAIION AND ITIHOLOGICAL DESCRIPIIION OF SAMPLES}

\begin{tabular}{|c|c|c|}
\hline company: & Intera Rescurces & Well: WIPP site \\
\hline $\begin{array}{c}\text { Sample } \\
\text { Identification }\end{array}$ & Depth, feet & Lithological Description \\
\hline IH & 630.0 & $\begin{array}{l}\text { DoL, bu, pkst, wl ind, slily lmy, vug, frac } \\
\text { w/calc cmut }\end{array}$ \\
\hline IV & 630.0 & $\begin{array}{l}\text { Dol, bu, pkst, wl ind, slily lmy, vug, frac } \\
\text { w/calc cmt }\end{array}$ \\
\hline $3 \mathrm{~V}$ & 681.0 & $\begin{array}{l}\text { Dol, bu, pkst, wl ind, slily Imy, vug, frac } \\
\text { w/calc cmt }\end{array}$ \\
\hline $4 \mathrm{~V}$ & 689.2 & DOI, bus,pkst, wl ind, slily Imy, vug \\
\hline$\sigma$ & 689.3 & $\begin{array}{l}\text { DoL, bu,pkst, wl ind, slily lmy, vug w/cl } \\
\text { inf }\end{array}$ \\
\hline $8 \mathrm{~V}$ & $682-640$ & $\begin{array}{l}\text { DOL, bu, pkst, wl ind,psool, slily lsy, } \\
\text { vug }\end{array}$ \\
\hline
\end{tabular}


CORE LABORATORIES, INC.

Special Core Alualy'ris

Page $\frac{2}{203}$ of $\frac{3}{250073}$

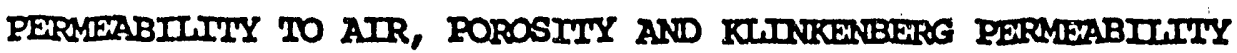

AS A FUNCTLON OF OVERBURDEN PRESSURE

Compary:

Intera Rescurces

Well: WIPP Site

Effective Overburden Pressure, psi

350

\begin{tabular}{|c|c|c|c|c|}
\hline $\begin{array}{l}\text { Sample } \\
\text { I.D. }\end{array}$ & $\begin{array}{l}\text { Depth, } \\
\text { feet }\end{array}$ & $\begin{array}{l}\text { Permeability } \\
\text { to Air } \\
\text { Millidareys }\end{array}$ & $\begin{array}{l}\text { Porosity } \\
\text { Percent }\end{array}$ & $\begin{array}{c}\text { Kinkenberg Permeability** } \\
\text { Millidarcys }\end{array}$ \\
\hline IH & 630.0 & $<0.01$ & 11.5 & 0.00801 \\
\hline IV & 630.0 & 0.02 & $6.6(7.3) * * *$ & 0.00847 \\
\hline $3 \mathrm{~V}$ & 681.0 & 4.5 & 20.2 & * \\
\hline $4 \mathrm{~V}$ & 689.2 & 4.1 & 11.3 & * \\
\hline$\sigma$ & 689.3 & 0.47 & 24.1 & * \\
\hline $8 \mathrm{~V}$ & $628-640$ & 1.6 & 20.4 & 0.61229 \\
\hline
\end{tabular}

CONVENITONAL CORE ANALYSIS DAIA - FIIE NO. 3806-78,52

$\begin{array}{llc}\begin{array}{c}\text { Sample } \\ \text { I.D. }\end{array} & \begin{array}{l}\text { Depth, } \\ \text { feet }\end{array} & \begin{array}{c}\text { Porosity } \\ \text { Percent }\end{array} \\ 1 & 635.8-36.2 & 14.2 \\ 2 & 639.8-40.2 & 13.6 \\ 3 & 671.4-71.7 & 17.4 \\ 4 \mathrm{~V} & 671.7-72.0 & 19.5 \\ 5 & 690.0-90.6 & 19.6 \\ 6 \mathrm{~V} & 517.0-17.3 & 22.0\end{array}$

* Indicates sample not requested for measurement.

** Permeability to Nitrogen

$\star * \star$ Remeasured value 


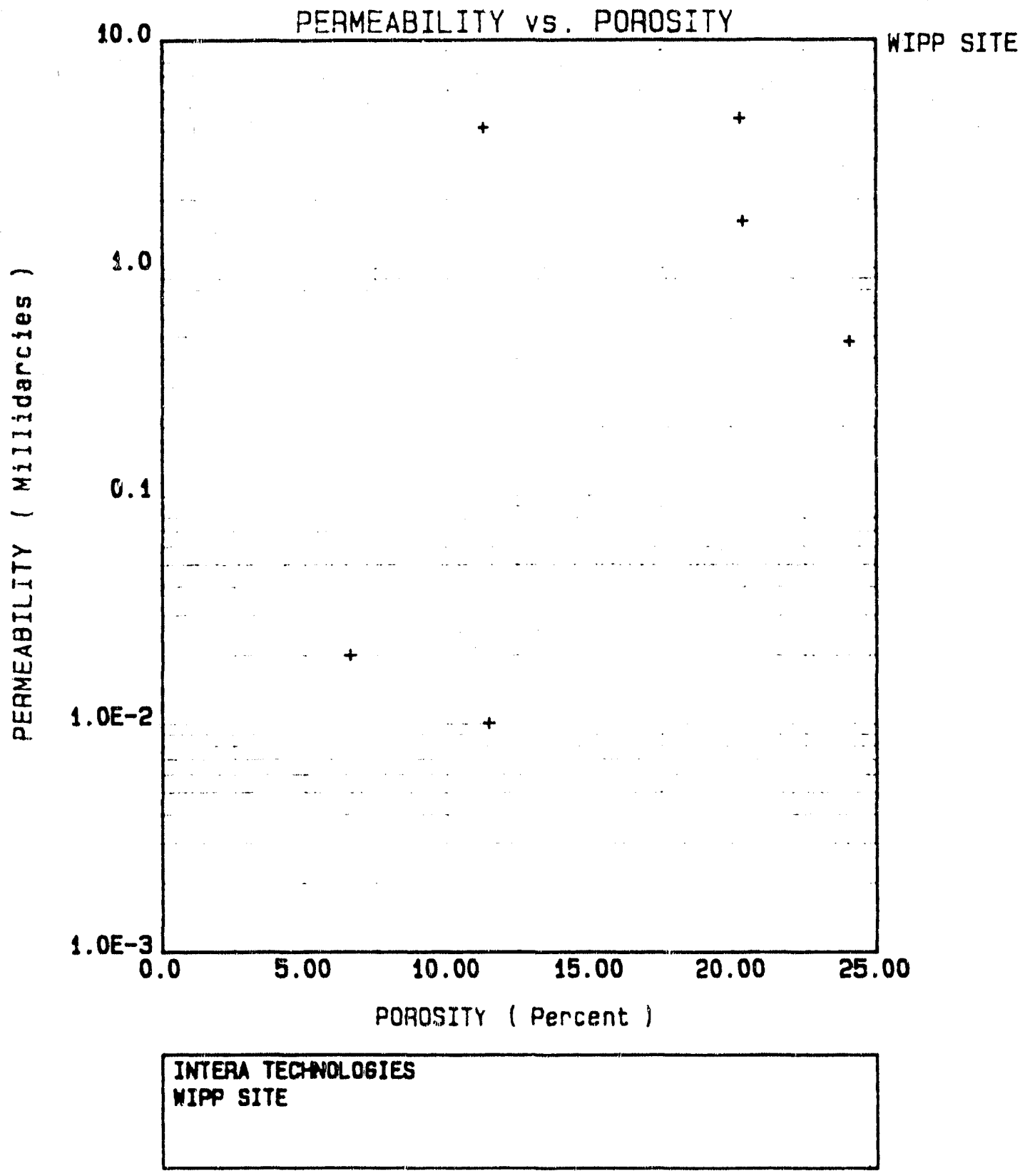


APPENDIX C

TERRA TEK CORE SERVICES REPORT

$0.1 \mid 0-2$ 


\title{
ERRATA
}

(Prepared by INTERA Inc.)

\begin{abstract}
Some sample numbers are incorrect on sume tables in the Terra Tek report. Refer to the following corrections when comparing these data to those presented in data tabulations in the report.
\end{abstract}

Table 1. $\mathrm{H}-2 \mathrm{~B}-1 \mathrm{~F}$ should read $\mathrm{H}-2 \mathrm{~B} 1-1 \mathrm{~F}$

H-5B-1 should read $H-5 B-1 A$

$H-7 B 2-1 F$ should read $H-7 C-1 F$

W-12-2B should read W-12-2

Table 2. H-5B1-3 should read $H-5 b-3$

Table 4. H-5b)-2 should read $H-5 b-2$

H-5bl-3 should read $H-5 b-3$

Table 6. H-5bl-2F should read $H-5 b-2 F$ 


\title{
Final Report
}

SPECIAL CORE ANALYSIS STUDY

OF THE CULEBRA DULOMITE

\author{
by \\ K. C. Rakop \\ T. Little \\ Submitted to: \\ INTERA TECHNOLOGIES, INC. \\ 6850 Austine Center Boulevard \\ Suite 300 \\ Austin, Texas 78731 \\ Attn: Van A. Kelley
}

TR $88-48$ R1

April, 1988

C- 5

$0978-006-081$ 
This program was designed to characterize core material from the culebra dolomite formation. Information received indicated this formation to be naturally fractured with secondary, dissolution-type porosity.

The samples submitted for use in the characterization study were taken from various core holes throughout the reservoir. Information supplied with the cores indicated the core material to be predominantly dolomite with a gypsum content that averaged $2-3 \%$ with a high of approximately $18 \%$. It was also reported that the cores contained low concentrations of several clays and about $2 \%$ nalite. All of the cores were 3-5 years old and had not been subjected to any type of preservation procedure prior to storage.

Specific characterization tests requested included the following: 1) permeability, 2) nelium porosity, 3) re-saturation porosity, and 4) formation factor. All of the testing was performed at ambient conditions. For the permeability ana formation factor medsurements, this is defined as 300 psi net effective stress and room temperature (approximately $72^{\circ} \mathrm{F}$ ). For the porosity measurements, ambient is defined as atmospheric conditions and room temperature. X-ray diffraction analyses were also requested on three special samples.

Table 1 summarizes the characterization data, including permeability and helium porosity data, for the 1 inch diameter samples. Due to the vugular nature of the samples, all of the bulk volumes were determined using caliper measurements of the core dimensions. The helium porosity was measured by gas expansion using Boyle's law. The helium porosity values ranged from 6.6-27.5\% with an average value of 14.9\%. Permeability was measured using standard steady-state techniques and ranged from 0.02-58.0 ma with an average value of 
3.7 md even though approximately $70 \%$ of the samples nad permeabilities less than $1 \mathrm{md}$.

Table 2 summarizes the characterization data, including the permeability and nelium porosity data, for the whole core samples. Although these samples were whole core, not plugs, it should be noted tnat the diameter of the samples ranged from 2.25 to 4.25 inches. The bulk volumes were determined using caliper measurements of the length and diameter of the cores with three exceptions, samples H11-1, H11B3-3 and H7B2-2. These samples contained no secondary porosity (vugs), but each sample had deep scribe marks running the length of the core which needed to be omitted from both the bulk and pore volume measurements. For this reason, the bulk volumes were determined using an Archimedes technique with toluene. Toluene was used because of the presence of water sensitive clays and salts in the core. The helium porosity values for the whole core samples ranged from 11.2 to $18.7 \%$ with an average value of $13.8 \%$.

Vertical permeability of the samples ranged from 0.081-52 md. The horizontal permeability of the samples varied from 0.046 to 368 md. All of the norizontal permeability measurements were performed using standard steadystate tecnniques with 90 degree screens placed on either side of the sample. According to Collins* and nis comformal mapping code, the correction factor to account for the path of flow is 1.0. The location of the screens was chosen arbitrarily; although, where possible, the directions of maximum and minimum permeability were chosen. The presence of natural fractures was used to determine these directions. The observed high variation in horizontal perme-

*Coliins, R.E., "Flow of Fluid Tnrough Porous Media," The Petroleum Publishing Company, Tulsa, 1976. 
ability is due primarily to the presence of these natural fractures in the core samples.

After the helium porosities and the gas permeabilities wore measured, selected samples were to have their porosity remeasured using Archimedes resaturation technique. Intera Technologies requested that these measurements be performed with deionized water. This decision was based upon information that chemical analyses performed on various brine samples taken across the field revealed significant variations in brine composition. This problem was further complicated by the fact that Intera Technologies did not have brine samples from all of the zones of interest in this study, and could not supply brine or brine compositions for some of the zones from which the core samples were taken. In addition, because of the wide variation observed in brine composition, they did not feel comfortable in specifying a "generic" brine. Intera Technologies, therefore, decided to perform the porosity measurements by resaturation witn deionized water.

Terra Tek was somewnat concerned about using deionized water in these tests due to the water sensitive clays and salts present in the reservoir. For this reason, it was suggested that a comparison be made between the performance of deionized water and simulated reservoir brine with some of the core samples to determine if any clay swelling or salt dissolution occurred with the deionized water. Table 3 details the data gathered from this test on twin plugs taken from the H5B1-1a and $1 \mathrm{~b}$ samples. These samples were chosen by Intera Technologies because it came from an area of the reservoir for which a representative brine analysis was available. It should be noted in passing, however, that this sample may not be representative of most of the samples tested because it contained no obvious fractures or gypsum stringers. As can De seen, the sample saturated with deionized water had only a $0.1 \%$ difference 
in the porosities measured with helium and water. The important thing to note here, however, is that the resaturation porosity is less tnan the helium porosity. This is indicative of nominal salt dissolution. There is no indication of significant clay swelling either. The latter conclusion is based upon the small difference observed between the two measured porosity values. The resolution of the porosimeter used is $\pm 1 \%$; therefore, the difference in observed porosity is within experimental error.

On the other hand, the resaturation porosity measured using the simulated reservoir brine had a nigner difference than the deionized water did, $0.4 \%$. The simulated brine is representative of this reservoir section and should have no adverse reactions with the reservoir rock material. The difference observed between the performance of the deionized water and that of the simulated reservoir brine cannot be explained with the data available. Through discussions with Intera Technologies, it was decided that the remaining tests would be performed using deionized water.

Tables 4 and 5 detail the nelium porosity and resaturation porosity values for botn the plugs and the whole core, respectively. Also reported is whetner or not any dissolution of the sample was observed. In most cases this dissolution was only slight, but in one case, W-28-2, it was severe. In those cases in which dissolution was observed, it appeared primarily in samples with obvious gypsum stringers or along fractures. It was not possible to determine dissolution of the interior of the samples by visual inspection. Although no dissolution was observed in the pilot brine/deionized water comparison tests on the $\mathrm{H} 5 \mathrm{~B} 1$ samples, there was al so no obvious fractures or gypsum stringers in these samples. Based on the data from those tests, however, there was no evidence of adverse effects caused by the deionized water. 
In approximately $57 \%$ of the samples, the resaturation porosity was greater than the helium porosity. This is not normally the trend observed in data of this type and is most likely due to dissolution of gypsum in those samples. Because of the mall molecular size of helium, this gas can normally access more pore volume than water can. For this reason, as a general rule, the observed helium porosity is greater than the resaturuation porosity. The average deviation between the two measured values was $0.4 \%$.

Table 6 and Figure 1 summarize the formation factor data for the 15 samples tested. The electrical samples were tested at ambient conditions saturated with a representative reservoir brine. The brine chemistry supplied was as foliows:

$\begin{array}{lr}\text { Calcium } & 1,400 \mathrm{mg} / 1 \\ \text { Magnesium } & 1,100 \mathrm{mg} / 1 \\ \text { Potassium } & 720 \mathrm{mg} / 1 \\ \text { Sodium } & 38,000 \mathrm{mg} / 1 \\ \text { Alkalinity }\left(\mathrm{HCO}_{3}\right)^{-1} & 52 \mathrm{mg} / 1 \\ \text { Chloride } & 65,000 \mathrm{mg} / 1 \\ \text { Sulfate } & 6,100 \mathrm{mg} / 1\end{array}$

The brine was made following the above chemistry with the exception of the sulfate. Since sulfate has the tendency to precipitate, it was omitted. The resistivity of the brine was $6.9 \mathrm{ohm}-\mathrm{cm}$.

The cementation factor calculated for each individual sample was based on an intercept of $1 / 1$ and the measured formation factor. The cementation factor ranged from 1.79 to 2.57 . The composite cementation factor for the culebra dolomite is 2.13. The variations observed in the cementation values are probably due to the various quantities of halite, gypsum and clays. The degree of secondary porosity will al so contribute to the variations observed.

Results from tests on the three samples submitted for $X$-ray diffraction are summarized in Table 7. These data reveal that Samples 1 and 3 contain significant amounts of calcite, aragonite, and brucite. Sample 3 also con- 
tains a large amount of gypsum; sample 1 contains none. The presence of brucite is not well understood. Brucite is a magnesium nydroxide clay mineral commonly associated with metamorphosed carbonate rocks. This sample may have come from the aquifer nost rock. Sample 2 is dominantly halite with only minor amounts of gypsum and calcite.

The Appendix includes a copy of our Quality Assurance Manual. Also included is a one page summary of the specific quality control checks taken in the measurements performed in this program. 
Table 1

Summary of Characterization Data One Inch Diameter Samples

\begin{tabular}{|c|c|c|c|c|c|}
\hline $\begin{array}{c}\text { Sample } \\
1.0 . \\
\end{array}$ & $\begin{array}{c}\text { Bulk } \\
\text { vol ume } \\
(c c) \\
\end{array}$ & $\begin{array}{l}\text { Pore } \\
\text { Vol ume } \\
\text { (cc) } \\
\end{array}$ & $\begin{array}{c}\text { Porosity } \\
(6) \\
\end{array}$ & $\begin{array}{l}\text { Grain } \\
\text { Volume } \\
(g \mathrm{~m} / \mathrm{cc}) \\
\end{array}$ & $\begin{array}{l}\text { Permedo ility } \\
\text { (md) }\end{array}$ \\
\hline $\begin{array}{l}A E C-8-1 \\
A E C-8-1 F \\
A E C-8=2 \\
H 2 A-1 \\
H 2 A-2\end{array}$ & $\begin{array}{l}25.038 \\
25.261 \\
25.038 \\
22.307 \\
23.606\end{array}$ & $\begin{array}{l}1.986 \\
3.082 \\
2.731 \\
2.594 \\
2.810\end{array}$ & $\begin{array}{l}7.9 \\
12.2 \\
10.9 \\
11.6 \\
11.9\end{array}$ & $\begin{array}{l}2.83 \\
2.82 \\
2.82 \\
2.82 \\
2.80\end{array}$ & $\begin{array}{l}0.26 \\
0.06 \\
0.31 \\
0.25 \\
0.10\end{array}$ \\
\hline $\begin{array}{l}\mathrm{H} 2 \mathrm{~B}-1 \mathrm{~F} \\
\mathrm{H} 2 \mathrm{~B} 1-1 \\
\mathrm{H} 2 \mathrm{~B} 1-2 \\
\mathrm{H} 2 \mathrm{~B} 1-3 \\
\mathrm{H}-5 \mathrm{~B}-1\end{array}$ & $\begin{array}{l}25.191 \\
23.592 \\
23.558 \\
23.606 \\
21.893\end{array}$ & $\begin{array}{l}2.645 \\
1.939 \\
3.182 \\
3.615 \\
2.726\end{array}$ & $\begin{array}{r}10.5 \\
8.2 \\
13.5 \\
15.3 \\
12.5\end{array}$ & $\begin{array}{l}2.83 \\
2.82 \\
2.78 \\
2.82 \\
2.82\end{array}$ & $\begin{array}{l}0.03 \\
0.24 \\
0.62 \\
0.27 \\
0.05\end{array}$ \\
\hline $\begin{array}{l}H-5 B 1-2 \\
H-5 B 1-2 F \\
H-5 B 1-1 B \\
H-7 B 1-1 \\
H-7 B 1-1 F\end{array}$ & $\begin{array}{l}24.936 \\
25.151 \\
24.949 \\
24.811 \\
25.191\end{array}$ & $\begin{array}{l}5.693 \\
6.237 \\
3.913 \\
4.385 \\
3.753\end{array}$ & $\begin{array}{l}22.8 \\
24.8 \\
15.7 \\
17.7 \\
14.9\end{array}$ & $\begin{array}{l}2.81 \\
2.80 \\
2.83 \\
2.84 \\
2.84\end{array}$ & $\begin{array}{r}3.60 \\
13.00 \\
0.08 \\
0.11 \\
0.10\end{array}$ \\
\hline $\begin{array}{l}H-7 B 1-2 A \\
H-7 B 2-1 \\
H-7 B 2-1 F \\
H-7 C-1 A \\
H-10 B-1\end{array}$ & $\begin{array}{l}24.924 \\
24.177 \\
18.882 \\
25.038 \\
24.949\end{array}$ & $\begin{array}{l}4.873 \\
3.479 \\
2.606 \\
3.134 \\
1.728\end{array}$ & $\begin{array}{r}19.6 \\
14.4 \\
13.8 \\
12.5 \\
6.9\end{array}$ & $\begin{array}{l}2.84 \\
2.83 \\
2.83 \\
2.83 \\
2.80\end{array}$ & $\begin{array}{l}0.10 \\
0.31 \\
0.11 \\
0.07 \\
0.04\end{array}$ \\
\hline $\begin{array}{l}H-10 B-2 \\
H-10 B-2 F \\
H-11-2 \\
H-11-2 F \\
H-11 B 3-1\end{array}$ & $\begin{array}{l}24.936 \\
25.191 \\
24.288 \\
25.201 \\
24.885\end{array}$ & $\begin{array}{l}2.879 \\
1.663 \\
2.402 \\
2.621 \\
6.841\end{array}$ & $\begin{array}{r}11.5 \\
6.6 \\
9.9 \\
10.4 \\
27.5\end{array}$ & $\begin{array}{l}2.76 \\
2.82 \\
2.78 \\
2.81 \\
2.84\end{array}$ & $\begin{array}{l}7.80 \\
0.14 \\
0.02 \\
0.04 \\
4.60\end{array}$ \\
\hline $\begin{array}{l}H-11 B 3-1 F \\
H-1183-2 \\
H-11 B 3-2 F \\
H-11 B 3-4 \\
H-11 B 3-4 F\end{array}$ & $\begin{array}{l}25.152 \\
24.936 \\
25.201 \\
24.949 \\
25.191\end{array}$ & $\begin{array}{l}5.609 \\
2.474 \\
3.100 \\
3.903 \\
5.643\end{array}$ & $\begin{array}{r}22.3 \\
9.9 \\
12.3 \\
15.6 \\
22.4\end{array}$ & $\begin{array}{l}2.84 \\
2.84 \\
2.83 \\
2.83 \\
2.83\end{array}$ & $\begin{array}{l}1.60 \\
0.05 \\
0.33 \\
0.27 \\
8.00\end{array}$ \\
\hline $\begin{array}{l}H-12-2 F \\
W-12-1 B \\
W-12-2 B \\
W-13-1 \\
W-13-2\end{array}$ & $\begin{array}{l}25.191 \\
23.488 \\
24.424 \\
25.676 \\
24.999\end{array}$ & $\begin{array}{l}3.401 \\
2.727 \\
2.834 \\
3.678 \\
5.487\end{array}$ & $\begin{array}{l}13.5 \\
11.6 \\
11.6 \\
14.3 \\
21.9\end{array}$ & $\begin{array}{l}2.82 \\
2.79 \\
2.82 \\
2.83 \\
2.84\end{array}$ & $\begin{array}{r}58.00 \\
0.17 \\
0.96 \\
6.00 \\
3.50\end{array}$ \\
\hline $\begin{array}{l}W-13-2 F \\
W-13-3 A \\
W-26-1 \\
W-26-1 F \\
W-26-3\end{array}$ & $\begin{array}{l}25.191 \\
24.823 \\
25.050 \\
25.191 \\
25.766\end{array}$ & $\begin{array}{l}6.550 \\
4.140 \\
3.095 \\
2.821 \\
3.295\end{array}$ & $\begin{array}{l}26.0 \\
16.7 \\
12.4 \\
11.2 \\
12.8\end{array}$ & $\begin{array}{l}2.84 \\
2.83 \\
2.82 \\
2.81 \\
2.82\end{array}$ & $\begin{array}{l}4.60 \\
3.60 \\
0.04 \\
0.04 \\
0.05\end{array}$ \\
\hline $\begin{array}{l}W-28-1 B \\
W-28-3 F \\
W-30-38 \\
W-30-3 F \\
W-30-4\end{array}$ & $\begin{array}{l}24.999 \\
25.191 \\
24.974 \\
25.191 \\
24.936\end{array}$ & $\begin{array}{l}3.254 \\
4.509 \\
3.472 \\
3.753 \\
5.586\end{array}$ & $\begin{array}{l}13.0 \\
17.9 \\
13.9 \\
14.9 \\
22.4\end{array}$ & $\begin{array}{l}2.83 \\
2.83 \\
2.79 \\
2.80 \\
2.83\end{array}$ & $\begin{array}{l}0.05 \\
0.41 \\
0.55 \\
2.50 \\
8.30\end{array}$ \\
\hline
\end{tabular}


Table?

Summary of Characterization Data Whole Core Samples

\begin{tabular}{|c|c|c|c|c|c|c|c|}
\hline \multirow{3}{*}{$\begin{array}{c}\text { Sample } \\
\text { I.D. }\end{array}$} & \multirow{3}{*}{$\begin{array}{c}\text { Bulk } \\
\text { vol ume } \\
\text { (cc) }\end{array}$} & \multirow{3}{*}{$\begin{array}{c}\text { Pore } \\
\text { volume } \\
\text { (cc) } \\
\end{array}$} & \multirow{3}{*}{$\begin{array}{l}\text { Porosity } \\
(\%)\end{array}$} & \multirow{3}{*}{$\begin{array}{l}\text { Grain } \\
\text { Density } \\
\text { (gm/cc) }\end{array}$} & \multicolumn{3}{|c|}{ Permeability (md) } \\
\hline & & & & & & Hori & nta \\
\hline & & & & & Vertical & 0 & +90 \\
\hline & 219.33 & 33 & & 2. & 0 & 0.05 & 0.0 \\
\hline & & & & & & & 0.09 \\
\hline & & & & & & 5. & 0. \\
\hline ר. & & & & & & & 0 . \\
\hline $10 B-3$ & 398 & 44. & 11 & 2. & 0.21 & 0.62 & 0.44 \\
\hline 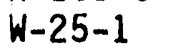 & & $? 9$ & & & 0.19 & 367.62 & 0.11 \\
\hline & & 78. & 12 & 2. & 52.06 & 29.01 & 0.07 \\
\hline $28-2$ & & 87 & 18 & & & 3.61 & 3.36 \\
\hline & & 92 & 17 & & 0 . & 0.30 & 0.31 \\
\hline & & 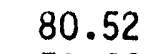 & 12 & 2. & 0.47 & 79.16 & 9.30 \\
\hline & & 70 & 15 & 2. & 0 . & 0.40 & 0.20 \\
\hline & & 125. & 13 & 2.82 & 1.65 & 19.32 & 24.21 \\
\hline
\end{tabular}

Table 3

Summary of Re-Saturation Porosity Comparisons

$\begin{array}{cccc}\begin{array}{c}\text { Sample } \\ \text { I.D. }\end{array} & \begin{array}{c}\text { Saturating } \\ \text { Fluid }\end{array} & \begin{array}{c}\text { Helium } \\ \text { Porosity }\end{array} & \begin{array}{c}\text { Re-Saturation } \\ \text { Porosity }\end{array} \\ \text { H5B1-1a } & \text { Deionized Water } & 10.78 \% & 10.68 \% \\ \text { H5B1-1b } & \text { Formation Brine } & 12.45 \% & 12.07 \%\end{array}$


Table 4

Summary of Comparison Data for Helium ard Re-Saturation Porosities One Inch Diameter Samlpes

\begin{tabular}{|c|c|c|c|c|c|}
\hline \multirow[b]{2}{*}{$\begin{array}{l}\text { Sample } \\
\text { I.C. }\end{array}$} & \multicolumn{2}{|c|}{ Pore Volume } & \multicolumn{2}{|r|}{ Porosity } & \\
\hline & $\begin{array}{l}\text { Helium } \\
\text { (cc) }\end{array}$ & $\begin{array}{l}\text { Re-Saturation } \\
\text { (cc) }\end{array}$ & $\begin{array}{l}\text { HeTium } \\
(q)\end{array}$ & $\begin{array}{l}\text { Re-Saturation } \\
(\%)\end{array}$ & Comments \\
\hline $\begin{array}{l}A E C-8-1 \\
A E C-8-2 \\
H 2 A-1 \\
H 2 B 1-1 \\
H 2 B 1-3 \\
H-5 B 1-2 \\
H-7 B 1-1 \\
H-7 B 2-1 \\
H-7 C-1 A \\
H-10 B-2 \\
H-11-2 \\
H-11 B 3-1 \\
H-11 B 3-2 \\
W-12-2 \\
W-13-1 \\
W-13-2 \\
W-26-1 \\
W-30-3 B\end{array}$ & $\begin{array}{l}1.986 \\
2.731 \\
2.594 \\
1.939 \\
3.615 \\
5.693 \\
5.385 \\
3.479 \\
3.134 \\
2.879 \\
2.402 \\
6.841 \\
2.474 \\
2.834 \\
3.678 \\
5.487 \\
3.095 \\
3.472\end{array}$ & $\begin{array}{l}2.142 \\
2.659 \\
2.528 \\
2.084 \\
3.717 \\
5.942 \\
4.459 \\
3.567 \\
3.226 \\
2.933 \\
2.726 \\
6.844 \\
2.575 \\
2.916 \\
3.908 \\
5.639 \\
3.036 \\
3.477\end{array}$ & $\begin{array}{r}7.9 \\
10.9 \\
11.6 \\
8.2 \\
15.3 \\
22.8 \\
17.7 \\
14.4 \\
12.5 \\
11.5 \\
9.9 \\
27.5 \\
9.9 \\
11.6 \\
14.3 \\
21.9 \\
12.4 \\
13.9\end{array}$ & $\begin{array}{r}8.6 \\
10.6 \\
11.3 \\
8.8 \\
15.8 \\
23.7 \\
18.1 \\
14.8 \\
12.9 \\
11.7 \\
11.3 \\
27.5 \\
10.3 \\
11.9 \\
15.2 \\
22.6 \\
12.2 \\
13.9\end{array}$ & $\begin{array}{l}\text { None } \\
\text { None } \\
\text { Gypsum Dissolution } \\
\text { Gypsum Dissolution } \\
\text { None } \\
\text { None } \\
\text { None } \\
\text { None } \\
\text { None } \\
\text { None } \\
\text { None } \\
\text { None } \\
\text { Sample Chipped } \\
\text { Gypsum Dissolution } \\
\text { None } \\
\text { Sample Parted } \\
\text { None } \\
\text { Gypsum Dissolution }\end{array}$ \\
\hline
\end{tabular}

Table 5

Summary of Comparison Data for Helium and Re-Saturation Porosities Whole Core Samlpes

\begin{tabular}{|c|c|c|c|c|c|}
\hline \multirow[b]{2}{*}{$\begin{array}{c}\text { Sample } \\
\text { I.D. }\end{array}$} & \multicolumn{2}{|c|}{ Pore Volume } & \multicolumn{2}{|r|}{ Porosity } & \multirow[b]{2}{*}{ Comments } \\
\hline & $\begin{array}{l}\text { Helium } \\
\text { (cc) }\end{array}$ & $\begin{array}{l}\text { Re-Saturation } \\
(\mathrm{cc})\end{array}$ & $\begin{array}{l}\text { Helium } \\
(\%)\end{array}$ & $\begin{array}{c}\text { Re-Saturation } \\
(q)\end{array}$ & \\
\hline $\begin{array}{l}H-11-1 \\
H-7 B 2-2 \\
H-11 B 3-3 \\
W-25-1 \\
H-5 B 1-3 \\
H-10 B-3 \\
W-26-2 \\
W-28-2 \\
W-28-3 \\
W-30-1 \\
W-30-2 \\
W-12-3\end{array}$ & $\begin{array}{l}33.99 \\
27.26 \\
33.32 \\
29.92 \\
62.35 \\
44.70 \\
78.68 \\
87.21 \\
92.78 \\
80.52 \\
70.66 \\
125.31\end{array}$ & $\begin{array}{l}33.77 \\
29.59 \\
32.22 \\
31.15 \\
59.81 \\
42.17 \\
78.84 \\
87.55 \\
92.48 \\
77.49 \\
71.22 \\
121.64\end{array}$ & $\begin{array}{l}15.5 \\
11.8 \\
13.0 \\
11.5 \\
13.3 \\
11.2 \\
12.6 \\
18.7 \\
17.0 \\
12.8 \\
15.0 \\
13.4\end{array}$ & $\begin{array}{l}15.3 \\
12.9 \\
12.6 \\
12.0 \\
12.8 \\
10.6 \\
12.6 \\
18.8 \\
16.9 \\
12.4 \\
15.2 \\
13.0\end{array}$ & $\begin{array}{l}\text { None } \\
\text { None } \\
\text { None } \\
\text { None } \\
\text { None } \\
\text { Gypsum Dissolution } \\
\text { None } \\
\text { Severe Grain Loss } \\
\text { None } \\
\text { Gypsum Dissolution } \\
\text { None } \\
\text { Gypsum Dissolution }\end{array}$ \\
\hline
\end{tabular}


Table 6

Summary of Formation Factor Data

\begin{tabular}{|c|c|c|c|}
\hline Sample I.D. & Helium Porosity & Formation Factor & Cementation \\
\hline $\begin{array}{l}A E C-8-1 F \\
H-2 B 1-1 F \\
H-5 B 1-2 F \\
H-7 B 1-1 F \\
H-7 C-1 F \\
H-10 B-2 F \\
H-11-2 F \\
H-11 B 3-1 F \\
H-11 B 3-2 F \\
H-11 B 3-4 F \\
W-12-2 F \\
W-13-2 F \\
W-26-1 F \\
W-28-3 F \\
W-30-3 F\end{array}$ & $\begin{array}{r}12.2 \\
10.5 \\
24.8 \\
14.9 \\
13.8 \\
6.6 \\
10.4 \\
22.3 \\
12.3 \\
22.4 \\
13.5 \\
26.0 \\
11.2 \\
17.9 \\
14.9\end{array}$ & $\begin{array}{r}90.09 \\
326.77 \\
12.20 \\
73.49 \\
79.61 \\
406.78 \\
94.82 \\
36.35 \\
101.93 \\
32.74 \\
47.30 \\
13.26 \\
68.77 \\
26.30 \\
31.49\end{array}$ & $\begin{array}{l}2.14 \\
2.57 \\
1.79 \\
2.25 \\
2.21 \\
2.21 \\
2.01 \\
2.39 \\
2.21 \\
2.33 \\
1.93 \\
1.92 \\
1.93 \\
1.90 \\
1.81\end{array}$ \\
\hline
\end{tabular}

Table 7

Summary of $X$-Ray Diffraction Analysis

$\begin{array}{lrrr}\text { Sample I.D. } & \# 1 & \# 2 & \# 3 \\ \text { Sample Depth }(\mathrm{ft}) & 735 & 805 & 723 \\ & & & \\ \text { Calcite } & 58 & 1 & 21 \\ \text { Aragonite } & 20 & & 18 \\ \text { Gypsum } & & 1 & 45 \\ \text { Halite } & 3 & 98 & 5 \\ \text { Brucite* } & 19 & & 11\end{array}$

*NOTE: Brucite values shown are residual percentages left over after summing all other phases. No brucite standard; percentages must be considered approximate. 


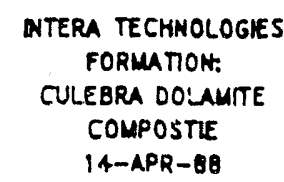

\section{FORMATION RESISTIVITY FACTOR VERSUS POROSITY}

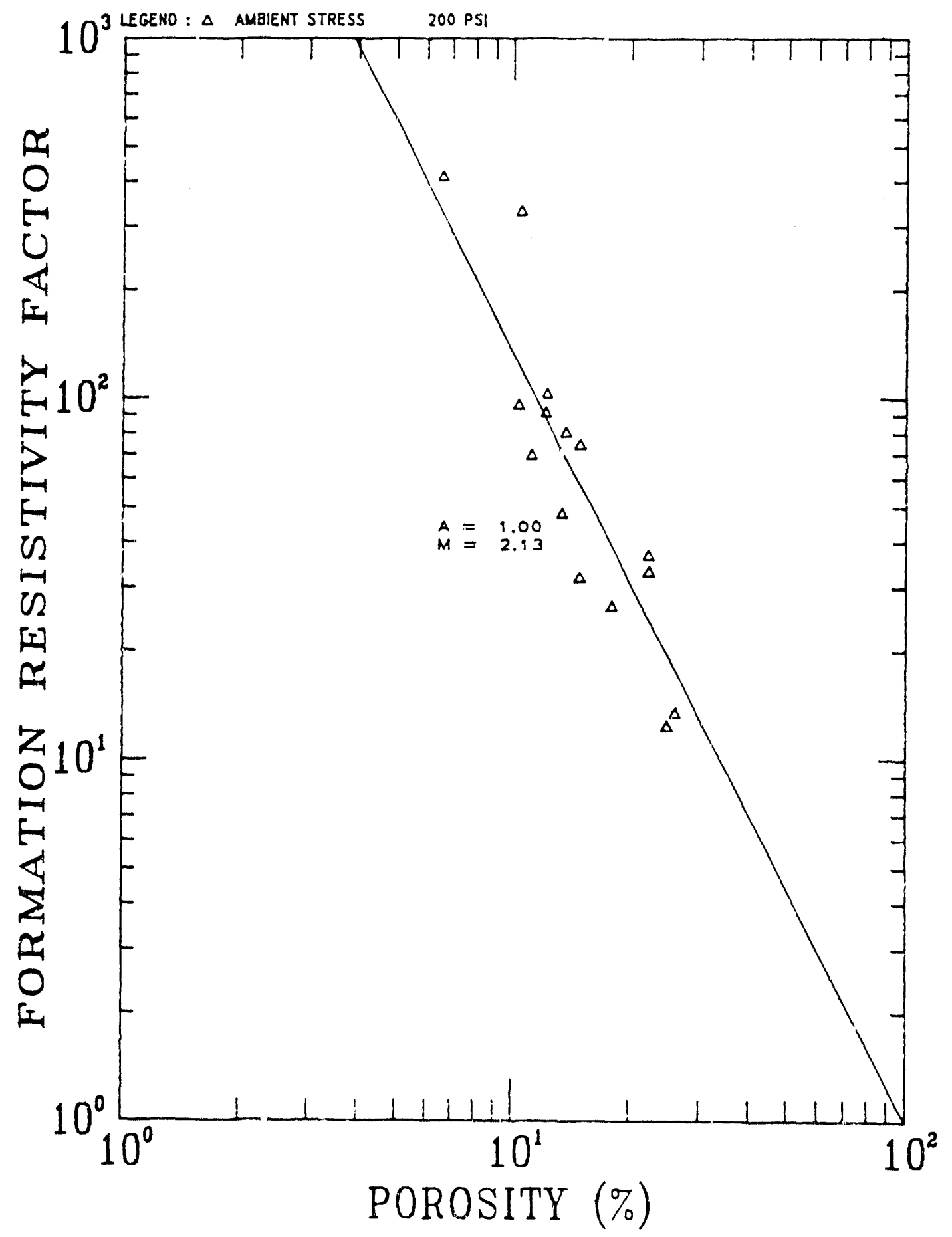


APPENDIX

$$
\text { C.II }
$$




\section{QUALITY CONTROL}

\section{Porosimeter}

1. The porosimeter is calibrated at the beginning of each shift or prior to each testing period which ever is applicable.

2. It is calibrated with a steel billet of known volume for repeatability within $1 \%$.

\section{Bulk Volumes}

1. The temperature of the test bath is monitored for correction of fluid density.

2. ihe scales are calibrated once a month by the Ruality Assurance Laboratory which is maintained for government contract work.

\section{Dry Weights}

1. Weight measurements are taken once a day until there is less than a $0.05 \mathrm{gm}$ loss in a 24 hour period.

\section{Re-saturation Porosity}

1. The scales used for wet and bouyant weights are calibrated once a month by the Quality Assurance Laboratory which is maintained for government contract work.

2. The porosity determined by this method is checked against routine helium porosity measurements by porosimeter.

Permeability

1. The permeameter is checked ror leaks by using a steel billet sample and applying a known pressure to the upstream side of the system.

2. The system is calibrated at the beginning of each shift or at the beginning of each test period as is applicable.

3. The system is calibrated using standards of generic rock types. These standards have been used for some time by a number of commercial and research test laboratories. Measured permeabilities must fall within $1 \%$ of the pre-determined permeability values of these standards.

\section{Resistivity Measurements}

1. Performance of the system is checked by using a rock standard run with every project.

2. Values are checked against each other as testing progresses for a linear fit.

3. Saturations are checked at the end of the test program by comparing the volume of fluid expelled from the sample against the weight loss. 


\section{QUALITY}

\section{ASSURANCE}

MANUAL

TT-QA (Revision C)

May, 1985 


\section{QUALITY ASSURANCE MANUAL}

\section{Statement of Authority}

The purpose of this document is to formalize the quality assurance program instituted dy Terra Tek, Inc. The proyrain implements the pertinent requirements described in 5I/ASME N4b.2-1977 and ANSI/ASME NQA-1-1983 "i2Ua!ity Assurance Program Requirements for Nuclear Facilities" and addrasses ine 18 basic requirements contained in Appendix B of the code of Federal Reyulations 1UCFR Part 50 "Quality Assurance Criteria for Nuclear Power Plants and Fuel Reprocessing Plants". When quality assurance requirements are mandated, this Quality Assurance Nanual (QAM) shall provide the minimum requirements to be followed in preparing an appropriate Quality Assurance Plan (QAP) for specific programs.

The Quality Assurance Administrator (QAA) has been delegated the authority and responsibility for implementation of the provision of this vualicy Assurance Manual and the authority for assuring implementation. Changes =0 this manual must be docuinented and approved by the Quality Assurance Adininistrator.

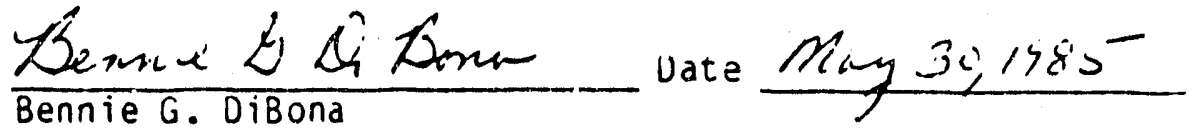
Senior Vice President Terra Tek, Inc.
} 


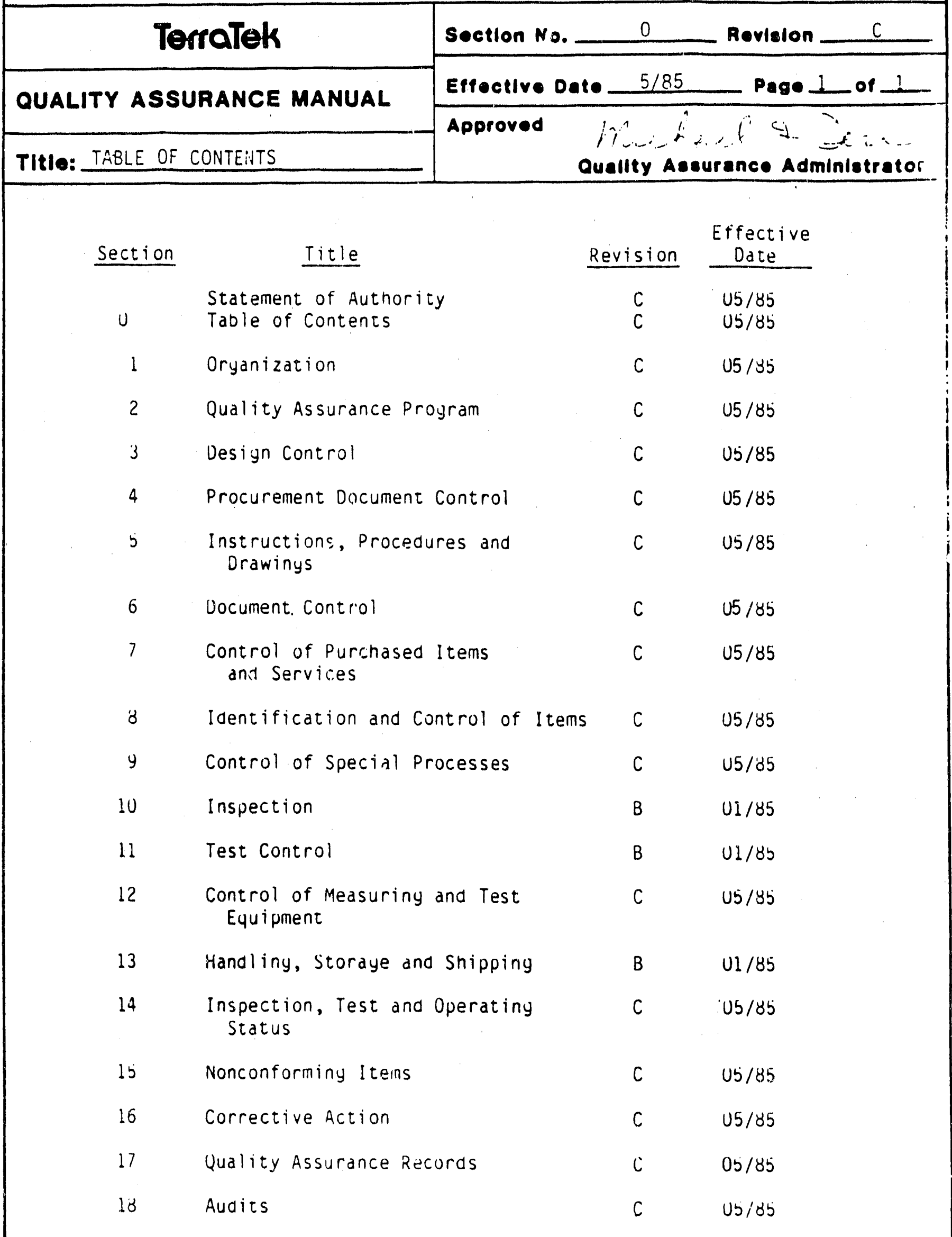




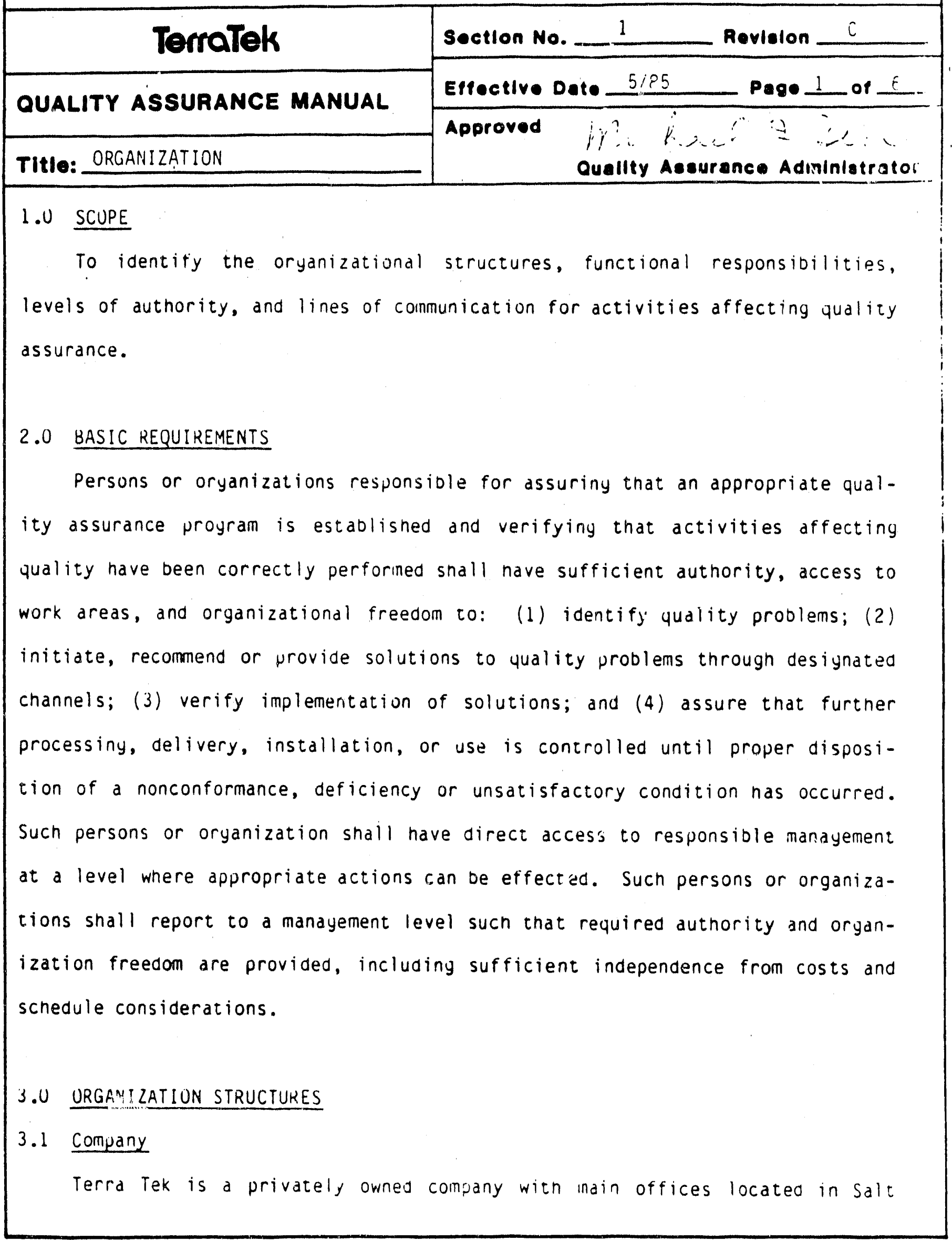




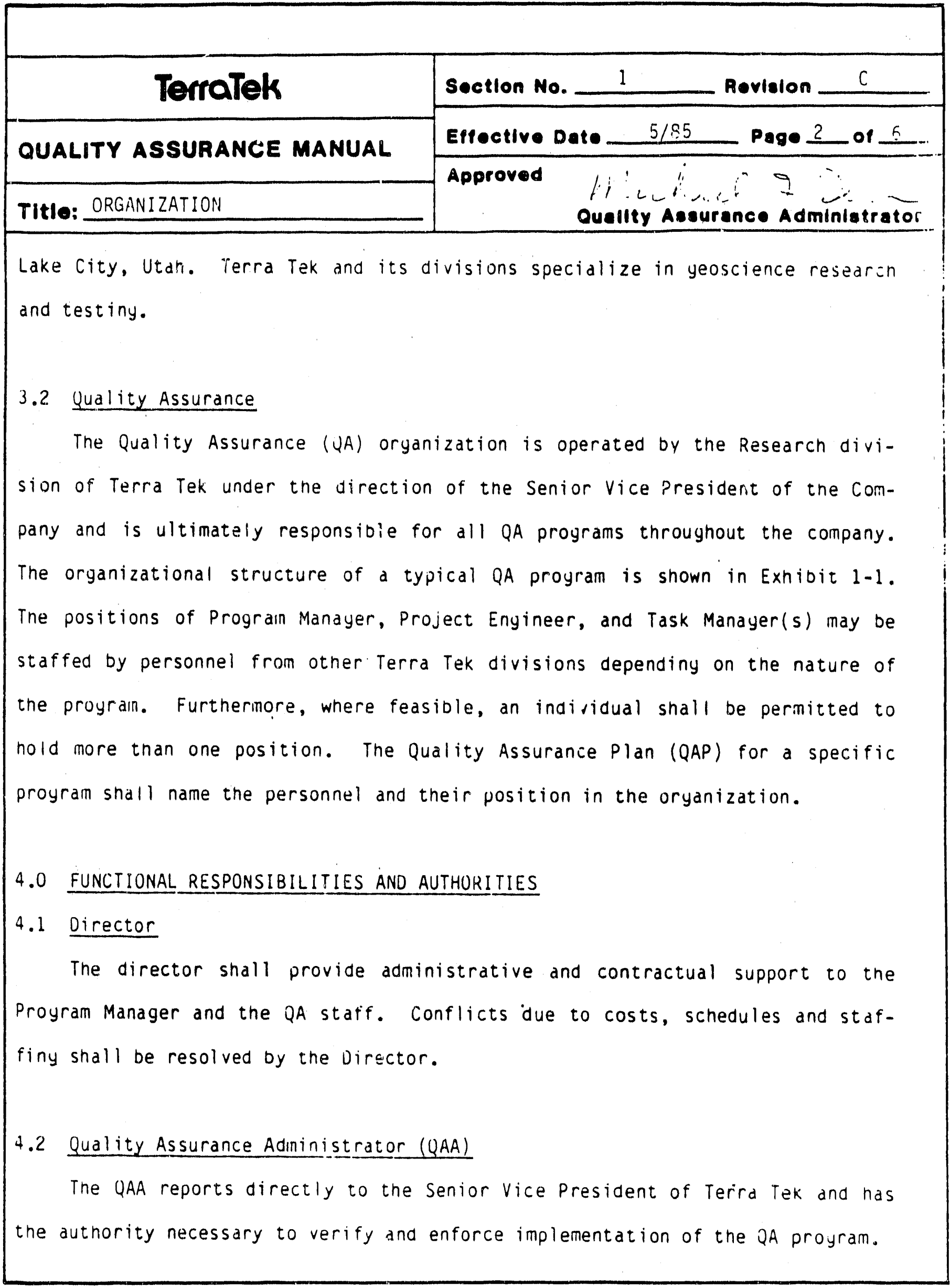




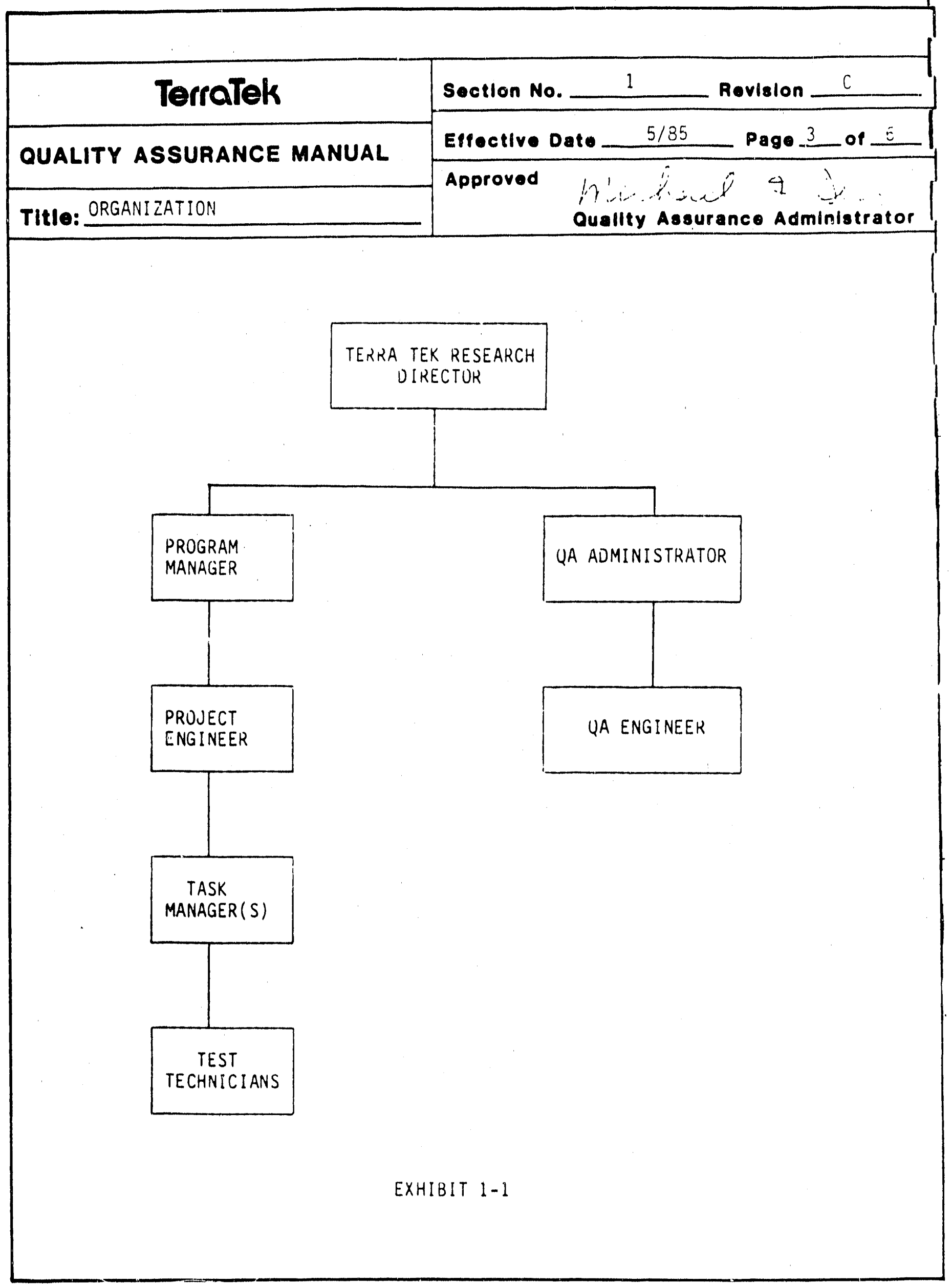




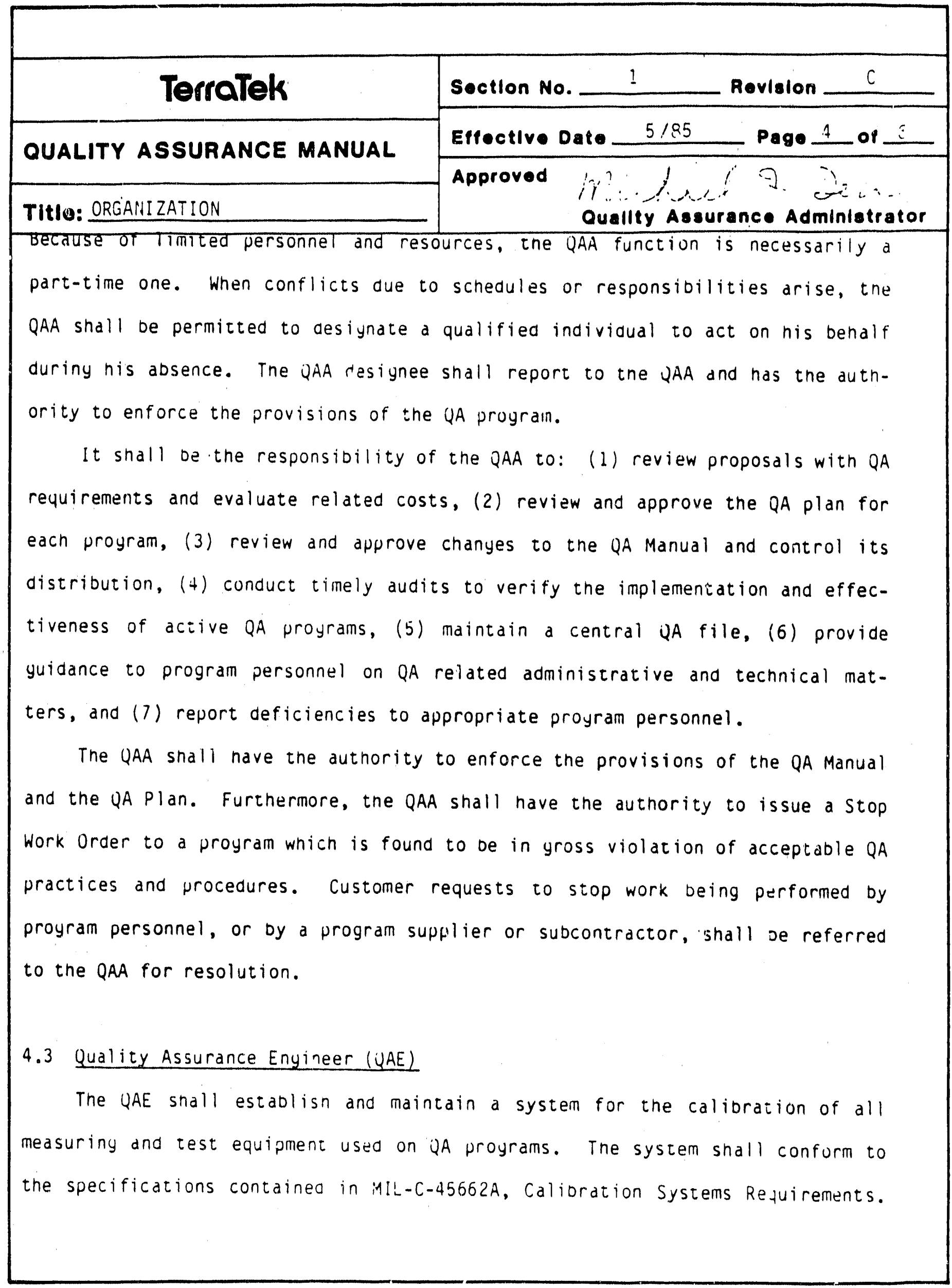




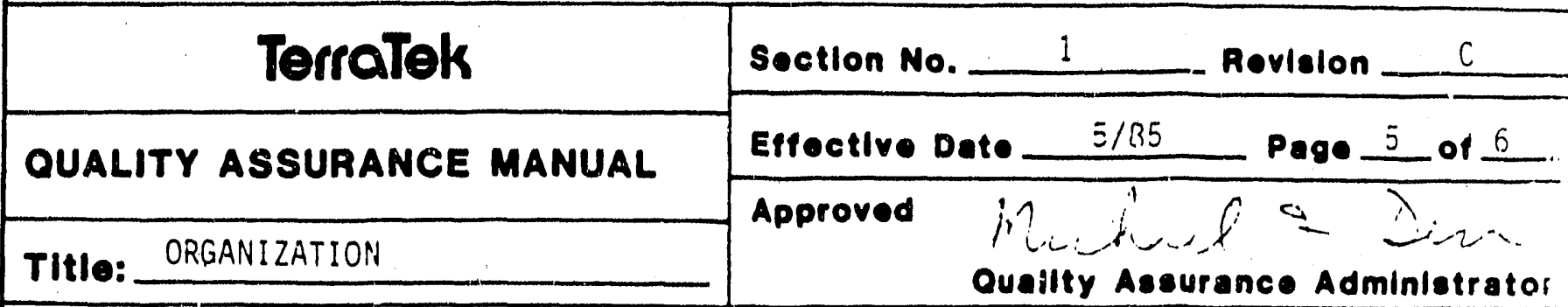

The QAE shall inaintain a listing of the applicable measurement standards, botn reference and transfer, and shall provide nomenclature, identification numbers, and calibration interval and source. The standards shall be traceable to the National Bureau of Standards. The QAE shall insure that measurement and test equipment and measurement standards are calibrated at periodic intervals established on the basis of stasility, purpose and degree of usage. Calibration recorcis consisting of certificates, data sheets, reports, and calibration schedules shall be maintained by the QAE for the purpose of verification.

\subsection{Proyram Manayer (PM)}

The PM shall have overail responsibility for: (1) contract neyotiations, (2) QA Plan preparation, (3) liaison between the Company the the contracting agency, major suppliers, and Task Manayers, and (4) administrative and technical management of the proyram. The PM shall also perform peer observations periodically to insure program personnel are complying with the provisiors of the QAP.

\subsection{Project Engineer (PE)}

The PE snall be responsible for the technical aspects of the prograin including design, testing, and data reduction and reporting. The PE shall coordinate the efforts of the Task Manayers and shall perform peer observations on a regular basis. Technical problems shall be referred to the pe for resolution. 


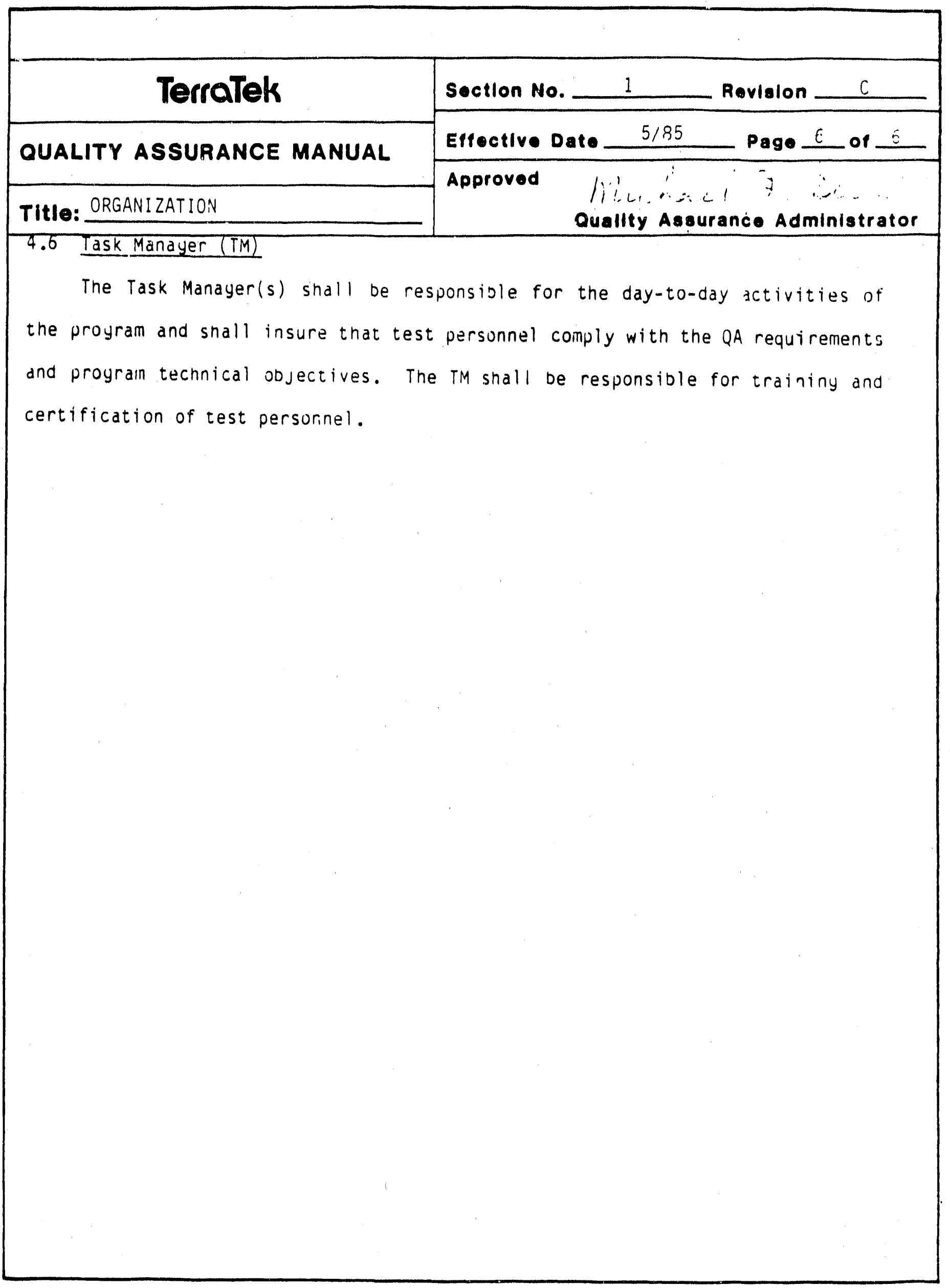

C. 27 


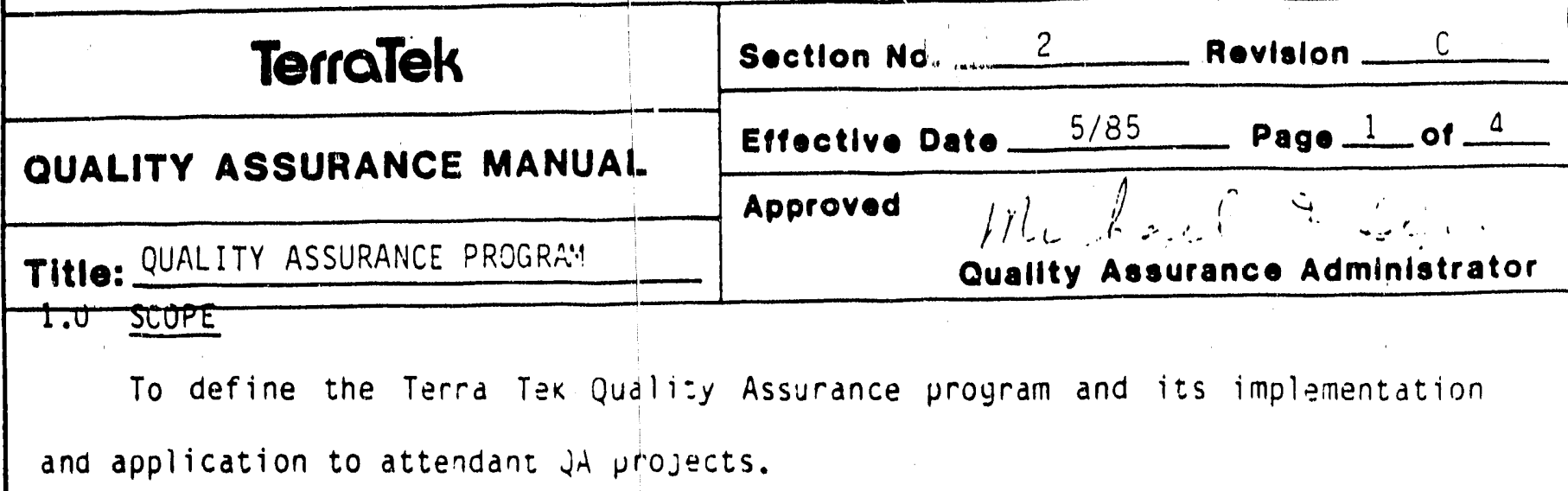

\section{U BASIC REQUIREMENTS}

A documented Quality Assurance proyrain shall be planned, implemented, and maintained in accordance witn this inanual, or portions thereof. The program shall identify the activities and itams to which it applies. The establishment of the proyram shall include consideration of the technical aspects of the activities affecting qualizy. The proyram shall provide control over activities affecting quality to an extent consistent with their importance. The prograrn shall be established at the earliest time consistent with the schedule for accomplishing the activities.

The proyram shall provide for the planning and accomplishment of activities affecting quality under suitasly controlled conditions. Controlled conditions include the use of appropriate equipinent, suitable environmental conditions for accomplishing the activity, and assurance that prerequisites for the yiven activity nave been satisfied. The proyran shall provide for any suecial controls, processes, test equipment, t0.0ls, and skills to attain the required quality and for verification of quality.

The prograin shall provide for indoctrination and training as necessary, of personnel performing aczivizies affezzing quality to assure that suitable proficiency is achieved and mintained. 


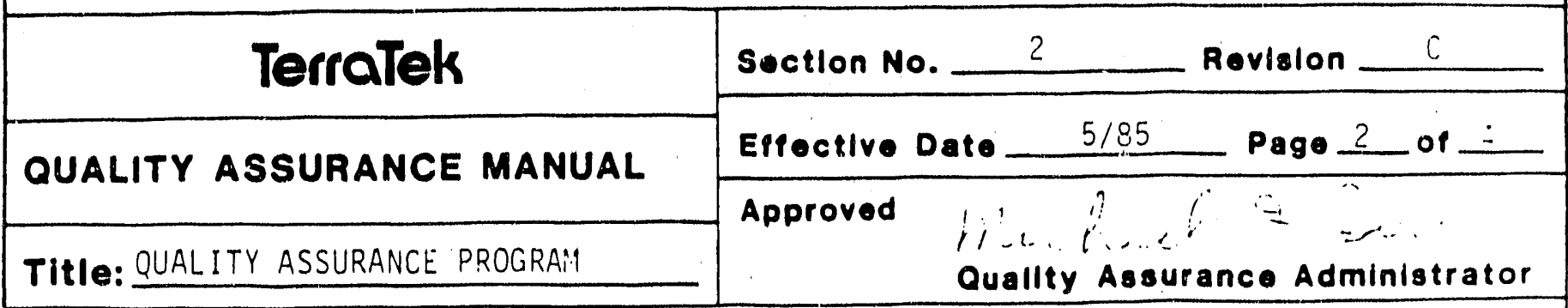

Management of those oryanizations implementing the quality assurance program, or portions thereof, shall regularly assess the adequacy of that part of the proyram for which they are responsible and shall assure its effective injlementation.

\subsection{APPLICATION}

Projects which contain QA requirements shall structure their QA programs as described in this Quality Assurance Manual (QAM). This Terra Tek QAM is the top document upon which the individual project Quality Assurance Plans (QAP's) shall be based. In the event an Owner (customer) proposes QA requirements which exceed those contained in this indnual, the QA Administrator sinall review the proposed program for impact on the Company.

\subsection{Quality Assurance Plan}

A Quality Assurance PIan (QAP) shall be prepared at the onset of a project and prior to initiating technical work. The Proyram Manager shall nave responsitility for the preparation and maintenance of the QAP. The QAP shall De approved by the Director, the QA Adininistrator, the Pr yram Manager, and the Owner prior to reledse. The QAP shall be a controlled document.

The purpose of the QAP is to establish the procedures and structures of a project as they relate to quality assurance. As sucn, the QAP snould address the following topics where feasiole: 1) secions of the Terra Tek QA Manual invoked (sections 1 and 2 are inandatory); 2) UAP change procedures; 3 ) technical 


\begin{tabular}{|c|}
\hline TerraTek \\
\hline QUALITY ASSURANCE MANUAL \\
\hline TIIOS UAMP
\end{tabular}

Title: QUALITY ASSURANCE PROGRAM

\begin{tabular}{l} 
Section No. $\frac{2}{2}$ Rovision $\frac{C}{\text { Effective Date } \quad 5 / 85}$ Page 3 of 2 \\
\hline
\end{tabular}

procedures; 4) special skill, equipment or procedure requirements; 5 ) the controlled documents list; 6) the project records list; 7) training requirements and schedules, 8) peer observations and audits, and y) nonconformance reportiny. As a minimum, the QAP shall implement those requirements placed on the company by the Owner.

\subsection{Training and Qualification}

Personnel assigned to the project shall be qualified to perform their related work activity. Qualifications depend on past experience, training, and education. Where feasible, a training program shall be implemented using formal classroom training, on-the-jod training, or a combination thereof. The qualifications of personnel should be reviewed yearly and certified in writing. The QAA snall maintain a file of personnel qualifications using form TTQA-47.

Qualification requirements for project personnel are snown in Exhibit 2-1. These qualifications shall not be mandatory for every QA proyram, but are presented as a yuideline for Proyram Managers. The QAP shall state the qualification requirements that are in effect for the specific project. 


\begin{tabular}{|c|c|}
\hline Terratek & Sectlon No. 2 \\
\hline \multirow{2}{*}{ QUALITY ASSURANCE MANUAL } & Effective Date $5 / 25$ \\
\hline & $h^{\prime} i, i=9$ \\
\hline TItIe: QUALITY ASSLRAIVE P:OGRAPH & Quallty Aseurance Administrator \\
\hline
\end{tabular}

Level Job Title

Jualifications

$1 \quad$ Lab \& Test

Technician

Two years oi related experience in an equivalent activity; or high scnool diploma plus six months of related experience; or issocidte Deyree in related discipline plus three montens rela:ed experience.

II Task One year uf satisfactory performance as a Level I; or hiyh Manager schoul diplona plus three years related experience; or Associate Degree in related discipline plus one year of related experience; or four year college deyree plus six months of related experience.

III Project Six years of satisfactory performance as a Level II; or high Engineer, school diplima plus ten years of related experience; or Proyram Associate Deyree in related discipline plus seven years of Manager related experience; or four year college degree in related discipline ilus four years of related experience.

\subsection{Proyram Assessment}

Project inanayement snall rayularly assess the effectiveness of the associdted QA program and effect changes as deemed necessary to insure correct and efficient operation. 


\section{Terraïek}

\section{QUALITY ASSURANCE MANUAL}

TItIO: DESIGN CONTROL

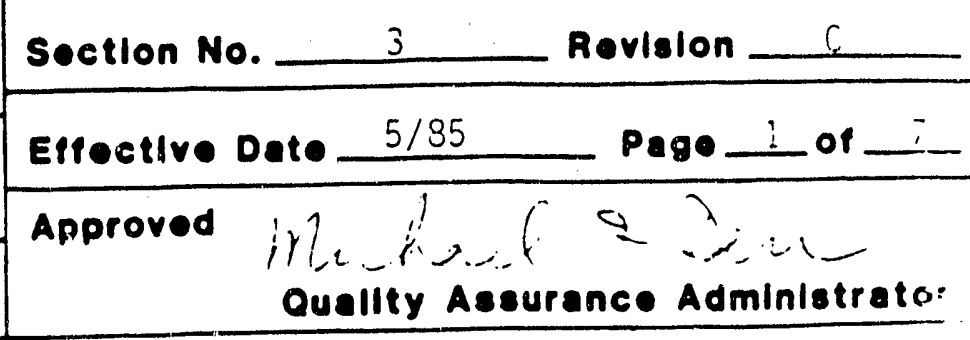

\section{U SCOPE}

To establish procedures for the definition, control and verification of design activities. For geoloyic investigations, design control encompasses all activities associated with: 1) :ne design of nardware components and systems, both production and prototypic, 2; experimental testing techniques, and 3) computer codes used for design analysis and data reduction. The intent of design control is to insure that the methodology used to acnieve the rinal design is complete; i.e., that the design base is accurate, the performance and reyulatory requirements are achieved, the documentation including codes and standards is correctly stated, interfaces are clearly defined, and approval by resionsible personnel is met. The implementazion of an approved design througn procedures, drawings and specifications is the subject of section 5 , Instructions, Procedures, and Drawings.

\subsection{BASIC REQUIREMENTS}

The design shall be defined, controlled, and verified. Applicade desiyn inputs shall be appropriately specified on a timely basis and correctly translated into design documents. Design interfaces shall be identified and controlled. Design adequacy shall be verified by persons other than tnose who designed the item. Design chanyes, including field chanyes, shall de governed by control measures commensurate with inose azplied to the original desiyn. 


\begin{tabular}{|c|c|}
\hline Terratek & Soction No. 3 \\
\hline QUALITY ASSURANCE MANUAL & Effective Date $5 / 85$ \\
\hline TItle: _ DESIGIV CONIROL & 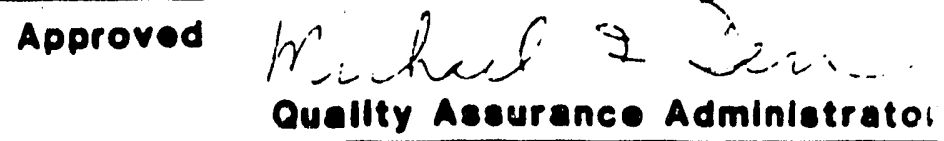 \\
\hline
\end{tabular}

\subsection{APPLICATIUN}

Oriyinally, design control was written for the construction of nuclear power plants and facilities where safety was a primary concern. As applied to yeoloyic work, design control yenerally translates to peer review since the inore conventional verification/validation methods are not available and the unique application of an established or standard practice is in effect. Peer review is also invaluable when the work yoes beyond the state-of-the-art and new or unusual experimental sechniques are contemplated. The steps necessary to achieve adequate design control are presented below.

\subsection{Responsibility}

The Project Engineer (PE) shall be responsible for design control. Where a significant design effort is in effect, the PE shall coordinate the design activities of the design team. The PE shall insure that approval and verification criteria are establisned, implemented, and documented. Approval by the Owner shall be required for desiyns which compromise or otherwise restrict the application of the final product.

\subsection{DESIGN INPUT}

Applicable design inputs, such as design bases, performance requirements, regulatory requirements, codes, and standards, shall be identified and documented, and their selection reviewed and approved by the responsible design organization. Changes from approved design inputs, including the reason for the chanyes, shall be identified, approved, documented, and controlled. 


\begin{tabular}{|c|}
\hline Terratek \\
\hline QUALITY ASSURANCE MANUAL \\
\hline TItIO: D_ DESIGIV CONTROL \\
\hline
\end{tabular}

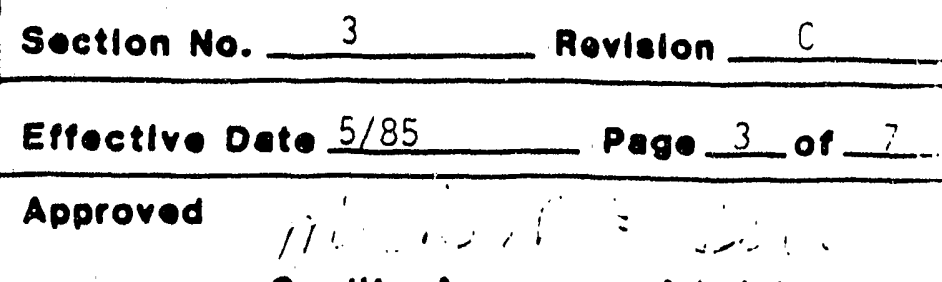

\section{U DESIGN PROCESS}

The responsible design oryanization shall prescribe and document the desiyn activities on a timely basis and to the level of detail necessary to perinit the desiyn process to be carried out in a correct manner, and to permit verification that the design meets requirements. Appropriate quality standards shall be identified and documented, and their selection reviewed and approved. Desiyn methods, inaterials, parts, equipment, and processes that are essential to the function of the final product, shall be selected and reviewed for suitability of application. The design output documents snall be relatable to the design input by documentation in sufficient detail to permit design verification, and shall identify assemblies and/or components that are part of the item being desiyned.

\subsection{Design Analysis}

Desiyn analyses shall be performed in a planned, controlled, and documented manner. The design analytical documents shali be sufficiently detailed as to purpose, method, assumptions, design input, references, and units that a person technically qualified in the subject can review and understand the analyses and verify the adequacy of the results. Computer prograins may be utilized for design analysis without individual verification of the program if they meet the requirements contained in parayraph 7 . 


\begin{tabular}{|c|c|}
\hline Terratek & Sectlon No. \\
\hline \multirow{2}{*}{ QUALITY ASSURANCE MANUAL. } & Esfoctlve Date $5 / 85 \quad$ Page 4 op 7 \\
\hline & \multirow{2}{*}{ 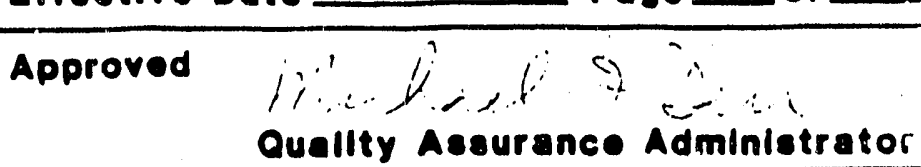 } \\
\hline DESIGIN COMTROL & \\
\hline
\end{tabular}

\section{U DESIGN VERIFICATION}

The approved design shall be verified as to adeyuacy through the use of design or peer reviews, dlternate calculations, or the performance of qualification tests. The design method and results shall be identified and clearly documented. Design verification shall be performed by any competent individual(s) other than those who perforined the oriyinal design. The extent of the desiyn verification required is a function of the importance to safety of the item under consideration, the complexity of the design, the deyree of standardization, the state-of-the-art, and the similarity with previously proven desiyns. The verification process need, not be duplicated for identical designs except where a new application is in effect. Where changes to previously verified desiyns have been made, design verification shall be required for the chanyes, including evaluation of the effects of those changes on the overall design. Verification using computer models shall be permitted if they meet the requirements of parayraph 7 .

\subsection{CUMPUTER CUDES}

The use of computer codes for desiyn analysis, verification, data acquisition, and data reduction snall be perinitted provided they meet the requirements Delow. Documentation for computer proyrains shall include the computer type, proyram name, revision number, and references to its verification and applicability. Source listinys shall be inade available to the Owner upon request provided the computer code is nonproprietary. 


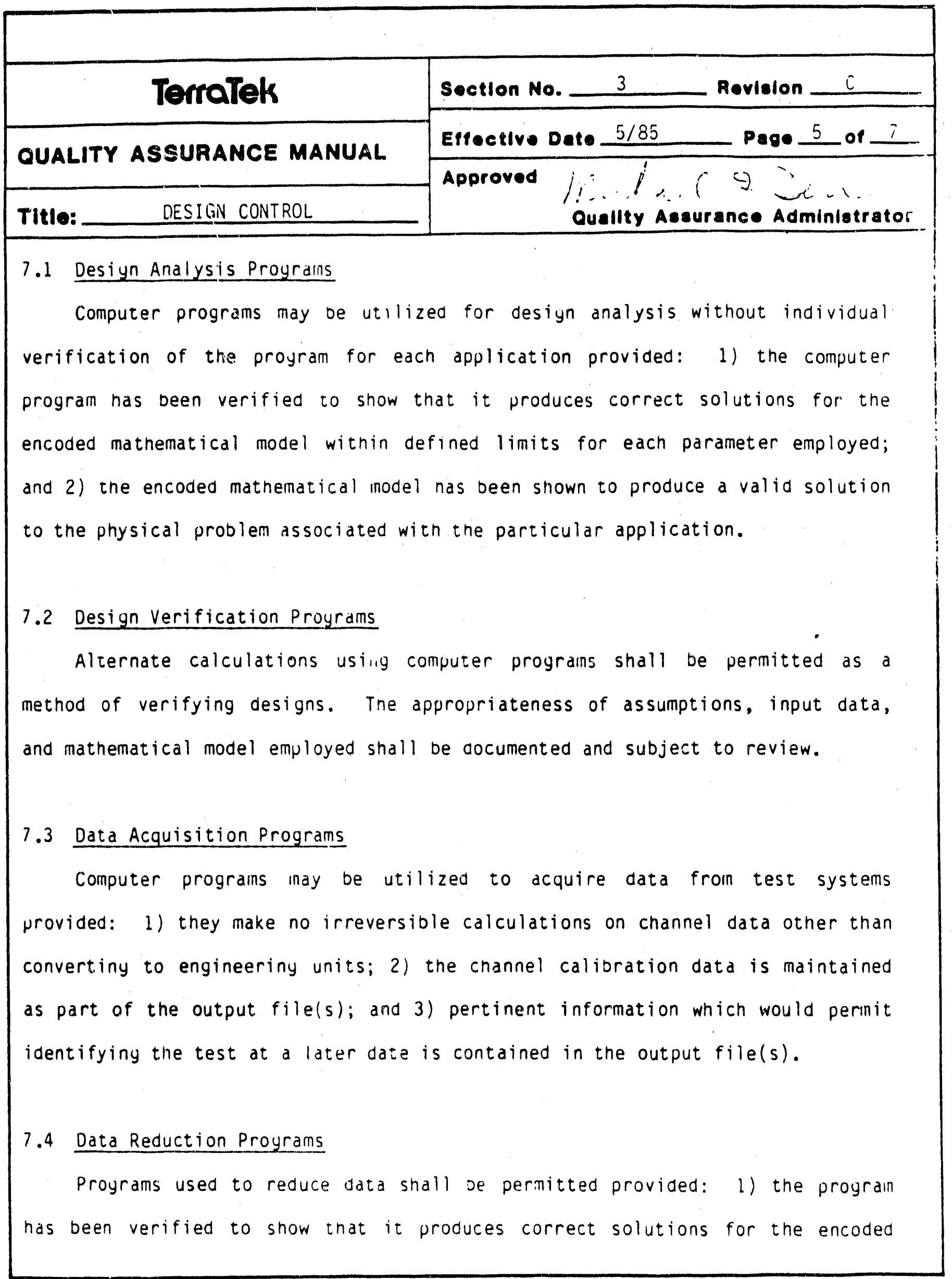




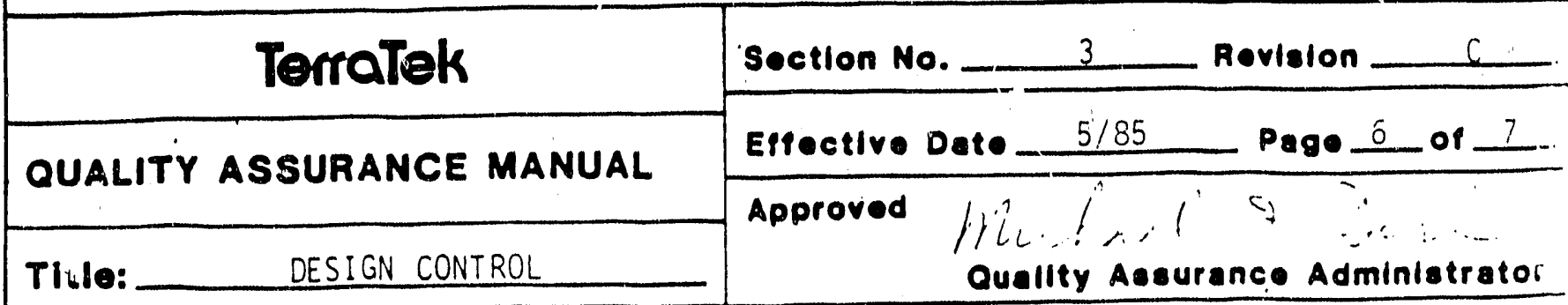

mathematical model within defined limits for each parameter employed; and 2) the encoded mathematical model has been shown to produce a valid solution to the physical problem associated with the particular application. The use of benchmarks, standards, past experience, or a combination thereof shall be sufficient for demonstrating verification and application. Data reduction programs shall be controlled.

\section{U CHANGE CONTRUL}

Chanyes to final designs, including field changes, shall be justified and subjected to design control measures commensurata with those applied to the original design and approved by the same affected oryanizations which approved the original design. Where a significant design change is necessary because of an incorrect design, the design process and verification procedure shall be reviewed and modified as necessary.

9.0 INTERFACE CUNTROL

Design efforts which involve more than one organization shall be coordinated by the Project Enyineer. Design interfaces shall be identified and controlled. Interface control shall include assignment of responsioility and the establishment of procedures among participating design organiza:ions for the review, approval, release, distribution, and revision of documents involviny design interfaces. Desiyn information transinitted across interfaces shall be documented and controlled. Where it is necessary to initially transinit design 


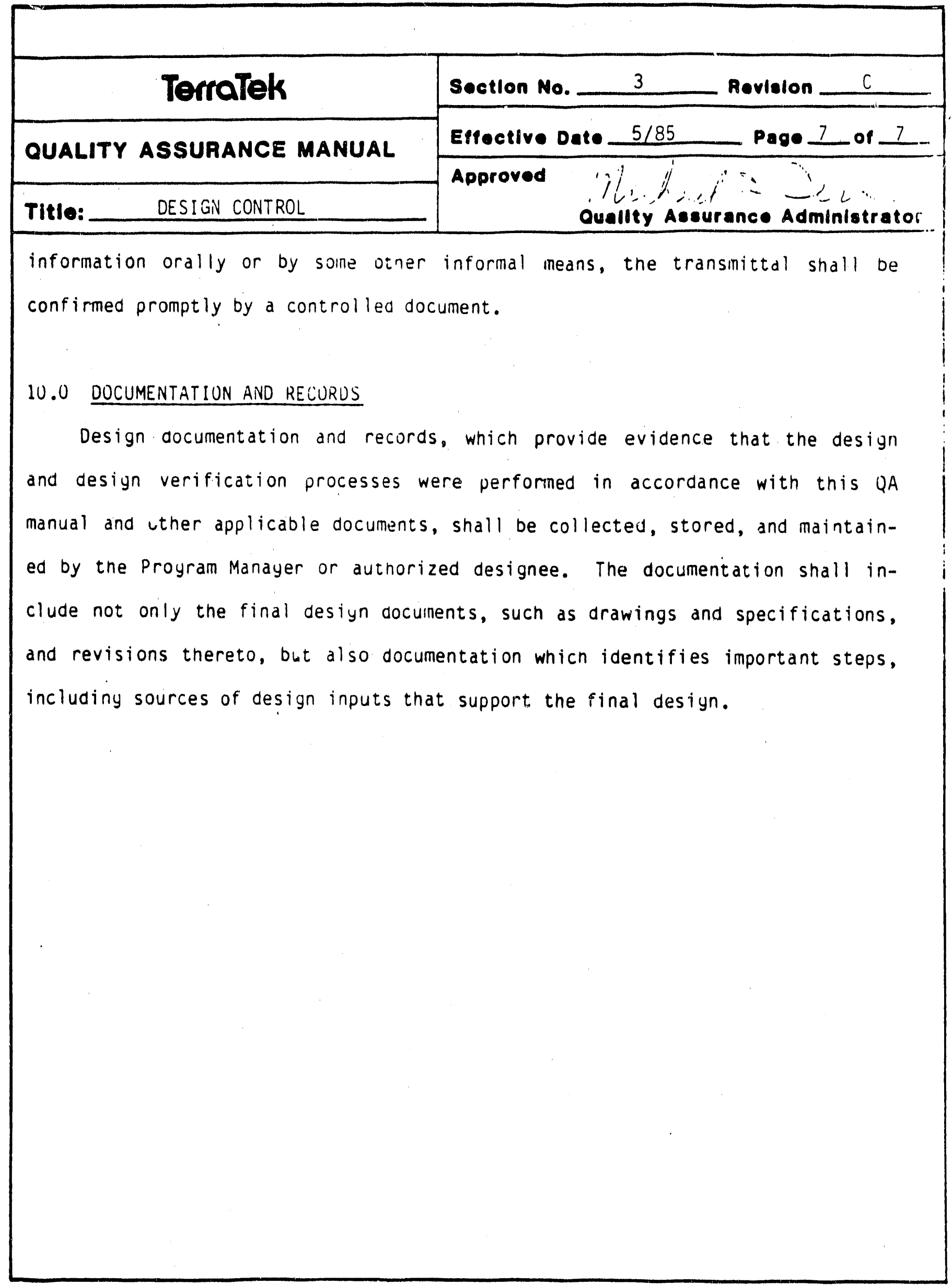




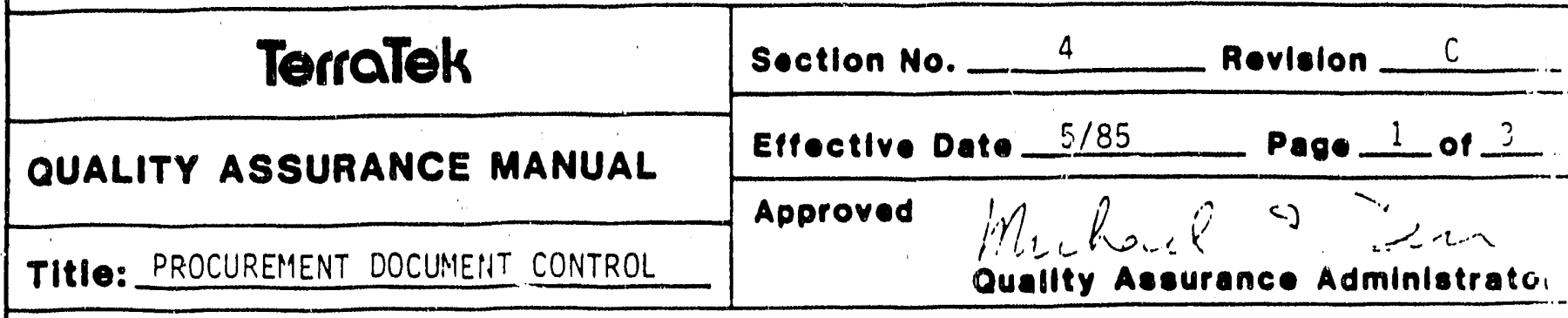

1.U SCOPE

To define the documentation associaced with the purchase of yoods and services. Excernally supplied yoods and services are subject to the same quality assurance requirements as the proyram ior wrich they are intended to be used. The documents authorizing purcnase snall explicitly state these requirements where applicable.

\section{U BASIC REQUIREMENTS}

Applicable desiyn bases and oiner reyuirements necessary to assure adequate quality shall be included or referenced in documents for procurement of items and services. To the extent necessary, procurement documents shall reyuire suppliers to have a quality assurance proyram consistent with the applicable requirements of this manual.

\section{U APPLICATION}

\subsection{QA Proyrams for Suppliers}

A formal quality assurance proyram is not mandatory for all suppliers. In most cases, contractual aucuments must assure that required quality dctions are implemented in compliance with the associated UA proyraln. However, suppliers who furnish a critical component or service snall de required to certify that they have a QA proyraln for ene procuction of the item or service. The extent of the proyram required snall aepend upon :ne type and use of the item or service seiny procured. 


\section{TerraTek \\ QUALITY ASSURANCE MANUAL}

Sectlon No.

Effective Date $5 / 85$
Revision

Page 2 of 3

TItIE: PROCUREMENT DOCUMENT CONTROL

3.2 Technical Requirements

Where necessary, technical requirements shall be specified in the procursment documents. These requirements shall be specified by reference to specific drawings, specifications, codes, standards, reyulations, procedures, or instructions, including revisions thereto that describe the iteins or services to be furnished. In yeneral, comnercial yrace and off-the-shelf items are exempt from this requirement; a purchase order specifying part number or other identifyiny description is sufficient. Examples of the application of technical requirements would be unusual heat treatments, calibration services, exotic alloys, pressure vessels, and testiny services.

\subsection{Purchaser Inspection}

Where technical requirements are in effect, it shall be the responsioility of the purchaser to inspect the furnished item or service for compliance with the QA proyram. Section 14 of this manual provides amplified instructions for inspection requirements.

\subsection{Supplier Documents}

Documents to be subinitted by the supplier upon task completion shall de specified in the procurement documents. These subinitted documents may ranye from a simple Certificate of Conformance, or Nonconformance, to an extensive nistory record of the item or service isrnished. These documents shall de placed in the project record file and may ze subject to the archival requiremenis as specified in the QA plan. 


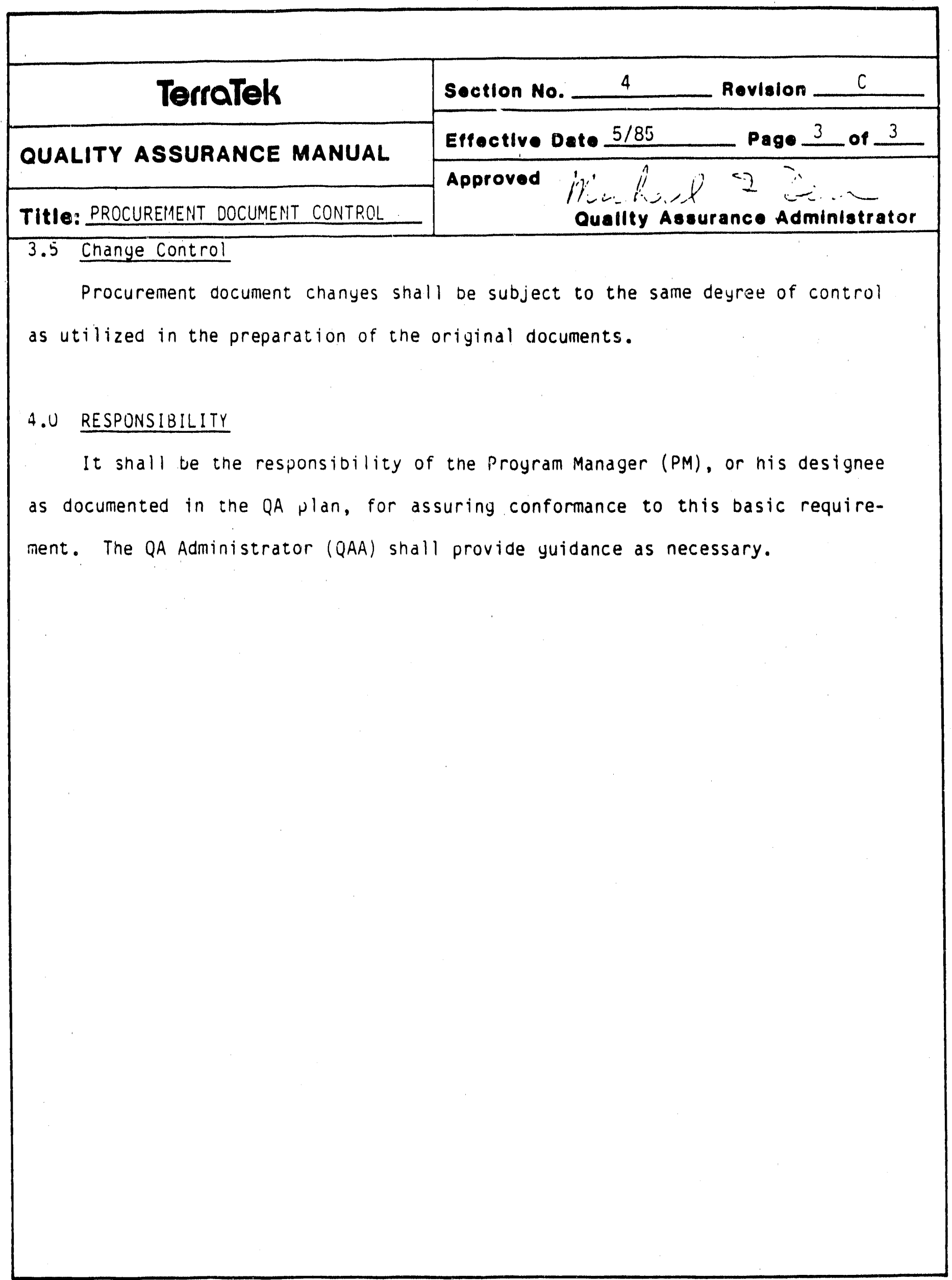




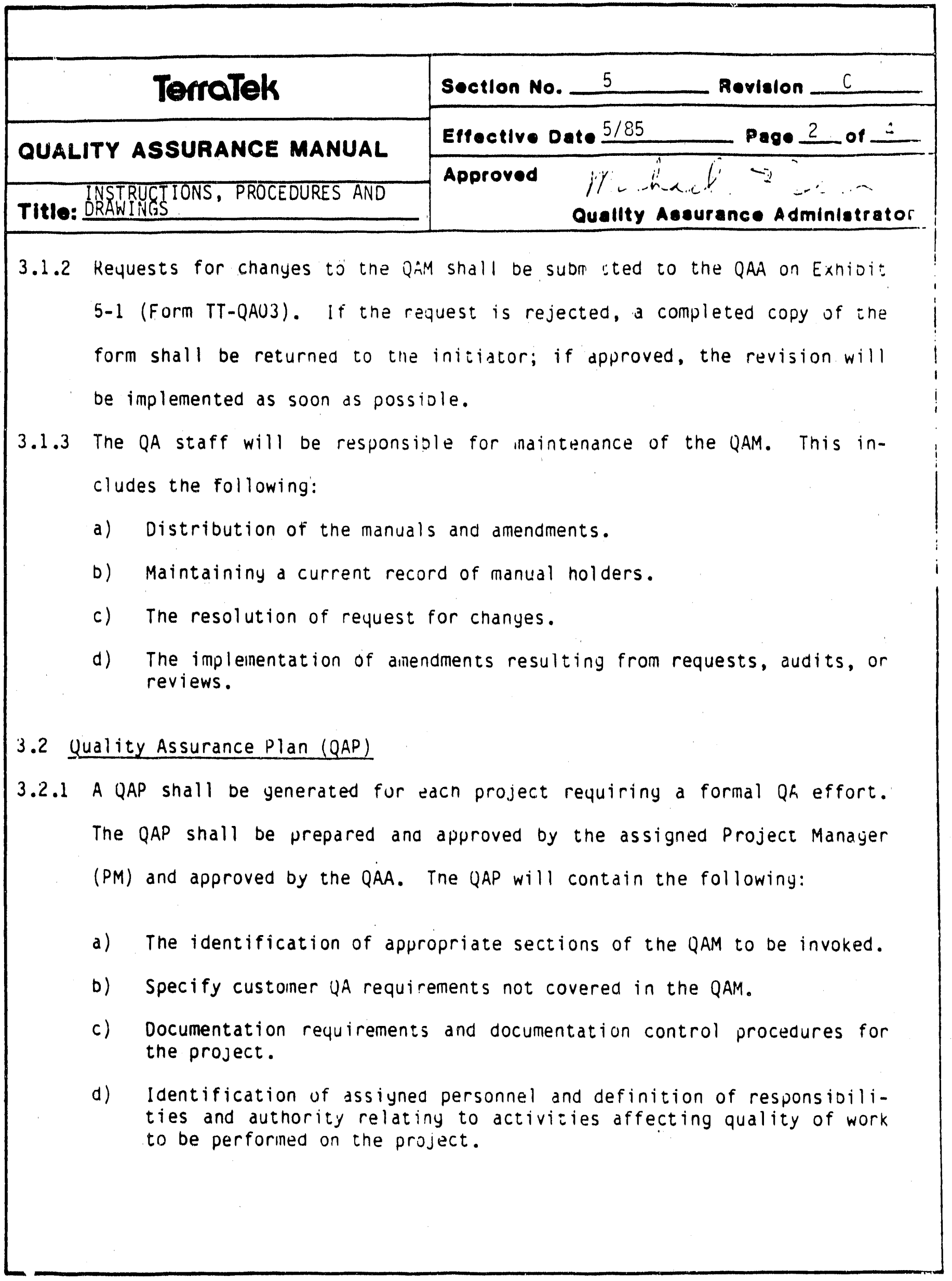




\section{Q A MANUAL CHANGE REQUEST}

\section{FROM:}

TO: Quality Assurance Administrâtor

DATE:

It is requested that the following change be made to:

Section No.

P.ev.

Page

Para.

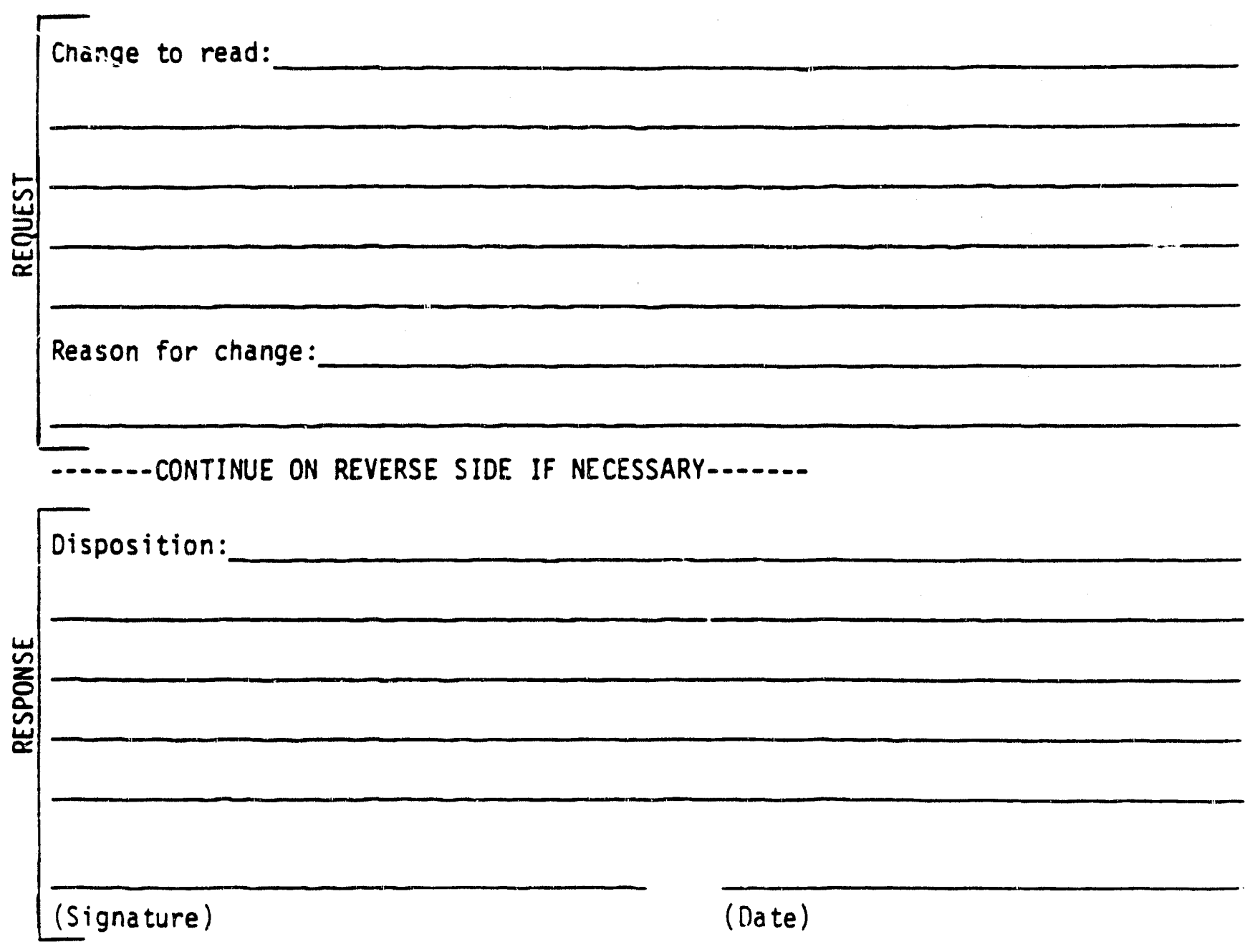



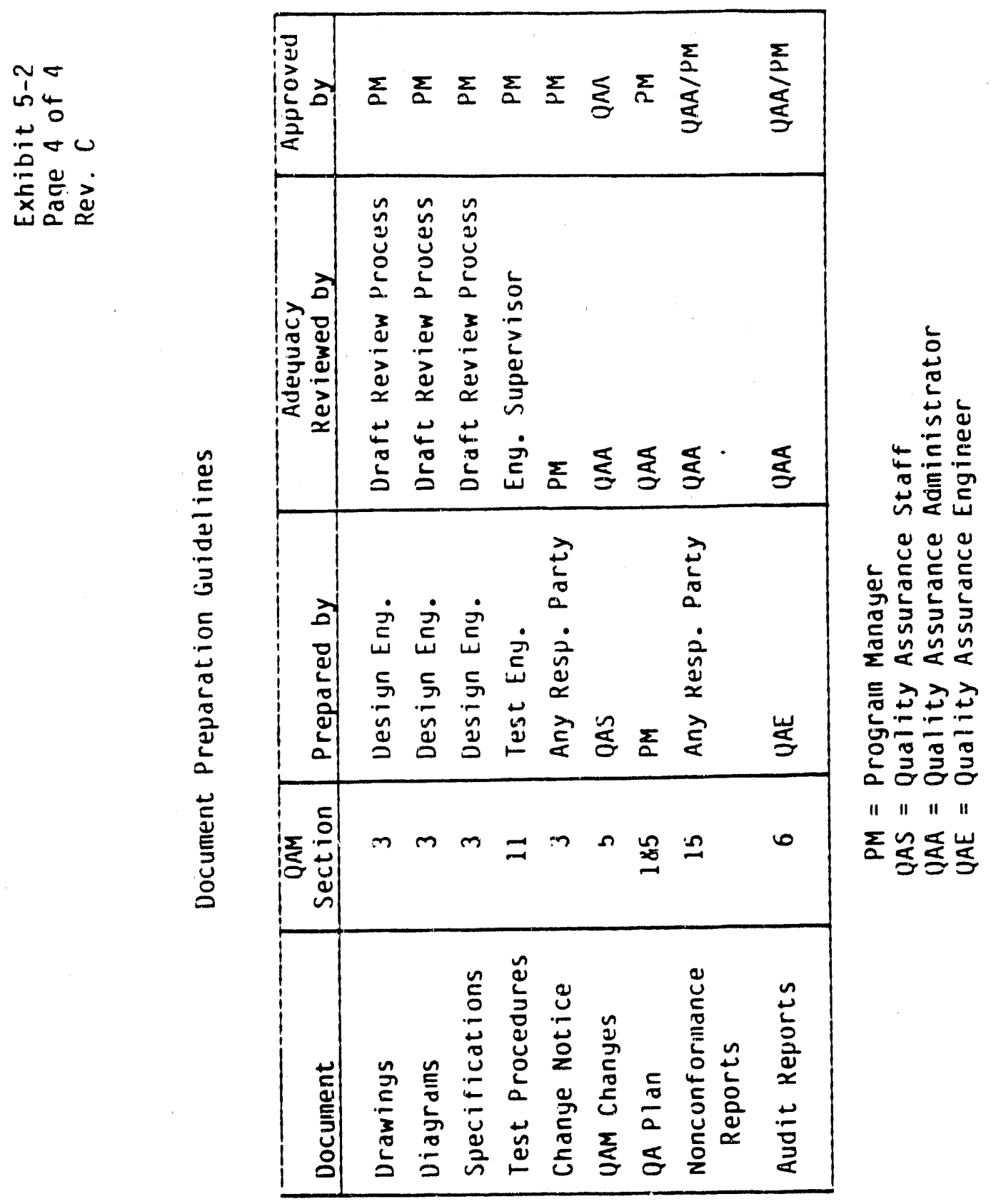


\begin{tabular}{|c|c|}
\hline Terratek & Section No. 6 \\
\hline QUALITY ASSURANCE MANUAL & Effective Date $5 / 85$ Page 1 of 3 \\
\hline Title: DOCUMENT CONTROL & $\begin{array}{l}\text { Approved } \\
\text { Quallty Assurance adminlstrator }\end{array}$ \\
\hline
\end{tabular}

To define controlled ducuments and establish procedures for document control. The basic intent of document contral is to insure that activities affectiny the quality of the final product are performed in an approved manner. This is accomplisned by generating procedures or other quality affecting documents which are jointly approved by authorized individuals representing the concerned organizations. The approved documents then are released in a controlled fashion to the personnel performiny the associated activity. Chanyes to the controlled documents are handled in a similar manner.

\subsection{BASIC REQUIREMENT}

The preparation, issue, and chanye of documents that specify quality requirements or prescribe activities affecting quality shall be controlled to assure that correct documents are beiny employed. Such documents, including changes thereto, snall be reviewed for adequacy and approved for release by authorized personnel.

\subsection{APPLICATION}

A controlled document is a document which defines procedures, specifies requirements, or releases data outside the company. A controlled document has a unique control number and a distribution list. Examples of controlled documents are the Quality Assurance Manual (QAM), ine Quality Assurance Plan (QAP), computer codes which reduce data, procurement documents, construction/assembly draw- 


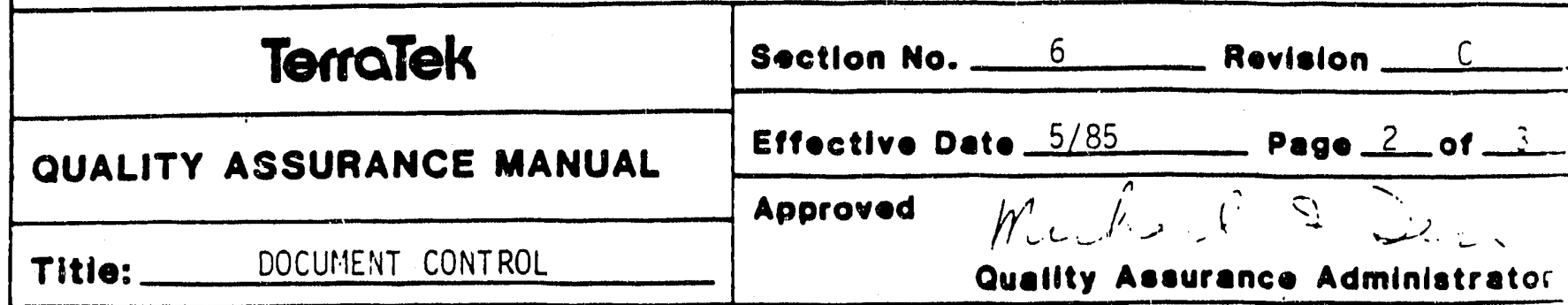

inys, contracts, and published final reports or interim data released to tne Owner. The QAP shall list those controlled documents applicable to the project.

\subsection{Preparation}

The oriyinator of the controlled document shall be identified and should De proficient and knowledgeable in the subject of interest. A format should be established which is complete and concise. Review of the document by competent, uninterested personnel is desireable.

\subsection{Approval}

Controlled documents shall be approved by responsible management personnel prior to release. All controlled documents shall be approved by the QAA. Controlled documents particular to a project shall require approval by the Prograin Manager as well.

\subsection{Distribution}

A controllea distribution shall be established to assure that those personnel requiring the documents will have them where they need them and that all copies are updated when changes are made. The QAA shall be responsible for issuiny a control number and for maintaining the control log. The Proyram Manager shall be responsible for determining the distribution list for project related documents. The control $\log$ and a copy of each controlled document shall be kept in the central QA file. 


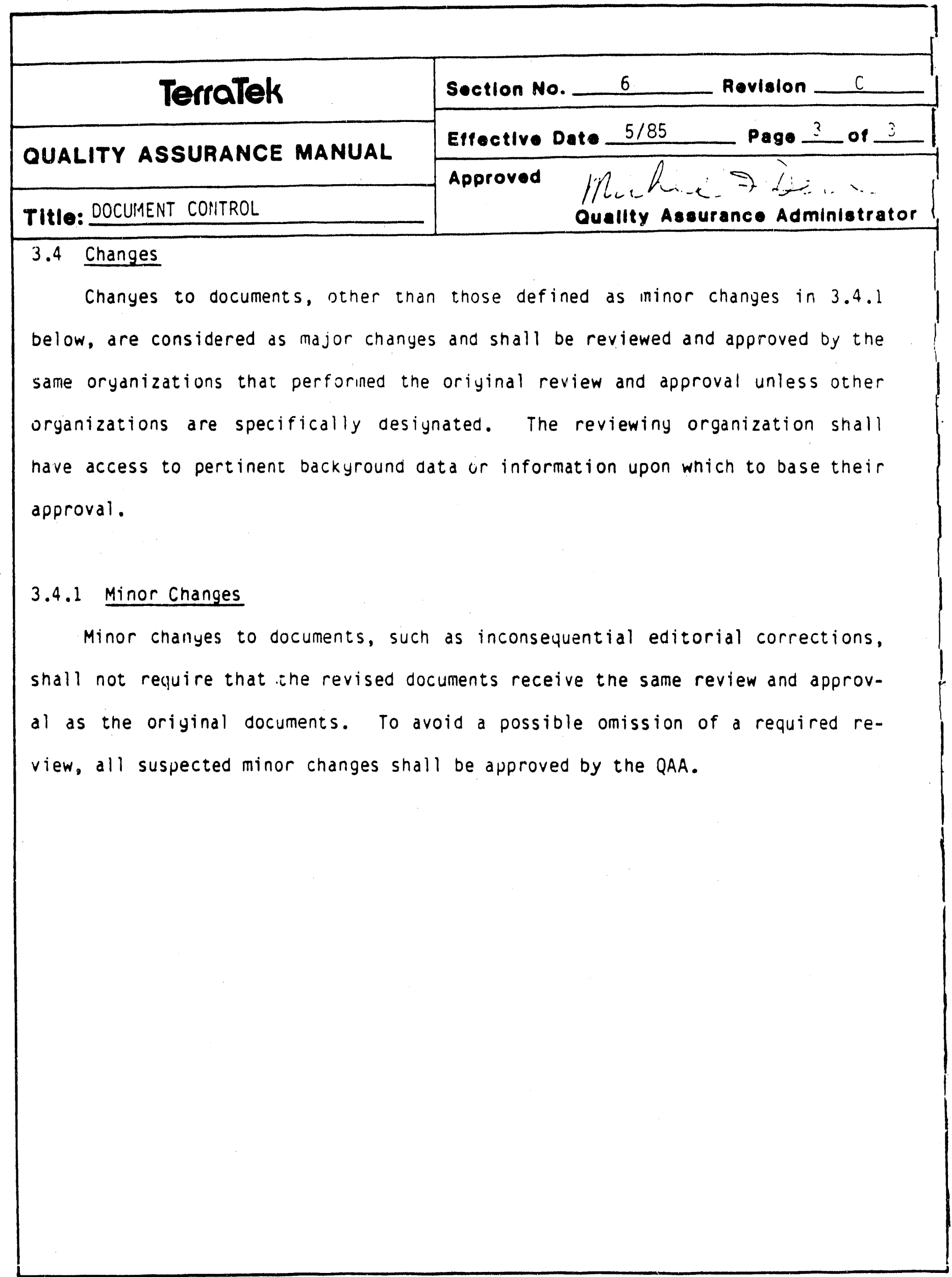




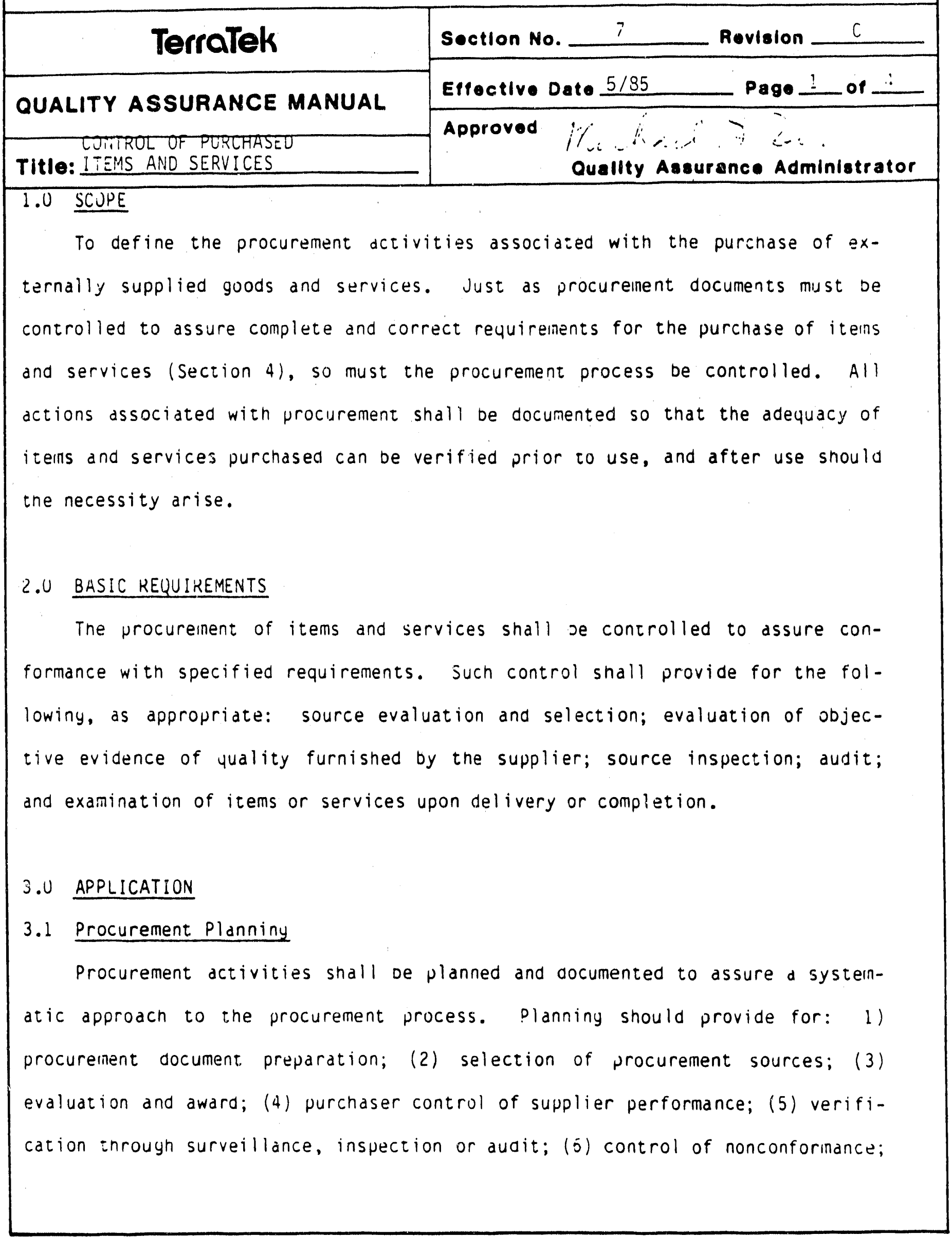




\begin{tabular}{|c|}
\hline TerraTeK \\
\hline QUALITY ASSURANCE MANUAL \\
\hline TITIE: ITEITS AND SERVICES
\end{tabular}

\begin{tabular}{|l|l|} 
Section No. $\frac{7}{\text { Eevialon }}$ Rectlve Date $\frac{5 / 85}{C}$ Page ? of $:$ \\
\hline Approved
\end{tabular}

(7) corrective action; ( 8 ) acceptance of icen or service; and $(y)$ quality assurance records.

\subsection{Supplier Evaluation and Selec:on}

The selection of suppliers snall de rased on evaluation of their capability to provide items or services in acisrdance with the requirements of the procureinent documents prior to contract award or purchase. Evaluation shall be based on: (1) technical considera:ions; (2) quality assurance requirements; (3) supplier's personnel; (4) supplier's production capability; (5) supplier's past performance; (6) alternates; and $i^{-}$excepsiuns.

\subsection{Verification}

The extent of verification acivities snall be a function of the relative importance, complexity, and quantizy of the itein or services procured, and the supplier's yuality periormance. Source surveillance and inspections, audits, receiving inspections, nonconformances, jispositions, waivers, and corrective actions shall be documented. Ac:ivities performed to verify conformance to procurement documents shall be recorded. These documents shall be reviewed periodically to assess ine effectiveness of the supplier's UA proyrain.

\subsection{Acceptance}

Prior to offeriny ine : :em or servize for acceptance, the supplier shall verify that the item or service caing furnisned complies with the procurement 


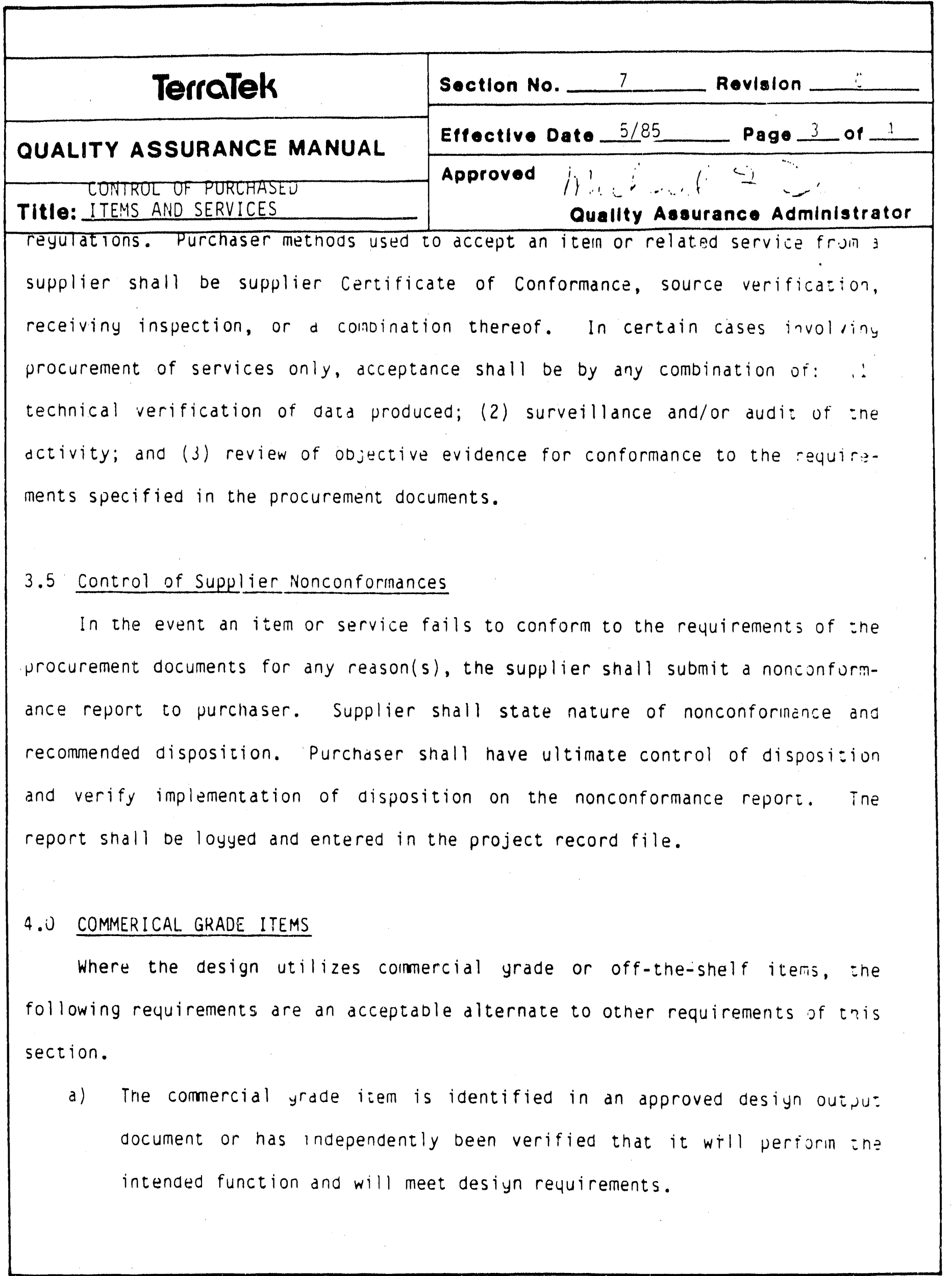




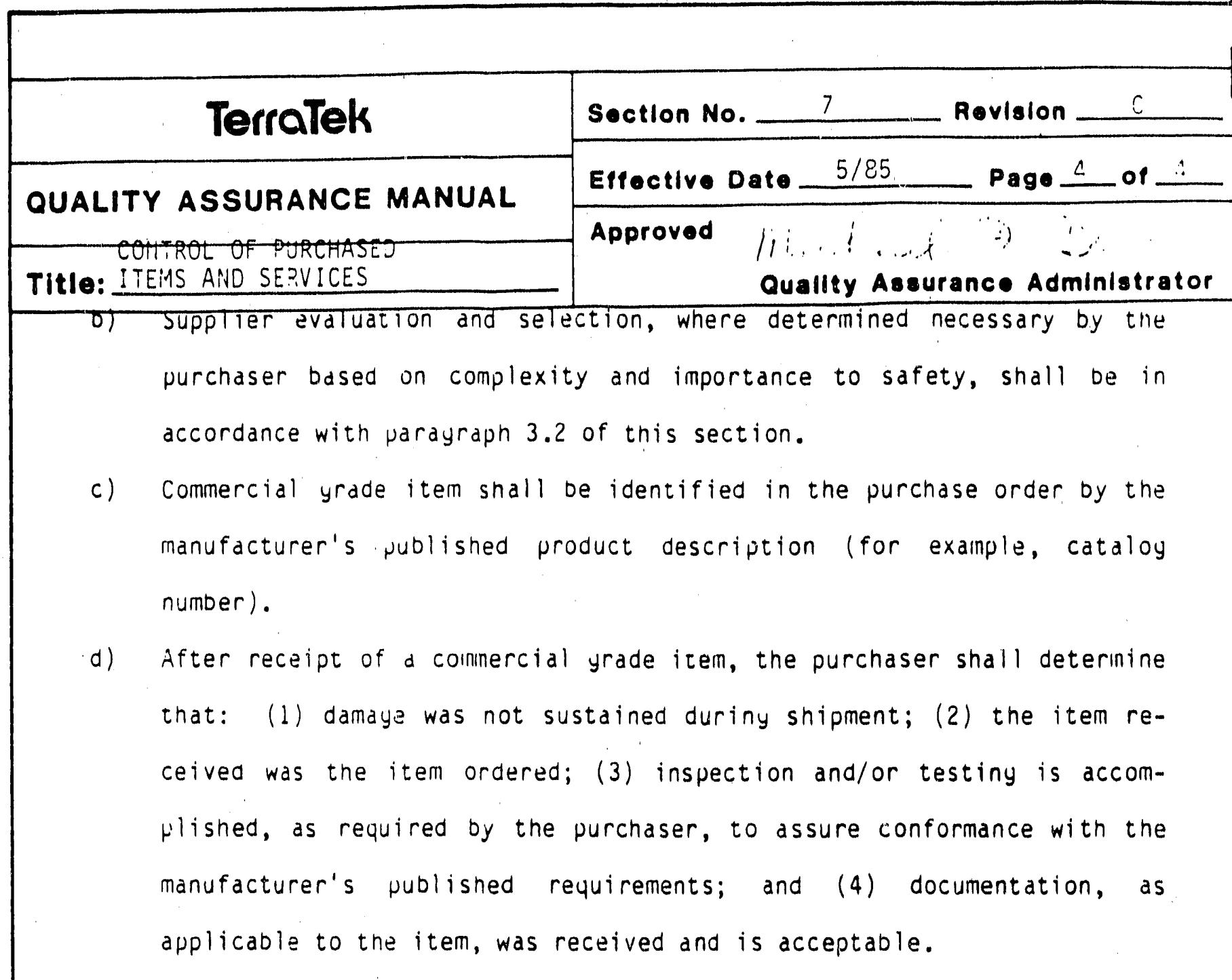




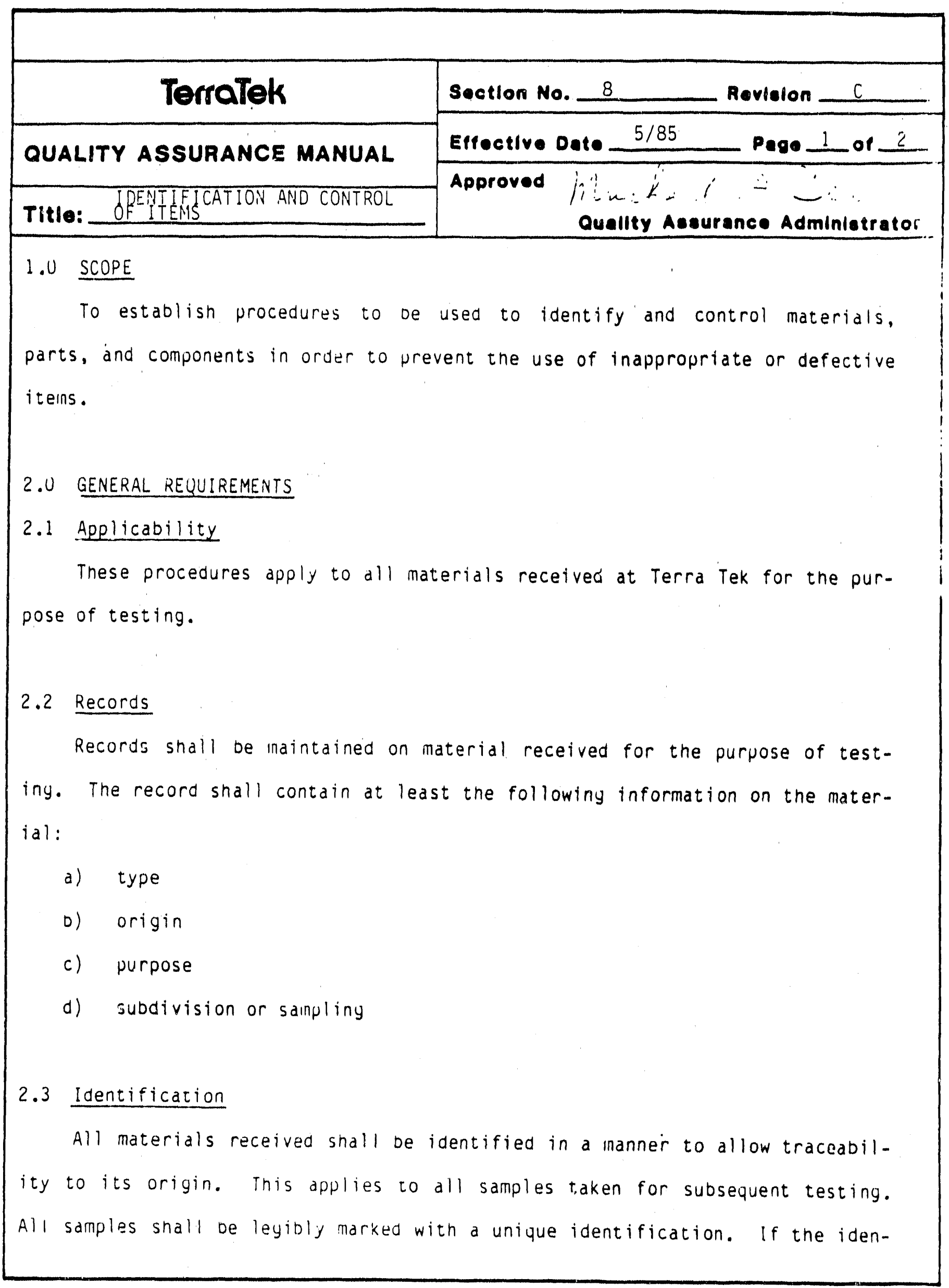




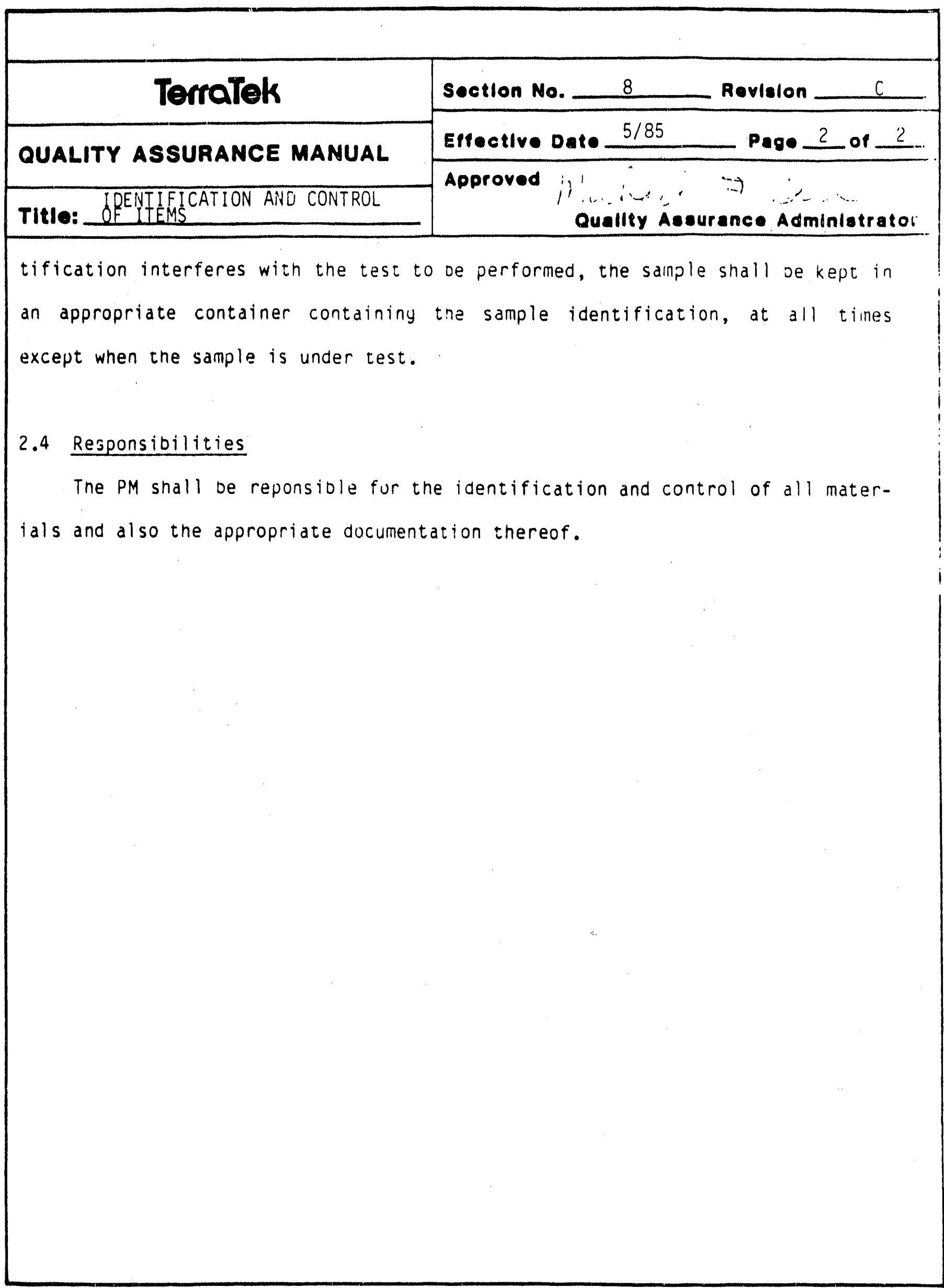




\begin{tabular}{|c|c|c|c|}
\hline Terratek & Section N & 10 & evision \\
\hline QUALITY ASSURANCE MANUAL & Effective & $1 / 35$ & Page 1 of 1 . \\
\hline TItIe: $\_$INSPECTION & Approved & Quallty Ases & nce Adminlatrator \\
\hline
\end{tabular}

To be added at a later date 


\begin{tabular}{|c|c|}
\hline TerraTek & Soction No. 11 Rovision B \\
\hline QUALITY ASSURANCE MANUAL & Effoctlve Dote_L $1 / 85$ \\
\hline & Approved $\mid i l \ldots$ \\
\hline Title: _ TEST CON & Quallity Acourance Adminletrato: \\
\hline
\end{tabular}

1.0 SCOPE

To establish the criterion for control of tests.

\subsection{GENERAL REQUIREMENTS}

\subsection{Test Procedures}

Test procedures shall be prepared by a cognizant engineer reviewed by an Engineer Supervisor and approved by the QAA, and made part of the QAP for each project. The test procedures shall address the following:
a) Objective (anticipated results).
b) Criteria for acceptance/rejection of test results.
c) Calibration requirements.
d) Personnel qualifications.
e) Documentation.
f) Review and certification.

\subsection{Responsibilities}

The assigned Test Group shall be responsible for the validity and documentation of all test procedures and data. 


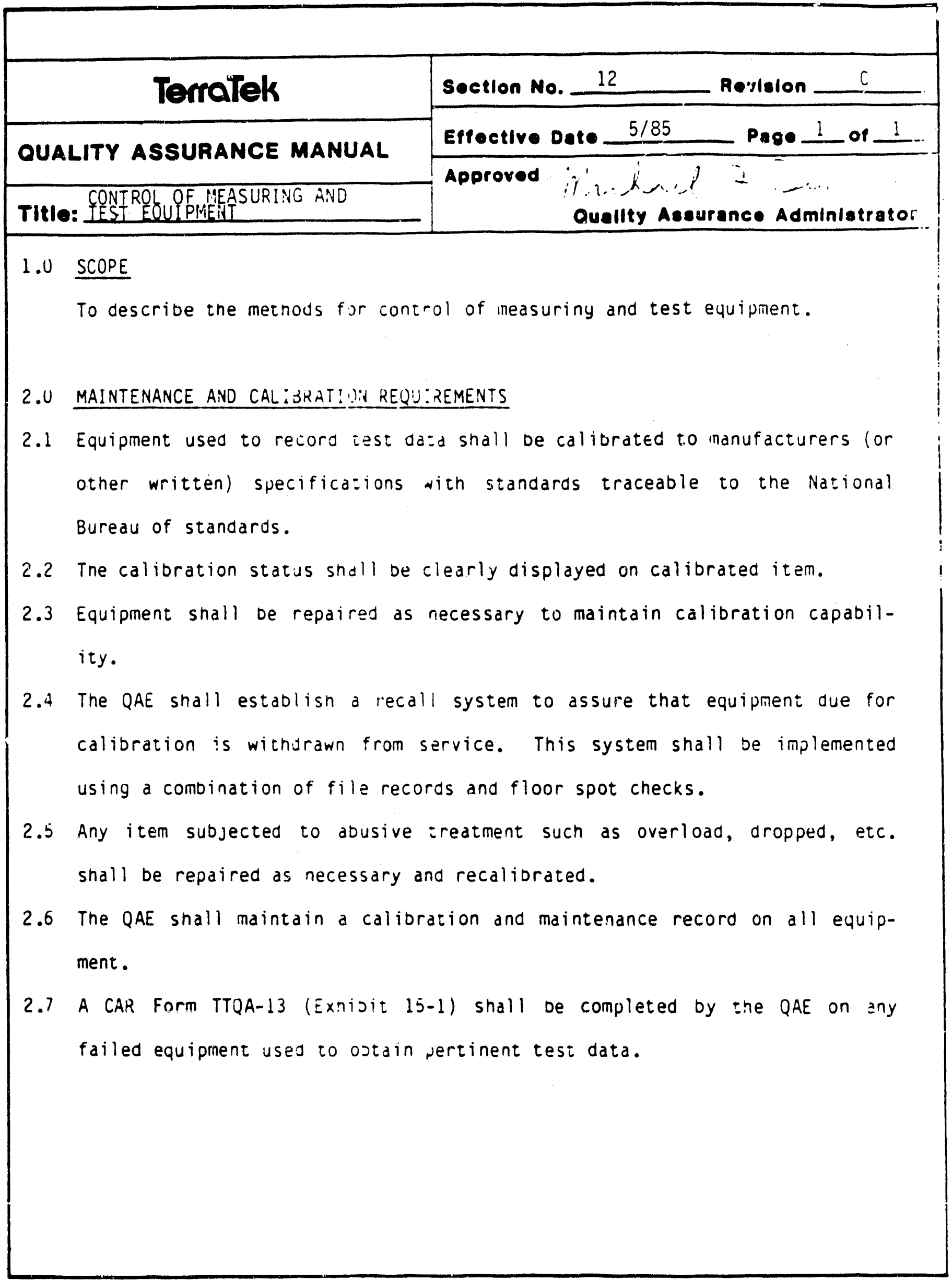




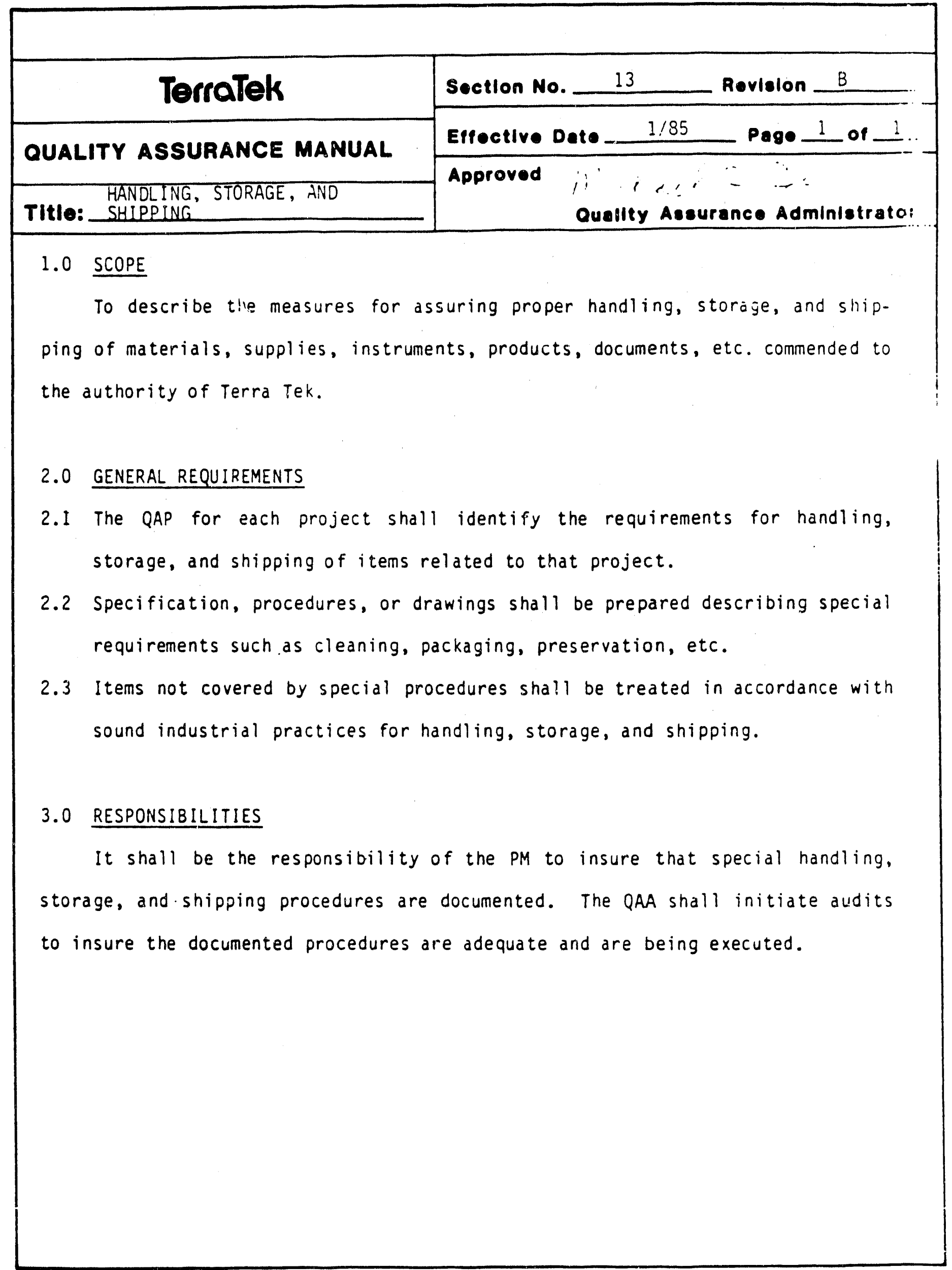




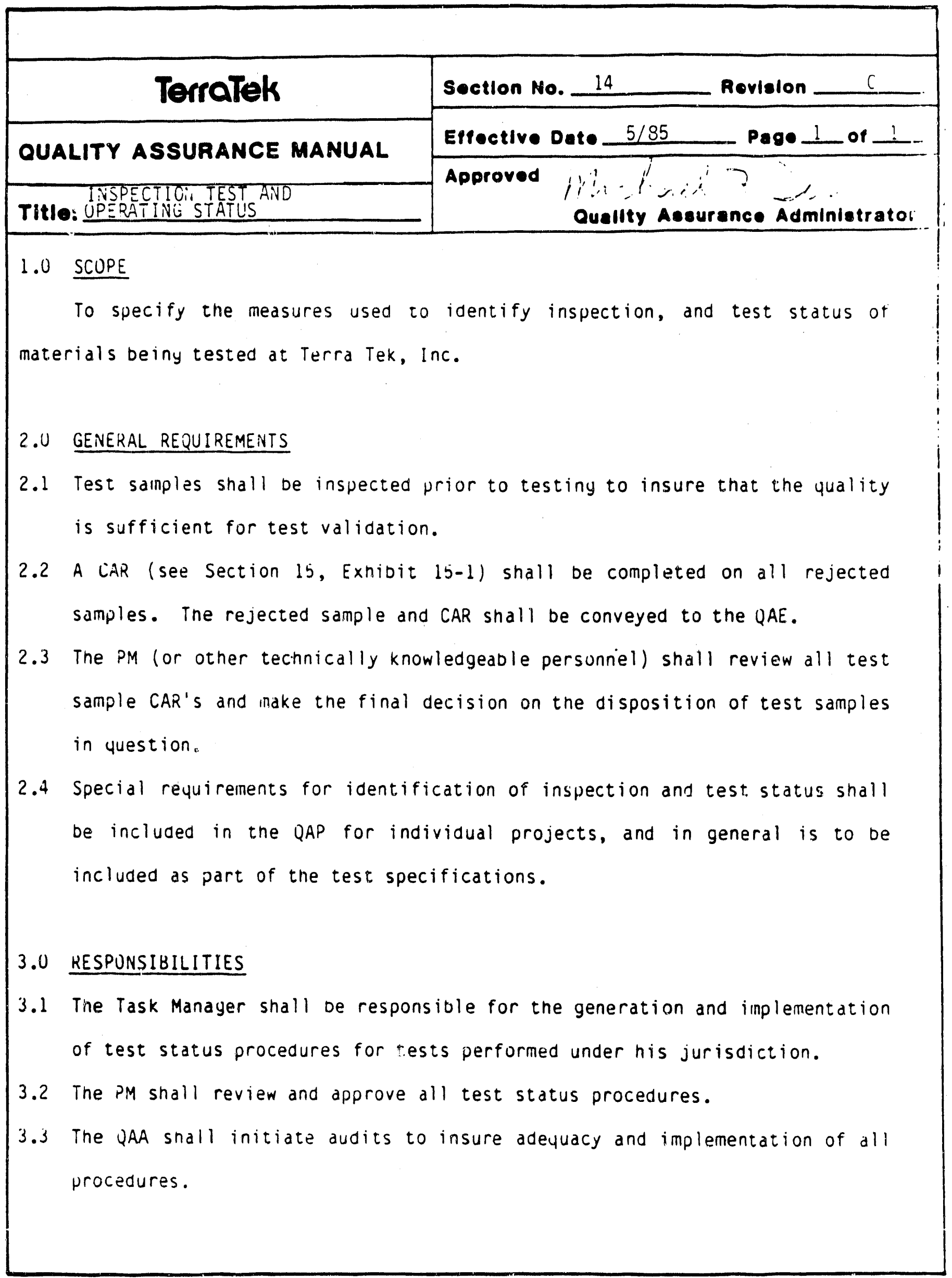




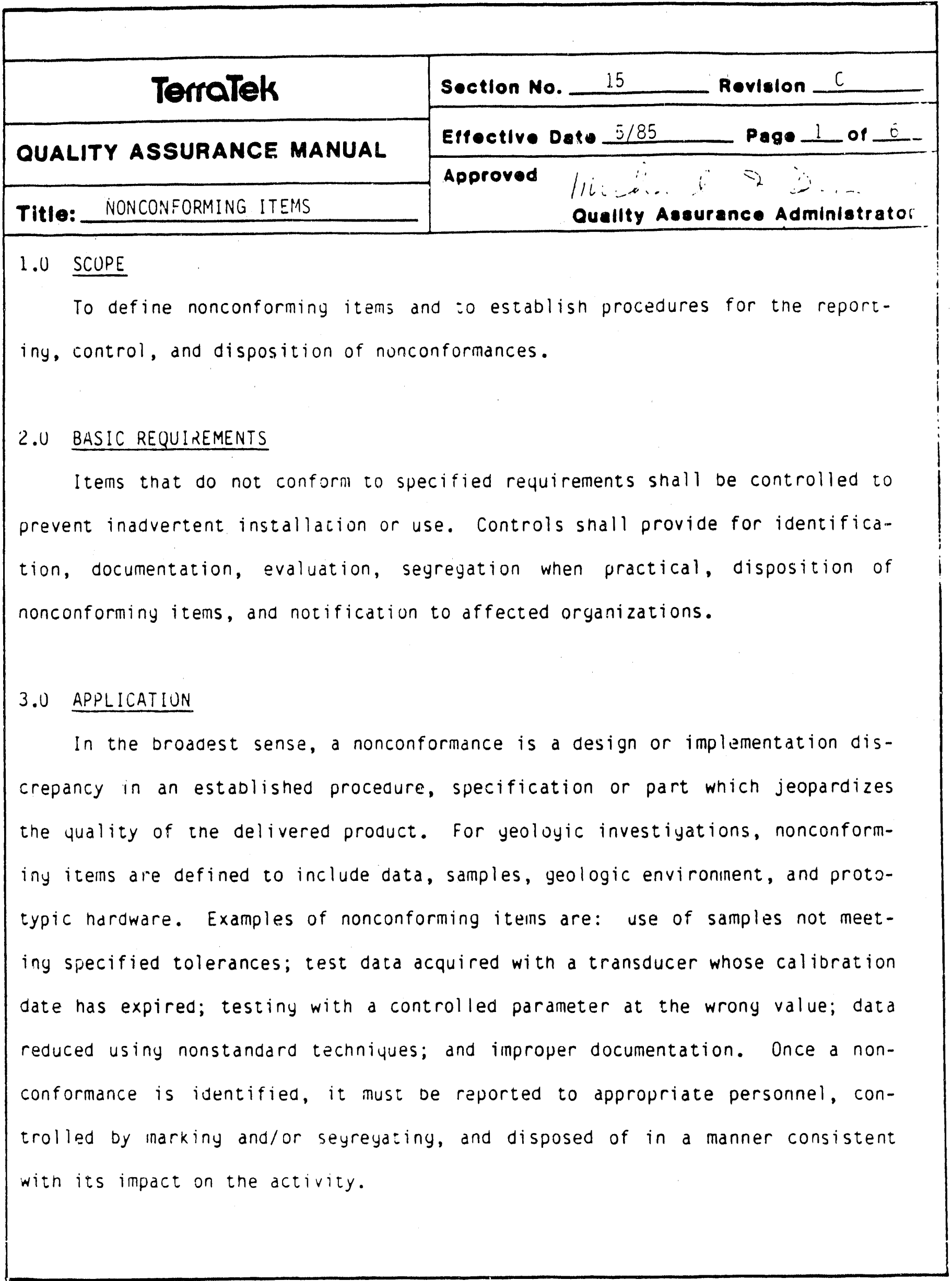




\section{TerraTek \\ QUALITY ASSURANCE MANUAL}

Title: NONCONFORMING ITEMS
Section No. Reviston

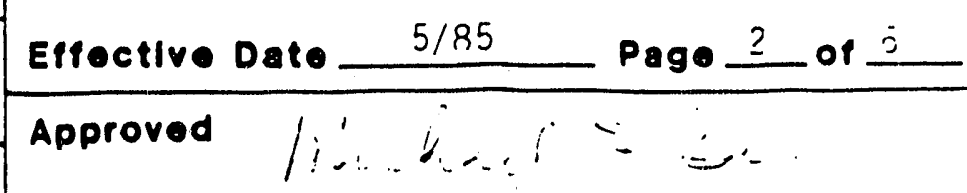

Guallty Assurance Administrator

\subsection{REPORTING OF NONCONFURMAIICES}

\subsection{Responsibility}

It shall de the responsibility of all project personnel to rapor: nonconforming items that are clearly in violdion of establisned procedures or sjecifications. Most nonconformances are found during the normal performance of work. Other common methods are throuyh audits, surveillances, peer reviews, inspections, statistical trends, and calibration activities.

\subsection{Procedure}

Nonconformances shall de reported by filling out a Nonconformancelincident and Corrective Action Report (CAR) form TTQA-13 (Exhidit 15-1). Tne paritally completed form shall be submitted to the QA Enyineer who loys the CAR and assigns it a number. The QAE in turn submits a copy of the CAR to ine associated Proyram Manayer for control and eventual disposition.

\section{U CUNTROL OF NUNCUNFURMING ITE.YS}

Nonconforming items snall de culitrolled to prevent their inadvertent use in subsequent activities. If use of the nonconforming item is absolu:ely critical to the proyrain, or if its impact is considered minimal, then use snall de permitted under controlled conditions pendiny evaluation and final diszosition. The QAE shall be responsiole for ideatification and storaye of the ites until disposition has been deterinines. 
Form TT(OA13) 4/85 ReV $B$

NONCONFORMANCE / INCIDENT AND CORRECTIVE ACTION REPORT

TO:

CAR

FROM:

Date:

Discrepant Condition:

Cause (If known)

Corrective Action, including action to prevent recurrence:

Comments by QA Representative: 


\begin{tabular}{|c|c|}
\hline Terratek & Soctlon No. 15 \\
\hline QUALITY ASSURANCE MANUAL & Eprective Date $5 / 85$ Page 4 _ of 6 \\
\hline NONCONFORIAING ITEMS & $\begin{array}{l}\text { i, lied a d } \\
\text { Quallty Assurance Administrator }\end{array}$ \\
\hline
\end{tabular}

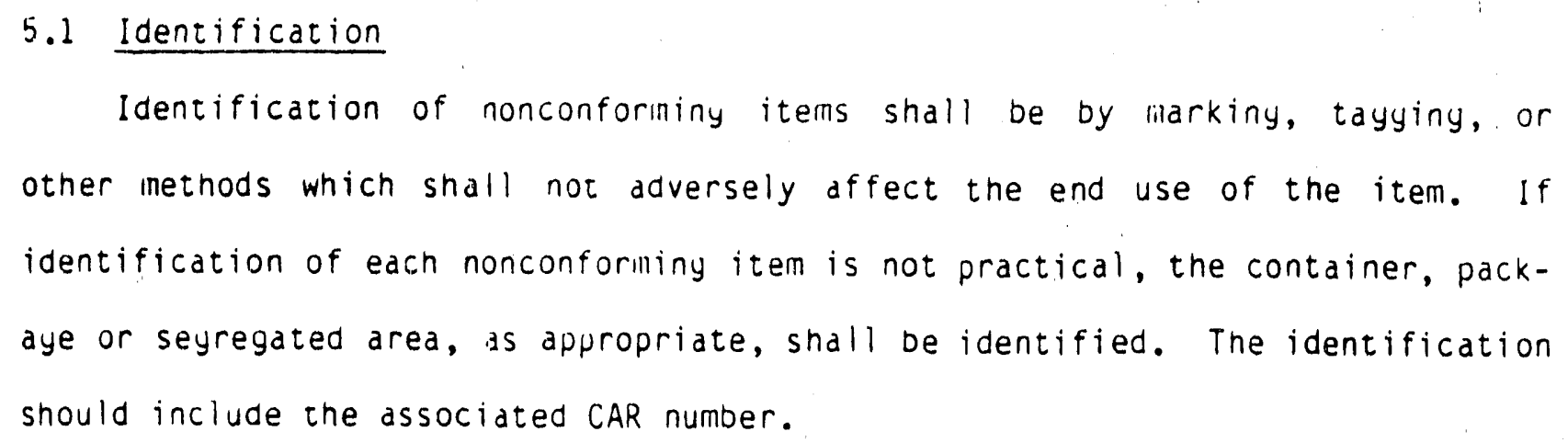

\section{j.2 Seyregation}

Nonconforminy items shall be sejreyated, when practical, by placiny them in a clearly identified and designated hold area until properly dispositioned. When seyregation is impractical or impossible due to physical conditions or access limitations, other precautions shall be employed to preclude inadvertent use of a nonconforming item.

6.0 UISPOSITION PROCEDURES

Nonconforminy characteristics of the item shall be reviewed and recommended dispositions shall be proposed and approved in accordance with procedures defined below.

\subsection{Responsibilitr}

The Program Manager shall have final authority for disposition of nonconforminy izems. Where significant impact to the proyram or validity of the data 


\begin{tabular}{|c|c|}
\hline Terratek & Soctlon No. 15 Rovislon $\quad C$ \\
\hline QUALITY ASSURANCE MANUAL & Effectlve Date $5 / 85$ Page 5 or 6 \\
\hline TItle: :IONCONFORMING ITEMS & $\begin{array}{l}\text { lic } \\
\text { Quallity Aseurance Adminietrator }\end{array}$ \\
\hline
\end{tabular}

is in question, approval from the Owner snall be required. Final disposition shall be coordinated by the QAA.

\subsection{Evaluation}

Personnel performiny evaluations to decermine a disposition shall have demonstrated competence in the specific area they are evaluating, have an adequate understanding of the requirements, and have access to pertinent background information. A peer review process shall be used, when justified, to assure technical adequacy of the evaluations.

\subsection{Final Disposition}

The final disposition, such as use-as-is, reject, repair, or rework, of nonconforming items shall be identified on the CAR. The technical justification for the acceptability of a nonconforming item, dispositioned repairirework, or use-as-is shall be documented on the CAR. The as-built records, if such records are required, shall reflect the accepted deviation.

\subsection{Repaired or Reworked Items}

Repaired or reworked items shall be reexamined in accordance with applicable procedures and with the original accepiance criteria unless the nonconforminy item disposition has estadished alternate crizeria. 


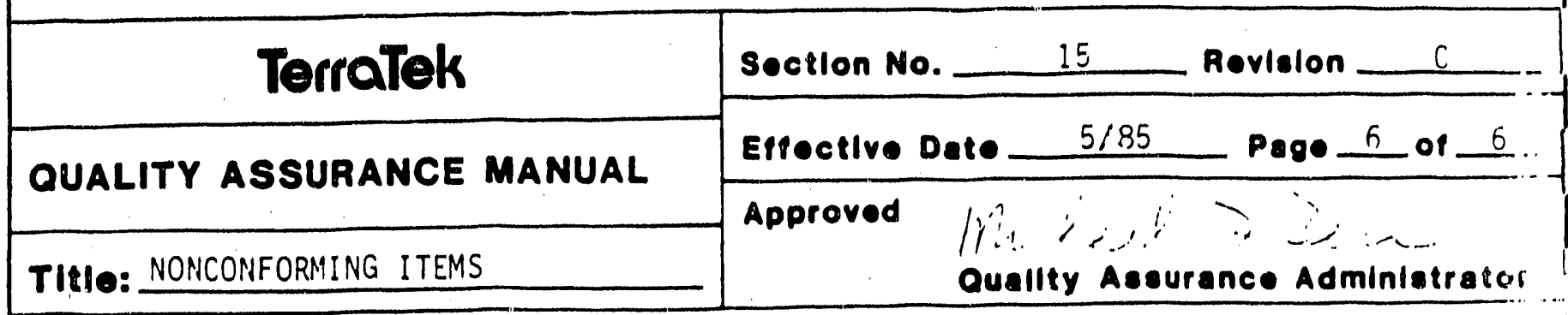

7.U DUCUMENTATIUN

Nonconforinance documentation shall consist of the completed CAR and Ioy maintained by the QAE. Completed CAR's she!l be filed in the central QA file. 


\begin{tabular}{|c|c|}
\hline Terratek & Soctlon No. 16 \\
\hline OUALITY ASSURANCE MANUAL & Effective Date $5 / 85$ Page 1 of 2 \\
\hline CORRECTIVE ACTION & $\begin{array}{l}\text { Helly Aasurance Adminletrator } \\
\text { Qualy }\end{array}$ \\
\hline
\end{tabular}

1.U SCUPE

To specify the requirements and establish Quality Assurance corrective dction procedures.

2.U GENERAL REQUIREMENTS

2.1 QA corrective action procedures shall provide:

a) Prompt identification and correction of conditions that may have an adverse effect on quality of services provided by Terra Tek, Inc.

b) Documentation on problem, cause, and action taken.

c) Follow-up measures to assess the effectveness of the corrective action taken.

2.2 The appropriate provisions of Section 15, "Nonconforming Items", and Section 18, "Audits" snall be considered part of the QA corrective action procedures.

2.3 The UAA is responsiole for the implementation of QA corrective action procedures, and shall initiate steps necessary to insure their effectiveness.

\subsection{PROCEDURES}

3.1 A Corrective Action Request (CAR, Exhibit 15-1) shall be initiated by any knowledyeable person who recoynizes a $Q A$ deficiency.

3.2 A "CAR", regardless of origin, shall be submitted to the OAE to be logyed and redistribused.

3.3 A "CAR" shall de iniziated on any unresolved nonconformance itan; refer to 


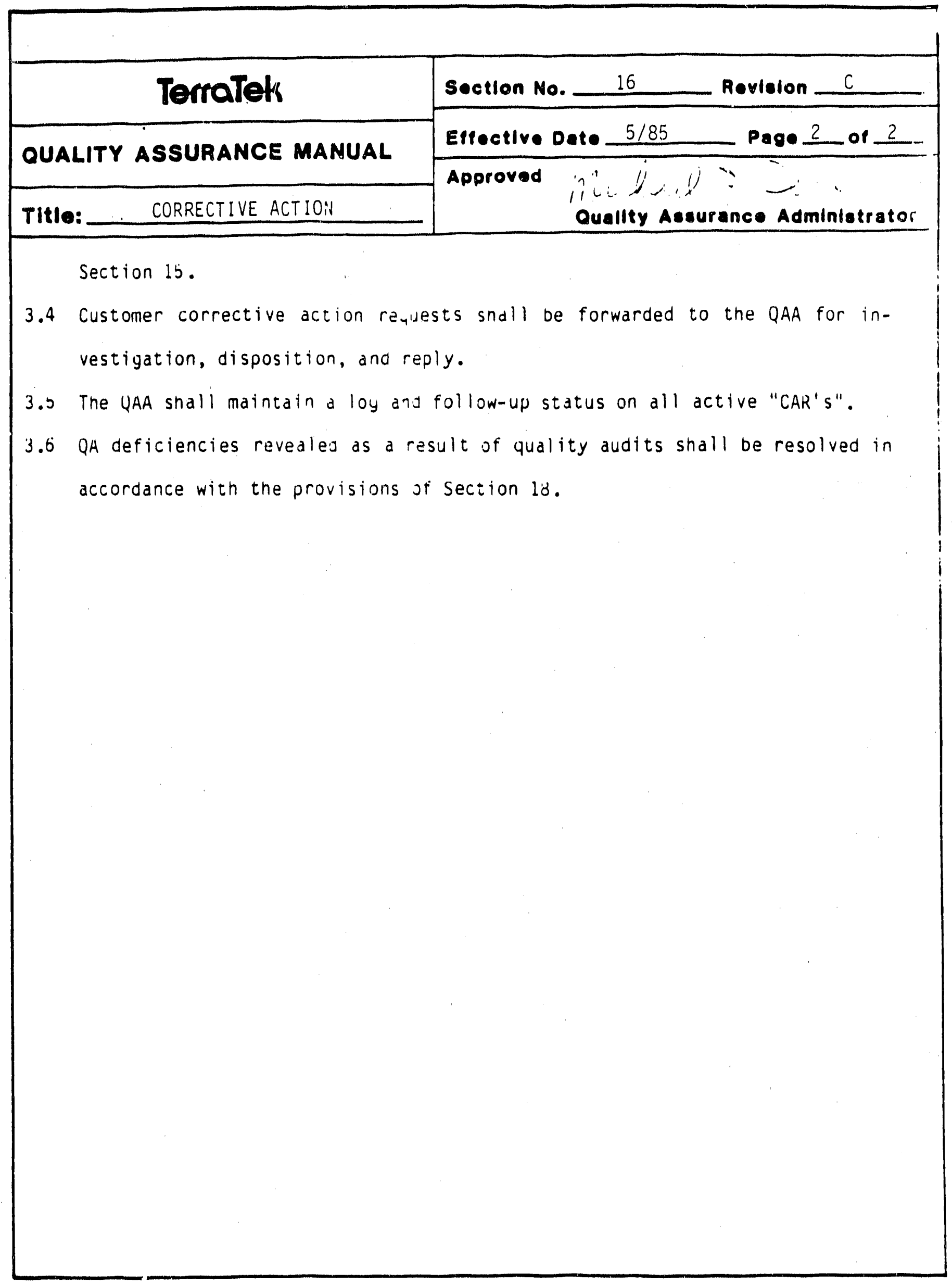

C. 68 


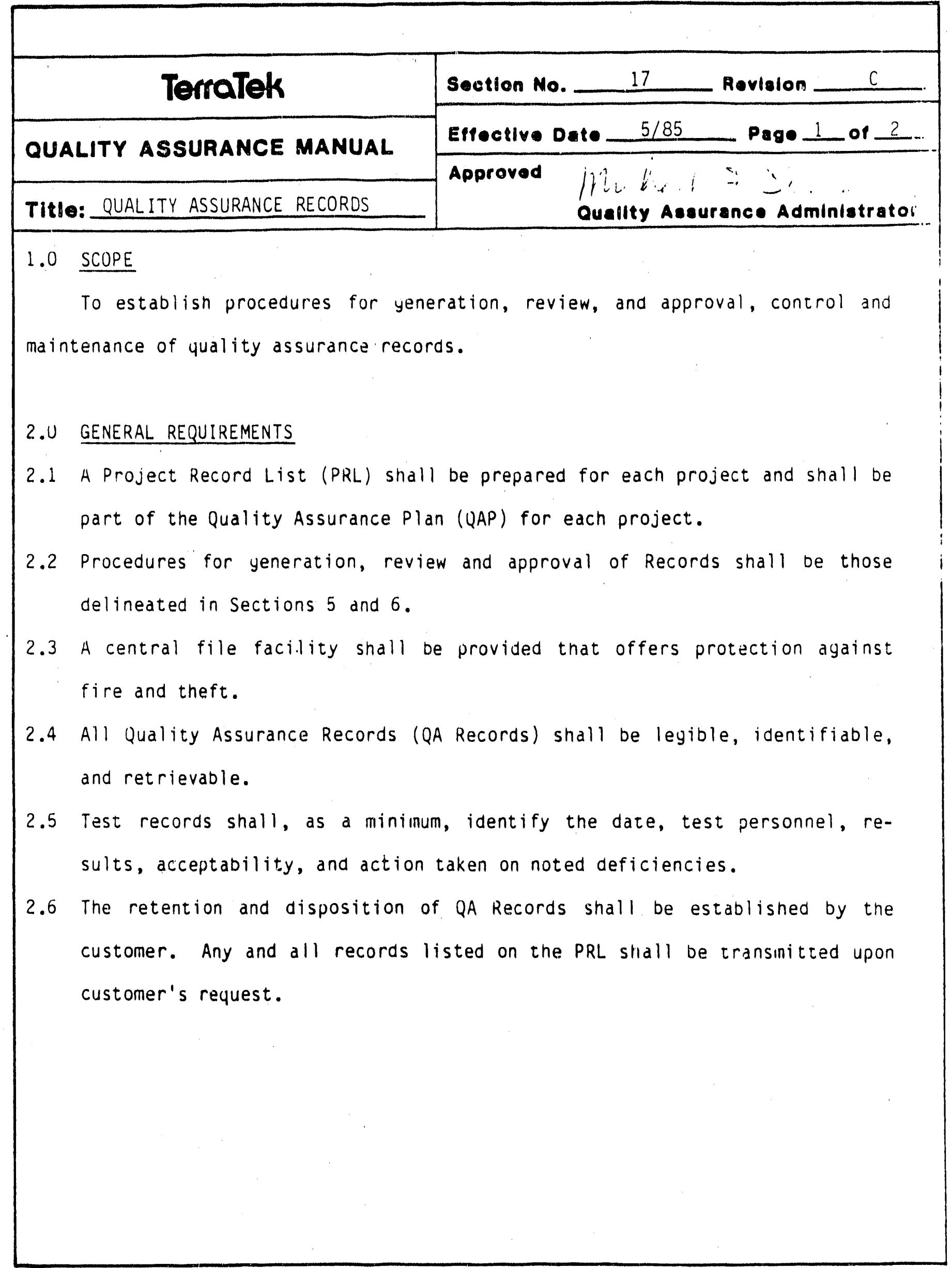




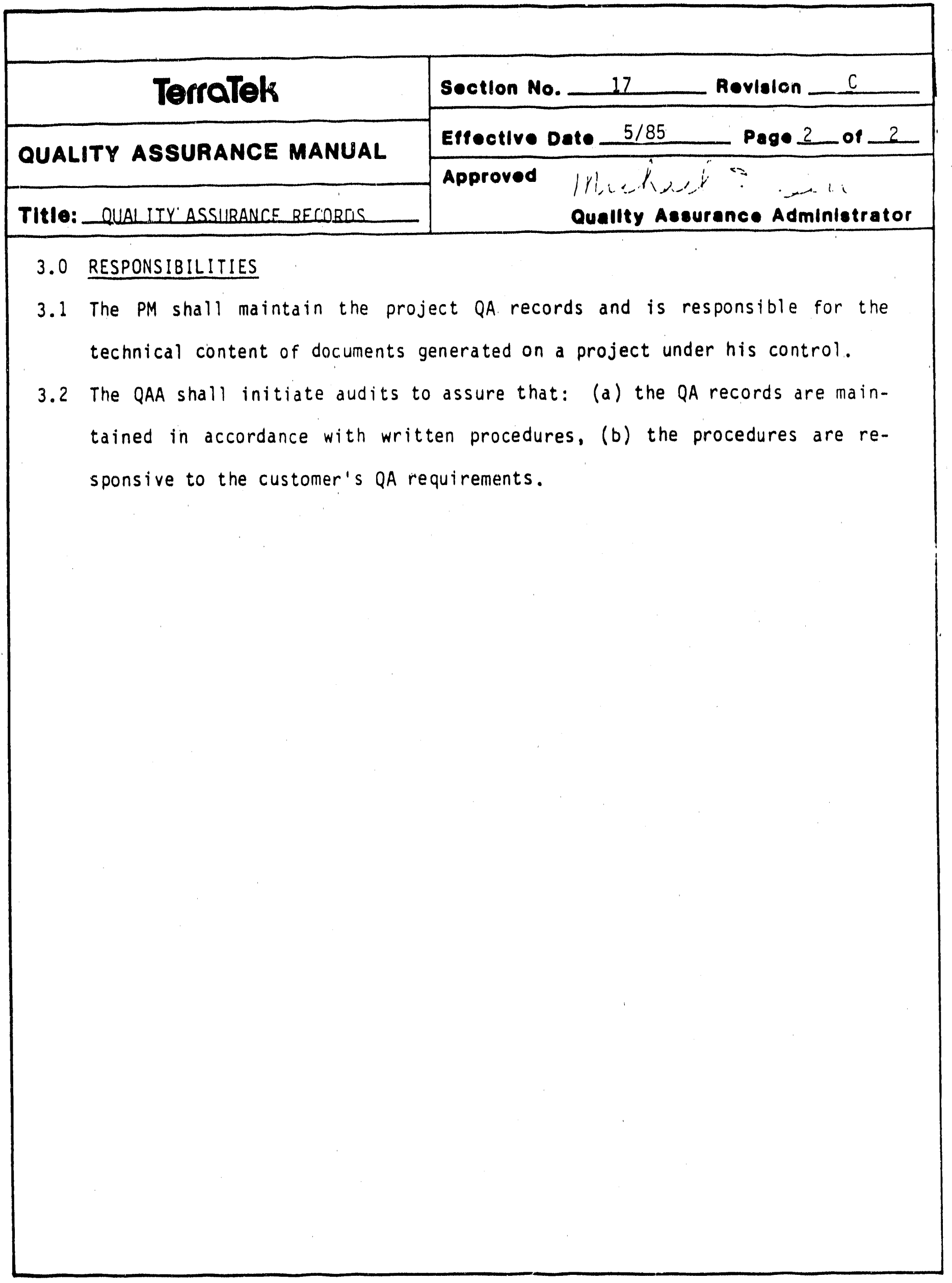

C-70 


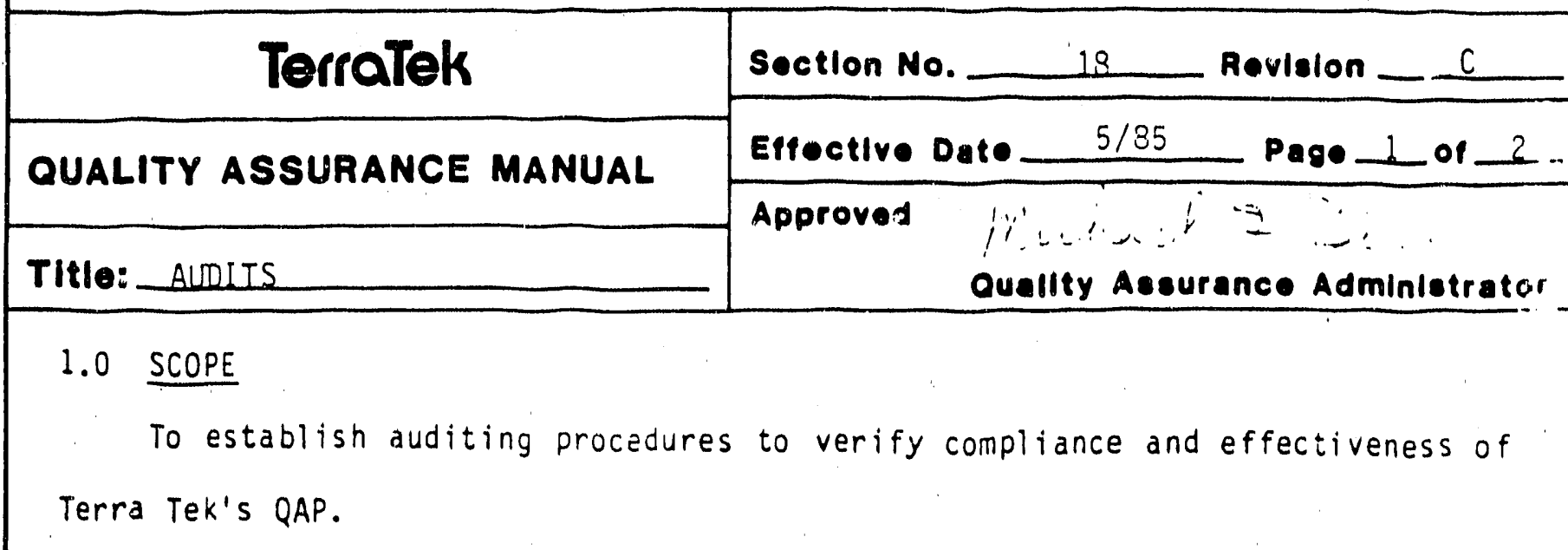

\subsection{GENERAL REQUIREMENTS}

Audits shall be performed to:

a) Provide an objective evaluation of compliance with established requirements, methods, and procedures.

b) Assess progress.

c) Determine adequacy of the QAP.

d) Verify implementation of recommended corrective action.

\subsection{PROCEDURES}

3.1 Audits shall be performed in accordance with written procedures or check lists.

3.2 Audits shall be conducted by the QAA or his designated representative.

3.3 Audit results shall be documented by the auditing personnel.

3.4 Audit reports shall be reviewed by management having responsibility in the area audited.

3.5 An Audit Schedule for each project shall be prepared and maintained by the QAA. The schedule may be periodic and/or keyed to project milestones.

3.6 Unscheduled audits are recommended when:

a) Significant changes are inade in the QAP. 


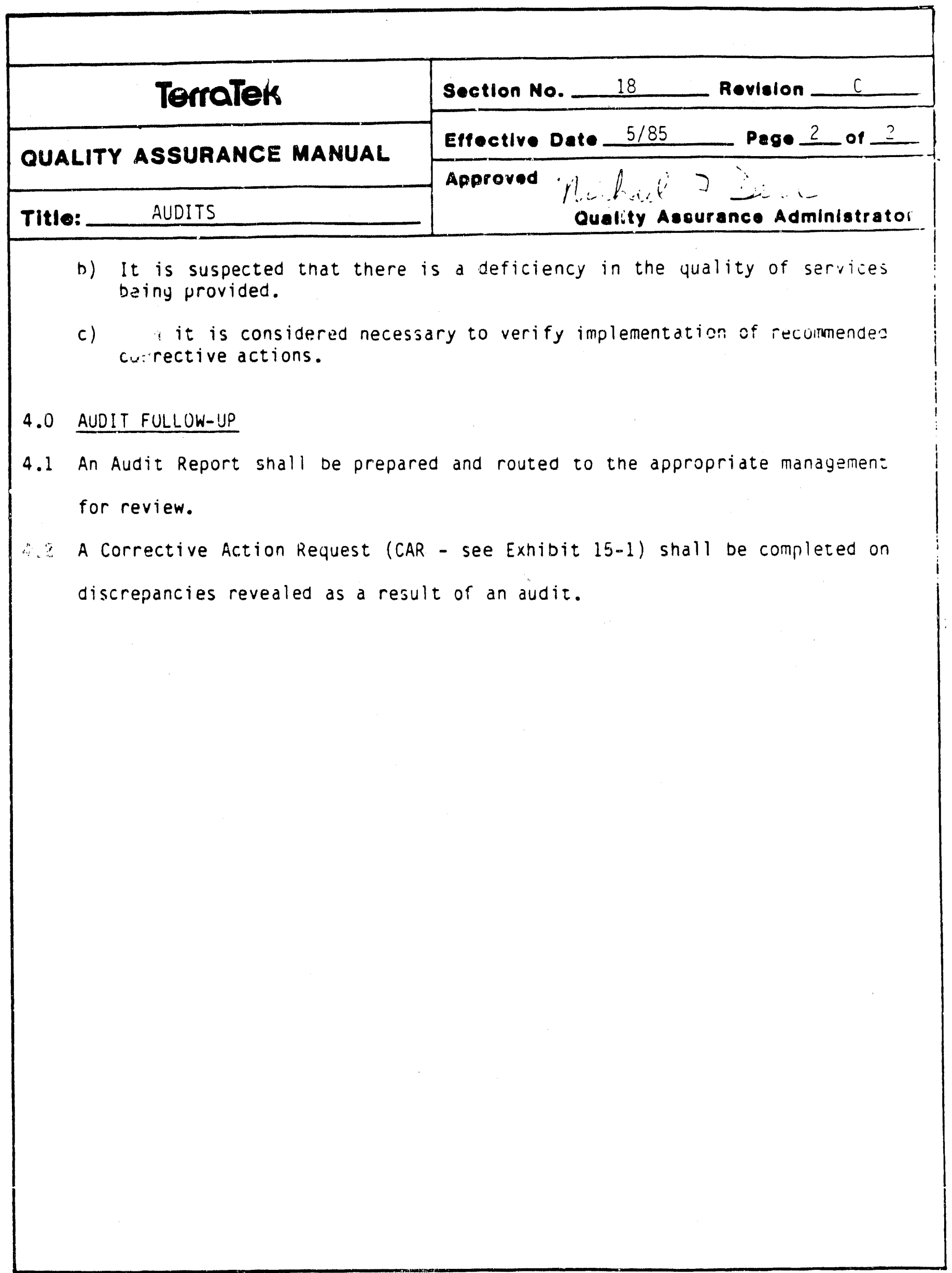


Acceptance Criteria: Specified limits slaced on characteristics of an item, process, ur service defined in cudes, standards, or other requirement documents.

Audit: A planned and docunented activity performed to determine by investiyation, examination, or evaluation of odjective evidence the adeuuacy of anc compliance witn establisned procedures, instructions, drawings, and other applicable documents, and ine effectiveness of implementation. An audit should not be confused with surveillance or inspection activities performea for the sole purpose of process control or product acceptance.

Certificate of Conforinance: A document signed by an authorized individual certifying the deyree to which items or services meet specified requirements.

Certification: The act of decermining, veritying, and attesting in writing to the qualifications of personnel, processes, procedures, or items in accordance with specified requirements.

Cnaracteristic: Any property or attribute of an item, process, or service that is distinct, describade, and measurade.

Condition Adverse to Quality: An all inclusive term used in reference to any of the following: failures, malfunctions, deficiencies, defective items, and nunconformances. A significant condition adverse to quality is one which, if uncorrected, could have a serious effect on safety or operability.

Corrective Action: Measures taken to rectify conditions adverse to qualizy and, where necessary, to preclude repetition.

Desiyn Inuut: Those criteria, paraneters, bases, or other design requirements upon which detailed final design is based.

Design Output: Documents, such ds drawinys, specifications, and other documents, defining technical requirements of structures, systems, and components.

Desiyn Process: Technical and inanayement processes that commerice with identification of design input and that lead to and include the issuance of design output documents.

Deviation: A departure tron specified reyuirements.

bocumen:: Any written or pictorial informacion describing, netining, specifyiny, reportiny, or certifyiny activities, requirements, procedures, or results. A document is not considered to De a Quality Assurance Record until it satisfies the definition of a Uuality Assurance Recora as defined in this Supplement.

External Audit: An audit of thuse porsions of another oryanization's gulality assurance proyram not under the direct control or witnin the oryanizational structure of the auditiny uryanization. 
Final Design: Approved design output documents and dpproved cnanyes thereto.

Guideline: A suggested practice that is not mandatury in proyranis intended to comply with a standara. The word should denotes a yuideline; the word shall denotes a requirement.

Inspector: A person who periorms inspection activities to verity conforinance to specific requirements.

Insuection: Examination or medsurement to verify whether an item or activity conforms to specified requirements.

Internal Audit: An audit of those portions of an organization's quality assurance prograin retained under its direct control and within its oryanizational structure.

Itern: An all inclusive terin used in place of any of the following: appurtenance, assembly, component, equipment, material, module, part, structure, subassembly, sudsystem, system, or unit.

Measuriny and Test Equipment ( $M \& T E$ ): Devices or systems used to calibrate, measure, gaye, tesi, or inspect in order to control or to acquire data to verify conformance to specified reyuirements.

Nonconformance: A deficiency in cnaracteristic, documentation, or procedure that renders the quality of an item or activity unacceptable or indeterminate.

Objective Evidence: Any documented statement of fact, other informat; on, or record, eitner quantitative or qualitative, pertaining to the quality of an item or activity, based on observations, measurements, or tests which can be verified.

Uwner: The person, group, company, ayency, or corporation who has or will have tisle to the final product.

Procedure: A document that specifies or describes how an activity is to be performed.

Procurement Docuinent: Purchase requisitions, purchase orders, drawinys, contracts, specifications, or instructions used to define requirements for purchase.

Purchaser: The oryanization responsible for establishment of procurement requirements and for issuance, administration, or both, of procurement docuinents.

Qualification (Personnel): The characteristics or doilities gained through education, training, or experience, ds measured against established requireinents, such as standaras or tests, that qualify an individual to perform a requires funcion.

Qualified Procedures: in dpproved procedure that has Deen demonstrated to meet the specified requirements for its intended purpose. 
Quality Assurance (QA): All chose planned and systematic actions necessary to provide adequate confidence that a structure, system, or component will perform satisfactorily in service. For yeoloyic investigations, all chose planned and systematic actions necessary to provide adeyuate confidence that data are valid, nave integrity, and are preserves and retrievable.

Quality Assurance Record: A completed document that furnisnes evidence of the quality of items and/or activities affecting quality.

Receiving: Taking delivery of an item at a designated locazion.

Repair: The process of restoring a nonconforming characteristic to a condition such that the capability of an item to function reliably and safely is unimpaired, even though that item still does not conform to the oriyinal requirement.

Rework: The process by which an item is made to conform to oriyinal requirements by completion or correction.

Riyht of Access: The right of a Purcnaser or designated representative to enter the premises of a Supplier for the purpose of inspection, surveillance, or quality assurance audit.

Service: The performance of activities such as design, fabrication, inspection, nondestructive examination, repair, or installation.

Special Process: A process, the results of which are nighly dependent on the control of the process or the skill of the operators, or both, and in which the specified quality cannot be readily determined by inspection or test of the product.

Supplier: Any inaiviacal or oryanization who furnishes items or services in accordance with a procurement document. An all inclusive term used in place of any of the following: vendor, seller, contractor, subcontractor, fabricator, consultant, and their subtier levels.

Surveillance: The act of monitoring or observing to verify whether an item or activity corforms to specified requirements.

Testing: An element of verification for the determination of the capability of an item to meet specified requirements by subjecting the item to a set of physical, chemical, environnental, or operating conditions.

Traceability: The ability to trace the history, application, or location of an irem ana like items or activities by means of recorded identification.

Use-as-is: A disposition perinitred for a nonconforming item when it can be estadished that ine item is satisfactory for its incended use.

Verification: The act of reviewiny, inspecting, testing, cnecking, auditing, or otnerwise determininy and documentiny whether items, processes, services, or documen:s conform to specified requirements.

Waiver: Jocumenizd autorization to depart from specified requirements. 
APPENDIX D

K \& A LABORATORIES REPORT

$$
\text { D-1/D-2 }
$$


Intera Technologies, Inc.

Final Results of High

Pressure Mercury Injection

Capillary Pressure Tests

D-3 
Intera Technologies, Inc. 6850 Austin Center Blvd. Suite 300 Austin, Texas 78731

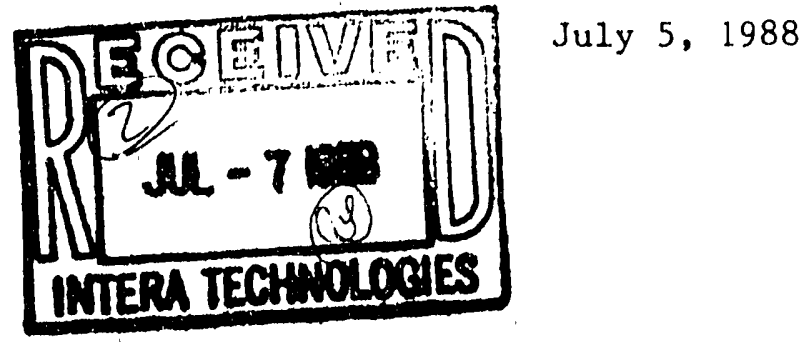

Attention: $\mathrm{Mr}$. Van Kelley

Re: Revised Final Report: Mercury Injection Capillary Pressure Tests Job Number 88-1056-14

Gentlemen:

This report presents the revised final results of the high pressure mercury injection captllary pressure tests performed on core samples supplied by Intera Technologies, Inc. These tests indicated a final mercury saturation ranging from 66.7 to 100.0 and averaged 95.4 percent pore volume. Although Sample No. 10 showed a lower final mercury saturation, 66.7 percent pore volume, it does correlate to the lower air permeablifty of the sample. Sample No. 10A, an endpiece of this same sample was also tested. These results showed a higher final mercury saturation of 95.2 percent pore volume, however note that the air permeability in Sample No. 10A is significantly higher than the original test sample. These differences may suggest a heterogeneous distribution of pore throat sizes within this core sample. Final results also yielded a mean pore throat diameter (at 30,000 psi injection pressure) of $0.00717 \mu \mathrm{m}$ using a a1r/mercury contact angle of $140^{\circ}$. As requested, pore surface area summaries (appendix 1), plus additional tabular pore size data (appendix 2) have been included in this report. The test procedures used are described below.

Following trimming of this samples to the required one-inch length, the samples were placed in a vacuum for 24 hours and then stored in a dessicator. Air permeabilities and porosities were then measured on the dried core samples. Mercury was then injected into each sample using pressures that ranged from 0.5 psia to 30,000 psia. Note Sample No. 10A was injected to a pressure of 20,000 psia. Pore throat size histograms were calculated from these results, using the cypical contact angle and surface tension for histogram $I$, and for histogram II, a surface tension of 360 dynes/cm and a contact angle cf $180^{\circ}$ was used. Capillary pressure relationships were also calculated from these data. Final results are presented in graphical and tabular form.

$$
\mathrm{D}-4
$$


Intera Technologies, Inc.

Page 2

The conditions under which this report is presented are described immediately following this report. We request that the report be used in its entirety if reproductions are to be made. Please contact us if you have any questions concerning these data, or if we nlay be of further service.

Respectfully submitted,

$K$ \& A LABORATORIES

JMC : ch

\section{FK \& At Laboratoures}


SUMMARY OF HIGH PRESSURE MERCURY INJECTION TEST RESULTS

INTERA TECHNOLOGIES, INC.

\begin{tabular}{|c|c|c|c|c|}
\hline $\begin{array}{l}\text { Sample } \\
\text { Number }\end{array}$ & $\begin{array}{c}\text { Identification } \\
\text { Number } \\
\end{array}$ & $\begin{array}{l}\text { Porosity, } \\
\text { Percent } \\
\end{array}$ & $\begin{array}{c}\text { Alr } \\
\text { Permeability, } \\
\text { md }\end{array}$ & $\begin{array}{c}\text { Endpoint } \\
\text { Mercury Saturation } \\
\text { @ } 30,000 \text { psi, Percent }\end{array}$ \\
\hline 1 & $\mathrm{H} 2 \mathrm{~A}-2$ & 12.5 & 0.143 & 88.5 \\
\hline 2 & H 2 B $1-2$ & 14.8 & 1.18 & 99.7 \\
\hline 3 & $\mathrm{H} 5 \mathrm{~B} 1-1 \mathrm{a}$ & 13.0 & 0.042 & 95.0 \\
\hline 4 & $\mathrm{H} 5 \mathrm{~B} 1-1 \mathrm{~b}$ & 15.5 & 0.069 & 95.3 \\
\hline 5 & $\mathrm{H} 7 \mathrm{~B} 1-2 \mathrm{a}$ & 21.5 & 0.108 & 91.6 \\
\hline 6 & $\mathrm{H} 7 \mathrm{Bl}-2 \mathrm{~b}$ & 27.8 & 0.521 & 99.5 \\
\hline 7 & H7 B $2-1$ & 17.3 & 0.294 & 96.5 \\
\hline 8 & $\mathrm{H} 7 \mathrm{C}-1 \mathrm{~b}$ & 16.5 & 0.074 & 94.8 \\
\hline 9 & $\mathrm{H} 7 \mathrm{C}-1 \mathrm{a}$ & 13.4 & 0.098 & 98.9 \\
\hline 10 & $\mathrm{H} 1 \mathrm{OB}-1$ & 10.8 & 0.012 & 66.7 \\
\hline $10 \mathrm{~A}$ & $\mathrm{H} 10 \mathrm{~B}-1$ & 9.0 & 0.174 & 95.2 \\
\hline 11 & H $11-2$ & 11.0 & 0.038 & 93.3 \\
\hline 12 & H11B3-1 & 33.1 & 1.33 & 99.9 \\
\hline 13 & H1 1B 3-4 & 14.8 & 0.186 & 99.9 \\
\hline 14 & $w-12-1 a$ & 2.8 & 0.270 & 98.2 \\
\hline 15 & $\mathrm{~W}-121 \mathrm{bl}$ & 11.2 & 0.086 & 99.9 \\
\hline 16 & $W-12-2$ & 13.6 & 1.38 & 99.4 \\
\hline 17 & $w-13-3 a$ & 19.0 & 4.94 & 97.5 \\
\hline 18 & $W-13-3 b$ & 9.7 & 0.037 & 99.6 \\
\hline 19 & $W-26-3$ & 12.5 & 0.039 & 99.9 \\
\hline 20 & $W-28-1 a$ & 14.2 & 0.033 & 95.3 \\
\hline 21 & $W-28-1 b$ & 13.0 & 0.038 & 93.8 \\
\hline 22 & $W-30-3 a$ & 17.6 & 9.68 & 99.8 \\
\hline 23 & $w-30-3 b$ & 15.8 & 3.48 & 91.6 \\
\hline 24 & $W-30-4$ & 25.4 & 18.6 & 96.3 \\
\hline
\end{tabular}


$\mathrm{K} \& \mathrm{~A}$

Page 3 of 81

LABORATORIES

File $88-1056-14$

MERCURY INJECTION TEST RESULTS

INTERA TECHNOLOGIES, INC.

SAMPLE NUMBER 1

Air Permeability $=0.143 \mathrm{md}$

Porosity $=12.5 \%$

\section{0,000}

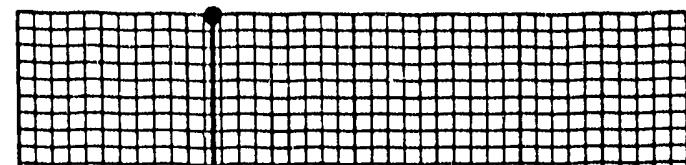

27,000

24,000

21,000

$\pi$

点 18,000

(

离

of 15,000

学

क

동

出 12,000

$=$

-

9,000

உஉ

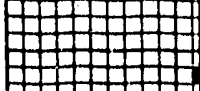

ஜ平地

帅

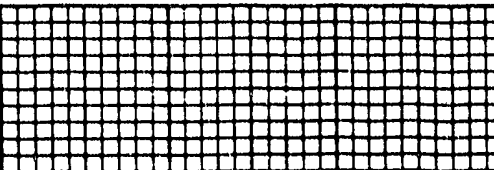

\

'



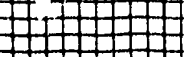

$\underbrace{2}$

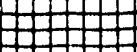

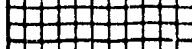

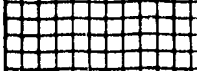

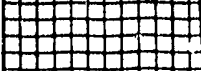

进俥

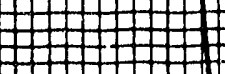

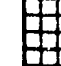

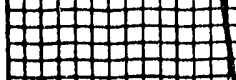

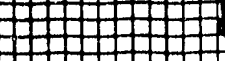

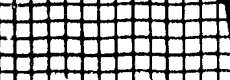

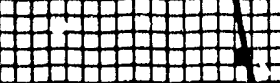

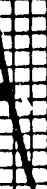

6,000

ஜ

Ð

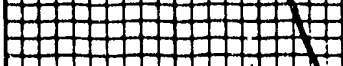

3,000
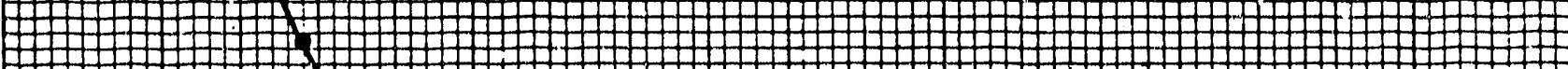

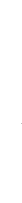

E

0

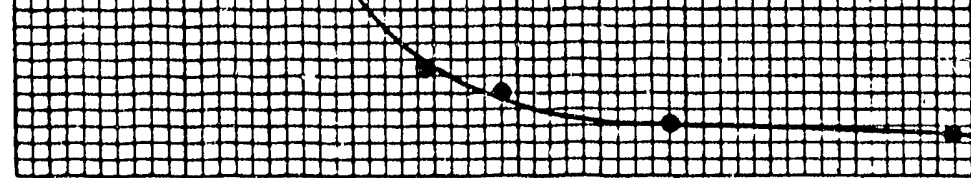

100

90

80

Mercury Saturation, Percent Pore Volume

D-7 

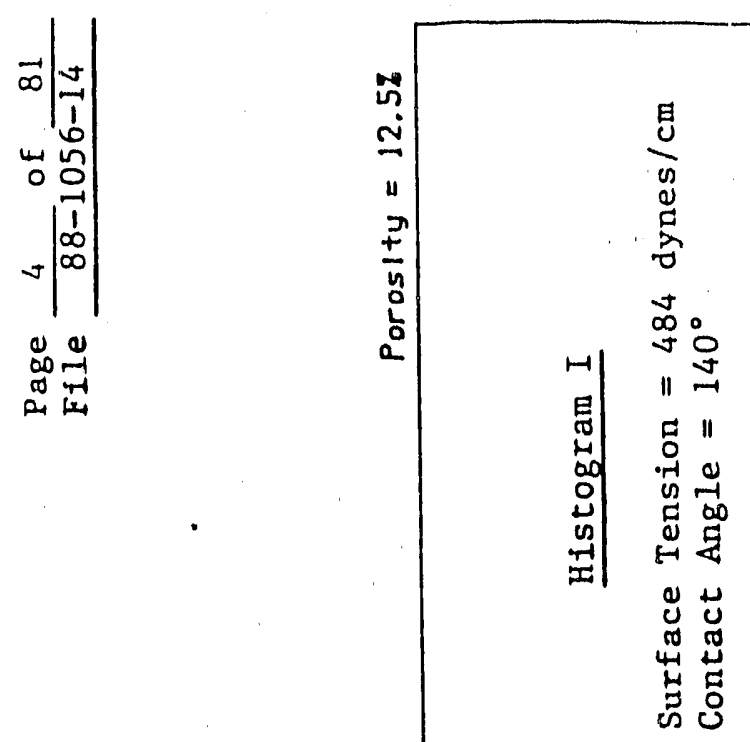

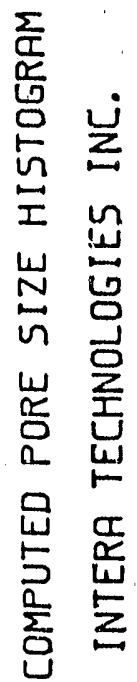
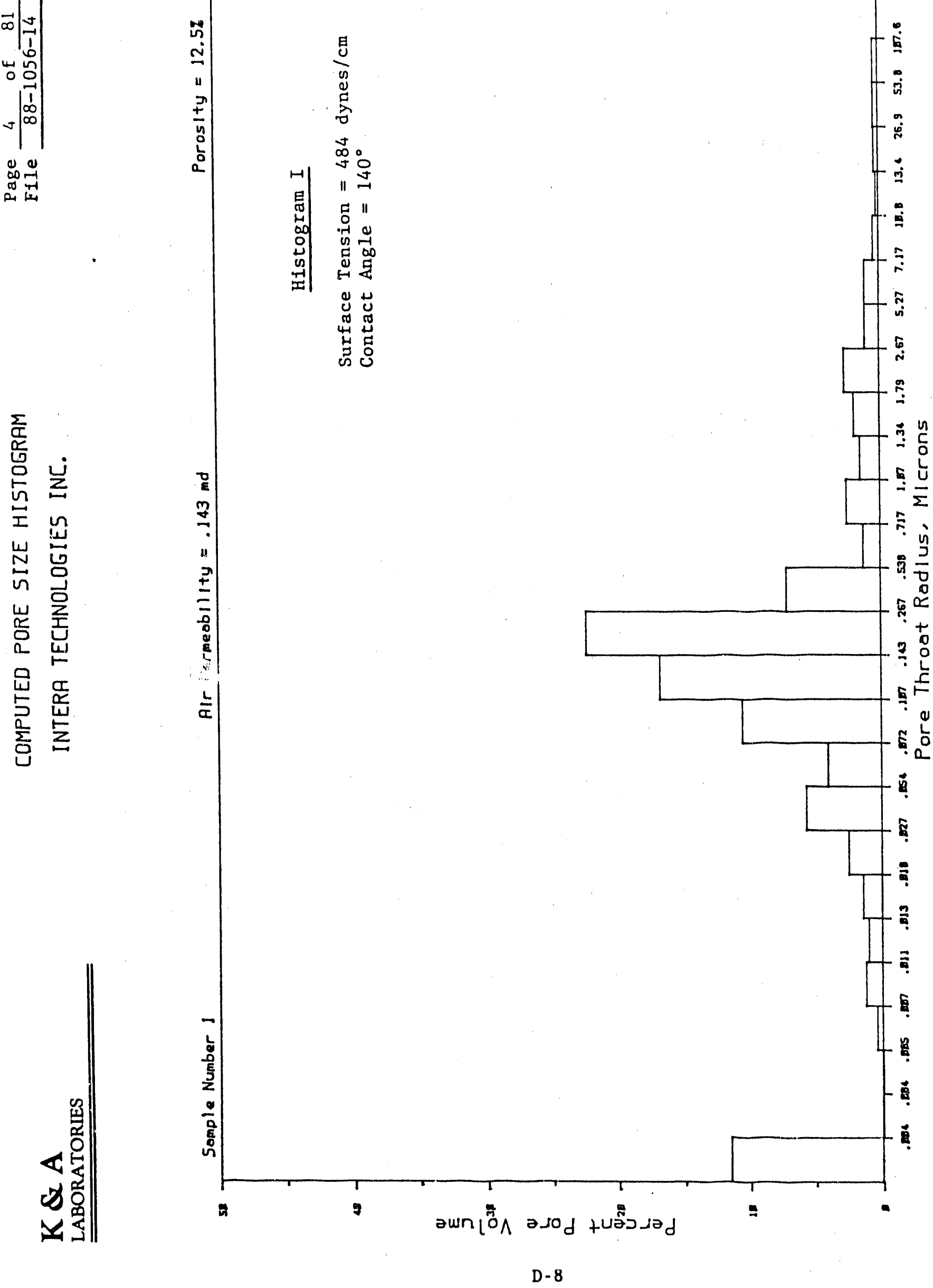


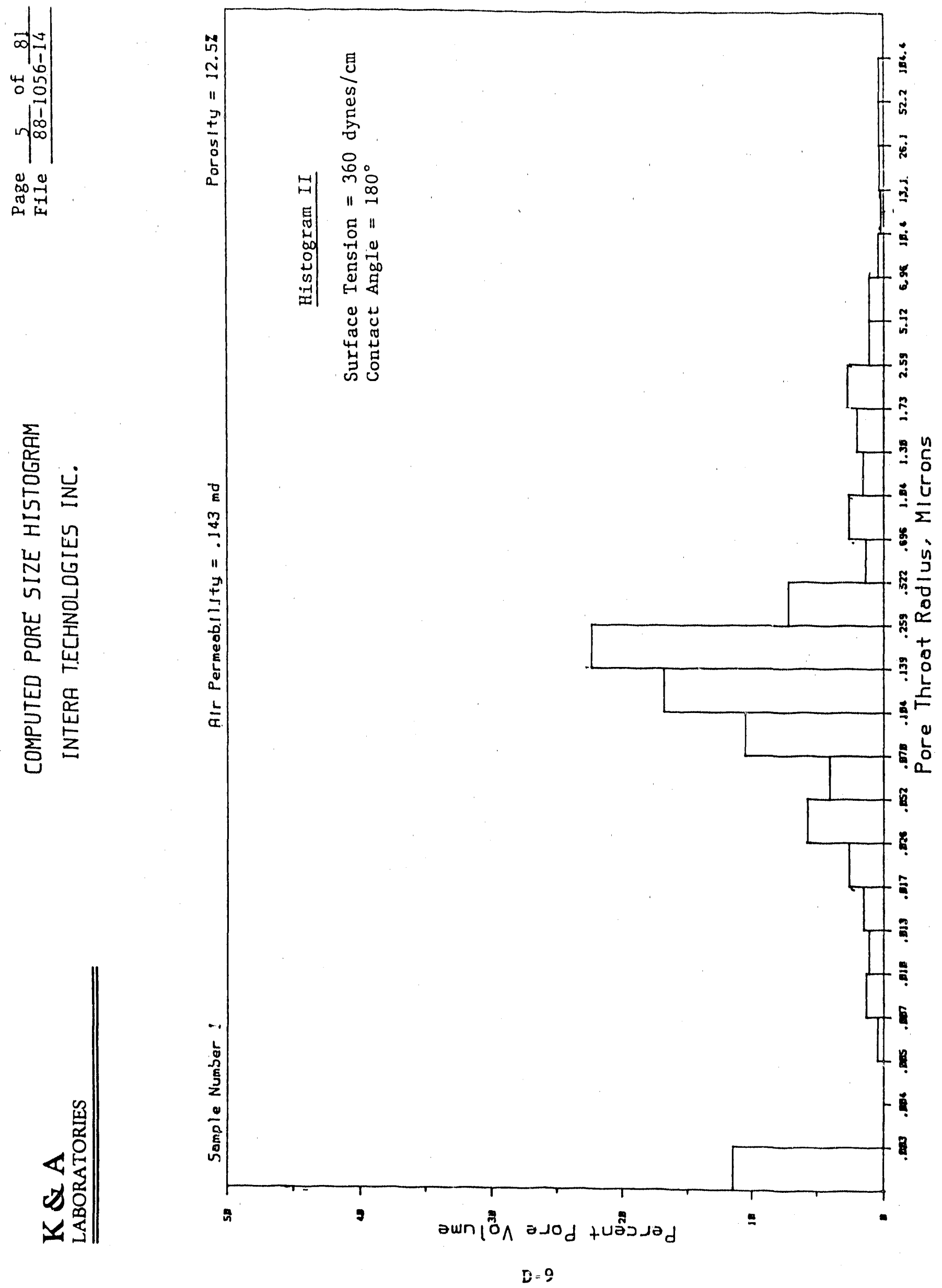


MERCURY INJECTION TEST RESULTS

INTERA TECHNOLOGIES, INC.

SAMPLE NUMBER 2

Air Permeability $=1.18 \mathrm{md}$

Porosity $=14.8 \%$

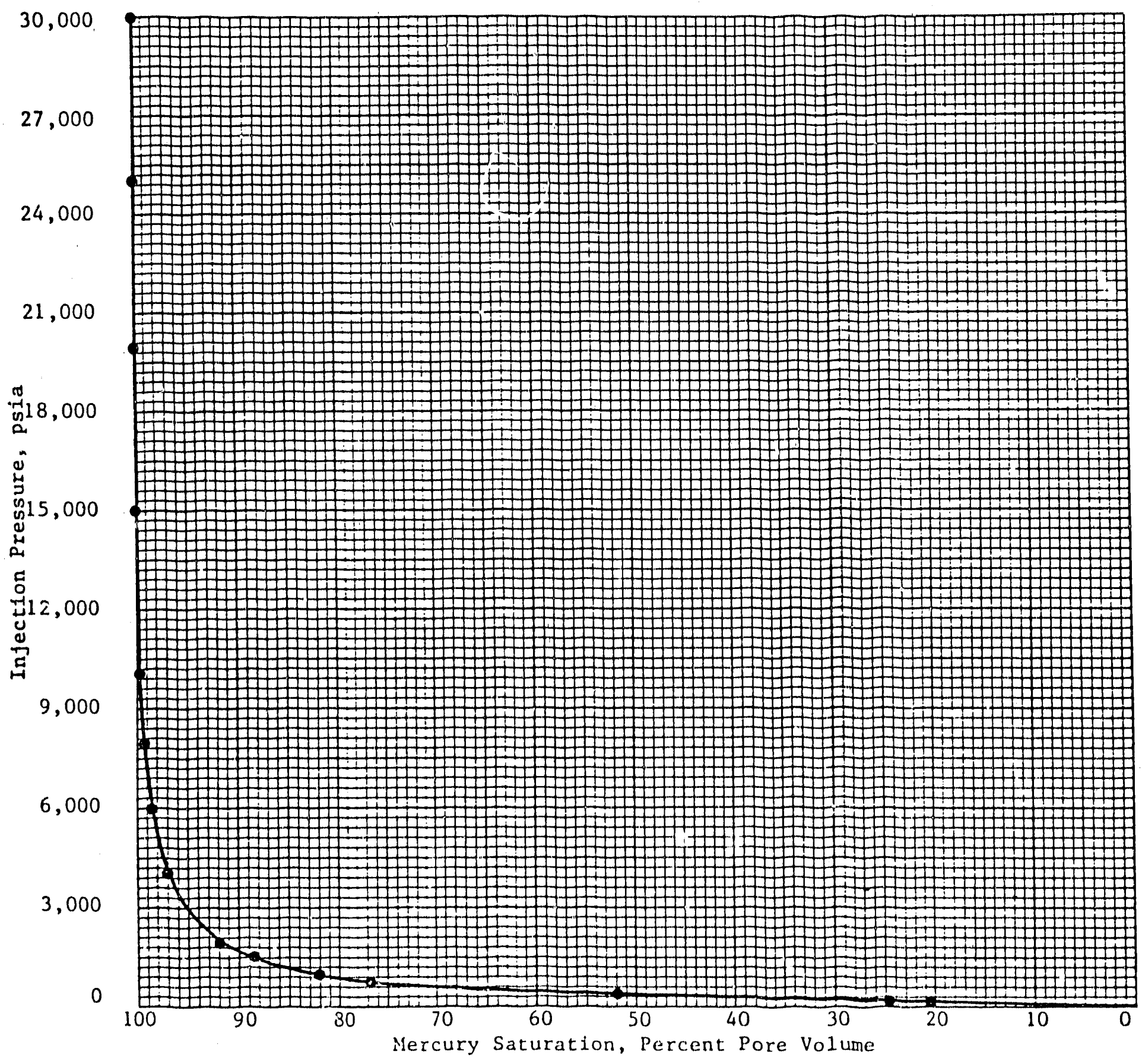

D-10 


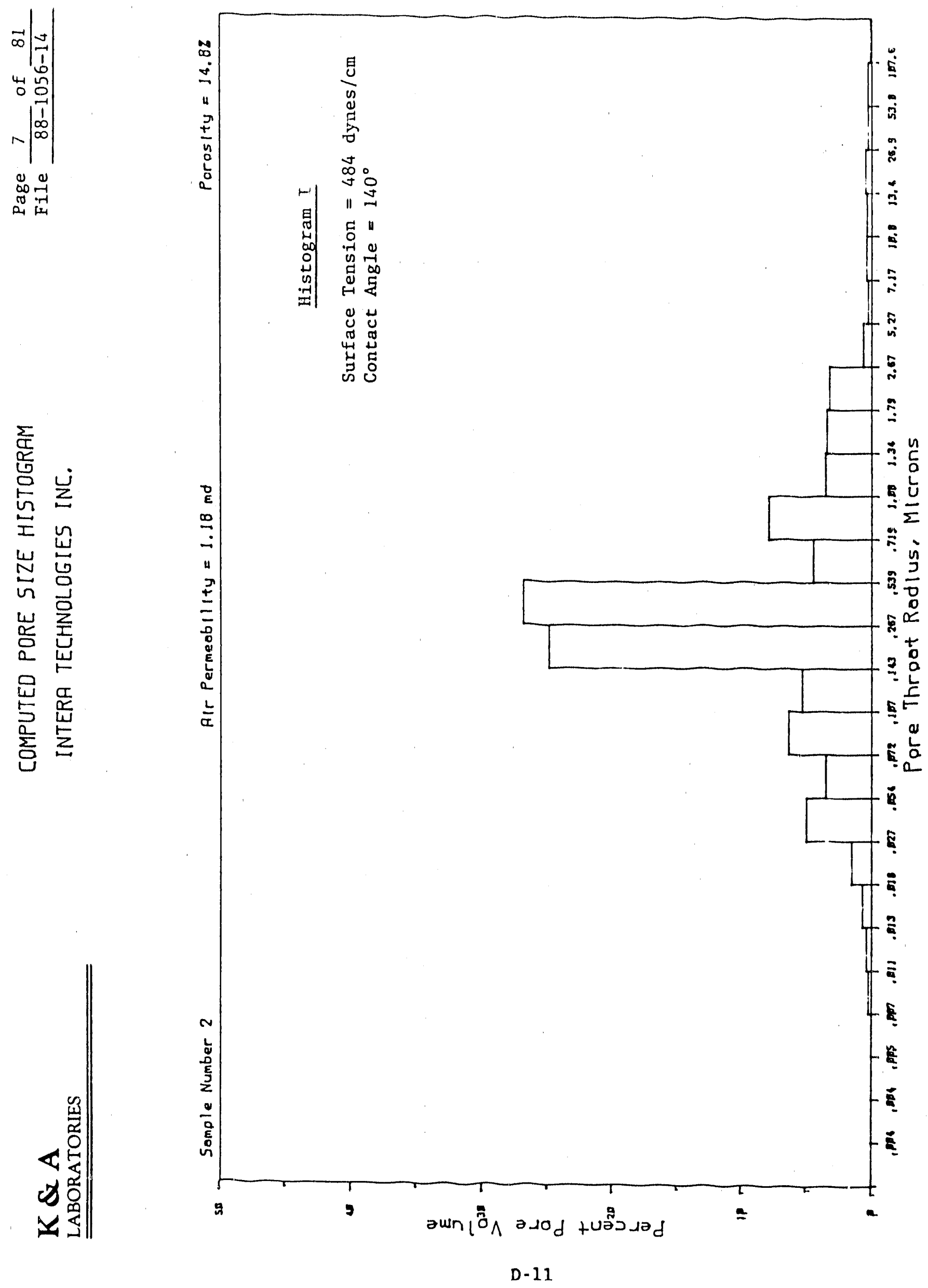



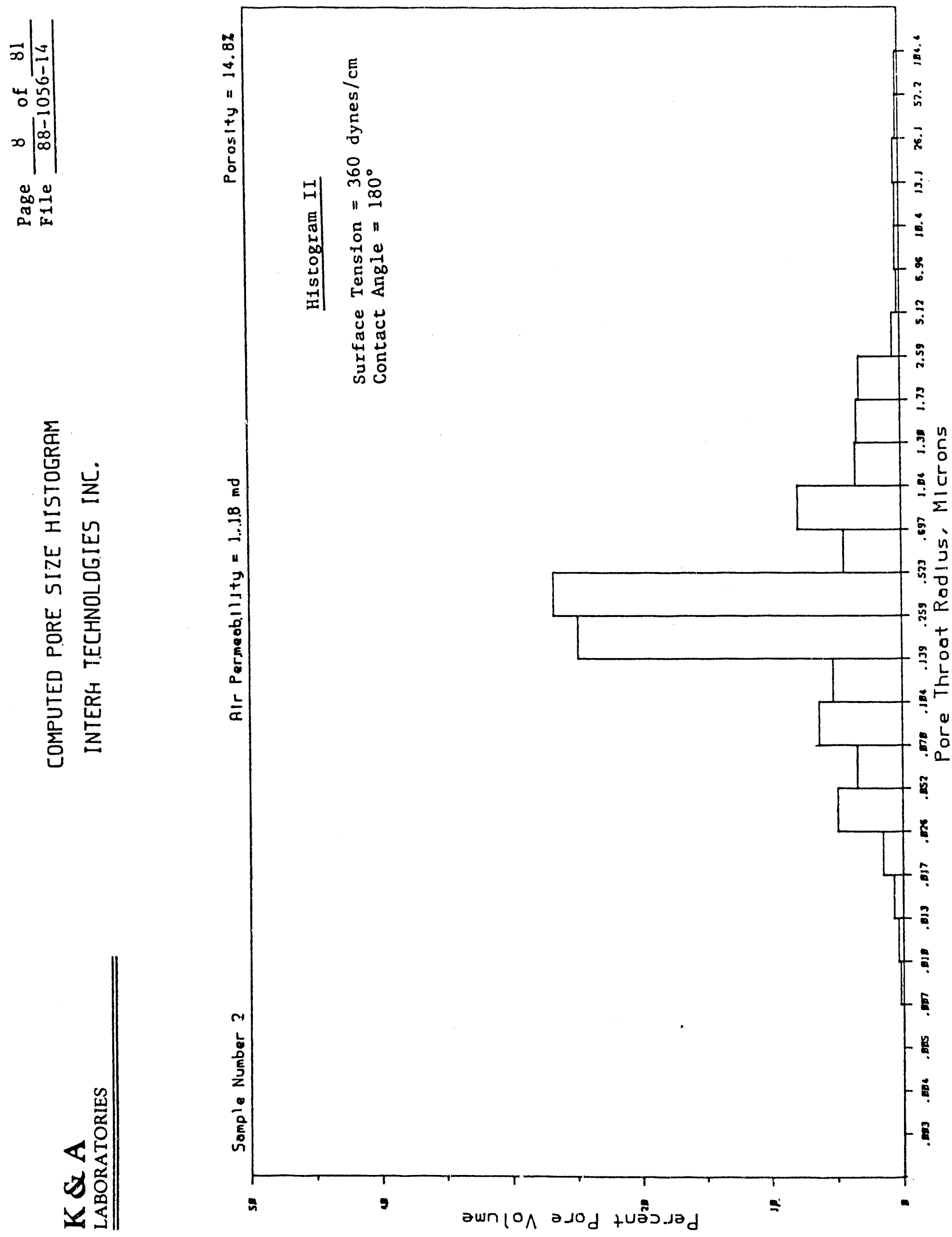

D -12 
Page 9 of 81

File $88-1056-14$

MERCURY INJECTION TEST RESULTS

INTERA TECHNOLOGIES, INC.

SAMPLE NUMBER 3

Air Permeability $=0.042 \mathrm{md}$

Porosity $=13.0 \%$

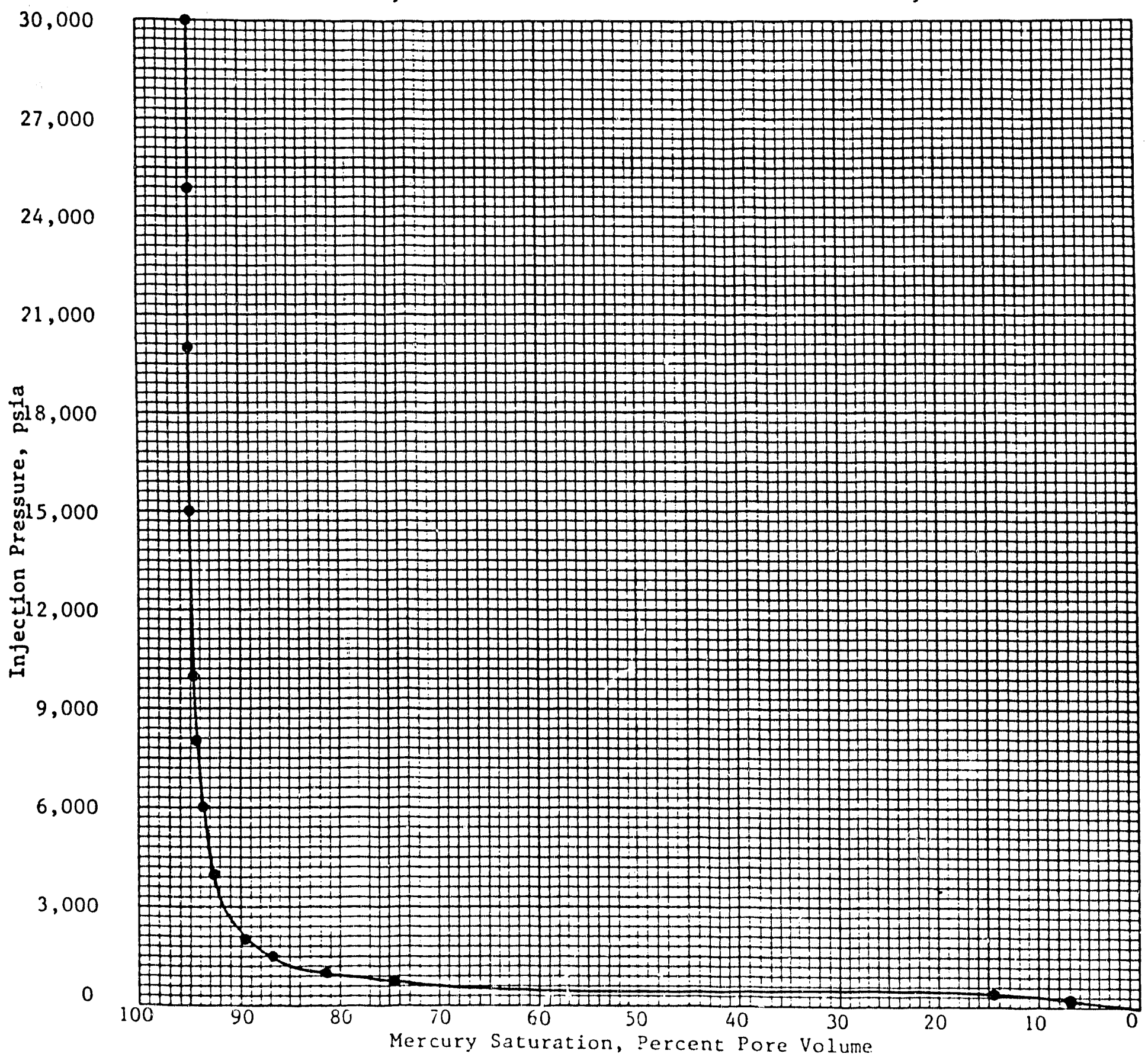

$\overline{\mathbf{D}}-\overline{1} \overline{3}$ 


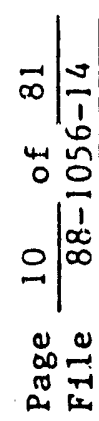

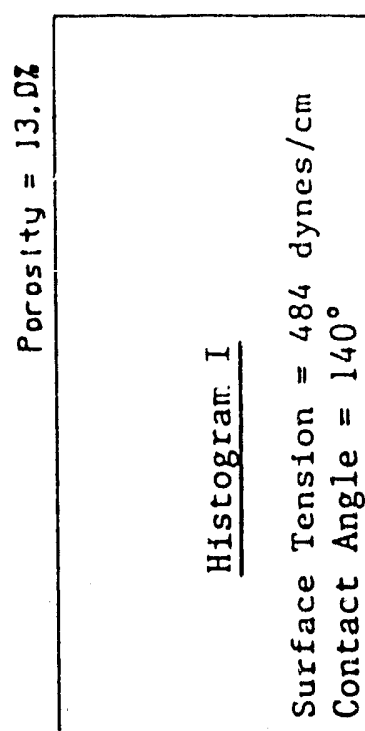

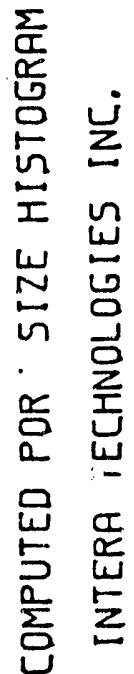

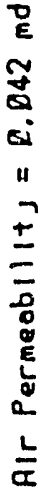

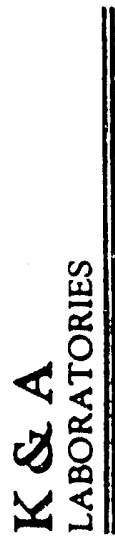

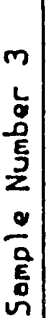

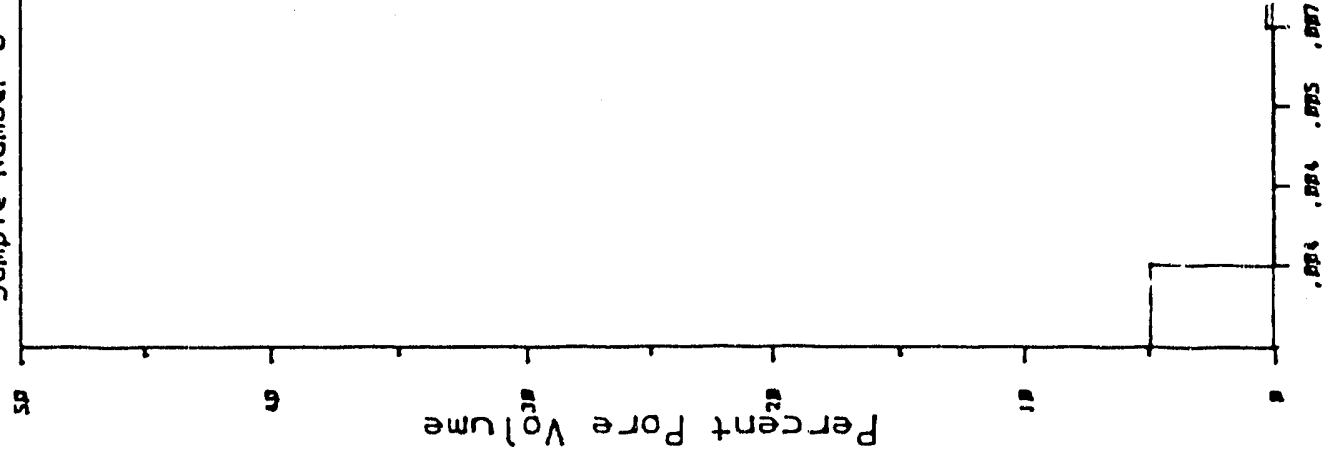

D-14 


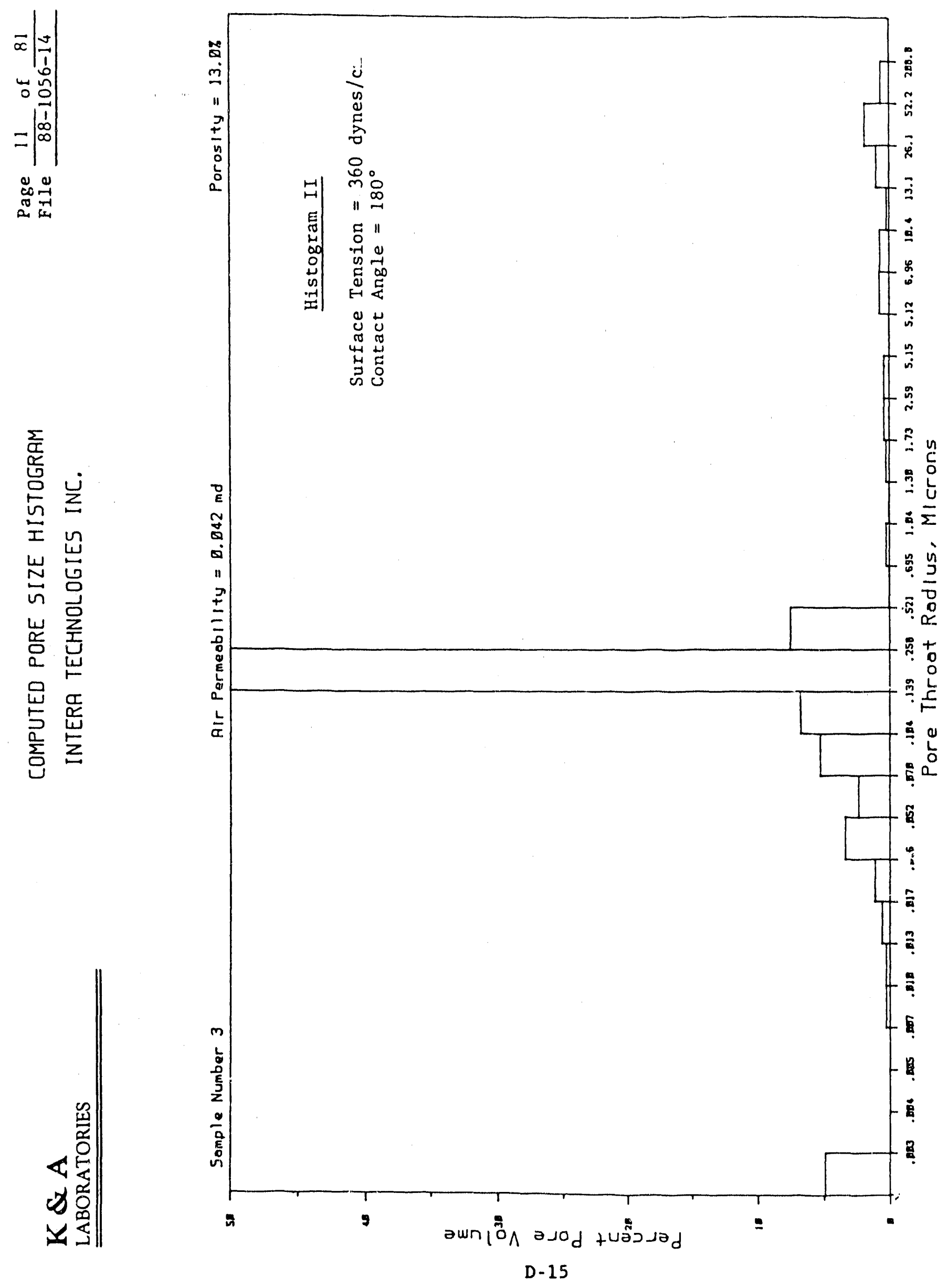


$\mathrm{K} \& \mathrm{~A}$

LABORATORIES
Page 12 of 81

File $88-1056-14$

MERCURY INJECTION TEST RESULTS

INTERA TECHNOLOGIES, INC.

SANPLE NUMBER 4

Air Permeability $=0.069 \mathrm{md}$

Porosity $=15.5 \%$

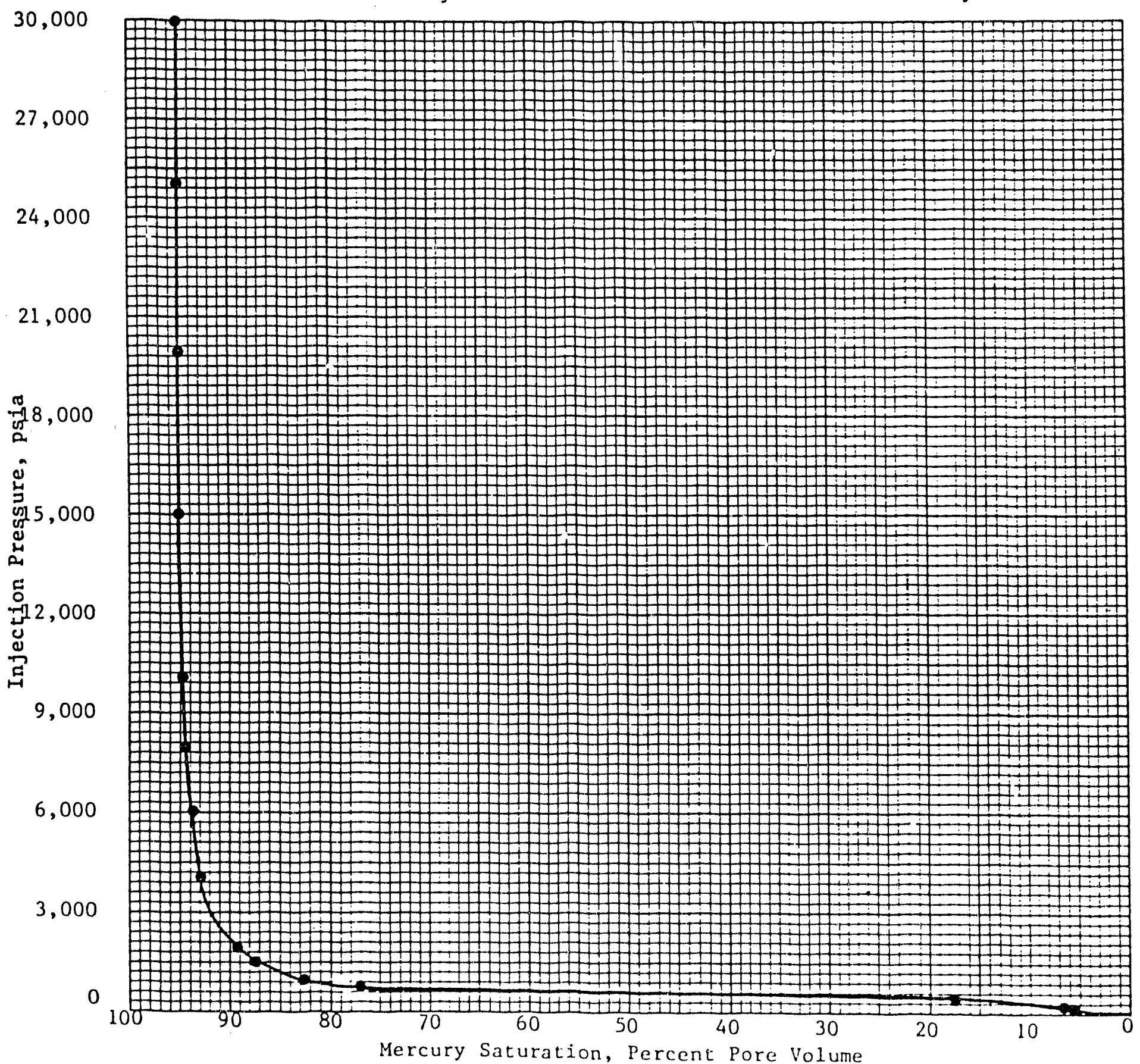




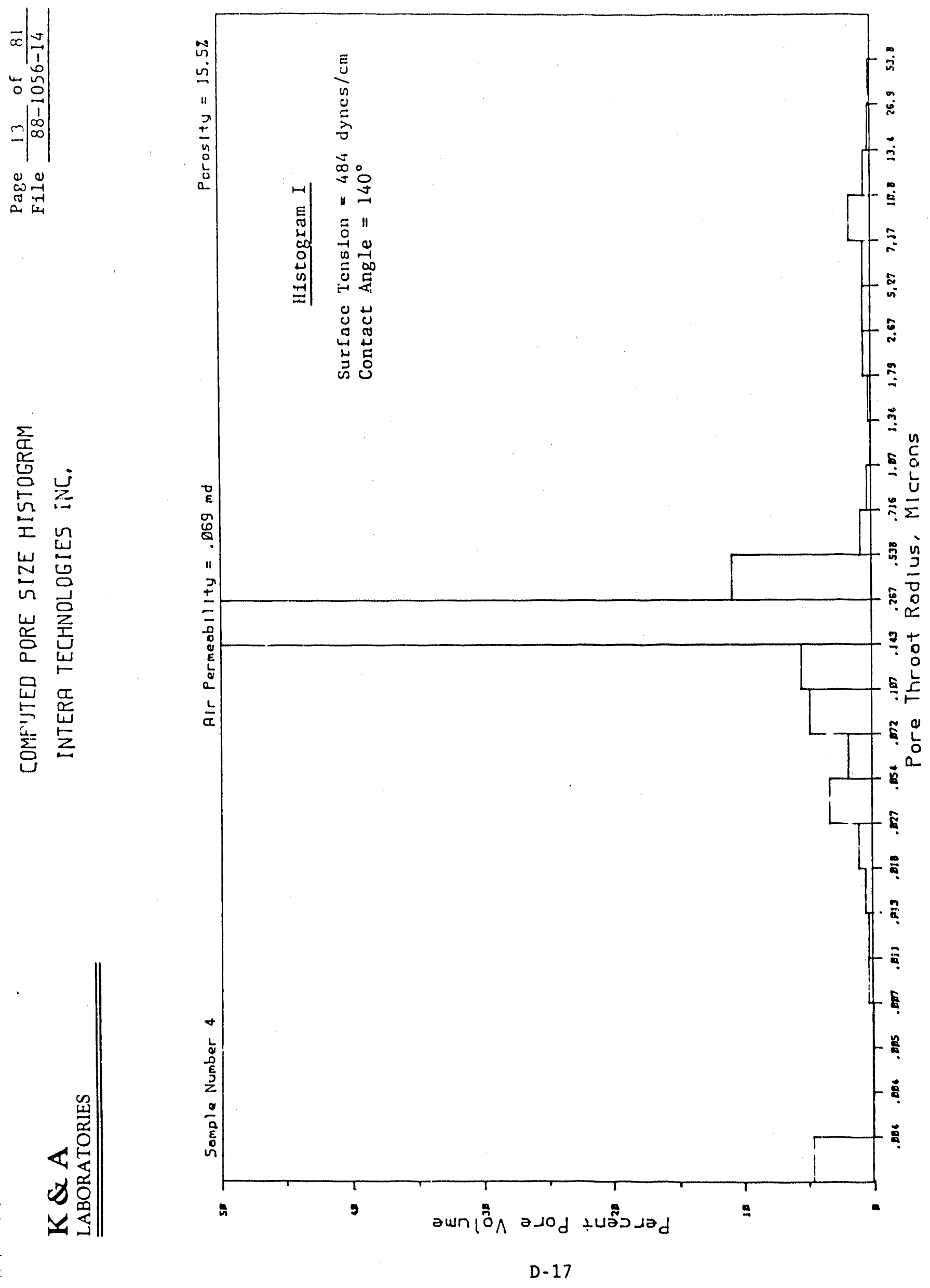




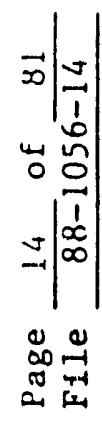

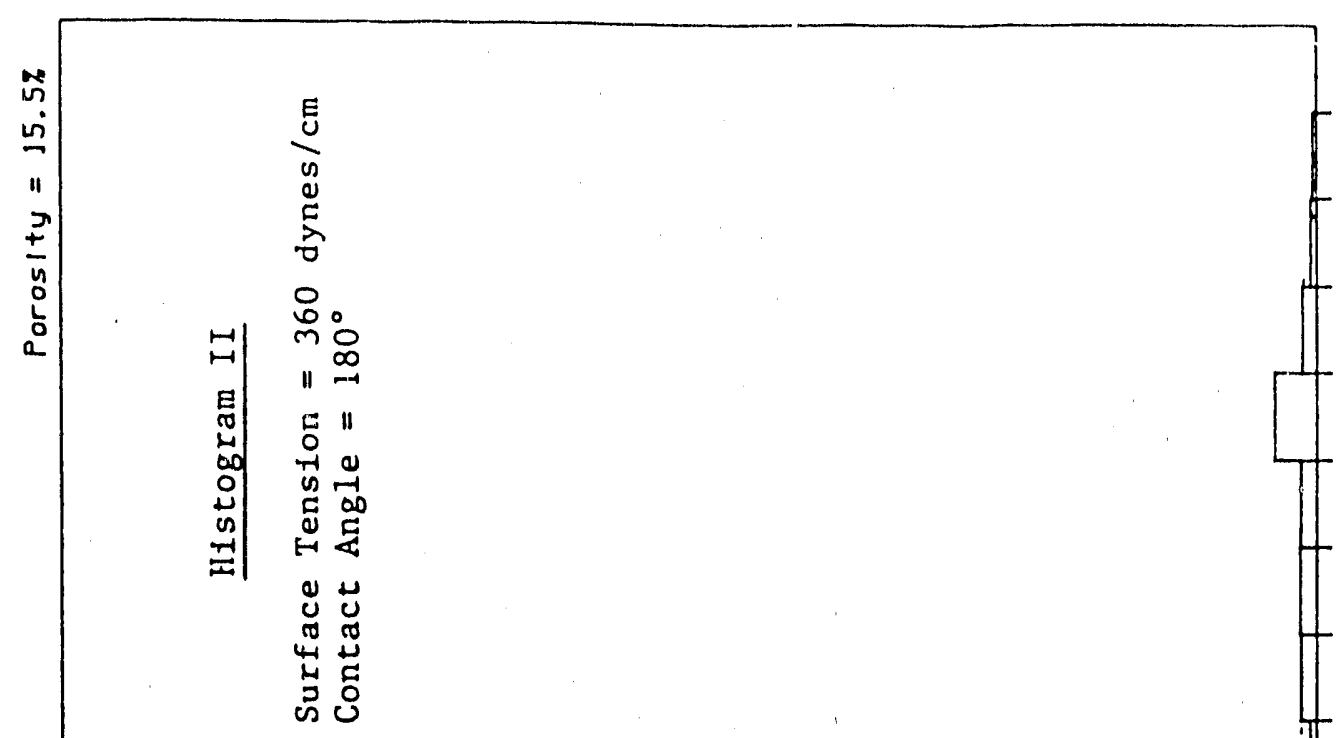

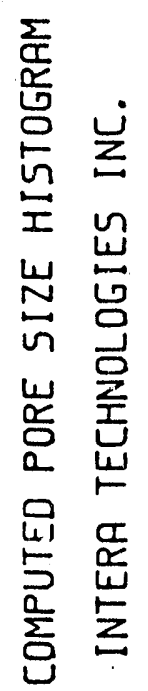

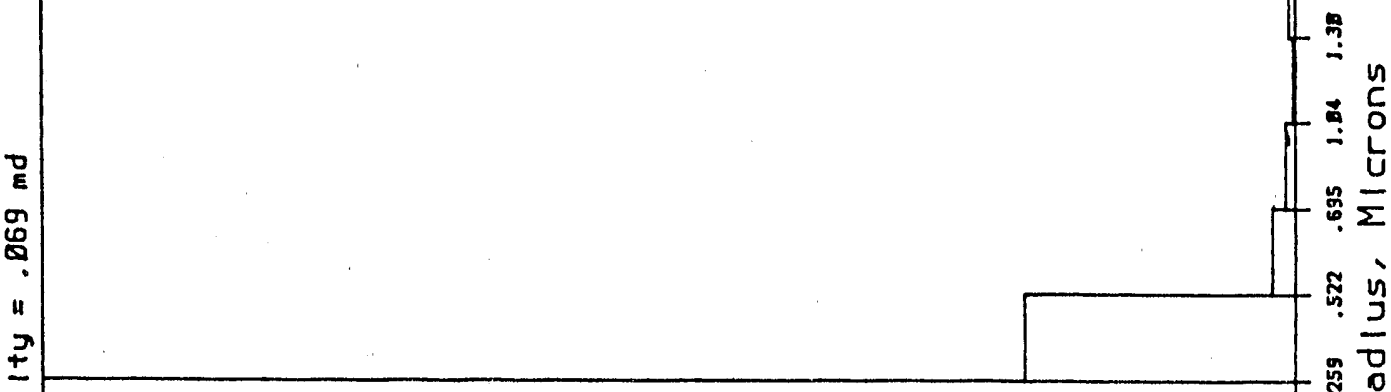


$K \& \mathbf{A}$

LABORATORIES
Page 15 of 81 File $\overline{88-1056-14}$

MERCURY INJECTION TEST RESULTS

INTERA TECHNOLOGIES, INC.

SAMPLE NUMBER 5

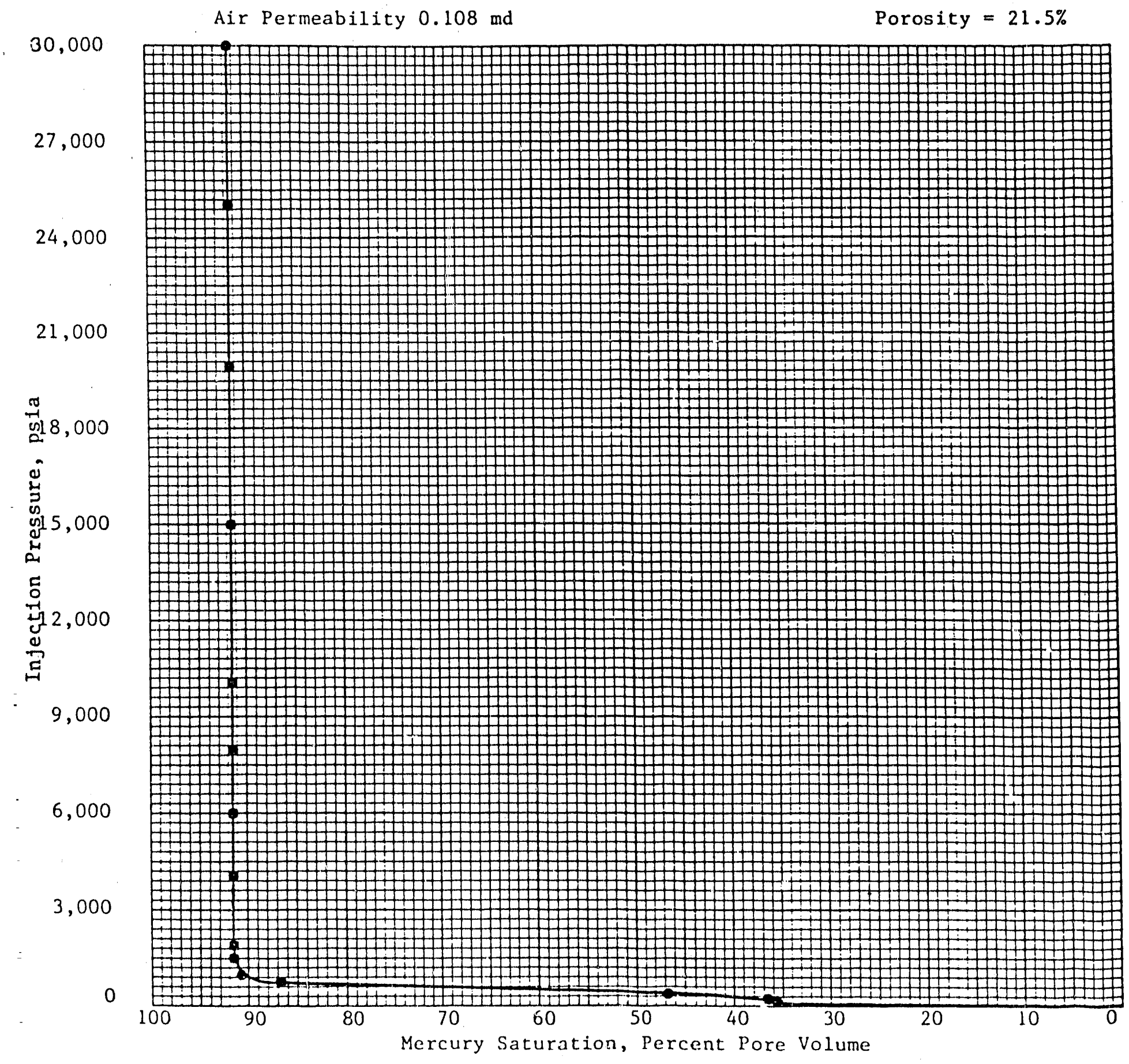

D- 19 


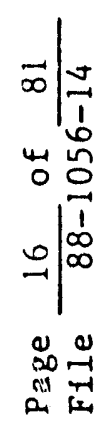

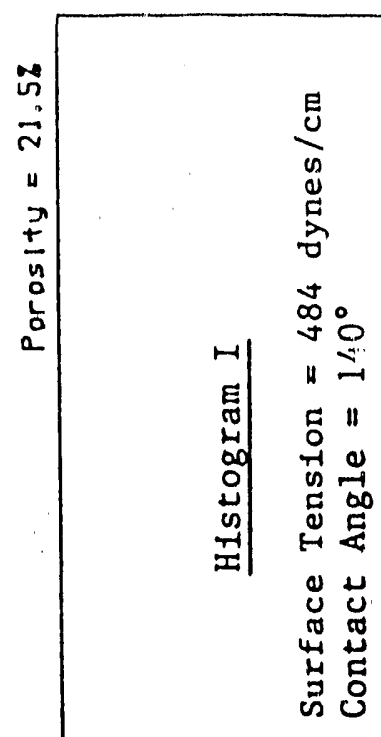

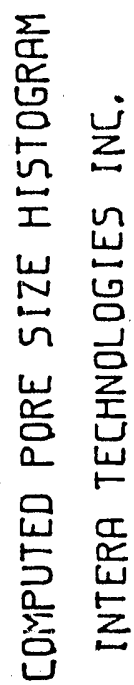
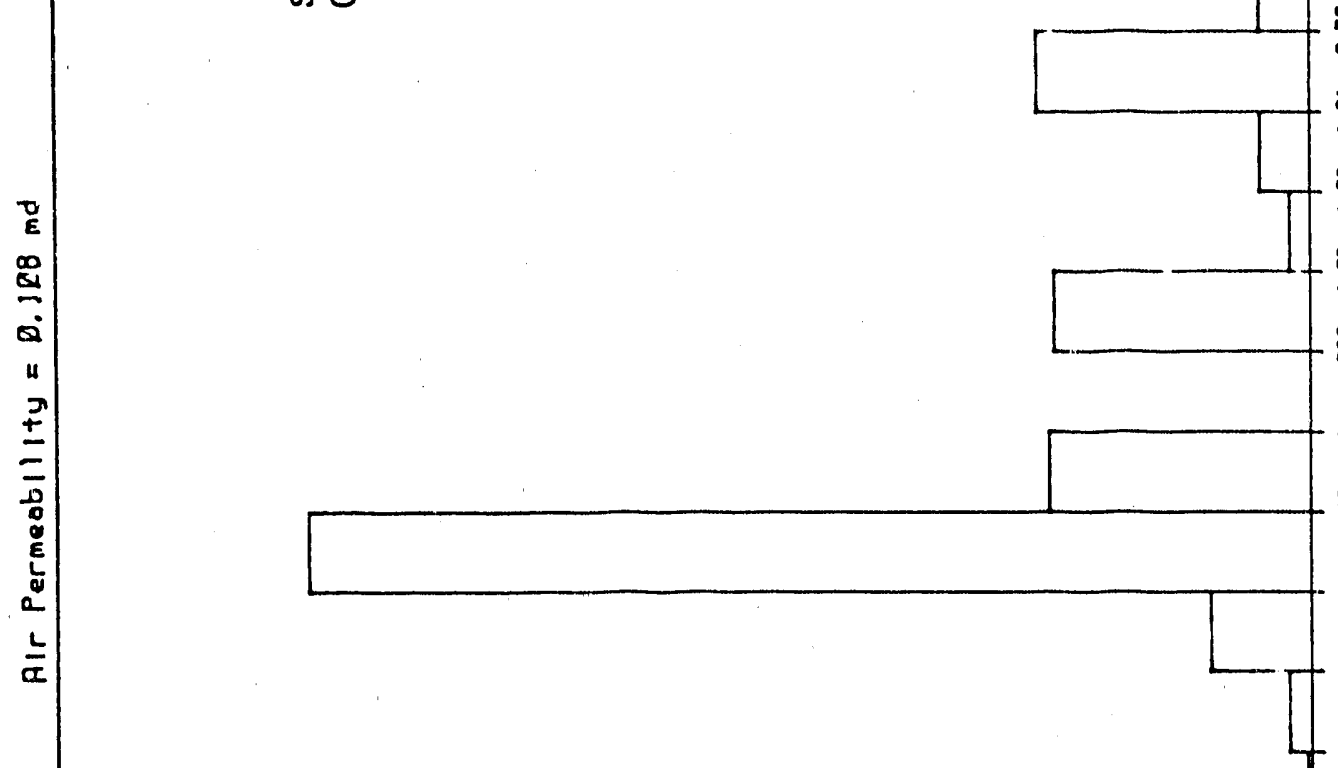

c

$-\frac{U}{\Sigma}$

นั

$=\frac{0}{0}$
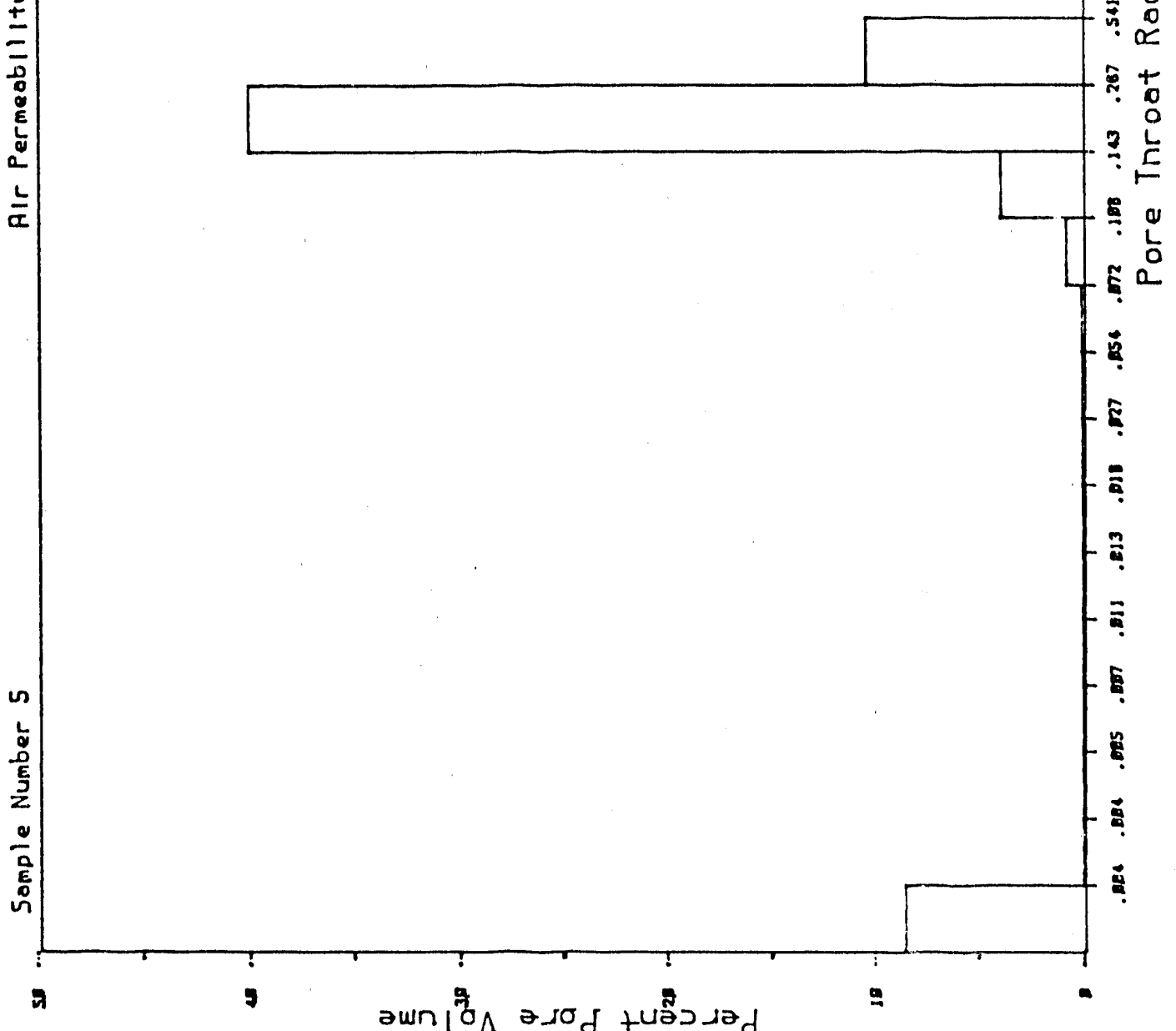

D- 20 


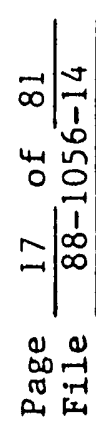

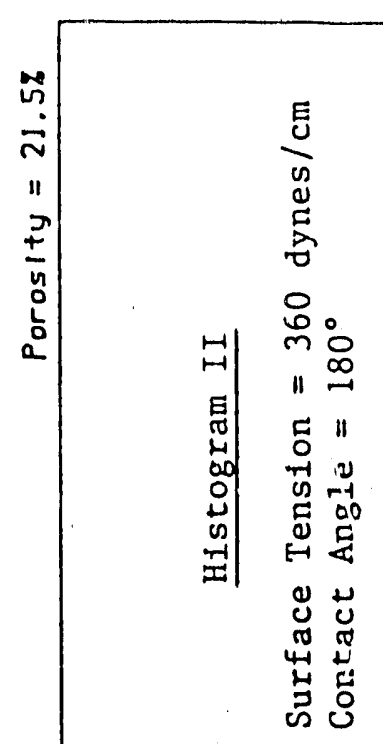

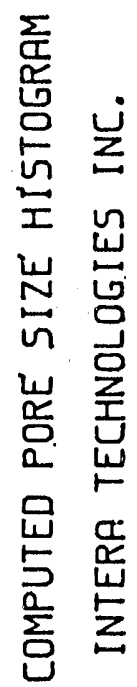
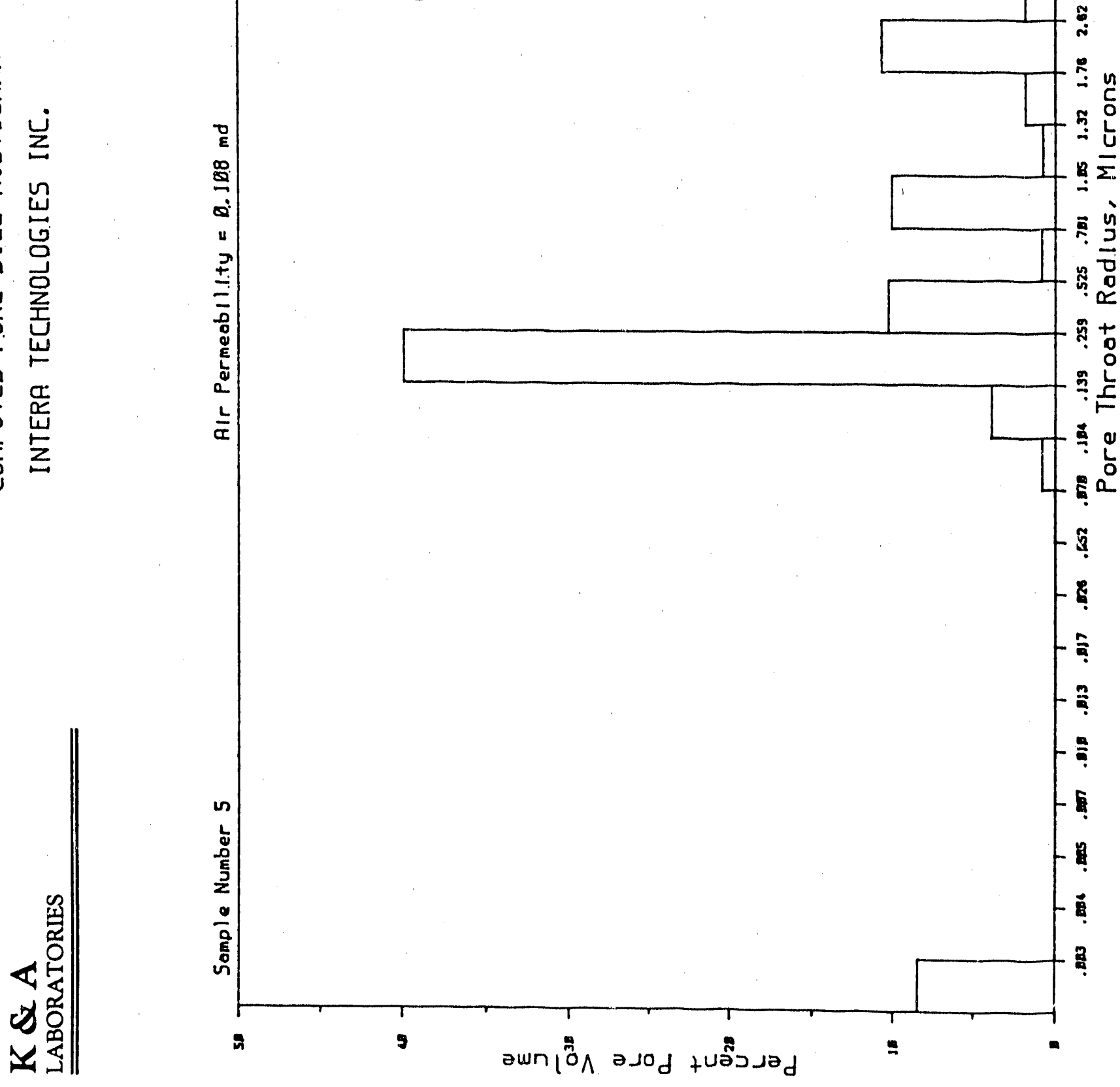

D- 21 
$K \& A$

LABORATORIES

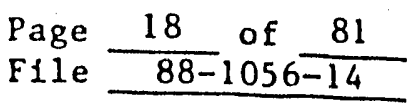

MERCURY INJECTION TEST RESULTS

INTERA TECHNOLOGIES, INC.

SAYPLE NUMBER 6

Air Permeability $=0.521 \mathrm{md}$

Porosity $=27.8 \%$

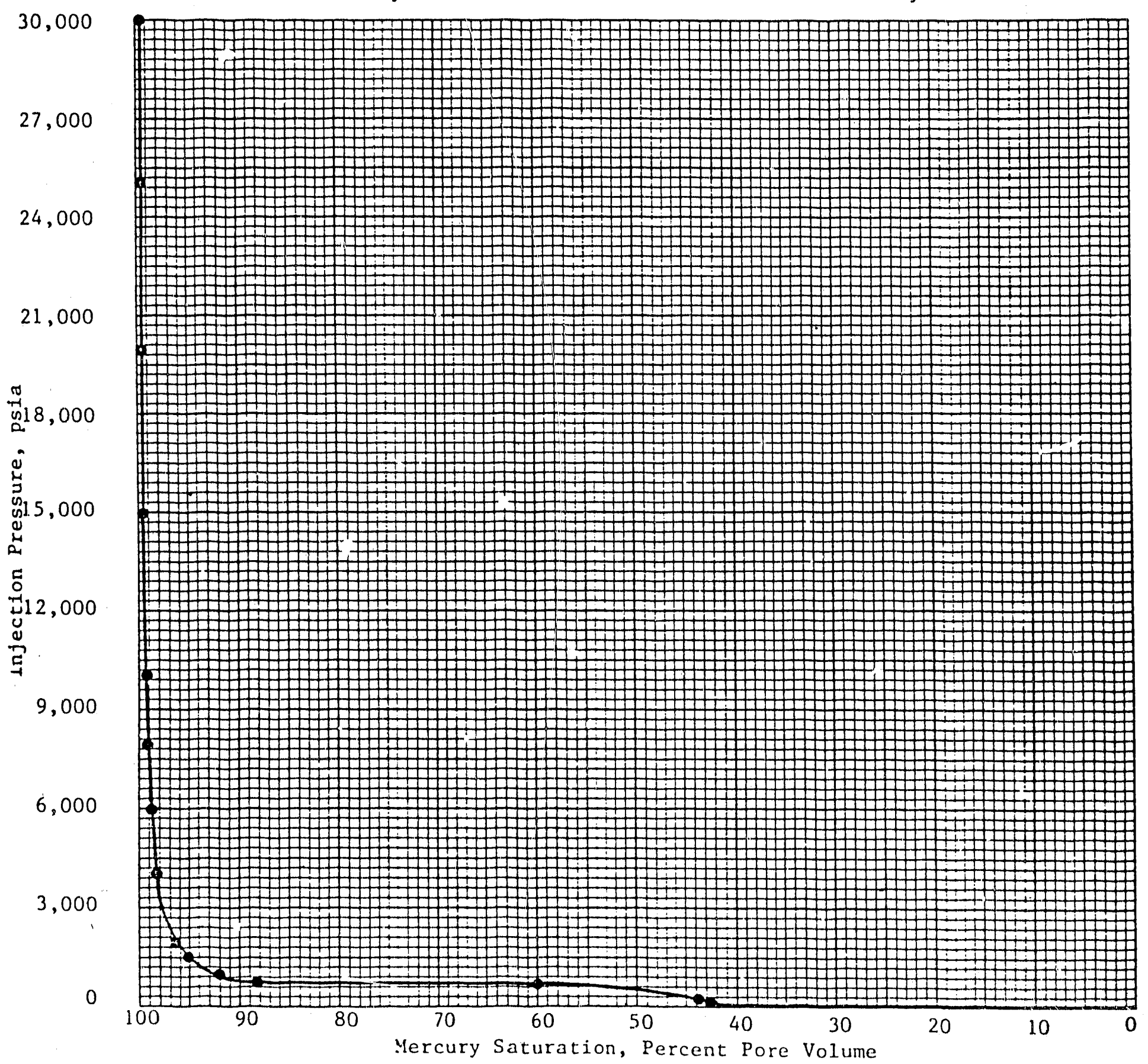




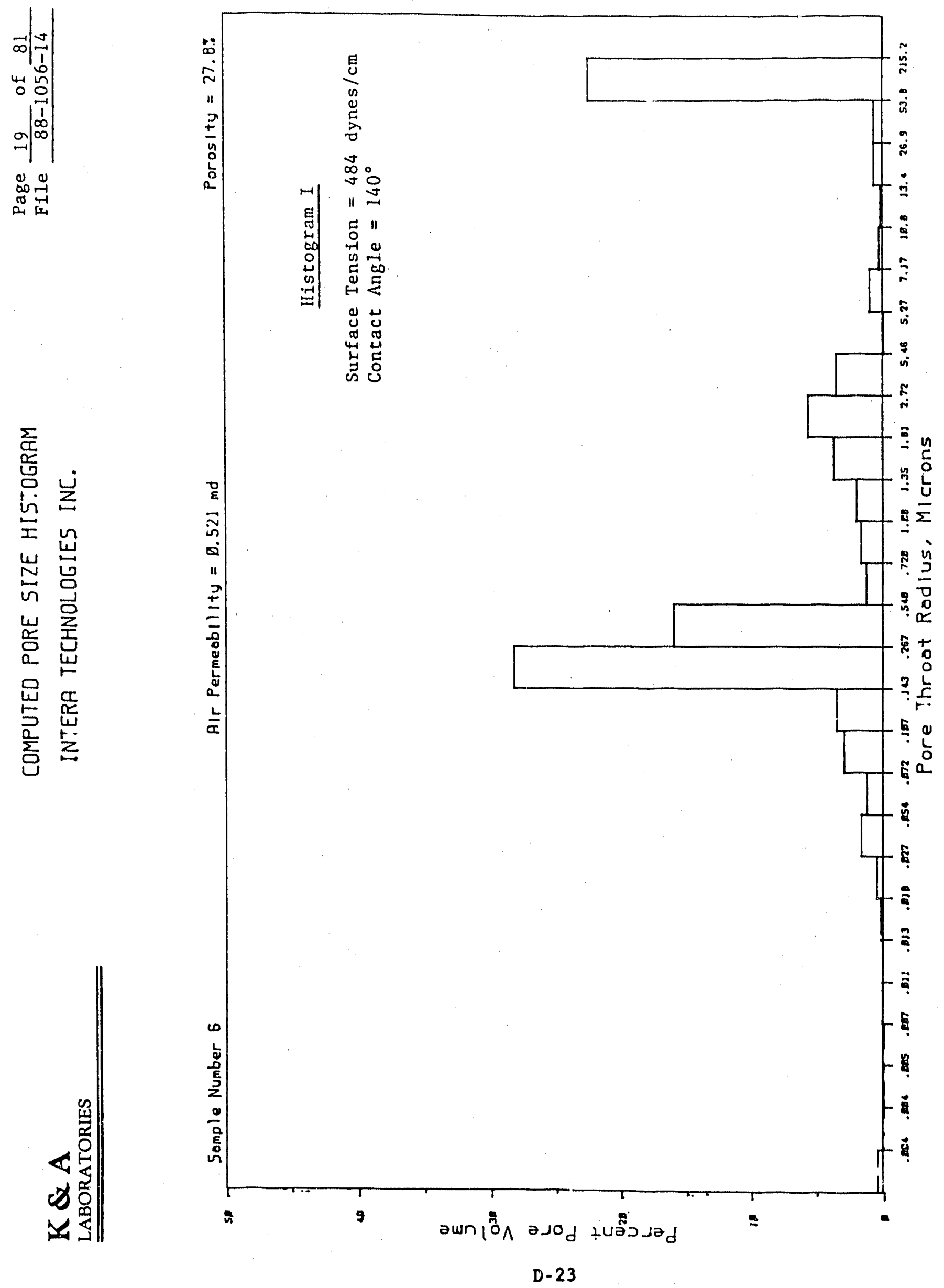




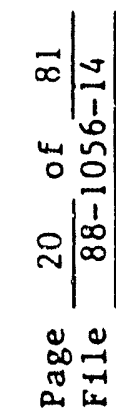

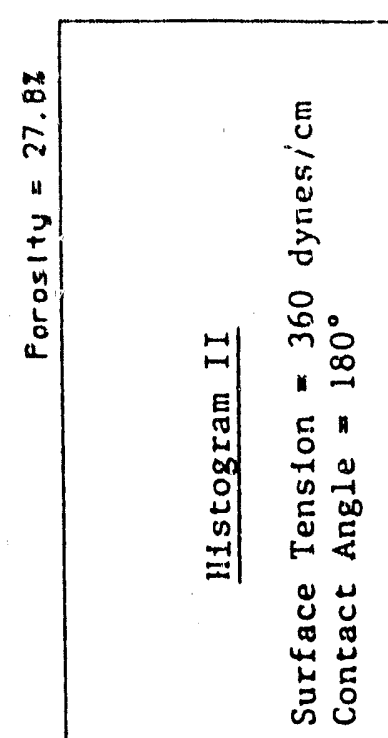

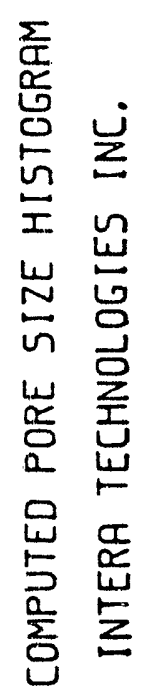

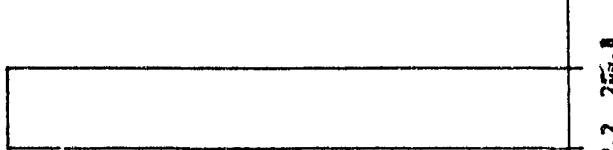

i

:े

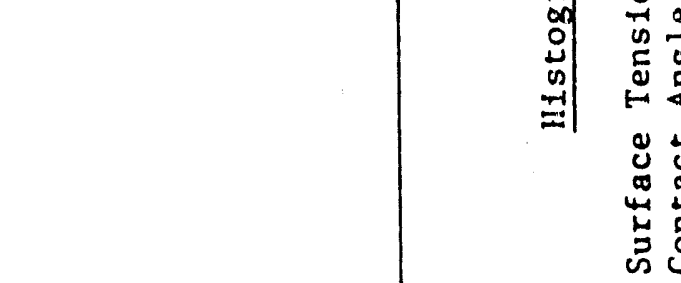

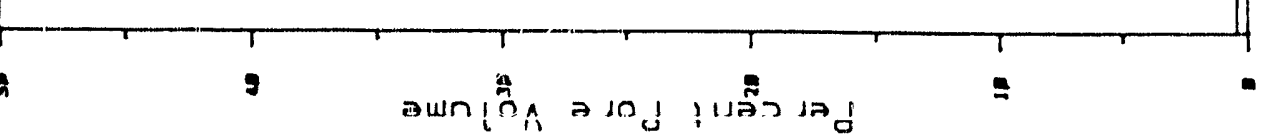


Page 21 of 81

MERCURY INJECTION TEST RESULTS

INTERA TECHNOLOGIES, INC.

SAYPLE NUMBER 7

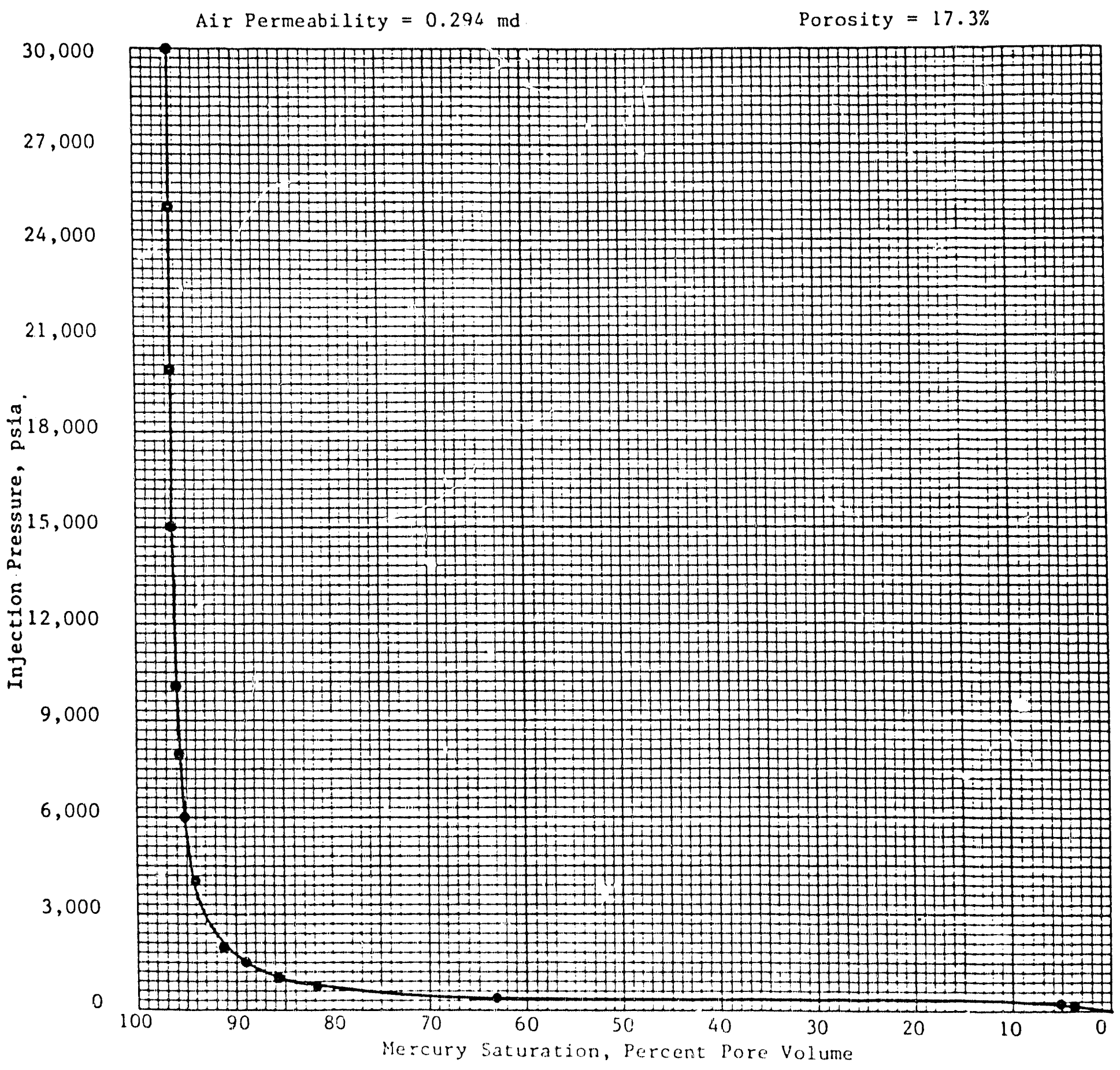




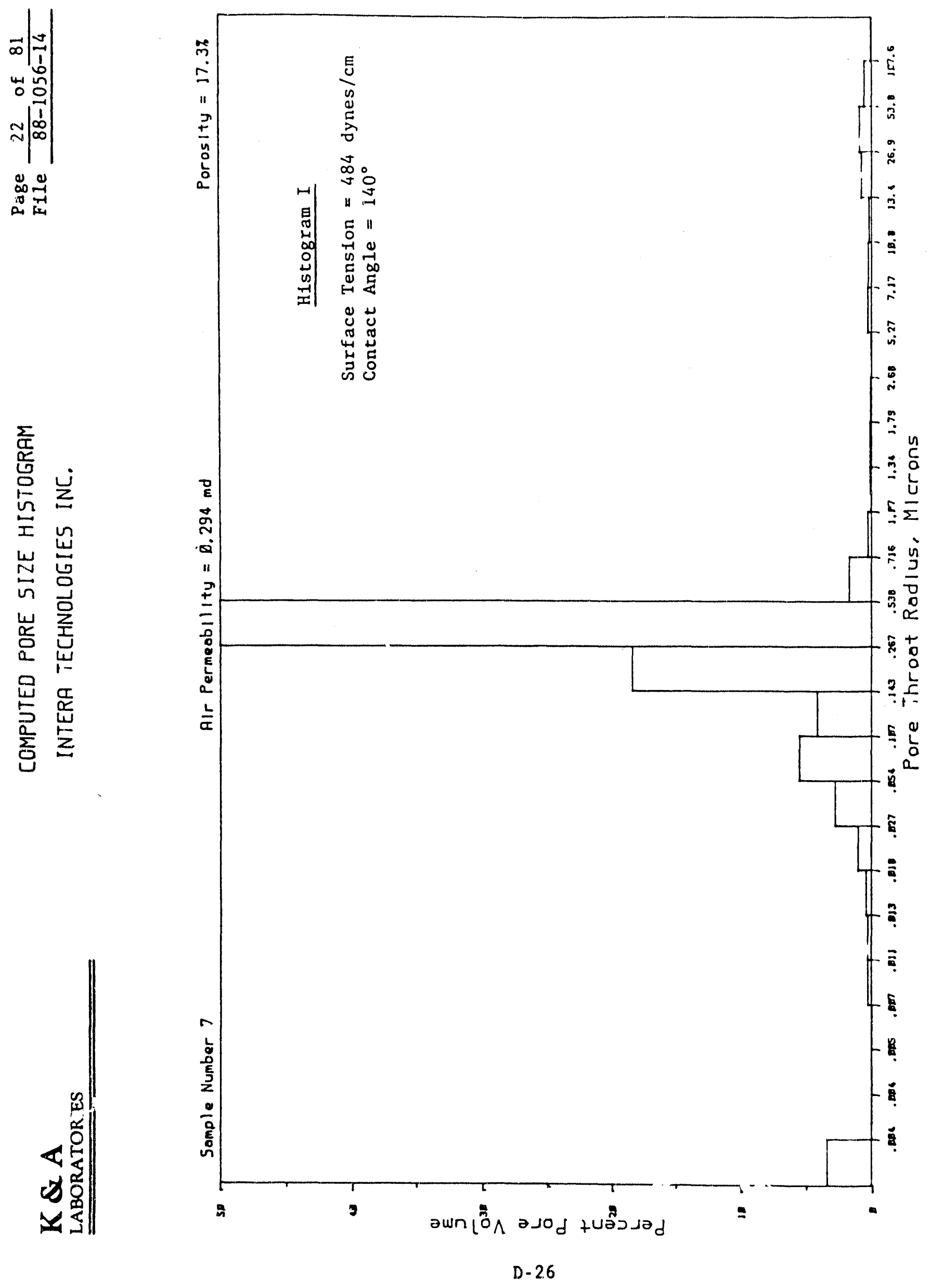




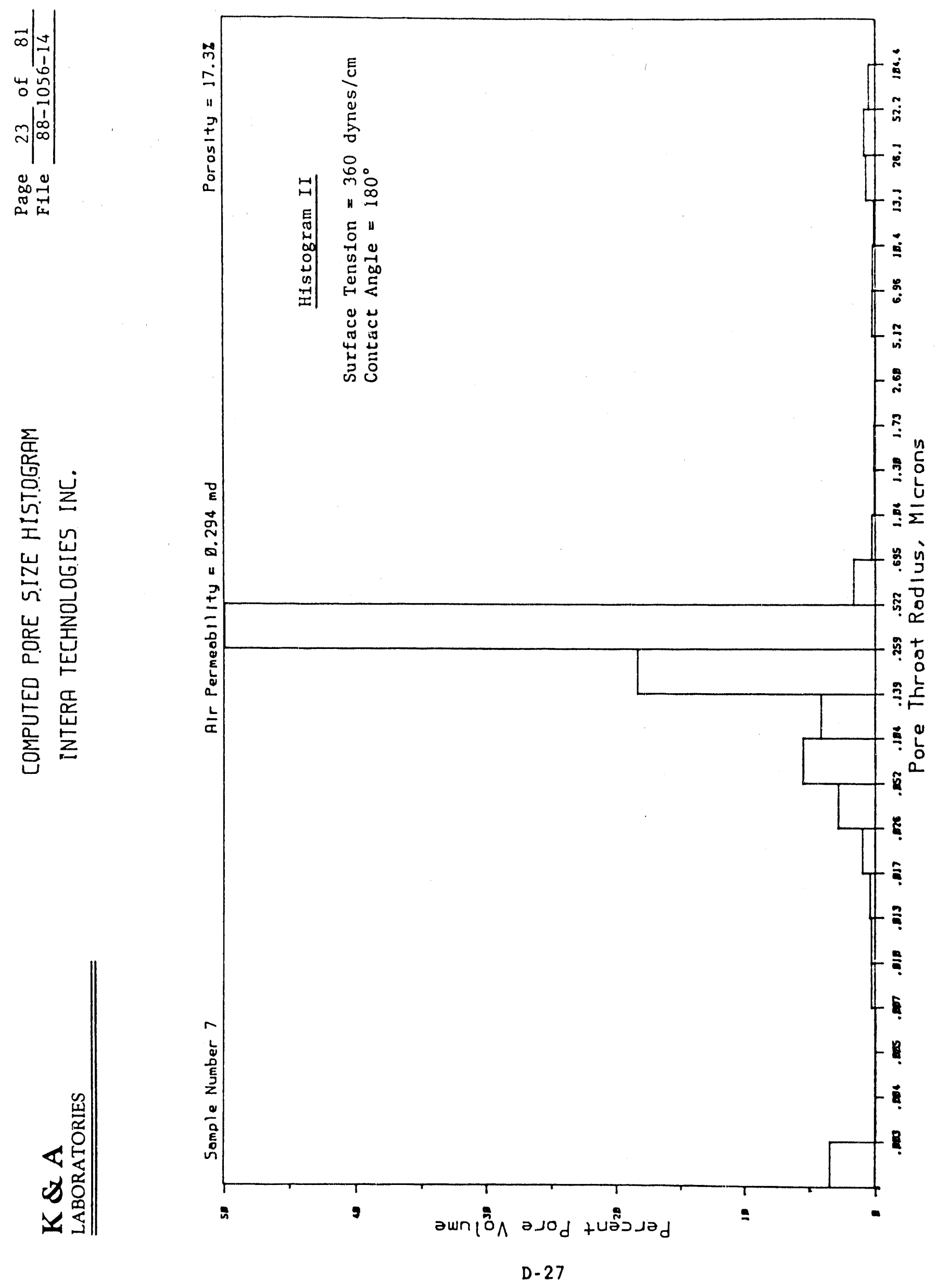


MERCURY INJECTION TEST RESULTS

INTERA TECHNOLOGIES, INC.

SAMPLE NUMBER 8

Air Permeability $=0.074 \mathrm{rd}$

Porosity $=16.5 \%$

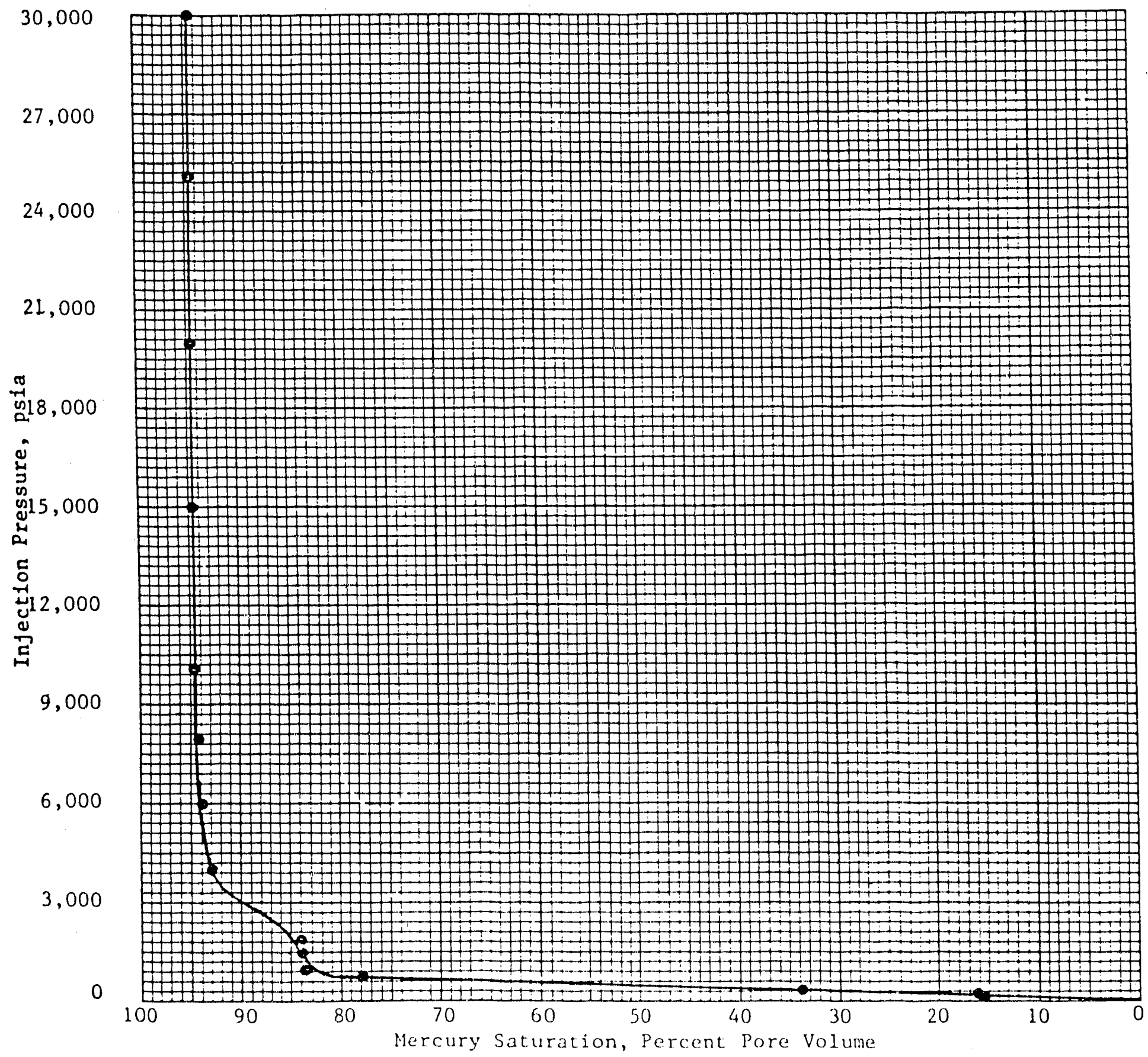




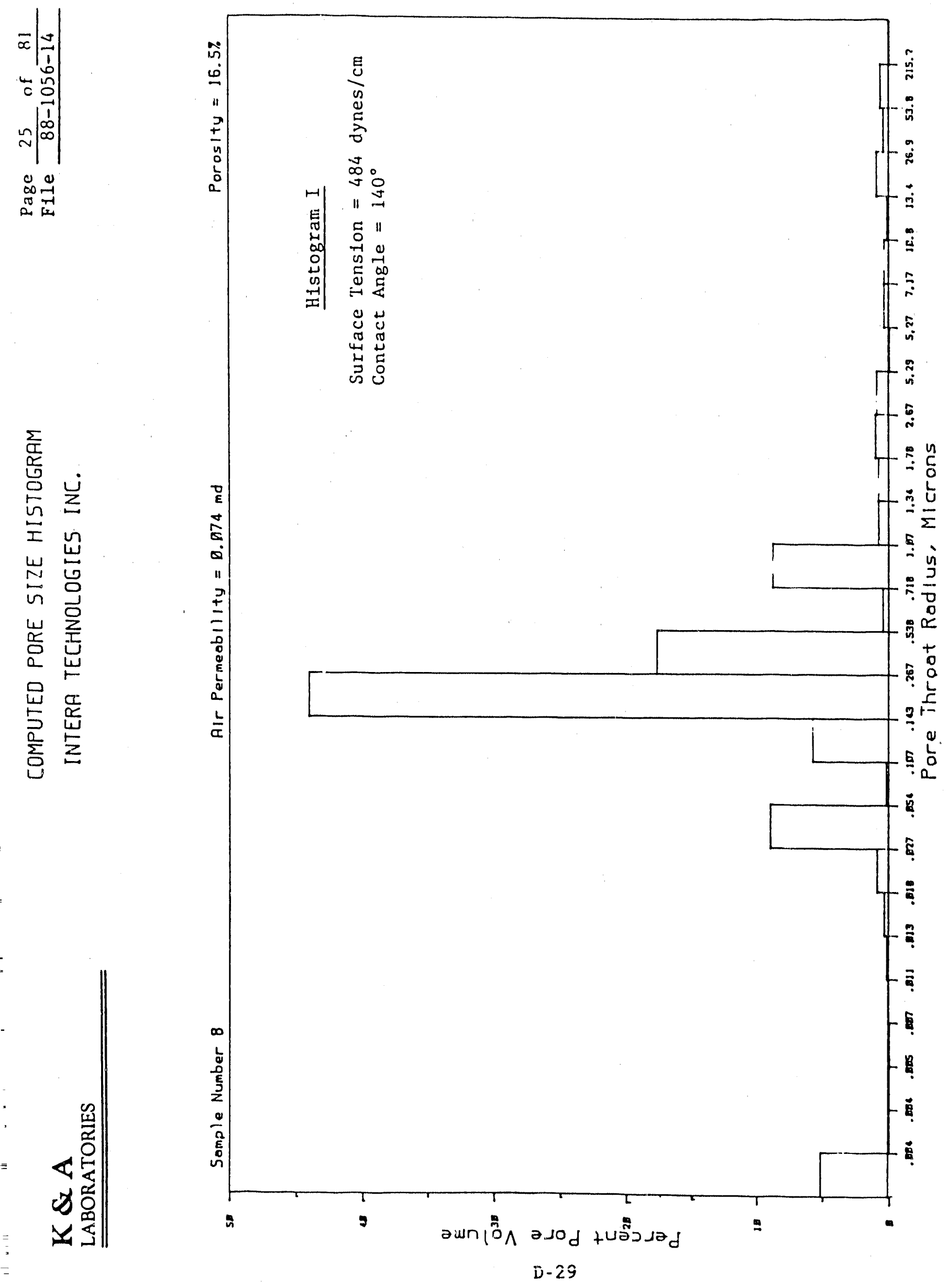




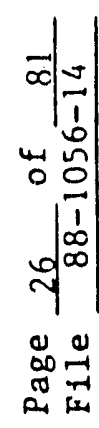

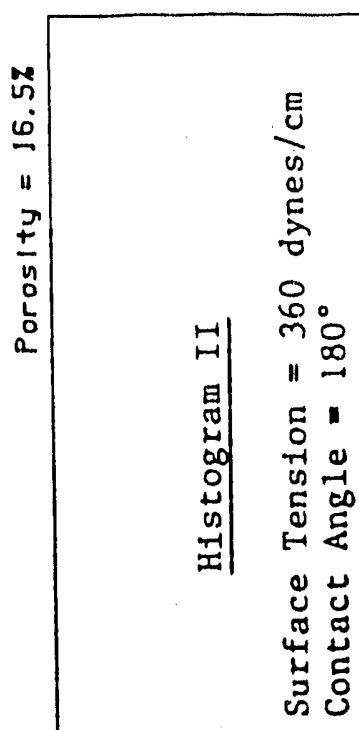

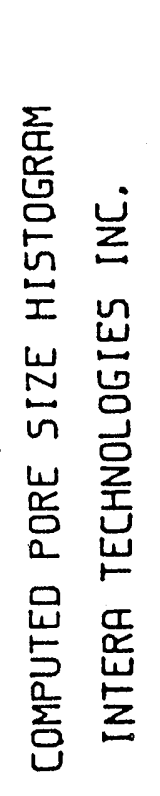

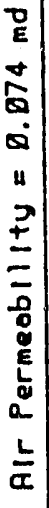

EN

斗

5

ปै

ऽ
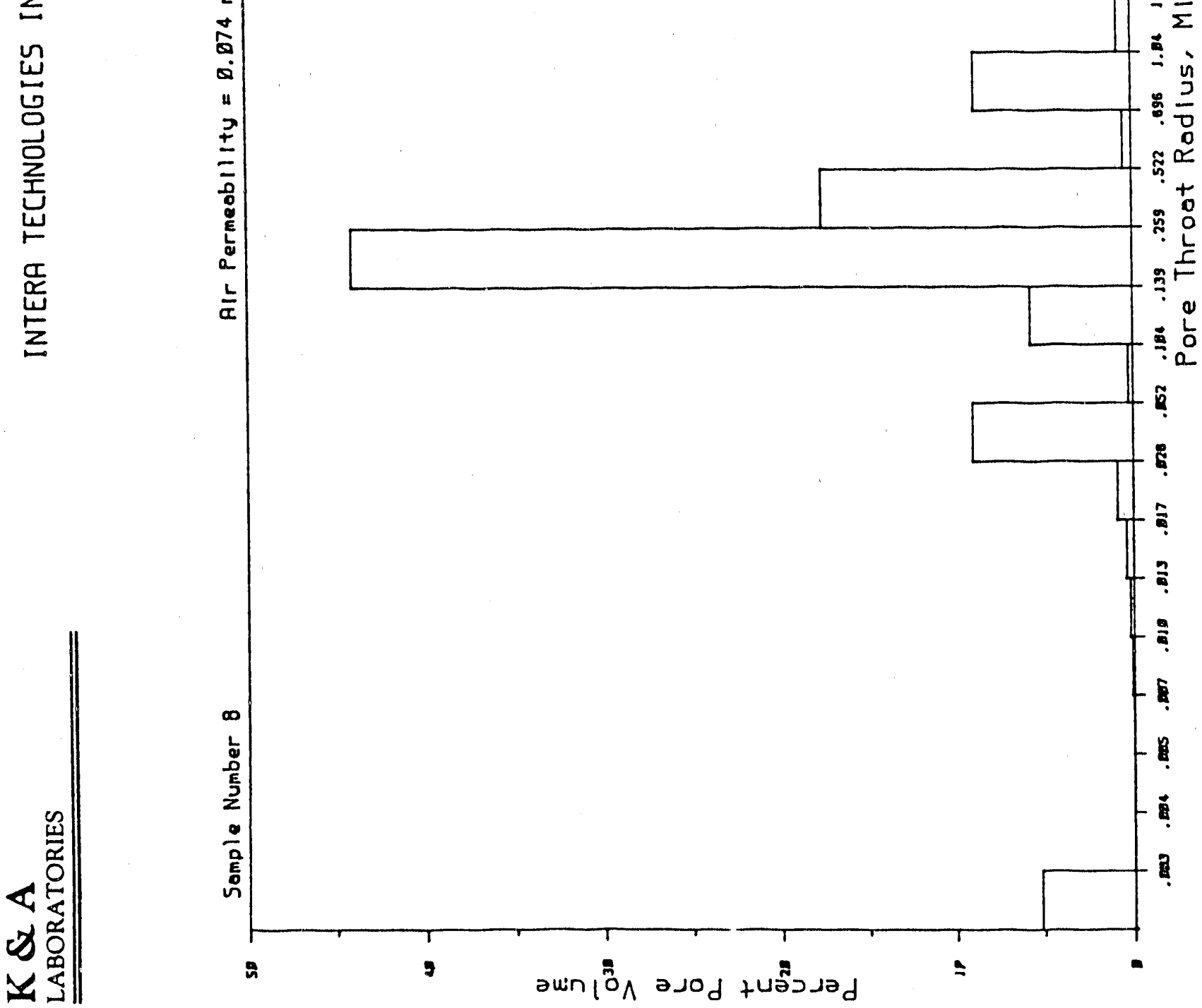

D- 30 
Page 27 of 81 LABORATORIES

File $\frac{27-1056-14}{88}$

MERCURY INJECTION TEST RESULTS

INTERA TECHNOLOGIES, INC.

SAMPLE NLMIBER 9

Air Permeability $=0.098$ md $\quad$ Porosity $=13.4 \%$

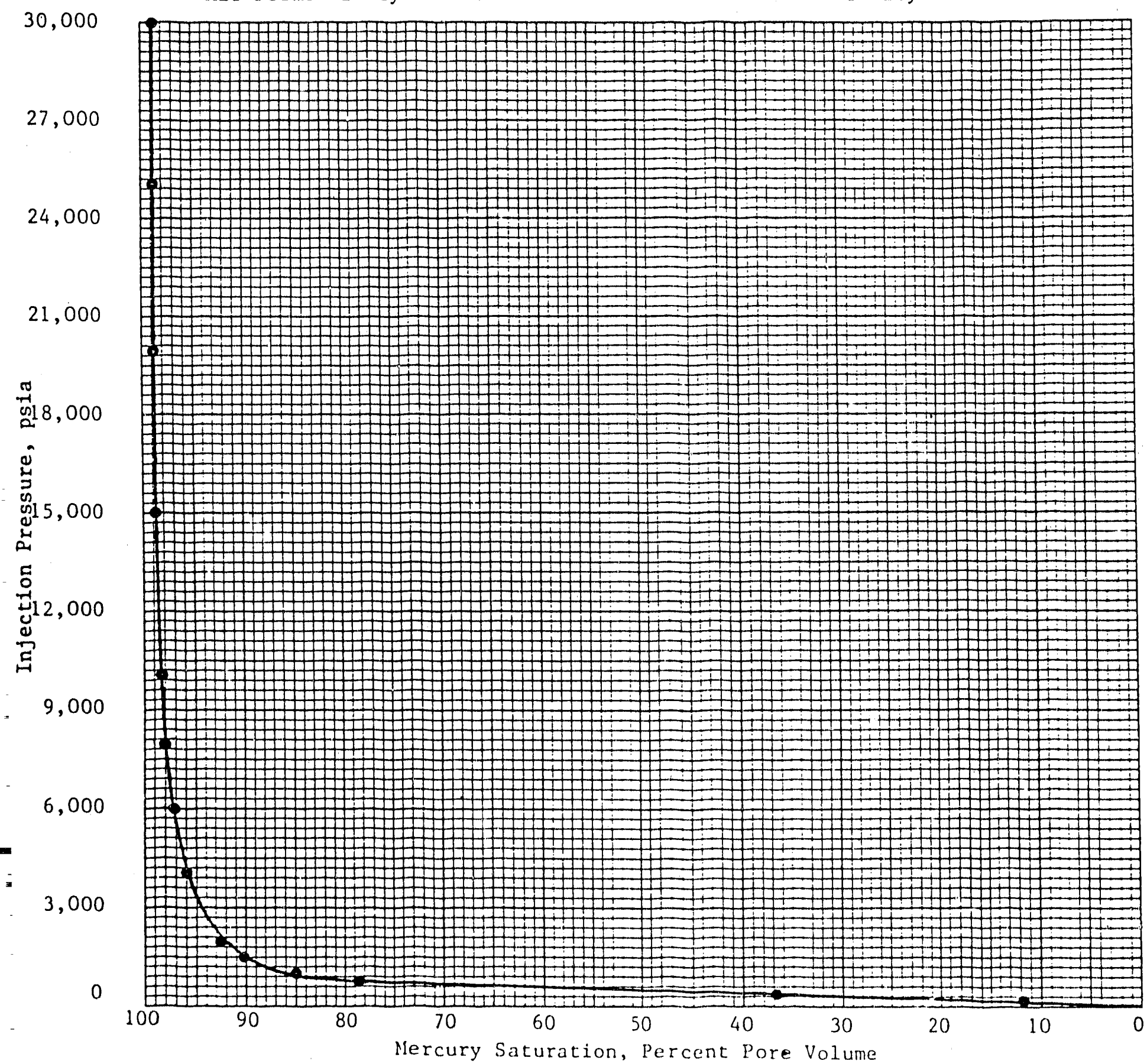

D-31 


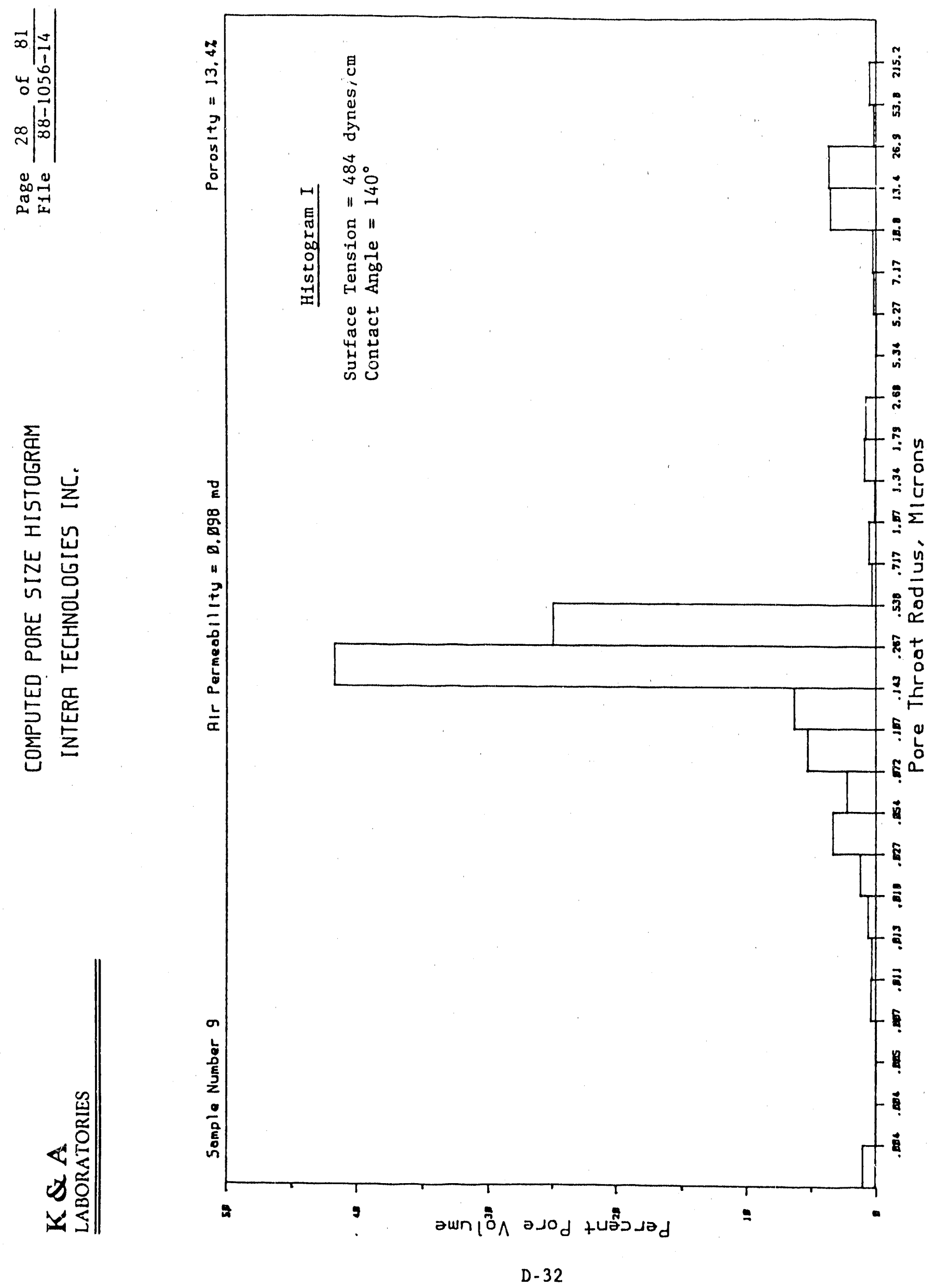




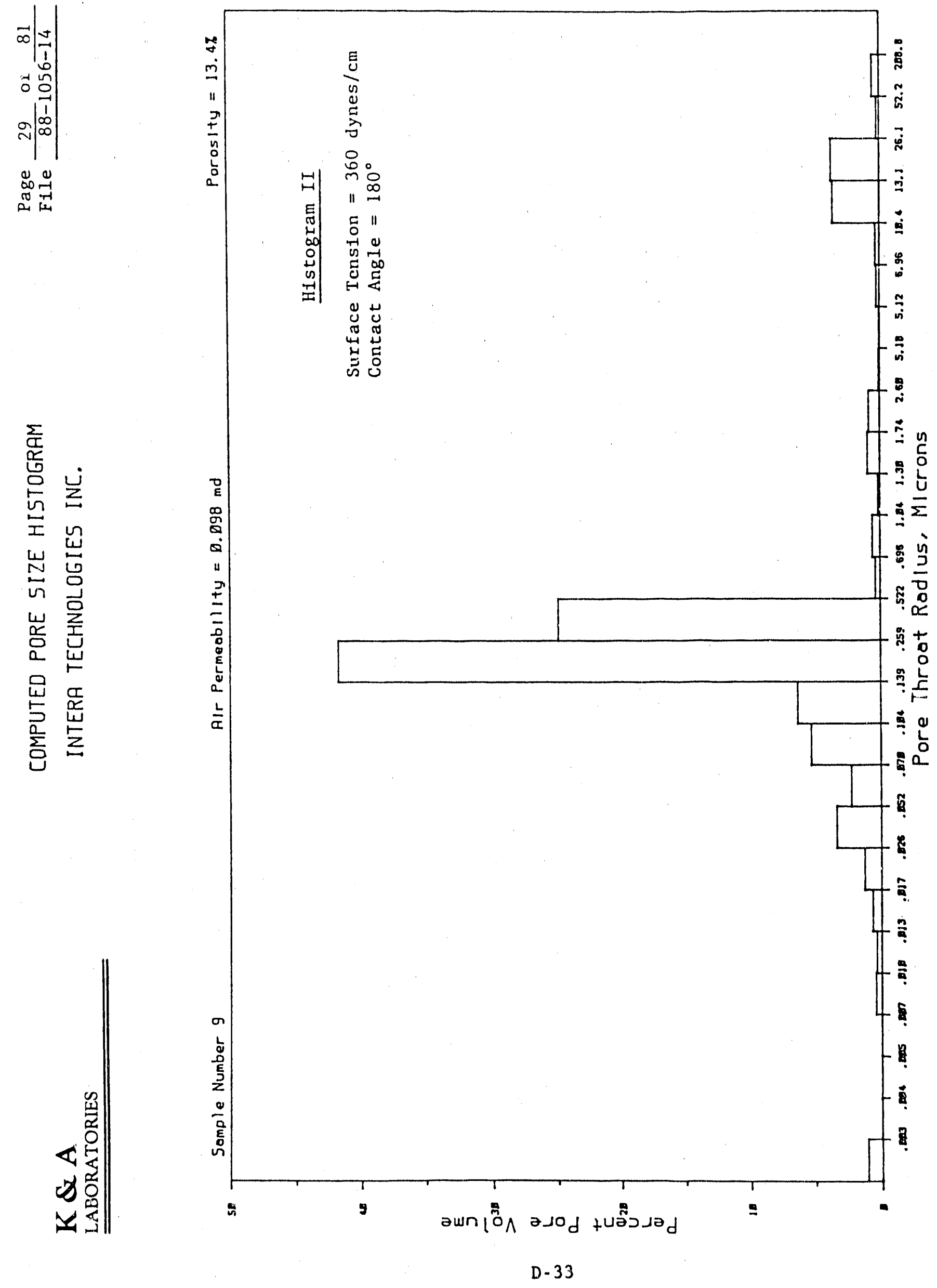


MERCURI' INJECTION TEST RESULTS

INTERA TECHNOLOCIES, INC.

SAMPLE NUMBER 10

Air Permeability $=0.012$ md

Porosity $=10.8 \%$

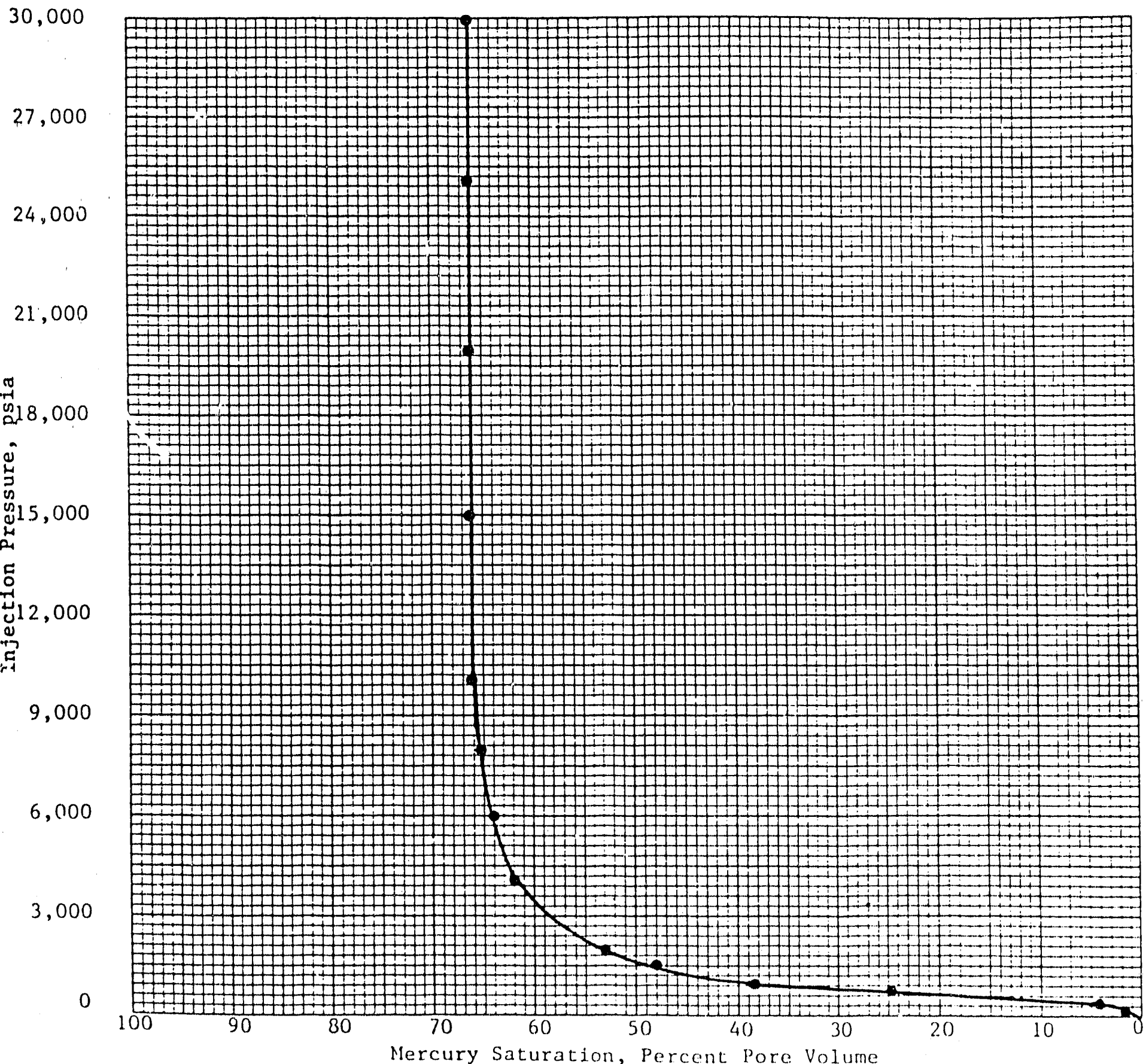




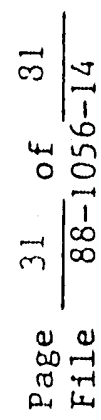

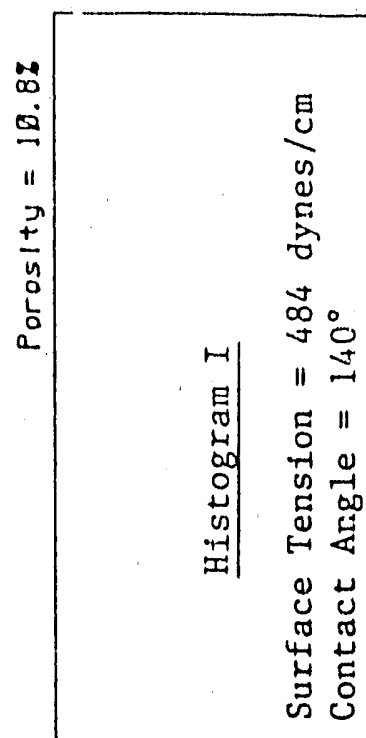

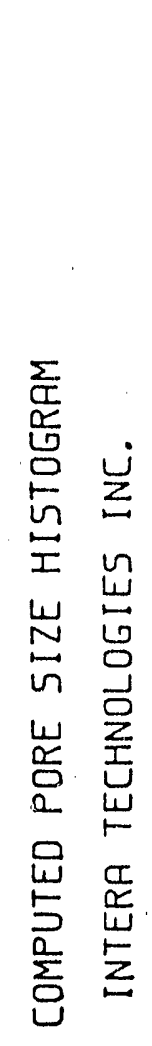

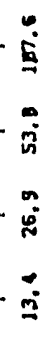
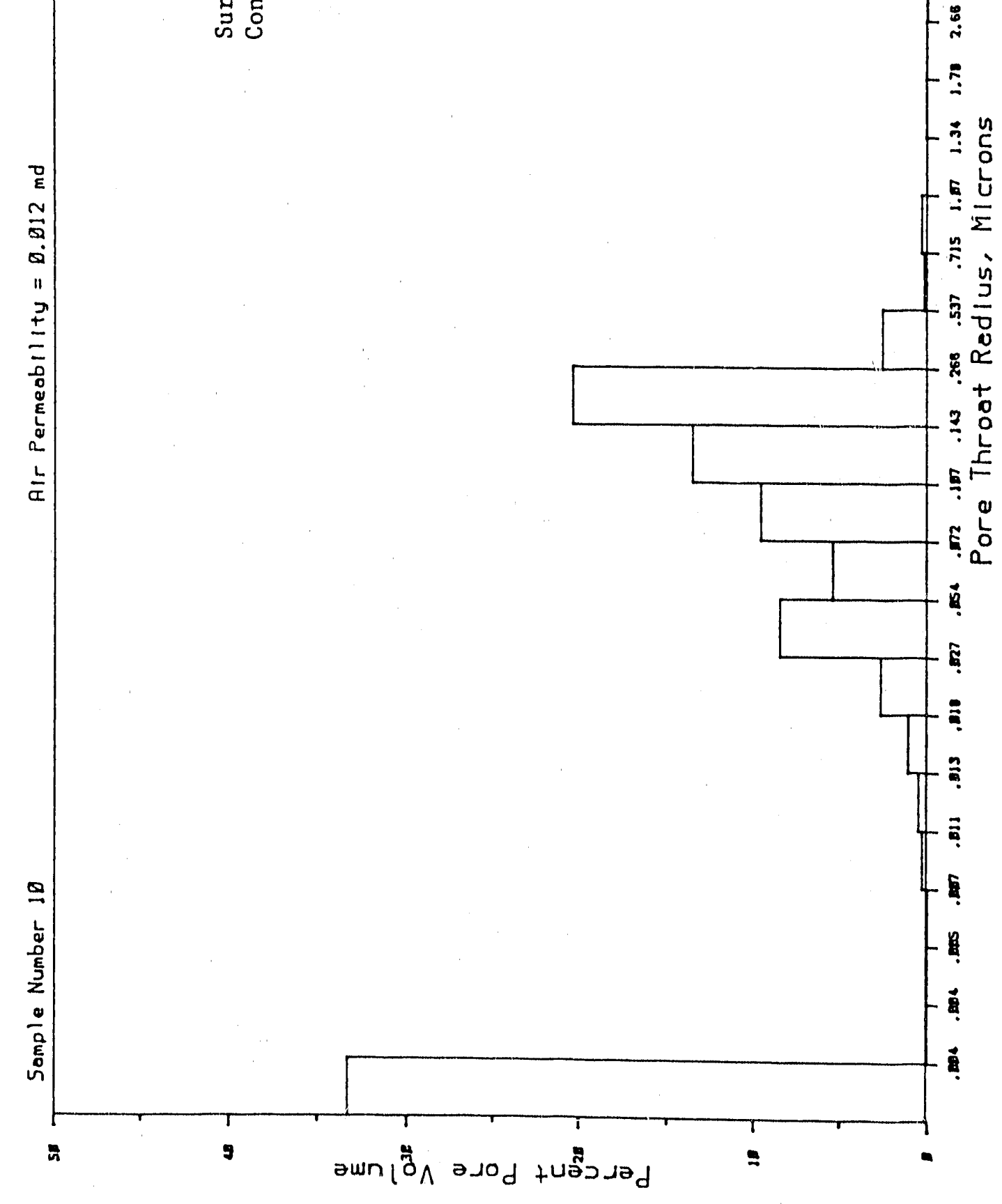

D- 35 


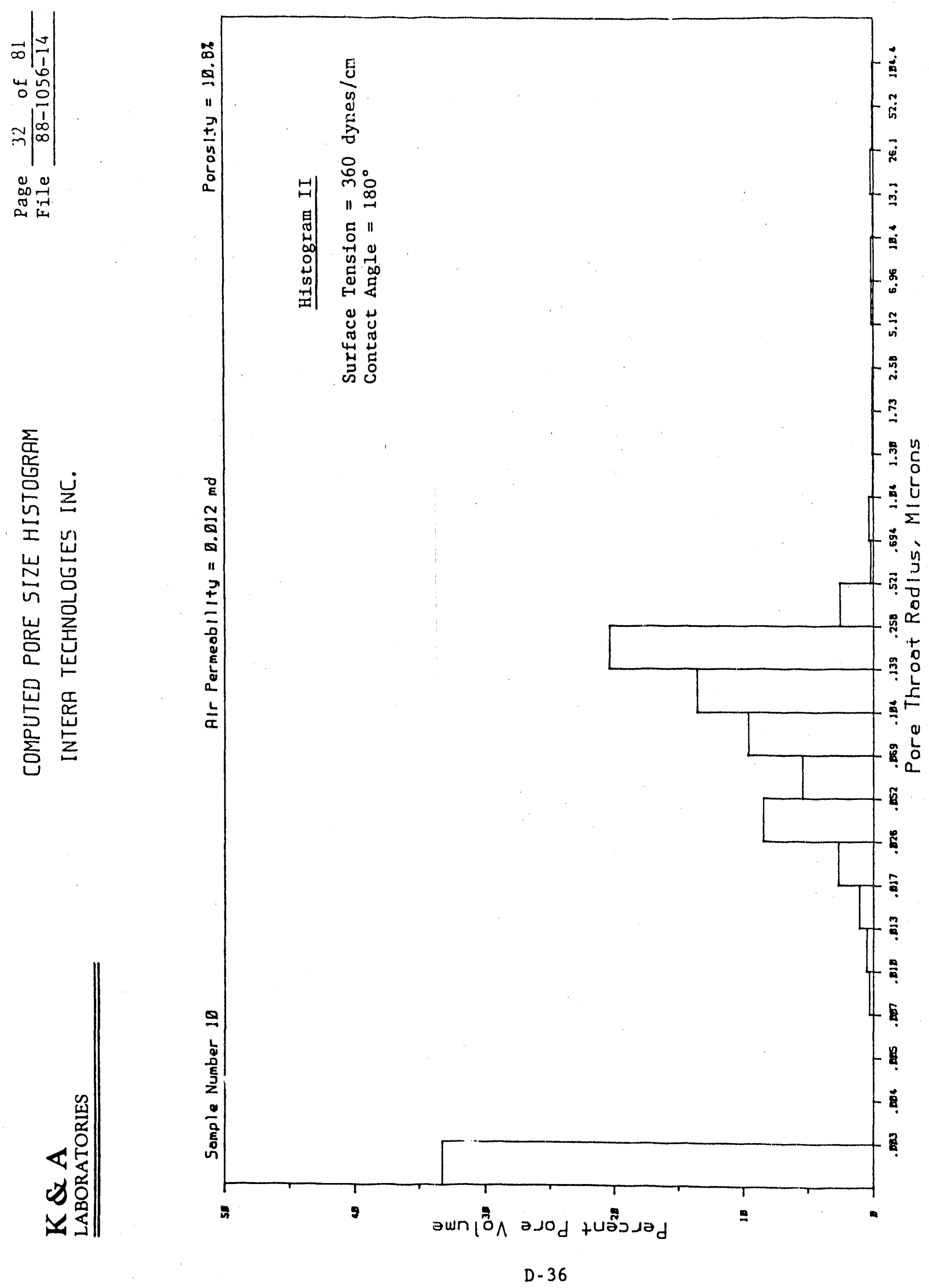


Page $32 \mathrm{a}$ of 81

$K \boldsymbol{\&} A$

File $\overline{88-1056-14}$

MERCURY/INJECTION TEST RESULTS

INTERA TECHINOLOGIES, INC.

SAMPLE NUMBER 10A

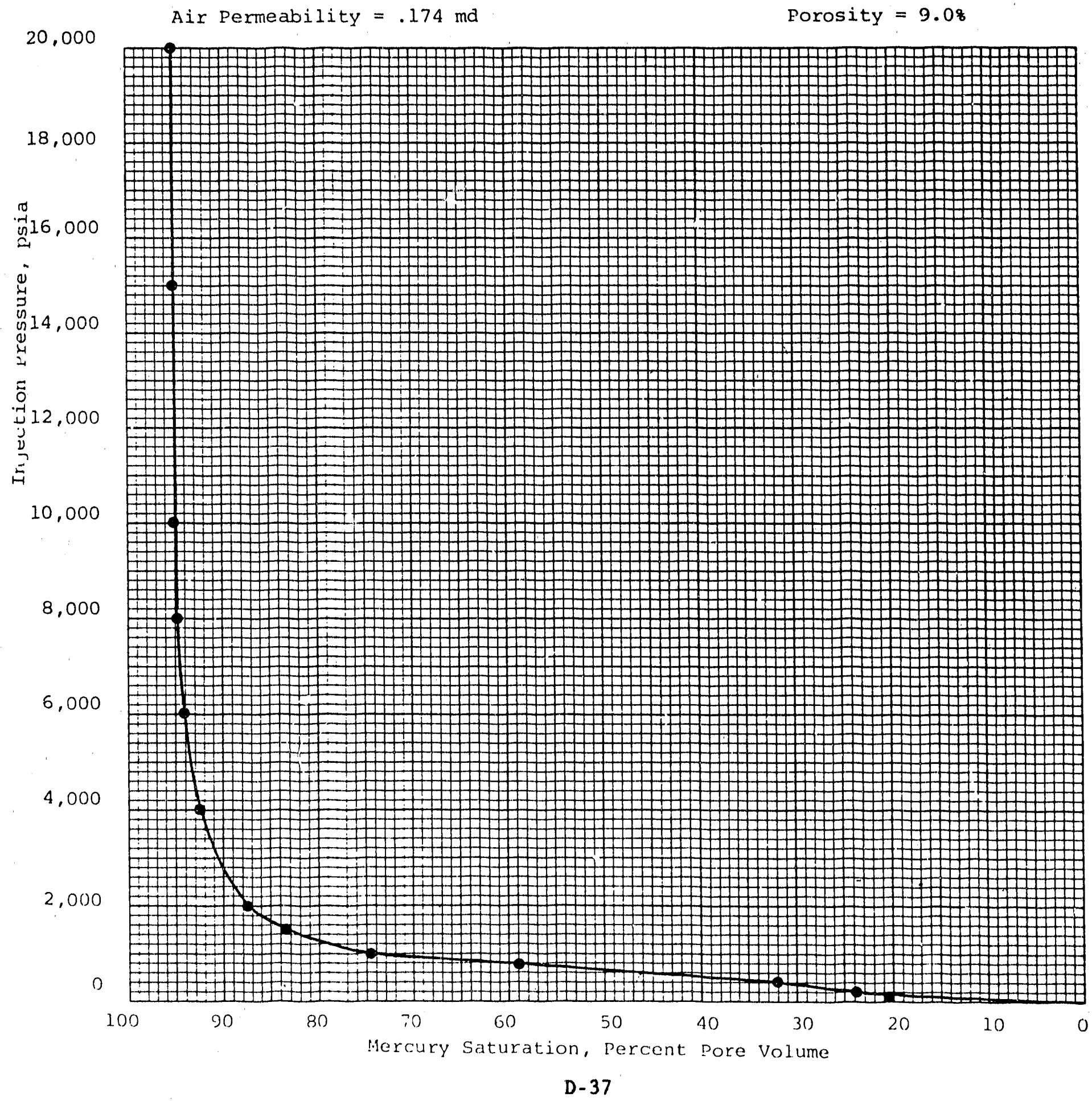




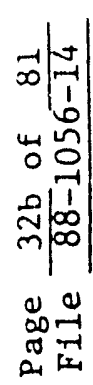

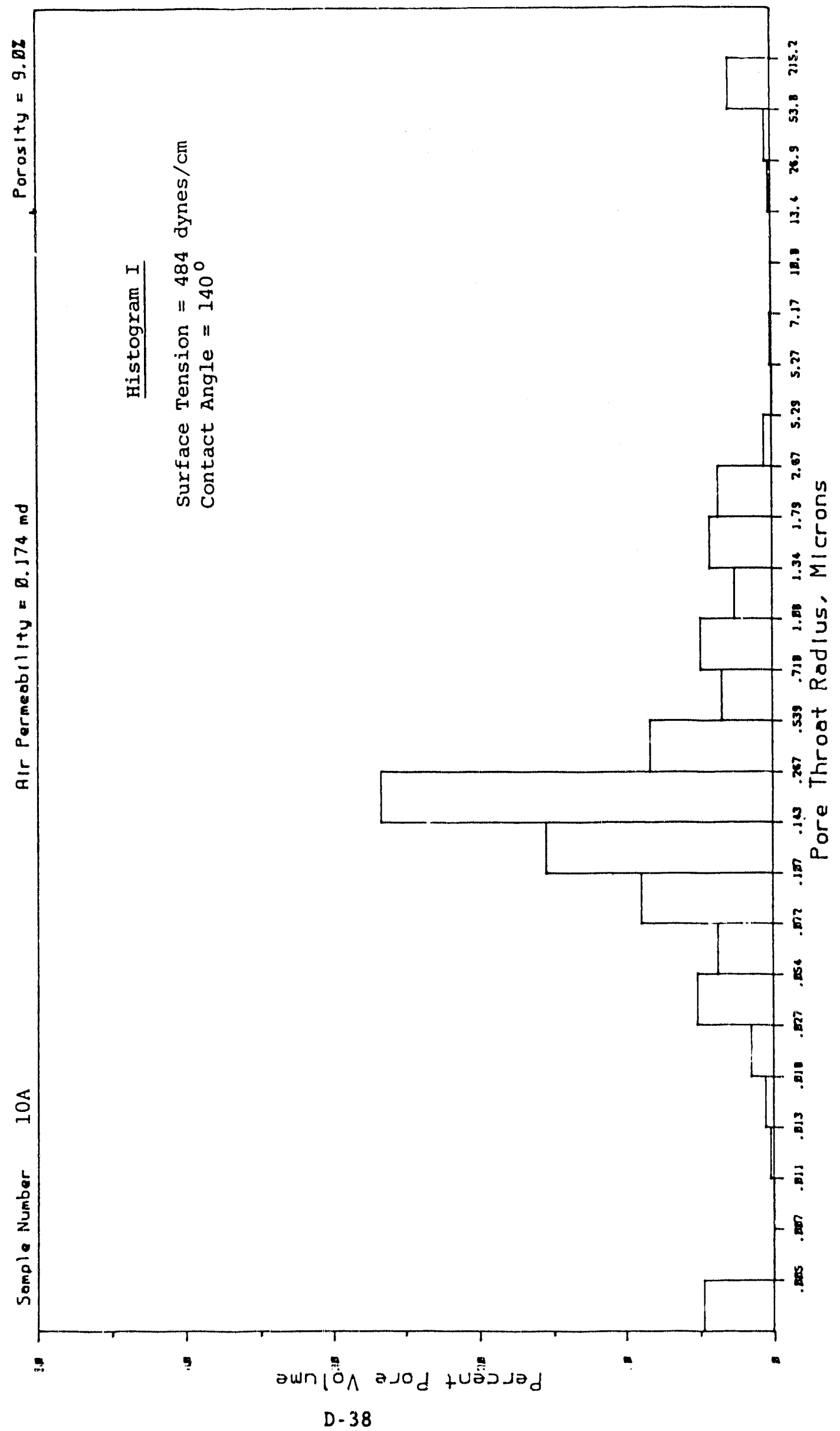



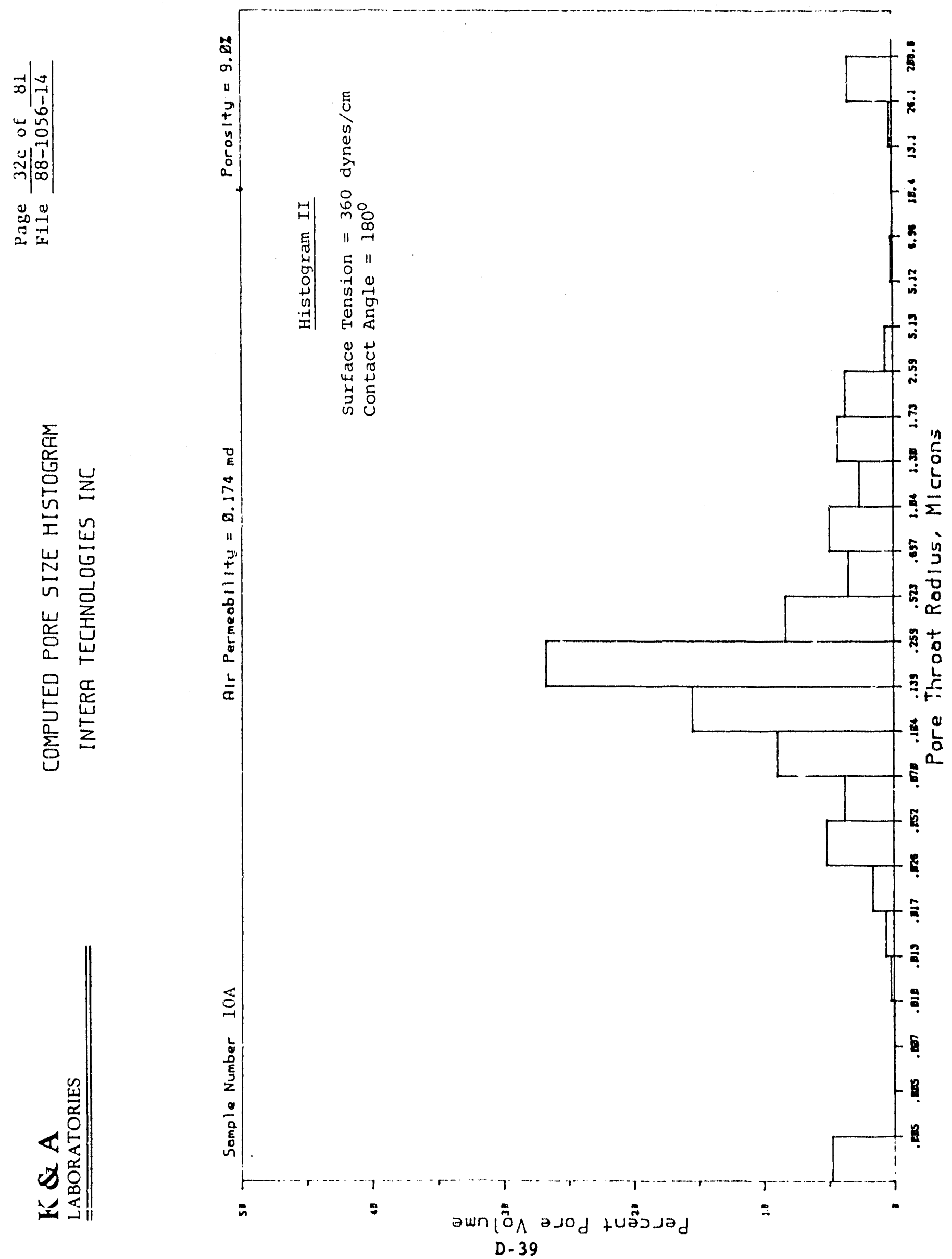
MERCURY INJECTION TEST RESULTS

INTERA TECHNOLOGIES, INC.

SAIPLE NUMBER 11

Air Permeability $=0.038 \mathrm{md}$

Porosity $=11.0 \%$

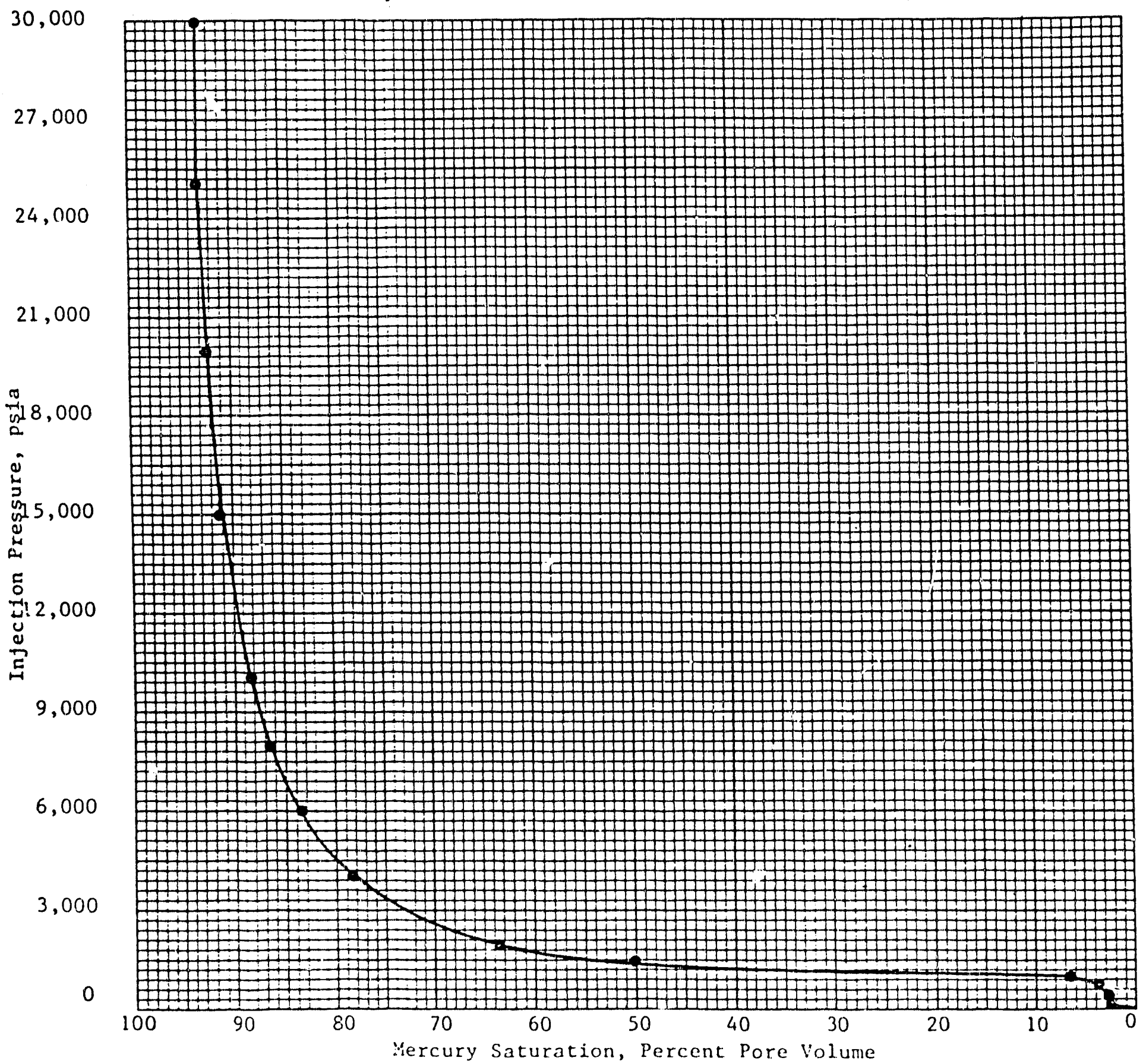




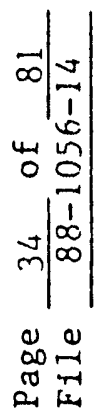

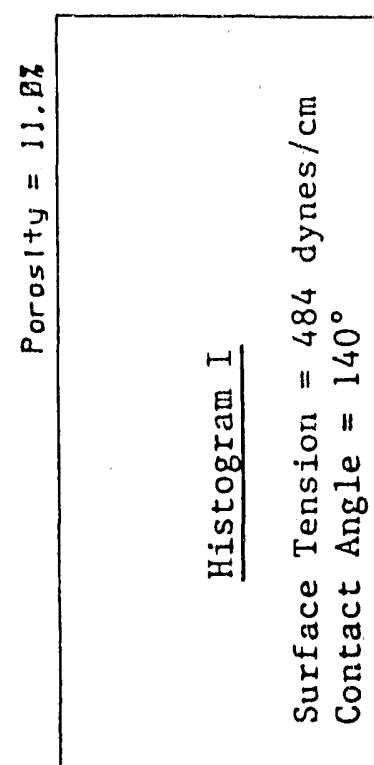

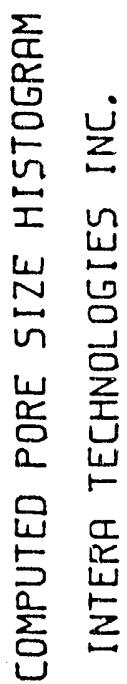

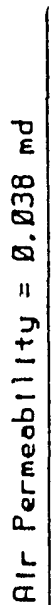
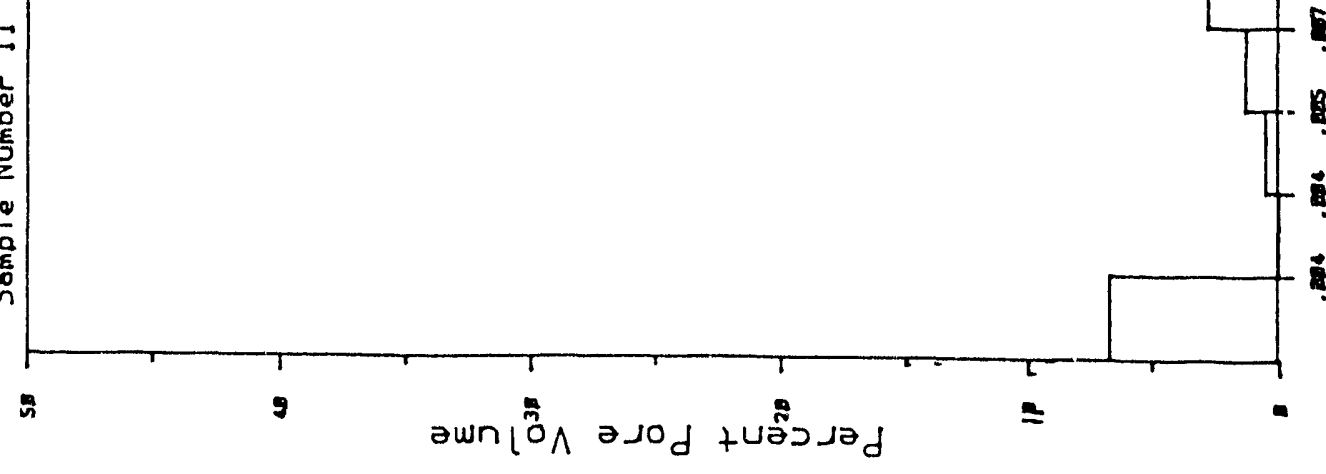


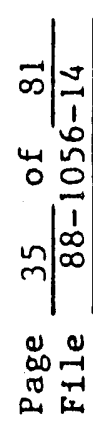

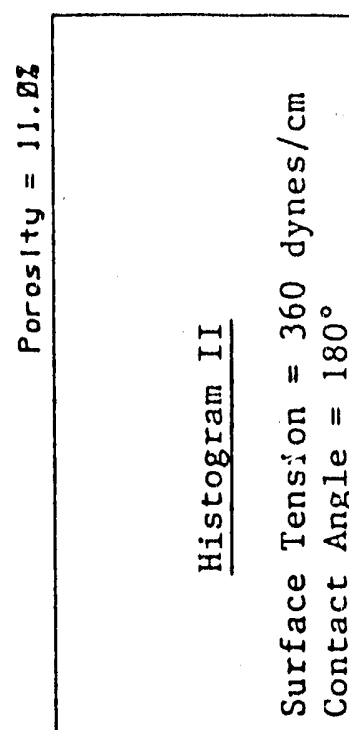

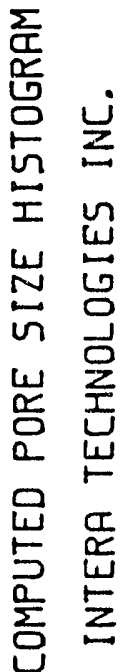
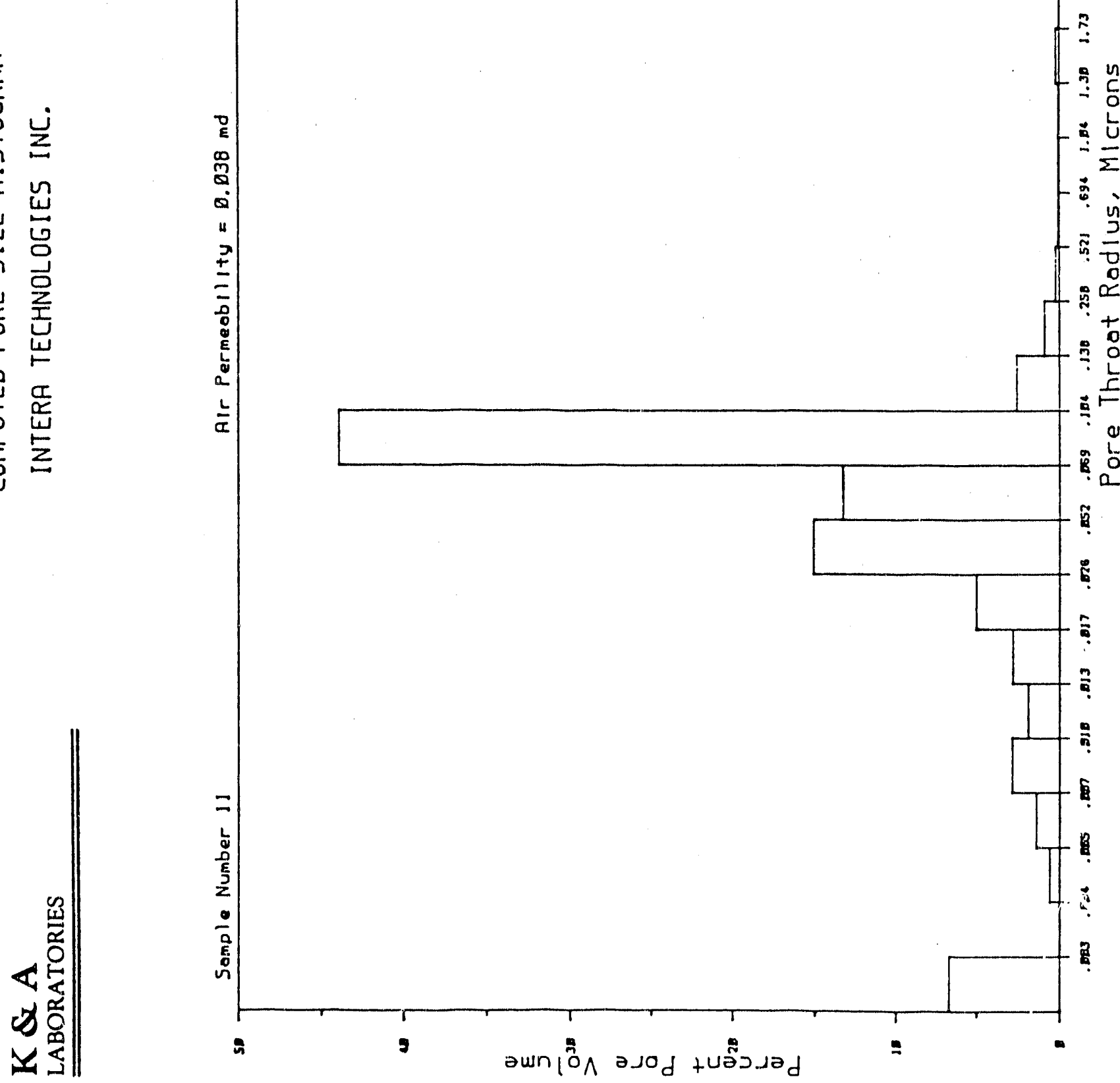

D -42 
MERCLRY INJECTION TEST RESULTS

INTERA TECHNOLOGIES, INC.

SAIPLE NUMBER 12

Air Permeability $=1.33 \mathrm{md}$

Porosity $=33.1 \%$

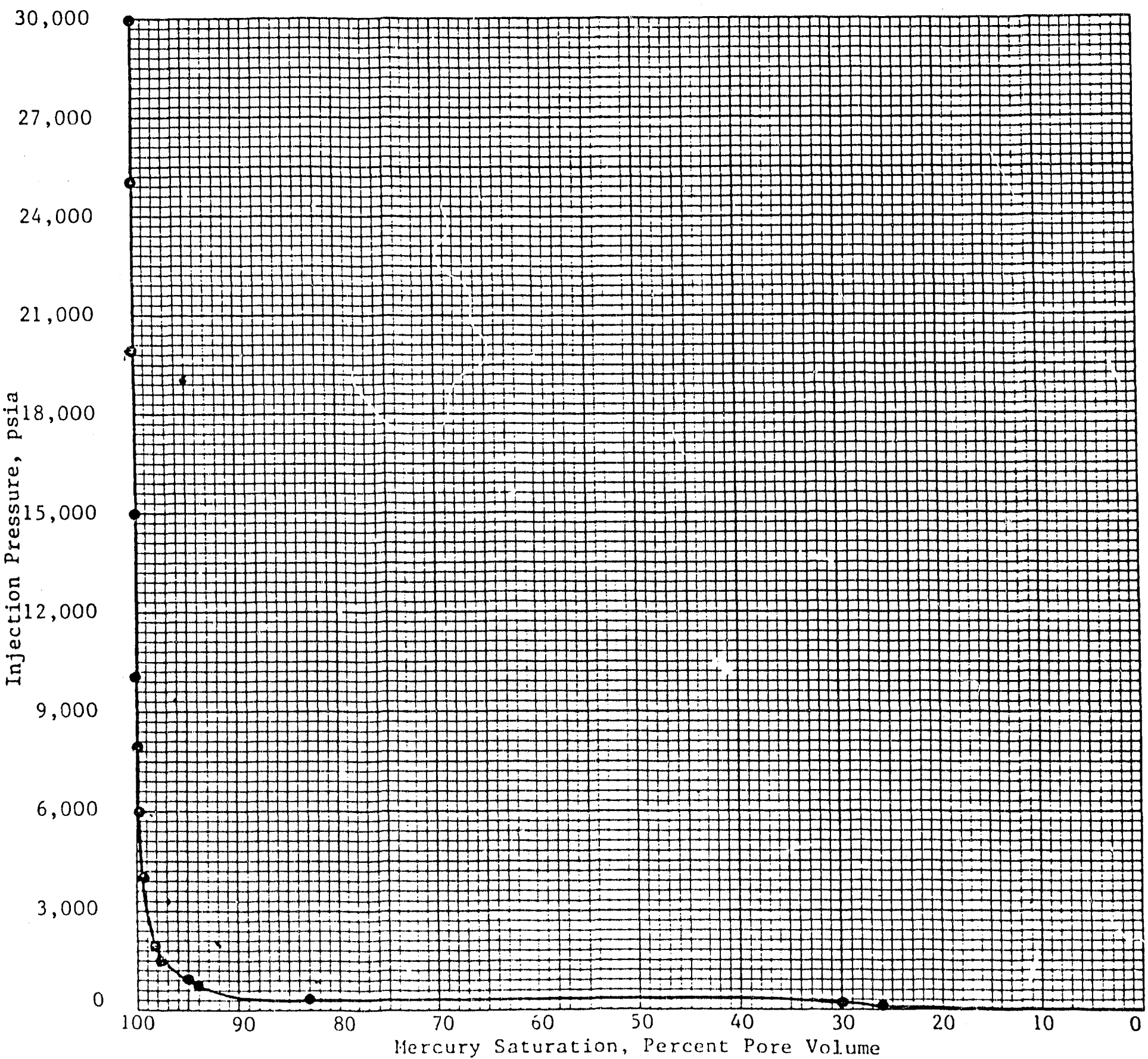




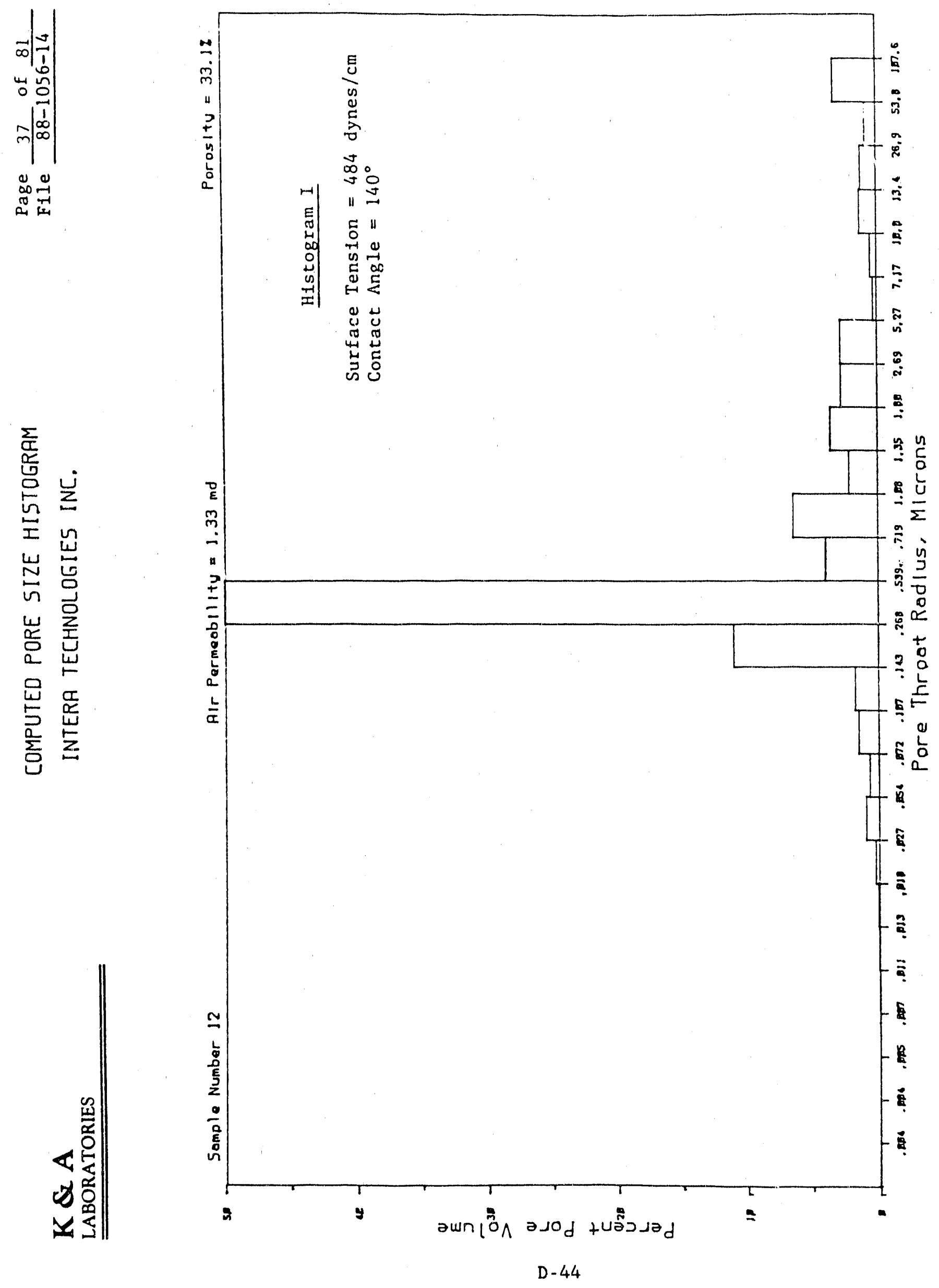




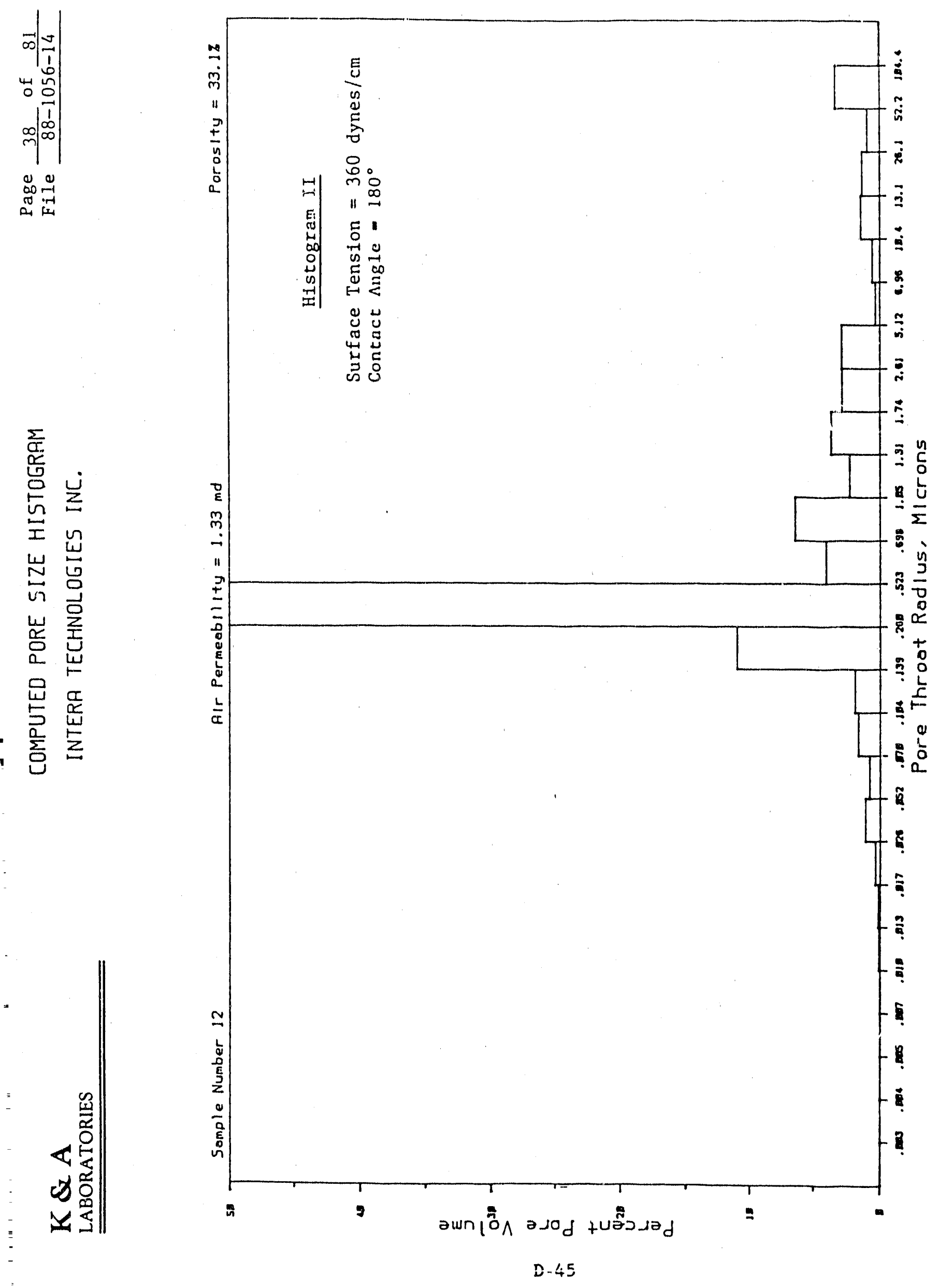


MERRCURY INJECTION TEST RESULTS

INTERA TECHNOLOGIES, INC.

SANPLE NUMBER 13

Air Permeability $=0.186 \mathrm{md}$

Porosity $=14.8 \%$

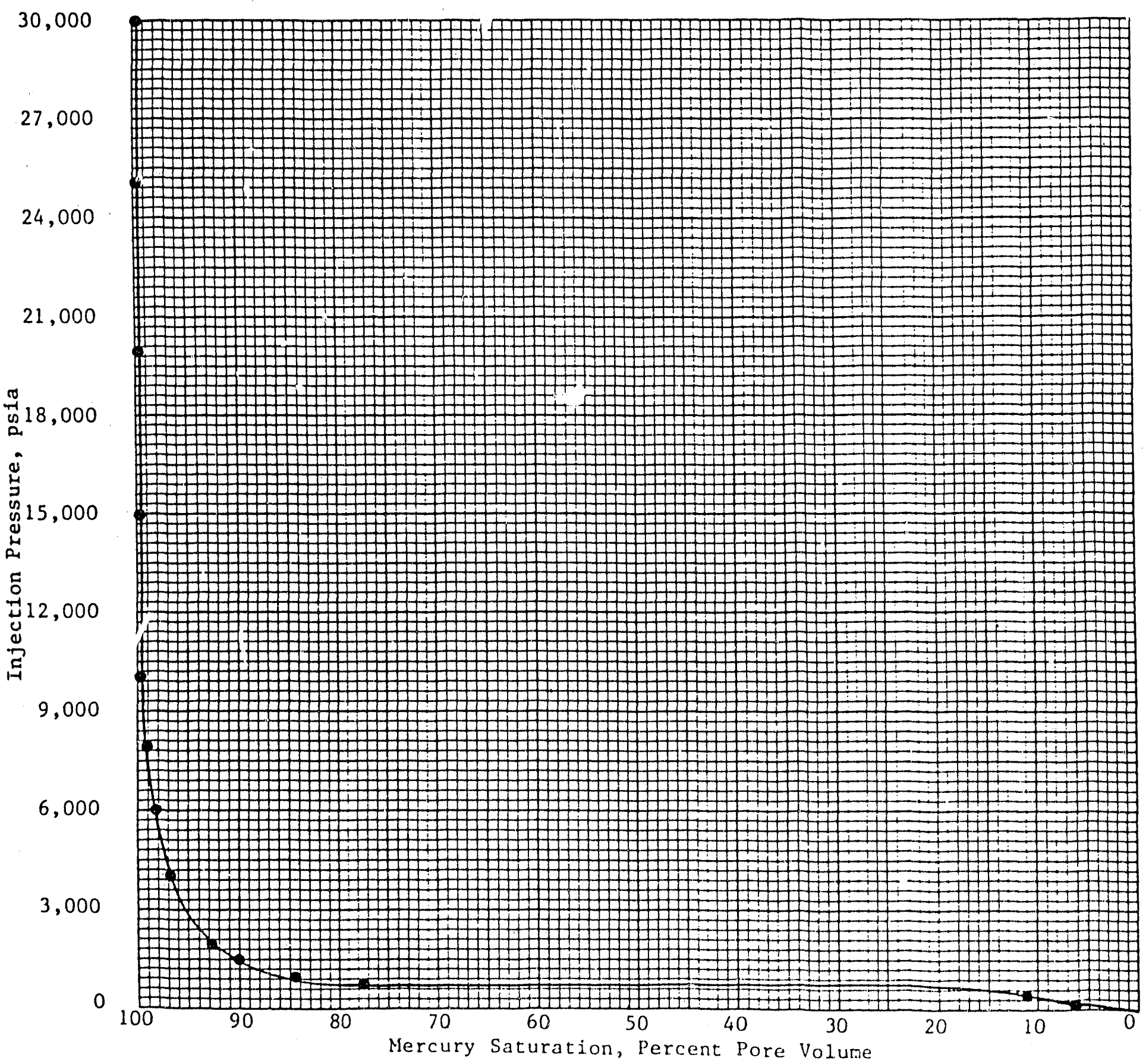




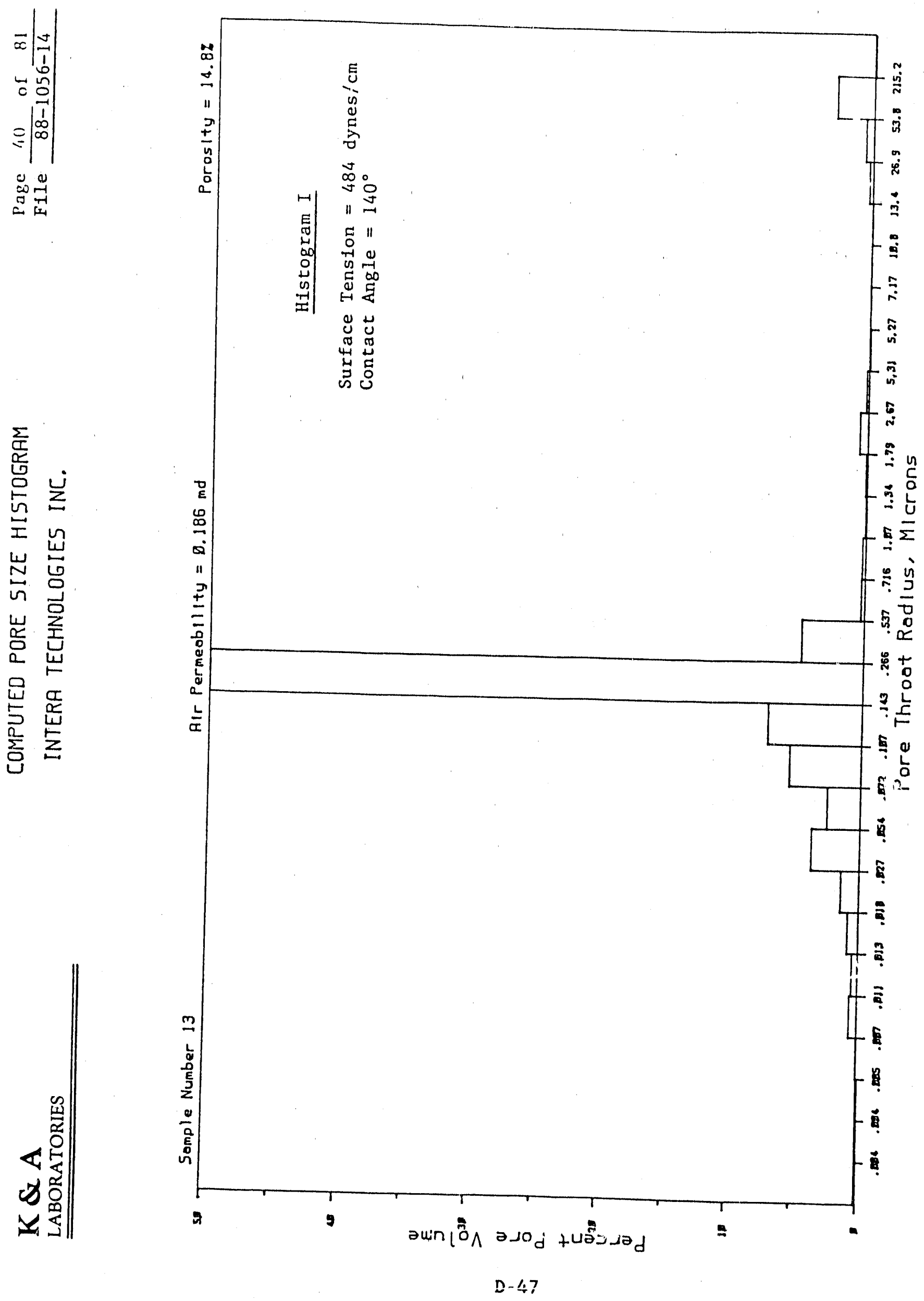




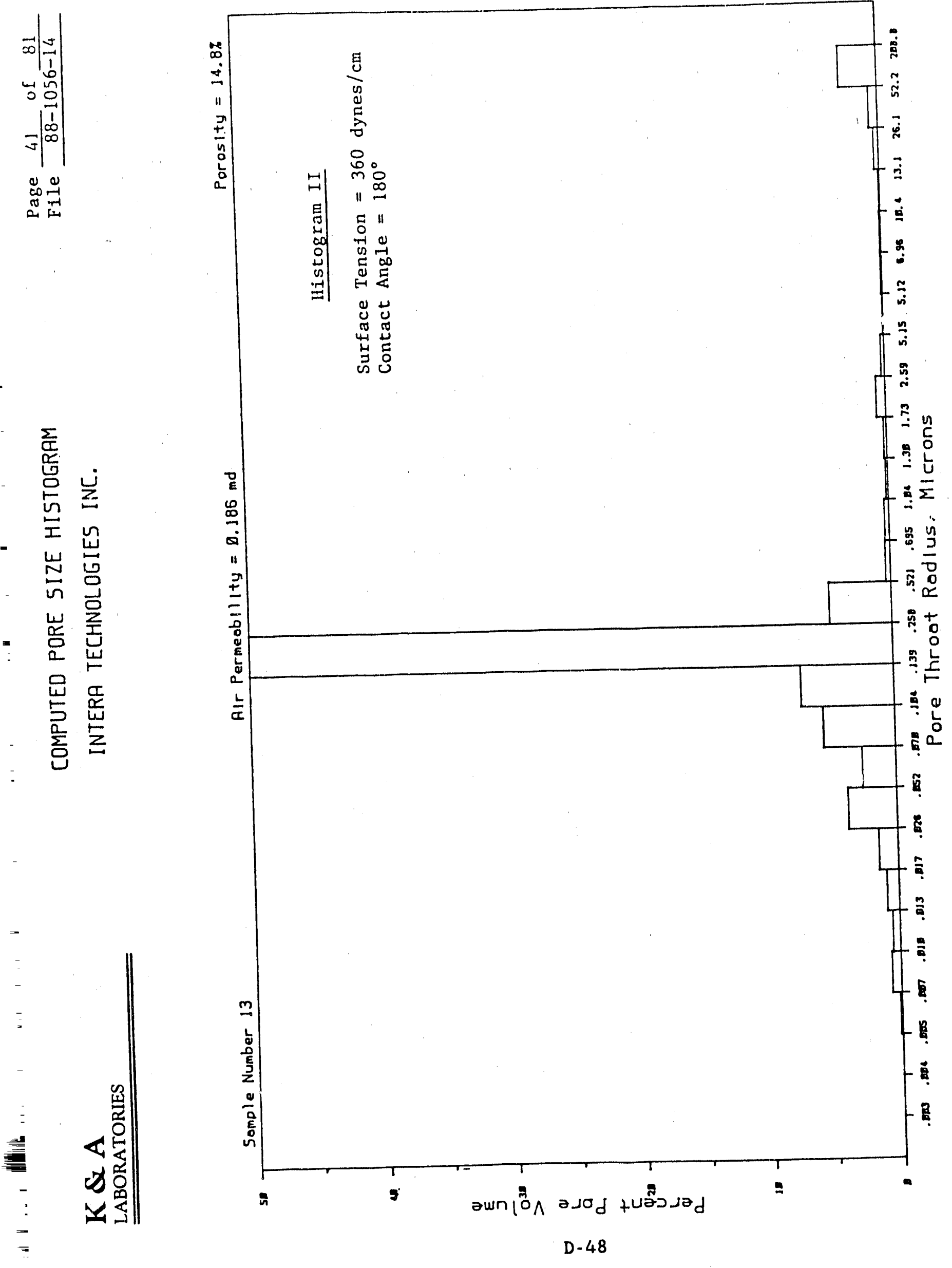


Page 42 of 81

$K \& A$

File $88-1056-14$

MERCURY INJECTION TEST RESULTS

INTERA TECHNOLOGIES, INC.

SAMPLE NUMBER 14

Air Permeability $=0.270 \mathrm{md}$

Porosity $=2.8 \%$

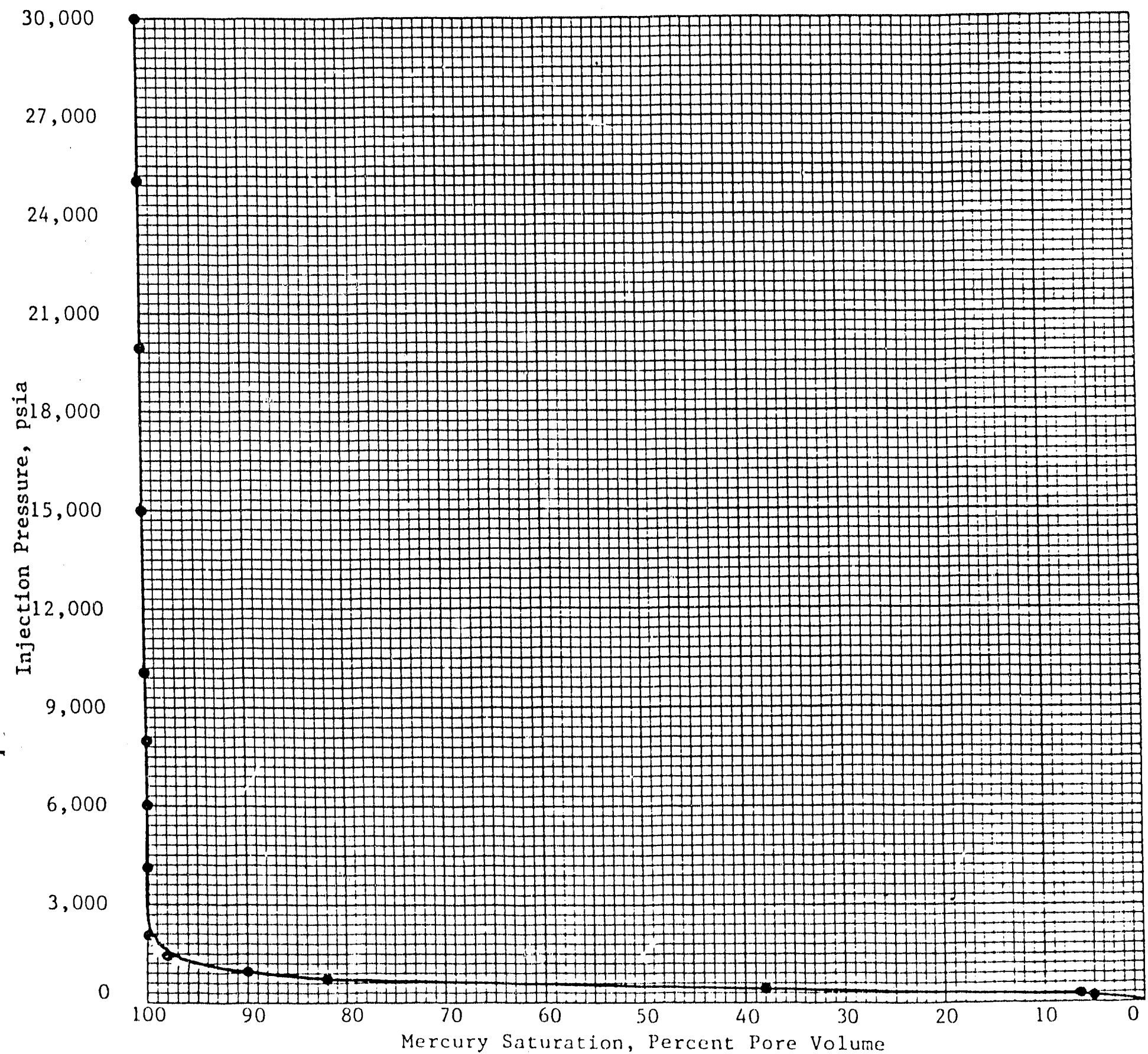


1
0

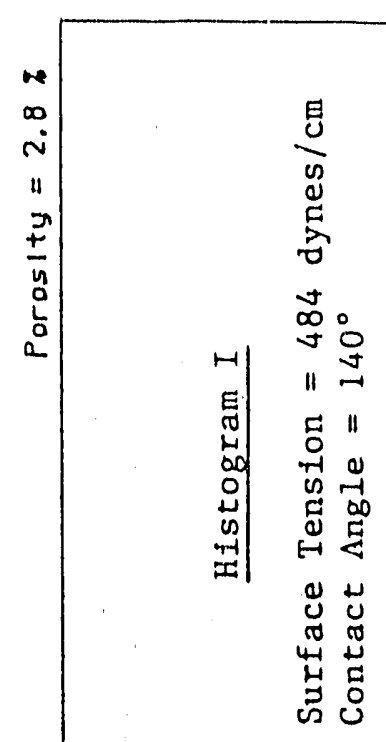

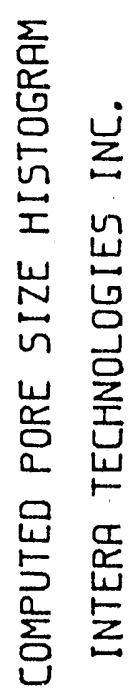

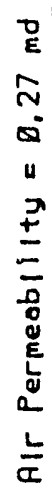
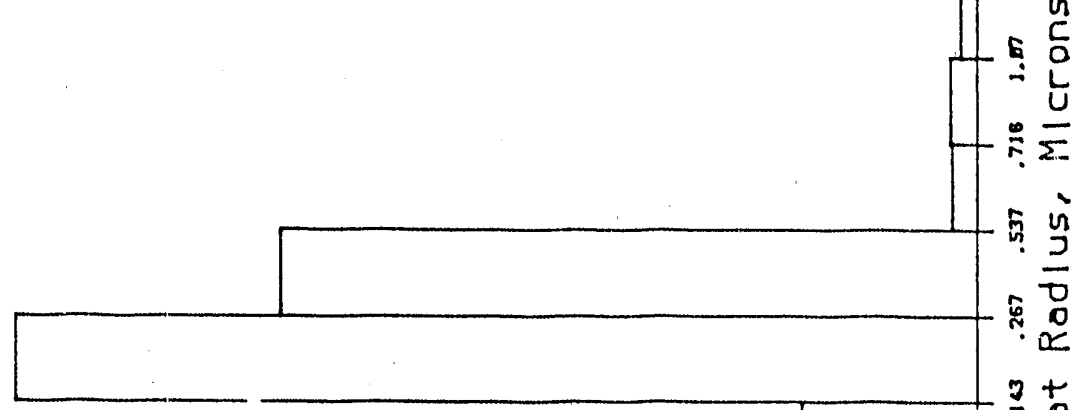

$2+$

$\because 0$

들

는 능

0

L
g
E
2
0
$\frac{0}{0}$
ह

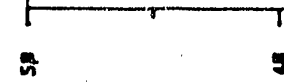

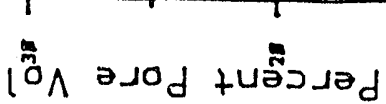

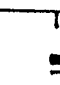

D -50 


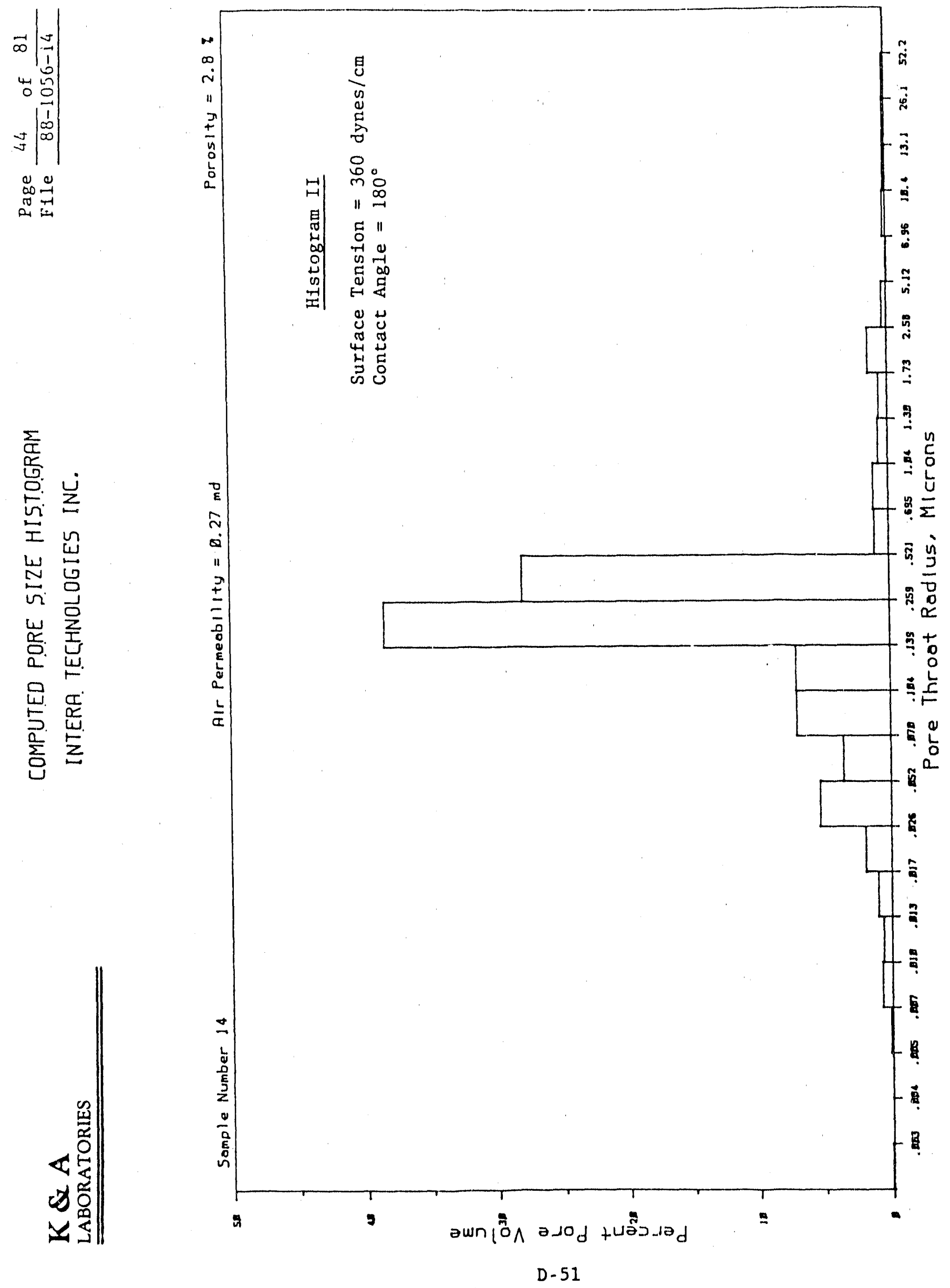


MERCURY INJECTION TEST RESULTS

INTERA TECHNOLOGIES, INC.

SAMPLE NUMBER 15

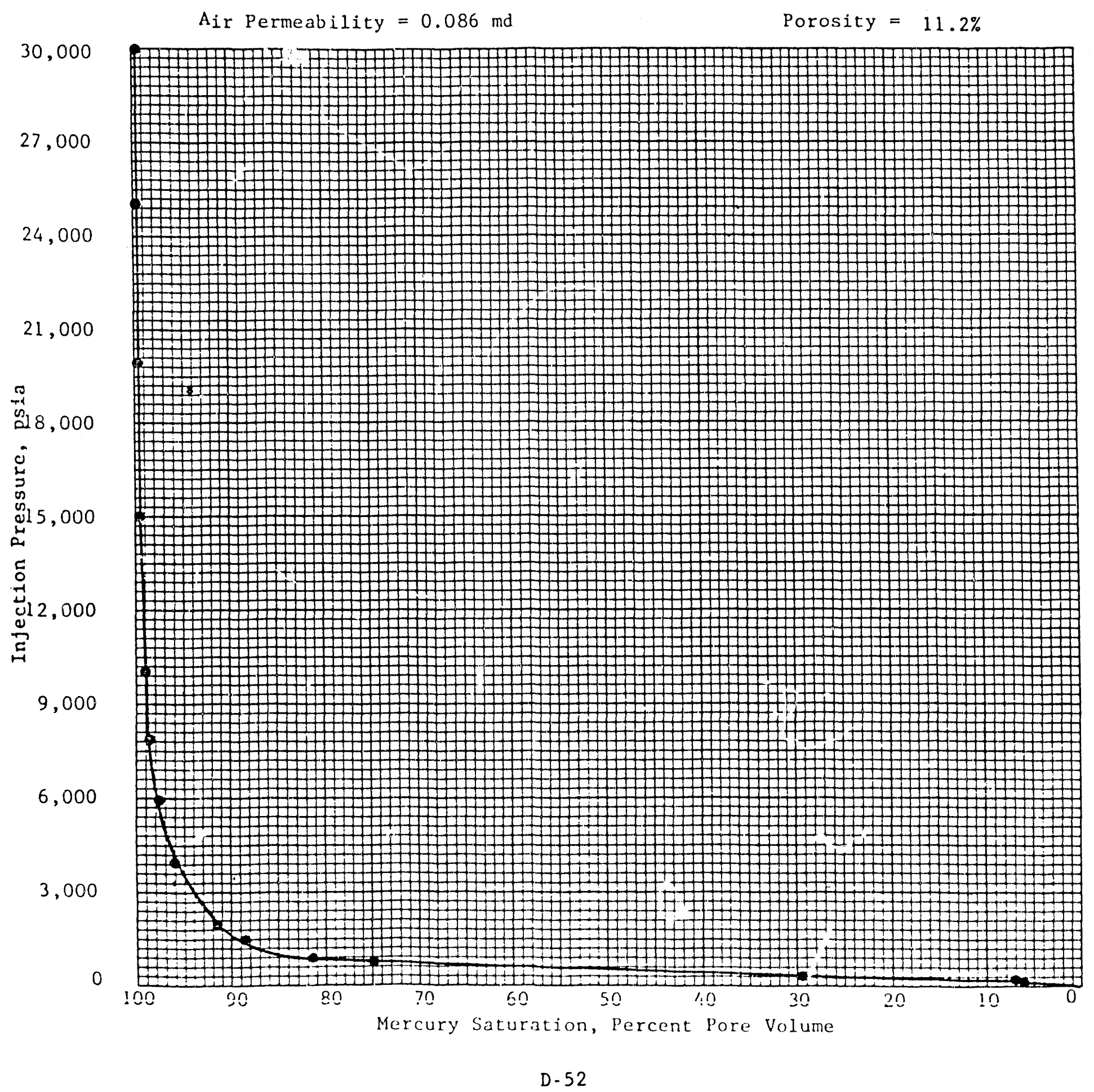



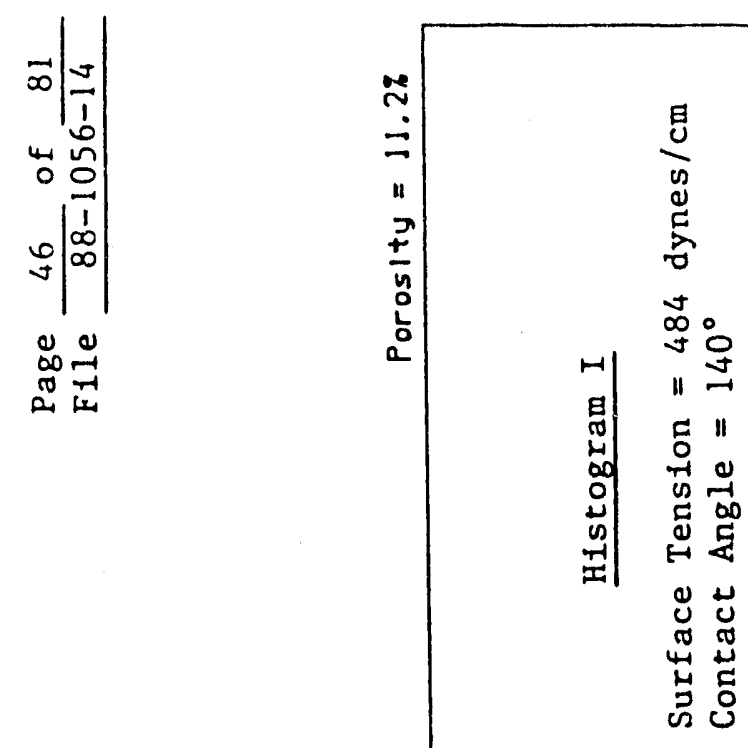

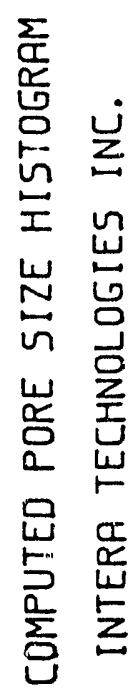
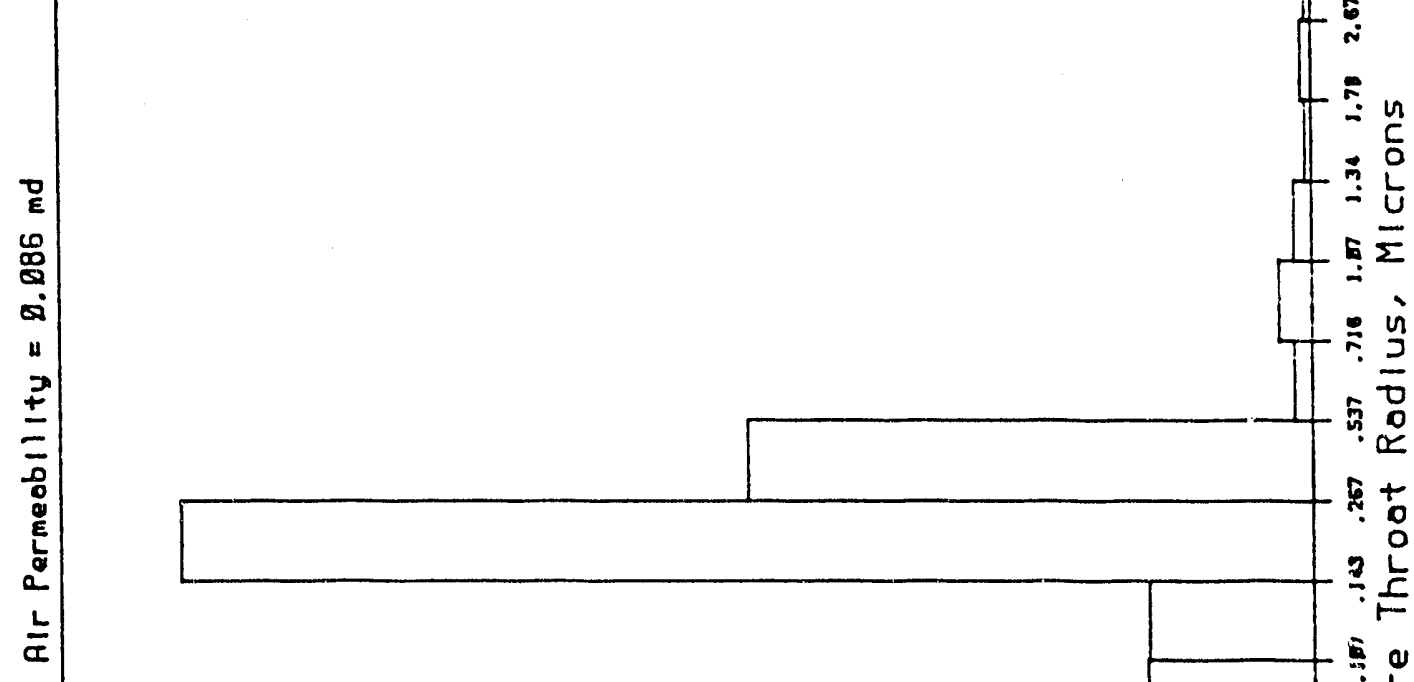

논

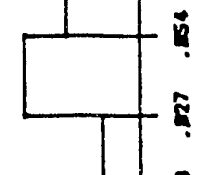




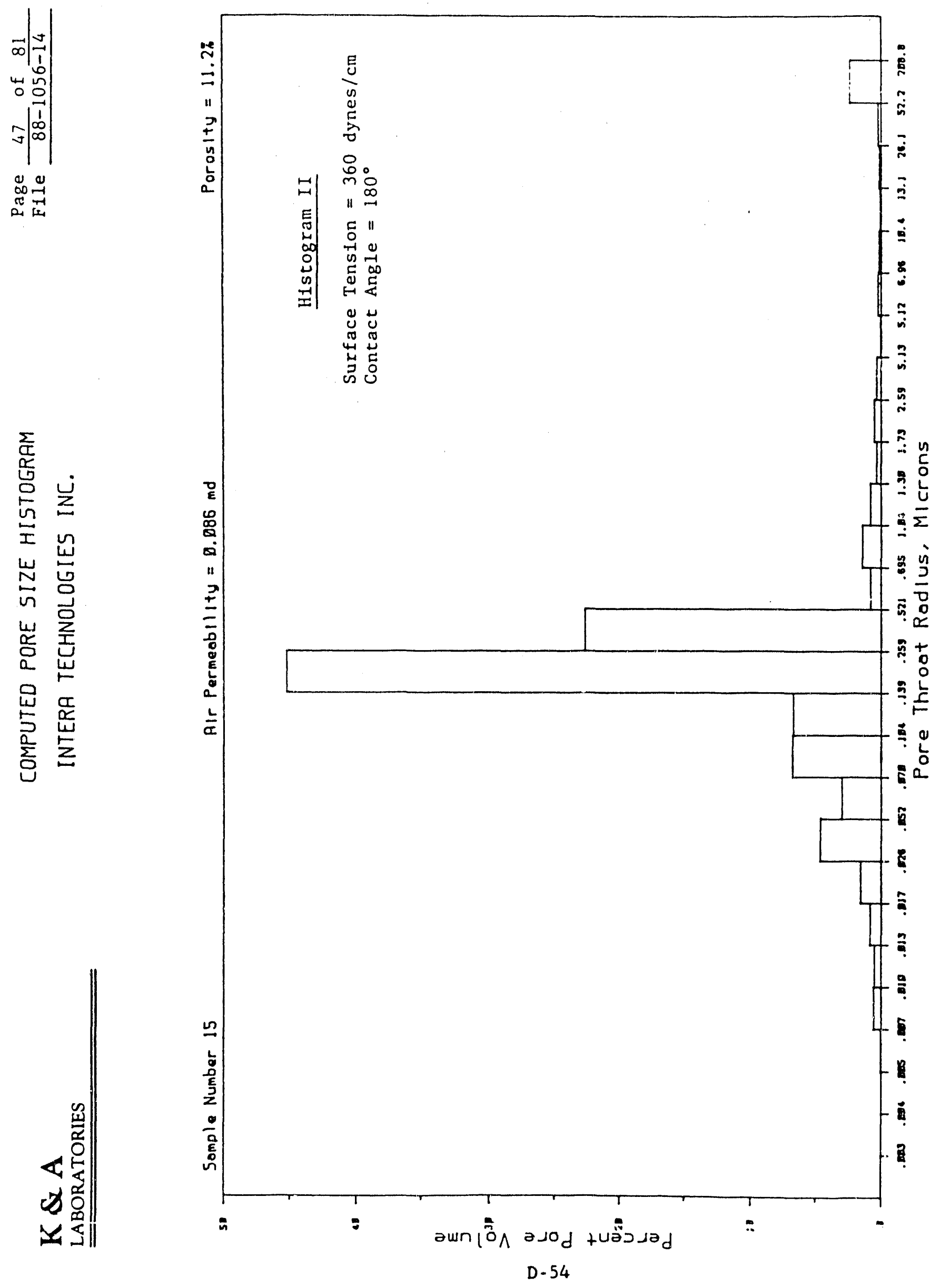


MERCURY INJECTION TEST RESULTS

INTERA TECHNOLOGIES, INC.

SAMPLE NUMBER 16

Air Permeability $=1.38 \mathrm{md}$

Porosity $=13.6 \%$

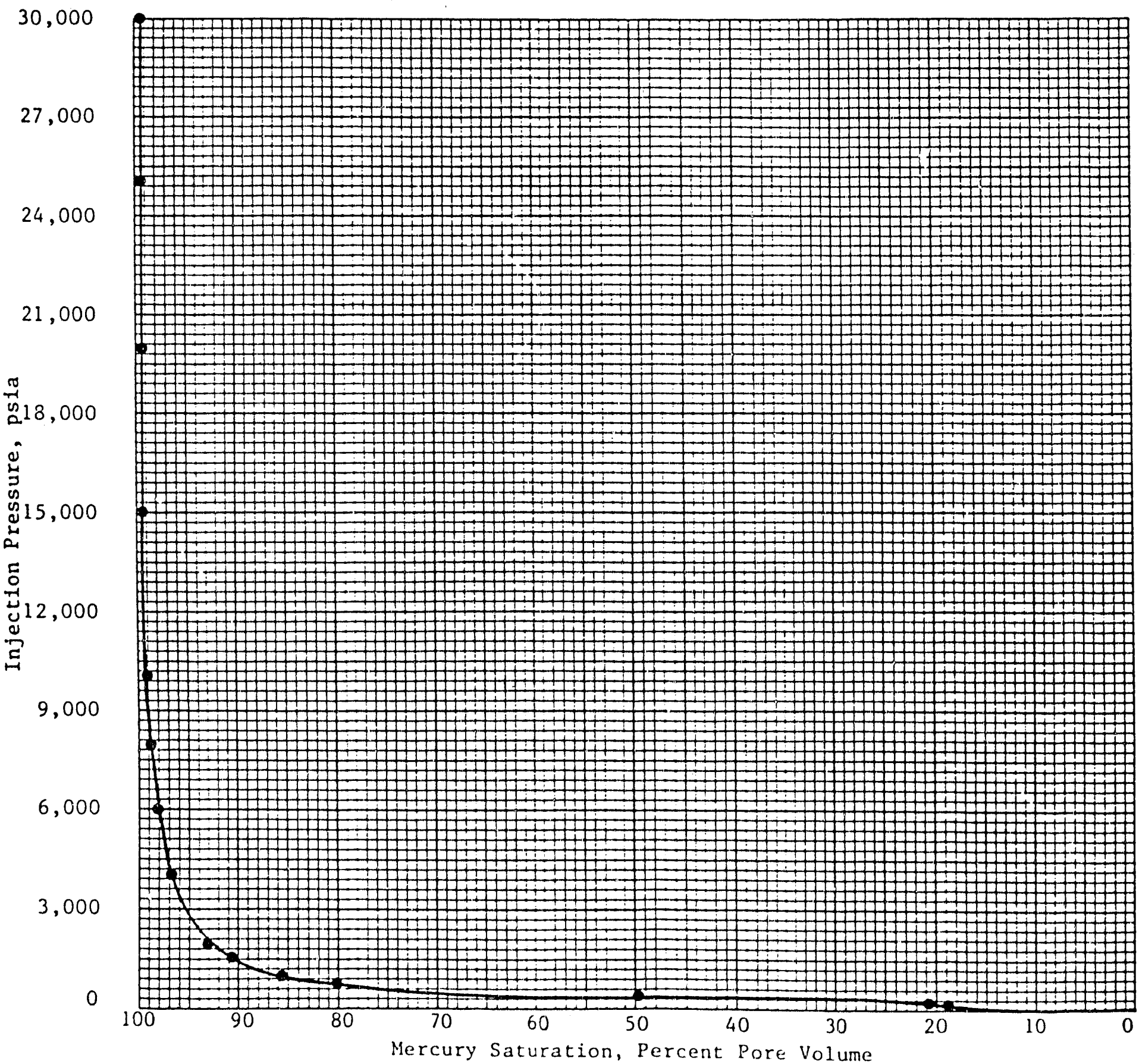




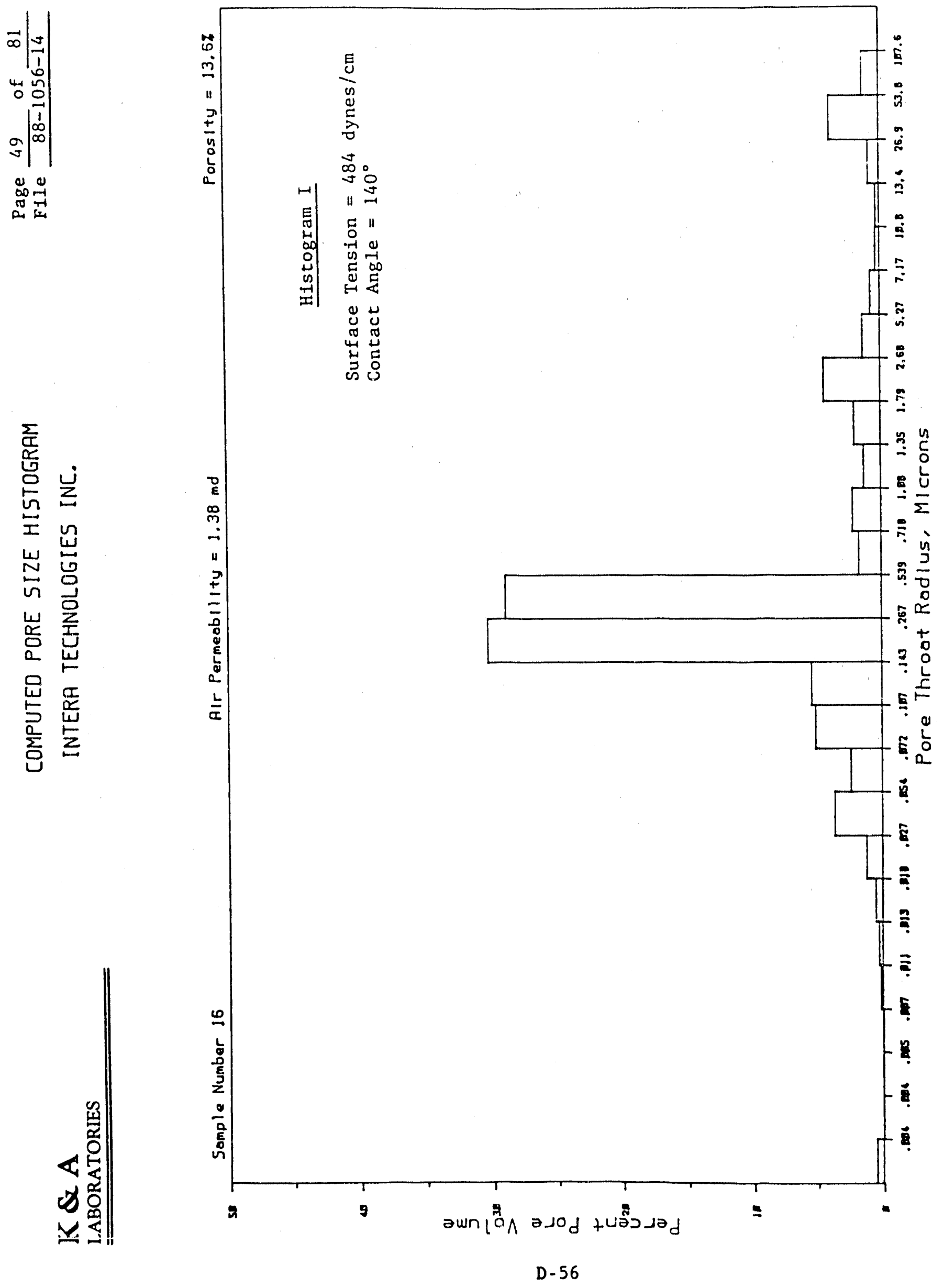




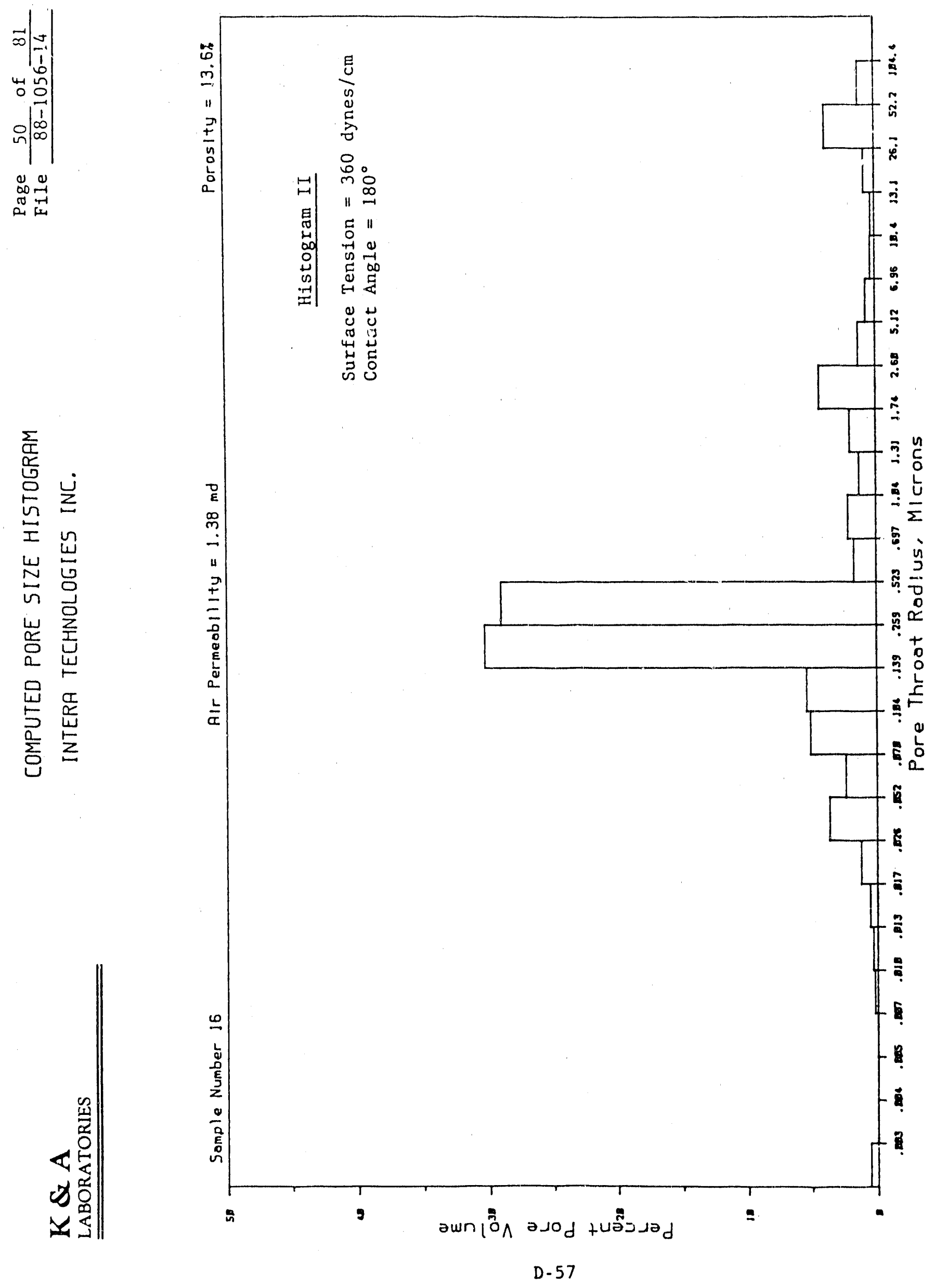


$\mathrm{K} \& \mathrm{~A}$

LABORATORIES
Page 51 of 81

File $\frac{51}{88-1056-14}$

MERCUR: INJECTION TEST RESULTS

INTERA TECHNOLOGIES, INC.

SANPLE NUNBER 17

Air Permeability $=4.94$ and

Porosity $=19.0 \%$

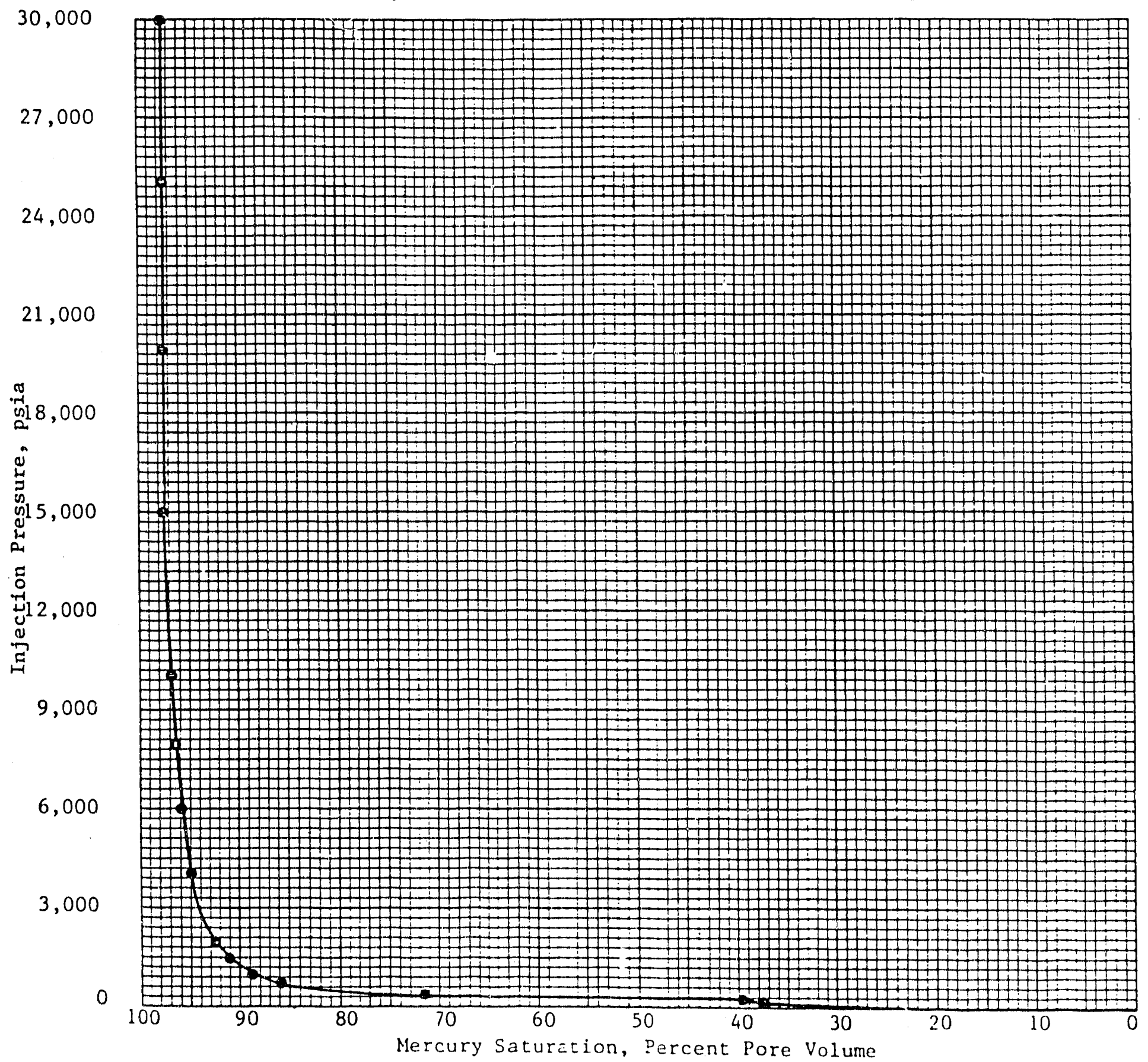




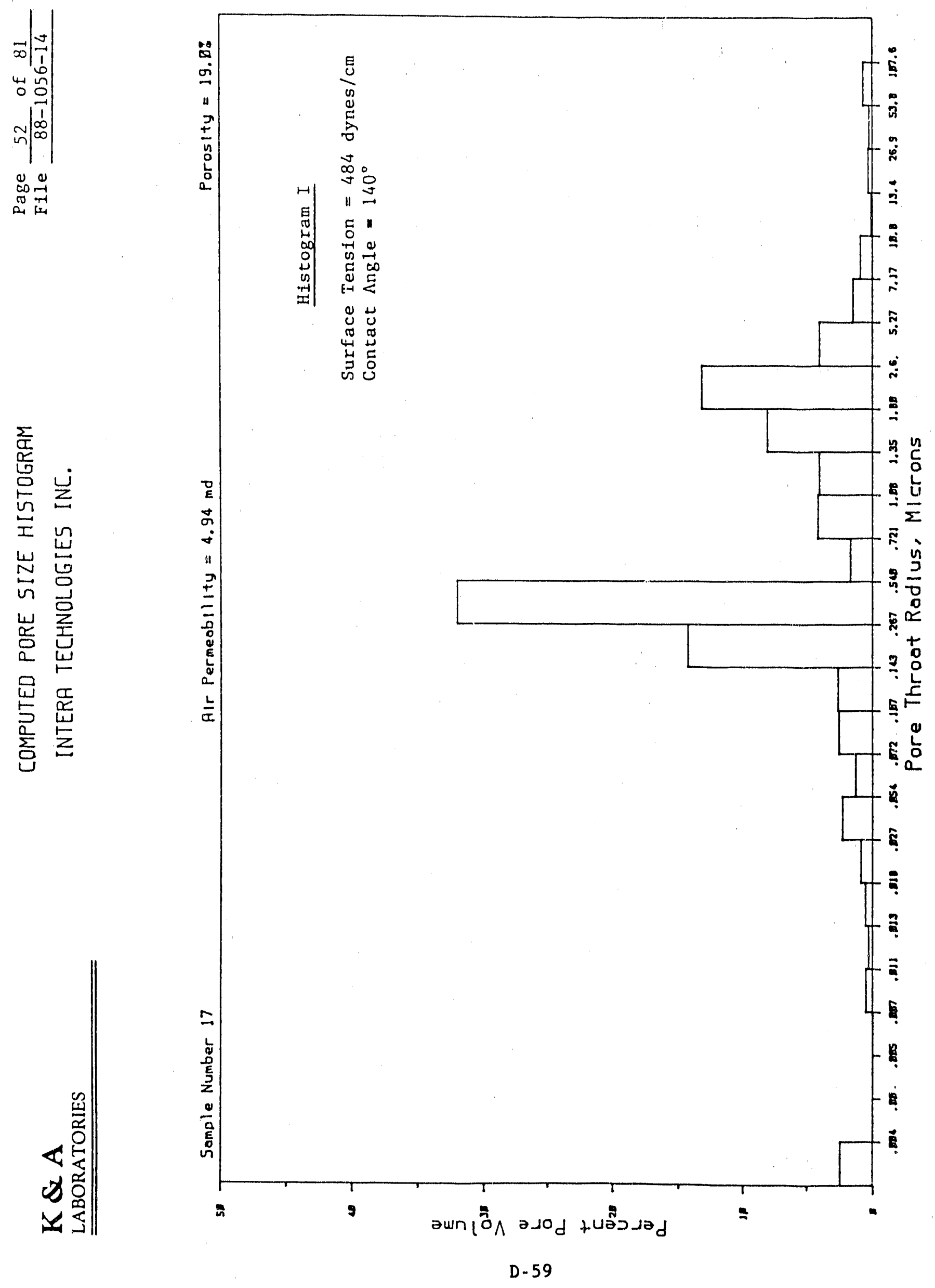




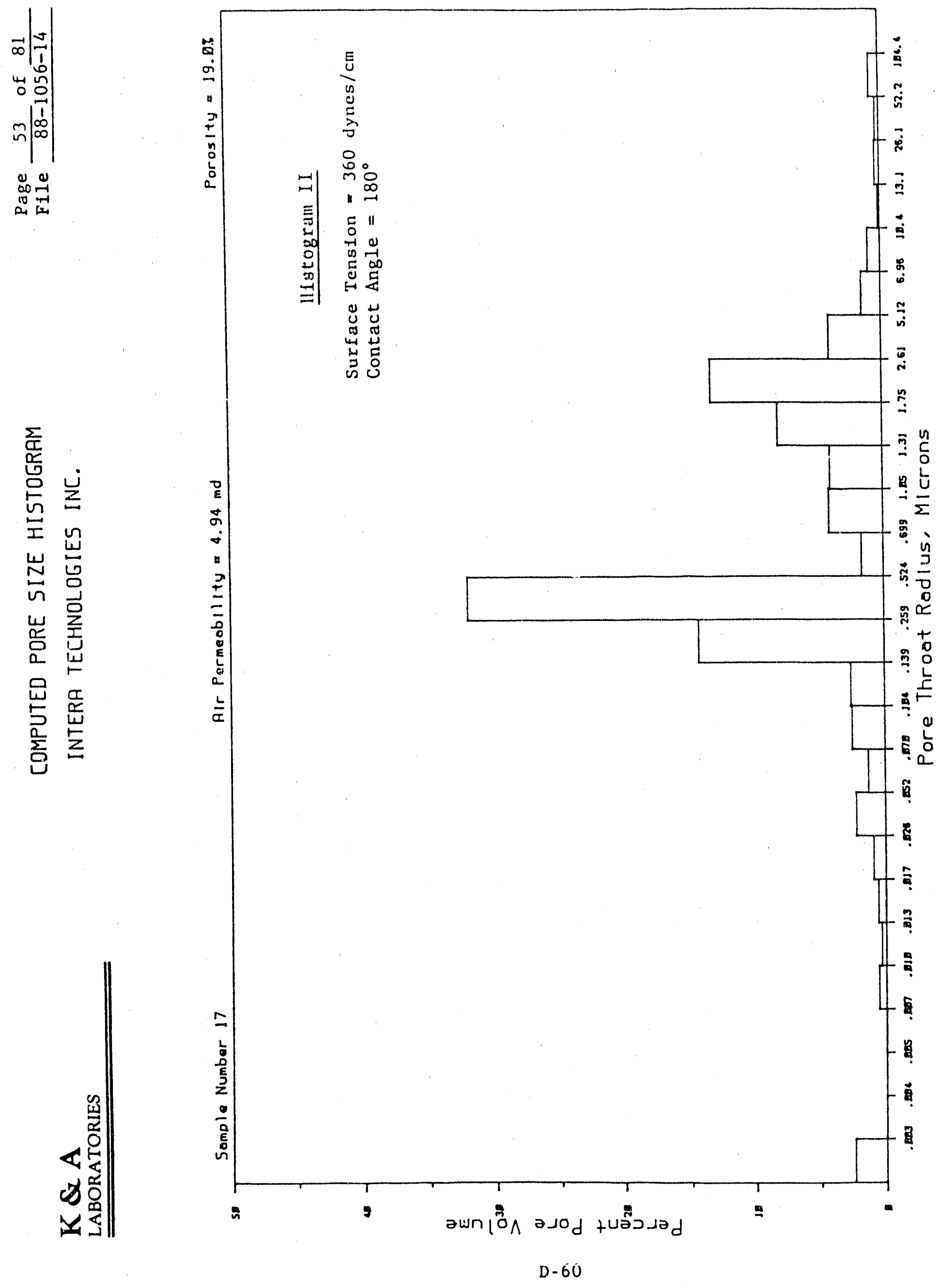


$\mathrm{K} \& \mathrm{~A}$

LABORATORIES
Page 54 of 81

File $88-1056-14$

MERCURY INJECTION TEST RISUULTS

INTERA TECHNOLOGIES, INC.

SAMPLE NUMBER 18

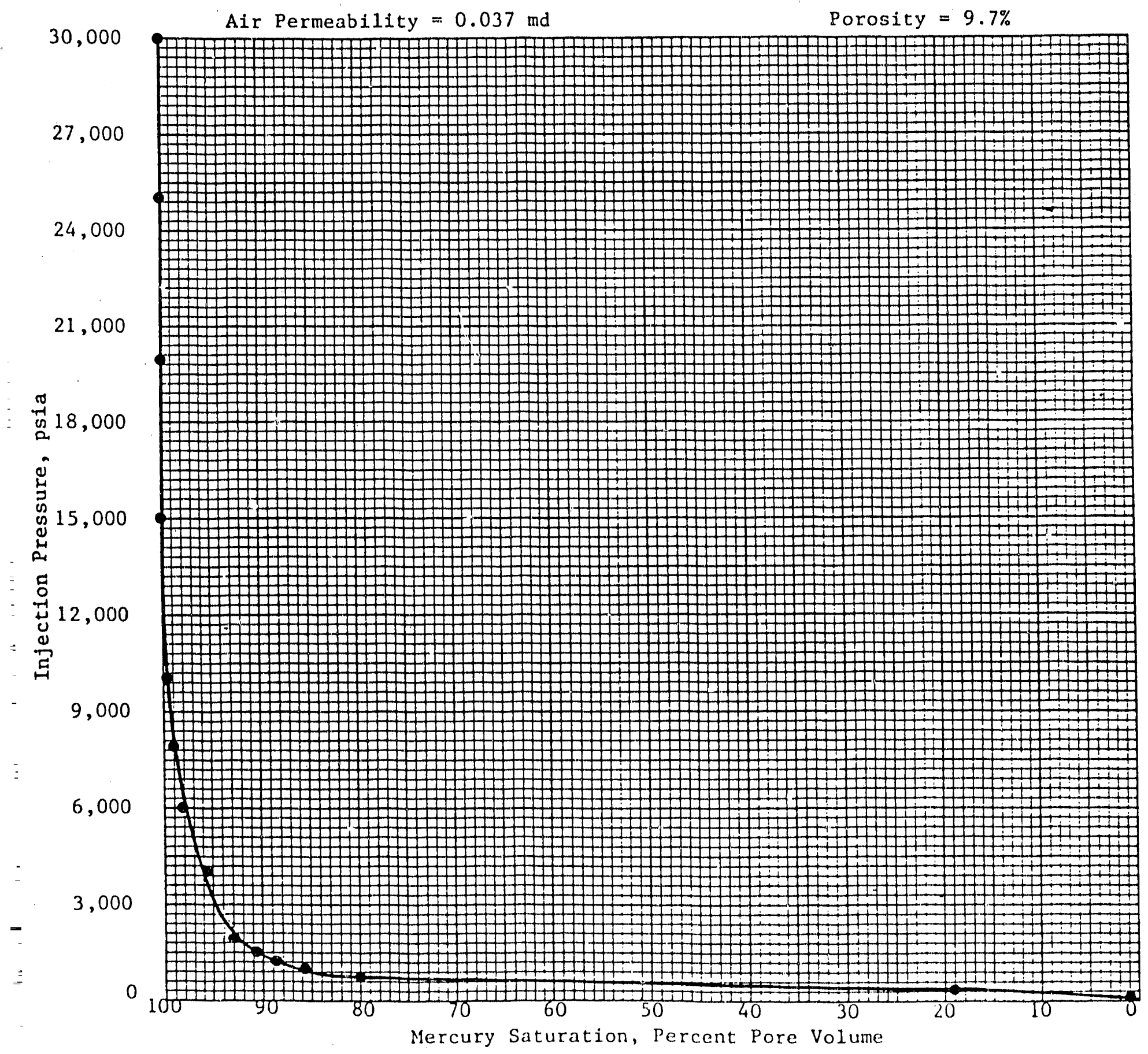

D- 61 


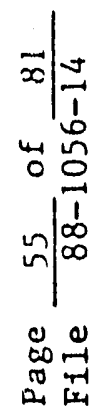

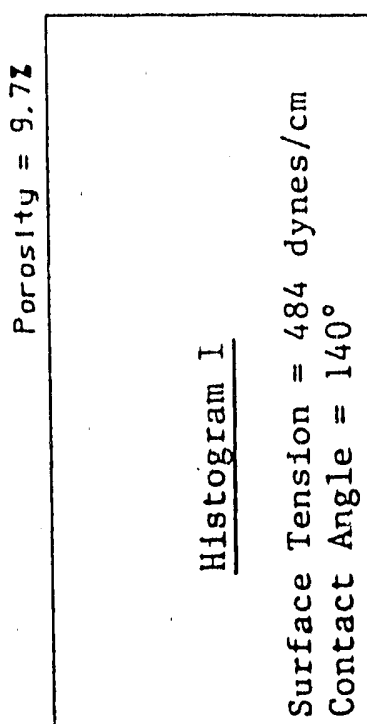

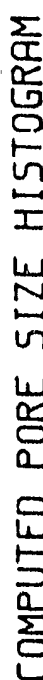
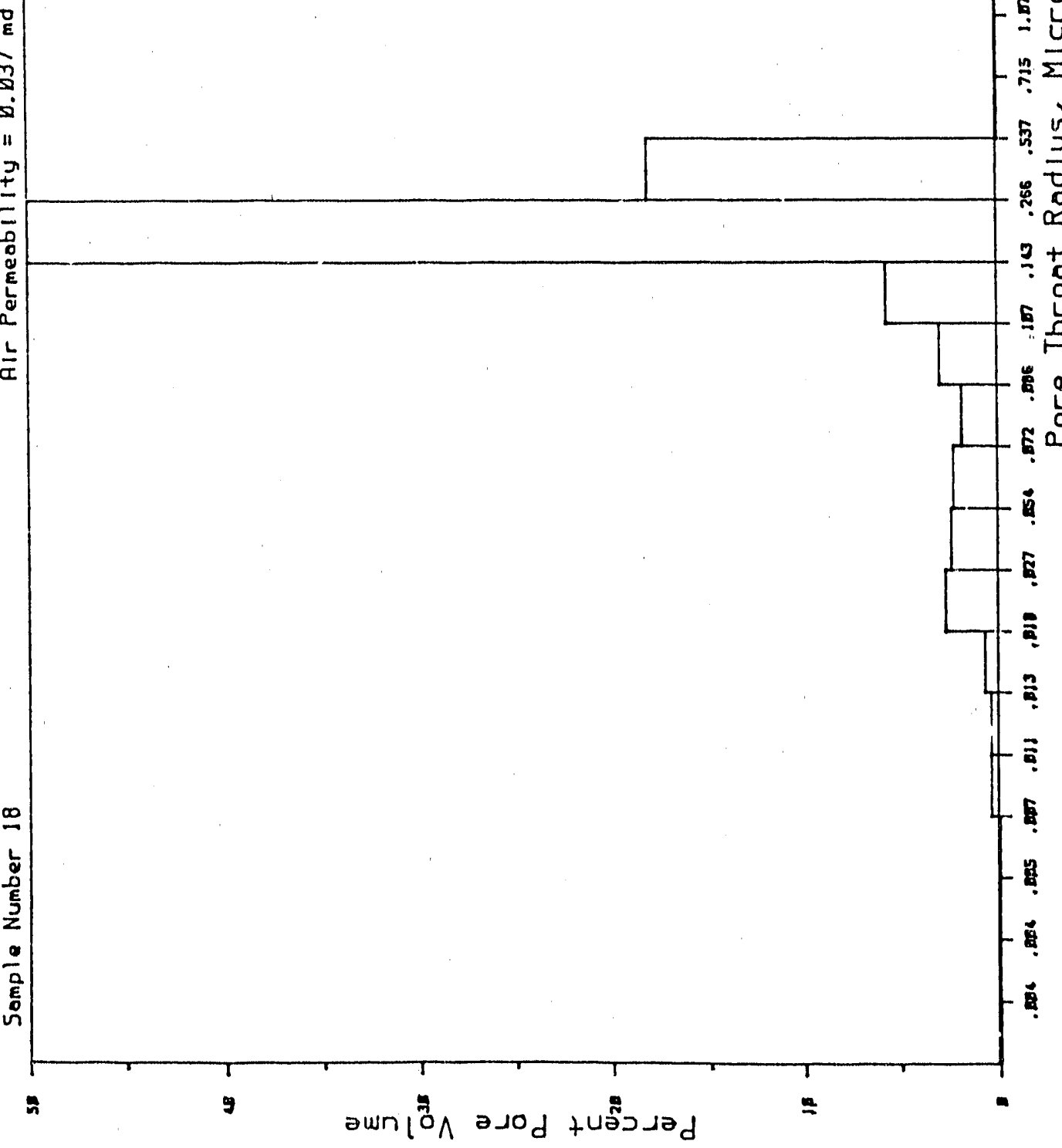

D- 62 


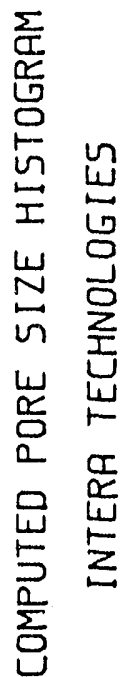
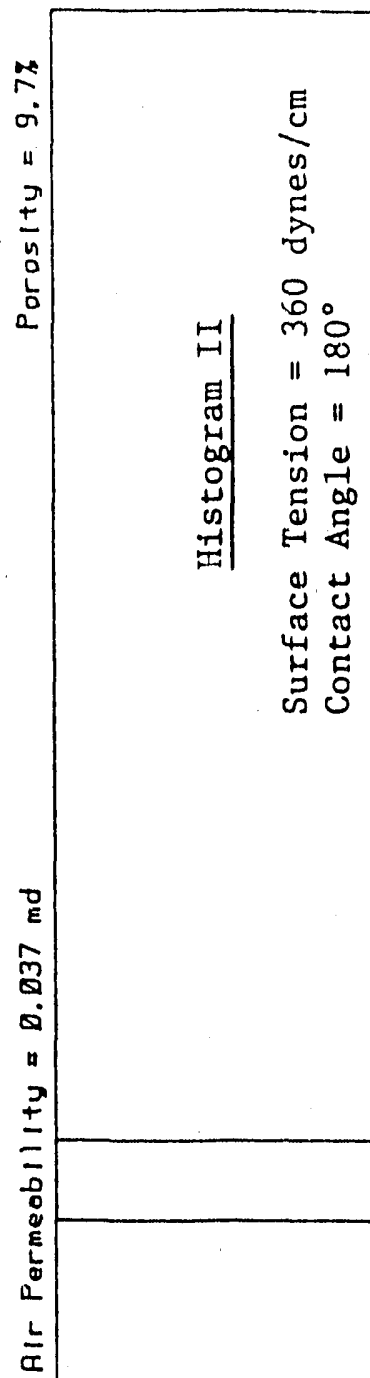

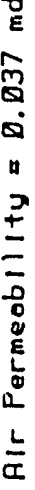

1

สั

드

S.

$\leftrightarrow$

ปै

营

कै
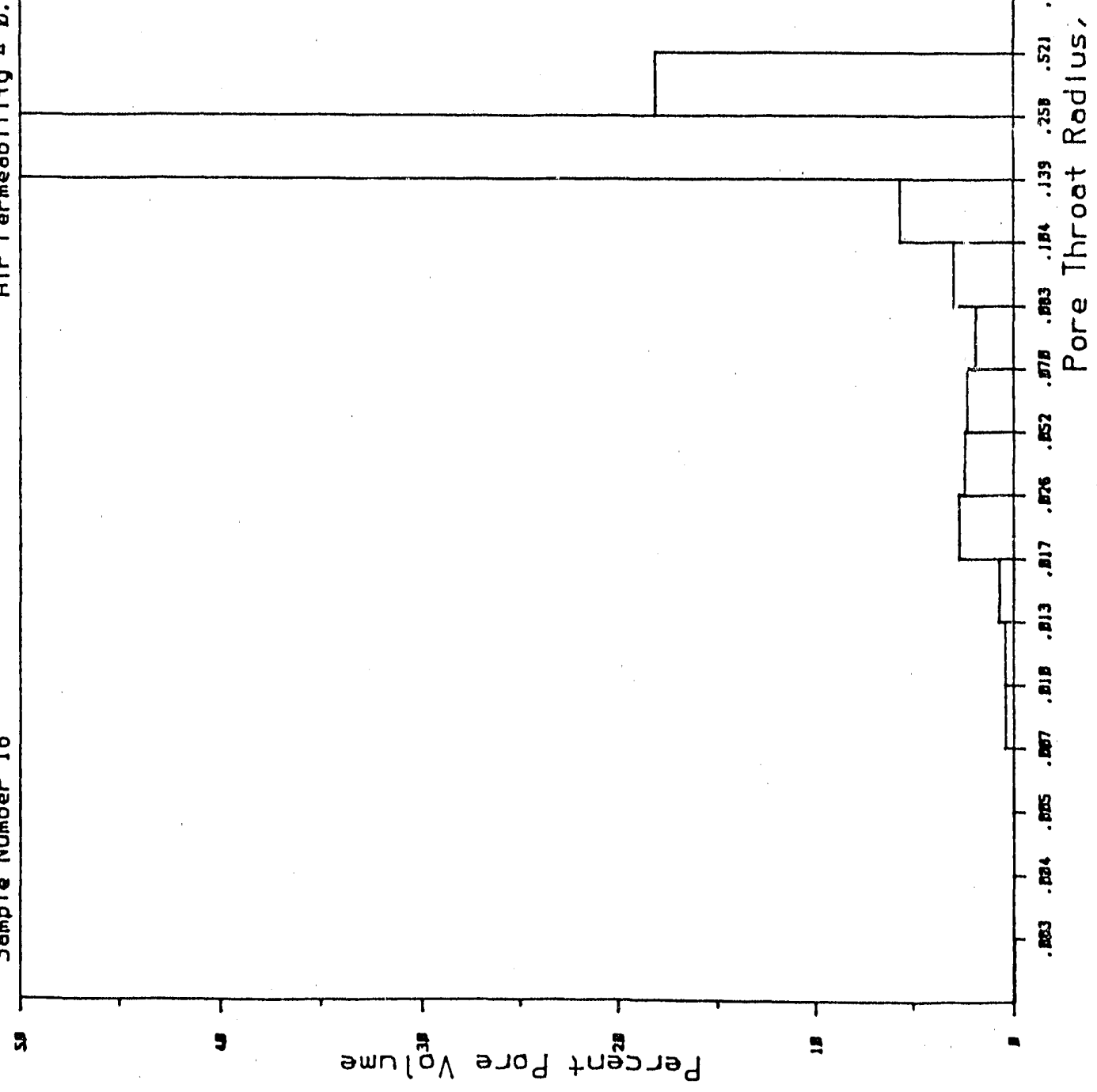

D. 63 
Page 57 of 81 LABORATORIES

File $88-1056-14$

MERCURY INJECTION TEST RESULTS

INTERA TECHNOLOGIES, INC.

SAMPLE NUMBER 19

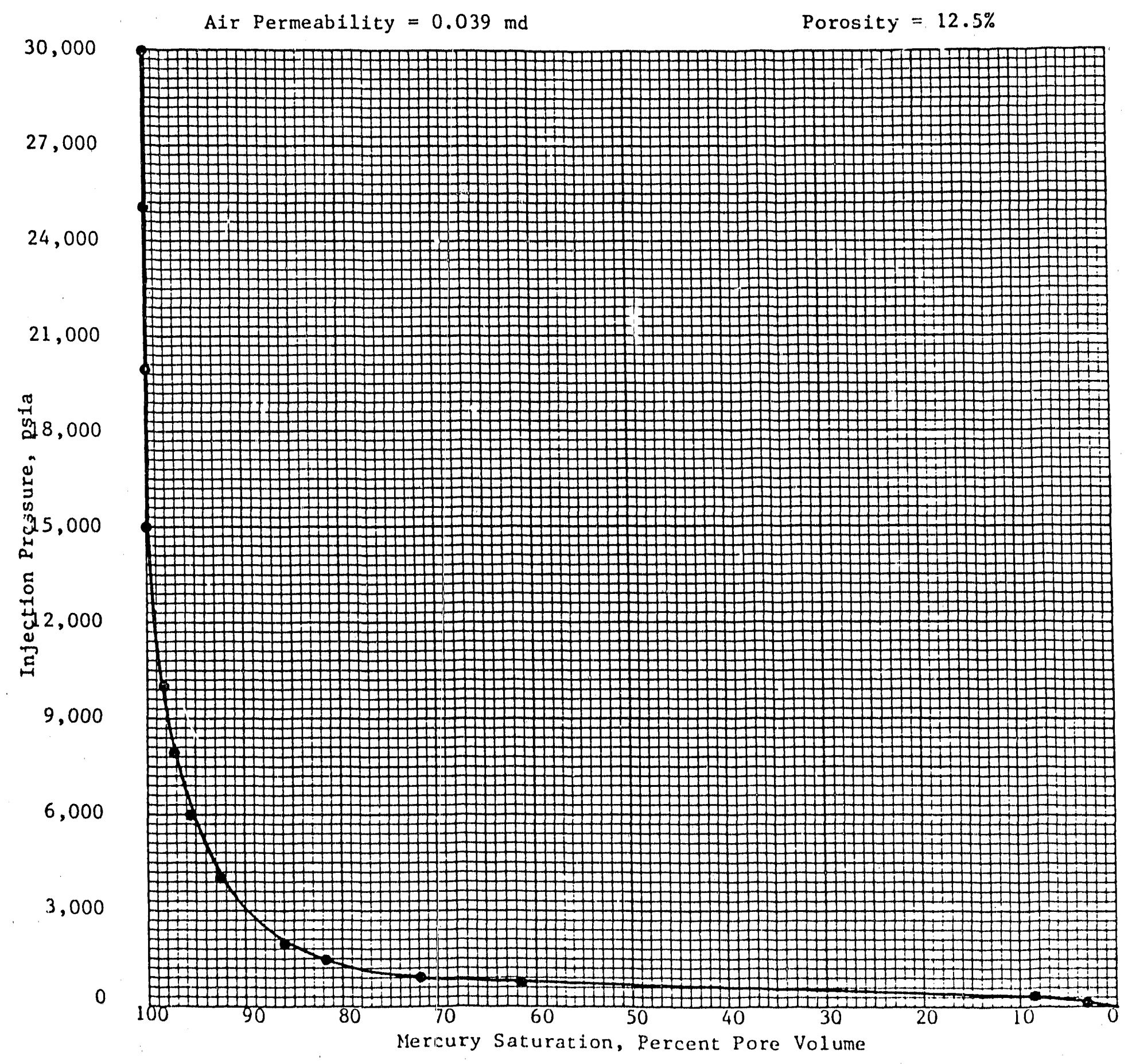



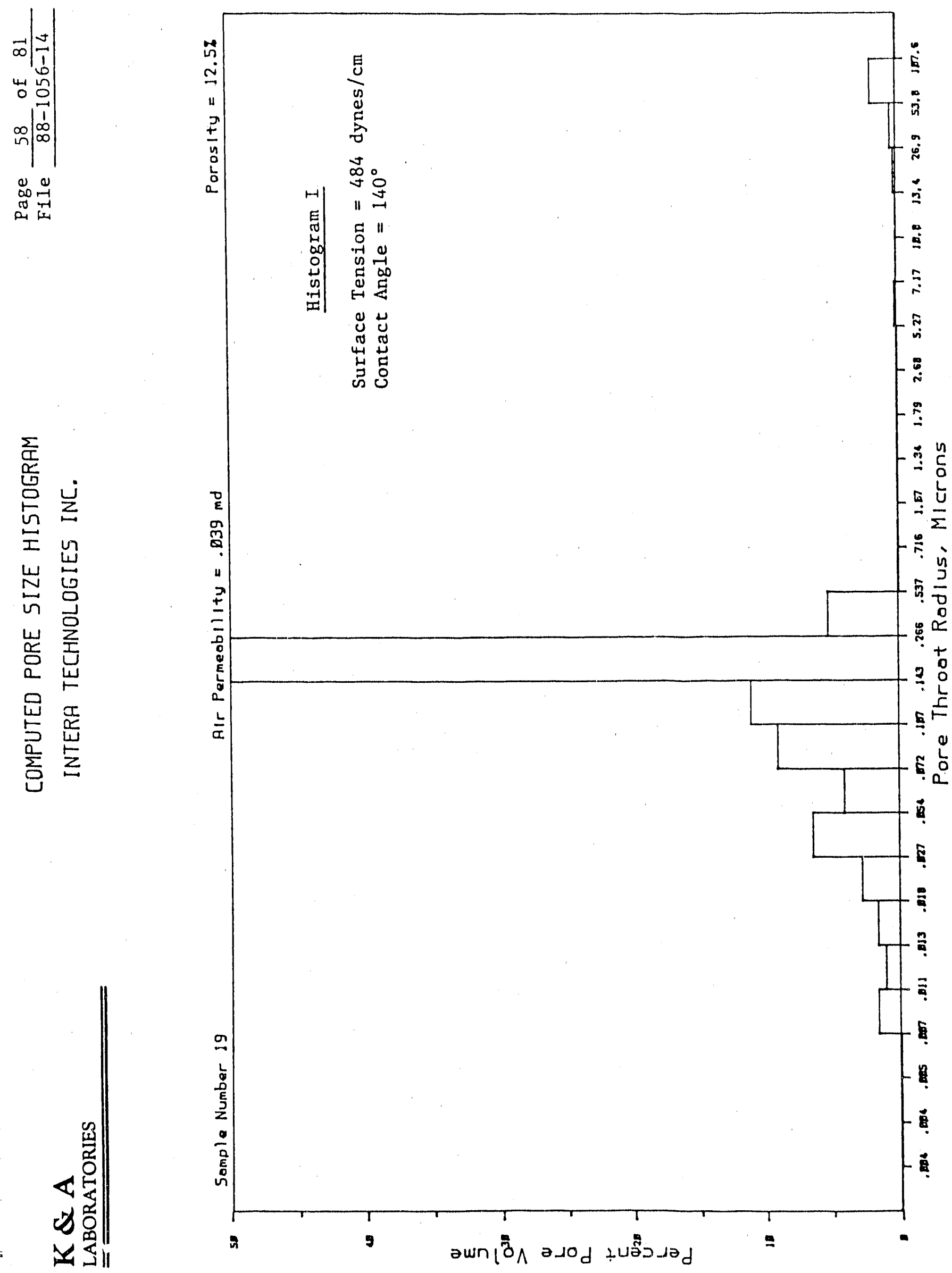

D- 65 


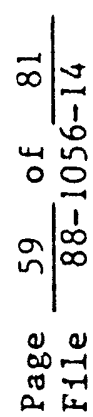

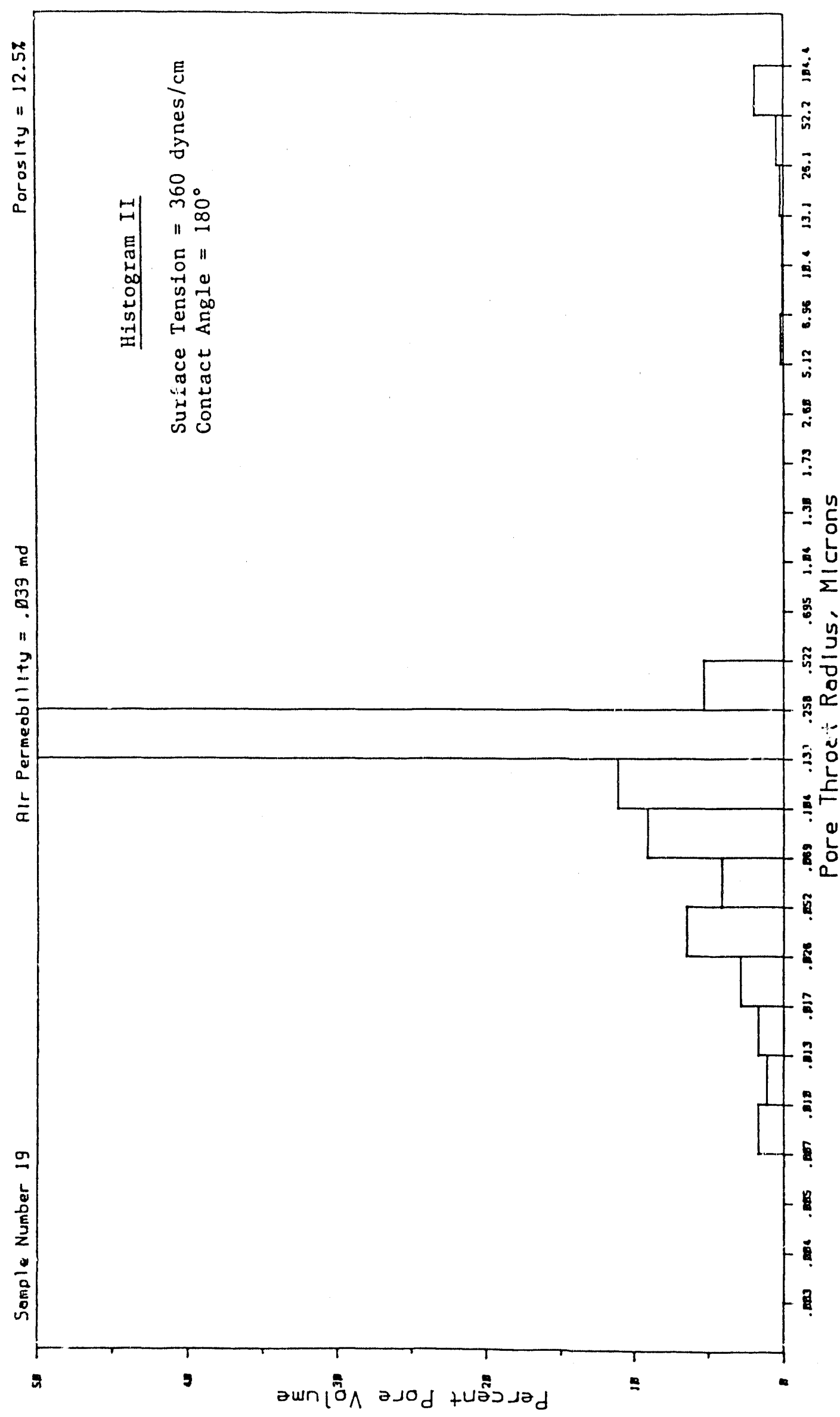

D. 66 
MERCURI INJECTION TEST RESULTS

INTERA TECHNOLOGIES, INC.

SAMPLE NUMBER 20

Air Permeability $=0.033 \mathrm{md}$

Porosity $=14.2 \%$

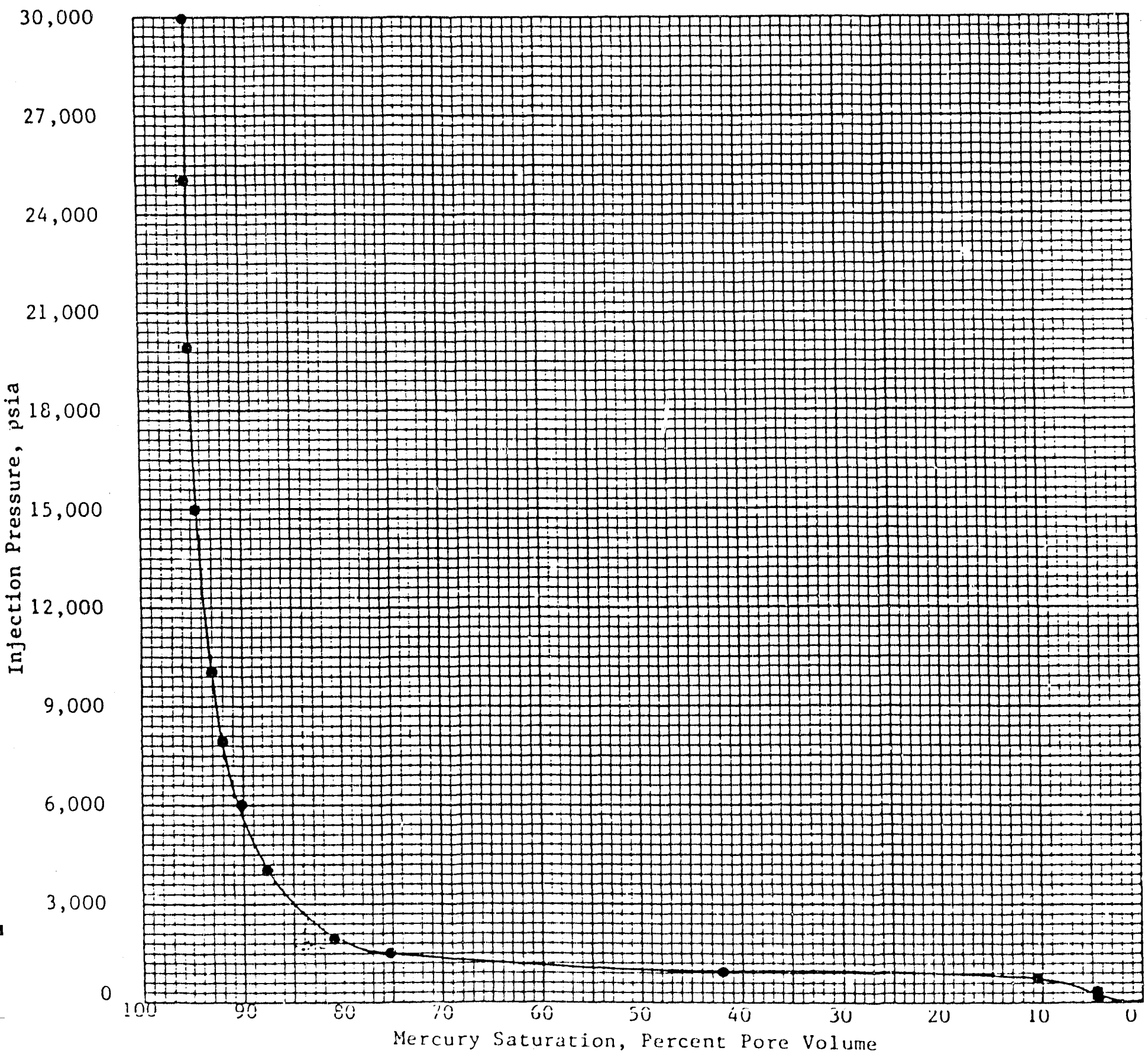




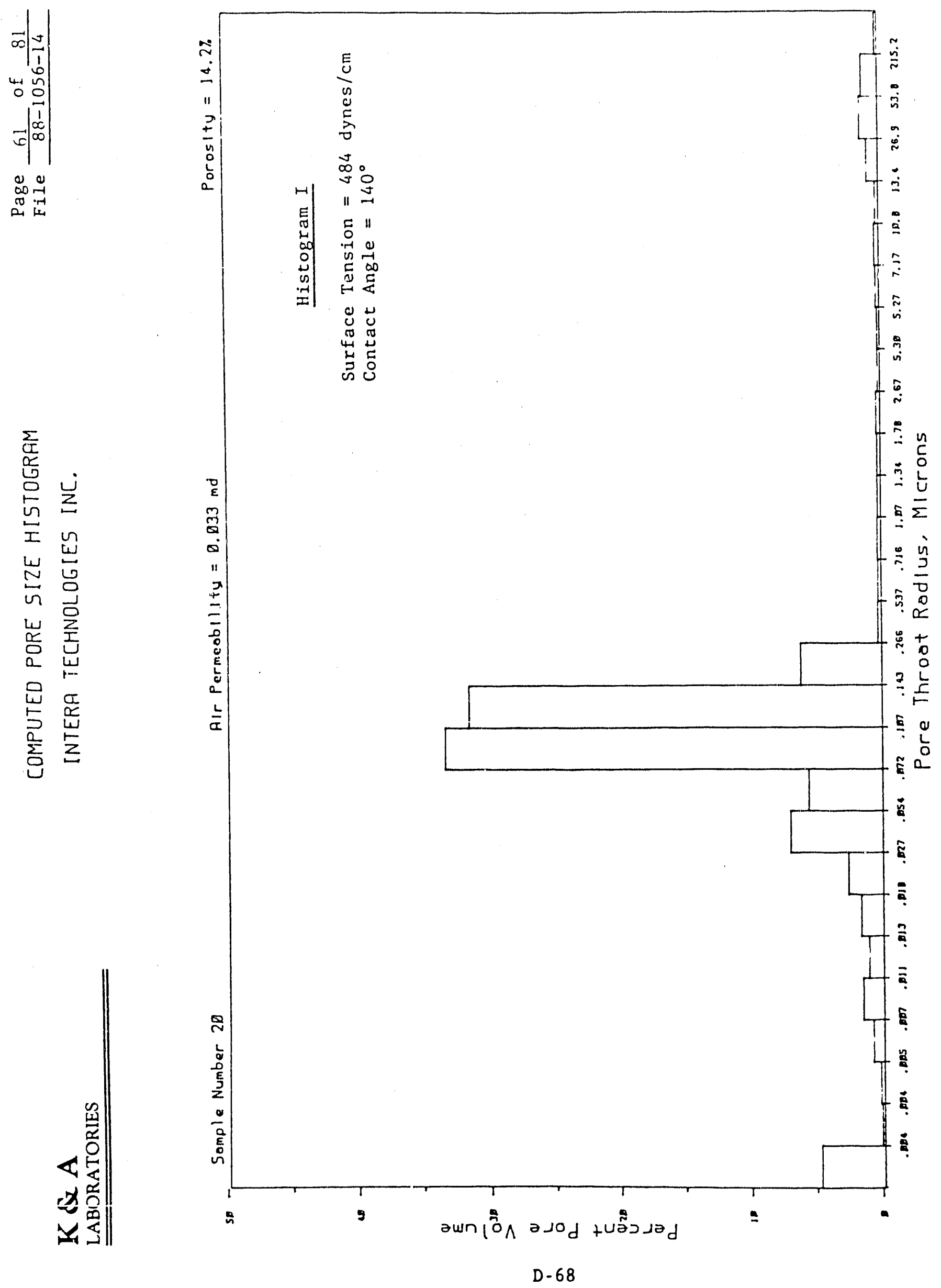



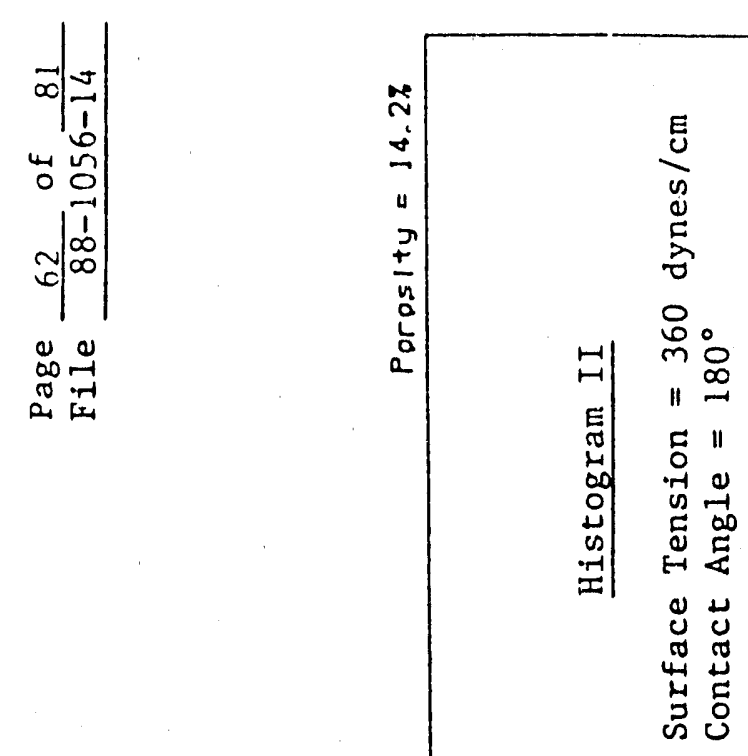

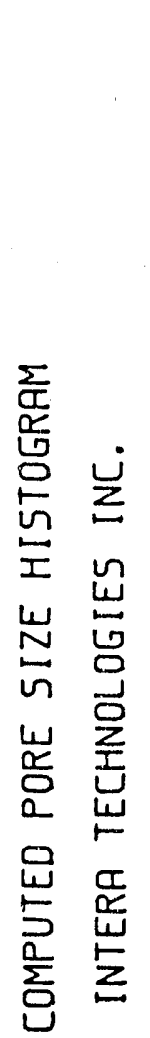

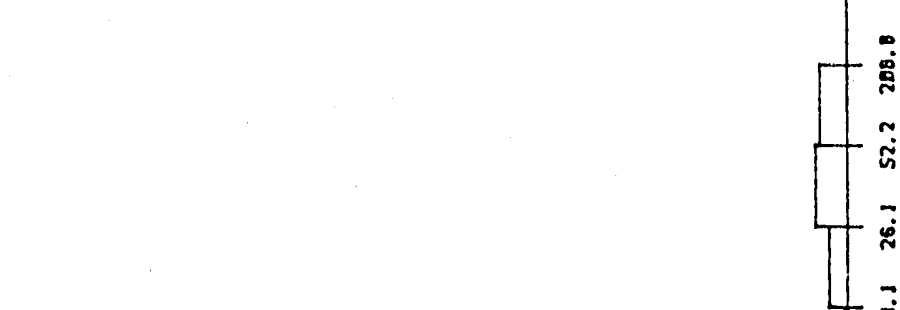

$=$

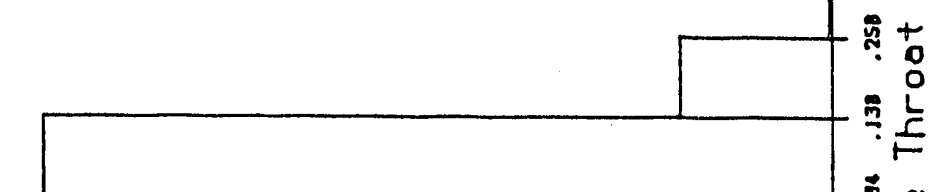

는

安

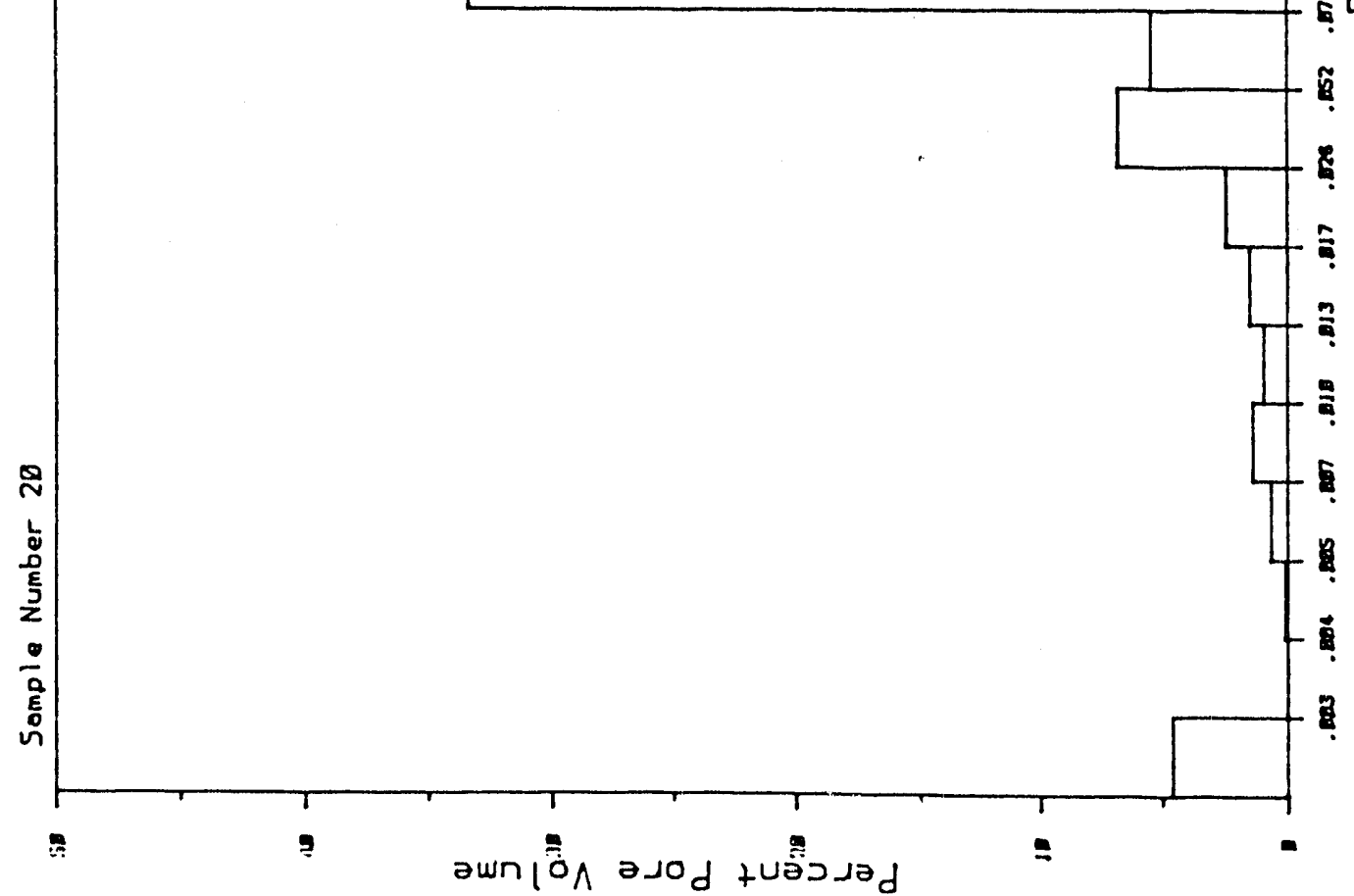


MERCURY INJECTION: TEST RESULTS

INTERA TECHNOLOGIES, INC.

SMPLE NINBER 21

Air Permeability $=0.038 \mathrm{md}$

Porosity $=13.0 \%$

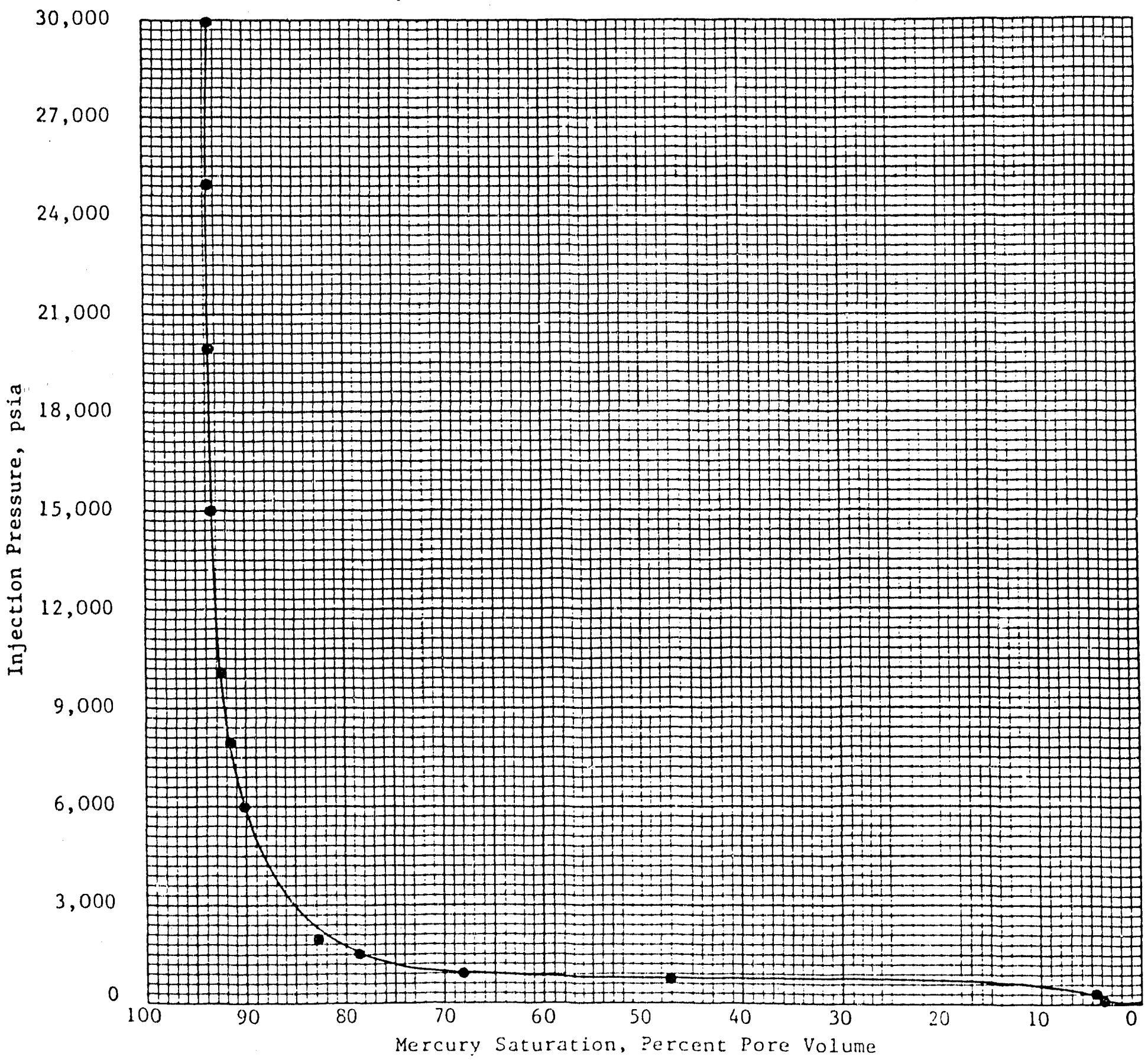




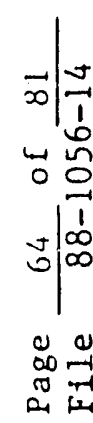

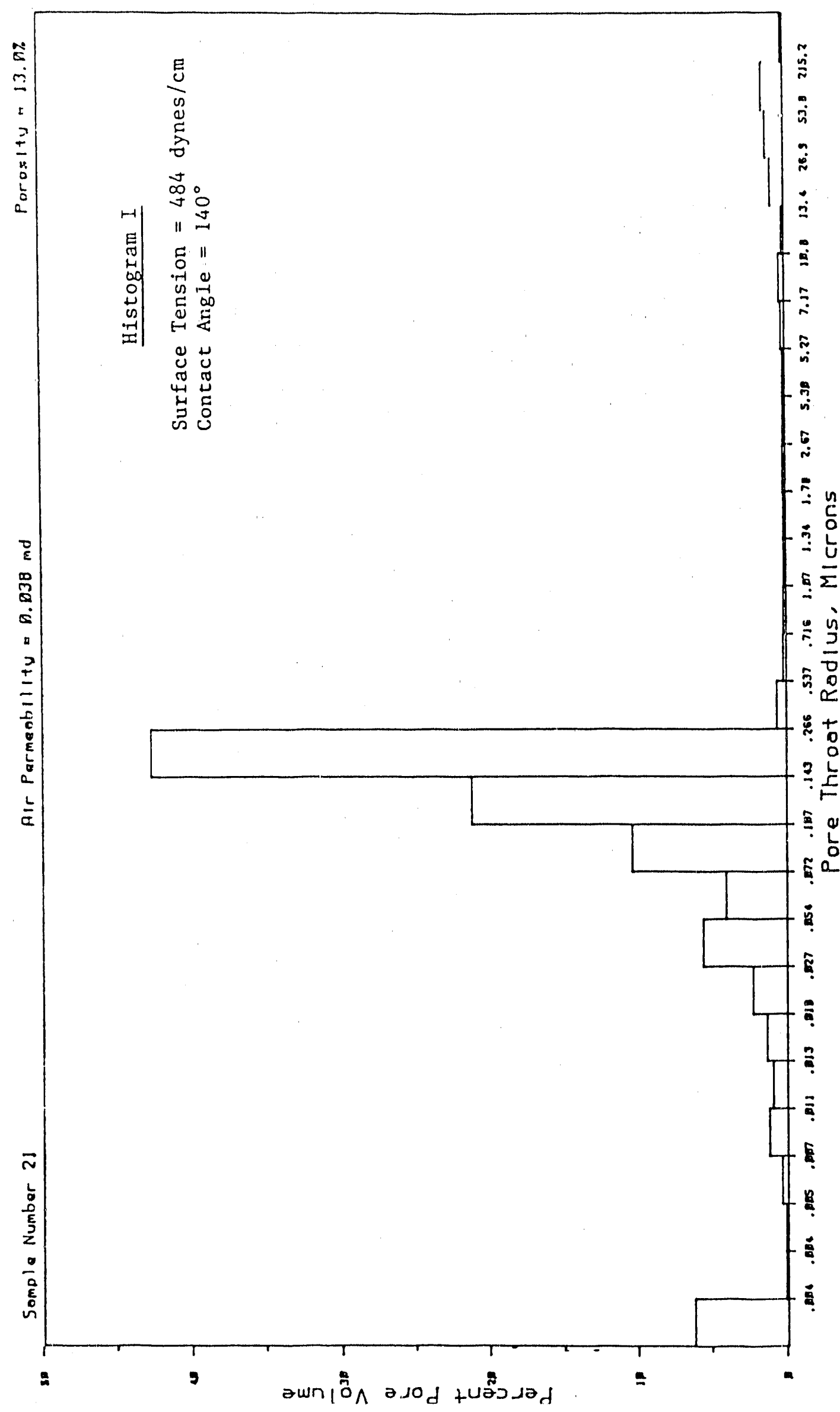

D. 71 

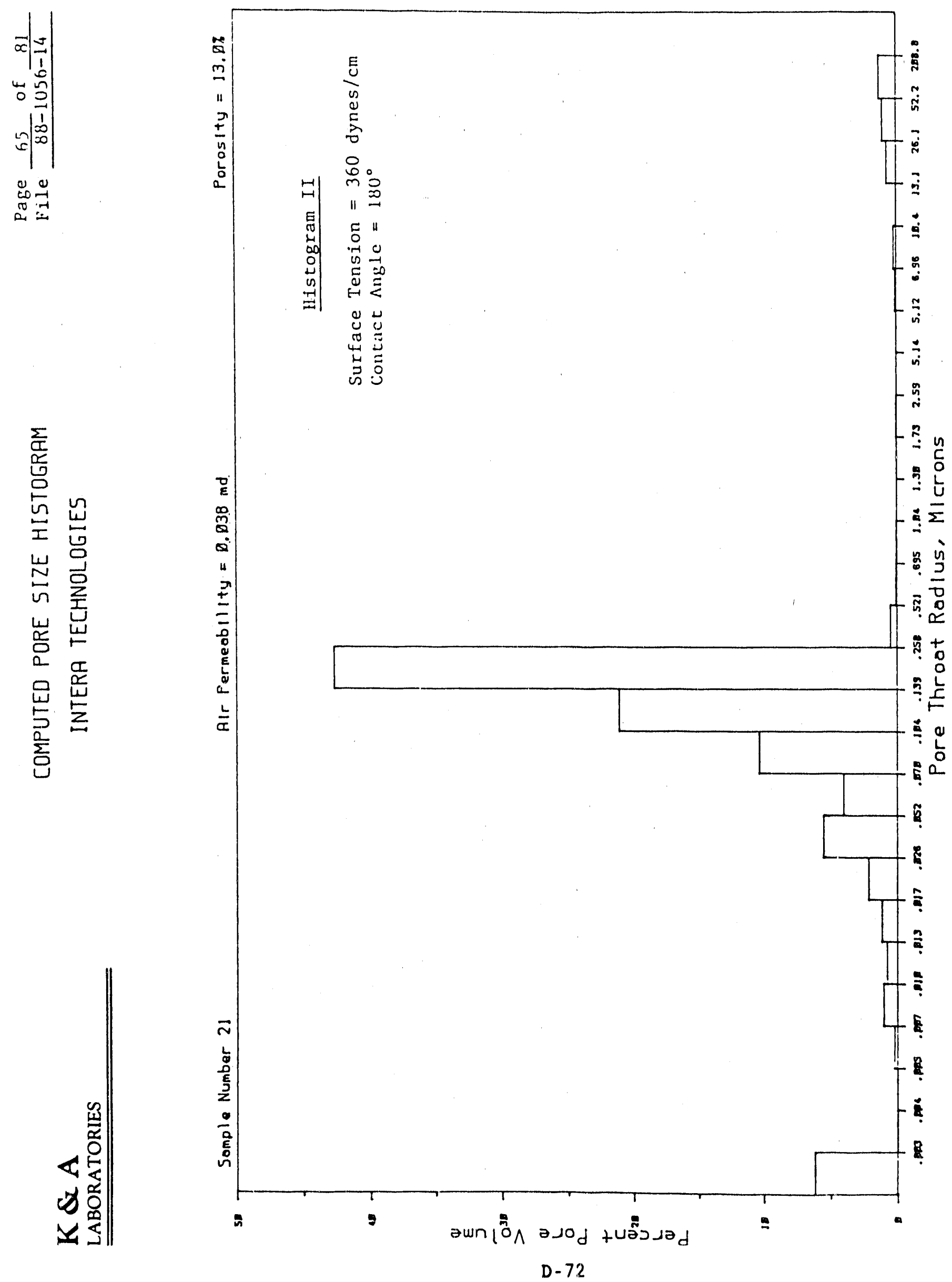
MERCURY INJECTION TEST RESULTS

INTERA TECHNOLOGIES, INC.

SAMPLE NUMBER 22

Air. Permeability $=9.68 \mathrm{md}$

Porosity $=17.6 \%$

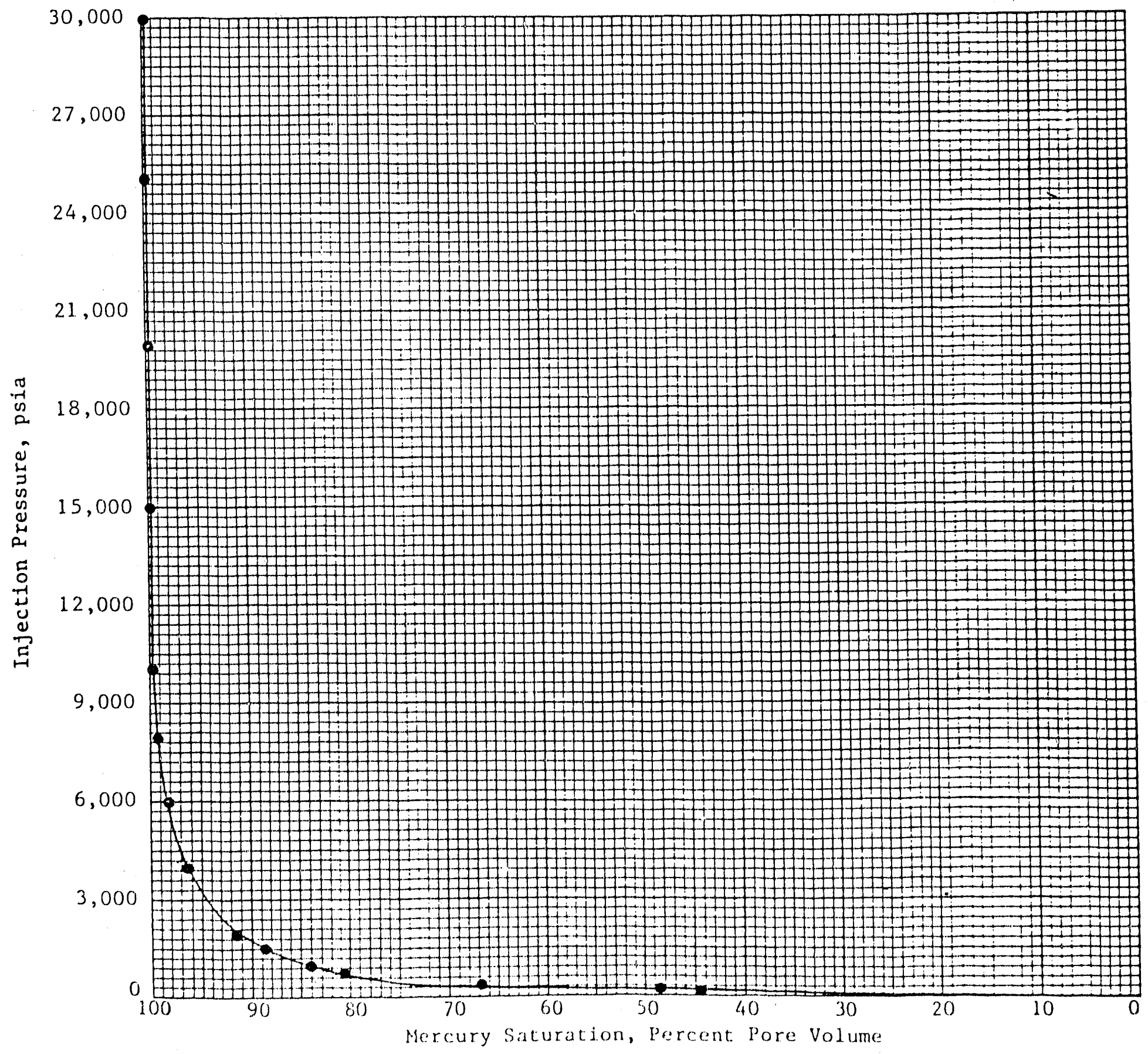




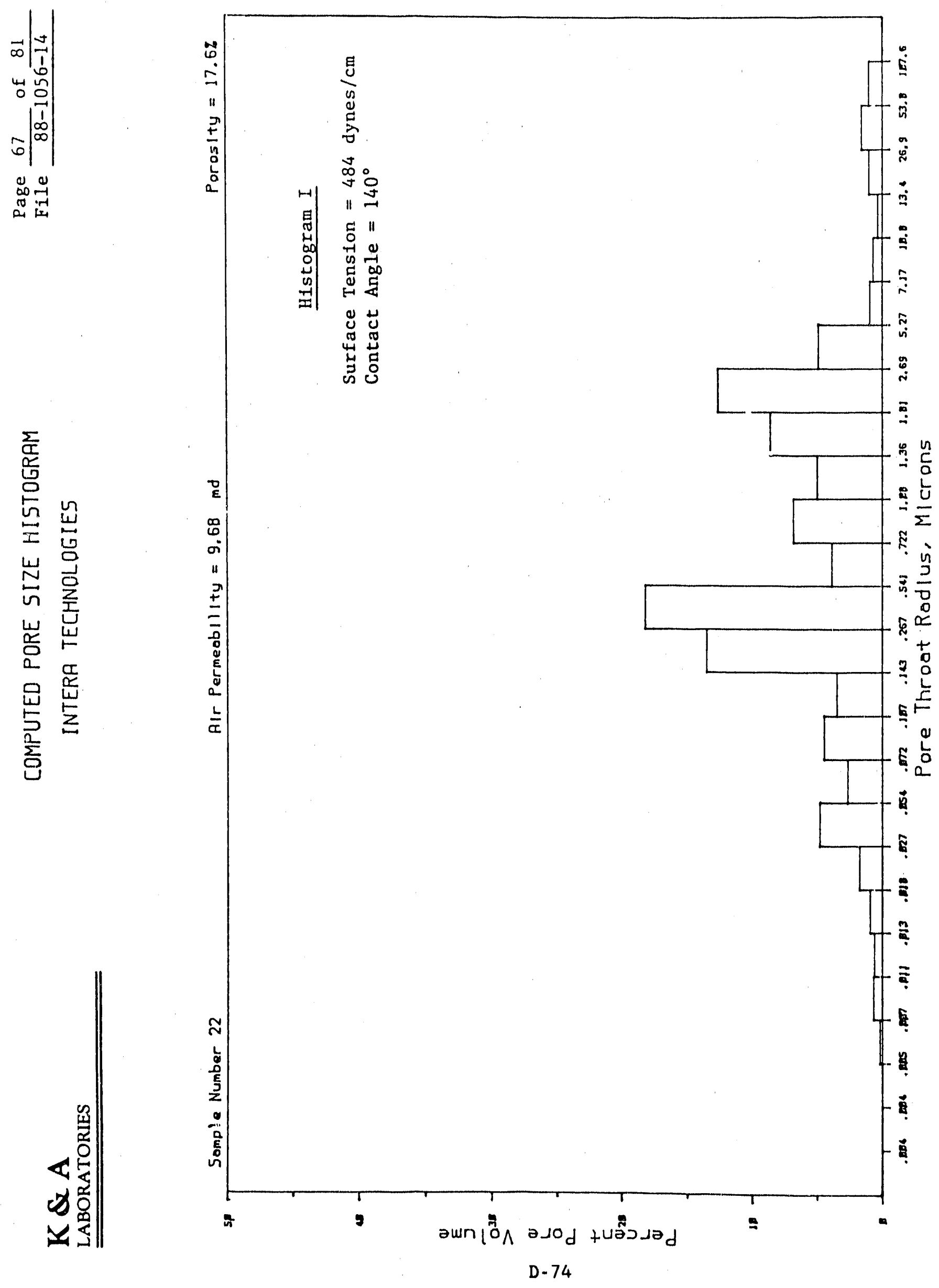




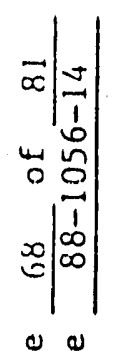

品

句

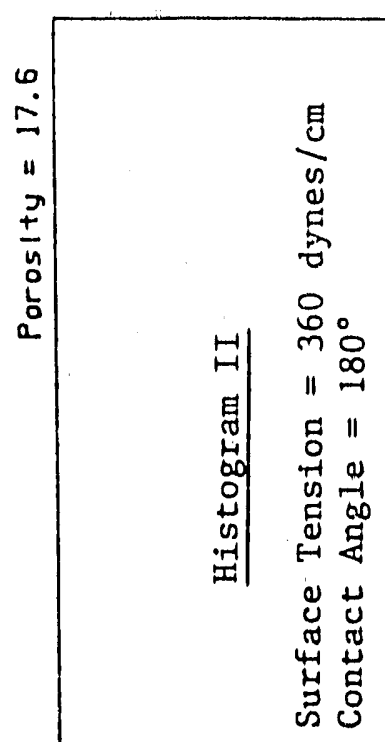

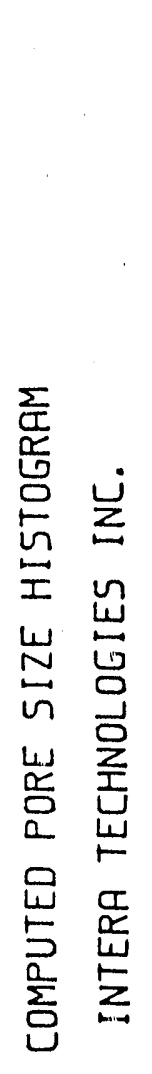

음

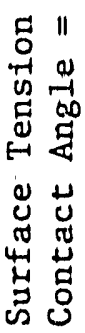
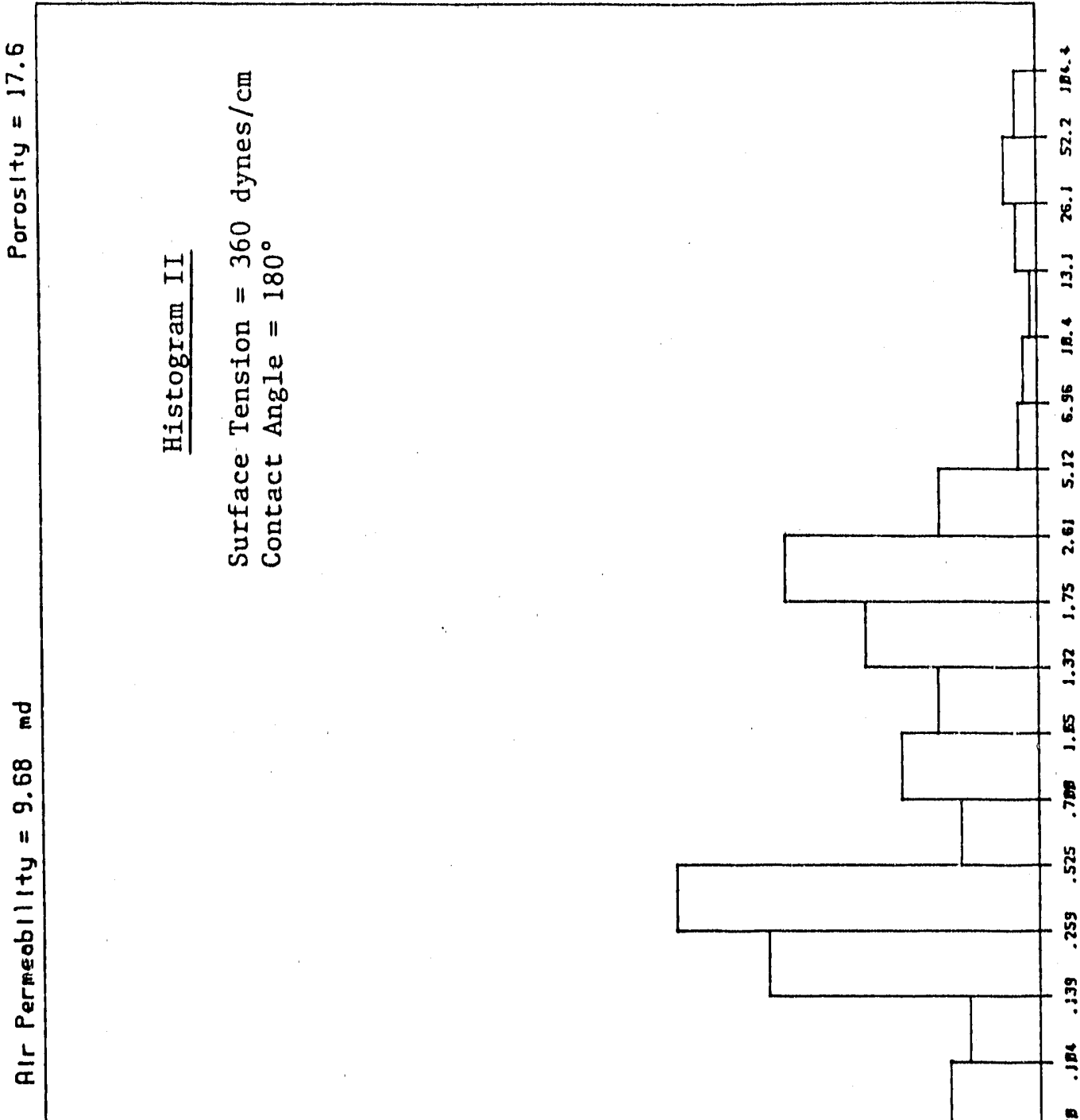

$\stackrel{n}{5}$
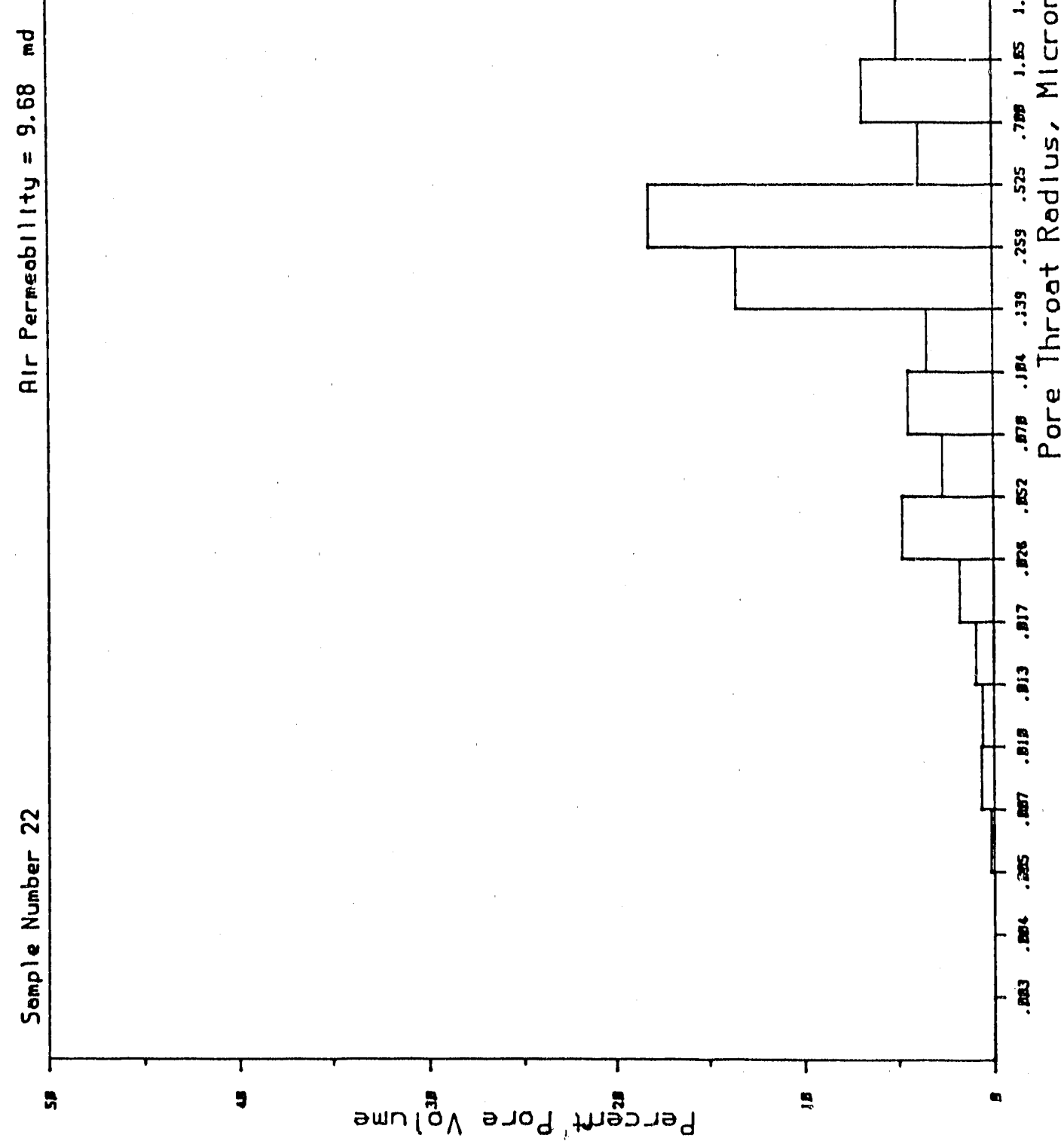
$K \& A$

LABORATORIES
Page 69 of 81

File $\frac{88-1056-14}{8}$

MERCURY INJECTION TEST RESULTS

INTERA TECHNOLOGIES, INC.

SMMPLE NUMBER 23

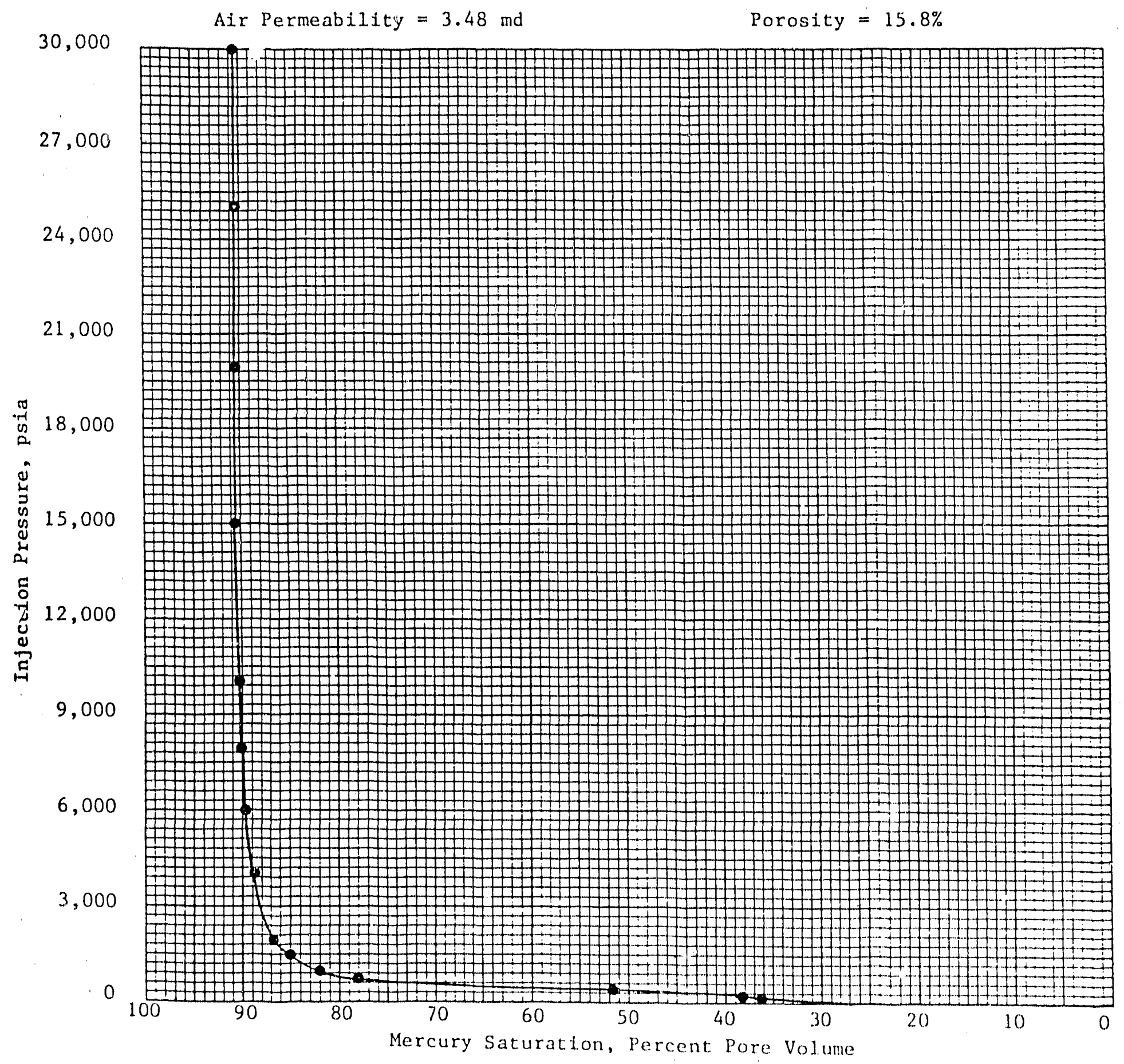

D.76 


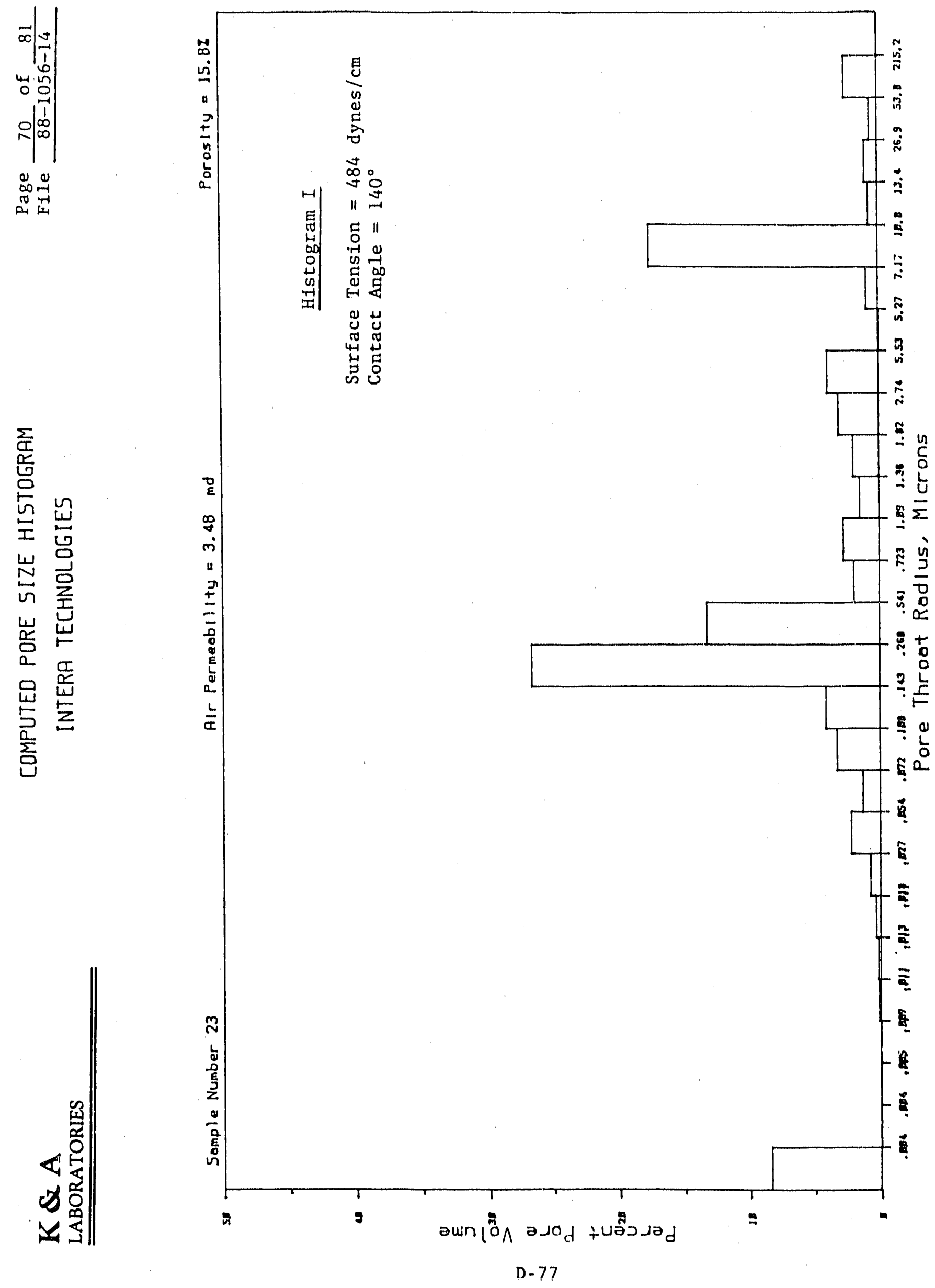




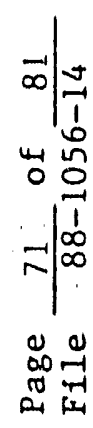

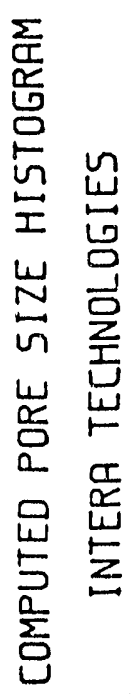

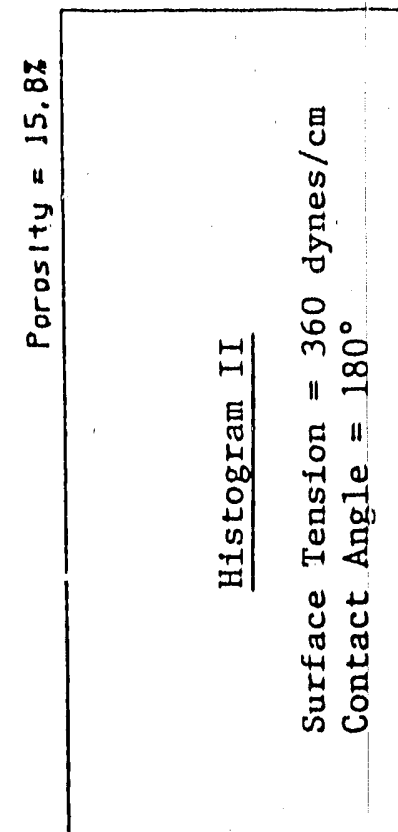

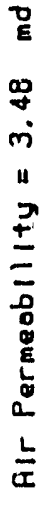

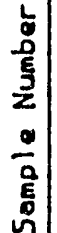
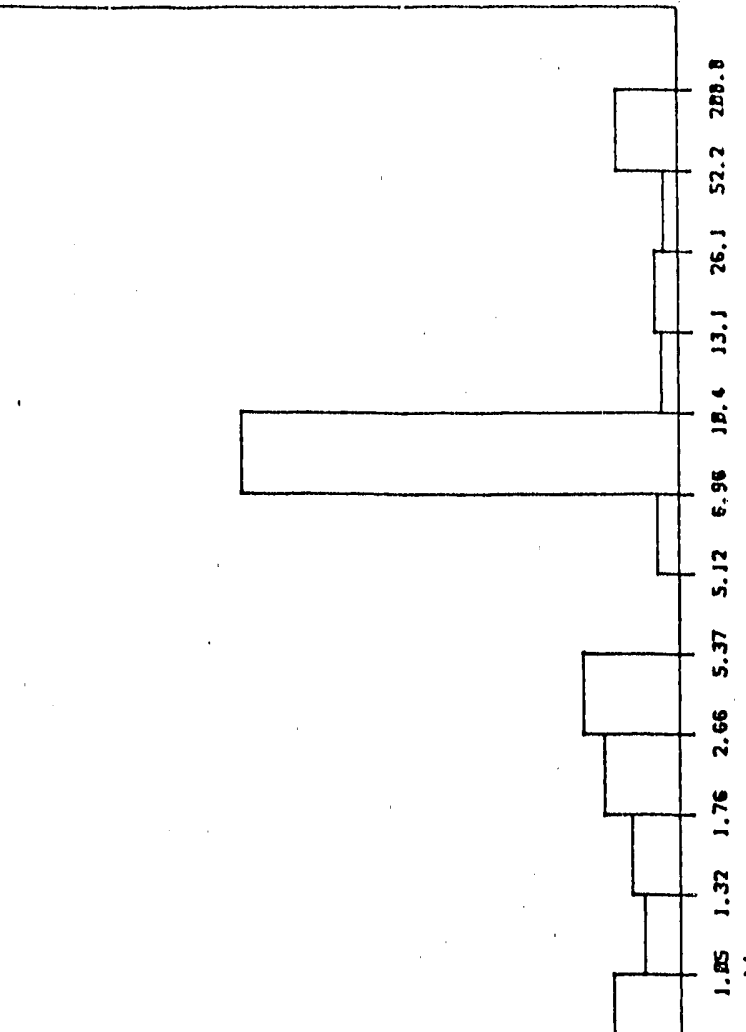

$-$

- in

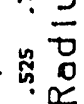

号

는

$-\frac{\square}{0}$

ลํ.

ก

.

$-$

m

-

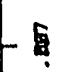


MERCURY INJECTION TEST RESULTS

INTERA TECHNOLOGIES, INC.

SANPLE NUMBER 24

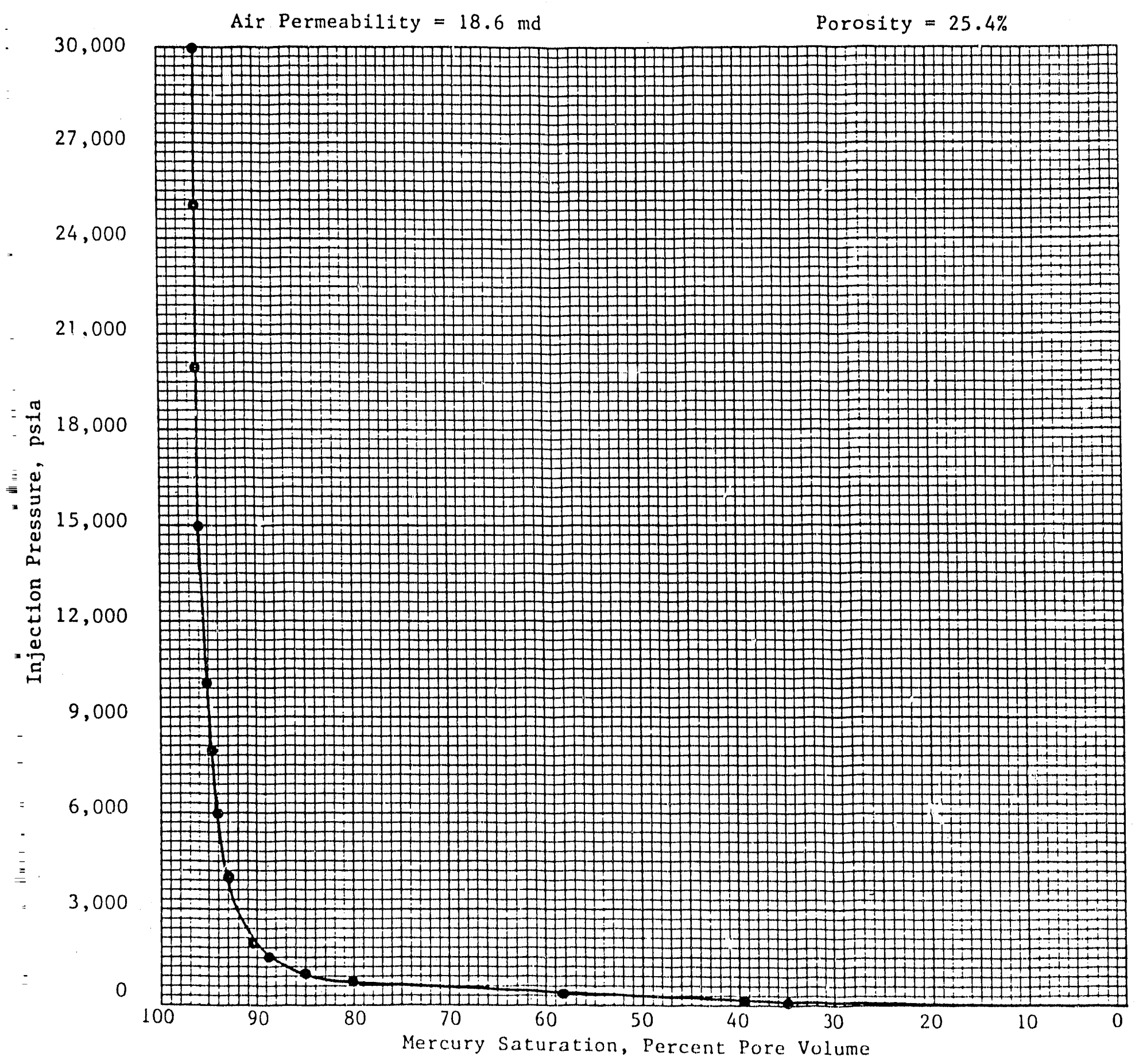




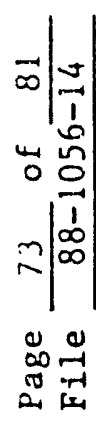

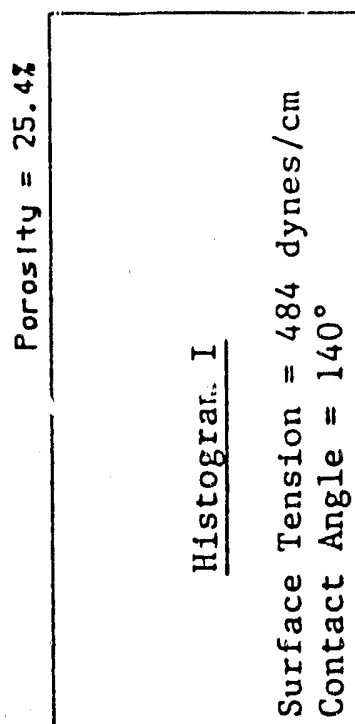

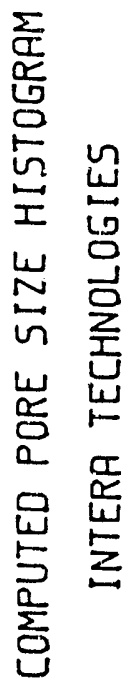

$\infty$ 。

옥

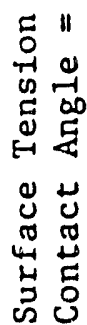

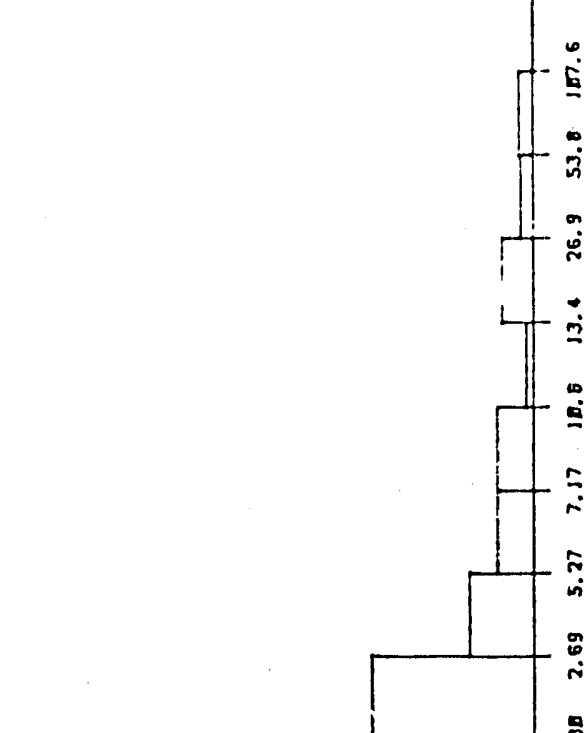

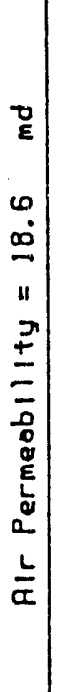
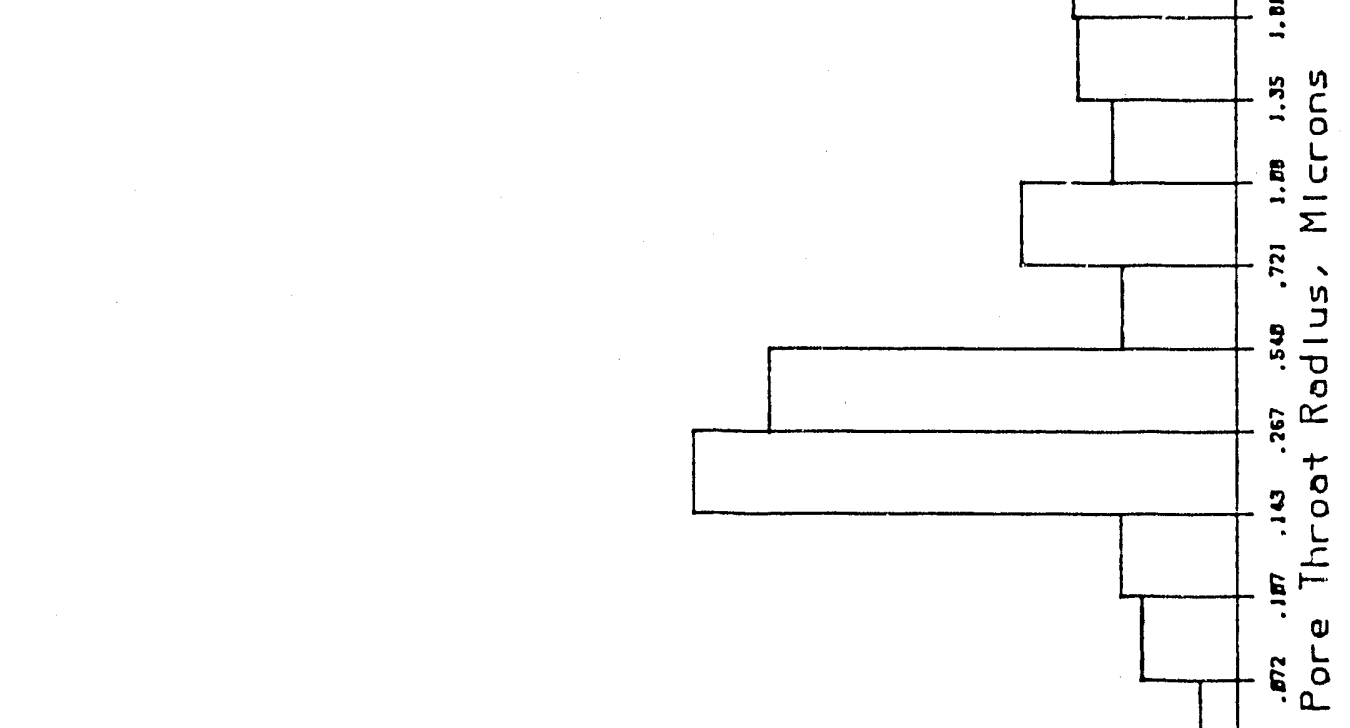

으

$7 \stackrel{0}{0}$

$\div$ 는

EF

ธั

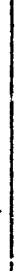

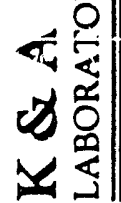

岃

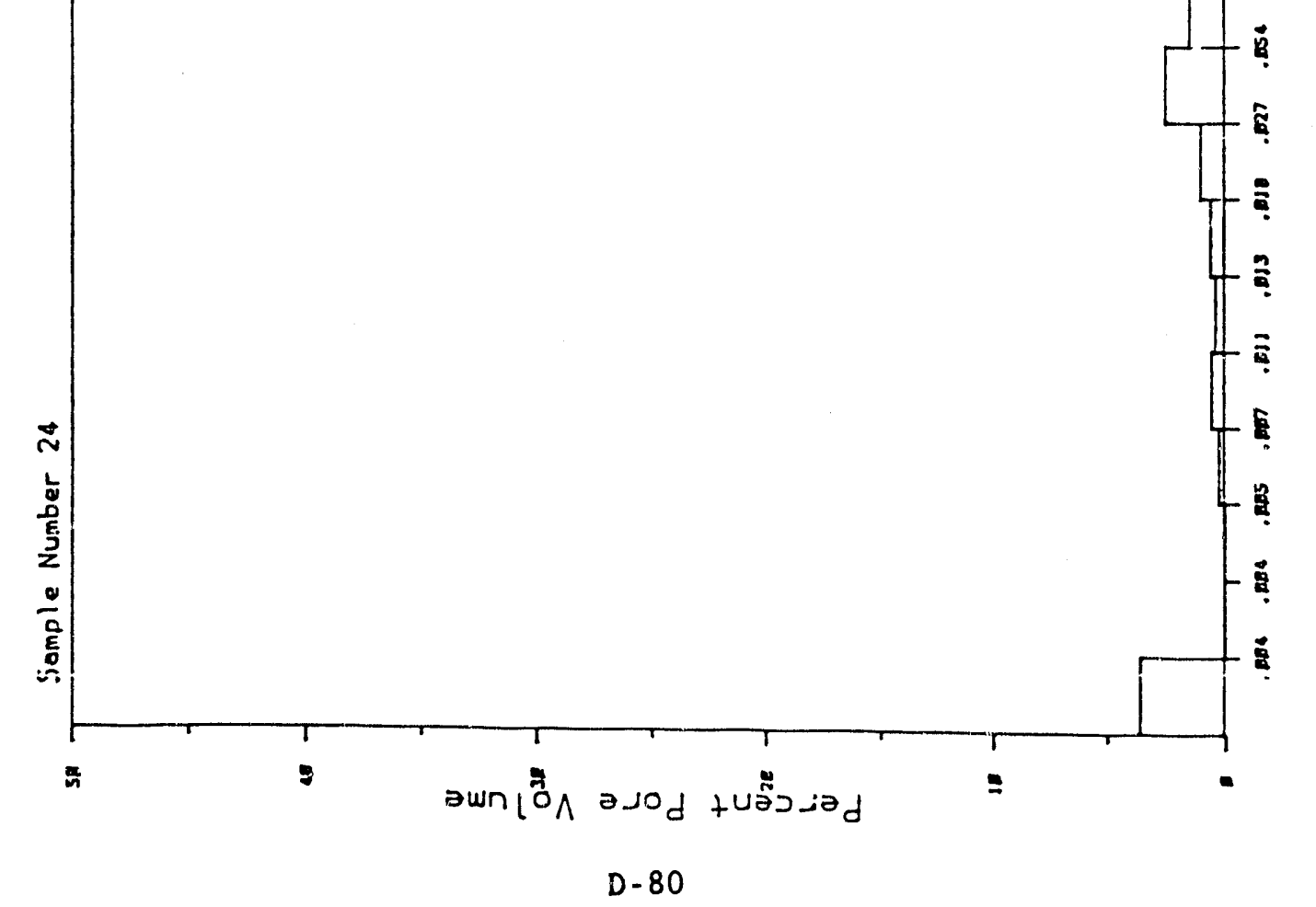




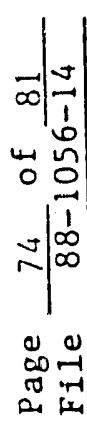

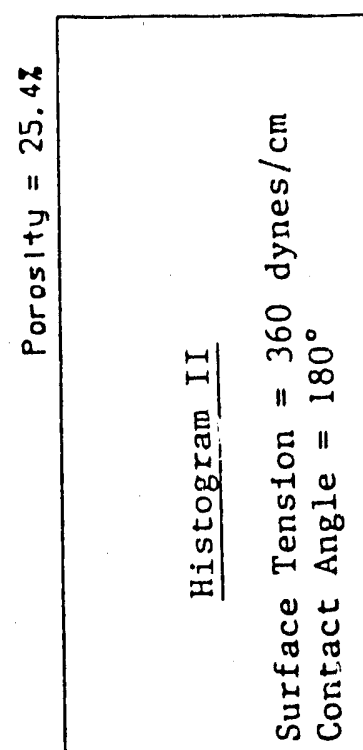

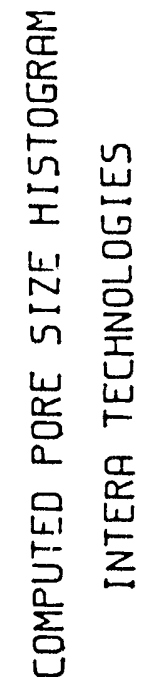

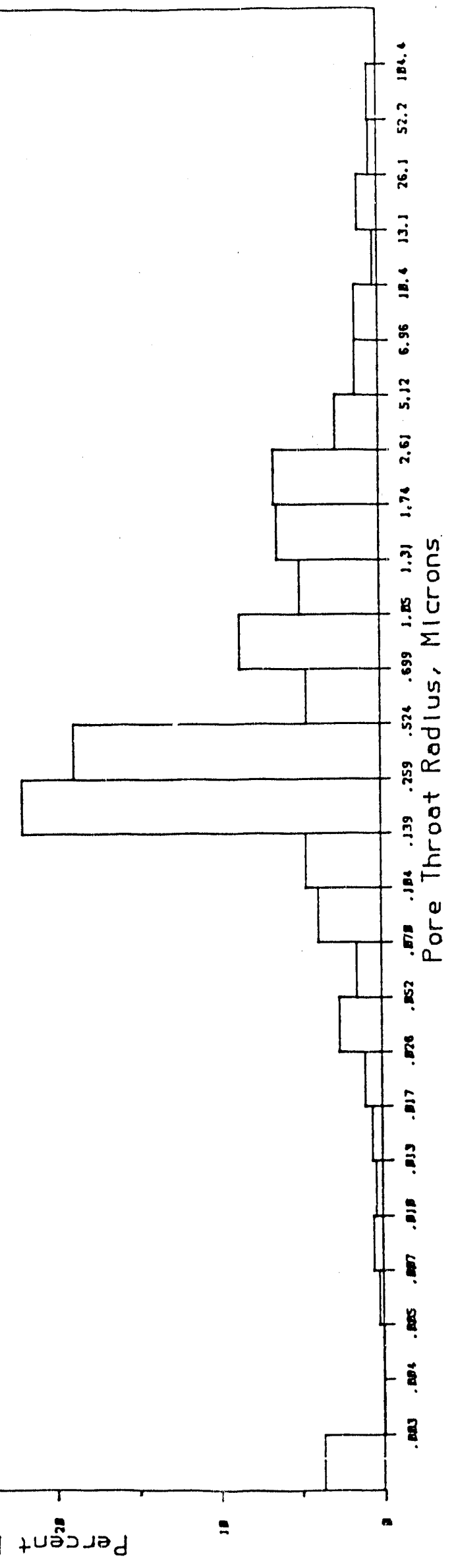




\section{HIGH PRESSURE MERCURY INJECTION TEST RESULTS}

INTERA TECHNOLOGIES, INC.

\begin{tabular}{l} 
Sample Number: \\
Sample Identification Number: \\
Alr Permeability, md: \\
Porosity, Percent: \\
Injection \\
Pressure, psia \\
\hline 0.5 \\
1 \\
2 \\
4 \\
8 \\
10 \\
15 \\
20.4 \\
40 \\
60 \\
80 \\
100 \\
150 \\
200 \\
400 \\
750 \\
1,000 \\
1,500 \\
2,000 \\
4,000 \\
6,000 \\
8,000 \\
10,000 \\
15,000 \\
20,000 \\
25,000 \\
30,000 \\
\end{tabular}

$\begin{array}{rrrr}1 & 2 & 3 & 4 \\ \mathrm{H} 2 \mathrm{~A}-2 & \mathrm{H} 2 \mathrm{~B} 1-2 & \mathrm{H} 5 \mathrm{~B} 1-1 \mathrm{a} & \mathrm{H} 5 \mathrm{~B} 1-1 \mathrm{~b} \\ 0.143 & 1.18 & 1.18 & 0.042 \\ 12.5 & 14.8 & 13.0 & 15.5\end{array}$

Mercury Saturation, Percent Pore Volume

$\begin{array}{rrrr}0.0 & 0.0 & 0.0 & 0.0 \\ 0.0 & 0.0 & 0.3 & 0.0 \\ 0.4 & 0.2 & 0.7 & 0.0 \\ 0.9 & 0.4 & 2.6 & 0.2 \\ 1.3 & 0.9 & 3.6 & 0.4 \\ 1.5 & 1.2 & 3.8 & 1.0 \\ 1.9 & 1.6 & 4.5 & 2.8 \\ 3.1 & 1.9 & 5.3 & 3.5 \\ 4.2 & 2.5 & 5.8 & 4.3 \\ 6.9 & 5.7 & 6.2 & 4.9 \\ 9.0 & 9.1 & 6.5 & 5.3 \\ 10.6 & 12.6 & 0.6 & 5.3 \\ 13.2 & 20.5 & 6.9 & 5.8 \\ 14.6 & 24.9 & 7.0 & 6.7 \\ 21.8 & 51.8 & 14.5 & 17.6 \\ 44.2 & 76.8 & 74.6 & 77.0 \\ 61.1 & 82.1 & 81.4 & 82.5 \\ 71.6 & 88.5 & 86.7 & 87.4 \\ 75.6 & 92.0 & 89.1 & 89.4 \\ 81.4 & 97.0 & 92.5 & 92.7 \\ 84.0 & 98.5 & 93.7 & 93.9 \\ 85.5 & 99.3 & 94.4 & 94.5 \\ 86.6 & 99.7 & 94.7 & 94.9 \\ 88.0 & 99.7 & 95.0 & 95.3 \\ 88.5 & 99.7 & 95.0 & 95.3 \\ 88.5 & 99.7 & 95.0 & 95.3 \\ 88.5 & 99.7 & 95.0 & 95.3\end{array}$


INTERA TECHNOLOGIES, INC.

\begin{tabular}{|c|c|c|c|c|c|}
\hline $\begin{array}{l}\text { Sample Number: } \\
\text { Sample Identification Number: } \\
\text { Air Permeability, md: } \\
\text { Porosity, Percent: }\end{array}$ & $\begin{array}{r}5 \\
\text { H } B 1-2 \mathrm{a} \\
0.108 \\
21.5\end{array}$ & $\begin{array}{r}6 \\
\mathrm{H} 7 \mathrm{~B} 1-2 \mathrm{~b} \\
0.521 \\
27.8\end{array}$ & $\begin{array}{r}7 \\
\mathrm{H} 7 \mathrm{~B} 2-1 \\
0.294 \\
17.3\end{array}$ & & $\begin{array}{r}8 \\
\mathrm{H} 7 \mathrm{C}-1 \mathrm{~b} \\
0.074 \\
16.5\end{array}$ \\
\hline $\begin{array}{c}\text { Injection } \\
\text { Pressure, psia }\end{array}$ & \multicolumn{2}{|c|}{ Mercury Satura } & Percent & Pore & Volume \\
\hline 0.5 & 0.0 & 0.0 & 0.0 & & 0.0 \\
\hline 1 & 0.4 & 1.5 & 0.0 & & 0.4 \\
\hline 2 & 0.7 & 22.5 & 0.6 & & 0.7 \\
\hline 4 & 5.0 & 23.3 & 1.5 & & 1.2 \\
\hline 8 & 5.8 & 24.0 & 2.3 & & 2.2 \\
\hline 10 & 9.5 & 24.2 & 2.5 & & 2.3 \\
\hline 15 & 9.9 & 24.6 & 2.7 & & 2.7 \\
\hline 20.4 & 10.3 & 25.6 & 3.0 & & 3.2 \\
\hline 40 & 12.2 & 29.3 & 3.1 & & 4.1 \\
\hline 60 & 23.0 & 35.0 & 3.1 & & 5.2 \\
\hline 80 & 24.9 & 38.8 & 3.3 & & 6.0 \\
\hline 100 & 25.6 & 41.0 & 3.4 & & 6.8 \\
\hline 150 & 35.7 & 42.7 & 3.7 & & 15.7 \\
\hline 200 & 36.5 & 44.1 & 5.4 & & 16.2 \\
\hline 400 & 46.8 & 60.1 & 63.2 & & 33.9 \\
\hline 750 & 86.7 & 88.4 & 81.7 & & 77.9 \\
\hline 1,000 & 90.7 & 92.1 & 85.9 & & 83.8 \\
\hline 1,500 & 91.5 & 95.2 & 89.0 & & 83.9 \\
\hline 2,000 & 91.6 & 96.5 & 91.4 & & 84.0 \\
\hline 4,000 & 91.6 & 98.3 & 94.2 & & 93.1 \\
\hline 6,000 & 91.6 & 98.8 & 95.3 & & 94.0 \\
\hline 8,000 & 91.6 & 99.2 & 95.8 & & 94.4 \\
\hline 10,000 & 91.6 & 99.3 & 96.2 & & 94.7 \\
\hline 15,000 & 91.6 & 99.5 & 96.5 & & 94.8 \\
\hline 20,000 & 91.6 & 99.5 & 96.5 & & 94.8 \\
\hline 25,000 & 91.6 & 99.5 & 96.5 & & 94.8 \\
\hline 30,000 & 91.6 & 99.5 & 96.5 & & 94.8 \\
\hline
\end{tabular}


HIGH PRESSURE MERCURY INJECTION TEST RESULTS

INTERA TECHNOLOGIES, INC.

Sample Number:

Sample Idenitifcation Number:

Air Permeability, md:

Porosity, Percent:

$\begin{array}{rr}9 & 10 \\ \mathrm{H} 7 \mathrm{C}-1 \mathrm{C} & \mathrm{H} 10 \mathrm{~B}-1 \\ 0.098 & 0.012 \\ 13.4 & 10.8\end{array}$

Injection

Pressure, psia

\section{5}$$
1
$$

2

4

8

10

15

20.4

40

60

80

100

150

200

400

750

1,000

1,500

2,000

4,000

6,000

8,000

10,000

15,000

20,000

25,000

30,000

\section{Mercury Saturation, Percent Pore Volume}

$\begin{array}{rrrr}0.0 & 0.0 & 0.0 & 0.0 \\ 0.3 & 0.0 & 0.0 & 0.0 \\ 0.6 & 0.1 & 1.1 & 3.3 \\ 0.8 & 0.2 & 1.6 & 4.2 \\ 4.5 & 0.5 & 2.0 & 5.5 \\ 8.1 & 0.6 & 2.0 & 7.0 \\ 8.5 & 0.8 & 2.2 & 7.5 \\ 8.7 & 1.0 & 2.3 & 7.8 \\ 8.8 & 1.0 & 2.3 & 10.7 \\ 9.7 & 1.1 & 2.4 & 13.5 \\ 10.6 & 1.2 & 2.6 & 17.2 \\ 10.8 & 1.3 & 2.6 & 19.5 \\ 11.4 & 1.6 & 2.6 & 26.0 \\ 11.8 & 1.8 & 2.7 & 30.0 \\ 36.8 & 4.4 & 2.9 & 83.0 \\ 78.6 & 24.8 & 3.8 & 94.1 \\ 85.0 & 38.4 & 6.4 & 96.0 \\ 90.3 & 48.1 & 50.3 & 97.6 \\ 92.6 & 53.5 & 63.5 & 98.3 \\ 96.0 & 62.0 & 78.6 & 99.4 \\ 97.3 & 64.7 & 83.7 & 99.7 \\ 98.0 & 65.8 & 86.5 & 99.9 \\ 98.4 & 66.4 & 88.4 & 99.9 \\ 98.9 & 66.7 & 91.3 & 99.9 \\ 98.9 & 66.7 & 92.7 & 99.9 \\ 98.9 & 66.7 & 93.3 & 99.9 \\ 98.9 & 66.7 & 93.3 & 99.9\end{array}$


HIGH PRESSURE MERCURY INJECTION TEST RESULTS

INTERA TECHNOLOGIES, INC.

Sample Number:

Sample Idenitifcation Number: Air Permeability, md:

Porosity, Percent:

\author{
13 \\ H $11 B 3-4$ \\ 0.186 \\ 14.8
}

15

$\mathrm{W}-12-1 \mathrm{bi}$

0.086

11.2
16
$\mathrm{W}-12-2 \mathrm{~b}$
1.38
13.6

Injection

Pressure, psia

0.5
1
2
4
8
10
15
20.4
40
60
80
100
150
200
400
750
1,000
1,500
2,000
4,000
6,000
8,000
10,000
15,000
20,000
25,000
30,000

Mercury Saturation, Fercent Pore Volume

$\begin{array}{llll}0.0 & 0.0 & 0.0 & 0.0 \\ 1.8 & 0.0 & 2.0 & 0.0\end{array}$

2.9

3.6

4.0

4.1

4.1

4.3

4.5

5.2

5.5

5.6

5.9

6.3

11.1

77.0

84.2

89.7

92.4

96.2

97.7

98.6

99.2

99.9

99.9

99.9

99.9
0.0

0.2

0.3

0.5

0.7

0.7

1.0

2.6

3.4

4.1

5.4

6.6

38.4

82.1

90.2

98.2

98.2

98.2

98.2

98.2

98.2

98.2

98.2

98.2

98.2
2.4

2.6

2.7

2.8

2.9

3.1

3.4

4.0

4.3

5.0

6.5

7.3

29.9

75.2

81.9

88.6

91.6

96.3

97.9

98.8

99.3

99.9

99.9

99.9

99.9
0.0

1.3

5.2

6.0

6.3

6.7

7.4

8.8

13.2

15.3

16.7

18.9

20.7

49.8

80.1

85.6

90.7

93.2

96.9

98.1

98.8

99.1

99.4

99.4

99.4

99.4 
HIGH PRESSURE MERCURY INJECTION TEST RESULTS

INTERA TECHNOLOGIES, INC.

Sample Number:

Sample Idenitifcation Number:

Air Permeability, md:

Porosity, Percent:

Injection

Pressure, psia

0.5
1
2
4
8
10
15
20.4
40
60
80
100
150
200
400
750
1,000
1,500
2,000
4,000
6,000
8,000
10,000
15,000
20,000
25,000
30,000

$\begin{array}{rr}17 & 18 \\ W-13-3 a & W-13-3 b \\ 4.94 & 0.037 \\ 19.0 & 9.7\end{array}$
19
W-26-3
0.039
12.5
20
$\mathrm{W}-28-1 \mathrm{a}$
0.033
14.2

Mercury Saturation, Percent Pore Volume

$\begin{array}{rrrr}0.0 & 0.0 & 0.0 & 0.0 \\ 0.0 & 0.0 & 0.0 & 0.7 \\ 0.8 & 0.4 & 1.9 & 1.2 \\ 1.1 & 0.6 & 2.4 & 2.5 \\ 1.4 & 0.7 & 2.7 & 3.3 \\ 1.6 & 0.8 & 2.8 & 3.4 \\ 2.5 & 0.9 & 2.9 & 3.6 \\ 4.1 & 1.0 & 3.2 & 3.7 \\ 8.2 & 1.0 & 3.2 & 3.7 \\ 21.5 & 1.0 & 3.2 & 3.9 \\ 29.5 & 1.0 & 3.2 & 4.0 \\ 33.6 & 1.0 & 3.2 & 4.1 \\ 37.9 & 1.0 & 3.2 & 4.3 \\ 39.6 & 1.0 & 3.2 & 4.4 \\ 71.6 & 19.2 & 8.5 & 4.5 \\ 85.9 & 80.1 & 61.6 & 10.6 \\ 88.6 & 85.8 & 72.7 & 42.1 \\ 91.3 & 90.8 & 81.8 & 75.4 \\ 92.6 & 93.1 & 86.0 & 81.0 \\ 95.0 & 95.6 & 92.5 & 87.9 \\ 95.9 & 98.3 & 95.4 & 90.4 \\ 96.5 & 99.1 & 97.1 & 92.0 \\ 96.9 & 99.6 & 98.2 & 93.0 \\ 97.5 & 99.6 & 99.9 & 94.5 \\ 97.5 & 99.6 & 99.9 & 95.2 \\ 97.5 & 99.6 & 99.9 & 95.3 \\ 97.5 & 99.6 & 99.9 & 95.3\end{array}$


HIGH PRESSURE MERCURY INJECTION TEST RESULTS

INTERA TECHNOLOGIES, INC.

Sample Number:

Sample Identtifcation Number: Air Permeability, and:

Porosity, Percent:

$\begin{array}{rr}21 & 22 \\ W-28-1 b & W-30-3 a \\ 0.038 & 9.68 \\ 13.0 & 17.6\end{array}$

Injection

Pressure, psia
0.5

1

2

4

8

10

15

20.4

40

60

80

100

150

200

400

750

1,000

1,500

2,000

4,000

6,000

8,000

10,000

15,000

20,000

25,000

30,000
Mercury Saturation, Percent Pore Volume

0.0

0.8

1.4

2.5

3.2

3.3

3.5

3.7

3.7

3.7

3.8

3.8

3.8

3.9

4.5

47.2

68.3

78.6

82.7

88.2

90.4

91.6

92.4

93.5

93.8

93.8

93.8
0.0

0.0

1.1

2.7

3.8

4.1

4.8

5.8

10.8

23.5

32.2

37.3

44.2

48.1

66.4

80.0

83.5

88.1

90.8

95.7

97.5

98.5

99.1

99.8

99.8

99.8

99.8
0.0

1.8

2.6

3.2

4.2

4.9

22.5

23.5

27.4

30.5

32.5

34.0

36.8

38.8

52.1

78.8

83.0

86.3

87.6

89.9

90.7

91.1

91.4

91.6

91.6

91.6

91.6
0.0

0.0

0.6

1.2

2.5

2.8

4.3

5.8

8.5

15.1

21.4

26.3

35.0

39.5

58.4

80.3

85.0

88.9

90.5

93.1

94.2

94.9

95.3

96.0

96.3

96.3

96.3 
HIGH PRESSURE MERCURY INJECTION TEST RESULTS

INTERA TECHNOLOGIES, INC。

\begin{tabular}{cl} 
Sample Number: & $10 \mathrm{~A}$ \\
Sample Identification Number: & H10B-1 \\
Air Permeability, md: & 0.174 \\
Porosity, Percent: & $9.0 \%$ \\
& \\
Injection & \\
Pressure, psia & Mercury Saturation, Percent Pore Volume \\
\hline & \\
0.5 & 0.0 \\
1 & 0.3 \\
2 & 3.0 \\
4 & 3.5 \\
8 & 3.7 \\
10 & 3.8 \\
15 & 3.8 \\
20.4 & 4.0 \\
40 & 4.6 \\
60 & 8.4 \\
80 & 12.7 \\
100 & 15.4 \\
150 & 20.4 \\
200 & 23.9 \\
400 & 32.2 \\
750 & 59.0 \\
1,000 & 74.6 \\
1,500 & 83.6 \\
2,000 & 87.4 \\
6,000 & 92.6 \\
8,000 & 94.2 \\
10,000 & 94.9 \\
15,000 & 95.2 \\
20,000 & 95.2 \\
& 95.2 \\
\hline &
\end{tabular}




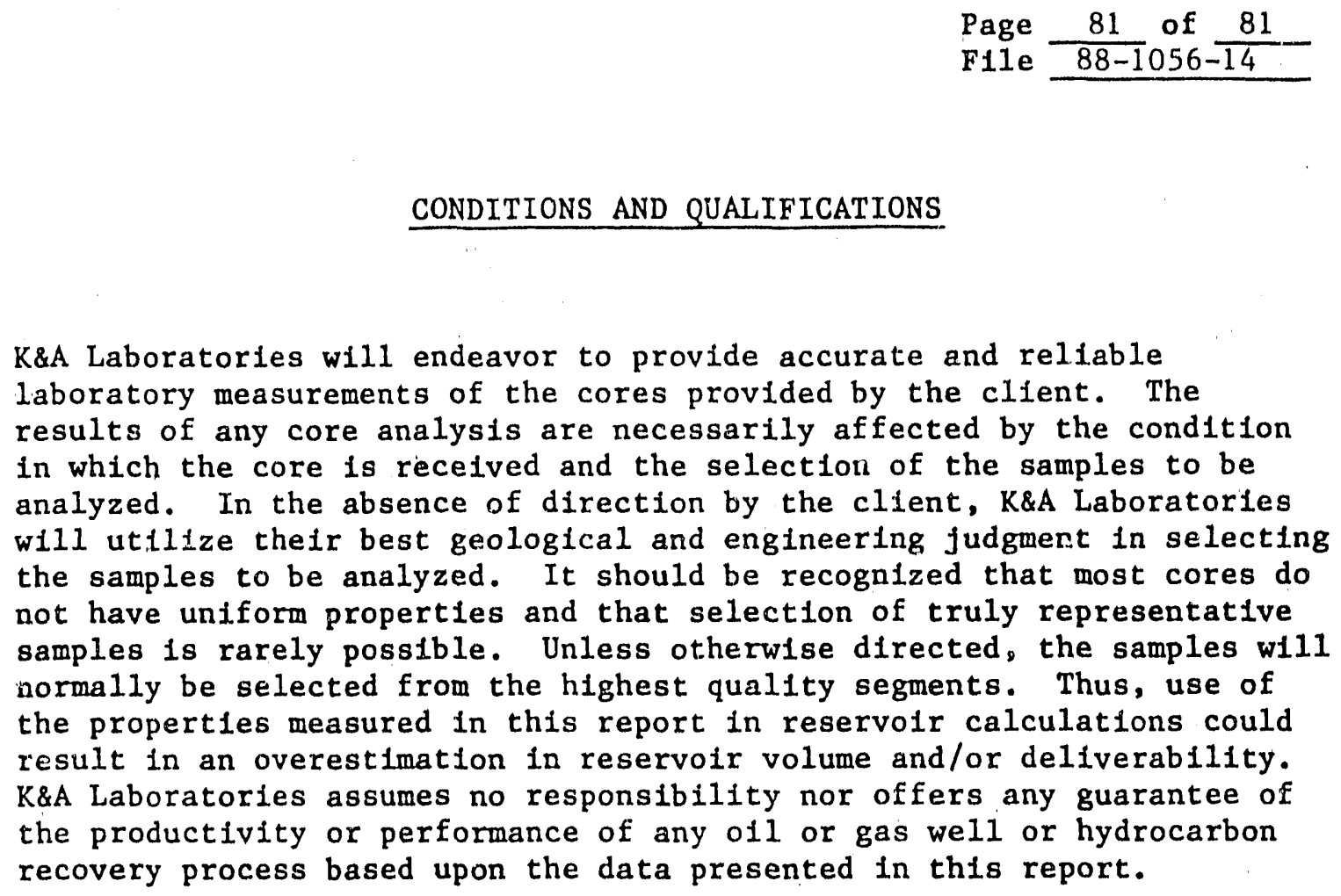

CONDITIONS AND QUALIFICATIONS

K\&A Laboratories will endeavor to provide accurate and reliable laboratory measurements of the cores provided by the client. The results of any core analysis are necessarily affected by the condition in which the core is received and the selection of the samples to be analyzed. In the absence of direction by the client, K\&A Laboratories will utilize their best geological and engineering judgment in selecting the samples to be analyzed. It should be recognized that most cores do not have uniform properties and that selection of truly representative samples is rarely possible. Unless otherwise directed, the samples will normally be selected from the highest quality segments. Thus, use of the properties measured in this report in reservoir calculations could result in an overestimation in reservoir volume and/or deliverability. K\&A Laboratories assumes no responsibility nor offers any guarantee of the productivity or performance of any oil or gas well or hydrocarbon recovery process based upon the data presented in this report.

D-89 
Page of

File 88-1056-14

PORE SURFACE AREA SUMMARY

INTERA TECHNOLOGIES, INC.

Sample Number:

Sample Identification Number: Alr Permeability, md: Porosity, Percent:

Dry Sample Welght (gm):

Cumulative

Injection

Pressure, psia

2

4

8

10

15

20.4

40

60

80

100

150

200

400

750

1000

1500

2000

4000

6000

8000

10000

15000

20000

25000

30000
Volume

Injected

cc

0

.0058

.0114

.0167

.0195

.0256

.0406

.0556

.0924

.1196

.1405

.1761

.1945

.2899

.5878

.8121

.9520

1.006

1.0822

1.1170

1.1376

1. 1523

1.1704

1.1771

1. 1771

1.1771
1

(H2A-2)

.143

$12.5 \%$

27.00
Surface Area

(\%)

215.

71.7

35.9

17.9

12.0

8.61

6.08

3.56

2.15

1.54

1.20

.861

.615

.359

.187

.123

.0861

.0615

.0359

.0215

.0154

.0120

.00861

.00615

.00478

.00391
Cumulative

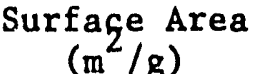

0

$7.25 \mathrm{E}-6$

$21.3 \mathrm{E}-6$

$47.8 \mathrm{E}-6$

$68.8 \mathrm{E}-6$

132. E-6

354. E-6

731. E-6

.00226

.00385

.00542

.00913

.0118

.0357

.178

.342

.488

.566

.757

.902

1.02

1.13

1.32

1.42

1.42

1.42
0

511. E-6

.00150

.00337

.00485

.00733

.0249

.0515

.160

.271

.382

.643

.833

2.51

12.6

24.1

34.4

39.9

53.4

63.6

72.0

79.8

93.1

100.

100.

100 . 
Page of File $88-1056-14$

PORE SURFACE AREA SUMMARY

INTERA TECHNOLOGIES, INC.

Sample Number:

Sample Identification Number: Air Permeability, md:

Porosity, Percent:

Dry Sample Welght (gm):

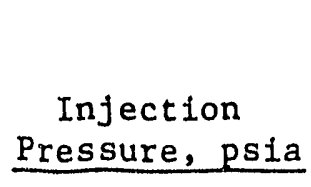

60

80

100

150

200

400

750

1000

1500

2000

4000

6000

8000

10000

15000

20000

25000

30000

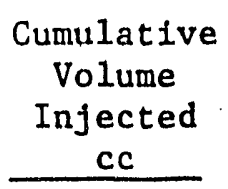

0.

.0036

.0067

.0139

.0189

.0248

.0284

.0376

.0865

.1385

.1925

.3133

.3814

.7926

1.1737

1.255

1.3526

1.4063

1.4825

1.5067

1.5181

1.5243

1.5284

1.5284

1.5284

1.5284
2

(H2B 1-2)

1.180

$14.8 \%$

26.40

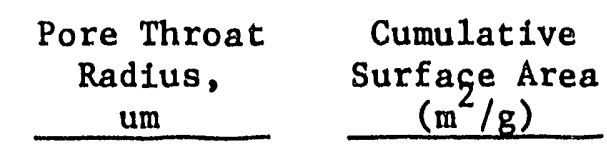

215.

71.7

35.9

17.9

12.0

8.61

6.08

3.56

2.15

1.54

1. 20

.861

.615

.359

.187

.123

.0861

.0615

.0359

.0215

.0154

.0120

.00861

.00615

.00478

.00391
0 .

$4.6 \mathrm{E}-6$

$12.5 \mathrm{E}-6$

$49.3 \mathrm{E}-6$

$87.7 \mathrm{E}-6$

151. E-6

205. E-6

442. E-6

.00253

.00563

.00977

.0226

.0328

.138

.325

.385

.489

.569

.764

.867

.935

.983

.983

.983

.983

.983
Surface Area

(\%)

0.

468. E-6

.00127

.00502

.00892

.0153

.0208

.0449

.257

.573

.994

2.30

3.34

14.0

33.0

39.2

49.8

57.9

77.8

88.2

95.2

100.

100.

100.

100.

100. 
PORE SURFACE AREA SUMMARY

INTERA TECHNOLOGIES, INC.

Sample Number:

Sample Identification Number:

Alr Permeability, md:

Porosity, Percent:

Dry Sample Welght (gm):

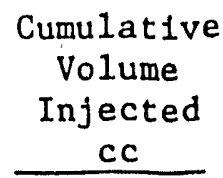

Injection
Pressure, psia

.5

1

2

4

8

10

15

20.4

40

60

80

100

150

200

400

750

1000

1500

2000

4000

6000

8000

10000

15000

20000

25000

30000

0 .

.0039

.0097

.0373

.0523

.0554

.0659

.0773

.0840

.0910

.0951

.0960

.1004

.1015

.2114

1.0886

1.1879

1.2661

1.3009

1. 3509

1. 3682

1.3776

1.3827

1.3874

1.3874

1.3874

1. 3874
3

(H5B 1-1A)

.042

$13.0 \%$

27.75

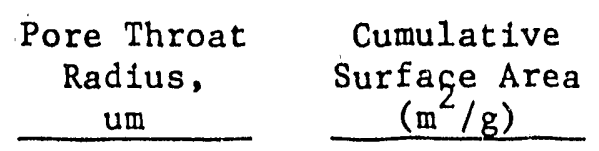

0.

$2.37 \mathrm{E}-6$

$9.43 \mathrm{E}-6$

76.6 E-6

.00015

.000172

.000279

.000442

.000606

.00089

.00112

.00119

.00163

.00179

.0285

.437

.508

.587

.637

.758

.828

.882

.919

.967

.967

.967

.967
Surface Area

0 .

245. E-6

975. E-6

.00792

.0155

.0178

.0288

.0457

.0627

.0921

.116

.123

.169

.185

2.95

45.3

52.6

60.8

65.9

78.4

85.7

91.2

95.1

100.

100.

100.

100. 
Page

File $88-1056-14$

PORE SURFACE AREA SUMMARY

INTERA TECHNOLOGIES, INC.

Sample Number:

Sample Identification Number:

Air Permeability, md:

Porosity, Percent:

Dry Sample Welght (gm):

\section{4}

(H5B 1-1B)

.042

$13.0 \%$

26.85

\begin{tabular}{|c|c|c|c|c|}
\hline $\begin{array}{l}\text { Injection } \\
\text { Pressure, psia } \\
\end{array}$ & $\begin{array}{c}\text { Cumulative } \\
\text { Volume } \\
\text { Injected } \\
\text { cc } \\
\end{array}$ & $\begin{array}{c}\text { Pore Throat } \\
\text { Radius, } \\
\text { um } \\
\end{array}$ & $\begin{array}{c}\text { Cumulative } \\
\text { Surfage Area } \\
\left(\mathrm{m}^{2} / \mathrm{g}\right)\end{array}$ & $\begin{array}{c}\text { Surface Area } \\
(\%) \\
\end{array}$ \\
\hline 2 & 0 . & 108. & 0 . & 0 \\
\hline 4 & .0031 & 35.9 & $7.79 \mathrm{E}-6$ & 674. E-6 \\
\hline 8 & .0075 & 17.9 & $29.9 \quad E-6$ & .00259 \\
\hline 10 & .0178 & 12.0 & 108. $E-6$ & .0093 \\
\hline 15 & .0479 & 8.61 & 423. $E-6$ & .0366 \\
\hline 20.4 & .0598 & 6.08 & 599. E-6 & .0518 \\
\hline 40 & .0723 & 3.56 & 916. E-6 & .0792 \\
\hline 60 & .0840 & 2.15 & .00141 & .122 \\
\hline 80 & .0893 & 1.54 & .00172 & .148 \\
\hline 100 & .0907 & 1.20 & .00182 & .158 \\
\hline 150 & .0979 & .861 & .00258 & .223 \\
\hline 200 & .1143 & .615 & .00498 & .431 \\
\hline 400 & .2991 & .359 & .0514 & 4.45 \\
\hline 750 & 1.3087 & .187 & .538 & 46.5 \\
\hline 1000 & 1.4027 & .123 & .607 & 52.5 \\
\hline 1500 & 1.4859 & .0861 & .694 & 60.0 \\
\hline 2000 & 1.5190 & .0615 & .743 & 64.2 \\
\hline 4000 & 1.5754 & .0359 & .884 & 76.4 \\
\hline 6000 & 1.5955 & .0215 & .969 & 83.7 \\
\hline 8000 & 1.6069 & .0154 & 1.040 & 89.5 \\
\hline 10000 & 1.6130 & .012 & 1.08 & 93.5 \\
\hline 15000 & 1.6202 & .00861 & 1.16 & 100 \\
\hline 20000 & 1.6202 & .00615 & 1.16 & 100 \\
\hline 25000 & 1.6202 & .00478 & 1.16 & 100 \\
\hline 30000 & 1.6202 & .00391 & 1.16 & 100 \\
\hline
\end{tabular}


Page of

File $88-1056-14$

\section{PORE SURFACE AREA SUMMARY}

INTERA TECHNOLOGIES, INC.

Samp 'umber: 5

Sample Identification Number: (H7B1-2A)

Air Permeability, ad:

Porosity, Percent:

Dry Sample Weight $(\mathrm{gm})$ :
.108

$21.5 \%$

25.02
Injection

Pressure, psia

0.5

1

2

4

8

10

15

20.4

40

60

80

100

150

200

400

750

1000

1500

2000

4000

6000

8000

10000

15000

20000

25000

30000
Cumulative

Volume

Injected

cc

0 .

.0078

.0122

.0940

.1088

.1769

.1850

.1928

.2284

.4295

.4652

.4788

.6677

.6833

.8755

1.6222

1.6954

1.7107

1.7120

1.7126

1.7126

1.7126

1.7126

1.7126

1.7126

1.712 .

1.7126
Pore Throat

Radius,

um

430.

143.

71.7

35.9

17.9

12.

8.61

6.08

3.56

2.15

1.54

1.20

.861

.615

.359

.187

.123

.0861

.0615

.0359

.0215

.0154

.0120

.00861

.00615

.00478

.00391
Cumulative

Surfage Area

$$
\left(\mathrm{m}^{2} / \mathrm{g}\right)
$$

0 .

$5.26 \mathrm{E}-6$
$11.2 \mathrm{E}-6$

232. E-6

312. E-6

863. E-6

954. E-6

.00108

.00204

.0111

.0133

.0144

.0357

.0381

.0900

.476

.534

.551

.553

.555

.555

.5 .55

. 5

נגن.

.

.555
Surface Area

(\%)

948. E-6

.00202 .

.0418

.0562

.155

.172

.195

.368

2.00

2.40

2.59

6.43

6.86

16.2

85.5

$96 . ?$

99.3

99.6

100.

100.

100.

1.00 .

100.

100.

100.

100 . 
Page 8 of

PORE SURFACE AREA SUMMAR:

INTERA TECHNOLOGIES, INC.

Sample Number:

Sample Identification Number:

Air Permeability, md:

Porosity, Percent:

Dry Sample Weight (gm):
6

( $\mathrm{H} 7 \mathrm{~B} 1-2 \mathrm{~B})$

C. 521

$27.8 \%$

22.98

Cumulative

Injection

Pressure, psia

0.5

1

2

4

8

10

15

20.4

40

60

80

100

150

200

400

750

1000

1500

2000

4000

6000

8000

10000

15000

20000

25000

30000
Volume

Injected

cc

0.

.0303

.4500

.4644

.4793

.4838

.4903

.5117

.5848

.6986

.7758

.8182

.8534

.8799

1.2009

1.7661

1.8395

1.9012

1.9271

1.9626

1.9740

1.9802

1.9833

1.9871

1.9871

1.9871

1.8971

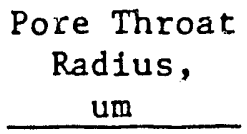

430.

143.

71.7

35.9

17.9

12.0

8.61

6.08

3.56

2.15

1.54

1.20

.861

.615

.359

.187

.123

.0861

.0615

.0359

.0215

.0154

.012

.00861

.00615

.00478

.00391
Cumulative

Surfaģe Area

$\left(\mathrm{m}^{2} / \mathrm{g}\right)$

0 .

$22.3 \mathrm{E}-6$

639. $E-6$

681. E-6

768. E-6

808. E-6

888. E-6

.00126

.00342

.00899

.0143

.0180

.0223

.0269

.121

.439

.502

.578

.622

.726

.782

.825

.852

.899

.899

.899

.899
Surface Area

(\%)

.00248

.0711

.0758

.0854

.0899

.0988

.140

.380

1.00

1.59

2.00

2.48

2.99

13.5

48.8

55.8

64.3

09.2

80.8

87.0

91.8

94.8

100.

100.

100.

100. 
\begin{tabular}{l} 
Page \\
File $88-1056-14$ \\
\hline
\end{tabular}

PORE SURFACE AREA SUMMARY

INTERA TECHNOLOGIES, INC.

Sample Number:

Sample Identification Number:

Afr Permeability, md:

Porosity, Percent:

Dry Sample Weight (gm):

Injection

Pressure, psta

1

2

4

8

10

15

20.4

40

60

80

100

150

200

400

750

1000

2000

4000

6000

8000

10000

15000

20000

25000

30000
Cumulative

Volume

Injected

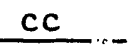

0.

.0076

.0209

.0318

.0341

.0378

.0421

.0424

.0434

.0454

.0467

.0507

.0749

.8760

1.1314

1.1894

1.2659

1. 3053

1. 3202

1. 3269

1.3318

1.3365

1.3365

1. 3365

1. 3365
7

(H7B2-1)

0.294

$17.3 \%$

25.99

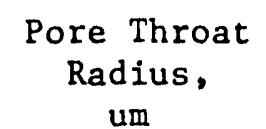

215.

71.7

35.9

17.9

12.0

8.61

6.08

3.56

2.15

1.54

1.20

.861

.615

.359

.187

.123

.0717

.0359

.0215

.0154

.0120

.00861

.00615

.00478

.00391
Cumulative

Surfaçe Area $\left(\mathrm{m}^{2} / \mathrm{g}\right)$

0.

9.87 E-6

$44.4 \mathrm{E}-6$

101. E-6

119. E-6

159. E-6

225. E-6

233. E-6

276. E-6

397. E-6

498. E-6

931. E-6

.00460

.213

.340

.384

.488

.581

.645

.686

.724

.775

.775

.775

.775
Surface Area (\%)

0 .

.00127

.00573

.013

.0154

.0205

.029

.030

.0356

.0513

.0643

.120

.593

27.4

43.9

49.5

62.9

74.9

83.3

88.5

93.4

100.

100.

100.

100. 
Page

File 88-1056-14

PORE SURFACE AREA SUMMARY

INTERA TECHNOLOGIES, INC.

Sample Number:

Sample Identification Number: Air Permeability, md:

Porosity, Percent:

Dry Sample WeIght (gm):

Injection

Pressure, psia

0.5

1

2

4

8

10

15

20.4

40

60

80

100

150

200

400

750

1000

2000

4000

6000

8000

10000

15000

20000

25000

30000
Cumulative

Volume

Injected

cc

0.

.0053

.0095

.0159

.0289

.0312

.0367

.0426

.0551

.0693

.0801

.0912

.2098

.2164

.4524

1.0413

1.1189

1.1225

1.2433

1.2558

1.2616

1.2660

1.2661

1.2661

1.2661
1. 2647
8

(H7C-1B)

.074

$16.5 \%$

26.67

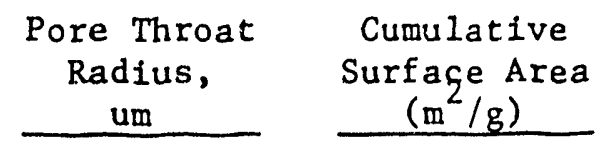

430.

143.

71.7

35.9

17.9

12.0

8.61

6.08

3.56

2.15

1.54

1.20

.861

.615

.359

.187

.123

.0717

.0359

.0215

.0154

.0120

.00861

.00615

.00478

.00391
0.

$3.35 \mathrm{E}-6$

8.67 E-6

24.9 E-6

90.7 E-6

108. E-6

166. E-6

254. E-6

573. E-6

.00117

.00181

.00265

.0152

.0161

.0759

.362

.419

.423

.729

.782

.816

.840

.853

.855

.855

.855
Surface Area

(\%)

0.

392. E-6

.00101

.00291

.0106

.0126

.0194

.0297

.067

.137

.212

.310

1.77

1.89

8.87

42.3

49.0

49.5

85.3

91.5

95.5

98.2

99.8

100.

100 . 
\begin{tabular}{l} 
Page \\
File $88-1056-14$ \\
\hline
\end{tabular}

PORE SURFACE AREA SUMMARY

INTERA TECHNOLOGIES, INC.

Sample Number:

Sample Identification Number:

Air Permeability, md:

Porosity, Percent:

Dry Sample Weight (gm):

Cumulative

Volume

Injection

Pressure, psia

0.5

1

2

4

8

10

15

20.4

40

60

80

100

150

200

400

750

1000

1500

2000

4000

6000

8000

10000

15000

20000

25000

30000
Injected

$c c$

0.

.0045

.0075

.0103

.0606

.1091

.1138

.1171

.1177

.1294

.1424

.1441

.1525

.1577

.4927

1.0527

1.1384

1.2099

1.2408

1.2867

1. 3042

1.3137

1.3187

1. 3251

1. 3251

1. 3251

1. 3251
9

(H7C-1A)

.098

$13.4 \%$

27.63

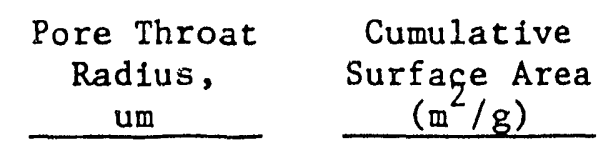

430.

143.

71.7

35.9

17.9

12.0

8.61

6.08

3.56

2.15

1.54

1.2

.861

.615

.359

.187

.123

.0861

.0615

.0359

.0215

.0154

.0120

.00861

.00615

.00478

.00391
0 .

2.75 E-6

6.41 E-6

$13.3 E-6$

259. E-6

614. E-6

662. E-6

710. E-6

725. E-6

.0012

.00194

.00207

.00292

.00366

.0855

.348

.409

.482

.526

.638

.709

.763

.800

.865

.865

.865

.865
Surface Area

(\%)

0 .

318. $\therefore-6$

741. E-6

.00153

.0299

.0710

.0766

.0821

.0838

.139

.225

.239

.338

.423

9.89

40.2

47.3

55.7

60.8

73.7

82.0

83.2

92.5

100.

100.

100. 


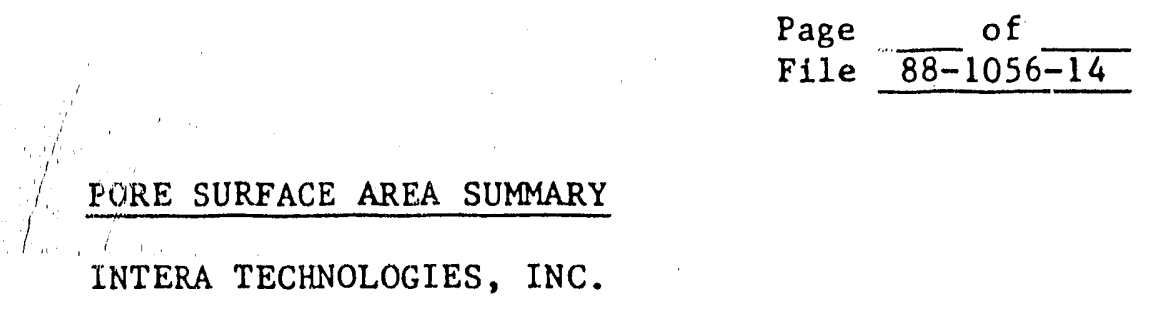

Sample Number:

Sample Identification Number:

Air Permeability, an:

Porosity, Percent:

Dry Sample Welght (gm):

Cumulative

Injection
Pressure, psia

1

2

4

8

10

20.4

40

60

80

100

150

200

400

750

1000

1500

2000

4000

6000

8000

10000

15000

20000

25000

30000

\section{Volume}

Injected

cC

0 .

.0014

.0028

.0061

.0070

.0095

.0117

.0117

.0128

.0142

.0150

.0195

.0220

.0531

.2980

.4607

.5767

.6421

.7442

.7767

.7898

.7962

.8004

.8004

.8004

.8004
10

( $\mathrm{H}-1 \mathrm{OB}-1)$

.012

$10.8 \%$

29.65

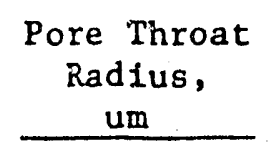

215.

71.7

35.9

17.9

12.0

8.61

6.08

3.56

2.15

1.54

1.20

.861

.615

.359

.187

.123

.0861

.0615

.0359

.0215

.0154

.0120

.00861

.00615

.00478

.00391
Cumulative

Surfage Area $\left(\mathrm{m}^{2} / \mathrm{g}\right)$

0.

$1.59 \mathrm{E}-6$

$4.78 \mathrm{E}-6$

$19.8 \mathrm{E}-6$

26.0 E-6

$49.7 \mathrm{E}-6$

$79.2 \mathrm{E}-6$

$79.2 \mathrm{E}-6$

121. E-6

195. E-6

250. E-6

677. E-6

.00101

.00809

.115

.223

.333

.420

.652

.776

.845

.889

.929

.929

.929

.929
Surface Area

$(\%)$

0.

172. E-6

515. E-6

.00213

.00279

.00535

.00853

.00853

.0130

.0210

.0269

.0729

.109

.871

12.4

24.0

35.9

45.2

70.2

83.5

91.0

95.7

100.

100.

100.

100. 
\begin{tabular}{l} 
Page \\
File \\
\hline $88-1056-14$
\end{tabular}

PORE SURFACE AREA SUMMARY

INTERA TECHNOLOGIES, INC.

Sample Number:

Sainple Identification Number:

Alr Permeability, md:

Porosity, Percent:

Dry Sample Weight (gm):
$10 \mathrm{~A}$

(HIOB-1)

.174

$9.0 \%$

33.07

\begin{tabular}{|c|c|c|c|c|}
\hline $\begin{array}{c}\text { Injection } \\
\text { Pressure, psia }\end{array}$ & $\begin{array}{c}\text { Cumulative } \\
\text { Volume } \\
\text { Injected } \\
\text { cc } \\
\end{array}$ & $\begin{array}{c}\text { Pore Throat } \\
\text { Radius, } \\
\text { um } \\
\end{array}$ & $\begin{array}{c}\text { Cumulative } \\
\text { Surfaçe Area } \\
\left(\mathrm{m}^{2} / \mathrm{g}\right)\end{array}$ & $\begin{array}{r}\text { Surface Area } \\
(\%) \\
\end{array}$ \\
\hline .5 & 0 & 430. & 0 & \\
\hline 1 & .0036 & 143. & $1.84 E-6$ & .000285 \\
\hline 2 & .0339 & 71.7 & $32.8 \quad E-6$ & .00507 \\
\hline 4 & .0398 & 35.9 & $44.8 \Sigma-6$ & .00694 \\
\hline 8 & .0426 & 17.9 & 56.2 E-6 & .00871 \\
\hline 10 & .0434 & 12.0 & $61.1 \mathrm{E}-6$ & .00947 \\
\hline 15 & .0442 & 8.61 & 67.9 E-6 & .0105 \\
\hline 20.4 & .0462 & 6.08 & 92. $E-6$ & .0143 \\
\hline 40 & .0534 & 3.56 & 240. E-6 & .0372 \\
\hline 60 & .0965 & 2.15 & .00171 & .264 \\
\hline 80 & .1466 & 1.54 & .00409 & .634 \\
\hline 100 & .1772 & 1.20 & .00597 & .924 \\
\hline 150 & .2345 & .861 & .0108 & 1.68 \\
\hline 200 & .2751 & .615 & .0157 & 2.43 \\
\hline 400 & .3708 & .359 & .0352 & 5.45 \\
\hline 750 & .6788 & .187 & .156 & 24.1 \\
\hline 1000 & .8577 & .123 & .262 & 40.6 \\
\hline 1500 & .9612 & .0861 & .350 & 54.3 \\
\hline 2000 & 1.0051 & .0615 & .402 & 62.4 \\
\hline 4000 & 1.0649 & .0359 & .525 & 81.3 \\
\hline 6000 & 1.0836 & .0215 & .588 & 91.1 \\
\hline 8000 & 1.0914 & .0154 & .625 & 96.9 \\
\hline 10000 & 1.0947 & .0120 & .646 & 100 \\
\hline 15000 & 1.0947 & .0120 & .646 & 100 \\
\hline 20000 & 1.0947 & .0120 & .646 & 100 \\
\hline
\end{tabular}


\begin{tabular}{l} 
Page \\
File \\
\hline $88-1056-14$
\end{tabular}

PORE SURFACE AREA SUMMARY

INTERA TECHNOLOGIES, INC.

Sample Number:

Sample Identification Number:

Air Permeability, md:

Porosity, Percent:

Dry Sample Weight (gm):
11

(H11-2)

.038

$11.0 \%$

27.92

\begin{tabular}{|c|c|c|c|c|}
\hline $\begin{array}{c}\text { Injection } \\
\text { Pressure, psia } \\
\end{array}$ & $\begin{array}{c}\text { Cumulative } \\
\text { Volume } \\
\text { Injected } \\
\text { cc } \\
\end{array}$ & $\begin{array}{c}\text { Pore Throat } \\
\text { Radius, } \\
\text { um }\end{array}$ & $\begin{array}{c}\text { Cumulative } \\
\text { Surface Area } \\
(\mathrm{m} / \mathrm{g}) \\
\end{array}$ & $\begin{array}{c}\text { Surface Area } \\
(\%) \\
\end{array}$ \\
\hline 1 & 0. & 215. & 0. & \\
\hline 2 & .0131 & 71.7 & 15.8 E-6 & 610. E-6 \\
\hline 4 & .0200 & 35.9 & 32.5 E-6 & .00125 \\
\hline 8 & .0242 & 17.9 & 52.8 E-6 & .00204 \\
\hline 10 & .0250 & 12.0 & 58.6 E-6 & .00226 \\
\hline 15 & .0267 & 8.61 & $75.8 \quad E-6$ & .00293 \\
\hline 20.4 & .0284 & 6.08 & 100. E-6 & .00386 \\
\hline 40 & .0287 & 3.56 & 107. E-6 & .00413 \\
\hline 60 & .0289 & 2.15 & 115. E-6 & .00444 \\
\hline 80 & .0314 & 1.54 & 256. E-6 & .00988 \\
\hline 100 & .0320 & 1.20 & $300 . E-6$ & .0116 \\
\hline 150 & .0325 & .861 & 350. E-6 & .0135 \\
\hline 200 & .0331 & .615 & 435. E-6 & .0168 \\
\hline 400 & .0359 & .359 & .00111 & .0429 \\
\hline 750 & .0465 & .187 & .00602 & .232 \\
\hline 1000 & .0782 & .123 & .0284 & 1.10 \\
\hline 1500 & .6182 & .0861 & .572 & 22.1 \\
\hline 2000 & .7815 & .0615 & .803 & 31.0 \\
\hline 4000 & .9670 & .0359 & 1.25 & 48.3 \\
\hline 6000 & 1.0293 & .0215 & 1.50 & 57.9 \\
\hline 8000 & 1.0644 & .0154 & 1.70 & 65.6 \\
\hline 10000 & 1.0872 & .0120 & 1.87 & 72.2 \\
\hline 15000 & 1.1231 & .00861 & 2.23 & 86.1 \\
\hline 20000 & 1.1401 & .00615 & 2.47 & 95.4 \\
\hline 25000 & 1.1470 & .00478 & 2.59 & 100 \\
\hline 30000 & 1.1470 & .00391 & 2.59 & 100. \\
\hline
\end{tabular}


\begin{tabular}{l} 
Page \\
F1le \\
of \\
\hline
\end{tabular}

PORE SURFACE AREA SUMMARY

INTERA TECHNOLOGIES, INC.

Sample Number:

Sample Identification Number: Air Permeability, md:

Porosity, Percent:

Dry Sample Weight (gm):

Cumulative

Injection

Pressure, psia

1

2

4

8

10

15

20.4

40

60

80

100

150

200

400

750

1000

1500

2000

4000

6000

8000

10000

15000

20000

25000

30000
Volume

Injected

cc

0.

.0779

.0990

.1289

.1621

.1743

.2485

.3153

.4007

.4546

.6063

.6999

1.9365

2.1938

2.2379

2. 2756

2.2925

2. 3175

2. 3258

2. 3289

2. 3314

2. 3316

2. 3316

2. 3316

2. 3316
.1813
12

(H11B3-1)

1.330

$33.1 \%$

21.41
Surface Area

$(\%)$

0 .

.0137

.0212

.0423

.0775

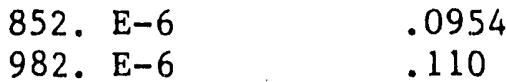

$.00312 \quad .349$

$.00663 \quad .742$

$.0129 \quad 1.45$

.0180

.0379

.0551

.445

.600

.641

.691

.722

.800

.844

.867

.891

.893

.893

.893

.893
2.02

4.25

6.17

49.8

67.2

71.8

77.3

80.8

89.6

94.5

97.1

99.7

100 .

100 .

100.

100. 
Page
File

\section{PORE SURFACE AREA SUMMARY}

INTERA TECHNOLOGIES, INC.

Sample Number:

Sample Identification Number:

Air Permeability, md:

Porosity, Percent:

Dry Sample Weight (gm):

Cumulative

Volume

Injection

Pressure, psia

0.5

1

2

4

8

10

15

20.4

40

60

80

100

150

200

400

750

1000

1500

2000

4000

6000

8000

10000

15000

20000

25000

30000
Injected

cc

0.

.0303

.0484

.0601

.0665

.0673

.0687

.0707

.0751

.0871

.0907

.0929

.0985

.1049

.1847

1.2781

1.3977

1.4898

1.5334

1.5963

1.6213

1.6369

1.6461

1.6575

1.6600

1.6600

1.6600
13

(H11B3-4)

.186

$14.8 \%$

26.90

$$
\begin{array}{cc}
\begin{array}{c}
\text { Pore Throat } \\
\text { Radius, } \\
\text { um }
\end{array} & \begin{array}{c}
\text { Cumulative } \\
\text { Surfage Area } \\
\left(\mathrm{m}^{2} / \mathrm{g}\right)
\end{array} \\
\hline
\end{array}
$$

430.

143.

71.7

35.9

17.9

12.0

8.61

6.03

3.56

2.15

1.54

1.20

.861

.615

.359

.187

.123

.0861

.0615

.0359

.0215

.0154

.0120

.00861

.00615

.00478

.00391

\begin{tabular}{c}
$\begin{array}{c}\text { Surface Area } \\
(\mathrm{m} / \mathrm{g})\end{array}$ \\
\hline
\end{tabular}

0.

19.0 E-6

$41.7 \mathrm{E}-6$

$71.1 \mathrm{E}-6$

103. E-6

109. E-6

124. E-6

153. E-6

265. E-6

766. E-6

977. E-6

.00114

.00173

.00267

.0227

.549

.636

.732

.796

.954

1.05

1.15

1.22

1. 34

1.37

1.37

1.37
Surface Area

(\%)

0 .

.00138

.00303

.00517

.00751

.00794

.00901

.0112

.0192

.0557

.0711

.0831

.126

.194

1.65

39.9

46.3

53.3

57.9

69.4

77.0

83.:

88.7

$9 \pi .3$

100.

100 . 
Page

F1le $\overline{88-1056-14}$

PORE SURFACE AREA SUMMARY

INTERA TECHNOLUIIES, INC.

Sample Number:

Sample Identification Number:

Alr Permeability, md:

Porosity, Percent:

Dry Sample Weight (gm):
14

$(\mathrm{W}-12-1 \mathrm{~A})$

.270

$2.8 \%$

28.27
Cumulative

Injection

Pressure, psia

2
4
8
10
15
20
40
60
80
100
150
200
400
750
1000
1.500
2000
4000
6000
8000
10000
15000
20000
25000
30000

Volume

Injected

cc

0

.0022

.0047

.0067

.0100

.0092

.0145

.0378

.0481

.0593

.0776

.0949

.5494

1.1743

1.2892

1.4038

1.4617

1.5462

1.5793

1.5960

1.6058

1.6175

1.61 .94

1.6194

1.6194

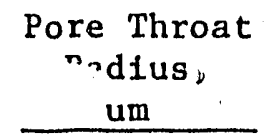

108

35.9

17.9

12.0

8.61

6.08

3.56

2.15

1.54

1.20

.861

.615

.359

.187

.123

.0861

.0615

.0359

.0215

.0154

.0120

.00861

.00615

.00478

.00391
Cumulative

Surfage Area

$\left(\mathrm{m}^{2} / \mathrm{g}\right)$

0

$5.25 \mathrm{E}-6$

$17.2 \mathrm{E}-6$

$31.5 \mathrm{E}-6$

$64.3 \mathrm{E}-6$

$53.1 \mathrm{E}-6$

180. E-6

.00111

.00168

.00248

.0043

.00671

.115

.401

.481

.595

.676

.882

1.01

1.10

1.17

1.29

1.31

1.31

1. 1
Surface Area

(\%)

0

.0004

.00131

.0024

.0049

.00404

.0138

.0844

.128

.189

.328

.512

8.78

30.6

36.7

45.4

51.5

67.2

76.7

83.8

89.1

98.

100.

100.

100. 
Page of

File $88-1056-14$

\section{PORE SURFACE AREA SUMMARY}

INTERA TECHNOLOGIES, INC.

Sample Number:

Sample Identification Number: Air Permeability, md:

Porosity, Percent:

Dry Sample Weight (gm):

Cumulative

Injection

Pressure, psia

0.5

1

2

4

8

10

15

20.4

40

60

80

100

150

200

400

750

1000

1500

2000

4000

6000

8000

10000

15000

20000

25000

30000

0.

.0248

.0295

.0320

.0337

.0345

.0362

.0387

.0426

.0490

.0526

.0623

.0798

.0896

.3697

.9286

1.0110

1.0944

1.1317

1.1893

1. 2091

1.2199

1.2263

1.2335

1.2341

1. 2341

1. 2341
15

(W-12-1B-1)

.086

$11.2 \%$

24.80

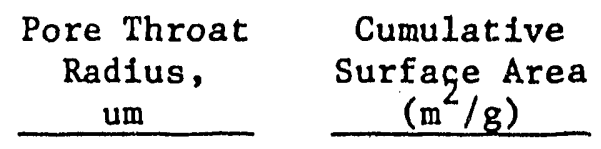

430.

143.

71.7

35.9

17.9

12.0

8.61

6.08

3.56

2.15

1.54

1.2

.861

.615

.359

.187

.123

.0861

.0615

.0359

.0215

.0154

.0120

.00861

.00615

.00478

.00391
0.

16.9 E-6

23.3 E-6

30.1 E-6

39.3 E-6

45.9 E-6

65.1 E-6

105. E-6

212. E-6

502. $E-6$

731. E-6

.00152

.00351

.00506

.0813

.373

.438

.533

.592

.749

.839

.907

.950

1.04

1.05

1.05

1.05
Surface Area

0 .

.00161

.00221

.00286

.00374

.00436

.0062

.0100

.0202

.0478

.0696

.145

.334

.482

7.74

35.5

41.7

50.7

56.4

71.3

79.8

86.3

91.3

99.1

100.

100 . 
Page
File $88-1056-14$

PORE SURFACE AREA SUMMARY

INTERA TECHNOLOGIES, INC.

Sample Number:

Sample Identification Number:

Alr Permeability, md:

Porosity, Percent:

Dry Sample Weight (gm):

Cumulative

Volume

Injection

Pressure, psia

1

2

4

8

10

15

20.4

40

60

80

100

150

200

400

750

1000

1500

2000

4000

6000

8000

10000

15000

20000

25000

30000
16

(W-12-2)

1. 380

$13.6 \%$

27.67

\section{Pore Throat Radius, \\ Cumulative \\ Surfaçe Area}

um

215.

71.7

35.9

17.9

12. 0

8.61

6.08

3.56

2.15

1.54

1.20

.861

.615

.359

.187

.123

.0861

.0615

.0359

.0215

.0154

.0120

.00861

.00615

.00478

.00391 $\left(\mathrm{m}^{2} / \mathrm{g}\right)$

0 .

21. $E-6$

146. E-6

201. E-6

229. E-6

277. E-6

421. E-6

873. E-6

.00322

.00481

.00611

.00916

.0125

.106

.293

.345

.414

.459

.579

.648

.694

.731

.765

.765

.765

.765
Surface Area

(\%)

0.

.00274

.0191

.0262

.0300

.0362

.0550

.114

.422

.629

.800

1.2

1.64

13.9

38.3

45.1

54.1

60.1

75.7

84.8

90.7

95.6

100.

100 .

100 .

100 . 
Page

of

File $\overline{88-1056-14}$

PORE SURFACE AREA SUMMARY

INTERA TECHNOLOGIES, INC.

Sample Number:

Sample Identification Number: Air Permeability, md:

Porosity, Percent:

Dry Sample Weight (gm):
17

$(\mathrm{W}-13-3 \mathrm{~A})$

4. 940

$19.0 \%$

26.74

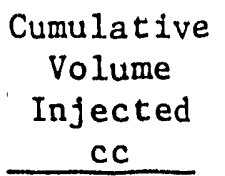

Pressure, psia

1

2

4

8

10

15

20.4

40

60

$\mathrm{cO}$

100

150

200

400

750

1000

1500

2000

4000

6000

8000

10000

15000

20000

25000

30000
0.

.0146

.0199

.0268

.0292

.0477

.0769

.1534

.4019

.5533

.6298

.7090

.7418

1.3414

1.6098

1.6601

1.7095

1.7344

1.7784

1.7970

1.8082

1.8149

1.8258

1.8258

1.8258

1.8258
Pore Throat

Radius, um

215.

71.7

35.9

17.9

12.0

8.61

6.08

3.56

2.15

1.54

1.20

.861

.615

.359

.187

.123

.0861

.0615

.0359

.0215

.0154

.0120

.00861

.00717

.00478

.00391
Cumulative Surfage Area $\left(\mathrm{m}^{2} / \mathrm{g}\right)$

0.

$18.4 \mathrm{E}-6$

$31.8 \mathrm{E}-6$

$66.6 \mathrm{E}-6$

$84.8 \mathrm{E}-6$

279. E-6

714. E-6

.00266

.0131

.022

.0278

.0362

.0410

.192

.322

.359

.411

.448

.559

.637

.703

.754

.869

.869

.869

.869
Surface Area

(\%)

0.

.00212

.00366

.00767

.00977

.0322

.0822

.306

1.51

2.54

3.2

4.16

4.72

22.1

37.1

41.4

47.3

51.6

64.4

73.4

81.0

86.8

100.

100.

100.

100. 
Page of

Fıle 88-1056-14

PORE SURFACE AREA SUMMARY

INTERA TECHNOLOGIES, INC.

Sample Number:

Sample Identification Number:

Air Permeability, md:

Porosity, Percent:

Dry Sample Weight (gm):

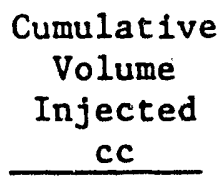

Injection

Pressure, psia

1

2

4

8

10

15

20.4

40

60

80

100

150

200

400

750

1000

1250

1500

2000

4000

6000

8000

10000

15000

20000

25000

30000

0.

.0050

.0070

.0083

.0086

.0106

.0108

.0108

.0108

.0108

.0108

.0111

.0111

.2173

.9075

.9723

1.0071

1.0285

1.0549

1. 0828

1. 1142

1. 1231

1.1284

1.1334

1.1334

1. 1334

1. 1334
18

(W-13-3B)

.037

$9.7 \%$

29.59

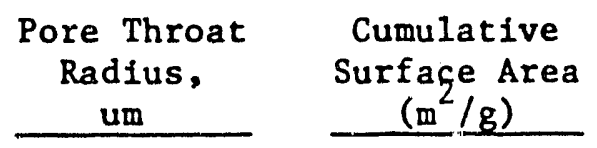

215.

71.7

35.9

17.9

12.0

8.61

6.08

3.56

2.15

1.54

1.20

.861

.615

.359

.187

.123

.0956

.0783

.0615

.0359

.0215

.0154

.0120

.00861

.00717

.00478

.00391
0.

$5.7 \mathrm{E}-6$

10.3 E-6

$16.2 \mathrm{E}-6$

18. $2 \mathrm{E}-6$

$37.3 \mathrm{E}-6$

40. $E-6$

40. E-6

40. E-6

40. E-6

40. E-6

$68.5 \mathrm{E}-6$

08.5 E-6

.0471

.349

.392

.422

.444

.479

.543

.662

.710

.746

.784

.784

.784

.784
Surface Area

(\%)

0.

727. E-6

.00131

.00207

.00233

.00475

.0051

.0051

.0051

.0051

.0051

.00873

.00873

6.01

44.5

50.0

53.8

56.7

61.1

69.3

84.5

90.5

95.2

100.

100.

100.

100. 
Page of

File $88-1056-14$

PORE SURFACE AREA SUMMARY

INTERA TECHNOLOGIES, INC.

Sample Number:

Sample Identification Number:

Air Permeability, md:

Porosity, Percent:

Dry Sample Weight (gm):

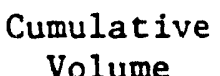

Injection

Pressure, psia

1

2.

4

8

10

15

20.4

40

60

80

100

150

200

400

750

1000

1500

2000

4000

6000

8000

10000

15000

20000

25000

30000

0.

.0282

.0354

.0394

.0408

.0424

.0457

.0457

.0457

.0457

.0457

.0457

.0461

.1236

.8915

1.0529

1.1851

1.2457

1.3398

1.3815

1.4064

1.4223

1.4471

1.4471

1.4471
19

(W-26-3)

.039

$12.5 \%$

28.60

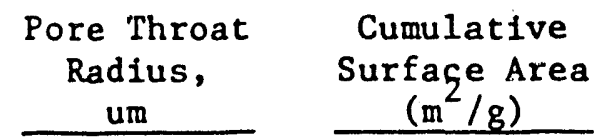

1.4471
215.

71.7

35.9

17.9

12.0

8.61

6.08

3.56

2.15

1.54

1.20

.861

.615

.359

.187

.123

.0861

.0615

.0359

.0215

.0154

.0120

.00861

.00717

.00478

.00391
0.

33.3 E-6

50.3 E-6

69.2 E-6

79.1 E-6

94.8 E-6

141. E-6

141. E-6

141. E-6

141. E-6

141. $E-6$

196. E-6

.0185

.357

.482

.612

.695

.917

1.08

1.22

1.33

1.57

1.57

1.57

1.57
141. E-6
Surface Area

(\%)

0 .

.00211

.00319

.00439

.00502

.00602

.00894

.00894

.00894

.00894

.00894

.00894

.0124

1.17

22.7

30.6

38.8

44.1

58.2

68.7

77.4

84.6

100 .

100.

100 .

100. 
Page
File $88-1056-14$

PORE SURFACE AREA SUMMARY

INTERA TECHNOLOGIES, INC.

Sample Number:

Sample Identification Number:

Alr Permeability, md:

Porosity, Percent:

Dry Sample WeIght (gm):

Injection

Pressure, psia

0.5

1

2

4

8

10

15

20.4

40

60

80

100

150

200

400

750

1000

1500

2000

4000

6000

8000

10000

15000

20000

25000

30000
Cumulative
Volume Injected cc

0.

.0106

.0184

.0395

.0520

.0537

.0537

.0595

.0595

.0626

.0640

.0654

.0676

.0693

.0712

.1680

.6693

1.1996

1.2878

1.3974

1.4380

1.4631

1.4786

1.5020

1.5131

1.5156

1.5156
20

(W-28-1A)

.033

$14.2 \%$

27.14

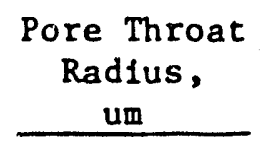

430.

143.

71.7

35.9

17.9

12.0

8.61

6.08

3.56

2.15

1.54

1.20

.861

.615

.359

.187

.123

.0861

.0615

.0359

.0215

.0154

.0120

.00861

.00615

.00478

.00391
Cumulative Surfage Area $\left(m^{2} / g\right)$

0.

$6.59 \mathrm{E}-6$

16.3 E-6

$68.8 \mathrm{E}-6$

131. E-6

144. E-6

144. E-6

229. E-6

229. E-6

357. E-6

438. E-6

543. E-6

771. E-6

.00102

.00149

.0476

.411

.961

1.09

1.36

1.53

1.68

1.79

2.03

2.19

2.24

2.24
Surface Area

(\%)

0.

294. E-6

727. E-6

.00307

.00584

.00641

.00641

.0102

.0102

.0159

.0196

.0242

.0344

.0454

.0665

2.13

18.4

42.9

48.6

60.7

68.3

74.8

79.9

90.7

97.9

100.

100. 
Page
File

PORE SURFACE AREA SUMMARY

INTERA TECHNOLOGIES, INC.

Sample Number:

Sample Identification Number:

Afr Permeability, md:

Porosity, Percent:

Dry Sample Weight (gm):
21

(W-28-1B)

.038

13. $0 \%$

27.60

\begin{tabular}{|c|c|c|c|c|}
\hline $\begin{array}{c}\text { Injection } \\
\text { Pressure, psia } \\
\end{array}$ & $\begin{array}{c}\text { Cumulative } \\
\text { Volume } \\
\text { Injected } \\
c c \\
\end{array}$ & $\begin{array}{c}\text { Pore Throat } \\
\text { Radius, } \\
\text { um } \\
\end{array}$ & $\begin{array}{c}\text { Cumulative } \\
\text { Surfage Area } \\
\left(\mathrm{m}^{2} / \mathrm{g}\right)\end{array}$ & $\begin{array}{c}\text { Surface Area } \\
(\%) \\
\end{array}$ \\
\hline 0.5 & 0. & 430. & 0. & \\
\hline 1 & .0117 & 143. & $7.15 \mathrm{E}-6$ & 476. E-6 \\
\hline 2 & .0193 & $71 . \%$ & $17.1 \mathrm{E}-6$ & .00114 \\
\hline 4 & .0359 & 35.9 & 56.4 E-6 & .00376 \\
\hline 8 & .0473 & 17.9 & 112. E-6 & .00747 \\
\hline 10 & .0476 & 12.0 & 114. E-6 & .00760 \\
\hline 15 & .0515 & 8.61 & 154. E-6 & .0103 \\
\hline 20.4 & .0534 & 6.08 & 182. E-6 & .0121 \\
\hline 40 & .0534 & 3.56 & 182. E-6 & .0121 \\
\hline 60 & .0542 & 2.15 & 214. E-6 & .0143 \\
\hline 80 & .0548 & 1.54 & 248. E-6 & .0165 \\
\hline 100 & .0551 & 1.20 & 270. $E-6$ & .0180 \\
\hline 150 & .0562 & .861 & 383. E-6 & .0255 \\
\hline 200 & .0576 & .615 & 582. E-6 & .0388 \\
\hline 400 & .0657 & .359 & .00256 & .171 \\
\hline 750 & .6885 & .187 & .295 & 19.7 \\
\hline 1000 & .9973 & .123 & .515 & 34.3 \\
\hline 1500 & 1.1481 & .0861 & .668 & 44.5 \\
\hline 2000 & 1.2071 & .0615 & .753 & 50.2 \\
\hline 4000 & 1.2881 & .0359 & .951 & 63.4 \\
\hline 6000 & 1.3198 & .0215 & 1.08 & 72.0 \\
\hline 8000 & 1.3376 & .0154 & 1.18 & 78.7 \\
\hline 10000 & 1.3493 & .0120 & 1.27 & 84.7 \\
\hline 15000 & 1.3654 & .00861 & 1.43 & 95.3 \\
\hline 20000 & 1.3699 & .00615 & 1.50 & 100 \\
\hline 25000 & 1.3699 & .00478 & 1.50 & 100 \\
\hline 30000 & 1.3699 & .00391 & 1.50 & 100. \\
\hline
\end{tabular}


Page
File $88-1056-14$

PORE SURFACE AREA SUMMARY

INTERA TECHNOLOGIES, INC.

Sample Number:

Sample Identification Number: Air Permeability, md:

Porosity, Percent:

Dry Sample Weight (gm):

Injection

Pressure, psia

1

2

4

8

10

15

20.4

40

60

80

100

150

200

400

750

1000

1500

2000

4000

6000

8000

10000

15000

20000

25000

30000

\section{Cumulative}

Volume

Injected

cc

0.

.0212

.0543

.0752

.0818

.0961

.1156

.2147

.4691

.6427

.7438

.8813

.9601

1.3245

1.5965

1.6671

1.7579

1.8122

1.9096

1.9461

1.9656

1.9779

1.9914

1.9961

1.9961

1.9961
22

$(W-30-3 A)$

9.680

$17.6 \%$

25.18
Surface Area

(\%)

0.

215.

71.7

35.9

17.9

12.0

8.61

6.08

3.56

2.15

1.54

1.20

.861

.615

.359

.187

.123

.0861

.0615

.0359

.0215

.0154

.0120

.00861

.00615

.00478

.00391
0.

28.4 E-6

117. E-6

229. E-6

282. E-6

442. E-6

750. E-6

.00342

.0148

.0256

.0338

.0491

.0615

.159

.299

.354

.456

.540

.802

.965

1.09

1.19

1.34

1.41

1.41

1.41
.00202

.00831

.0163

.02

.0314

.0532

.243

1.05

1.82

2.4

3.49

4.36

11.3

21.2

25.1

32.3

38.3

56.9

68.4

77.2

84.1

94.8

100.

100.

100. 
Page of

File $88-1056-14$

\section{INTERA TECHNOLOGIES}

Sample Nớ: 1

\section{Radius of Pore Apertures}

107.6

53.8

26.9

13.5

10.8

7.17

5.27

2.67

1.79

1.34

1.07

.717

.538

.267

.143

.107

.072

.054

.027

.018

.013

.011

.007

.005

.004

.004
Mercury

Saturation

(\% Pore Volume)

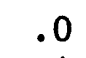

.4

.9

1.3

1.5

1.9

3.1

4.2

6.9

9.0

10.6

13.2

14.6

21.8

44.2

61.1

71.6

75.6

81.4

84.0

85.5

86.6

88.0

88.5

88.5

88.5

Sample No: 2

\section{Radius \\ of Pore \\ Apertures}

107.6

53.8

26.9

13.5

10.8

7.17

5.27

2.67

1.79

1.34

1.07

.719

.539

.267

.143

.107

.072

.054

.027

.018

.013

.011

.007

.005

.004

.004
Mercury

Saturation

( $z$ Pore Volume)

.0

.2

.4

.9

1.2

1.6

1.9

2.5

5.7

9.1

12.6

20.5

24.9

51.8

76.8

82.1

88.5

92.0

97.0

98.5

99.3

99.7

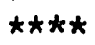

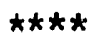

$\star \star \star \star \star *$

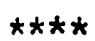


Sample No: 3

\begin{tabular}{cc}
$\begin{array}{c}\text { Radius } \\
\text { of Pore } \\
\text { Apertures }\end{array}$ & $\begin{array}{c}\text { Mercury } \\
\text { Saturation } \\
\text { (\% Pore Volume) }\end{array}$ \\
\cline { 2 - 2 } 215.2 & .0 \\
107.6 & .3 \\
53.8 & .7 \\
26.9 & 2.6 \\
13.5 & 3.6 \\
10.8 & 3.8 \\
7.17 & 4.5 \\
5.27 & 5.3 \\
2.67 & 5.8 \\
1.79 & 6.2 \\
1.34 & 6.5 \\
1.07 & 6.6 \\
.716 & 6.9 \\
.538 & 7.0 \\
.266 & 14.5 \\
.143 & 74.6 \\
.107 & 81.4 \\
.072 & 86.7 \\
.054 & 89.1 \\
.027 & 92.5 \\
.018 & 93.7 \\
.013 & 94.4 \\
.011 & 94.7 \\
.007 & 95.0 \\
.005 & 95.0 \\
.004 & 95.0 \\
.004 & 95.0
\end{tabular}

Sample No: 4

\author{
Radius \\ of Pore \\ Apertures
}

53.8
2.6 .9
13.5

10.8

7.17

5.27

2.67

1.79

1.34

1.07

.716

.538

.267

.143

.108

.072

.054

.027

.018

.013

.011

.007

.005

.004

.004
Mercury

Saturation

(\% Pore Volume)

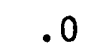

.2

.4

1.0

2.8

3.5

4.3

4.9

5.3

5.3

5.8

6.7

17.6

77.0

82.5

87.4

89.4

92.7

93.9

94.5

94.9

95.3

95.3

95.3

95.3 


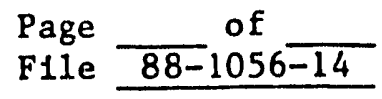

\section{INTERA TECHNOLOGIES}

Sample No: 5

\begin{tabular}{cc} 
Radius & Mercury \\
of Pore & Saturation \\
Apertures & $(\%$ Pore Volume $)$ \\
\hline
\end{tabular}

$\begin{array}{rr}215.2 & .0 \\ 107.6 & .4 \\ 53.8 & .7 \\ 26.9 & 5.0 \\ 13.5 & 5.8 \\ 10.8 & 9.5 \\ 7.17 & 9.9 \\ 5.27 & 10.3 \\ 2.70 & 12.2 \\ 1.81 & 23.0 \\ 1.36 & 24.9 \\ 1.08 & 25.6 \\ .723 & 35.7 \\ .541 & 36.5 \\ .267 & 46.8 \\ .143 & 86.7 \\ .108 & 90.7 \\ .072 & 91.5 \\ .054 & 91.6 \\ .027 & 91.6 \\ .018 & 91.6 \\ .013 & 91.6 \\ .011 & 91.6 \\ .007 & 91.6 \\ .005 & 91.6 \\ .004 & 91.6 \\ .004 & 91.6\end{array}$

Sample No: 6

\begin{tabular}{cc}
$\begin{array}{c}\text { Radius } \\
\text { of Pore }\end{array}$ & $\begin{array}{c}\text { Mercury } \\
\text { Saturation }\end{array}$ \\
Apertures & $(\%$ Pore Volume $)$ \\
\hline
\end{tabular}

$\begin{array}{cr}215.2 & .0 \\ 107.6 & 1.5 \\ 53.8 & 22.5 \\ 26.9 & 23.3 \\ 13.5 & 24.0 \\ 10.8 & 24.2 \\ 7.17 & 24.6 \\ 5.27 & 25.6 \\ 2.72 & 29.3 \\ 1.81 & 35.0 \\ 1.35 & 38.8 \\ 1.08 & 41.0 \\ .721 & 42.7 \\ .540 & 44.1 \\ .267 & 60.1 \\ .143 & 88.4 \\ .107 & 92.1 \\ .072 & 95.2 \\ .054 & 96.5 \\ .027 & 98.3 \\ .018 & 98.8 \\ .013 & 99.2 \\ .011 & 99.3 \\ .007 & 99.5 \\ .005 & 99.5 \\ .004 & 99.5 \\ .004 & 99.5\end{array}$


\begin{tabular}{l} 
Page \\
File $88-1056-14$ \\
\hline
\end{tabular}

\section{INTERA TECHNOLOGIES}

Sample No: 7

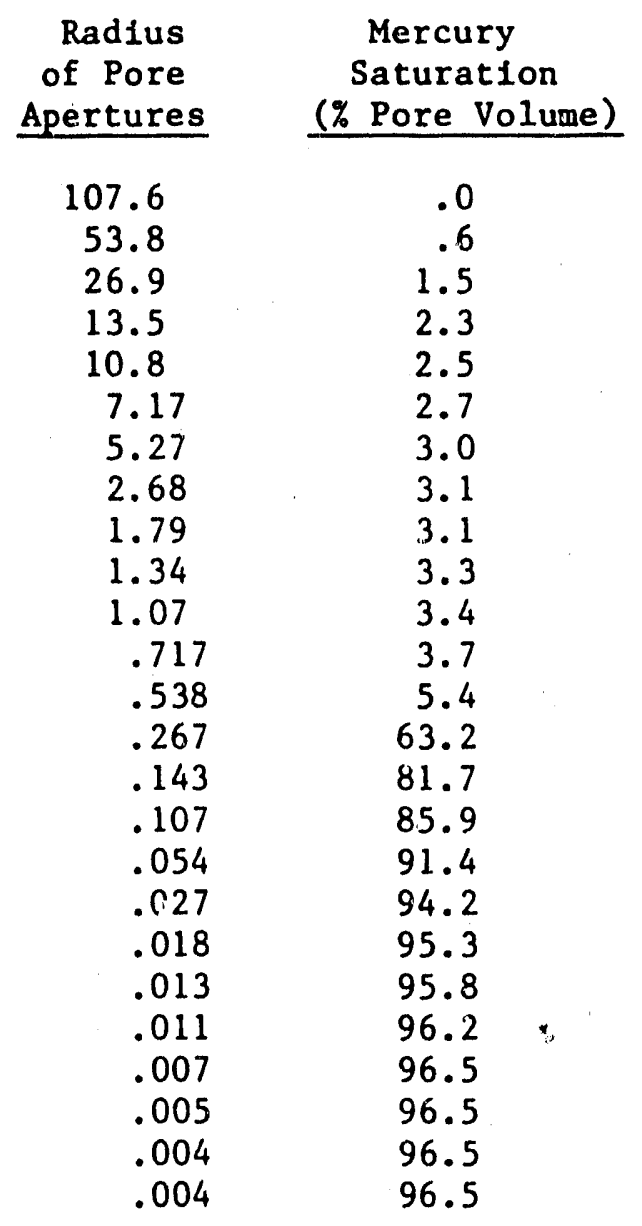

Sample No: 8

\begin{tabular}{cc}
$\begin{array}{c}\text { Radius } \\
\text { of Pore } \\
\text { Apertures }\end{array}$ & $\begin{array}{c}\text { Mercury } \\
\text { Saturation } \\
\text { (\% Pore Volume) }\end{array}$ \\
\cline { 3 - 3 } 215.2 & .0 \\
107.6 & .4 \\
53.8 & .7 \\
26.9 & 1.2 \\
13.5 & 2.2 \\
10.8 & 2.3 \\
7.17 & 2.7 \\
5.27 & 3.2 \\
2.68 & 4.1 \\
1.79 & 5.2 \\
1.34 & 6.0 \\
1.07 & 6.8 \\
.718 & 15.7 \\
.538 & 16.2 \\
.267 & 33.9 \\
.143 & 77.9 \\
.107 & 83.8 \\
.054 & 84.0 \\
.027 & 93.1 \\
.018 & 94.0 \\
.013 & 94.4 \\
.011 & 94.7 \\
.007 & 94.8 \\
.005 & 94.8 \\
.004 & 94.8 \\
.004 & 94.8
\end{tabular}


Page
File of
$88-1056-14$

\section{INTERA TECHNOLOGIES}

Sample Nơ: 9

\begin{tabular}{cc} 
Radius & Mercury \\
of Pore & Saturation \\
Apertures & (\% Pore Volume) \\
\hline
\end{tabular}

$\begin{array}{rr}215.2 & .0 \\ 107.6 & .3 \\ 53.8 & .6 \\ 26.9 & .8 \\ 13.5 & 4.5 \\ 10.8 & 8.1 \\ 7.17 & 8.5 \\ 5.27 & 8.7 \\ 2.68 & 8.8 \\ 1.79 & 9.7 \\ 1.34 & 10.6 \\ 1.07 & 10.8 \\ .717 & 11.4 \\ .538 & 11.8 \\ .267 & 36.8 \\ .143 & 78.6 \\ .107 & 85.0 \\ .072 & 90.3 \\ .054 & 92.6 \\ .027 & 96.0 \\ .018 & 97.3 \\ .013 & 98.0 \\ .011 & 98.4 \\ .007 & 98.9 \\ .005 & 98.9 \\ .004 & 98.9 \\ .004 & 98.9\end{array}$

Sample No: 10

\begin{tabular}{cc} 
Radius & Mercury \\
of Pore & Saturation \\
Apertures & (\% Pore Volurne) \\
\hline
\end{tabular}

107.6

53.8

26.9

13.5

10.8

7.17

5.27

2.66

1.78

1.34

1.07

.715

.537

.266

.143

.107

.072

.054

.027

.018

.013

.011

.007

.005

.004

.004

.0

.1

.2

.5

.6

.8

1.0

1.0

1.1

1.2

1.3

1.6

1.8

4.4

24.8

38.4

48.1

53.5

62.0

64.7

65.8

66.4

66.7

66.7

66.7

66.7 
$K \& A$

Page of

File $\overline{88-1056-14}$

Sample No: 10A

\begin{tabular}{cc}
$\begin{array}{c}\text { Radius } \\
\text { of Pore } \\
\text { Apertures }\end{array}$ & $\begin{array}{c}\text { Mercury } \\
\text { Saturation } \\
\text { (\% Pore Volume) }\end{array}$ \\
\cline { 2 - 2 } 215.2 & .0 \\
107.6 & .3 \\
53.8 & 3.0 \\
26.9 & 3.5 \\
13.5 & 3.7 \\
10.8 & 3.8 \\
7.17 & 3.8 \\
5.27 & 4.0 \\
2.67 & 4.6 \\
1.79 & 8.4 \\
1.34 & 12.7 \\
1.08 & 15.4 \\
.718 & 20.4 \\
.539 & 23.9 \\
.267 & 32.2 \\
.143 & 59.0 \\
.107 & 74.6 \\
.072 & 83.6 \\
.054 & 87.4 \\
.027 & 92.6 \\
.018 & 94.2 \\
.013 & 94.9 \\
.011 & 95.2 \\
.007 & 95.2 \\
.005 & 95.2 \\
&
\end{tabular}


Sample Nö: 11

\begin{tabular}{c} 
Radius \\
of Pore \\
Apertures \\
\hline
\end{tabular}

107.6
53.8
26.9
13.5
10.8
7.17
5.27
2.66
1.78
1.34
1.07
.716
.537
.266
.143
.107
.072
.054
.027
.018
.013
.011
.007
.005
.004
.004

Mercury

Saturation

(\% Pore Volume)

.0

1.1

1.6

2.0

2.0

2.2

2.3

2.3

2.4

2.6

2.6

2.6

2.7

2.9

3.8

6.4

50.3

63.5

78.6

83.7

86.5

88.4

91.3

92.7

93.3

93.3
Sample No: 12

\begin{tabular}{cc} 
Radius & Mercury \\
of Pore & Saturation \\
Apertures & (\% Pore Volume) \\
\hline
\end{tabular}

107.6

53.8

26.9

13.5

10.8

7.17

5.27

2.69

1.80

1.35

1.08

.719

.539

.268

.143

.107

.072

.054

.027

.018

.013

.011

.007

.005

.004

.004
.0

3.3

4.2

5.5

7.0

7.5

7.8

10.7

13.5

17.2

19.5

26.0

30.0

83.0

94.1

96.0

97.6

98.3

99.4

99.7

99.9

****

$\star \star \star \star *$

*t*k

$\star * * *$

$\star \star * * * *$ 
Page

File $88-1056-\overline{14}$

\section{INTERA TECHNOLOGIES}

Sample No: 13

Mercury

Saturation

of Pure

Apertures

215.2

107.6

53.8

26.9

13.5

10.8

7.17

5.27

2.67

1.79

1.34

1.07

.716

.538

.266

.143

.108

.072

.054

.027

.018

.013

.011

.007

.005

.004

${ } \mathrm{CO} 4$

1.8

2.9

3.6

4.0

4.1

4.1

4.3

4.5

5.2

5.5

5.6

5.9

6.3

11.1

77.0

84.2

89.7

92.4

96.2

97.7

98.6

99.2

99.9

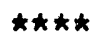

Sample No: 14

\begin{tabular}{cc} 
Radius & Mercury \\
of Pore & Saturation \\
Apertures & ( $z$ Pore Volume) \\
\hline
\end{tabular}

53.8

.0

26.9

13.5

.2

10.8

.3

7.17

5.27

2.66

1.78

1.34

1.07

.716

.537

.267

.143

.108

.072

.054

.027

.018

.013

.011

.007

.005

.004

.004
.7

.6

1.0

2.6

3.4

4.1

5.4

6.6

38.4

82.1

90.2

98.2

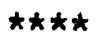

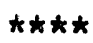

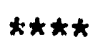

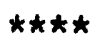

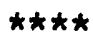

$\star \star * \star$

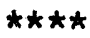

$\star \star \star \star *$

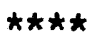


Page
File $88-1056-14$

INTERA TECHNOLOGIES

Sample No: 15

\begin{tabular}{cc} 
Radius & Mercury \\
of Pore & Saturation \\
Apertures & ( 7 Pore Volume) \\
\hline
\end{tabular}

215.2

107.6

53.8

26.9

13.5

10.8

7.17

5.27

2.67

1.78

1.34

1.07

.716

.537

.267

.143

.107

.072

.054

.02 ?

.018

.013

.011

.007

.005

.004

.004
.0

2.0

2.4

2.6

2.7

2.8

2.9

3.1

3.4

4.0

4.3

5.0

6.5

7.3

29.9

75.2

81.9

88.6

91.6

96.3

97.9

98.8

99.3

99.9

99.9

99.9

99.9
Sample No: 16

\begin{tabular}{cc}
$\begin{array}{c}\text { Radius } \\
\text { of Pore } \\
\text { Apeitures }\end{array}$ & $\begin{array}{c}\text { Mercury } \\
\text { Saturation } \\
\text { (\% Pore Volume) }\end{array}$ \\
\cline { 2 - 2 } 107.6 & .0 \\
53.8 & 1.3 \\
26.9 & 5.2 \\
13.5 & 6.0 \\
10.8 & 6.3 \\
7.17 & 6.7 \\
5.27 & 7.4 \\
2.68 & 8.8 \\
1.79 & 13.2 \\
1.35 & 15.3 \\
1.08 & 16.7 \\
.718 & 18.9 \\
.539 & 20.7 \\
.267 & 49.8 \\
.143 & 80.1 \\
.1 & 85.6 \\
.0 & 90.7 \\
.0. & 93.2 \\
.027 & 96.9 \\
.018 & 98.1 \\
.013 & 98.8 \\
.011 & 99.1 \\
.007 & 99.4 \\
.005 & 99.4 \\
.004 & 99.4 \\
.004 & 99.4 \\
&
\end{tabular}


$K \& A$

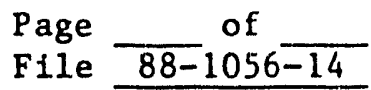

INTERA TECINOLOG IES

Sample Nớ: 17

\begin{tabular}{c} 
Radius \\
of Pore \\
Apertures \\
\hline
\end{tabular}

107.6

53.8

26.9

13.5

10.8

7.17

5.27

2.69

1.80

1.35

1.08

.721

.540

.267

.143

.107

.072

.054

.027

.018

.013

.011

.007

.005

.004

.004
Mercury

Saturation

(\% Pore Volume)

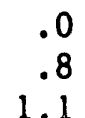

1.4

1.6

2.5

4.1

8.2

21.5

29.5

33.6

37.9

39.6

71.6

85.9

88.6

91.3

92.6

95.0

95.9

96.5

96.9

97.5

97.5

97.5

97.5
Sample No: 18

$\begin{array}{cc}\begin{array}{c}\text { Radius } \\ \text { of Pore } \\ \text { Apertures }\end{array} & \begin{array}{c}\text { Mercury } \\ \text { Saturation } \\ \text { (\% Pore Volume) }\end{array} \\ \begin{array}{c}107.6 \\ 53.8\end{array} & .0 \\ 26.9 & .4 \\ 13.5 & .6 \\ 10.8 & .7 \\ 7.17 & .8 \\ 5.27 & .9 \\ 2.66 & 1.0 \\ 1.78 & 1.0 \\ 1.34 & 1.0 \\ 1.07 & 1.0 \\ .715 & 1.0 \\ .537 & 1.0 \\ .266 & 1.0 \\ .143 & 19.2 \\ .107 & 80.1 \\ .086 & 85.8 \\ .072 & 88.9 \\ .054 & 90.8 \\ .027 & 93.1 \\ .018 & 95.6 \\ .013 & 98.3 \\ .011 & 99.1 \\ .007 & 99.6 \\ .005 & \star \star \star \star \\ .004 & \star \star \star \star \\ .004 & \star \star \star \star \\ & \star \star \star \star\end{array}$


$\mathrm{K} \& \mathrm{~A}$

\section{INTERA TECHNOLOGIES}

Sample No: 19

\section{Radius \\ of Pore \\ Apertures}

107.6

53.8

26.9

13.5

10.8

7.17

5.27

2.68

1.79

1.34

1.07

.716

.538

.266

.143

.107

.072

.054

.027

.018

.013

.011

.007

.005

.004

.004

.004
Mercury

Saturation

(\% Pore Vulume)

.0

1.9

2.4

2.7

2.8

2.9

3.2

3.2

3.2

3.2

3.2

3.2

3.2

8.5

61.1

72.7

81.8

86.0

92.5

95.4

97.1

98.2

99.9

99.9

99.9

99.9

95.3
Sample No: 20

\begin{tabular}{cc}
$\begin{array}{c}\text { Radius } \\
\text { of Pore }\end{array}$ & $\begin{array}{c}\text { Mercury } \\
\text { Saturation }\end{array}$ \\
\hline
\end{tabular}

215.2

107.6

53.8

26.9

13.5

10.8

7.17

5.27

2.67

1.78

1.34

1.07

.716

.537

.266

.143

.107

.072

.054

.027

.018

.013

.011

.007

.005

.004

.004 of

\section{File $\overline{88-1056-14}$}


Page
File $88-1056-14$

INTERA TECHNOLOGIES

Sample Nỡ: 21

\section{Radius \\ of Pore \\ Apertures}

215.2

107.6

53.8

26.9

13.5

10.8

7.17

5.27

2.67

1.78

1.34

1.07

.716

.537

.266

.143

.107

.072

.054

.027

.018

.013

.011

.007

.005

.004

.004
Mercury

Saturation

(\% Pore Volume)

.0

.8

1.4

2.5

3.2

3.3

3.5

3.7

3.7

3.7

3.8

3.8

3.8

3.9

4.5

47.2

68.3

78.6

82.7

88.2

90.4

91.6

92.4

93.5

93.8

93.8

93.8

Sample No: 22

\section{Radius \\ of Pore \\ Apercures}

107.6

53.8

26.9

13.5

10.8

7.17

5.27

2.69

1.81

1.36

1.08

.722

.541

.267

.143

.107

.072

.054

.027

.018

.013

.011

.007

.005

.004

.004
Mercury Saturation

(\% Pore Volume)

.0

1.1

2.7

3.8

4.1

4.8

5.8

10.8

23.5

32.2

37.3

44.2

48.1

66.4

80.0

83.5

88.1

90.8

95.7

97.5

98.5

99.1

99.8

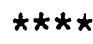

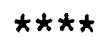

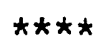


$K \& A$

Page
File

\section{INTERA TECHNOLOGIES}

Sample Nठ: 23

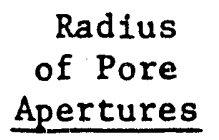

215.2

107.6

53.8

26.9

13.5

10.8

7.17

5.27

2.74

1.82

1.36

1.09

.723

.541

.268

.143

.108

.072

.054

.027

.018

.013

.011

.007

.005

.004

.004
Mercury

Saturation

(\% Pore Volume)

.0
1.8

2.6

3.2

4.2

4.9

22.5

23.5

27.4

30.5

32.5

34.0

36.8

38.8

52.1

78.8

83.0

86.3

87.6

89.9

90.7

91.1

91.4

91.6

91.6

91.6

91.6
Sample No: 24

\begin{tabular}{cc} 
Radius & Mercury \\
of Pore & Saturation \\
Apertures & $(\%$ Pore Volume $)$ \\
\hline
\end{tabular}

107.6

53.8

26.9

13.5

10.8

7.17

5.27

2.69

1.80

1.35

1.08

.721

.540

.267

.143

.107

.072

.054

.027

.018

.013

.011

.007

.005

.004

.004
.0

.6

1.2

2.5

2.8

4.3

5.8

8.5

15.1

21.4

26.3

35.0

39.5

58.4

80.3

85.0

88.9

90.5

93.1

94.2

94.9

95.3

96.0

96.3

96.3

96.3 

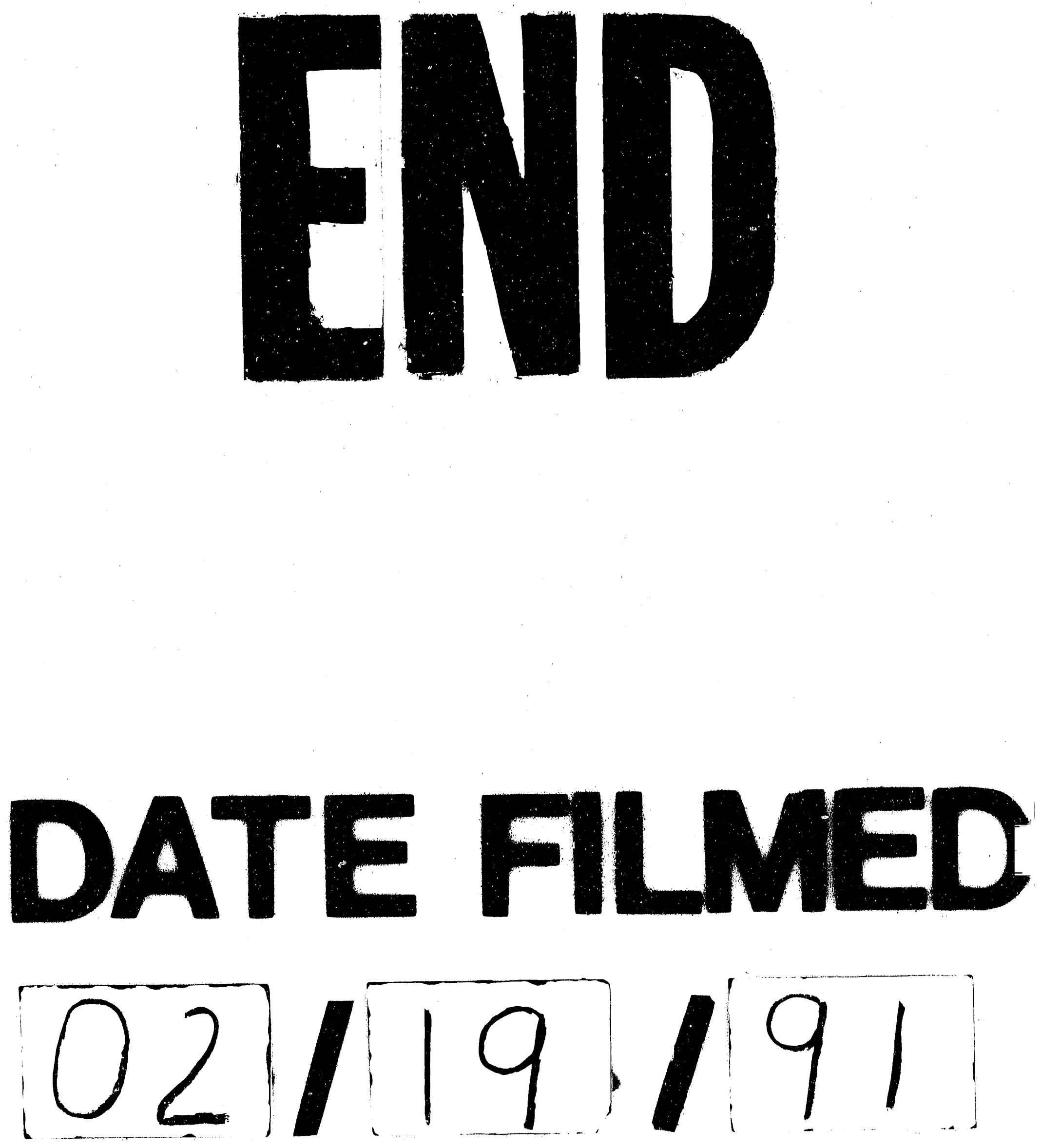
